\title{
Structural control on fluid migration in inverted sedimentary basins
}

\author{
Applicability of analogue studies in CCS research
}

\author{
Dissertation \\ zur Erlangung des mathematisch-naturwissenschaftlichen Doktorgrades \\ "Doctor rerum naturalium" \\ der Georg-August-Universität Göttingen \\ im Promotionsprogramm Geowissenschaften/Geographie \\ der Georg-August University School of Science (GAUSS) \\ vorgelegt von \\ Florian Duschl \\ aus Passau
}

Göttingen 2018 
Betreuungsausschuss:

Prof. M. Sauter

Dr. A. van den Kerkhof

Dr. B. Leiss
Abteilung für Angewandte Geologie, GZG

Abteilung für Angewandte Geologie, GZG

Abteilung für Strukturgeologie und Geodynamik, GZG

$\underline{\text { Mitglieder der Prüfungskommission }}$

$\begin{array}{lll}\text { Referent/in: } & \text { Prof. M. Sauter } & \text { Abteilung für Angewandte Geologie, GZG } \\ \text { Korreferent/in: } & \text { Prof. J. Kley } & \text { Abteilung für Strukturgeologie und Geodynamik, GZG }\end{array}$

weitere Mitglieder der Prüfungskommission:

Dr. A. van den Kerkhof

Dr. B. Leiss

Prof. I. Moeck

Prof. H. von Eynatten
Abteilung für Angewandte Geologie, GZG

Abteilung für Strukturgeologie und Geodynamik, GZG

Abteilung für Angewandte Geologie, GZG

Abteilung für Sedimentologie, GZG

Tag der mündlichen Prüfung: 19. November 2018 


\section{Acknowledgements}

First and foremost, I am grateful to Prof. Martin Sauter and Prof. Jonas Kley for giving me the opportunity of conducting this research, writing this thesis within the scope of the PANACEA-project and finally finish it.

Secondly, I owe my profound and sincere gratitude to my advisors Dr. Alfons M. van den Kerkhof and $\mathrm{Dr}$. Bernd Leiss for the continuous support of my $\mathrm{PhD}$ study and related research, for their patience, motivation, and immense knowledge.

Besides my advisors, I would like to thank Prof. Inga Moeck and Prof. Hilmar von Eynatten, for agreeing to serve on my dissertation committee.

Special thanks are due to Dr. Graciela Sosa, Dr. Axel Vollbrecht, Dr. Bettina Wiegand, and Dr. Uli Hein for their great support and invaluable advice.

I am grateful to Dr. Klaus Simon for conducting LA-ICP-MS analysis and for his help during data evaluation. I am also grateful to Dr. Burkhardt Schmidt for supporting me during Laser-Raman analysis, and to Dr. Volker Lüders for carrying out stable isotope analysis related to my research.

I would like to thank my former students Philipp Wischhöfer, Steffen Nolte, Carla Hillebrand, Torben Schulze, and Ali Seyed Anas for the fruitful scientific cooperation during my studies.

I would also like to express my gratitude to my colleagues Dr. Nina Albrecht and Dr. Rebecca Kühn for numerous helpful discussions, mostly held during coffee break.

My sincere thanks also goes to Dr. Alexandru Tatomir who encouraged me to trust my own writing.

Dr. Bianca Wagner and Dr. Klaus Wemmer are to be thanked for lab-, field- and software support and helpful discussions associated therewith.

Many thanks to Dr. Jordi Cama and Timea Kovacs for providing sample material from the BasqueCantabrian Basin as well as helpful background information on the study area.

Furthermore, I am grateful to the British Geological Survey and Wintershall Holding GmbH for providing sample material and related data, and for granting me access to drill cores.

I also acknowledge the deep support of my parents Dietlinde and Manfred and my whole family during my doctoral thesis.

Above all, I would like to express my deepest gratitude to Sarah "Schnou" Goeth for her profound encouragement, admirable patience, and tremendous confidence all through my career.

Finally, I would like to thank all colleagues and friends who helped to write and improve my $\mathrm{PhD}$ thesis! 


\begin{abstract}
Analogue studies in earth sciences are crucial for the understanding of various geological environments that may serve as future storage sites for carbon dioxide captured at an industrial scale. The feasibility of CCS pilot sites and of future investments dealing with CCS technologies depends on our detailed knowledge about processes taking place in reservoir rocks, from micro to macro scale. Important parameters to describe the reservoir quality of natural analogues are (a) the caprock integrity, (b) the petrological and petrophysical properties of the reservoir rock, and (c) the composition, the physical properties and the mobility of fluids present in the reservoir rock, with special emphasis in $\mathrm{CO}_{2}$.

In order to describe the quality of a reservoir rock supposed for carbon dioxide storage we compare four different natural analogues (two tight $\mathrm{CO}_{2}$-reservoirs, two outcrop analogue) in similar structural settings (i.e. inverted sedimentary basins) with a special focus on the long-term reservoir behaviour on a geological time scale, possible failure mechanism (leakage) in varying stress regimes, and the impact of the leakage on the reservoir quality. Key subjects and relevant rock properties considered for this study include: geologic and tectonic history of the reservoir, mineral composition of the reservoir rock, microfabrics, fluid chemistry and origin, timing of fluid migration, reservoir pressure and temperature conditions, water-rock-interaction, cementation history (porosity/permeability), fracture mechanics (fracture gradient/paleo-stress field), as well as fracture networks and related mineralization.

Therefore, a variety of different methods was applied and a new methodology was developed, that helped to gain as much information on the respective reservoir rocks and their geologic history as possible. The reasonable combination of various established laboratory techniques and the use of stateof-the-art basin modelling software lead to an innovative approach for a comprehensive reservoir characterization, that may help to improve our understanding of long-term carbon storage and carbon utilization in geological formations. The aim of this study is to prove the applicability of this newly developed approach and to detect uncertainties in its methodology that will allow us to narrow down the limitations of the proposed method. Since carbon capture and storage and utilization technologies represent a relatively new industry to reduce $\mathrm{CO}_{2}$ pollution in a worldwide context, their public acceptance is still low. Thus, the validity of reservoir quality predictions appears to be fundamental for the assessment of future injection sites.
\end{abstract}




\section{Zusammenfassung}

Die Untersuchung natürlicher Analogreservoire stellt im Kontext der geowissenschaftlichen Erkundung häufig die einzige Methode dar, um die strukturellen und geomechanischen Eigenschaften verschiedener Georeservoire, die als zukünftige Speicher für in industriellem Maßstab produziertes Kohlendioxid dienen können, besser zu verstehen.

Die Machbarkeit von CCS-Pilotprojekten und den damit verbundenen Investitionen, die sich im Wesentlichen mit der Entwicklung von Speichertechnologien befassen, hängt von unserem detaillierten Wissen über jene geologischen Prozesse ab, die in mikroskopischem wie makroskopischem Maßstab in natürlichen Reservoir- und Deckgesteinen stattfinden. Wichtige Parameter zur Beschreibung der Reservoir-Qualität von natürlichen Analogstandorten sind u.a. (a) die Unversehrtheit des Deckgesteins, (b) die petrologischen und petrophysikalischen Eigenschaften des Speichergesteins und (c) die Zusammensetzung, sowie die physikalischen Eigenschaften und die Mobilität der im Reservoir vorhandenen Fluide, mit einem besonderem Schwerpunkt auf $\mathrm{CO}_{2}$.

Um die Qualität eines für die langfristige Speicherung von Kohlendioxid relevanten Speichergesteins zu beschreiben, wurden im Rahmen der vorliegenden Studie vier verschiedene natürliche Analoga (je zwei intakte und zwei $\mathrm{CO}_{2}$-freie Analoga) mit sehr ähnlicher geologischer Entwicklungsgeschichte im Umfeld invertierter Sedimentbecken untersucht und relevante Analogeigenschaften miteinander verglichen. Ein besonderer Fokus lag dabei auf der Beurteilung des Langzeitverhaltens von Reservoiren hinsichtlich der Speichereigenschaften im Allgemeinen, sowie den möglichen Versagensmechanismen in unterschiedlichen tektonischen Regimen und deren Auswirkungen auf die Reservoir-Qualität im Speziellen.

Kernthemen sowie maßgebliche Gesteinseigenschaften, die im Rahmen dieser Doktorarbeit berücksichtigt wurden, sind unter anderem: die geologische und tektonische Entwicklung der einzelnen Reservoire, Zusammensetzung und (Mikro-)Gefüge der Speichergesteine, Fluidchemie und Fluidgenese, Zeitpunkt der Fluidmigration, Druck- und Temperaturbedingungen, Wasser-GesteinsWechselwirkung, Zementationsgeschichte mit Bezug auf Porosität und Permeabilität in Poren und Klüften, bruchmechanische Gesteinseigenschaften (Paläo-Spannungsfelder), sowie Bruchnetzwerke und zugehörige Kluft-Mineralisationen. Daher wurde eine Vielzahl verschiedener Methoden angewandt und eine neue Methodik entwickelt, die dazu beitrug, möglichst viele Informationen über die jeweiligen Speichergesteine und deren geologische Geschichte zu gewinnen. Die sinnvolle Kombination etablierter Labortechniken und der Einsatz modernster Beckenmodellierungssoftware führen zu einem innovativen Ansatz für eine umfassende Reservoir-Charakterisierung, der dazu beitragen kann, das Risiko einer langfristigen $\mathrm{CO}_{2}$-Speicherung zu minimieren und mögliche Schadensbilder frühzeitig zu erkennen. Da Technologien zur $\mathrm{CO}_{2}$-Speicherung eine relativ neue Industrie zur Verringerung der globalen $\mathrm{CO}_{2}$ Belastung darstellen, ist ihre Akzeptanz in der Öffentlichkeit nach wie vor gering. Das Ziel dieser Studie ist es deshalb, die Anwendbarkeit dieses neu entwickelten Ansatzes zu prüfen und Unsicherheiten in der Methodik aufzudecken, um dadurch innovativen Technologien der $\mathrm{CO}_{2}$-Speicherung zukünftig eine solide Datenbasis zu liefern. 
Table of contents

\section{Contents}

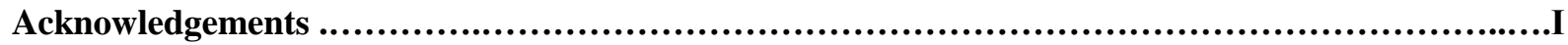

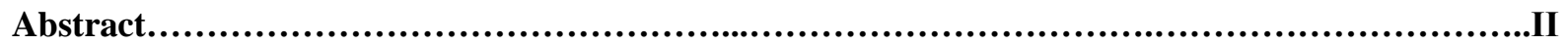

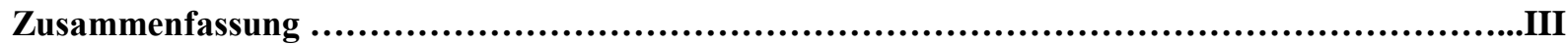

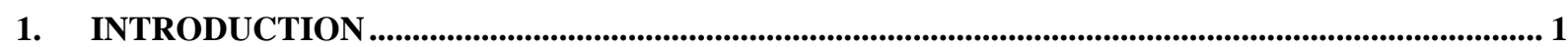

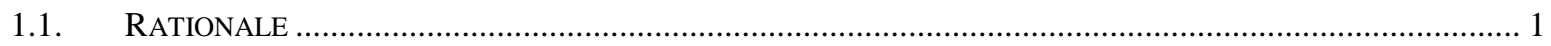

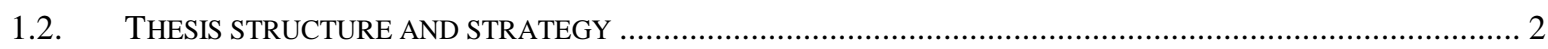

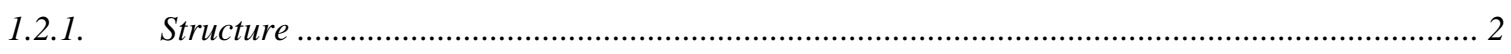

1.2.2. Strategy

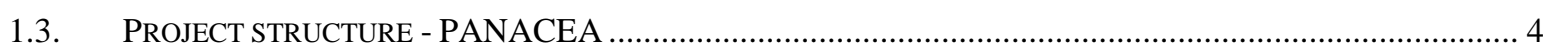

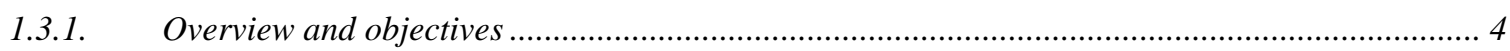

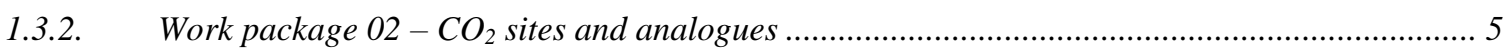

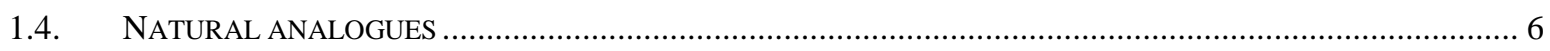

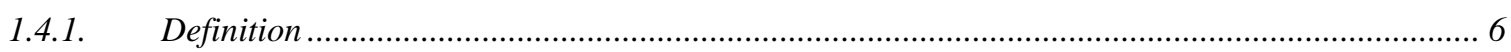

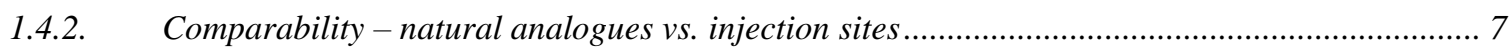

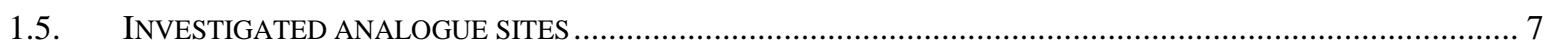

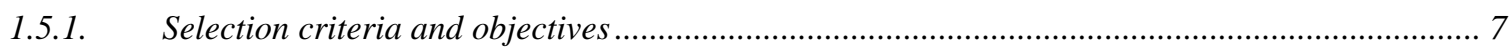

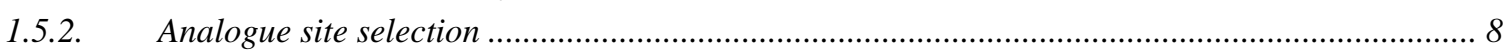

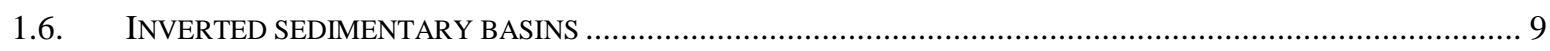

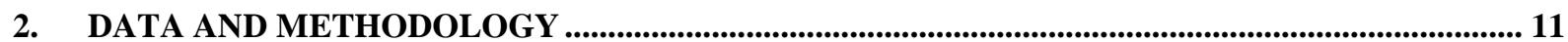

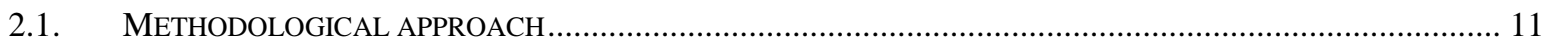

2.2. MICROSCOPIC ANALYSIS AND FLUID INCLUSION STUDIES.............................................................. 14

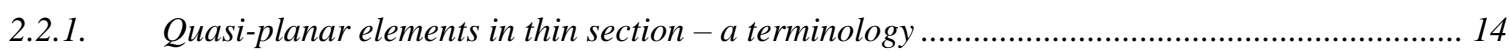

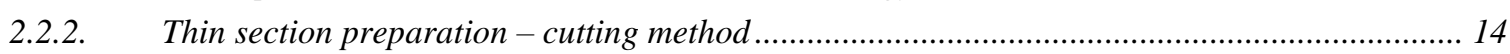

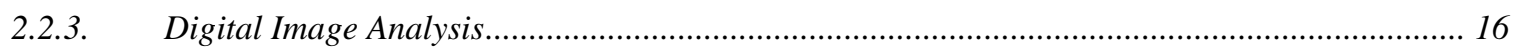

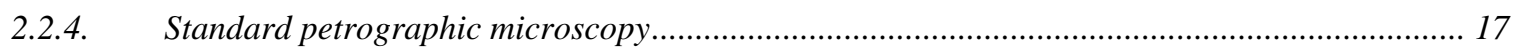

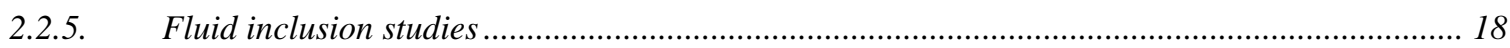

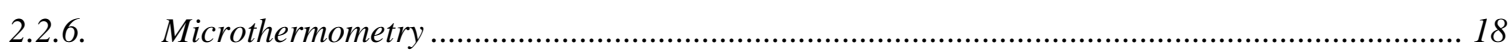

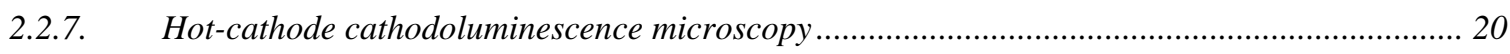

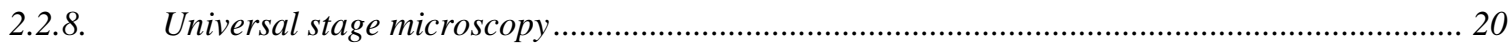

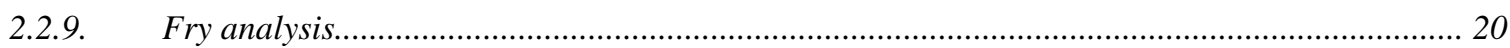

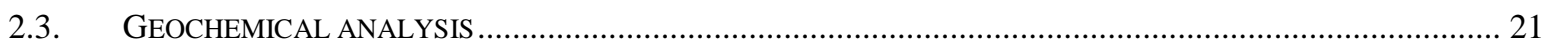

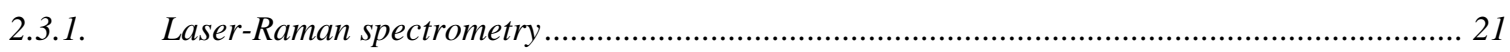

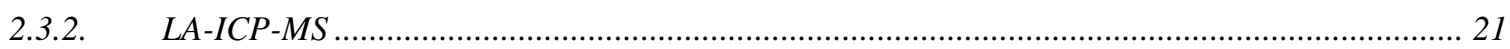

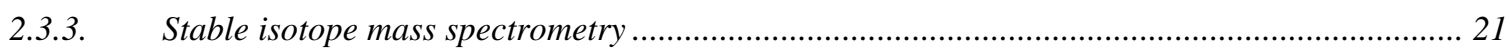

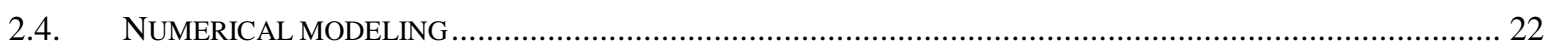

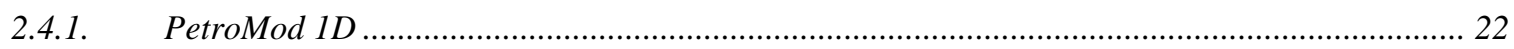

3. POST-DEPOSITIONAL TECTONIC CONTROL ON FLUID MIGRATION IN THE SOUTHERN PERMIAN BASIN - MICROFABRIC AND FLUID INCLUSION STUDIES ON AEOLIAN SANDSTONES (ROTLIEGEND) FROM THE FIZZY FIELD DRILL SITE (UK) .................................... 23

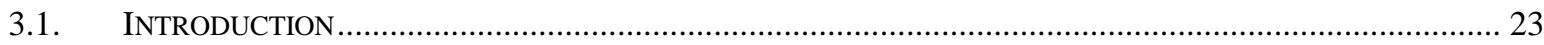

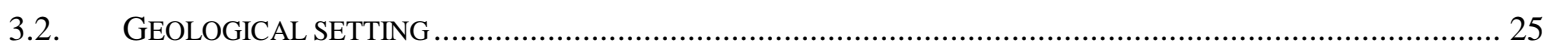




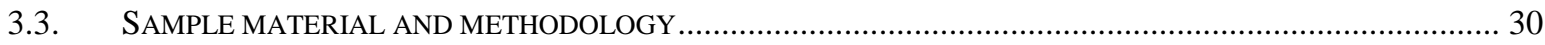

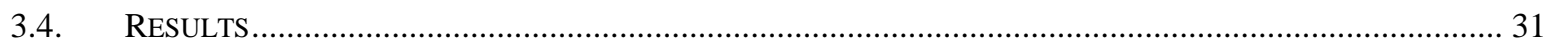

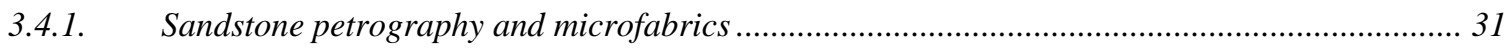

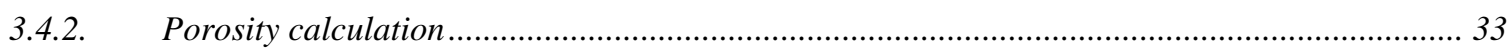

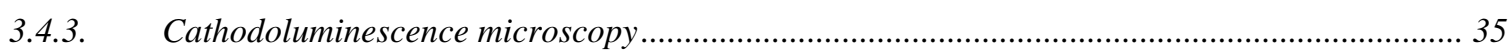

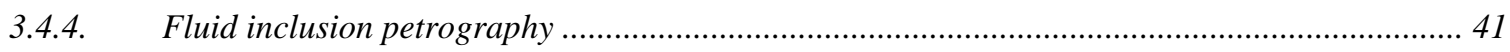

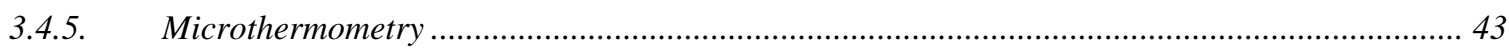

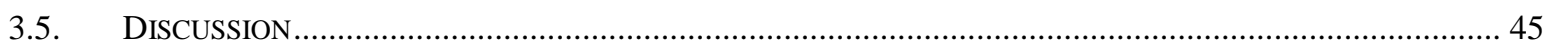

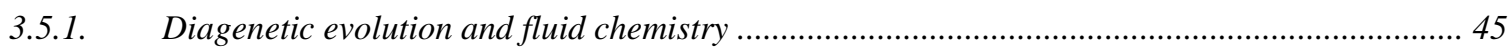

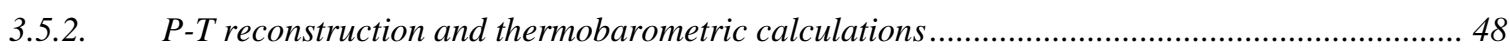

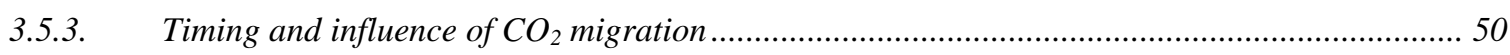

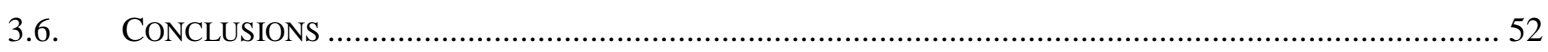

4. FLUID INCLUSION AND MICROFABRIC STUDIES ON ZECHSTEIN CARBONATES (CA2) AND RELATED FRACTURE MINERALIZATION - FLUID EVOLUTION AND GAS MIGRATION IN

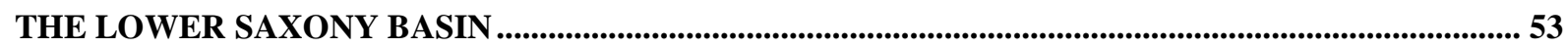

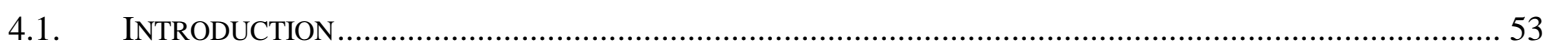

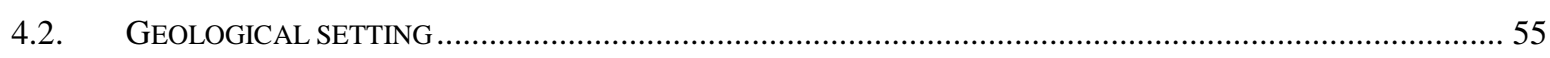

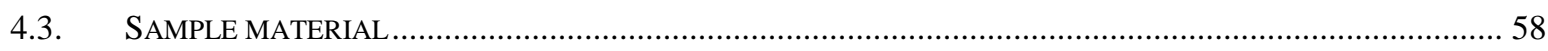

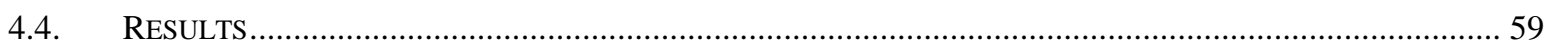

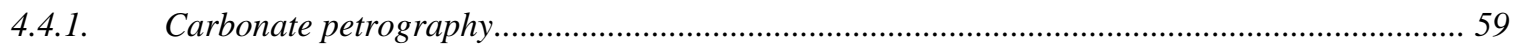

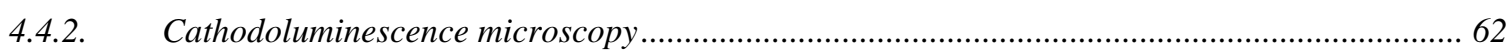

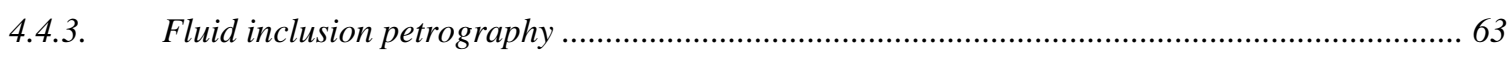

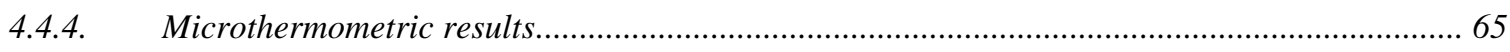

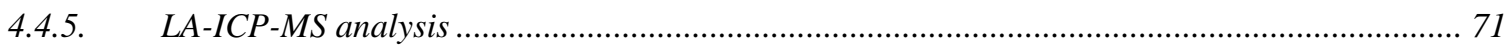

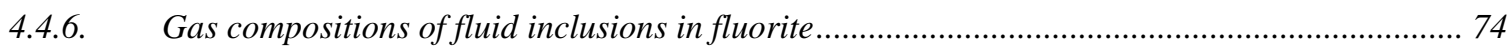

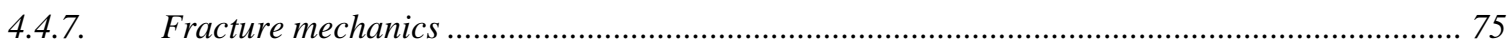

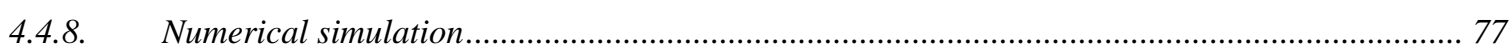

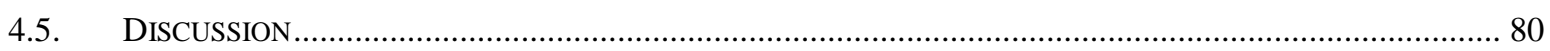

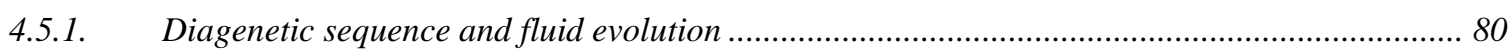

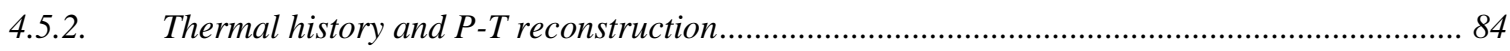

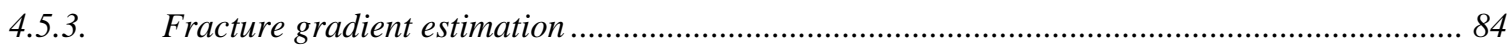

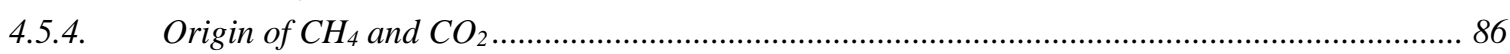

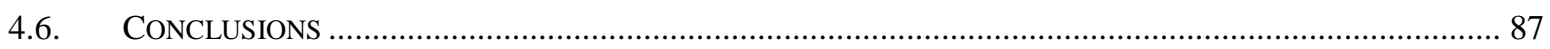

5. SYNDIAGENETIC STRATABOUND FLUORITE IN ZECHSTEIN CARBONATES (CA2) FROM THE LOWER WERRA ANTICLINE - A SHALLOW BURIAL ANALOGUE FOR HYDROTHERMAL FLUORITE MINERALIZATION IN THE NORTH GERMAN BASIN? .................................................8 88

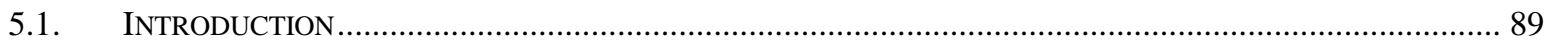

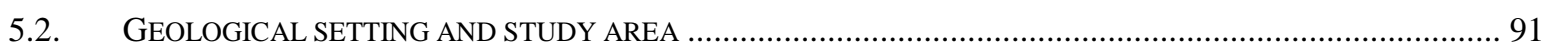

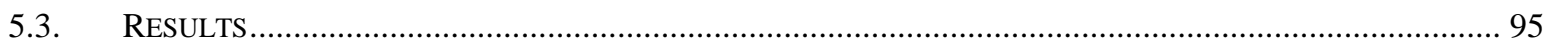

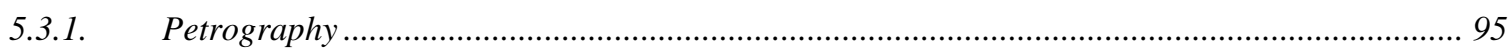

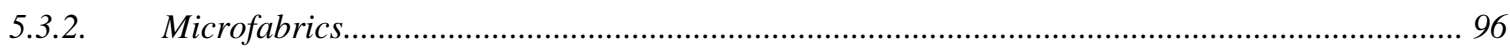

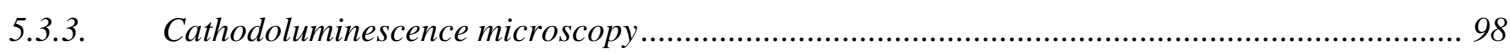

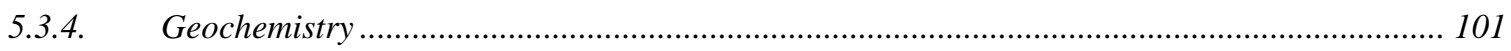

5.3.5. Fluid inclusion petrography and microthermometry ......................................................... 103

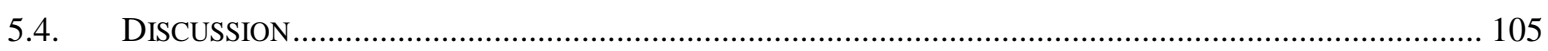

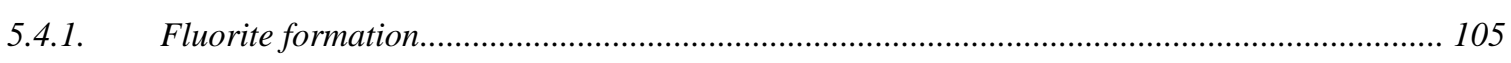

5.4.2. Thermal evolution - Deep burial versus local thermal anomaly........................................... 106 


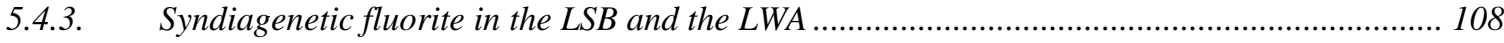

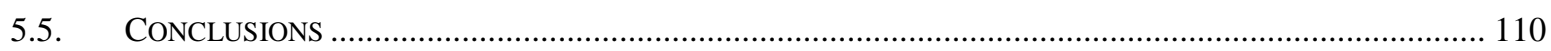

6. PROGRESSIVE FRACTURE-NETWORK DEVELOPMENT IN A CARBONATE RESERVOIR A COMBINED PALEO-STRESS FIELD AND MICROSTRUCTURAL ANALYSIS ON SEDIMENTARY ROCKS FROM THE LOWER JURASSIC OF THE WESTERN BASQUE-

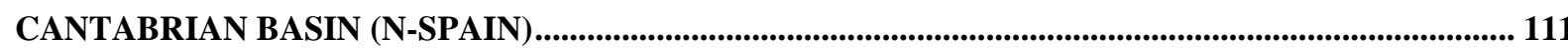

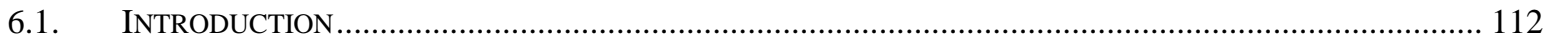

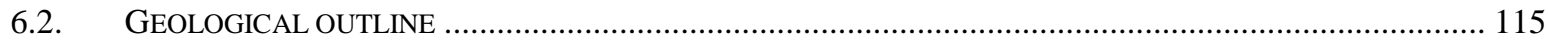

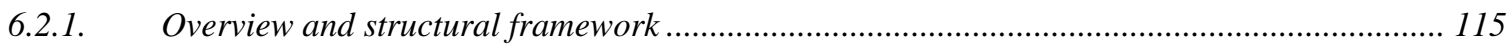

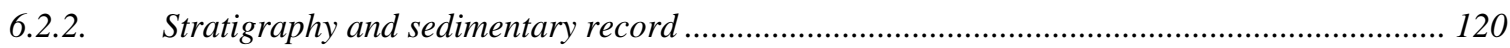

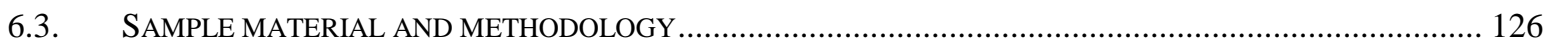

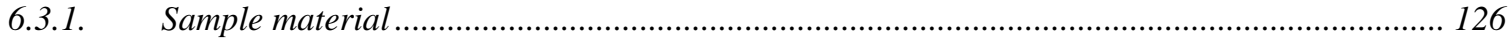

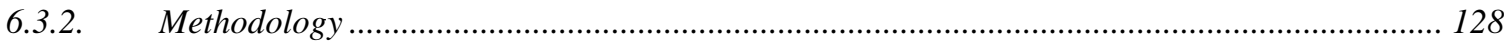

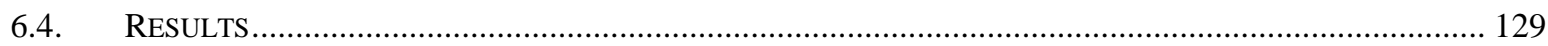

6.4.1. Carbonate petrography and microstructures.................................................................... 129

6.4.2. Cathodoluminescence microscopy of microstructures.......................................................... 136

6.4.3. Fry analysis of compactional volume reduction: compaction and pressure solution ............... 148

6.4.4. Paleo-stress field analysis............................................................................................... 149

6.4.5. Fluid inclusion petrography and microthermometry ......................................................... 150

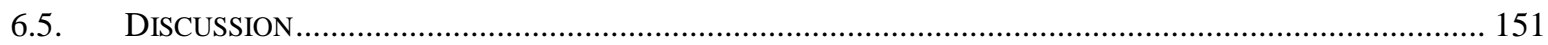

6.5.1. Diagenetic evolution and structural elements................................................................... 151

6.5.2. Paleo-stress field and fracture-network development ....................................................... 154

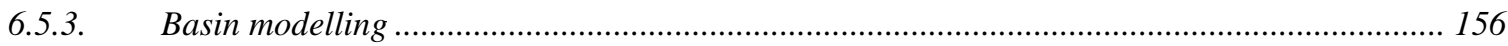

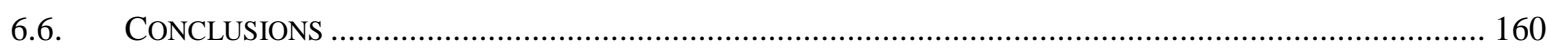

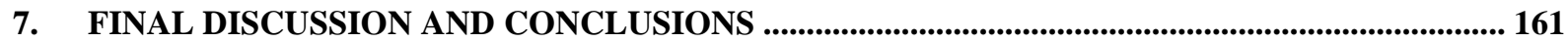

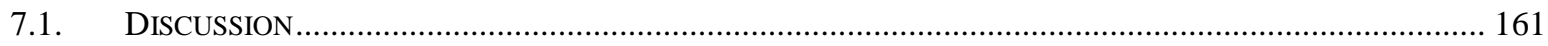

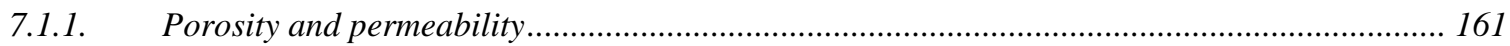

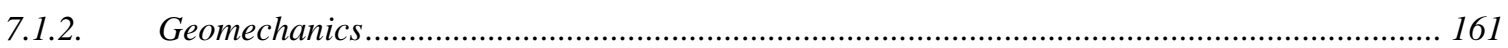

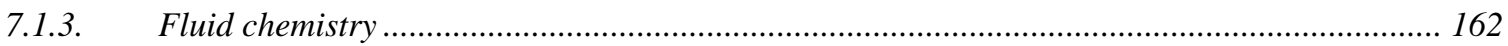

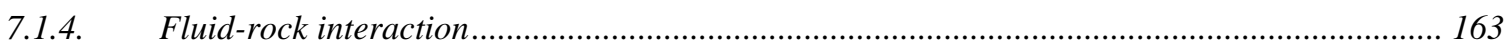

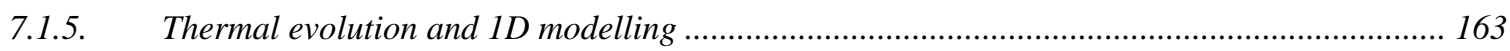

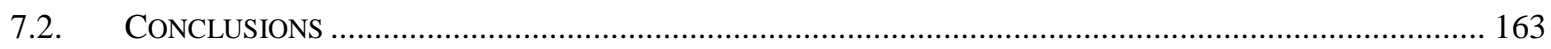

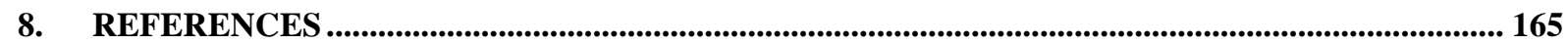

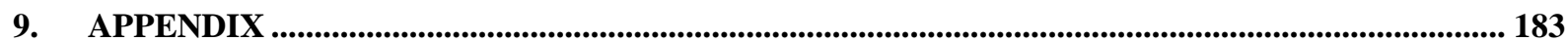




\section{Introduction}

\subsection{Rationale}

The massive and still increasing worldwide emission of $\mathrm{CO}_{2}$, the most prominent anthropogenic greenhouse gas (Le Quéré et al., 2015; Le Quéré et al., 2013) calls for a simple and economical solution. For example, the worldwide $\mathrm{CO}_{2}$-emission in 2013 was $35779 \mathrm{Mt}$ (Germany: $836 \mathrm{Mt}$ ), of which about half can be linked to emission from large-scale industrial facilities and coal-fired power stations (source: http://www.globalcarbonatlas.org/en/CO2-emissions). Since reducing $\mathrm{CO}_{2}$ emission from industrial facilities, as well as households and combustion engines (e.g. motor vehicles) is hard to achieve, other solutions are required.

In this regard, the storage of industrially captured carbon dioxide in geological formations, especially within saline aquifers (Michael et al., 2009), depleted oil- and gas fields (Underschultz et al., 2011; Whittaker et al., 2011), or coalbeds (Wo and Liang, 2005; Bromhal et al., 2005) offers a viable and relatively cheap solution. Furthermore, $\mathrm{CO}_{2}$ storage in deep-seated geological reservoirs may imply other practical opportunities such as enhanced oil recovery (Li et al., 2015), and carbon capture and mineralization, among others (Cuéllar-Franca and Azapagic, 2015; Leung et al., 2014). A brief introduction to carbon capture and storage technologies and related topics can be found in IPCC (2005). Critical and detailed overviews on the current status of CCS technologies and possible future applications are given by Grobe et al., 2009, Leung et al. (2014) and Boot-Handford et al. (2014).

A mandatory requirement for the successful injection of $\mathrm{CO}_{2}$ into geological formations is a suitable reservoir rock that does not only provide sufficient capacity and infrastructural connection (IPCC, 2005), but that is also sufficient with respect to physical and geochemical properties, such as for example the mechanical load capability of the caprock and the chemical stability of the reservoir rock concerning a long-term storage (>1000 y) (IPCC, 2005; US Environmental Protection Agency, OAR, Climate Change Division, 2008). Therefore, existing CCS pilot projects dealing with the investigation of suitable geological formations as well as the applicability of CCS technologies also focus on monitoring technologies (IPCC, 2005; Oldenburg et al., 2003) and the technical handling of test injection sites regarding their behavior upon reservoir pressure increase due to $\mathrm{CO}_{2}$ injection (e.g. Ivanova and Lüth, 2015; Bauer et al., 2016; Underschultz et al., 2011).

Beside engineering challenges in running a $\mathrm{CO}_{2}$ injection facility, fracture propagation, formation of fluid-conduction pathways and subsequent reservoir leakage due to mechanical overload of the caprock (pressure buildup, overpressure) (Gibbs et al., 1973; Healy et al., 1968; Raleigh et al., 1976; Sminchak et al., 2002; IPCC, 2005; Streit, J.E. \& Siggins, A. F., 2005; Streit, J.E. \& Watson, M., 2005; Wo et al., 2005) or reactivation of previously existing faults (Omre et al., 1994; Lewicki et al., 2006; Wilkins and Naruk, 2007) represent some of the main concerns for the failure of a storage site. Since reference values for operating a $\mathrm{CO}_{2}$ pilot injection site on a long term are still relatively rare, the investigation of natural $\mathrm{CO}_{2}$ analogues, i.e. natural geologic accumulations of $\mathrm{CO}_{2}$, can make an important contribution to the assessment of failure probability of a test injection site (e.g. Pearce et al., 1996; Cawley et al., 2005; Baines and Worden, 2004).

Especially the deformation behaviour of caprock and reservoir rock within the context of the structural evolution of a natural analogue is of great importance for the understanding of reservoir response on artificial pressure build-up. Though caprock fracturing and subsequent leakage represent some of the main failure risks for CCS projects, only little research has been spent on local stress fields and existing fault zones (active/inactive) in the vicinity of planned injection sites. A comprehensive 
investigation on local stress conditions and the mechanical properties of the caprock and reservoir rock units is crucial for a reliable evaluation of reservoir integrity.

Hence, the main objective of the present study, which is funded by the EU-financed PANACEA project (www.panacea-co2.org; Grant Number: 282900, 7th Framework Programme) is a comprehensive description of possible causes for and resulting consequences of fracturing due to compressive and tensile deformation in caprock and reservoir rocks anticipated for CCS projects. All studied reservoirs, i.e. two deep-seated natural $\mathrm{CO}_{2}$ analogues, one carbonate reservoir related to a test injection site (alternative analogue), as well as another supplementary shallow-burial analogue are located within the geological setting of inverted sedimentary basins, which are characterized by both, extensional and compressional tectonic deformation.

\subsection{Thesis structure and strategy}

\subsubsection{Structure}

The presented thesis is structured as a monography and organized in seven chapters, which are supplemented by an appendix.

An introductory chapter (Chapter 1) provides a brief overview on the study background and outlines the motivation, as well as the scientific focus of the presented thesis.

After a short description of main characteristics of and differences between natural analogues and (test) $\mathrm{CO}_{2}$ injection sites, the selection criteria for natural analogues featured in this study are introduced and the final analogue selection is explained. Moreover, a brief introduction to the structural evolution of inverted sedimentary basins and their importance for understanding structurally controlled fluid flow is presented.

Chapter 2 deals with the detailed explanation of the analytical methods applied for this investigation. Thereby, the methodological approach for this study is introduced as well

The original research part of this study contains four chapters with the following topics:

Chapter 3 focuses on a well explored $\mathrm{CO}_{2}$ reservoir hosted in aeolian sandstones from the Rotliegend group (Leman sandstone) of the Southern Permian Basin (Fizzy Field, UK). The main goal of this study is to reveal the fracture development and the cementation history of the sandstone based on microstructural investigations and fluid inclusion studies. This information is necessary in order to understand the influence of the structural evolution of the basin on caprock integrity, fluid migration, and trapping of $\mathrm{CO}_{2}$. Another focus is on revealing changes in (paleo-) fluid chemistry and subsequent dissolution-precipitation processes due to increased acidity resulting from $\mathrm{CO}_{2}$ dissolution. Therefore, various microscopic methods are applied in order to investigate the (paleo-) porosity evolution of the reservoir rock and to finally reveal the structural control on $\mathrm{CO}_{2}$ migration and trap formation.

The next chapter (Chapter 4) provides a detailed reconstruction of a natural $\mathrm{CO}_{2}$ accumulation hosted in Zechstein carbonate rocks (Stassfurt carbonate, Ca2) in the Lower Saxony Basin (Germany), covering the time frame from sedimentation in Upper Permian to present day. The relatively high $\mathrm{CO}_{2}$ concentration in the reservoir (75-100\%) and its location in the vicinity of a major fault zone at the northern boundary of the Lower Saxony Basin are of special interest for analogue studies. Besides, the high amount of published data and existing basin models that deal with the structural evolution of the Lower Saxony Basin allow a comprehensive comparison with our own data; this is supposed to result in an almost comprehensive petrographical, structural and geochemical profile of the gas field. The aim 
of this chapter is to reveal the origin of $\mathrm{CO}_{2}$ and its timing of migration, as well as to describe the influence of tectonic events on the fluid mobilization in the basin (rifting versus inversion).

Chapter $\mathbf{5}$ is thematically linked to Chapter 4 and was chosen as a supplementary shallow-burial analogue site for the investigated $\mathrm{CO}_{2}$ accumulation in the Lower Saxony Basin. The study area is located at the southern end of the so-called Lower Werra Anticline, a prominent structural feature in northern Hesse (Germany). Fluorite-bearing sample material was collected from Zechstein units (Stassfurt carbonate/Ca2) and investigated with respect to microfabrics, fluid inclusion chemistry, fluorite geochemistry, and P-T development in a shallow-burial reservoir, that was likely exposed to exceptionally high temperatures due to the temporary existence of a volcanogenic-hydrothermal system.

Finally, the investigation of oriented outcrop samples that come from the vicinity of a future injection site (Hontomín, Spain) is supposed to provide information on the deformation behaviour of the respective carbonate reservoir rocks (Chapter 6). Hereby, the study focuses less on geochemistry and fluid inclusion studies, but more on a detailed investigation of calcitic fracture mineralization within the carbonate rock, the reconstruction of paleo-stress fields responsible for fracturing, and the assignment of respective stress fields into the tectonic history of the Basque-Cantabrian Basin.

The last chapter (Chapter 7) features a concluding evaluation of findings obtained and methods applied within the scope of this study. It is intended to provide a risk assessment regarding potential sources of risk for the long-termed carbon storage in geological formations in terms of injection-related fracturing and fluid flow.

Featured references and supplementary material, as well as a CV are added at the end of the thesis.

\subsubsection{Strategy}

The investigation of fluid inclusions, rock microfabrics, and other microstructural features in rocks such as (micro) fractures and fracture mineralization, as well as the description of respective deformation mechanisms are the preferred methods to determine the reservoir properties of natural $\mathrm{CO}_{2}$ analogues and future injection sites. Samples come from carbonate and sandstone hosted $\mathrm{CO}_{2}$ reservoirs of two natural $\mathrm{CO}_{2}$ analogues (Lower Saxony Basin, Germany/Fizzy Field, UK) and one pilot injection site (Hontomín, Spain), as well as one supplementary inversion-related structure (Lower Werra Anticline, Germany), which is intended to complement data on reservoir evolution of the North German Basin area. Optical analyses are carried out using standard petrographic microscopy, and hot cathodoluminescence microscopy. In order to reveal the most influential properties responsible for generation, storage and mobilization of $\mathrm{CO}_{2}$ and other fluids in respective $\mathrm{CO}_{2}$ reservoirs, results from microscopic analysis are complemented by geochemical investigations on fluid inclusions and fracture mineralization. Moreover, quantitative microstructural studies on carbonate rocks from Hontomín using universal stage microscopy provide essential information on fracture propagation due to tectonic processes in the reservoir and complement this comprehensive approach.

The detailed reconstruction of reservoir history using microfabric studies and fluid-/geochemical investigations represents the main advantage of this methodology. In this way all relevant petrophysical and geochemical properties can be collected and interpreted in a single research approach. Thereby, special benefit is taken from paleo stress field analysis that forms an essential link between structural geology and the other, mainly analytical methods that provide information on fluid properties and geochemistry. In conclusion the presented rock properties can be used to develop new or refine existing basin models. 
Unfortunately, available sample material (Fizzy Field, Lower Saxony Basin: drill core samples; Eschwege and Basque-Cantabrian Basin: outcrop samples) sometimes show different rock properties (presence or absence of fluid inclusions within fracture mineralization or cement phases) and information on sample orientation cannot always be provided. Thus, not all presented methods can be applied on each suite of samples and data from a single site may be incomplete. Therefore, four different natural analogues were chosen for this study in order to carry out as many methods as possible and to test and compare their applicability. In order to select any relevant aspects from a broad variety of datasets, each site is presented in a single chapter with its own research focus. Thereby, not only different analytical methods, but also various geologic settings can be compared.

\subsection{Project structure - PANACEA}

\subsubsection{Overview and objectives}

All studies presented in this thesis were carried out within the scope of the PANACEA-Project (,Predicting and monitoring the long-term behaviour of $\mathrm{CO}_{2}$ injected in deep geological formations '), a multidisciplinary research project within EU's, $7^{\text {th }}$ Framework Programme ', which aims to improve the understanding of the long-term fate of geologically-stored $\mathrm{CO}_{2}$. The project is divided into nine work packages, of which two deal with project management (WP01) and communication, dissemination and topics of public acceptance (WP09), whereas work packages 2 to 8 address specific aspects of industrialized carbon capture and storage and related technologies, as well as the geological characterization of both, natural analogues and injection sites (see Fig. 1.1). The basic idea behind PANACEA is to establish a scientifically based technological approach, which helps to combine research efforts and newly developed technologies for large-scale, industrial $\mathrm{CO}_{2}$ storage. Major project goals are therefore to (a) identify and quantify all aspects that may influence the long-term $\mathrm{CO}_{2}$ storage capability of deep-seated geological formations; (b) determine factors responsible for reservoir integrity and vulnerability; (c) assess the impact of stored $\mathrm{CO}_{2}$ on adjacent reservoirs in case of leakage; (d) establish monitoring, measurement and verification tools that provide valuable information on longterm behaviour of stored $\mathrm{CO}_{2}$; and (e) develop a cooperating network with similar projects dealing with CCS technologies in a broader sense. 


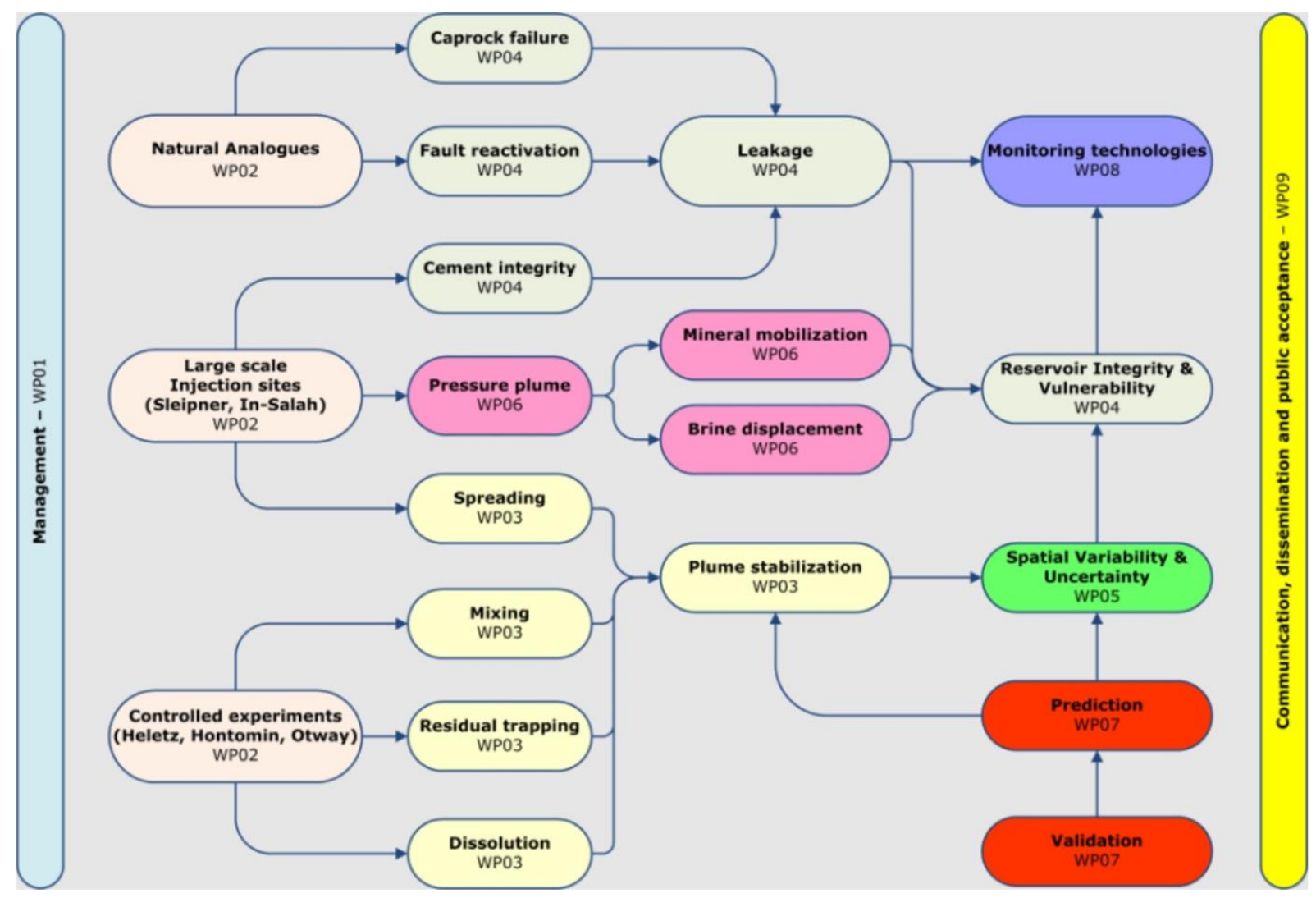

Fig. 1.1. Organisation chart compiling and illustrating all nine work packages within the PANACEA-project, as well as their structural relations (image source: http://www.panacea-co2.org/).

\subsubsection{Work package $\mathrm{O} 2-\mathrm{CO}_{2}$ sites and analogues}

This study is part of work package 2 (WP02), which deals with natural $\mathrm{CO}_{2}$ occurrences used as analogues for possible future large scale injection sites, and controlled experiments in terms of gas injection into shallow, well monitored reservoirs. Major objectives of WP 02 are (from http://www.panacea-co2.org/):

- Assemble comprehensive datasets for the calibration, validation and verification of conceptual and computational simulation models of the term $\mathrm{CO}_{2}$ storage in deep seated saline aquifers

- Construct a comprehensive database of pressure, temperature, stress directions and fluid composition of $\mathrm{CO}_{2}$ contained and failed storage analogues over geological time scales (St. Johns and Fizzy Field).

- Develop a set of methodological approaches for the determination of pressure, temperature, and stress history and fluid composition pertinent to long-term $\mathrm{CO}_{2}$ storage characteristics of geological reservoirs (St. Johns, Fizzy Field).

- Provide large and small scale contemporary experimental data (Hontomín, Heletz, Maguelone Otway, Goldeneye, Sleipner, Snohvit, Weyburn, Miranga and In Salah).

- Evaluate possible leakage scenarios based on analogues.

- Analyse data and information from artificial storage underground facilities of natural gases, as potential analogues of the $\mathrm{CO}_{2}$ storage. 
Therefore, a broad variety of analytical approaches and numerical methods were applied in order to collect data for assessing all aspects of industrial $\mathrm{CO}_{2}$ storage. Respective methods are compiled in Fig. 1.2 .

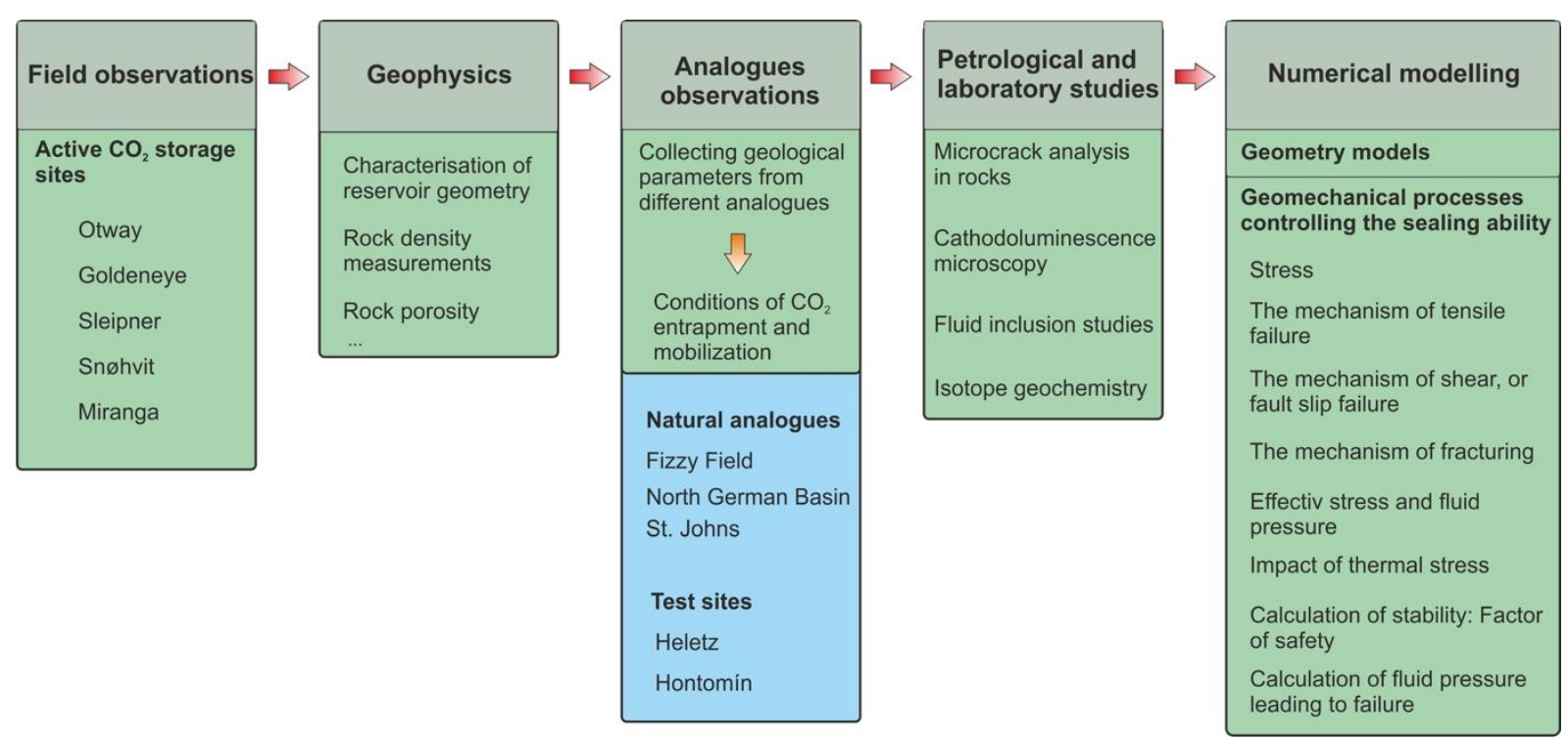

Fig. 1.2. Flow chart exemplifying the different steps of procedure in WP 02. All analytical procedures dealing with field observations of active $\mathrm{CO}_{2}$ storage sites, geophysics, natural analogue studies, and petrological and laboratory studies provide crucial information for developing proper geomechanical models.

\subsection{Natural analogues}

\subsubsection{Definition}

Analogy in general refers to the ancient greek word , ana-logon', which means equivalence between two different structures in relation to the same, $\operatorname{logos}^{`}(\mathrm{~A}: \mathrm{B}=\mathrm{C}: \mathrm{D})$. According to Jevons (1874), 'analogy denotes a resemblance not between things, but between the relation of things'. With analogy you describe structures of relations between two different object matters, e.g. between basic area $\mathrm{X}$ and target area $\mathrm{Y}$; thus, $\mathrm{Y}$ is analogue to $\mathrm{X}$, and vice versa, when there are not just likenesses between single properties but between the relations among properties. And therefore, analogy adds a heuristic quality to science in order to form hypothesis, which may consequently lead to valid theories (Hentschel, 2010). Analogues are commonly defined as exemplary systems that provide insights into or exhibit specific aspects of equivalent systems of interest, which are often accessible only to a limited extent or lack information on relevant processes, and are therefore poorly understood. Thus, an ideal analogue should possess as many structural characteristics as possible with regard to the relevant system, so that structural similarities predominate over differences.

Natural $\mathrm{CO}_{2}$ analogues are geological formations such as structural traps where $\mathrm{CO}_{2}$ naturally occurs as either stored (e.g., trapped under a seal) or leaking (e.g., geyser) gas. They favourably show strong similarities with injection sites intended for large-scale $\mathrm{CO}_{2}$ storage in terms of trapping mechanism, reservoir quality, caprock integrity, reservoir depth, accessibility, and infrastructural connection, to name a few. Natural $\mathrm{CO}_{2}$ analogues typically contain large volumes (i.e. several $\mathrm{Mt}$ ) of natural $\mathrm{CO}_{2}$, which has been stored for a relatively long period of time (>100 ky), and show no evidence for leakage (Miocic et al., 2013). Thus, natural $\mathrm{CO}_{2}$ analogues are studied in order to provide valuable information 
necessary for a better understanding of processes that may take place within reservoirs designated for anthropogenic $\mathrm{CO}_{2}$ storage.

\subsubsection{Comparability - natural analogues vs. injection sites}

The validity of analogue studies strongly depends on the comparability of respective aspects of interest. For example, several geological processes such as diagenesis and tectonic evolution, timing of $\mathrm{CO}_{2}$ production and migration, trap formation, etc., have a major influence on reservoir quality of both, natural analogues and injection sites. However, some observations made on analogue sites cannot be directly extrapolated to injection sites, since many processes, such as pressure build-up, fluid migration or fluid-rock interaction are time-dependent and often take place on completely different time scales (days or weeks vs. My). Natural analogues have typically undergone complex reservoir-forming processes during several million years of basin evolution, thus being currently in a more or less stable state of chemical and geomechanical equilibrium. Injection sites on the other hand are supposed to compensate significant changes in reservoir conditions in terms of chemical, physical and geomechanical properties within relatively short time periods due to gas-injection, and thus may respond to the significant injection-related changes in current reservoir conditions in an unexpected way. Therefore, prior to natural analogue studies a detailed evaluation of different aspects of interest has to be carried out in order to define comparable properties relevant for industrial $\mathrm{CO}_{2}$ storage. Consequently, preconditions for CCS injection sites have to be determined first:

- Reservoir structure (trap character)

- Intact caprock

- Relatively high pore space

- Solid information about geological history (diagenesis, burial and uplift, porosity and permeability, timing of gas production, migration, and trapping)

- Low fracture density in order to prevent fluid migration

- Monitoring and detection of possible leakage pathways (fracture formation or reactivation)

- Pressure and temperature conditions necessary for supercritical $\mathrm{CO}_{2}\left(\mathrm{scCO}_{2}\right)(>800 \mathrm{mbs})$

- Chemical composition of formation fluid favourable for precipitation of $\mathrm{CO}_{2}$ as solid phases (calcite, dawsonite, etc.)

\subsection{Investigated analogue sites}

\subsubsection{Selection criteria and objectives}

Natural $\mathrm{CO}_{2}$ analogues as well as test injection sites considered for this study were evaluated with respect to different aspects that guarantee suitability for analogue studies such as well-known geological setting, available sample material, $\mathrm{CO}_{2}$ occurrence, caprock integrity, fault character (tight vs. leaking), and reservoir depth (overburden $>800 \mathrm{~m}$ ). Appropriate candidates, which include the following natural analogues: the St. Johns Dome (Arizona/USA), the Fizzy Field drill site (North Sea/UK), and a $\mathrm{CO}_{2}$ occurrence in the Lower Saxony Basin (Germany) (see Tab. 1.1 for compiled site characteristics), as well as two pilot injection sites (Hontomín/Spain; Heletz/Israel) were investigated by several members of the Göttingen research team (UGOE) with regard to (a) volume oriented characterisation of fluidrock contact in the field, (b) determination of bulk temperatures in fractured-porous rock at borehole 
scale, (c) simulation of hydraulic, solute, and heat transport processes at borehole scale, (d) petrographic characterisation of fluid inclusions and reconstruction of the thermal history of the reservoir, (e) determination of microcrack frequency and chronology (stress history, $\mathrm{P}-\mathrm{T}$ conditions, paleo-fluid systems), and (paleo-) connectivities/permeabilities, and (f) geochemical and isotopic characterisation and modelling of subsurface environments, fluid sources, water-rock interaction, dissolutionprecipitation reactions along flow paths (modified from http://www.panacea-co2.org/).

Tab. 1.1. Compiled reservoir characteristics for considered deep-seated analogues.

\begin{tabular}{|c|c|c|c|c|c|c|c|c|c|}
\hline Site & $\begin{array}{c}\text { Sampling } \\
\text { depth (mbs) }\end{array}$ & $\begin{array}{c}\text { Burial } \\
\text { depth }(m)\end{array}$ & Uplift (m) & $\begin{array}{c}\text { Trap } \\
\text { character }\end{array}$ & $\begin{array}{c}\text { Fluid } \\
\text { mobilization }\end{array}$ & $\begin{array}{c}\text { Fault } \\
\text { character }\end{array}$ & Caprock & $\begin{array}{c}\text { Reservoir } \\
\text { rock }\end{array}$ & Overburden \\
\hline Fizzy Field & $2300-2400$ & ca. 2800 & $400-500$ & $\begin{array}{c}\text { structural } \\
\text { trap }\end{array}$ & fault & sealed & \begin{tabular}{|c|}
$\begin{array}{c}\text { carbonate/evaporite } \\
\text { (Zechstein) }\end{array}$ \\
\end{tabular} & sandstone & ca. $2000 \mathrm{~m}$ \\
\hline $\begin{array}{c}\text { Lower } \\
\text { Saxony } \\
\text { Basin }\end{array}$ & $3100-3400$ & ca. 5000 & ca. 1300 & $\begin{array}{l}\text { structural } \\
\text { trap }\end{array}$ & fault & sealed & $\begin{array}{c}\text { carbonate/evaporite } \\
\text { (Zechstein) }\end{array}$ & $\begin{array}{c}\text { carbonate } \\
\text { (Hauptdolomit) }\end{array}$ & ca. $2800 \mathrm{~m}$ \\
\hline Hontomín & $1225-1515$ & --- & --- & $\begin{array}{c}\text { structural } \\
\text { trap }\end{array}$ & fault & sealed & shale & carbonate & ca. $1200 \mathrm{~m}$ \\
\hline
\end{tabular}

\subsubsection{Analogue site selection}

Since the focus of present thesis, however, is on fracture-related fluid flow within deep-seated reservoirs controlled by brittle deformation, only a reduced number of analogue sites is worth considering. The St. Johns Dome site, for example, is a well-studied leaking shallow-burial reservoir and therefore of limited use, while sample material from the Heletz pilot injection site turned out to be insufficient for our analytical approach. Due to organisational reasons, no drill-core sample material from the Hontomín test injection site was available at the start of this study. Therefore, alternative sample material coming from according lithological formations from several outcrops in the Basque-Cantabrian Basin, which was provided by project partners Jordi Cama and Timea Kovac, was used for our investigations. It should be noted that both, the Hontomín test site and the sampled outcrops are related to the same structural framework, which is an inverted Mesozoic sedimentary basin. Since a special focus of work package 02 is on the detailed reconstruction of the thermal reservoir history, another comparatively shallow-burial natural analogue in the North German Basin (Lower Werra Anticline) was investigated and compared to a deep-seated equivalent in the Lower Saxony Basin in order to provide a more detailed view on diagenetic and tectonic processes that may favour or hinder the storage quality of respective reservoirs; besides this supplementary study allowed to determine the influence of relatively shorttermed thermal pulses on various reservoir properties. In summary, four analogue sites related to the tectonic framework of sedimentary basins, which all experienced both extension and contraction (inversion) during their evolution, were selected for our study (Fig. 1.3). 


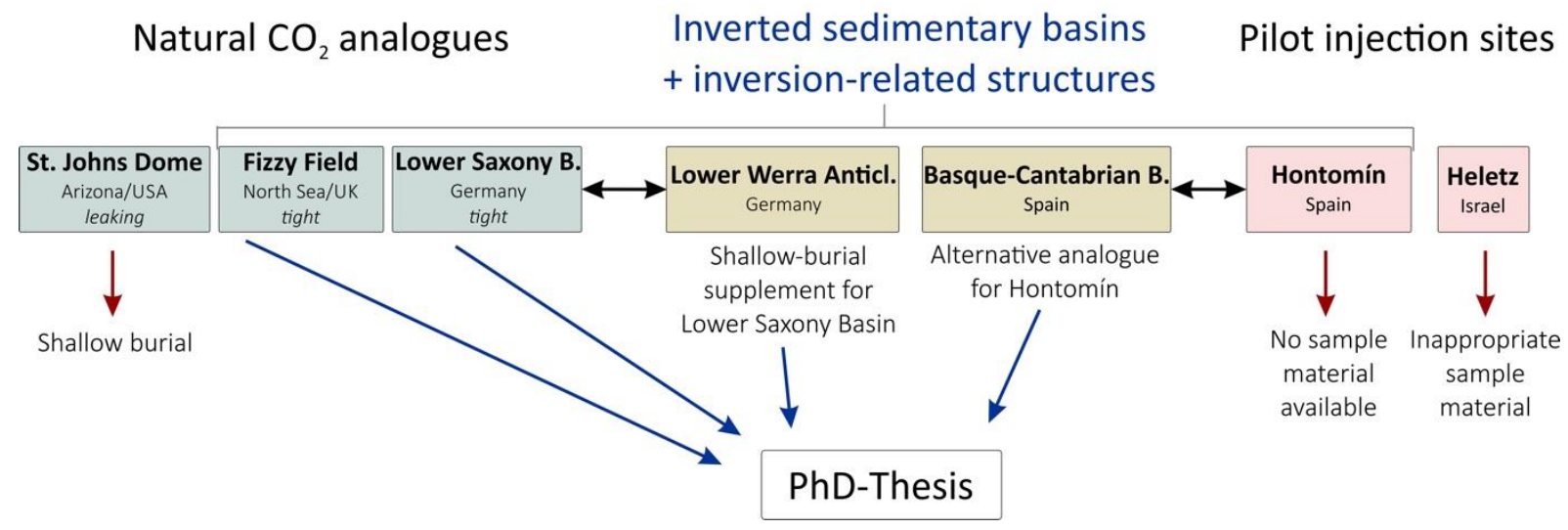

Fig. 1.3. Chart showing all natural analogues investigated by the Göttingen research group within WP02, as well as those considered for this thesis.

\subsection{Inverted sedimentary basins}

Since fluid injection into aquifers is accompanied by mechanical stress as a result of intra-formational pressure build-up (Birkholzer et al., 2015), the study of caprock and reservoir rock behaviour upon tectonic deformation is a crucial aspect of natural analogue studies in CCS research. In order to address the need for comparable natural systems that may provide insight into the response of sedimentary rock on different tectonic scenarios, which preferably include extensional and compressional regimes, and simultaneously host significant $\mathrm{CO}_{2}$ accumulations, inverted basins seem most appropriate candidates.

Although a concise definition is still missing, inverted basins are commonly referred to as basinal structures, which opened and consequently subsided due to extension tectonics and were subsequently inverted due to a reversed stress field that caused contraction (Cooper and Williams, 1989). During basin inversion the sedimentary infill of the basin experiences uplift and is therefore exposed to erosion. Prominent examples for inverted basins in the broadest sense in Europe include the East Shetland Basin, the Broad Fourteens Basin, and the Sole Pit Basin in the UK, the Lower Saxony Basin in Germany, or the West Netherlands Basin in the Netherlands, to name a few (Pharaoh et al., 2010).

The geometry of inverted basins is characterized by normal faults that usually trace the outer boundaries of the basin, and were subsequently reactivated as reverse faults due to a reversed stress field. Different stages of inversion kinematics include pre-, syn-, and post-rift stage, which are all expressed by an according characteristic sedimentary sequence (Hayward and Graham, 1989). While basin infill often reaches a thickness of several $1000 \mathrm{~m}$, inversion-related uplift is usually less pronounced and its effect can be heterogeneous throughout the basin, as the architectural faultframework often shows local differences; however, inversion tectonics likely result in positive morphological features (Williams et al., 1989). Inversion tectonics are not restricted to sedimentary basins, though, as several structural features such as for example the Harz Mountains suggest (Tanner and Krawczyk, 2016).

Due to their often complex structural evolution, which allows the study of a variety of processes related to reservoir development, inverted basins provide a number of geological settings ideal for natural analogue studies. Moreover, many inverted basins are well investigated in terms of structure and fluid content as respective basins have been studied in great detail by petroleum geologists as they host many important hydrocarbon provinces (Doornenbal and Stevenson, 2010; Littke et al., 2008). Therefore, inverted basins involve extension- and compression-related structural features such as 
Chapter 1 - Introduction

vertical fractures that result from horizontal minimum stresses and hydraulic fracturing during extension (Meng et al., 2017) and subsequently serve as conduits for inter- and intraformational fluid migration. Besides, inverted basins provide the structural evolution necessary for fluid generation $\left(\mathrm{CO}_{2}+\right.$ hydrocarbons) in terms of source/reservoir rock, increased temperatures and heat flow due to burial and rifting, as well as trap formation; they furthermore reveal details about the role of basinal fluids during fault reactivation (Sibson, 1995). 


\section{Data and methodology}

\subsection{Methodological approach}

A detailed microfabric analysis is crucial at the beginning of the investigative chain in order to evaluate geochemical, physical and geomechanical processes and their influence on the reservoir rock, as well as to determine their chronological order. Apart from standard petrographic microscopy in combination with point counting analysis, which provides qualitative and quantitative information on mineral composition, and the description of microfabrics, the application of hot-cathode cathodoluminescence on the same thin section allows a significant enhancement in terms of analytical options, especially with regard to the analysis of sedimentary rocks (Boggs and Krinsley, 2006). Cathodoluminescence microscopy allows to visualize otherwise invisible mineral-specific microstructural elements such as growth zoning, twinning, relative age relations of microfractures etc., and furthermore provides insight into geochemical properties, for example mineral composition, trace element distribution, formation conditions, dissolution-precipitation, etc. (Marshall, 1988). This detailed petrographic investigation allows to reveal all relevant mineralogical and microstructural aspects of the reservoir rock's evolution and at the same time it is a precondition for the selection of further appropriate analytical steps on the respective object (sample, thin section, fluid wafer).

On that basis, a number of additional geochemical analytical methods (Laser-ablation inductively coupled plasma mass spectrometry, Laser-Raman spectrometry, microthermometry, stable isotope geochemistry) not only allow the subsequent characterization of pore fluids and related fracturemineralization with regard to composition, fluid-rock interaction, genetic origin. In combination with cathodoluminescence imaging it also helps to determine the timing of fluid mobilisation by comparing relative age relations of different cement generations and fluid inclusions trapped therein.

Universal stage microscopy was applied in order to reconstruct paleo-stress fields evidenced by microfractures in rock matrix and single mineral grains, which indicate minimum principal stress directions during fracturing. This method provides information on the tectonic regime that caused brittle deformation within the reservoir.

Fluid inclusion studies und microthermometry not only provide valuable information about the composition of basinal fluids and their relative time of migration and trapping, but also allow to estimate trapping pressures and temperatures. Thereby, help to complement existing ideas regarding the tectonic and thermal evolution of respective basins by complementing published data and related burial curves.

In conclusion, this broad variety of analytical methods and concepts in combination with numerical models leads to a comprehensive scientific approach with regard to natural analogue characterization. A compilation of all respective data possibly obtained from fracture analysis is given in Fig. 2.1, while Fig. 2.2 shows a detailed workflow chart, which illustrates the chronological order and hierarchical structure of all methods applied within the scope of this thesis. 
Chapter 2 - Data and methodology

\section{Microstructures in rocks}

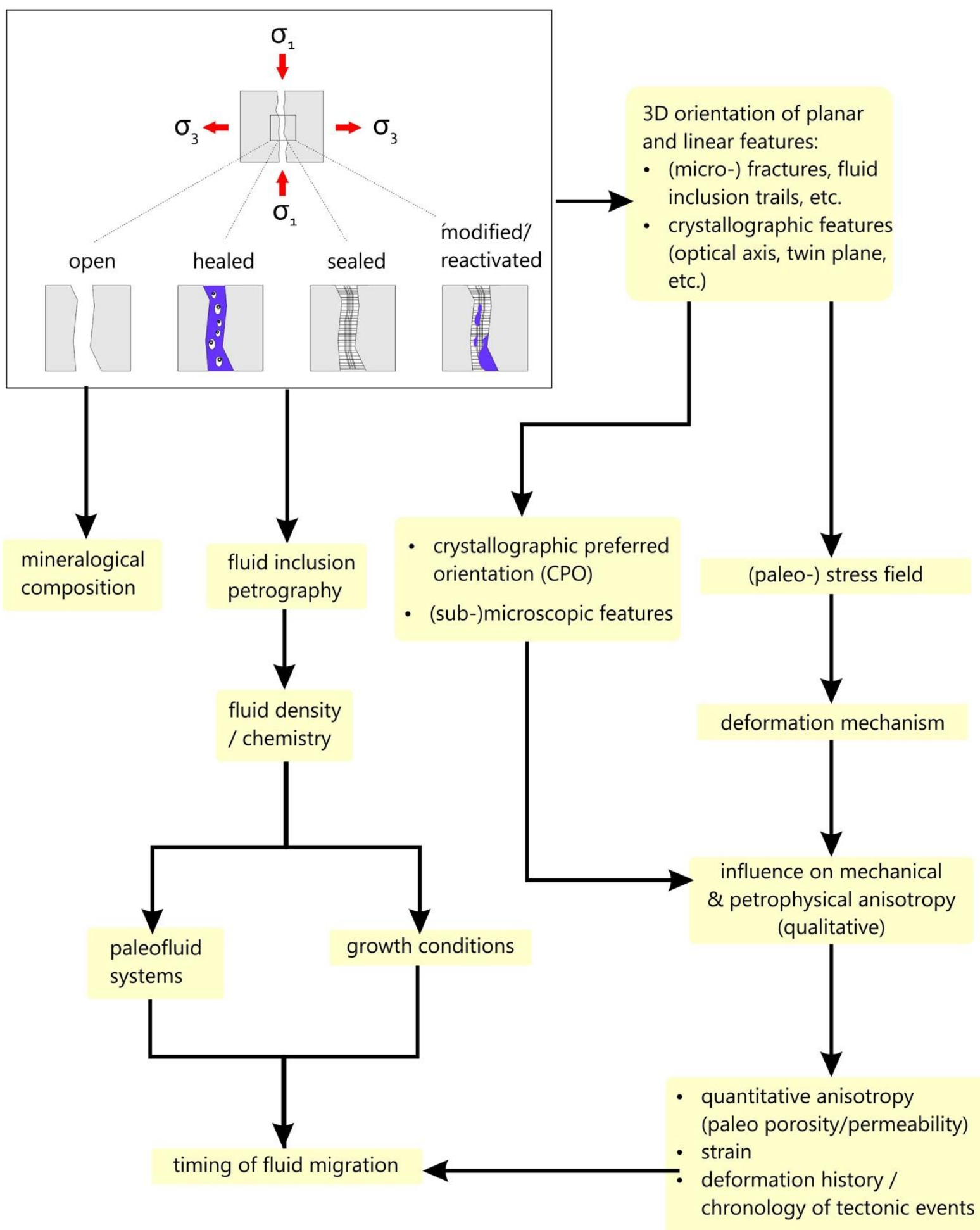

Fig. 2.1. Microfracture analysis provides a variety of information on different aspects of reservoir evolution, of which the most important are compiled in this chart (based on methodology developed by Axel Vollbrecht). 
Chapter 2 - Data and methodology

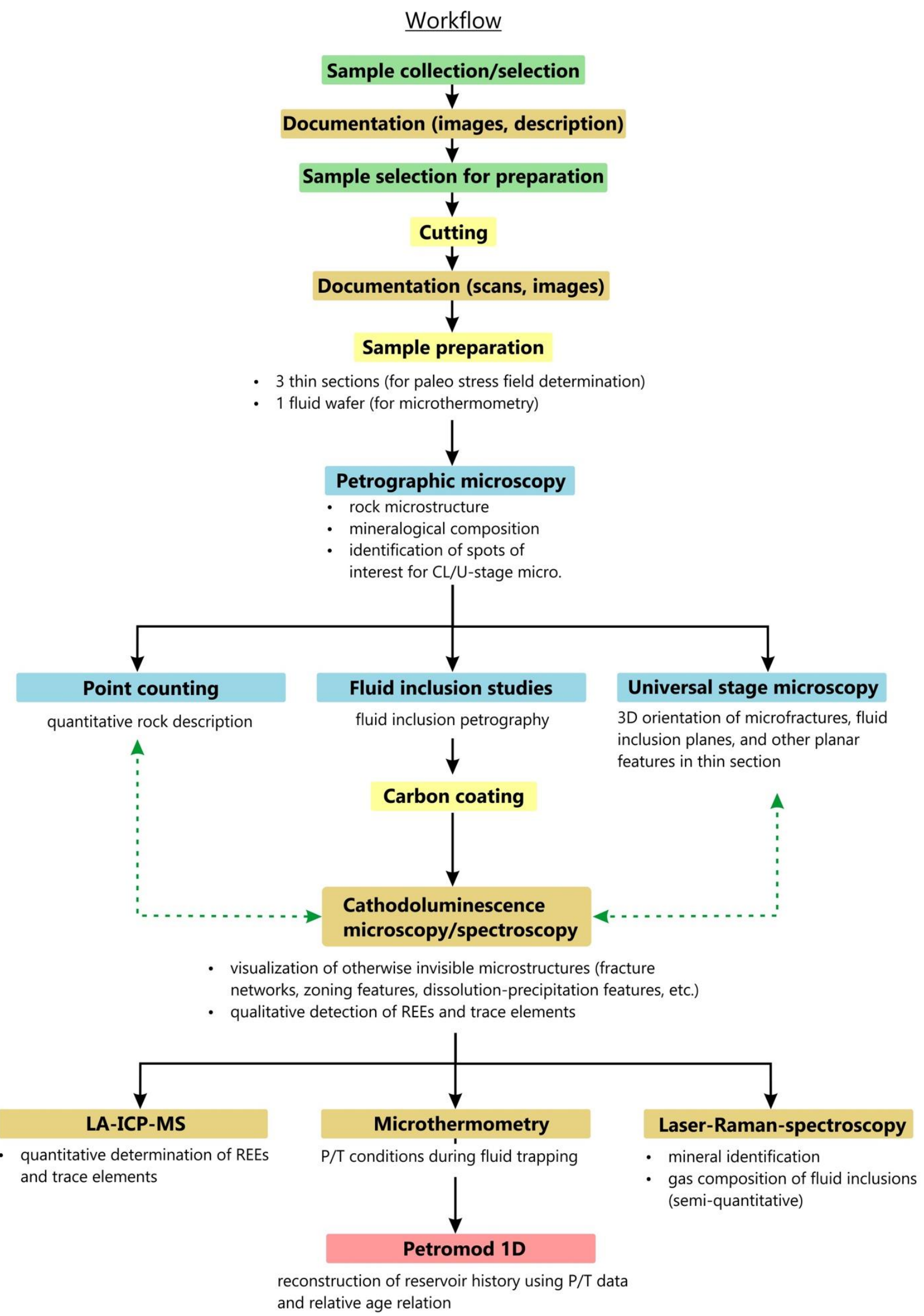

Fig. 2.2. Workflow chart showing chronological order of method application, as well as relations between different analytical methods. 


\subsection{Microscopic analysis and fluid inclusion studies}

\subsubsection{Quasi-planar elements in thin section - a terminology}

Universal stage microscopy in combination with an intersection method, which allows to reconstruct the orientation of planar elements from two or three linears related to the same fracture set (see below), was applied in order to detect planar brittle deformation features on the microscale that demonstrate the rock's response to extensional and/or compressional stress. Therefore, seven types of planar elements (i.e. discontinuities, fractures etc.) were distinguished according to their appearance in the microscope and in hand-specimen:

Bedding plane orientation was reconstructed by intersection of bedding linears from three orthogonal thin sections (A, B, C; for explanation see below) of one and the same sample using stereographic projection (intersection method).

Stylolite orientation was determined using the intersection method described before (see bedding plane); the direction of compression was estimated from stylolite teeth, which follow the main stress direction.

Microcracks: In this study microcracks are defined as microscopic planar discontinuities in rock resulting from brittle deformation. They are either open or healed; the latter type commonly contains (pseudo-)secondary fluid inclusions (fluid inclusion trails). Microcracks are characterized by a total width of less than $1 \mu \mathrm{m}$, their spatial orientation can only be determined by universal stage microscopy. Microcracks are commonly not affected by dissolution.

Fractures or microfractures: Though commonly used as an umbrella term for all kinds of brittle deformation features, fractures in this context are defined as mineralized discontinuities with a width between 15 and $500 \mu \mathrm{m}$ or more. Their spatial orientation can be determined by the intersection method or roughly estimated in hand specimen. In contrast to microcracks, fractures often show prominent dissolution features and thereby prove intense fluid-rock-interaction and fluid circulation.

Calcite twins, or twin lamellae result from a response to mechanical stress even at relatively low temperatures and confirm intracrystalline strain. Though twin formation is a temperature independent mechanism, deformation temperatures and strain rates can be roughly estimated by the maximum width of individual twin lamellae; in general, their orientation is \pm normal to the major principal stress direction (Burkhard, 1993).

\subsubsection{Thin section preparation - cutting method}

In the context of three-dimensional evaluation of rock properties, special emphasis has to be given to appropriate thin section preparation. Thin section and fluid wafers used for this study were cut according to an orthogonal system, which means that three thin sections normal to each other were produced out of every singly rock sample; the related cutting schedule is shown in Fig. 2.3. This method allows to determine the spatial orientation of linear and planar elements by comparing their relative orientation in all three section planes. Per definition, the so-called A-section represents a horizontal plane (Clar notation: 000/00) marked with an arrow, which preferentially indicates true north; otherwise it simply defines a false north within the respective reference system. Section B and C are cut parallel to true or representative W-E (B) or N-S (C) axis and normal to the A-plane, thus representing 180/90 and 090/90 planes in the stereonet. Sections $\mathrm{B}$ and $\mathrm{C}$ are marked by arrows pointing downwards. All arrows used as marks show one (A) or two (B/C) short lines branching off in $90^{\circ}$ angles, which results in an 
asymmetric shape that guarantees distinctiveness between samples, thin sections and mirrored fluid wafers.
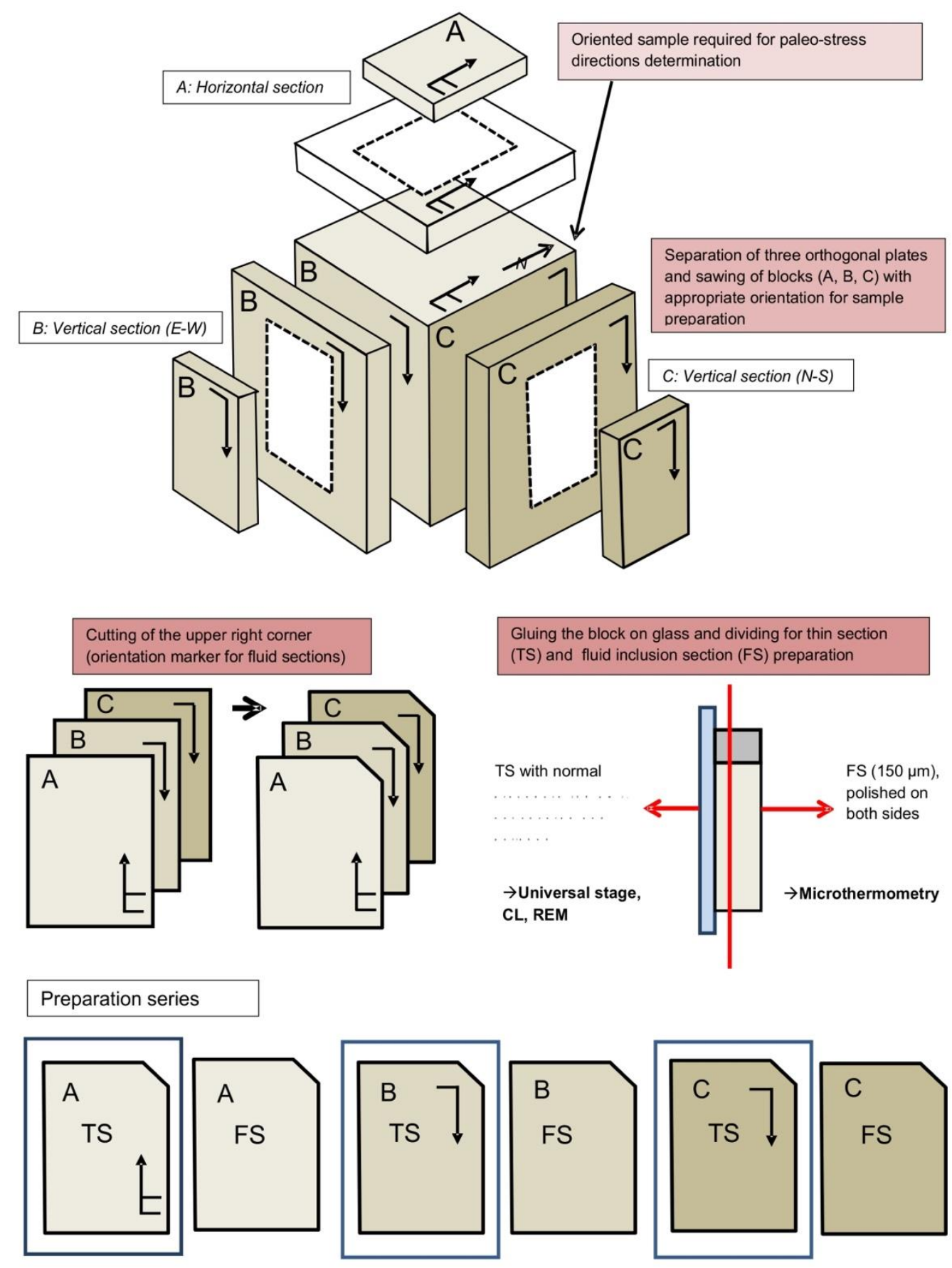

Fig. 2.3. Cutting schedule for 3D microcrack analysis and direction-oriented microthermometry of secondary fluid inclusions (image courtesy of Axel Vollbrecht).

A simple demonstration of the spatial intersection of linear elements and the resulting planar element using a stereonet is presented in Fig. 2.4. 

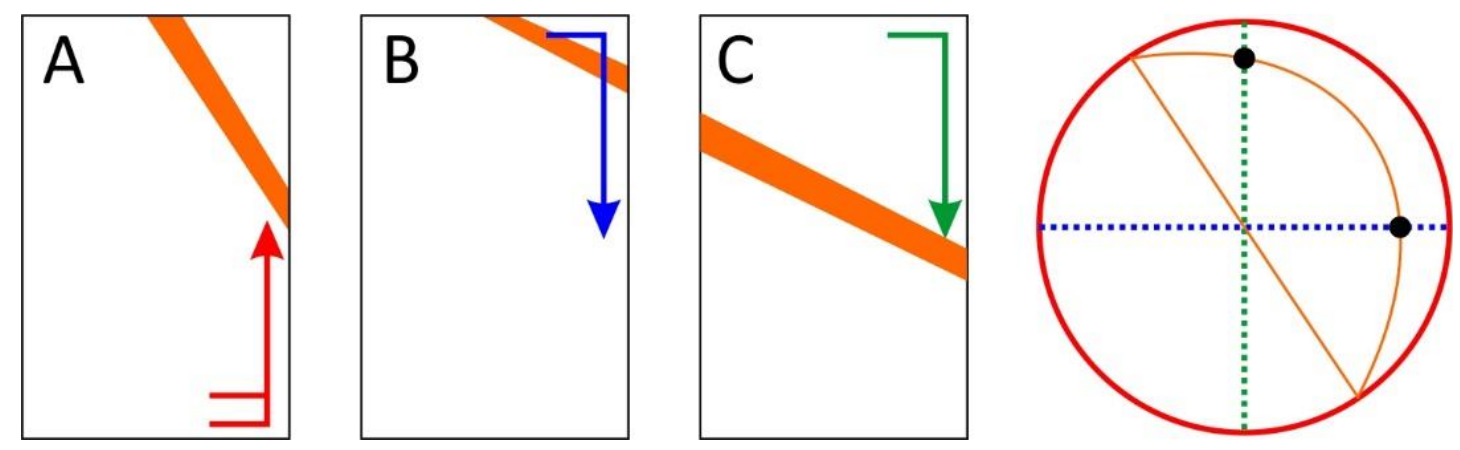

Fig. 2.4. Example illustrating the intersection method using a stereonet construction (Schmidt net, lower hemisphere). Given a planar element of known character, e.g. a bedding plane (orange), which is found as a linear element in all three thin sections prepared according to the cutting schedule explained above, it is possible to determine its spatial orientation. Therefore, the strike of the linear element in a horizontal section (A: 000/00, red circle) is plotted in a stereonet. Then, inclination of according element in section B (180/90; blue dotted line) and section C (090/90; green dotted line) is plotted as linear elements (black dots $=$ pole points). Now, the strike line and the great circle, which includes both poles from sections $B$ and $C$, result in a planar element (bedding plane) of defined orientation.

\subsubsection{Digital Image Analysis}

Samples were impregnated with epoxy mixed with blue dye to create higher contrast in thin section, when effective pore space was filled with blue epoxy, while the detrital particles and cements remained colourless or opaque in linear polarized light. Thin section scans were processed using ImageJ software (version 1.48); thereby 24-bit colour images were transformed into 8-bit grey scale images in order to separate both pore space (dark) and matrix (bright). To increase contrast and to avoid similarities in grey scale distribution between relatively dark mineral grains (esp. cloudy dolomite grains or ore minerals) and blue epoxy, the blue colour from epoxy was digitally replaced with red colour. Pore space was then calculated using a thresholding tool, where areas smaller than 10 pixels were neglected. Different steps of thin section-based pore space determination are shown in Fig. 2.5, for method and software details see Rasband (1997). 


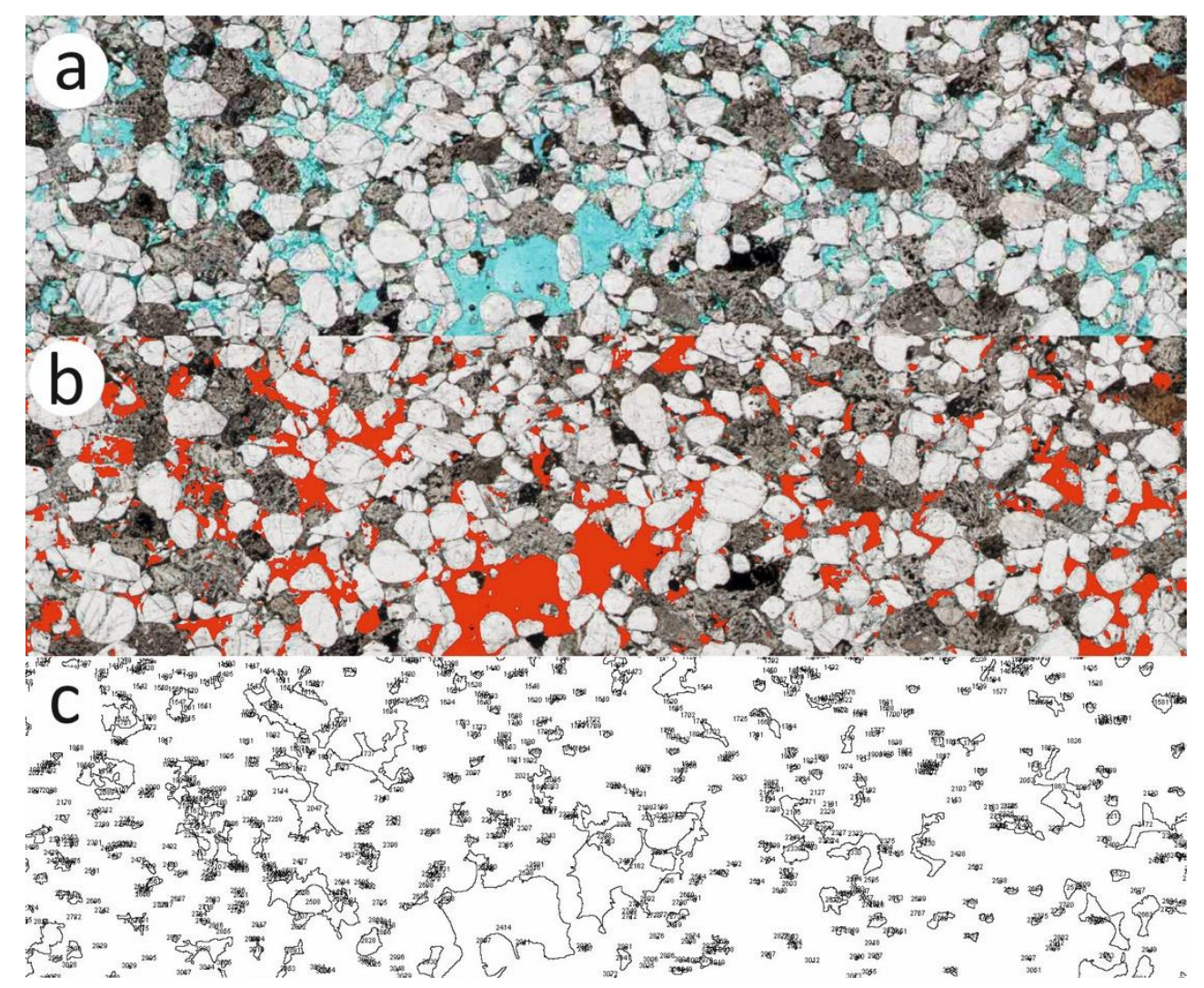

Fig. 2.5. Different steps of digital image analysis: (a) thin section scan with colourless and grey detrital particles and blue pore space; (b) blue pore space was digitally replaced with red colour in order to enhance contrast between particles and pore space. (c) Resulting image showing outlines of single pores considered for pore space calculation and according labels.

\subsubsection{Standard petrographic microscopy}

Principally microscopy in earth science means the use of polarized light for investigating minerals in thin sections as well as analysing structural details within the rock mass (Kerr, 1977). Doubly polished standard thin sections $(30 \mu \mathrm{m})$ from different stratigraphic positions of available drill cores and outcrop samples were investigated and documented. After that, appropriate samples were chosen for further analysis with microthermometry and cathodoluminescence methods. Laboratory investigations were done using a Leica DMCP microscope equipped with a set of lenses with different magnification $(2.5 \mathrm{x} / 5 \mathrm{x} / 10 \mathrm{x} / 20 \mathrm{x} / 63 \mathrm{x})$ and an attached Kappa Zelos-655C GV camera system (resolution 5 megapixels). Beside qualitative mineral and rock description using standard petrographic microscopy, the point counting method or Gazzi-Dickinson method was applied to some samples. This method was developed and introduced by (Gazzi, 1966) and (Dickinson, 1970) and allows to quantify mineral phases and pore space. Therefore, a thin section is installed in a mechanical stage, which can be gradually moved in clearly defined steps $(0.1 / 0.2 / 0.3 \ldots \mathrm{mm})$ along two perpendicular horizontal axes. After every stop in a row or a column, the object visible in the eyepiece lens is documented. Thus, after several hundred steps a representative ratio between pore space and mineral phases can be calculated. The accuracy of this method strongly depends on the chosen step size (this study: $0.1 \mathrm{~mm}$ ) and the total number of steps (this study: $\mathrm{N} \geq 300$ ), which should guarantee a representative area of the thin section has been analysed. However, the Gazzi-Dickinson method turned out to be a useful supplement to digital image analysis. 


\subsubsection{Fluid inclusion studies}

Fluid inclusions are trapped as "primary" or "pseudosecondary" inclusions during crystal growth, or as "secondary" inclusions along partially healed fractures (van den Kerkhof and Hein, 2001). The primary fluids represent trapped relics of the mineralizing fluid. In sandstones e.g., they typically correspond to the cementing stage of quartz or carbonate during diagenesis. Besides, fluid inclusions are found in veinlets of quartz, carbonate, fluorite etc., which likely formed during later stages of fluid mobilization. Fluid inclusions in different rock-forming minerals reflect the development of the fluid system in sedimentary reservoirs. They are also indicators of fluid migration, notably of $\mathrm{CO}_{2}-\mathrm{H}_{2} \mathrm{O}$-bearing fluids in caprock and thereby prove reservoir leakage. The information if the cap rock was capable of holding fluids in the past is indicative also of the present permeability properties.

Fluid inclusions normally formed at different temperatures and pressures than presently found at the drill hole sampling sites. The fluid densities and compositions, together with mineralogical data allow the calculation of the fluid trapping conditions and the construction of the corresponding geothermal (paleo-)gradient. By comparing past and present gradients conclusions can be drawn about uplift or subsidence of the area since the time of fluid entrapment. Consequently, fluid inclusion studies help us to understand the migration of $\mathrm{CO}_{2}-\mathrm{H}_{2} \mathrm{O}$-bearing fluids through the cap rock. Furthermore, it allows us the:

- Determination of temperature and pressure conditions during fluid trapping

- Construction of the geothermal (paleo-)gradient

- Comparison of paleo-fluids with present pore and circulating fluids

- Estimate uplift or subsidence of the area since the time of fluid entrapment

After analysing the fluid inclusion content with microthermometric methods (see below), we measured the relative quantity of gases within gaseous and aqueous inclusions in order to determine fluid evolution, time of fluid mobilisation, origin of gas mixtures, as well as the time of hydrocarbon generation. This information helps us to reconstruct the thermal evolution of respective reservoirs (Goldstein and Reynolds, 1994).

\subsubsection{Microthermometry}

Fluid inclusions in minerals were studied using an Olympus BH-2 microscope equipped with a Linkam heating and freezing microscope stage (THMS $-\mathrm{G} 600$ ) in the temperature range of $-196^{\circ} \mathrm{C}$ to $+600^{\circ} \mathrm{C}$ (Shepherd et al., 1985). The stage was controlled using a Linkam T95 LinkSys control unit. Fluid inclusion wafers had a thickness between 150 and $180 \mu \mathrm{m}$. The calibration standard was a synthetic $\mathrm{H}_{2} \mathrm{O}-\mathrm{CO}_{2}$ ( \pm Ar)-standard (triple point at $-56.7^{\circ} \mathrm{C}$, accuracy $= \pm 0.1^{\circ} \mathrm{C}$ ). Imaging of the fluid inclusions was performed using a QICam camera system with a resolution of $1.4 \mathrm{mpx}$.

Each fluid inclusion underwent at least three cooling-heating cycles for cryometric investigations before heating above room temperature for determining halite melting and homogenization temperatures (Roedder, 1984). Fluid inclusion petrography, especially with respect to cathodoluminescence studies was done according instructions given in van den Kerkhof and Hein (2001). The methods developed by Thiery et al. (1994) and van den Kerkhof and Thiéry (2001) were applied for calculating composition and molar volume of gaseous inclusions in the system $\mathrm{CO}_{2}-\mathrm{CH}_{4}$ $\mathrm{N}_{2}$. Salt concentrations in the system $\mathrm{H}_{2} \mathrm{O}-\mathrm{NaCl}-\mathrm{CaCl}_{2}$ were determined after (Steele-MacInnis et al., 2011). Densities for aqueous, aqueous-carbonic and $\mathrm{CO}_{2}$-dominated inclusions were calculated using 
BULK software, isochores of according fluid inclusions were determined using ISOC software, both part of the software package FLUIDS 1 established by Bakker (2003). Salinity and density determinations using clathrate melting were performed following the method by Bakker (1997) (ICE software).

Isochore calculation of fluid inclusions is often used for the so-called crossing isochore method (Goldstein, 2001), a common method in the study of sedimentary fluids that allows to estimate fluid trapping conditions in terms of ,true“ pressure and temperature. Therefore, isochores are plotted in a P$\mathrm{T}$ diagram together with lithostatic gradients typically found in sedimentary basin systems, and a hydrostatic gradient. The area of intersection between isochores and respective gradients reveals corrected P-T conditions. However, since according lithostatic gradients are based on specific geothermal gradients (usually $30^{\circ} \mathrm{C} / \mathrm{km}$ ), corrected P-T values thus may not reflect the true thermal environment that existed during fluid trapping. Consequently, various geothermal gradients were applied, wherefore geothermal gradients obtained from 1D basin modelling was used for comparison. A detailed description of the crossing isochore method applied for this study is given in Fig. 2.6.
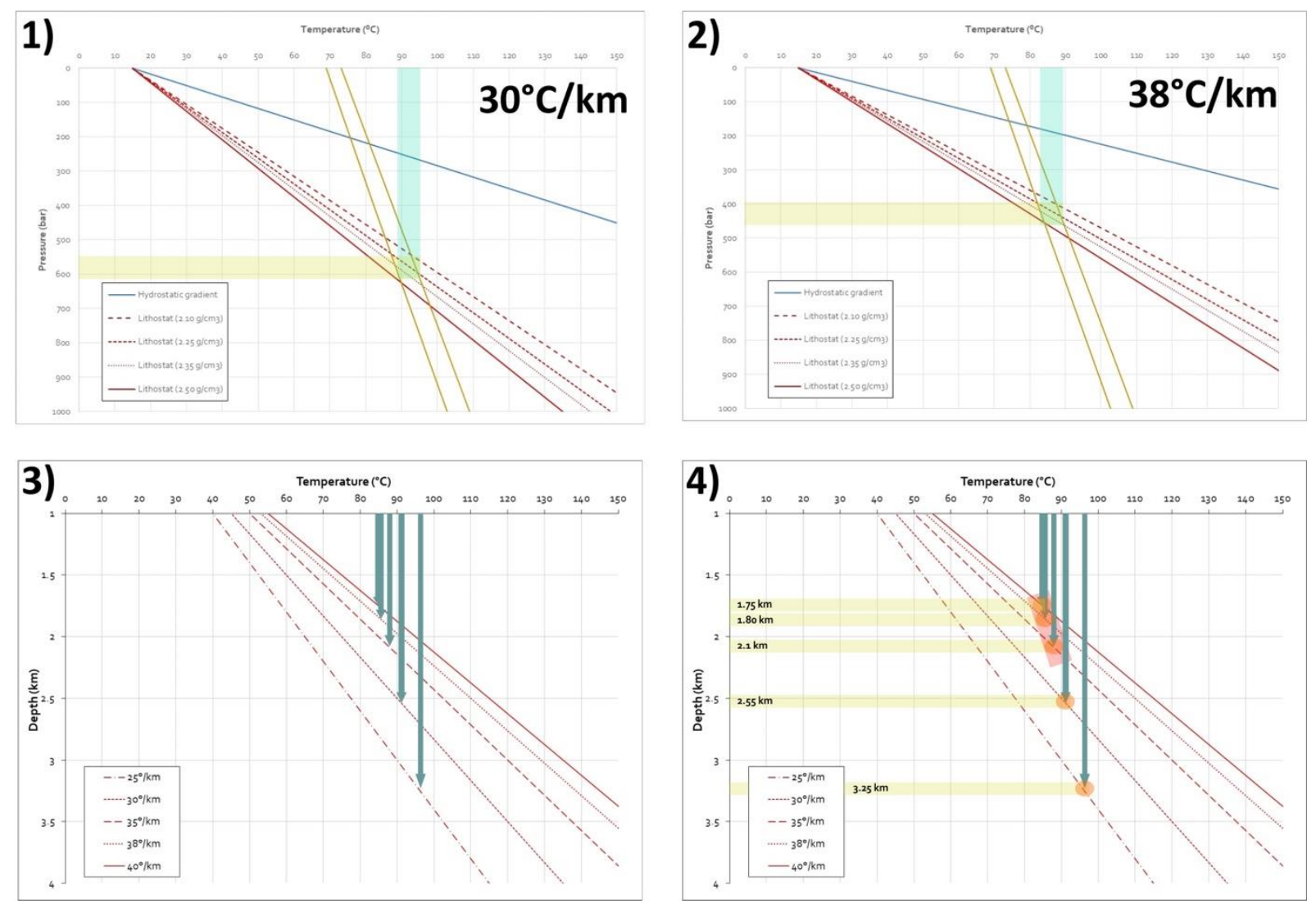

Fig. 2.6. Workflow for P-T correction (crossing isochores method). (1) Isochores and different lithostatic gradients are plotted in P-T diagram (bar vs. ${ }^{\circ} \mathrm{C}$ ) according to a specific geothermal gradient $\rightarrow$ Points of intersection between isochores and lithostatic gradients define $P$ and $T$ conditions during trapping with respect to a specific geothermal gradient. (2) Vary geothermal gradient $\rightarrow$ increased during riftinglextension, lower during inversion. (3) Plot geothermal gradients in D-T diagram ( $\left.\mathrm{km} \mathrm{vs.}{ }^{\circ} \mathrm{C}\right)$. Integrate corrected $T$ data for specific geothermal gradient-lithostatic gradient scenarios into D-T diagram. Note: corrected $P$ and T from crossing isochore calculations are lower when higher geothermal gradients are applied, and vice versa. Only corrected T data is used for further calculations. (4) According depth of formation for several temperature scenarios can now be derived directly from the depth scale. The red shaded area for example defines a P-T scenario typical for extensional settings (high heat flow). 


\subsubsection{Hot-cathode cathodoluminescence microscopy}

Thin sections were carbon coated for cathodoluminescence imaging. A hot-cathode microscope (HC3LM, Simon-Neuser) with a coupled Peltier-cooled Kappa PS 40C -285 (DX) camera system (resolution $1.5 \mathrm{mpx}$ ) attached to an Olympus BH-2 microscope was used for visualizing internal structures and zoning in minerals. The electron gun was operated at a voltage of $14 \mathrm{keV}$ under high vacuum $\left(10^{-4} \mathrm{bar}\right)$ with a filament current of $0.18 \mathrm{~mA}$; the diameter of the electron beam was ca. $0.4 \mathrm{~cm}$.

\subsubsection{Universal stage microscopy}

The universal stage is a mechanical accessory that can be attached to a petrographic microscope (Emmons, 1943; Fedorov, 1894, 1892). It allows one to tilt and rotate a thin section that is mounted between two glass hemispheres around four different axes, and thus, to measure the orientation of crystallographic (crystal c-axis, optical axis, optical angle, twin plane, etc.) or microfabric features (healed/sealed microfractures) (Muir, 1981; Reinhard, 1931). Though universal stage microscopy is commonly used to determine minerals and their crystallographic properties in thin section, it is also a helpful method to identify paleo-stress in deformed rocks (Kruhl et al., 2007), as microfractures typically form normal to the minimum principal stress (Mode I fractures).

Since microcracks represent recent (open) and paleo (healed, sealed) fluid pathways, they significantly contribute to the bulk permeability of rocks (e.g. leakage through cap rocks), in particular in areas where macroscopic fracture systems are lacking. Solid dense rocks mostly contain several generations of microcracks that formed progressively under varying conditions and hence can be used as records mainly of late stages of the geological history - in particular regarding paleo-stress fields.

A 3D-approach requires the observation of cracks and fractures in three perpendicular sections and the application of universal stage microscopy (see Fig. 2.3). In addition, microthermometry of secondary fluid inclusions, trapped in healed microcracks, can yield information on the P-T conditions of crack formation/healing. In this way, crack chronology can be related to different paleo-stress configurations. For our study a common Leitz 4-axis universal stage attached to a Leitz Ortholux standard petrographic microscope was used. Glass hemispheres were chosen with respect to birefringence of fracture-hosting minerals (calcite, quartz).

\subsubsection{Fry analysis}

The so-called Fry analysis or centre-to-centre method is a useful tool to quantify the strain and volume reduction a rock has experienced due to compression, be it compaction resulting from subsidence and burial or tectonic compression. In order to apply this method, the rock unit itself has to fulfil specific conditions, which are described in Fry (1979) in detail. In the first place, only particles with a more or less random and homogeneous distribution (anti-clustered distribution), i.e. with almost equal distances to each other can be considered. Particles used for calculation should be almost the same size and should not be recrystallized or altered in any way after deformation. Besides, a relatively high number of particles ('the more the better') is necessary for calculation in order to provide statistically significant results, in our case the minimum number of counts is $\mathrm{N}=>30$. Since ooids and detrital grains are quasispherical objects the initial R-value for the major number of particles considered in our approach would be $\mathbf{R}_{\mathbf{i}}=\mathbf{1}$. Only sections normal to the bedding plane were considered for our calculations, providing a 
two-dimensional strain along the z-axis (vertical). Strain ellipses were manually adjusted if necessary (Vollmer, 2017). Ten different sections were used for measurements and results were averaged.

\subsection{Geochemical analysis}

\subsubsection{Laser-Raman spectrometry}

We used a confocal Horiba Jobin-Yvon HR800 UV Raman spectrometer with a coupled Ar ${ }^{+}$-laser unit (wavelength $488 \mathrm{~nm}$ ) attached to an Olympus BX41 microscope. For internal calibration, silicon $\left(520 \mathrm{~cm}^{-1}\right)$ was used as standard material. Spectra of gaseous inclusions were measured between 1000 and $4000 \mathrm{~cm}^{-1}$ and acquisition times were $20 \mathrm{~s}$ for each measuring step (i.e. $3 \times 20 \mathrm{~s}$ ). Gas compositions were calculated using LabSpec software (v. 5.17.17). Gas ratios were determined with respect to the wavelength-dependent relative Raman scattering cross-sections for a $488 \mathrm{~nm}$ laser unit (see Burke, 2001). All measurements were carried out at the Geoscience Centre Göttingen, Experimental and Applied Mineralogy Division.

\subsubsection{LA-ICP-MS}

Trace element compositions of fluorite were obtained from in-situ analyses using a Perkin Elmer Sciex Elan DRC2 ICPMS instrument that is coupled to a Lambda Physics Compex 110 ArF-Excimer Laser ablation unit. The device is working at $193 \mathrm{~nm}$ including a low volume sample chamber and an optical imaging system. Ar is used as carrier gas. Prior to and after each ablation spot measurement, the background was recorded for $20 \mathrm{~s}$. The laser spot diameter has been set to $120 \mu \mathrm{m}$, the laser pulse repetition rate was $7 \mathrm{~Hz}$. The NIST610 standard was used for calibration (Pearce et al., 1997). ICP-MS data were processed using Iolite, the precision was calculated according to the formula $2 \times \sigma / \sqrt{ } n$, and the error is below $5 \%$. All measurements were carried out at the Geoscience Centre Göttingen, Geochemistry Division.

\subsubsection{Stable isotope mass spectrometry}

The isotopic composition of certain elements of interest can be a powerful tool to distinguish sources of those elements and identify geochemical processes. In the context of $\mathrm{CO}_{2}$ analogue studies, sources of $\mathrm{CO}_{2}$, and the chemical composition and sources of fluids are critical factors to understand mineral dissolution and corrosion processes in the aquifer as well as the history of fluid generation and secondary mineral formation. Sources of $\mathrm{CO}_{2}$ may be identified using the $\mathrm{C}$ isotope composition $(\delta 13 \mathrm{C})$ in fluid inclusions to trace the origin of the $\mathrm{CO}_{2}$ gas hosted in fracture-fill mineralization (Lüders et al., 2012).

Stable carbon isotopic ratios of $\mathrm{CH}_{4}$ and $\mathrm{CO}_{2}$ in fluid inclusions were measured simultaneously using a sample crusher attached to an elemental analyser (EA)-IRMS system; for a detailed method explanation see Lüders et al. (2012). Measurements were conducted at the Geoforschungszentrum Potsdam (GFZ). 
Chapter 2 - Data and methodology

\subsection{Numerical modeling}

\subsubsection{PetroMod $1 D$}

In order to compare our results with other basin evolution models we ran one-dimensional (i.e. referred to one borehole) numerical simulations using PetroMod® 1D (v. 2011.1.1, Schlumberger). Various datasets were combined in order to achieve best results for different basin evolution models. In this way possible explanations for the partly high thermal maturity of the sediments (i.e. deep burial versus magmatic intrusion) could be estimated. Our 1D basin modelling followed the assumption of varying water depth and erosion; paleo-bathymetric and exhumation corrections were applied with respect to McKenzie's method for continental lithosphere extension (rifting) (McKenzie, 1978). Vitrinite reflectance calibration was calculated using the algorithm EASY\%Ro from Sweeney and Burnham (1990). Surface temperatures are based on the findings of Wygrala (1989) (Northern Europe, 70 degrees latitude). The kinetic model for the Lower Saxony Basin (Chapter 5) assumed methane generation from coal-bearing Carboniferous sediments (Westphalian A - D) after calculations from Krooss et al. (1993). Basin modelling was carried out with respect to the procedures suggested by Poelchau et al. (1997) and Leischner et al. (1993) with a special focus on the integration of fluid inclusion data into the model. 


\title{
3. Post-depositional tectonic control on fluid migration in the Southern Permian Basin - microfabric and fluid inclusion studies on aeolian sandstones (Rotliegend) from the Fizzy Field drill site (UK)
}

\begin{abstract}
The Fizzy Field gas accumulation is a well-known reservoir with exceptionally high $\mathrm{CO}_{2}$ concentration (borehole content 50\%), located along the north-eastern border of the Brown Graben (Southern Permian Basin). $\mathrm{CO}_{2}$ migration from lower units into the current reservoir within Rotliegend sandstones was supposedly initiated by inversion tectonics during the late Cretaceous. Core sample material, provided by the British Geological Survey has been analysed using petrographic microscopy, cathodoluminescence microscopy (CL), microthermometry, and Laser-Raman-spectroscopy in order to characterize different cement phases (quartz, dolomite) and syn-diagenetic fracture mineralization (barite), as well as their respective fluid inclusion (FI) content. Homogenization temperatures $\left(\mathrm{T}_{\mathrm{h}}\right.$ ) of fluid inclusions were used to estimate formation conditions during mineral precipitation. Due to its complex geological and tectonic history the Fizzy Field reservoir serves as an ideal natural analogue for carbon dioxide storage at industrial scale. The aim of this research was to better understand the processes of $\mathrm{CO}_{2}$-migration and -trapping in sedimentary basins and to determine the conditions necessary for carbon storage in a fault-related reservoir. The provided sample material is an aeolian sandstone (litharenite) from the Rotliegend Group (Leman Sandstone Formation) from wells 50/26-1 (2338.4 to 2402.9 mbs) and 50/26b-6 (2292.6 to 2440.5 mbs) of the Fizzy Field drill site. Early-diagenetic dolomite cement (DC-I) preserved water of meteoric composition within primary monophasic FI. Some inclusions show bubble nucleation after ice melting. Syntaxial quartz cement that was subsequently formed during burial shows brownish zoning features in CL revealing several cement generations (polyphase precipitation). Primary FI in quartz contain $\mathrm{NaCl}-\mathrm{H}_{2} \mathrm{O} \pm \mathrm{MgCl}_{2}$ fluids of medium salinity $(12.3 \mathrm{wt} \% \mathrm{NaCl}), \mathrm{T}_{\mathrm{h}}$ range from 81.2 to $107^{\circ} \mathrm{C}$. Syn-diagenetic barite veins of hydrothermal origin also contain $\mathrm{NaCl}-\mathrm{H}_{2} \mathrm{O} \pm \mathrm{MgCl}_{2}$ fluids of higher salinity within primary $(20.8 \mathrm{wt} \% \mathrm{NaCl}$ ) and pseudosecondary FI $(23.2 \mathrm{wt} \% \mathrm{NaCl})$. Primary FI show minimum $\mathrm{T}_{\mathrm{h}}$ of $135^{\circ} \mathrm{C}$ and suggest that high thermal maturity in the study area was restricted to faults; $\mathrm{T}_{\mathrm{h}}>160^{\circ} \mathrm{C}$ in pseudo-secondary FI are caused by necking down. Rhombohedral dolomite cement (DC II + III) that formed prior to or during basin inversion sometimes overgrows early diagenetic dolomite that was previously partially dissolved by $\mathrm{CO}_{2}$-saturated, acidic brines (Heinemann et al., 2013). Primary FI in late diagenetic dolomite contain high salinity (23.1 wt $\% \mathrm{NaCl}$ ) Ca-Na-dominated aqueous solutions, proving intense fluid-rock interaction which resulted in a typical basinal brine; $\mathrm{T}_{\mathrm{h}}$ range from 61 to $74^{\circ} \mathrm{C}$.
\end{abstract}

No $\mathrm{CO}_{2}$ was preserved within FI.

Our results support the idea of gas trapping at a relatively late stage of basin development. $\mathrm{CO}_{2}$ must have migrated along faults and accumulated within the reservoir shortly before or during uplift (Late Cretaceous - Early Paleogene). Simultaneously, a late diagenetic dolomite likely precipitated from a then $\mathrm{CO}_{2}$-saturated fluid (Heinemann et al., 2013) at significantly lower depth compared to calculated maximum burial conditions. The calculated uplift between maximum burial and late diagenetic dolomite precipitation is about $700 \mathrm{~m}$; the total uplift ranges between 800 and $1000 \mathrm{~m}$.

\subsection{Introduction}

The discovery of $\mathrm{CO}_{2}$ - and $\mathrm{N}_{2}$-dominated gas occurrences within Rotliegend Group-hosted reservoirs in the Southern Permian Basin in 1995 came as a surprise, because by then the Leman Sandstone 
Formation reservoir play fairway was known as a methane-dominated gas province (Underhill et al., 2009; Yielding et al., 2011). Unexpected discoveries of $\mathrm{CO}_{2}$ occurrences represent a danger to drilling projects and therefore must be avoided in petroleum and gas exploitation. In order to better understand the evolution of $\mathrm{CO}_{2} / \mathrm{N}_{2}$ occurrences not only the origin of respective gases is of interest, but also the role of the structural and the thermal evolution of related basins and associated trap structures. Previous studies on the geology of Rotliegend reservoirs in the Southern North Sea mostly deal with the structural setting of the area (Underhill, 2009; Underhill et al., 2009). Special emphasis is given on the differentiation of the Southern Permian Basin (SPB) into various sub-basins due to syn-sedimentary rifting during the Permian as well as on the tectonic control of the late Cretaceous basin inversion on fluid migration throughout the basin.

Other research approaches focus on the fluid-rock-interaction within the reservoir prior to and after $\mathrm{CO}_{2}$ influx (Heinemann et al., 2013; Wilkinson et al., 2009). A major point of interest in basin evolution is the origin of the $\mathrm{CO}_{2}$. While a derivation from organic matter (Carboniferous Coal Measures) can be excluded, thermal alteration of sediments seems a possible explanation (Wycherley et al., 1999). Other authors argue, that mantle processes (degassing) during basin inversion (Hillis, 1995) or plutonic intrusions and the widespread formation of dykes during the Cenozoic may be responsible for the $\mathrm{CO}_{2}$ flux (Underhill, 2009), though dyke intrusion reportedly mostly affected reservoirs within Triassic sediments.

Due to its complex geological history, the Fizzy Field $\mathrm{CO}_{2}$ occurrence serves as an ideal analogue for a fault seal trap that guaranteed tight reservoir conditions over a significant geological time scale of approximately $50 \mathrm{ma}$ (Yielding et al., 2011). Beside the determination of major rock properties, seismic interpretation and geochemical analysis, a detailed investigation of possible burial and uplift scenarios in the respective basin is crucial for the reconstruction of fluid conduits and dissolution-precipitation processes that may deliver new information on the timing of $\mathrm{CO}_{2}$ migration and the influence of fracturing on reservoir integrity. Detailed petrographic studies on Leman sandstone samples with a special emphasis on cements and the diagenetic evolution were carried out by Arthur et al. (1986), Purvis (1992), and McNeil et al. (1998).

The primary objectives of the present study are the reconstruction of the diagenetic evolution of the Leman Sandstone Formation and, moreover, to reveal the fracture-related fluid migration in a complex graben system (Brown Graben/Southern North Sea) in order to complement its structural, geochemical and thermal history. The timing of fracture propagation as well as the time of reservoir-loading with $\mathrm{CO}_{2}$ and its subsequent impact on the sandstone porosity represent other major objectives of this approach.

In order to determine the mineralogical composition of the Leman Sandstone standard petrographic microscopy was applied. The volumetric distribution of minerals and cement phases was determined using the point counting method (Gazzi-Dickinson method). Hot-cathode cathodoluminescence microscopy was carried out to distinguish between different growth generations in quartz and dolomite cements. Hence, the relative age of cement phases and fracture mineralization could be determined. Together with fluid inclusion and microthermometric studies on fracture mineralization (barite) and cement phases (quartz, dolomite) the diagenetic history of the Leman Sandstone was revealed in detail. Using microthermometry the salinity of fluid inclusions as well as their density was determined in order to detect significant changes in fluid chemistry within the reservoir prior to and after basin inversion. Furthermore, calculated isochores of fluid inclusions derived from respective homogenization temperatures were correlated with various lithostatic gradients typically found in sedimentary basins. Thus, the respective depth of the Leman Sandstone Formation during mineral precipitation could be 
estimated. In consequence, associated formation temperatures could be defined and correlated with (paleo-) geothermal gradients at the time of formation.

Collected data helped us to better understand the influence of the local tectonic regime on burial and uplift, and its role for fluid migration and gas entrapment.

\subsection{Geological setting}

The Fizzy Field is a $\mathrm{CO}_{2}$ reservoir located along the eastern edge of the Brown Graben, a smaller sedimentary sub-basin within the major W-E striking Southern Permian Basin (SPB), below the UK sector of the Southern North Sea (Fig. 3.1). The SPB is an intra-cratonic basin that extends over 1500 $\mathrm{km}$ from the UK in the north-west to Poland and the Baltic states in the east (Doornenbal and Stevenson, 2010; Ziegler, 1990). The Brown Graben is a minor inverted graben structure located along the southern parts of the North Sea Basin (SNSB) Rotliegend play fairway (Yielding et al., 2011). With the Cleaver Bank High and the Indefatigable Shelf to its north, the Broad Fourteens Basin to its east, the Sole Pit Basin adjacent to its west, as well as the Winterton High to its south, the Brown Graben is located along the junction of several major structural elements within the SNSB (Underhill, 2003).

The lowermost units within the NW-SE striking Brown Graben are mostly of late Carboniferous age (or older) and mainly consist of coal-bearing sediments from the Coal Measures Group (Westphalian). As a consequence of the Variscan orogeny and the formation of a fold-and-thrust belt the sediments were deformed and tilted (Glennie, 1998; Glennie and Underhill, 1998; Underhill, 2009; Ziegler, 1990). The sediments of the Coal Measures Group were originally deposited in a foreland basin that stretched in front of the Variscan mountain belt (Glennie and Underhill, 1998). 


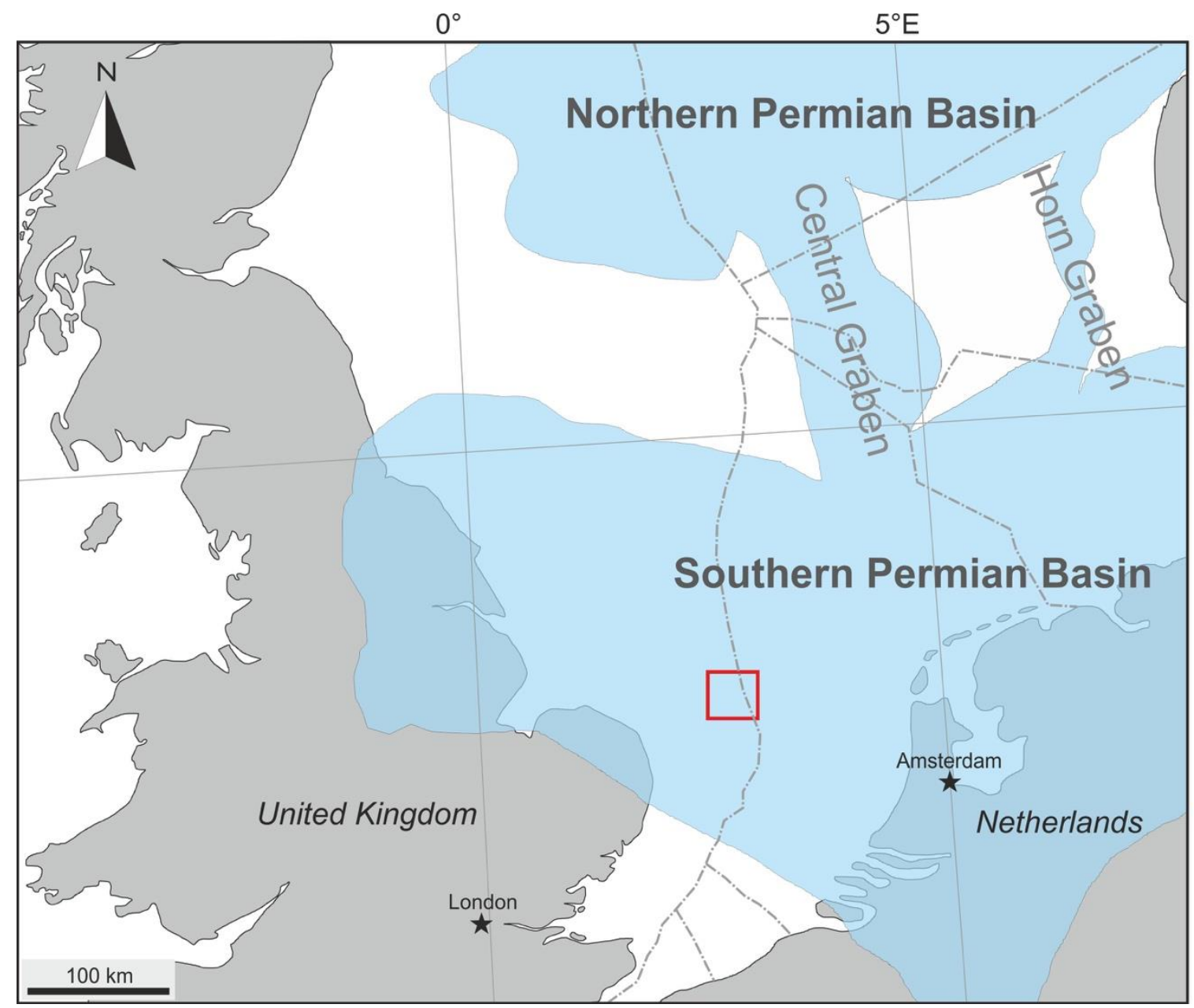

Fig. 3.1. Regional sketch of the Southern Permian Basin and adjacent areas. The extent of the Permian Basin is shaded in blue, the study area is marked by a red rectangle.

During the late Permian, following the Base Permian Unconformity (Corfield et al., 1996), aeolian wadi and sabkha depositional environments led to the formation of the Rotliegend Group (Fig. 3.2; Glennie, 1998). After sedimentation of the Rotliegend units in an arid environment, tectonic extension and the opening of the basin decreased (Geluk, 2005). 


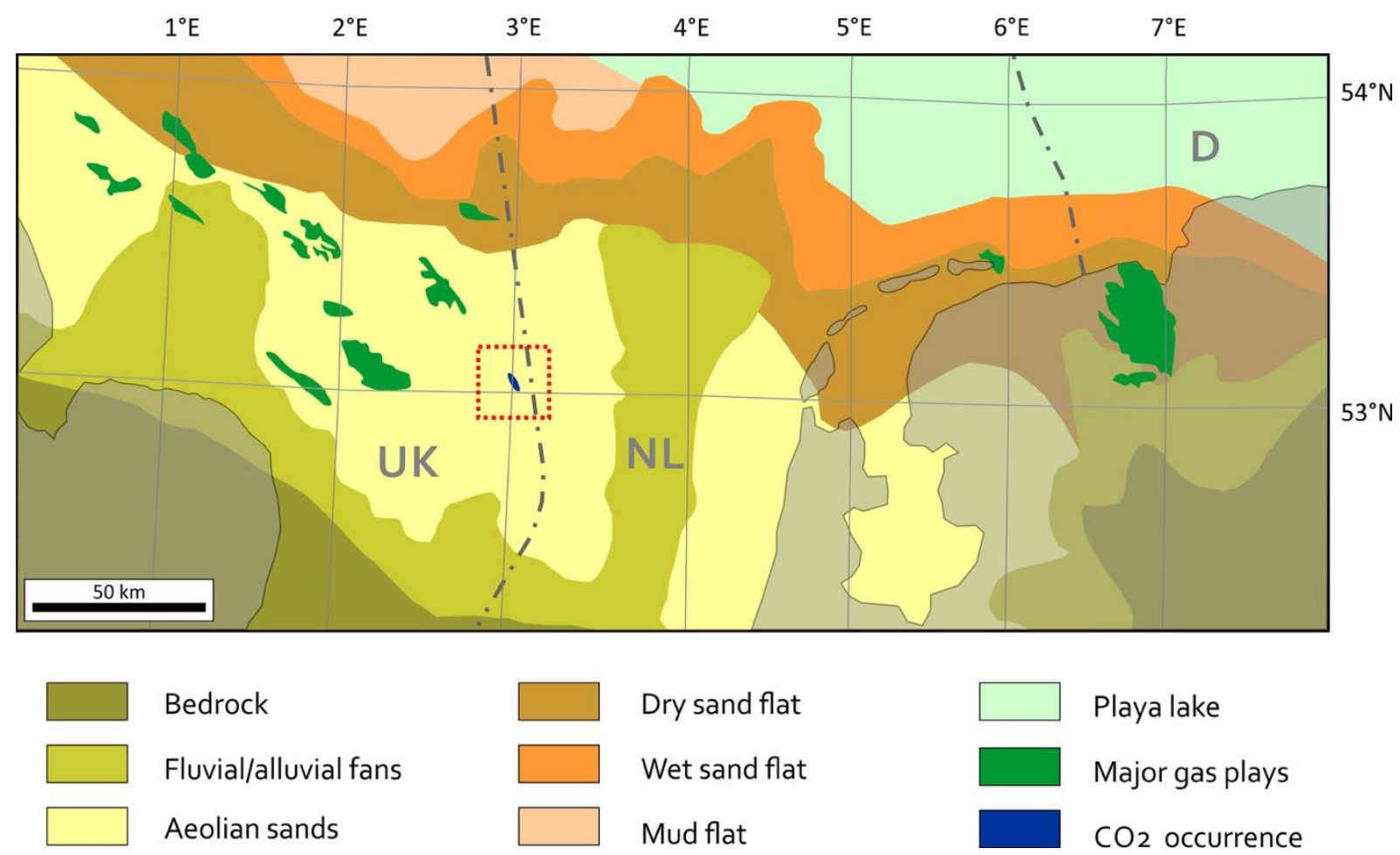

Fig. 3.2. Paleogeographic map showing the distribution of Rotliegend facies and related gas plays within the Southern North Sea Basin located between the Netherlands and the UK. The study area is marked by a red dotted rectangle (compiled and modified from Moscariello, 2005; Underhill, 2009; Ziegler, 1982).

The subsequent intrusion of seawater from the north into the resulting depression led to a marine recharge and evaporation during the late Permian, which caused the formation of the Zechstein Supergroup (Tucker, 1991), that consists of a cyclic sequence of carbonates and evaporates. Zechstein sediments are superimposed by continental clastic red-bed sediments of early to mid-Triassic age (Johnson et al., 1994), followed by sediments of Cretaceous and Paleogene to Neogene age. Jurassic and early Cretaceous units are missing due to erosion (mid - late Cimmerian Unconformity/Base Cretaceous Unconformity; Underhill et al., 2009). Basin inversion in the Fizzy Field area occurred during late Cretaceous and early Paleogene times. More extensive insights into the tectonic history of the area with special emphasis on inversion structures is given by Badley et al. (1989). A detailed stratigraphic overview together with a summary of major geologic events are illustrated in Fig. 3.3. 
Chapter 3 - Post-depositional tectonic control on fluid migration in the Southern Permian Basin

\begin{tabular}{|c|c|c|c|c|c|c|}
\hline \multirow{2}{*}{$\begin{array}{c}\text { Time } \\
\text { (million years } \\
\text { before present) }\end{array}$} & \multicolumn{3}{|c|}{ Chronostratigraphy } & \multirow{2}{*}{ Lithostratigraphy } & \multirow{2}{*}{ Formation/Member } & \multirow{2}{*}{ Major geologic events } \\
\hline & Era & Period & Epoch & & & \\
\hline 2.58 & \multirow{7}{*}{ 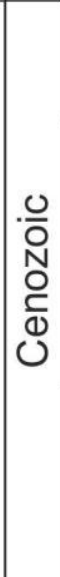 } & 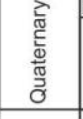 & $\begin{array}{l}\text { Holocene } \\
\begin{array}{l}\text { Pleisto- } \\
\text { cene }\end{array}\end{array}$ & & & $\begin{array}{l}\text { Uplift (?) \& } \\
\text { Erosion }\end{array}$ \\
\hline \multirow{3}{*}{5.3} & & \multirow{3}{*}{ 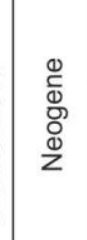 } & $\begin{array}{l}\text { Plio- } \\
\text { cene }\end{array}$ & & Nordland Group & \\
\hline & & & & & & Deposition \\
\hline & & & $\begin{array}{l}\text { Mio- } \\
\text { cene }\end{array}$ & & Westray Group & $\begin{array}{l}\text { Mid Tertiary } \\
\text { inversion }\end{array}$ \\
\hline 23 & & \multirow{3}{*}{$\begin{array}{l}0 \\
\stackrel{0}{0} \\
0 \\
\delta \\
\frac{d}{\pi} \\
0\end{array}$} & $\begin{array}{l}\text { Oligo- } \\
\text { cene }\end{array}$ & & \multirow{2}{*}{ Stronsay Group } & Dyke intrusion \\
\hline \multirow{2}{*}{56} & & & Eocene & & & \\
\hline & & & Paleo- & & Moray \& Montrose Group & $\begin{array}{l}\text { Deposition \& } \\
\text { subsidence }\end{array}$ \\
\hline \multirow{2}{*}{66} & \multirow{7}{*}{ 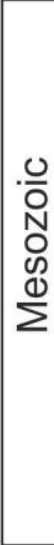 } & \multirow{4}{*}{ 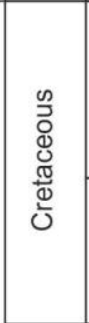 } & & & \multirow[b]{2}{*}{ Chalk Group } & \multirow{2}{*}{$\begin{array}{l}\text { Late Cretaceous } \\
\text { inversion }\end{array}$} \\
\hline & & & Upper & & & \\
\hline 100.5 & & & Lower & & Cromer-Knoll Group & $\begin{array}{l}\text { Deposition \& } \\
\text { subsidence }\end{array}$ \\
\hline \multirow{2}{*}{$\begin{array}{l}145 \\
201.3\end{array}$} & & & issic & $\begin{array}{c}\text { Base Cretaceous } \\
\text { Unconformity } \\
\text { Mid/Late }\end{array}$ & & \multirow{4}{*}{$\begin{array}{l}\text { Late Cimmerian } \\
\text { inversion } \\
\text { (extensionsal } \\
\text { thermal uplift) }\end{array}$} \\
\hline & & \multirow{3}{*}{ 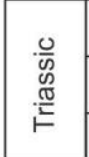 } & Upper & $\begin{array}{l}\text { Cimmerian } \\
\text { Unconformity }\end{array}$ & & \\
\hline \multirow{2}{*}{228} & & & Middle & & Haisborough Gruop & \\
\hline & & & Lower & & Bacton Group & \\
\hline 252.2 & \multirow{5}{*}{ 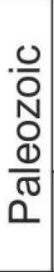 } & \multirow{3}{*}{ 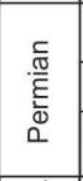 } & Loping- & \multirow{4}{*}{$\begin{array}{l}\text { Variscan } \\
\text { Unconformity }\end{array}$} & Zechstein Supergroup & \multirow{3}{*}{$\begin{array}{l}\text { Deposition \& } \\
\text { subsidence }\end{array}$} \\
\hline \multirow[t]{2}{*}{259.8} & & & $\begin{array}{l}\text { lan } \\
\text { Guada- } \\
\text { lupian }\end{array}$ & & $\begin{array}{l}\text { Rotliegend Group } \\
\text { (Leman Sst.) }\end{array}$ & \\
\hline & & & $\begin{array}{l}\text { Cisura- } \\
\text { lian }\end{array}$ & & & \\
\hline \multirow{2}{*}{$\begin{array}{l}298.9 \\
323.2\end{array}$} & & \multirow{2}{*}{ 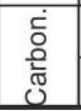 } & Upper & & & \multirow{2}{*}{$\begin{array}{c}\text { Post-variscan } \\
\text { inversion }\end{array}$} \\
\hline & & & Lower & & $\begin{array}{c}\text { Coneybeare \& } \\
\text { Whitehurst Group }\end{array}$ & \\
\hline
\end{tabular}

Fig. 3.3. Stratigraphy and tectonic history of the Brown Graben and adjacent structural units in the Southern Permian Basin. (modified from Underhill et al., 2009).

$\mathrm{CO}_{2}$ in the Fizzy Field structural trap occurs within aeolian sandstones of the Rotliegend group (Leman Sandstone Formation). It is superimposed by late Permian evaporates from the Zechstein Supergroup that represent the sealing unit (see Fig. 3.3, stratigraphic chart). The structure of the reservoir is linked to a major NW striking system of juxtaposed faults forming a fault-block structure, the Fizzy Horst. The Fizzy Horst represents the eastern rift shoulder of a NW-SE striking minor graben system, the Brown Graben (Fig. 3.4) 


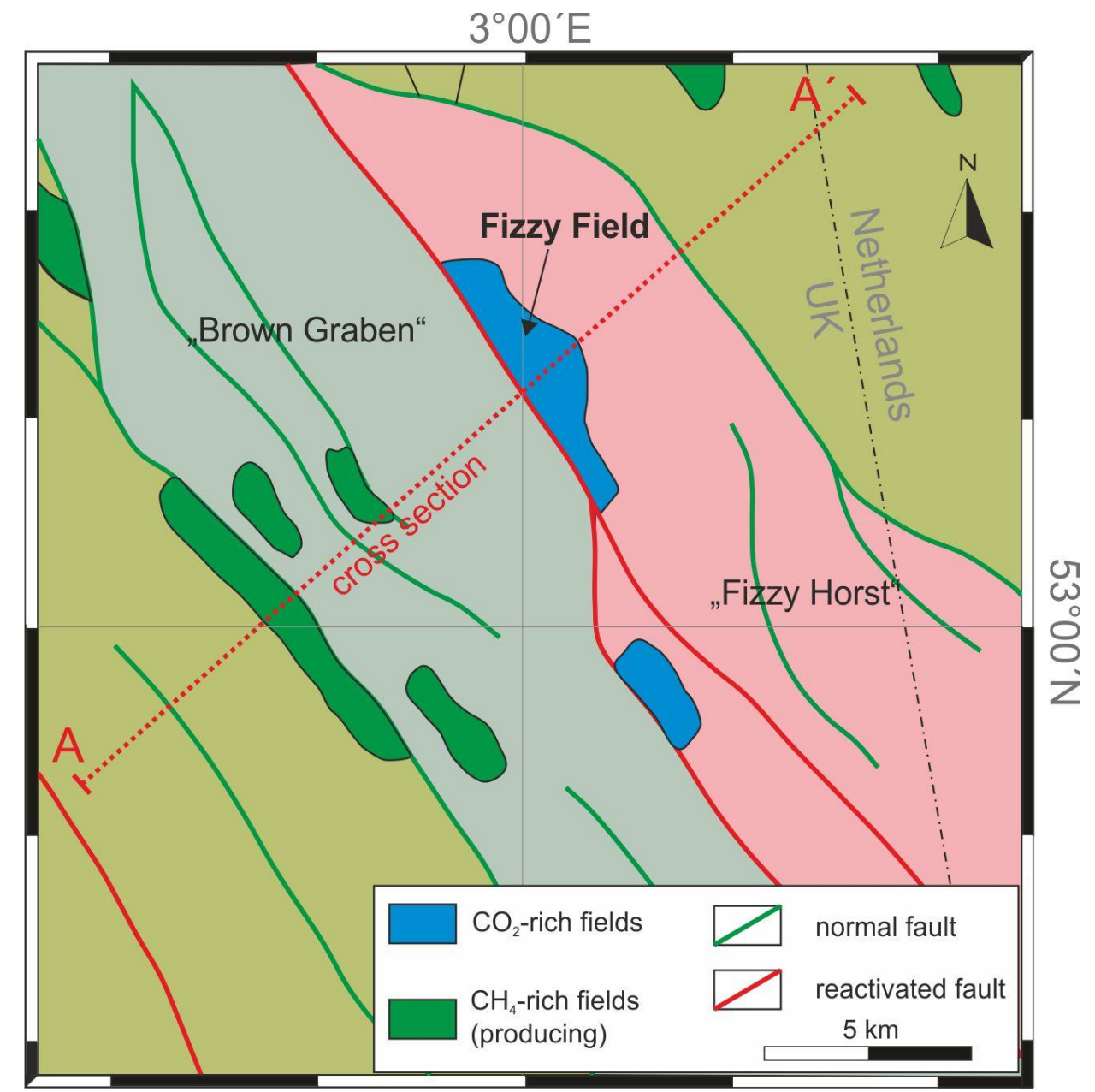

Fig. 3.4. Locality map showing the thectonic framework and the distribution of discovered gas accumulations in the Brown Graben area based on 3D seismic data. (modified from Underhill et al., 2009). The Fizzy Field gas accumulation is located along a major reactivated fault (see cross section Fig. 3.5).

Part of this graben structure was inverted during the late Cretaceous, when pre-existing normal faults from the late Permian rifting phase were reactivated due to compressional tectonics (Underhill et al., 2009). Sampling wells are located close to a steep south-west tending fault that formed during basin inversion and delimits the horst-structure at its western rim (Fig. 3.5). Based on information from Harper (1971) and Doornenbal and Stevenson (2010) the geothermal gradient at the Fizzy Field Horst can be estimated as ca. $29^{\circ} \mathrm{C}$, thus leading to current reservoir temperatures of ca. $82^{\circ} \mathrm{C}$. 


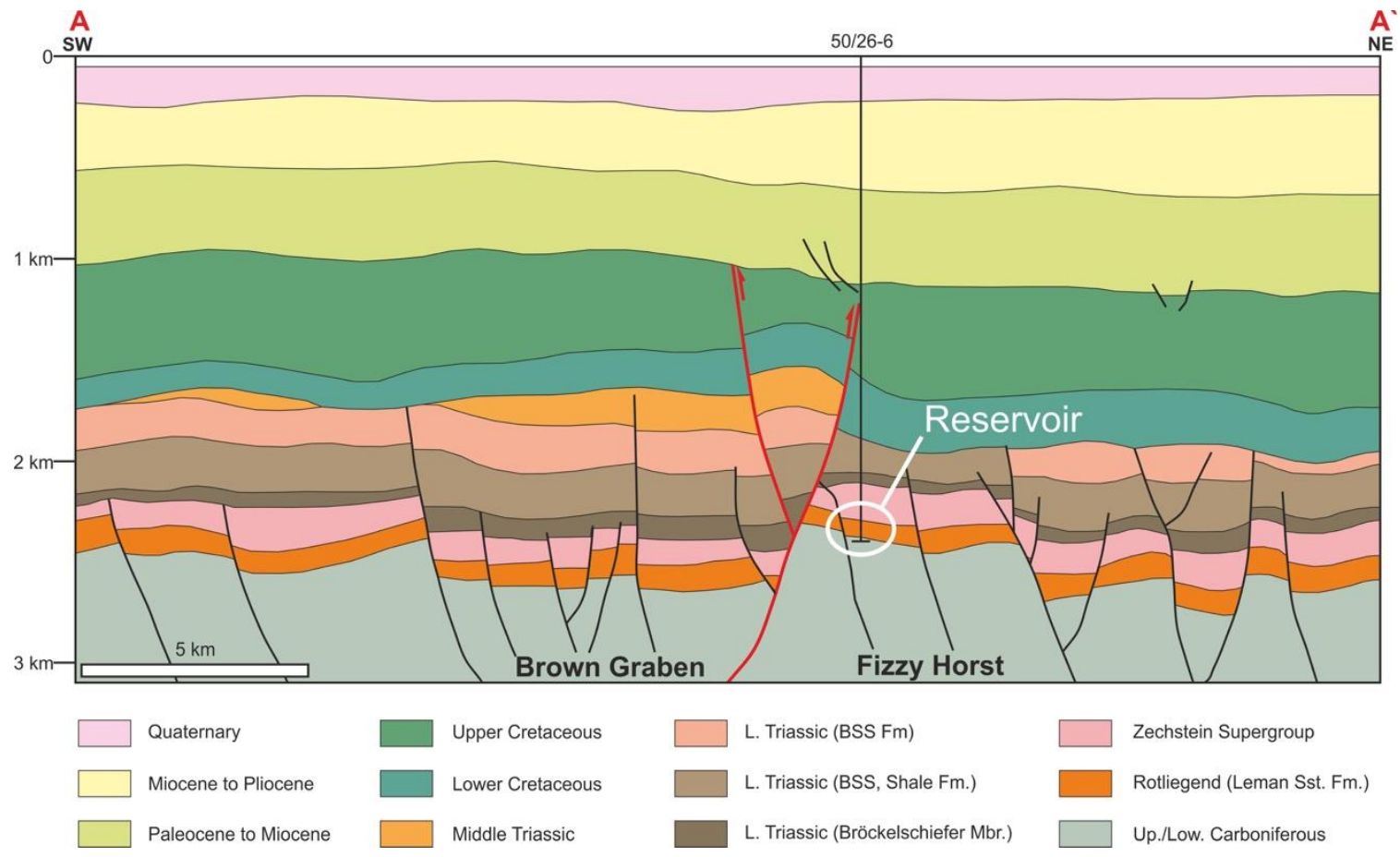

Fig. 3.5. Cross section through the NNW-SSE striking Brown Graben and the adjacent Fizzy Horst at its northeastern rim. The sampling location (well 50/26-6) is indicated by a solid black line (modified from Underhill et al., 2009). Pre-existing normal faults that were reactivated as reverse faults during basin inversion in late Cretaceous and early Cenozoic are marked by red lines and arrows. Sedimentation in the study area is characterized by several burial and subsequent uplift events that resulted in disconformities (compare Fig. 3.3).

\subsection{Sample material and methodology}

The provided sample material is an aeolian sandstone (litharenite) from the Rotliegend group (Leman Sandstone Formation) from wells 50/26-1 (2338.4 to $2402.9 \mathrm{mbs}$ ) and 50/26b-6 (2292.6 to $2440.5 \mathrm{mbs}$ ) of the Fizzy Field drill site. A number of different analytical methods have been applied in order to examine the (thermal) evolution of the basin, the diagenetic regimes, mineral crystallization and chemistry of related fluids. 11 polished thin sections were prepared, from which of them 3 a mirrored and doubly polished sample was used for fluid plate preparation. In this way fluid plates and thin sections of the same sample can be compared in the same orientation. Cathodoluminescence microscopy facilitates to distinguish primary or (pseudo-) secondary fluid inclusions. 11 standard thin sections $(30 \mu \mathrm{m})$ from different stratigraphic positions throughout the Rotliegend sequence of the available drill cores were investigated and documented using standard petrographic microscopy, cathodoluminescence microscopy, and point counting (Gazzi-Dickinson method). After that, appropriate samples were chosen for further analysis like point counting, microthermometry, and cathodoluminescence methods. A list of the samples can be seen below (Tab. 3.1). 
Chapter 3 - Post-depositional tectonic control on fluid migration in the Southern Permian Basin

Tab. 3.1. List of investigated samples from the Fizzy Field drill site.

\begin{tabular}{|c|c|c|c|c|c|}
\hline Name & Well & Drillers depth $(\mathrm{m})$ & gas or water & thin section & fluid plate \\
\hline Sample 1 & $50 / 26 b-6$ & $2292.6-2316.3$ & gas & $x$ & \\
\hline Sample 2 & $50 / 26 b-6$ & $2292.6-2316.3$ & gas & $x$ & $x$ \\
\hline Sample 3 & $50 / 26 b-6$ & $2292.6-2316.3$ & gas & $x$ & \\
\hline Sample 4 & $50 / 26 b-6$ & $2292.6-2316.3$ & gas & $x$ & \\
\hline Sample 5 & $50 / 26 b-6$ & $2292.6-2316.3$ & gas & $x$ & \\
\hline Sample 6 & $50 / 26 b-6$ & $2292.6-2316.3$ & gas & $x$ & \\
\hline Sample 7 & $50 / 26 b-6$ & $2292.6-2316.3$ & gas & $x$ & \\
\hline Sample 8 & $50 / 26 b-6$ & $2292.6-2316.3$ & gas & $x$ & \\
\hline Sample 9 & $50 / 26-1$ & $2338.4-2402.9$ & water & $x$ & \\
\hline Sample 10 & $50 / 26-1$ & $2338.4-2402.9$ & water & $x$ & \\
\hline Sample 11 & $50 / 26-1$ & $2338.4-2402.9$ & water & $\mathrm{x}$ & $\mathrm{x}$ \\
\hline
\end{tabular}

\subsection{Results}

\subsubsection{Sandstone petrography and microfabrics}

The mostly fine to medium grained sandstone contains 56 - 63\% of detrital quartz grains (mono-, poly-, and microcrystalline quartz), the rest of the matrix consists of feldspar grains (microcline) and lithoclasts (metamorphic-polycrystalline, igneous) (feldspar + lithoclasts: 6\%), as well as and carbonate grains (6 - 16\%). Detrital grains are moderately to well rounded. Intergranular pores (open pore space: $15-18 \%$ ) are often filled with kaolinite cement $(2-9 \%)$; other phyllosilicates comprise micas, illite, glauconite, and chlorite. Detrital quartz grains are mostly covered with a thin coating of Fe-oxides (Figs. 4.6-a/-b). Opaque minerals like sulfides (pyrite) are generally underrepresented; they are usually found within highly altered feldspar grains. Main accessory minerals are tourmaline and zircon. Samples show a pronounced stratification due to grain size variation, where the thickness of the layers varies between one to a few centimeters. Sometimes small layers of silt are visible.

Many detrital quartz grains show syntaxial quartz overgrowth (cement) from syn-diagenetic silica precipitation (Fig. 3.6-a). Pressure solution features along grain contacts are present as well, but relatively rare and the dissolved volume seems rather small compared to the amount of quartz cement present in the sandstone (Fig. 3.6-b). As the distribution of different cements varies throughout the provided core samples, point counting revealed that quartz cement only filled about $12 \%$ of the total initial pore space.

Carbonate cement (i.e. dolomite) represents the main cement phase in our samples filling about $40 \%$ of the total initial pore space. It occurs (a) as small and mostly isolated rhombohedral crystals around quartz and feldspar grains; sometimes the dolomite rhombs are overgrown by syntaxial quartz cement (Fig. 3.6-b), (b) as poikilotopic intergranular pore-filling cement (Fig. 3.6-c), (c) as rim cement around detrital feldspar and quartz grains; more often the dolomite crystals are tightly arranged around highly weathered feldspar grains forming typical cement rings (Fig. 3.6-d), and (d) as large euhedral dolomite 
grains within open pore space (Fig. 3.6-e) that are sometimes characterized by pronounced cleavage plains and growth zoning already visible in transmitted light (Fig. 3.6-f).
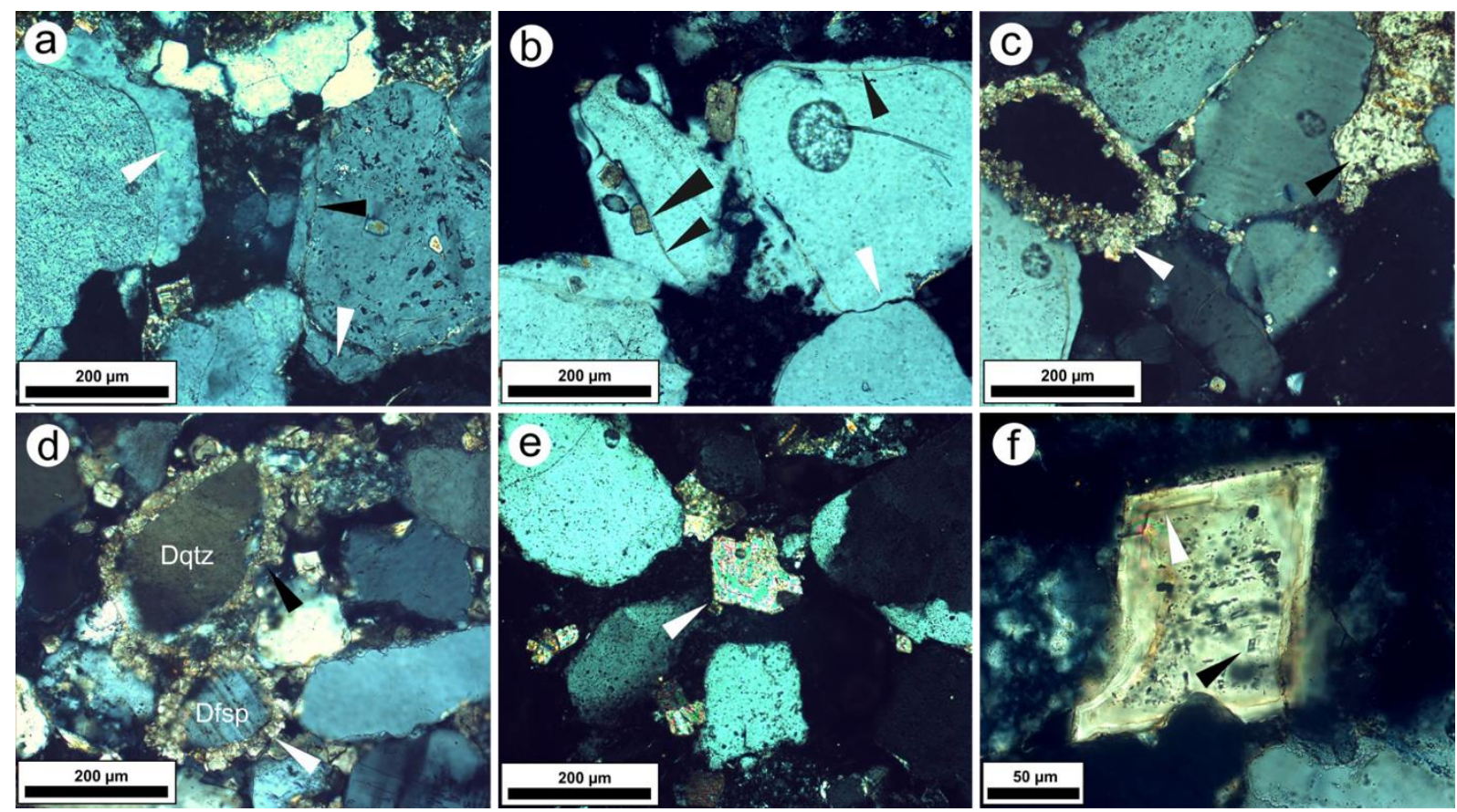

Fig. 3.6. (a) Photomicrograph illustrating a typical sandstone fabric with mostly monocrystalline detrital quartz grains. White arrows mark syntaxial quartz cements, the black arrow indicates a grain coating covering the detrital quartz grain (Sample_8, XPL). (b) Small black arrows: quartz grain coatings; large black arrow: euhedral dolomite overgrown by syntaxial quartz cement; white arrow: sutured pressure solution features along detrital quartz grain contact (Sample_4, XPL). (c) Black arrow: poikilotopic dolomite cement filling an intergranular pore; white arrow: rim of tightly packed euhedral dolomite rhombs surrounding a detrital quartz grain (Sample_4, XPL). (d) Cement rims consisting of euhedral dolomite crystals around a detrital quartz grain (=Dqtz) (black arrow), and a detrital feldspar grain $(=D f s p$, microcline) (white arrow), respectively (Sample_3, XPL). (e) Euhedral dolomite grain with growth zoning features visible in transmitted light (Sample_7, XPL). (f) Large euhedral dolomite grain with inclusion-free rim (white arrow) and an older core that contains numerous primary fluid inclusions (black arrow) (Sample_11, XPL).

Noticeable microfabrics among dolomite cements are dissolution features that affect older dolomite grains and sometimes also occur around completely weathered feldspar grains (Fig. 3.7-a/b). Dissolved dolomite cement and feldspar grains were partly or completely replaced by (younger) dolomite cement. This youngest dolomite cement also replaces syntaxial quartz cement (Fig. 3.7-c).

Kaolinite represents another cement phase that fills intergranular pore space and occupies between 6 $-26 \%$ of the total initial pore space. The amount of kaolinite cement shows a strong variation in our samples that may be due to the loss of kaolinite during thin section preparation. Kaolinite occurs as bent vermicular aggregates that appear light grey to weak brown in transmitted light (Fig. 3.7-d); the brown colour is likely caused by electron irradiation of epoxy resin during cathodoluminescence microscopy. Small fractures (width: $<5 \mathrm{~mm}$ ) are healed with acute or lath-shaped barite crystals $(<0,5 \mathrm{~mm})$, that typically show a white colour, while only few veins are characterized by a slightly reddish hue (Fig. 3.7-e/f). 


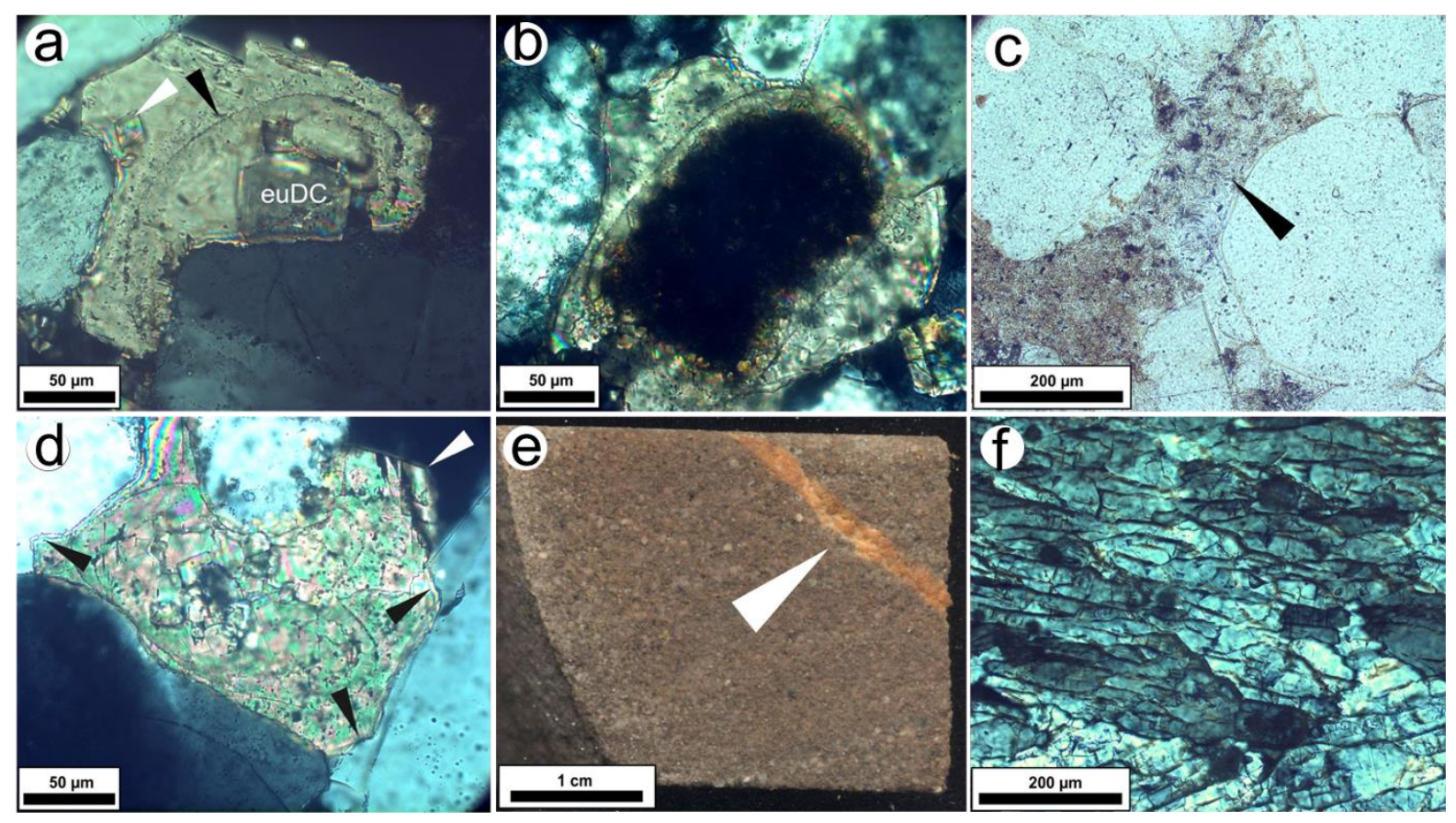

Fig. 3.7. (a) Intergranular dolomite cement showing a noticeable separation line (black arrow) between the core section and an outer, younger growth zone. The outer growth zone is overgrowing euhedral dolomite crystals of likely early diagenetic origin (white arrow). The inner core section itself also contains an older euhedral dolomite crystal (euDC) (Sample_9, XPL). (b) This photomicrograph shows a dark grain core consisting of clay minerals and/or microcrystalline sulfides and Fe-oxides that presumably replace a feldspar grain. The grain is overgrown by two dolomite cement generations that are divided by a thin dark line (corrosion surface, compare Fig. 3.6-g) (Sample_3, XPL). (c) Late dolomite cement overgrowing early euhedral dolomite rhombs. Black arrows indicate quartz replacement features. The dolomite-pore contact is characterized by typical rhombohedral faces (white arrow) (Sample_5, XPL). (d) Vermicular kaolinite filling intergranular pore space (Sample_4, LPL). (e) This image features a typical drill core sample from the Leman Sandstone Formation. A barite-healed fracture is indicated by a white arrow (Sample_6, scan). (f) Photomicrograph showing a detail from a barite-healed fracture. Barite crystals exhibit euhedral to subhedral shapes, no microfabrics indicating deformation could be observed (Sample_2, XPL).

\subsubsection{Porosity calculation}

Using the point counting method it is possible to reconstruct the paleo porosity in terms of porosity loss during diagenesis due to compaction (compactional porosity loss, COPL, Ehrenberg, 1995, 1989), as well as the total volume loss (compaction + cementation). The calculation of porosity loss was done by using the formula after Ehrenberg (1989):

$$
\mathrm{COPL}=\mathrm{OP}-(100 * \mathrm{IGV})-(\mathrm{OP} * \mathrm{IGV}) /(100-\mathrm{IGV}),
$$

with $\mathrm{COPL}=$ compactional porosity loss, IGV = intergranular volume, $\mathrm{OP}=$ original porosity (usually assumed as $40 \%$ ).

The cementational porosity loss (CEPL) can be calculated as:

$$
\mathrm{CEPL}=(\mathrm{OP}-\mathrm{COPL}) *(\mathrm{CEM} / \mathrm{IGV}),
$$

with CEM = cement (see formula 1 for further explanations). 
Chapter 3 - Post-depositional tectonic control on fluid migration in the Southern Permian Basin

All thin sections from provided Leman Sandstone samples were analyzed for porosity loss calculations. First calculations of paleo porosity show that about 8 to $16 \%$ of the former primary pore space in the sandstone was filled with quartz cement during early diagenesis, while between 18 and $40 \%$ was filled with rim and pore-filling dolomite. The amount of cement phases varies widely throughout the strata. The amount of quartz dissolved due to pressure solution cannot be determined. An example for the classification if the Leman Sandstone based upon compaction and cementation is shown in Fig. 3.8.

The results for two measured samples are as follows:
Sample 2:
COPL $=$
$26.0 \%$
$\mathrm{CEPL}=$
$15.7 \%$
Total Volume Loss $=41.7 \%$
Sample 11:
$\mathrm{COPL}=$
$25.4 \%$
$\mathrm{CEPL}=$
$16.1 \%$

Total Volume Loss $=41.5 \%$

These results represent a porosity distribution typically found in sandstones from the Rotliegend Supergroup in the Southern Permian Basin. These measurements only represent an approximation of compaction and porosity loss. For more accurate results, it is necessary to vary original porosity data (see Ehrenberg, 1995) and compare them with other data from well-studied sites.

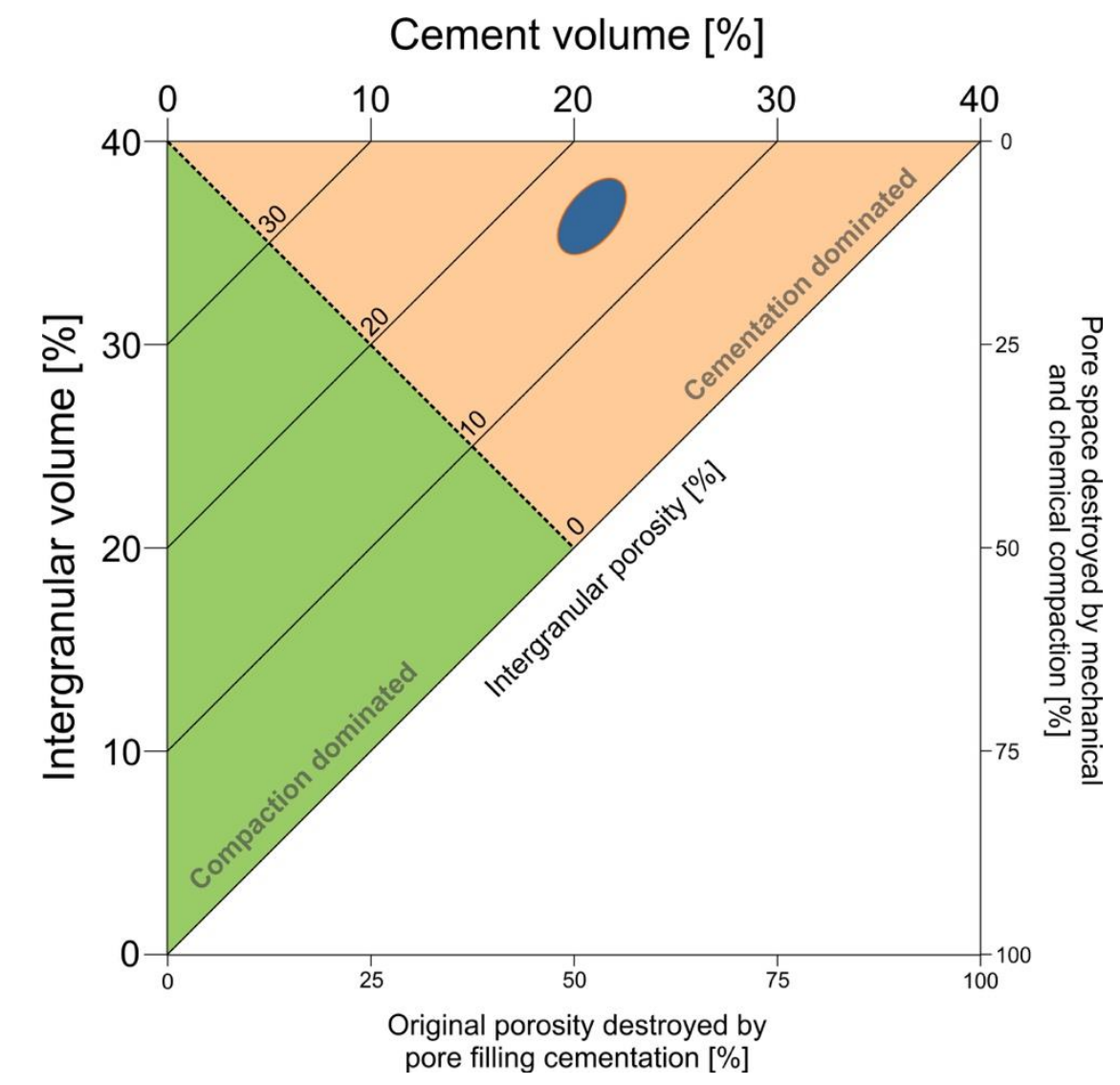

Fig. 3.8. Houseknecht diagram illustrating the role of compaction versus cementation for pore space reduction in a sandstone. The litharenite samples from Fizzy Field clearly plot in the cementation 
dominated field with a cement volume of about $21 \%$ (carbonate + quartz + kaolinite cement) and an intergranular porosity of about $15 \%$. Though pressure solution features are visible along detrital quartz grain contacts, pore space loss due to pressure solution played a minor role during diagenesis (modified from Houseknecht, 1989).

Results from point counting provide important information on compaction and cementation of the Leman Sandstone that clearly support previous observations by Sullivan et al. (1997) who not only described a polyphase quartz cementation, but also identified an external silica source responsible for quartz cementation. Since the amount of silica dissolved due to pressure solution along quartz grain contacts is rather small, silica input must have come from outside, i.e. from another fluid source. Thus, the amount of syntaxial quartz cement is probably higher than expected (depending on lithology) and open pore space is significantly reduced. Moreover, the reactive surface area of minerals exposed to acid brines is reduced as well, while on the other hand pore space reduction results in less space for carbonate cementation due to $\mathrm{CO}_{2}$-influx.

\subsubsection{Cathodoluminescence microscopy}

Cathodoluminescence (CL) microscopy was carried out on Leman Sandstone samples in order to reveal otherwise invisible microfabric features such as growth zoning in cements, as well as to identify different mineral species (e.g. kaolinite, end-members of the solid-solution series non-ferroan dolomite - ferroan dolomite - ankerite). Since most minerals show different cathodoluminescence intensities, varying exposure times have been applied. While for example carbonate cements exhibit intense emission colours at relatively short exposure times (between $200 \mathrm{~ms}$ and $1 \mathrm{~s}$ ), detrital quartz grains of igneous/metamorphic origin and, even more, syntaxial quartz cements typically show weak to very weak cathodoluminescence, and therefore longer exposure times (magnification 50x: 6 - 18 s; 100x: 12.6 $22.2 \mathrm{~s} ; 200 \mathrm{x}: 33-45.6 \mathrm{~s}$ ) are necessary in order to reveal microfabric details. Varying thickness of thin sections also affects exposure times, since thicker sections (> $30 \mu \mathrm{m}$ ) reduce CL transmission. CL image quality also depends on properly produced thin sections, as for example dispersed abrasive powder grains from the preparation process that remain in the epoxy resin also show intense emission colours (bright green and red), while air bubbles within the epoxy resin do result in strong light dispersion that may outshine CL details. Unfortunately, only few thin sections produced for the present study showed sufficient quality necessary for appropriate CL imaging.

As derived from petrographic microscopy, the Leman Sandstone matrix mainly consists of detrital quartz grains that are mostly of igneous origin (monocrystalline, no deformation or recrystallization features), quartz grains of metamorphic (polycrystalline, deformation/recrystallization features are sometimes visible) and hydrothermal (transient 'initial blue' CL emission, prominent growth and/or sector zoning) origin are underrepresented. Igneous quartz typically shows weak blue to weak red CL (Fig. 3.9), grains exhibiting oscillatory growth zoning are very rare. Metamorphic quartz CL is characterized by very weak reddish to brownish colours, that sometimes reveal typical mottled textures. Hydrothermal quartz grains are hard to identify since their most characteristic feature, the so-called 'initial blue' (i.e. a bright blue emission that fades after about $40 \mathrm{~s}$ of electron irradiation), is not always visible. Nevertheless, few quartz grains exhibit very sharp oscillatory growth and sectoral zoning that is also commonly found in hydrothermal quartz (e.g. Fig. 3.16).

Lithoclasts found within the Leman Sandstone show various mineralogical characteristics, and therefore cannot be classified as a uniform matrix constituent of distinct origin. As shown in Fig. 3.9 
(centre) some lithoclasts consist of a fine grained matrix with dark red to violet CL that contains various angular mineral grains such as mono- or polycrystalline quartz (identified as schist). Other commonly found lithoclasts consist of polycrystalline quartz, alkali feldspar (bright blue CL, see Fig. 3.11), micas (non-luminescent), and various minor constituents such as apatite (bright green CL, growth zoning) and zircon (bright white CL, growth zoning), and also show foliation features (e.g. shape preferred orientation) that prove their metamorphic origin. Other, less common lithoclasts are quartzite and chert.

Cements typically consist of carbonate, namely non-ferroan/ferroan dolomite (yellow luminescence/dull brownish or non-luminescent) and ankerite (non-luminescent), syntaxial quartz (dull brown CL), and kaolinite (intense blue CL) (see Fig. 3.9). The nature of dolomite luminescence is widely discussed (see Marshall, 1988; Pagel et al., 2000) and seems to be controlled by the presence of $\mathrm{Mn}^{2+}$ and $\mathrm{Fe}^{2+}$ as substituting elements, where manganese serves as an activator and iron as a quencher. However, high concentrations of Mn can result in self-quenching as well. Assuming reducing conditions during burial the luminescence of dolomite depends on the availability of $\mathrm{Mn}$ and $\mathrm{Fe}$ in the fluid.

According to Boggs and Krinsley (2006) clay minerals belonging to the kaolinite-group can be subdivided into two different groups of which one (kaolinite and halloysite) shows transient CL that fades after ca. $60 \mathrm{~s}$, while the other group (dickite, nacrite, and pyrophyllite) intensifies its CL emission during electron irradiation. As clay cement found in our samples usually exhibits intense blue CL that remains stable or intensifies slightly, it likely belongs to the latter group. However, the use of the term 'kaolinite' still seems the most appropriate in this case, as no further analysis was carried out in order to identify the clay content.
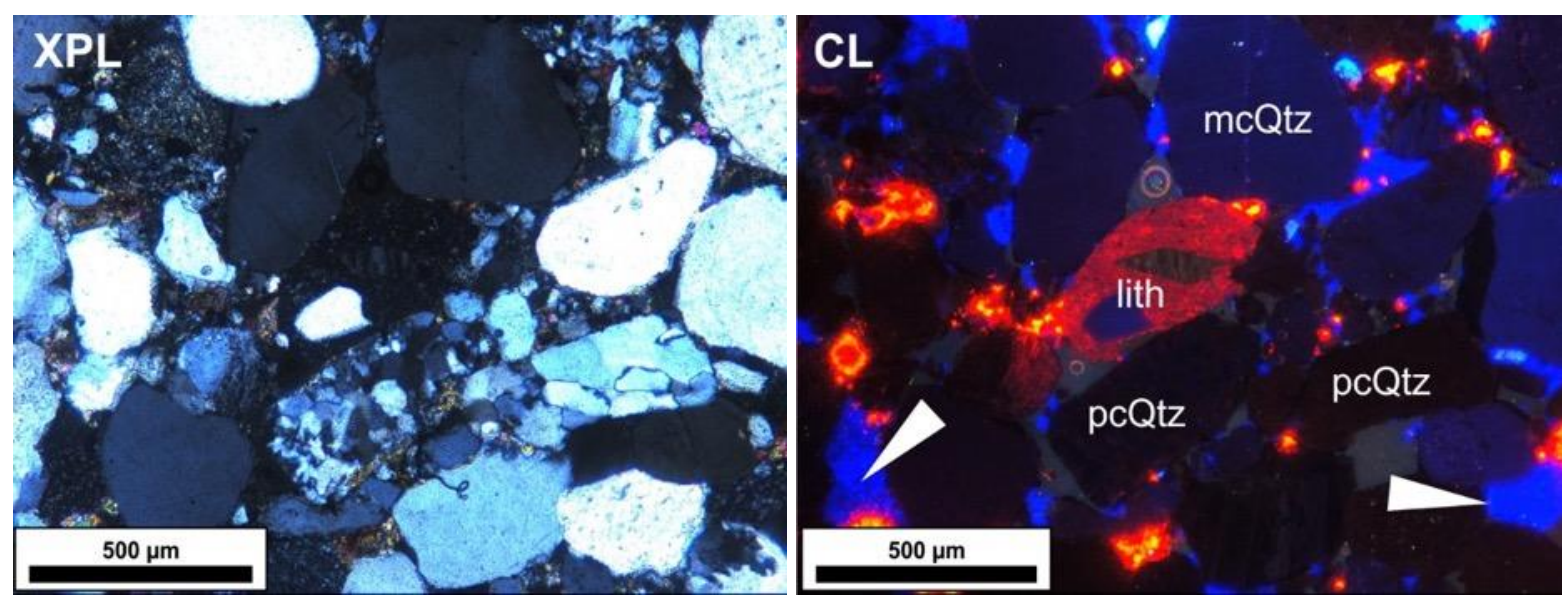

Fig. 3.9. Photomicrograph (XPL) of a typical sample from the Leman Sandstone Formation. The rock matrix mainly consists of monocrystalline (mcQtz) and polycrystalline ( $p c Q t z)$ detrital quartz grains, minor constituents are lithoclasts (lith) and alkali-feldspar grains. Cathodoluminescence $(C L)$ reveals typically weak blue and weak reddish colors for quartz grains; pore-filling kaolinite is characterized by intense blue luminescence (white arrows), while non-ferroan dolomite exhibits intense orange and yellow colors (Sample_5).

Carbonate cements exist in various shapes and dimensions. Most carbonate crystals are euhedral dolomite grains that occur isolated or in small clusters along detrital grain surfaces. They exhibit dull red to orange, and rarely intense yellow CL and mostly consist of weak ferroan (red CL) and non-ferroan (orange to yellow CL) dolomite. These very small dolomite crystals represent the oldest carbonate cement found in our samples, they predate syntaxial quartz cement and kaolinite cement as shown in Fig. 3.10. 

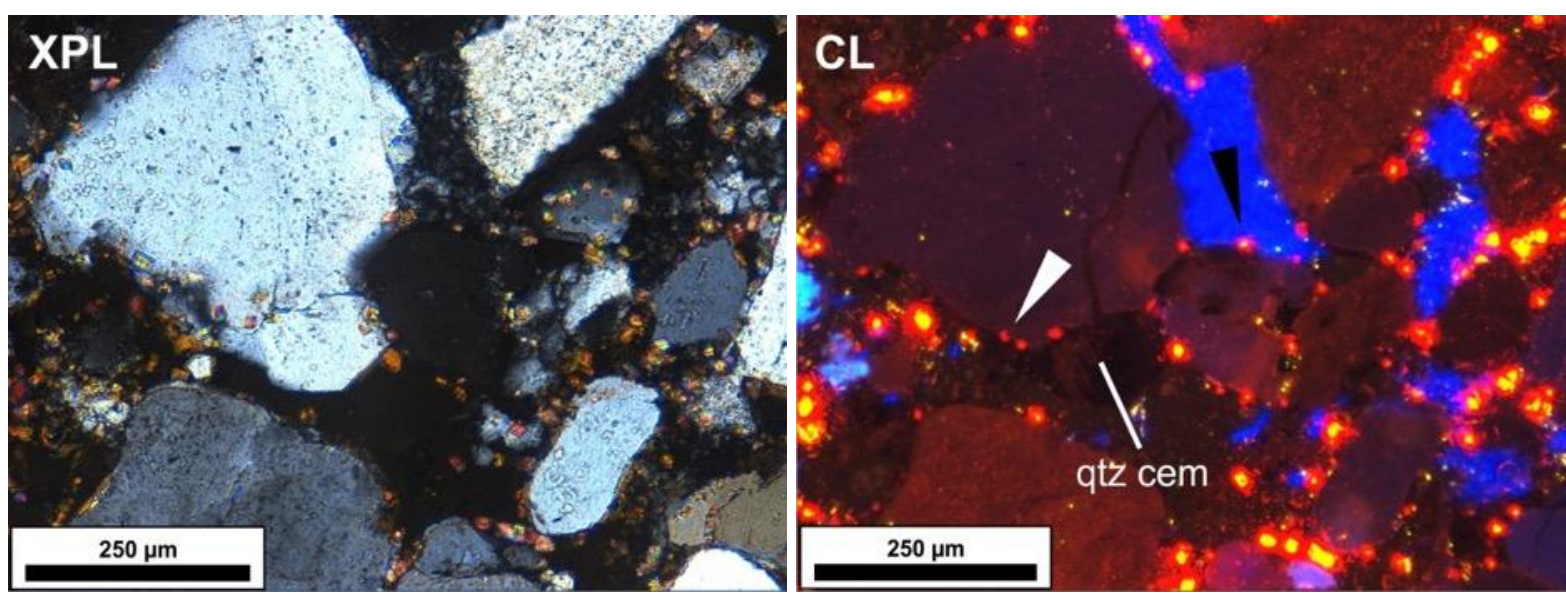

Fig. 3.10. Rhombohedral dolomite crystals represent the majority of dolomite cements within the sandstone samples. They mostly occur as isolated grains or small aggregates around detrital grains. An early dolomite generation is overgrown by quartz cement (white arrow), while kaolinite usually postdates dolomite precipitation (black arrow) (Sample_9).

Probably the most noticeable type among carbonate cements is a ring-shaped accumulation of subhedral dolomite rhombi surrounding detrital quartz or feldspar grains (grain-lining or circumgranular cement, compare Fig. 3.11). As circumgranular carbonate cement is supposed to form in early-diagenetic meteoric-phreatic environments (Flügel, 2004), it represents a very early carbonate phase in the Leman Sandstone Formation. Locally, circumgranular cements are filled with kaolinite cement that is probably a product of feldspar weathering (Fig. 3.11, white arrow), when a detrital feldspar (plagioclase?) grain was completely replaced with kaolinite. The dolomite ring probably formed as a grain lining cement before or, most likely, during feldspar alteration. As shown in Fig. 3.11 some alkali feldspar grains are affected by alteration and partly replaced with kaolinite (centre left, CL). It is not clear why some feldspar grains are partly or completely replaced with kaolinite or other weathering products, while some grains are barely or not weathered at all, and moreover, show no grain-lining dolomite cement. One explanation might be that mostly Ca-rich feldspar grains (plagioclase) were affected by alteration and replaced with kaolinite. Thereby, $\mathrm{Ca}^{2+}$ was released and subsequently favored immediate precipitation of dolomite along the grain surface. Why sometimes also quartz grains show dolomite cement rims remains unclear. Ring-shaped dolomite cement seemingly postdates quartz cement as no circumgranular cement shows quartz-overgrowth. However, this observation gives no distinct evidence since dolomite cement as a substrate does not support quartz precipitation on its surface.
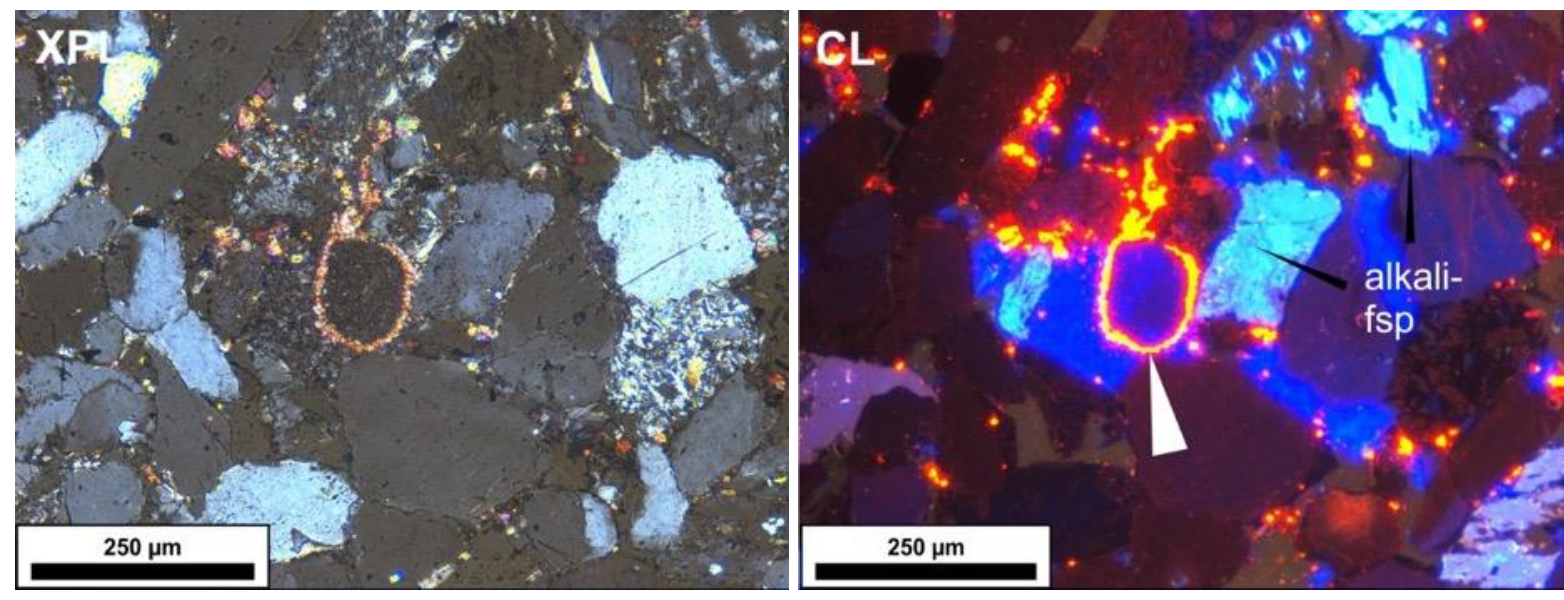
Fig. 3.11. Photomicrographs showing a typical circumgranular dolomite ring (yellow to red CL, white arrow) that consists of small and tightly packed subhedral dolomite crystals. The ring supposedly surrounded a feldspar grain that was completely replaced with kaolinite (intense blue CL). Note the bright blue alkali feldspar grains (black arrows) that show severe alteration features and are already partly replaced with kaolinite. Remarkably enough, these alkali feldspar grains (orthoclase) do not show grain lining dolomite cement (Sample_1).

Larger carbonate grains are typically more complex and consist of various growth generations as derived from petrographic microscopy (Fig. 3.7-a). CL microscopy reveals a sequence of at least three more or less continuous growth zones that sometimes overgrow a fourth, even older dolomite generation (i.e. small isolated dolomite grains). The sequence starts with a sometimes spheroidal or ellipsoidal core showing dull red or no luminescence (Fig. 3.12; 1; ferroan dolomite). This dolomite was sometimes partly dissolved and afterwards overgrown with another dolomite generation with intense red to orange CL (non-ferroan dolomite) (Fig. 3.12; 2). Generation number 2 was then continuously overgrown with non-luminescent carbonate, most likely ankerite (Fig. 3.12; 3), a Fe-rich carbonate that is characteristic for deep burial cements in the Southern Permian Basin (see Ziegler, 2006); ankerite sometimes also forms poikilotopic pore-filling cement (see Fig. 3.7-d).
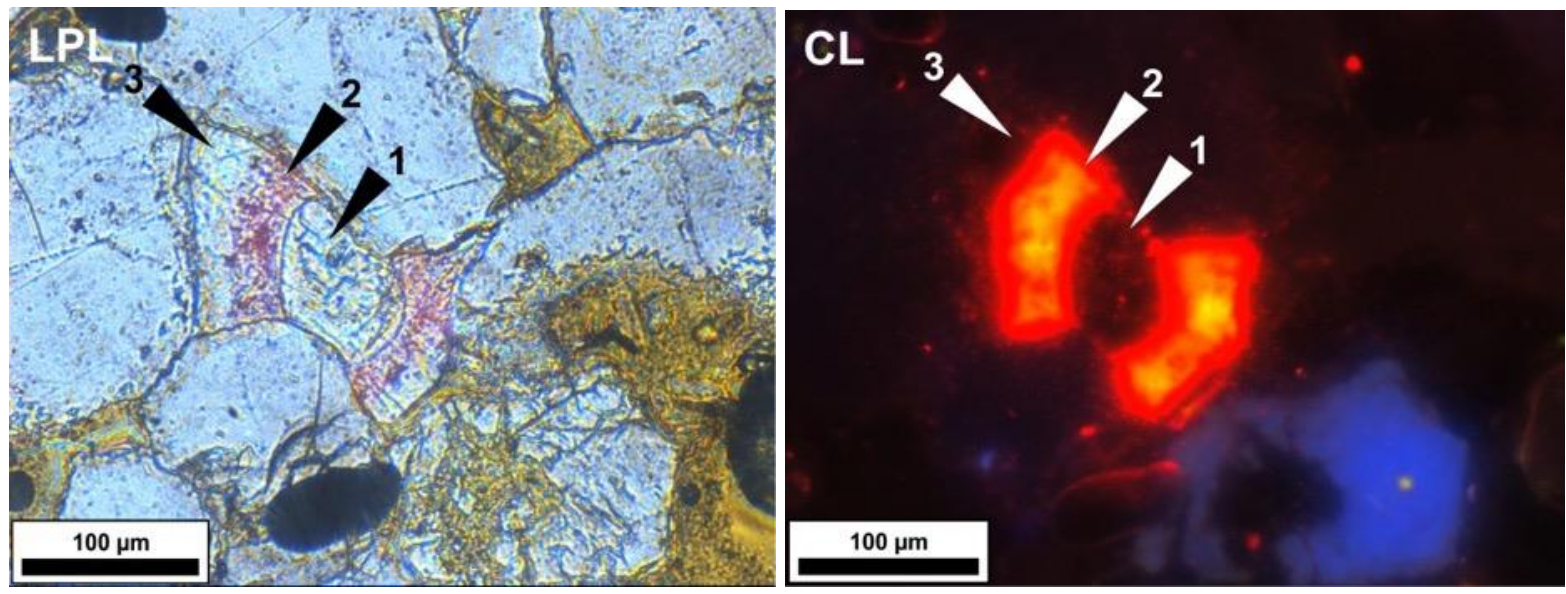

Fig. 3.12. Single dolomite grains with diameters above $>100 \mu \mathrm{m}$ are relatively rare. They show characteristic growth zoning and partial dissolution features. These grains typically exhibit three growth generations that can only be revealed in CL. The core (1) is non-to sometimes weak red luminescent (ferroan dolomite) and shows an almost spherical to ellipsoidal shape that is probably the result of partial dissolution (compare Fig. 3.7-a). This core is overgrown with another dolomite generation (2) that shows bright orange to yellow luminescence in CL (non-ferroan dolomite); its shape is almost euhedral. The outer rim (3) is non-luminescent (ankerite) and represents the latest growth generation that continues generation (2); no dissolution features are visible between (2) and (3) proving successive precipitation under changing chemical conditions (Sample_5).

A similar dolomite-ankerite sequence is featured in Fig. 4.13. Again, a single dolomite grain shows three growth zones, but unlike the situation shown in Fig. 3.12 the dissolution rim is located right within the non-ferroan dolomite zone (bright orange to yellow CL). Thus, carbonate dissolution did probably not occur right after precipitation of generation 1 and prior to precipitation of generation 2, respectively. Brine acidity most likely increased during precipitation of the non-ferroan dolomite zone (orange/yellow CL, generation 2) and supposedly caused dissolution of generation 1 and 2. In case of complete dissolution of generation 2 and partial dissolution of generation 1, the resulting dolomite sequence looks similar to the dolomite grain featured in Fig. 3.7-a; partial dissolution of generation 2 resulted in a 
dolomite-ankerite growth sequence as illustrated in Fig. 3.12 (the core (zone 1) was not affected by carbonate dissolution). The outer rim (zones 2 and 3) of the dolomite grain shown in Fig. 3.13 is characterized by a very irregular shape; it likely consists of several tightly packed subhedral dolomite crystals and resembles a typical grain lining cement.
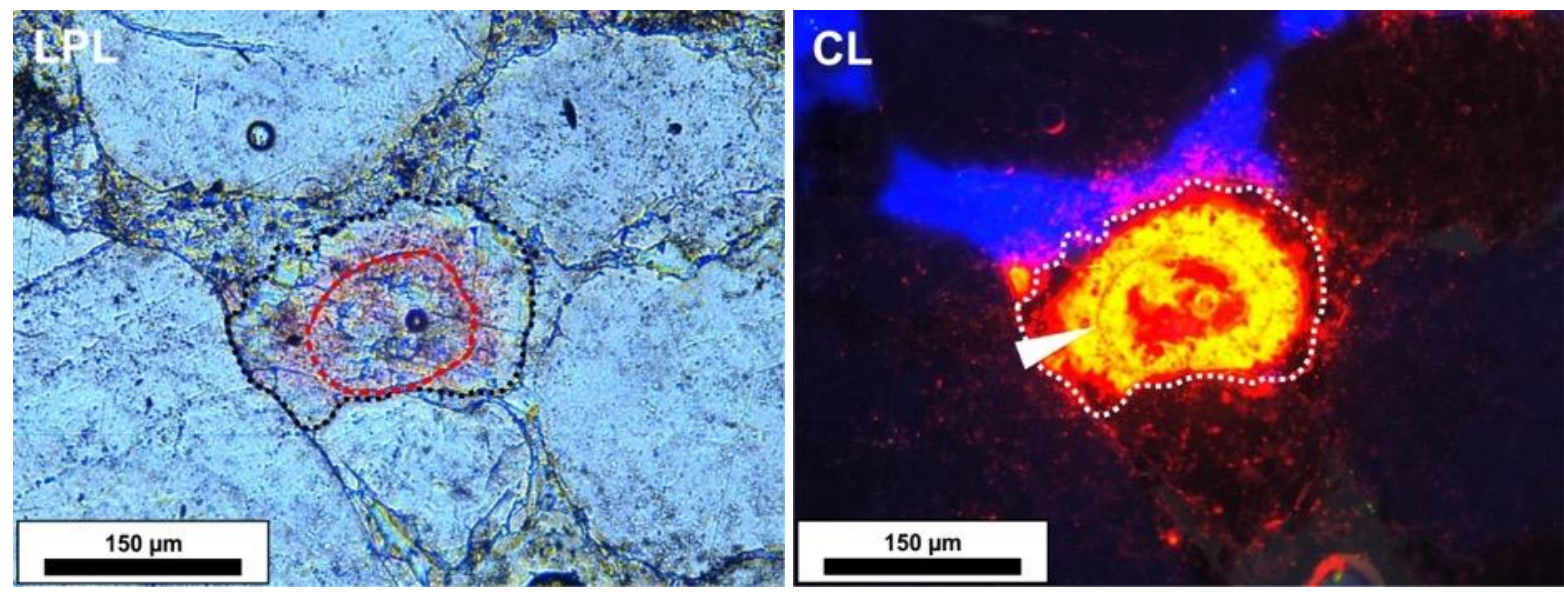

Fig. 3.13. Carbonate grains sometimes also show irregular shapes as shown in these images. The core of the featured carbonate grain exhibits dark red CL; it is overgrown with bright yellow $(C L)$ dolomite. Unlike in Fig. 3.7-f, corrosion of the grain did not occur between the dark core and the bright yellow dolomite, but during precipitation of the second growth generation. The dissolution surface is marked by a dashed red line (LPL) and by a white arrow $(C L)$, respectively. The second carbonate generation is continuously overgrown with non-luminescent carbonate that seems to consist of various smaller grains (rhombs?) resulting in an irregular grain shape. In this case carbonate precipitation did not result in a typical euhedral dolomite crystal (Sample_5).

The presented dolomite-ankerite growth sequence for larger carbonate grains with three distinct growth zones can show even more complex patterns with various smaller alternating zones (Fig. 3.14) instead of zones 2 and 3. Still, the succession is very similar throughout the samples, small differences in carbonate composition may depend on local effects (e.g. changing Fe/Mn-ratio due to water-rockinteraction, fluid circulation).
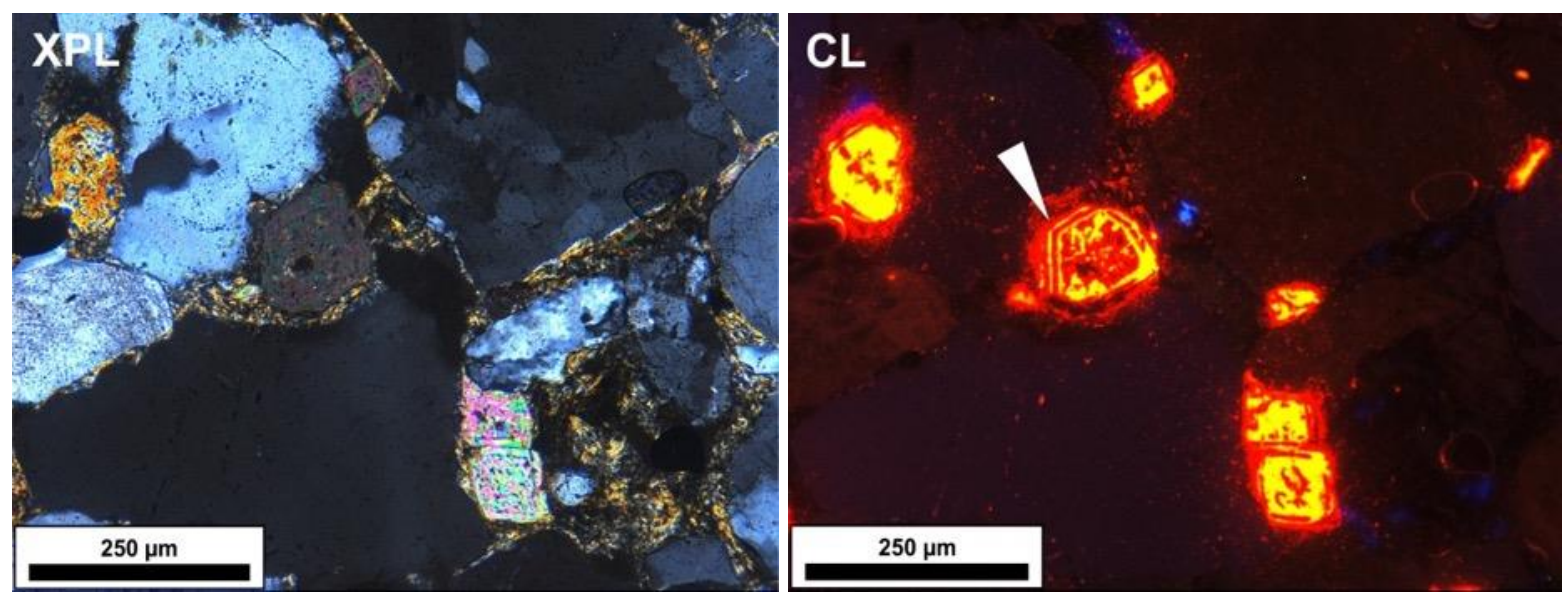

Fig. 3.14. Larger (> $25 \mu \mathrm{m}$ ) euhedral dolomite crystals sometimes show complex growth zoning features. While the cores of respective crystals are weak red or non-luminescent $(C L)$ followed by a typically orange to bright yellow rim, the outer growth zones appear more complex (white arrow) especially when compared to dolomite crystals with dissolution features (e.g. Fig. 3.12 and Fig. 3.13) (Sample_8). Note the smectite coating of quartz grains. 
Syntaxial quartz cement typically shows very weak cathodoluminescence; dark red or brownish zoning features are barely found. Quartz cement is restricted to monocrystalline quartz grains; polycrystalline quartz grains are never affected by diagenetic cement precipitation (Fig. 3.15). However, not all monocrystalline quartz grains are surrounded by syntaxial quartz cement. Dolomite cement or missing clay/Fe-(hydr-)oxide coatings obviously prevent silica precipitation along the grain surface (as do circumgranular dolomite cements).
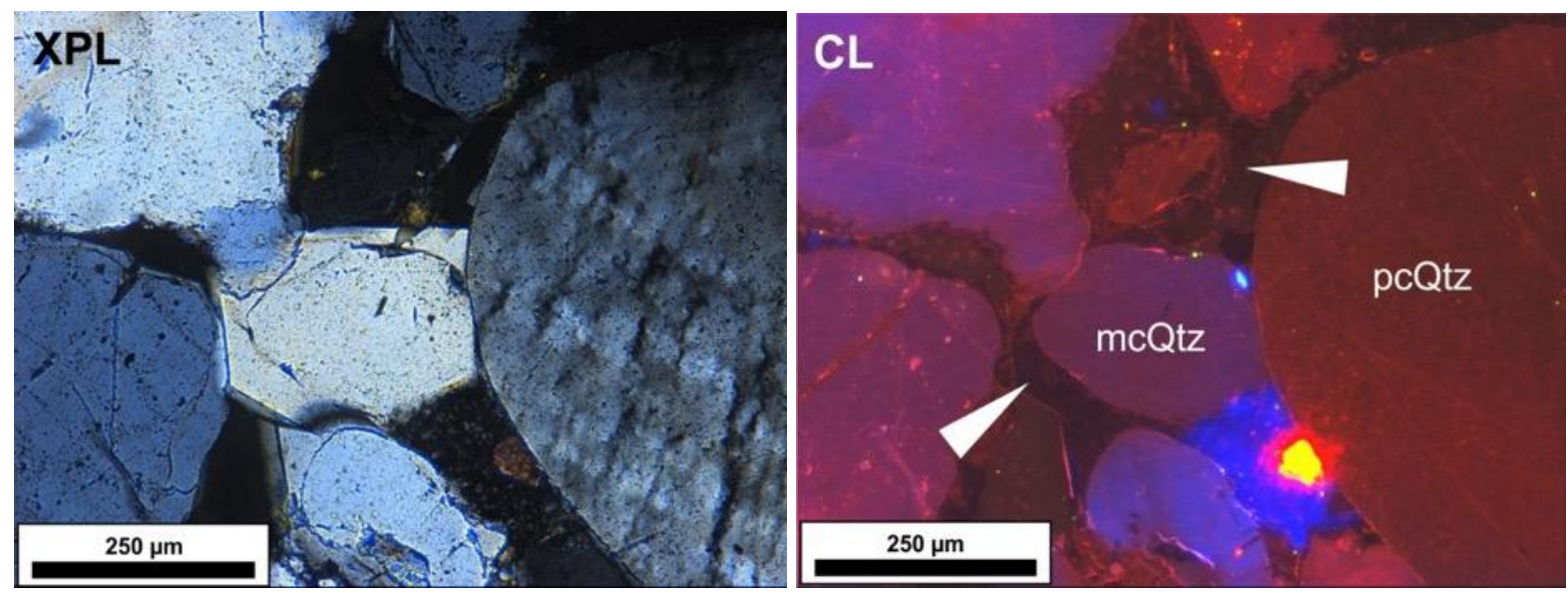

Fig. 3.15. This image illustrates the amount of quartz cement within the sandstone matrix. Though sutured contacts between quartz grains can be observed, pressure solution features are relatively rare. Thus, compaction and simultaneous pressure solution during burial only represent minor sources for silica precipitation around quartz grains. Please note the missing quartz cement around the polycrystalline quartz grain (pcQtz), only monocrystalline quartz (mcQtz) is affected by syntaxial quartz overgrowth (Sample_6).

As shown in Fig. 3.16, early diagenetic dolomite rhombs that formed isolated or in small clusters along detrital quartz grain surfaces are overgrown by syntaxial quartz cement. Sometimes euhedral dolomite crystals are found within quartz cement and therefore prove several precipitation events of quartz and early dolomite (synchronous precipitation during early burial).
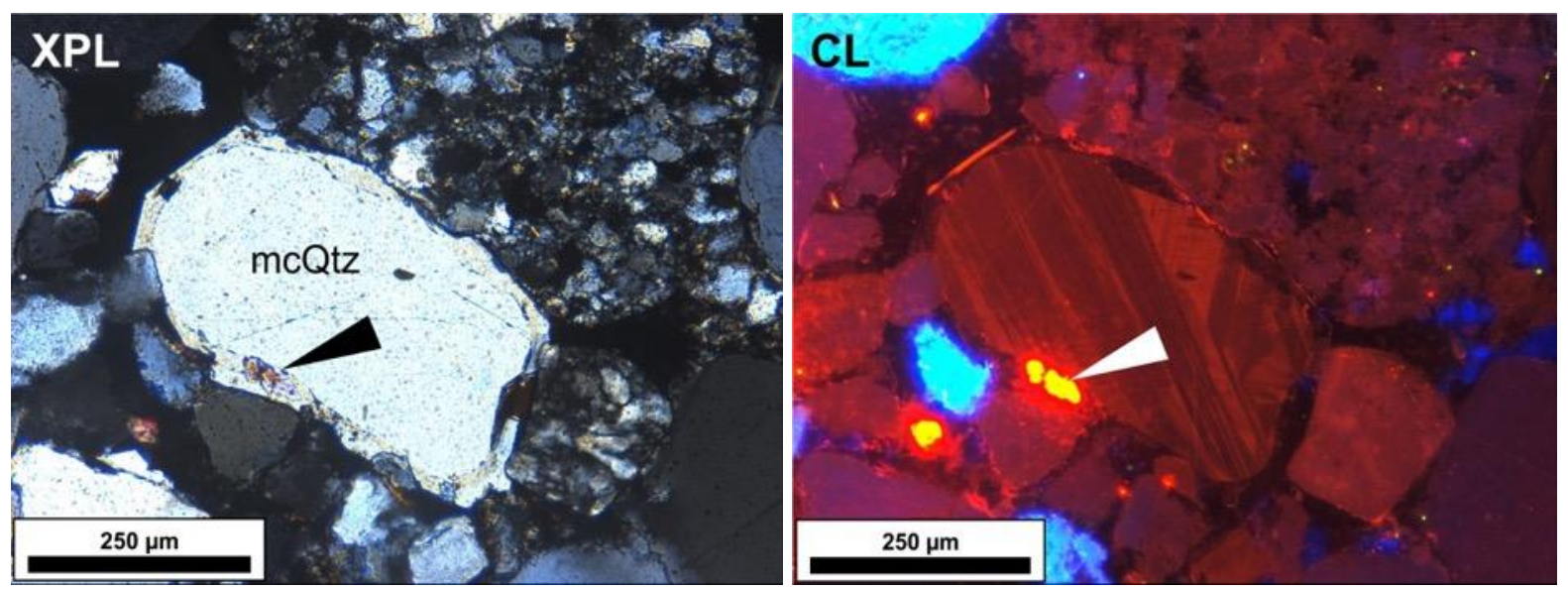

Fig. 3.16. Small dolomite rhombi (arrows) attached to a monocrystalline quartz grain (mcQtz) are overgrown by syntaxial quartz cement. These dolomite crystals are presumably of early diagenetic origin as they clearly predate the quartz cement. Note the distinct growth zoning features of the quartz grain (probably hydrothermal quartz) only visible in CL (Sample_6). 
A polyphase quartz precipitation is supported by detailed CL images (Fig. 3.17). Pore-filling quartz cement consists of at least two different growth generations (zones 1 and 3), a third generation (zone 2) cannot be excluded, but may also correlate with sectoral zoning. Oscillatory growth and sectoral zoning features in quartz cement are very rare, not all samples showed more than one growth zone. Our observations are in good agreement with previous studies on quartz cements from the Leman Sandstone Formation (compare Sullivan et al., 1997). Fracture-filling barite did not exhibit cathodoluminescence.
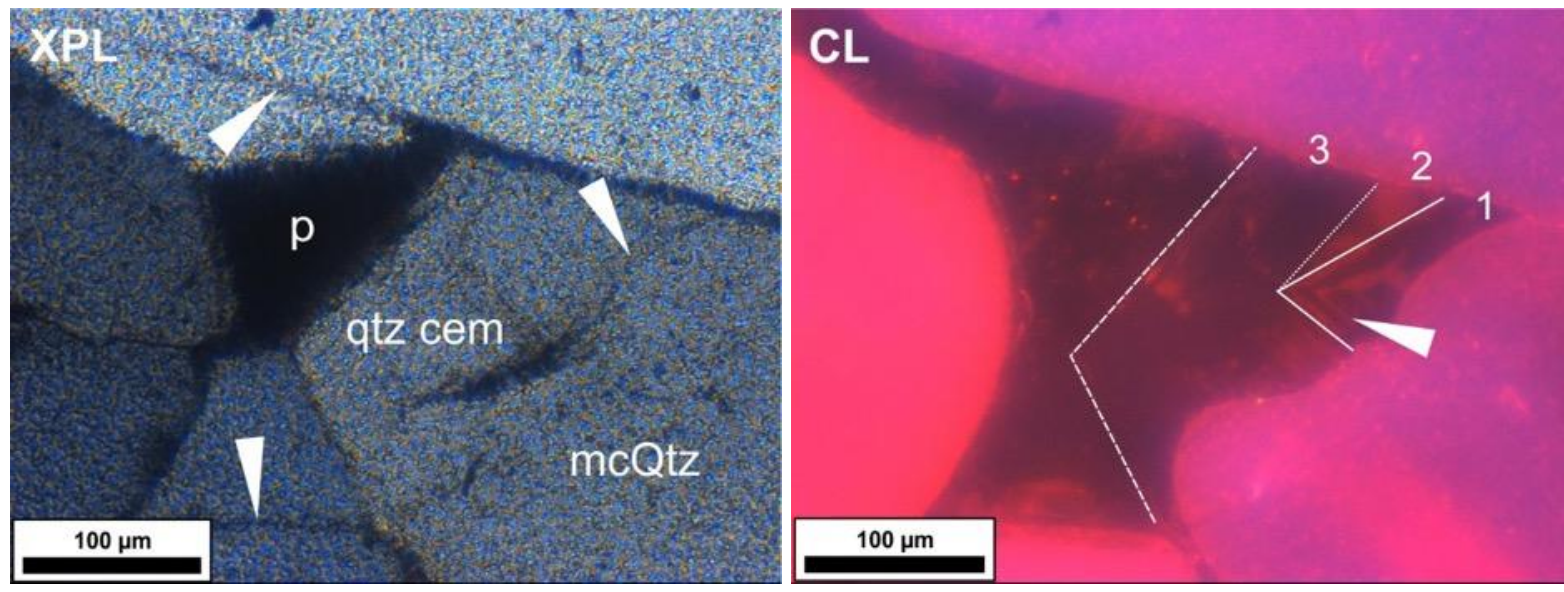

Fig. 3.17. Photomicrographs illustrating how pore space between monocrystalline detrital quartz grains (mcQtz) was partly filled with syntaxial quartz cement (qtz cem); open pore space (p) remains black. Cement-grain contacts are partly outlined by grain coatings (white arrows, XPL). Dark red to brownish CL emission in quartz cement is very weak and therefore, it is hard to identify zoning features (white arrow, $C L)$ and different growth generations. Nevertheless, cathodoluminescence revealed at least two different growth generations in quartz cement (1/solid white line; 3/dashed white line). A third growth feature (2/dotted white line) cannot be definitely assigned to a separate growth event, it likely represents sectoral zoning within growth zone 1 (Sample_8).

\subsubsection{Fluid inclusion petrography}

Fluid inclusions within detrital quartz grains are typically of secondary or pseudo-secondary origin and outline healed microfractures (Fig. 3.18-a) that formed due to mechanical stress (brittle deformation) prior to erosion. Fluid inclusions occur in various shapes and sizes; their fluid content is mostly aqueous (biphase) and/or gaseous (mono- and biphase); sometimes co-genetic trapping can be observed. Some fluid inclusions show decrepitation features (acicular edges).

Syntaxial quartz cement typically contains only very few fluid inclusions with diameters between 4 and $8 \mu \mathrm{m}$. All fluid inclusions found in our samples are of primary biphase character with an aqueous fluid content. Fluid inclusions occur in small clusters that are sometimes connected to the clay/Fe-(hydr)oxide coating of respective detrital quartz grains (Fig. 3.18-b). Their shape is mostly tubular with an orientation perpendicular to the quartz grain surface; some inclusions show spherical or ellipsoidal shapes. 

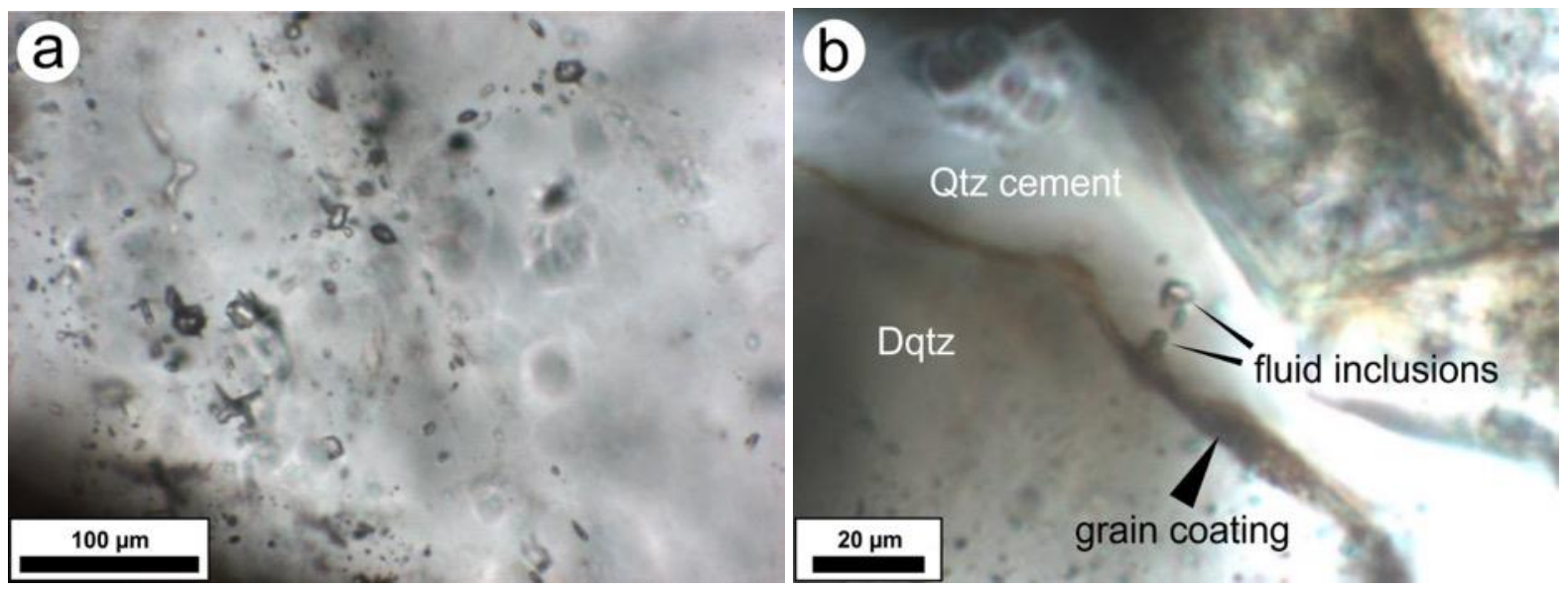

Fig. 3.18. (a) Various intersecting secondary fluid inclusion trails within a detrital quartz grain outlining healed microfractures that likely formed prior to erosion and sedimentation. Fluid inclusions in detrital quartz grains usually contain water with low salinities, and gas. Sometimes aqueous and gaseous fluid inclusions are co-genetic and therefore prove relatively high formation temperatures that do not correspond with supposed maximum temperatures during burial of the Brown Graben. Thus, the fluid content of respective fluid inclusions does not correlate with events related to basin evolution (Sample_2, $L P L$ ). (b) Primary fluid inclusions in syn-diagenetic quartz cement. Please note the dark brown grain coating that outlines the detrital quartz grain (Dqtz). The oldest fluid inclusions trapped close to the detrital grain show slightly elongated shapes perpendicular to the grain surface; they are partly attached to the grain coating which probably favoured fluid inclusion formation (Sample_6, LPL).

Early rhombohedral dolomite grains contain clusters $(\mathrm{n}>20)$ of very small $(<3 \mu \mathrm{m})$ primary fluid inclusions that do not show bubbles (monophase) (Fig. 3.19-a); their shape is mostly irregular; sometimes spherical shapes are visible.

Late dolomite usually contains clusters $(\mathrm{n}<10)$ of primary biphase or monophase fluid inclusions with diameters around $5 \mu \mathrm{m}$ or less, they barely exceed a diameter of $5 \mu \mathrm{m}$ (Fig. 3.19-b). Smaller fluid inclusions exhibit irregular to isomorphic shapes; larger inclusions are characterized by almost rectangular or acute edges. Sometimes fluid inclusions are arranged along crystallographic growth planes.
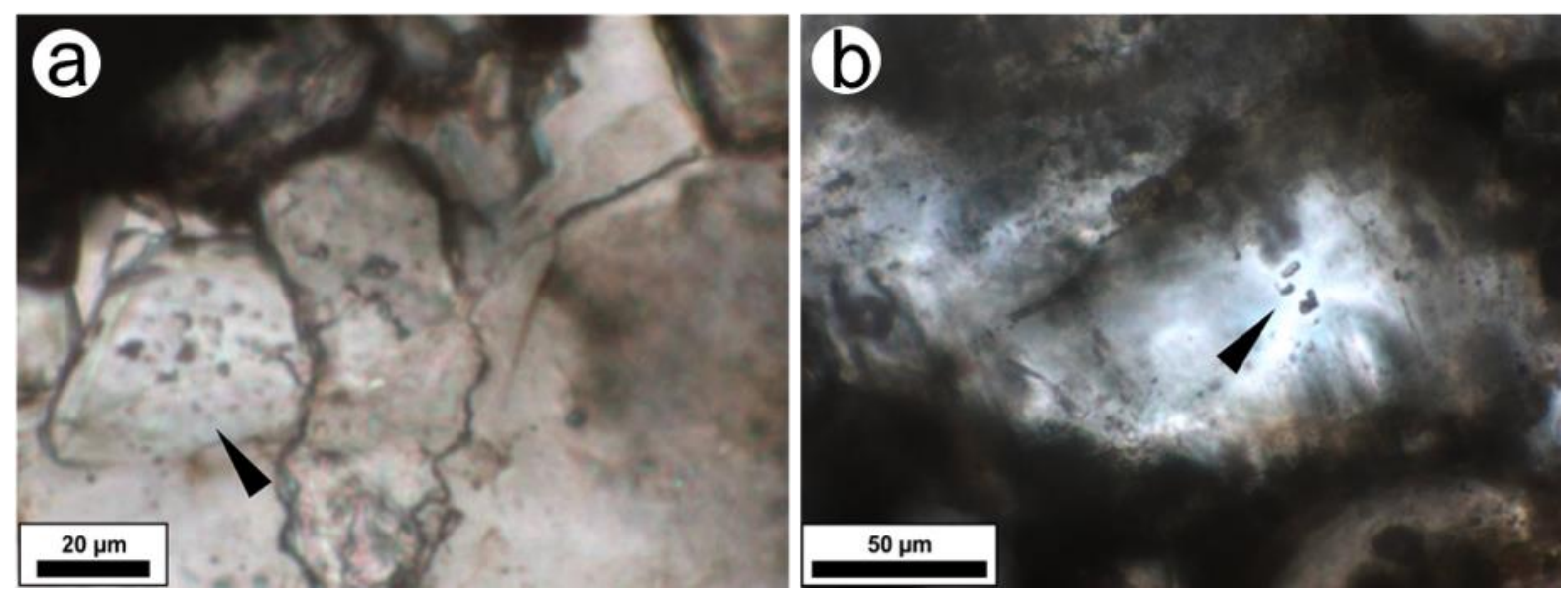

Fig. 3.19. (a) Photomicrograph of primary fluid inclusions trapped within an early diagenetic euhedral dolomite rhomb (black arrow). Fluid inclusions are typically arranged in small clusters, their size varies around $3 \mu \mathrm{m}$ or even less (Sample_2, LPL). (b) A small cluster of primary fluid inclusions (black arrow) within a late diagenetic dolomite grain is featured in this image. Sometimes dolomite-hosted fluid inclusions 
are arranged along crystallographic growth planes, larger fluid inclusions sometimes exhibit almost rectangular or acute-angled edges resembling negative crystal shapes (Sample_2, LPL).

Fracture-filling barite crystals mostly contain pseudo-secondary (Fig. 3.20-a), as well as primary (Fig. 3.20-b) aqueous fluid inclusions of biphase character. Monophase aqueous fluid inclusions are the result of necking down (restricted to pseudo-secondary inclusions). Pseudo-secondary fluid inclusions typically outline healed intra-crystalline microfractures that formed due to brittle deformation during barite precipitation. Their size varies between 8 and $3 \mu \mathrm{m}$, their shape is usually tubular with acicular ends that are formed by necking down. Primary fluid inclusions are rare and always occur isolated, mostly in the core regions of barite grains. Their size ranges from 5 to $10 \mu \mathrm{m}$, their shape is commonly isometric, edges are sometimes parallel to crystallographic growth planes.
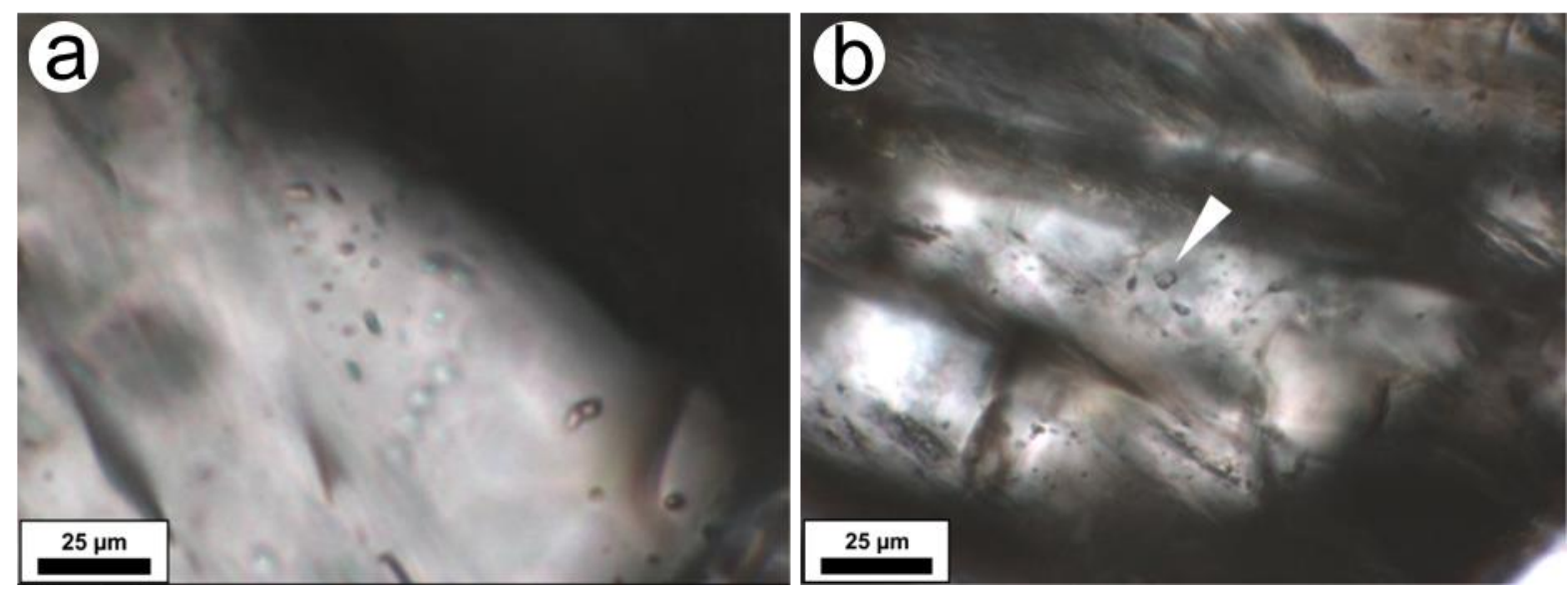

Fig. 3.20. (a) Barite vein showing pseudo-secondary aqueous fluid inclusions that formed during fracture healing. Fluid inclusions are arranged along healed intra-crystalline microfractures and show tubular shapes (Sample_2, XPL). (b) Primary fluid inclusions (white arrow) within barite crystals are rare; they usually occur isolated and mostly show isometric shapes (Sample_2, XPL).

\subsubsection{Microthermometry}

Aqueous fluids in detrital quartz grains commonly show relatively low salinity $\left(\mathrm{T}_{\mathrm{m} \text {, ice: }}-1.2 /-7.7^{\circ} \mathrm{C} ; 11.3\right.$ wt. $\%$ (eq.) $\mathrm{NaCl}$; system $\left.\mathrm{H}_{2} \mathrm{O}-\mathrm{NaCl}\right)$ and high homogenization temperatures $\left(>250^{\circ} \mathrm{C}\right)$; as derived from Laser-Raman-spectroscopy gaseous inclusions are typically $\mathrm{CO}_{2}$-dominated and show relatively high densities. Since fluids trapped within detrital quartz do obviously not correspond with brines related to basin evolution no additional microthermometric information is presented in this study.

Early diagenetic dolomite contains bubble-free (i.e. no vapour phase visible at room temperature) fluid inclusions with ice melting temperatures $\left(\mathrm{T}_{\mathrm{m} \text {,ice }}\right)$ close to the freezing point of water (between -2.3 and $0^{\circ} \mathrm{C} ; 3.8$ wt.\% (eq.) $\mathrm{NaCl}$ ). Thus, fluids of probably meteoric origin with low to no salinity were trapped at relatively low temperatures (bubble did not even nucleate after freezing/stretching). Fluid inclusions are too small for Laser-Raman-spectroscopic analysis, but no elevated $\mathrm{CO}_{2}$ concentrations are expected.

Syntaxial quartz cement contains aqueous inclusions with relatively low salinity $\left(\mathrm{T}_{\mathrm{m}}\right.$, ice: $-8.7^{\circ} \mathrm{C}$; ca. 12.3 mass $\% \mathrm{NaCl}$ ). Eutectic temperatures (Te) of about $-38^{\circ} \mathrm{C}$ suggest the presence of dissolved $\mathrm{MgCl}_{2}$. Syndiagenetic polyphase quartz cement shows increasing $\mathrm{T}_{\mathrm{h}}$ with increasing distance to the detrital grain 
(Fig. 3.21), while fluid composition shows no variation. Homogenization temperatures range from $81.2^{\circ} \mathrm{C}$ to $107^{\circ} \mathrm{C}$ (mean: $96^{\circ} \mathrm{C}$ ). The calculated fluid density for the $\mathrm{H}_{2} \mathrm{O}-\mathrm{NaCl}-\mathrm{MgCl}_{2}$ solution is $1.107 \mathrm{~g} / \mathrm{cm}^{3}$. According to results from Laser-Raman-spectroscopy fluid inclusions contain no $\mathrm{CO}_{2}$ and therefore indicate that no carbon dioxide was present in the reservoir during burial.

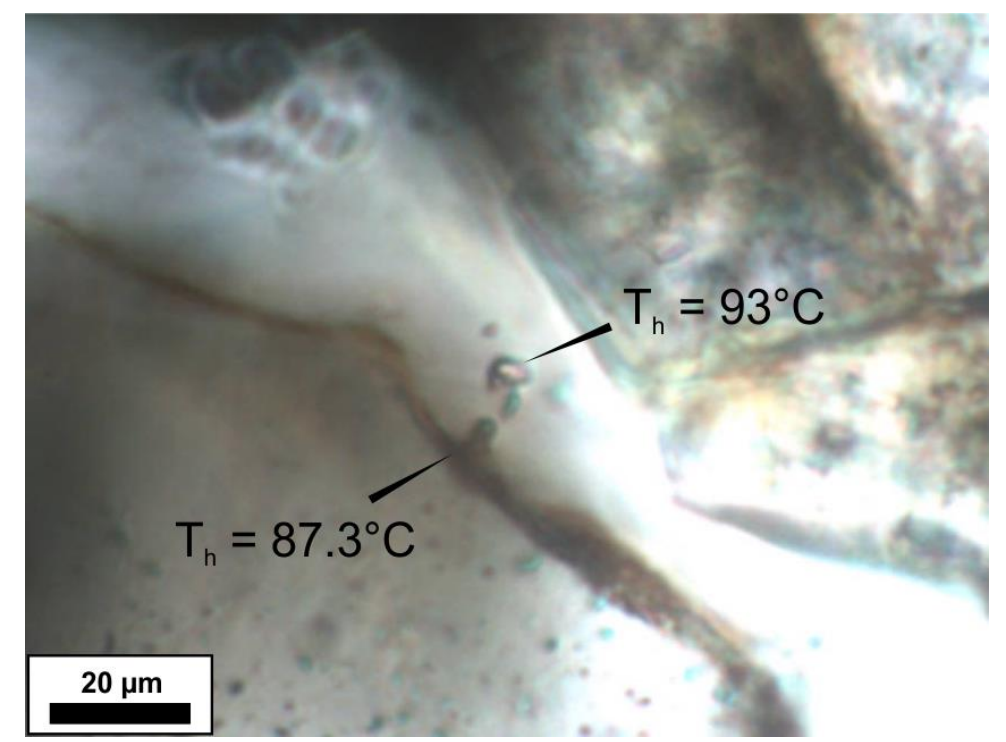

Fig. 3.21. Photomicrograph showing primary fluid inclusions trapped within syn-diagenetic quartz cement. Homogenization temperatures reveal increasing temperatures during continuous cement precipitation.

Barite crystals within fractures contain two different types of fluid inclusions, one type restricted to primary fluid inclusions, the other type restricted to pseudo-secondary fluid inclusions. Though both types contain fluid of similar composition $\left(\mathrm{T}_{\mathrm{e}}=-35.3^{\circ} \mathrm{C}\right.$; system $\left.\mathrm{H}_{2} \mathrm{O}-\mathrm{NaCl}-\mathrm{MgCl}_{2}\right)$, salinities and homogenization temperatures are different. Primary fluid inclusions show $\mathrm{T}_{\mathrm{m}}$, ice of $-17.8^{\circ} \mathrm{C}(20.8 \mathrm{wt} . \%$ (eq.) $\mathrm{NaCl}$ ) and $\mathrm{T}_{\mathrm{h}}$ of about $141^{\circ} \mathrm{C}$ (mean), while pseudo-secondary fluid inclusions are characterized by $\mathrm{T}_{\mathrm{m}}$, ice of $-21.2^{\circ} \mathrm{C}(23.2$ wt.\% (eq.) $\mathrm{NaCl})$ and $\mathrm{T}_{\mathrm{h}}$ of about $174^{\circ} \mathrm{C}$ (mean). Thus, the calculated fluid density for primary fluid inclusions is $1.064 \mathrm{~g} / \mathrm{cm}^{3}$, and $1.0484 \mathrm{~g} / \mathrm{cm}^{3}$ for pseudo-secondary fluid inclusions, respectively. Relatively high homogenization temperatures found in pseudo-secondary fluid inclusions (occasionally $>200^{\circ} \mathrm{C}$ ) may be caused by necking down. Thereby, a large fluid inclusion is partly healed during cooling and the fluid content of this single inclusion is separated into various smaller inclusions. The already existing bubble (gas phase) will then remain in one smaller inclusion with a relatively low fluid density, while another inclusion will probably nucleate no bubble at all (high density). Thus, the homogenization temperature of the vapor-rich fluid inclusion is higher than respective trapping conditions would suggest. Both, Laser-Raman-spectroscopy and microthermometry did not reveal any evidence for the presence of $\mathrm{CO}_{2}$ within fluid inclusions trapped in fracture-filling barite.

Mid- to late diagenetic euhedral dolomite grains contain high-saline $\mathrm{H}_{2} \mathrm{O}-\mathrm{NaCl}-\mathrm{CaCl}_{2}$ fluid inclusions with $\mathrm{T}_{\mathrm{e}}$ of about $-50.2^{\circ} \mathrm{C}, \mathrm{T}_{\mathrm{m}}$, ice of about $-21^{\circ} \mathrm{C}$, and $\mathrm{T}_{\mathrm{m}}$, hydrohalite of about $-19.2^{\circ} \mathrm{C}$ (ca. 21.8 wt.\% (eq.) $\mathrm{NaCl}$ ). Calculated density for the system $\mathrm{H}_{2} \mathrm{O}-\mathrm{NaCl}-\mathrm{CaCl}_{2}$ is $1.152 \mathrm{~g} / \mathrm{cm}^{3}$. Homogenization temperatures range from 63 and $74^{\circ} \mathrm{C}$ (mean: $69^{\circ} \mathrm{C}$ ); very small fluid inclusions $(<3 \mu \mathrm{m})$ sometimes show first nucleation of a bubble after freezing due to stretching. No $\mathrm{CO}_{2}$ was detected within fluid inclusions. 
Chapter 3 - Post-depositional tectonic control on fluid migration in the Southern Permian Basin

According to their petrographic characteristics, their relative time of trapping, and their microthermometric data all fluid inclusions can be assigned to individual fluid inclusion assemblages (FIA) (see compilation Tab. 3.2).

Tab. 3.2. Compilation of data obtained from fluid inclusion petrography and microthermometry.

\begin{tabular}{|c|c|c|c|c|c|c|c|c|c|}
\hline \multirow[t]{2}{*}{ Mineral } & \multirow[t]{2}{*}{ FIA } & \multirow{2}{*}{$\begin{array}{c}\text { Petrographic } \\
\text { character }\end{array}$} & \multirow{2}{*}{$\begin{array}{l}\text { Phase } \\
\text { transition }\end{array}$} & $\mathrm{Te}$ & Tm ice & $\mathrm{Tm} \mathrm{HH}$ & Th & Salinity & Density \\
\hline & & & & ${ }^{\circ} \mathrm{C}$ & ${ }^{\circ} \mathrm{C}$ & ${ }^{\circ} \mathrm{C}$ & ${ }^{\circ} \mathrm{C}$ & wt.\% (eq.) $\mathrm{NaCl}$ & $\mathrm{g} / \mathrm{cm} 3$ \\
\hline Detrital quartz & । & S, PS & $L V->L$ & -7.7 & -7.7 & $?$ & $>200$ & 11.3 & \\
\hline Early dolomite & ॥ & $P$ & $\begin{array}{l}\text { monophase, } \\
\text { liquid }\end{array}$ & -2.3 & -2.3 & & & 3.8 & \\
\hline Quartz cement & III & $P$ & $L V->L$ & -38 & -8.7 & $?$ & 96 & 12.3 & 1.107 \\
\hline Barite & IVa & $P$ & $L V->L$ & -35.3 & -17.8 & -18.2 & 141 & 20.8 & 1.064 \\
\hline Barite & $\mathrm{IVb}$ & PS & $L V->L$ & -35.2 & -21.2 & -21.2 & 174 & 23.2 & 1.048 \\
\hline Late dolomite & V & $\mathrm{P}$ & $L V->L$ & -50.2 & -21 & -19.2 & 69 & 23.1 & 1.152 \\
\hline
\end{tabular}

\subsection{Discussion}

\subsubsection{Diagenetic evolution and fluid chemistry}

The (diagenetic) history of the Leman Sandstone Formation started with the deposition of quartzdominated aeolian sands during the Rotliegend. Quartz grains and lithoclasts are common products of the erosion of igneous and metamorphic rocks, probably originating from the London-Brabant platform in the south-west. Fluids were most likely trapped prior to erosion, as exceptionally high homogenization temperatures and co-genetic trapping suggest.

Early diagenetic dolomite: As evident from fluid composition (meteoric to low saline fluids) and homogenization temperatures a first dolomite cement (DC-I) precipitated during shallow burial; this coincides with findings from previous studies (burial depth during early dolomite precipitation $<500 \mathrm{~m}$; see Ziegler, 2006). CL suggests carbonate precipitation from a fluid with slightly changing $\mathrm{Fe}^{2+}$ concentrations resulting in dull red (ferroan dolomite) to orange (non-ferroan dolomite) emission.

Quartz cement: Initiated by input of silica-saturated fluids from an external fluid source during advanced burial (compare Sullivan et al., 1997), the precipitation of syntaxial quartz cement started. Higher salinity of fluid inclusions trapped within quartz cements can be explained by severe water-rock interaction during burial and the infiltration of marine pore water during the Zechstein. Quartz precipitation was polyphase, as the presence of at least two distinct cement generations proves; homogenization temperatures of trapped fluids show evidence for increasing temperatures during progressive quartz precipitation.

Fracture propagation and barite precipitation: Shortly after or probably simultaneous to quartz cement precipitation extension due to thermal doming (Late Cimmerian Inversion, Fig. 3.3) occurred. Basin extension favoured the propagation of mm-wide extensional fractures (see Sibson, 1998) and the subsequent precipitation of barite within fractures. Most quartz grains along the matrix-fracture contact 
show sharp inter-crystalline breaking edges that affected both, the detrital grain and the cement, and therefore prove that fracture propagation must have occurred after quartz cement precipitation. However, some euhedral quartz cements were probably formed during or after fracture propagation and prior or simultaneous to barite formation, as they surround their host grain towards the fracture. Thus, quartz cement predates barite, and fracture formation occurred during or shortly after maximum burial, as homogenization temperatures of fluid inclusions within quartz cement (type III) reveal. $\mathrm{T}_{\mathrm{h}}$ of fluid inclusions in barite (type Iva/b) are exceptionally high and do certainly not represent reservoir conditions, they most likely precipitated from hydrothermal fluids driven by thermal convection ( Bjørlykke, 2010) that was favoured by thermal doming and extension during the late Jurassic - early Cretaceous. Composition of fluid inclusions in barite show slightly increased salinity compared to fluids in quartz cement, but the system $\mathrm{H}_{2} \mathrm{O}-\mathrm{NaCl}-\mathrm{MgCl}_{2}$ is still dominant. The increase in $\mathrm{NaCl}$ may be due to fluid mixing along fractures (Zechstein rock salt deposits).

Uplift and erosion: Maximum burial was followed by a period of uplift and erosion (Late Cimmerian Inversion), and another episode of deposition and subsidence. Little is known about this phase of basin evolution that ranges from the late Triassic to the late Cretaceous. Dolomite cements that post-date fracture-hosted barite are characterized by at least three different growth generations (DC-II/III/IV). These growth zones prove changes in fluid chemistry (DC-II: weak ferroan dolomite, DC-III: nonferroan dolomite, DC-IV: ankerite), a noticeable dissolution feature demonstrates increased brine acidity during precipitation of DC-III. Though, fluids trapped within DC-II/III show highest salinity and are enriched in $\mathrm{Ca}^{2+}$ (system $\mathrm{H}_{2} \mathrm{O}-\mathrm{NaCl}-\mathrm{CaCl}_{2}$ ), homogenization temperatures indicate shallower formation depth compared to $\mathrm{T}_{\mathrm{h}}$ of quartz cement and barite. $\mathrm{Ca}^{2+}$-dominated brines are typical for sedimentary basins and prove severe fluid-rock interaction (e.g. dissolution of plagioclase and carbonates). Dissolved $\mathrm{Mg}^{2+}$ was probably used up by the precipitation of dolomite.

Leaching of alkali feldspar grains probably occurred prior to DC-III formation, while kaolinite clearly postdates DC-II + III.

The diagenetic sequence of investigated core samples and the relative timing of respective minerals is compiled in Fig. 3.22. 
Chapter 3 - Post-depositional tectonic control on fluid migration in the Southern Permian Basin

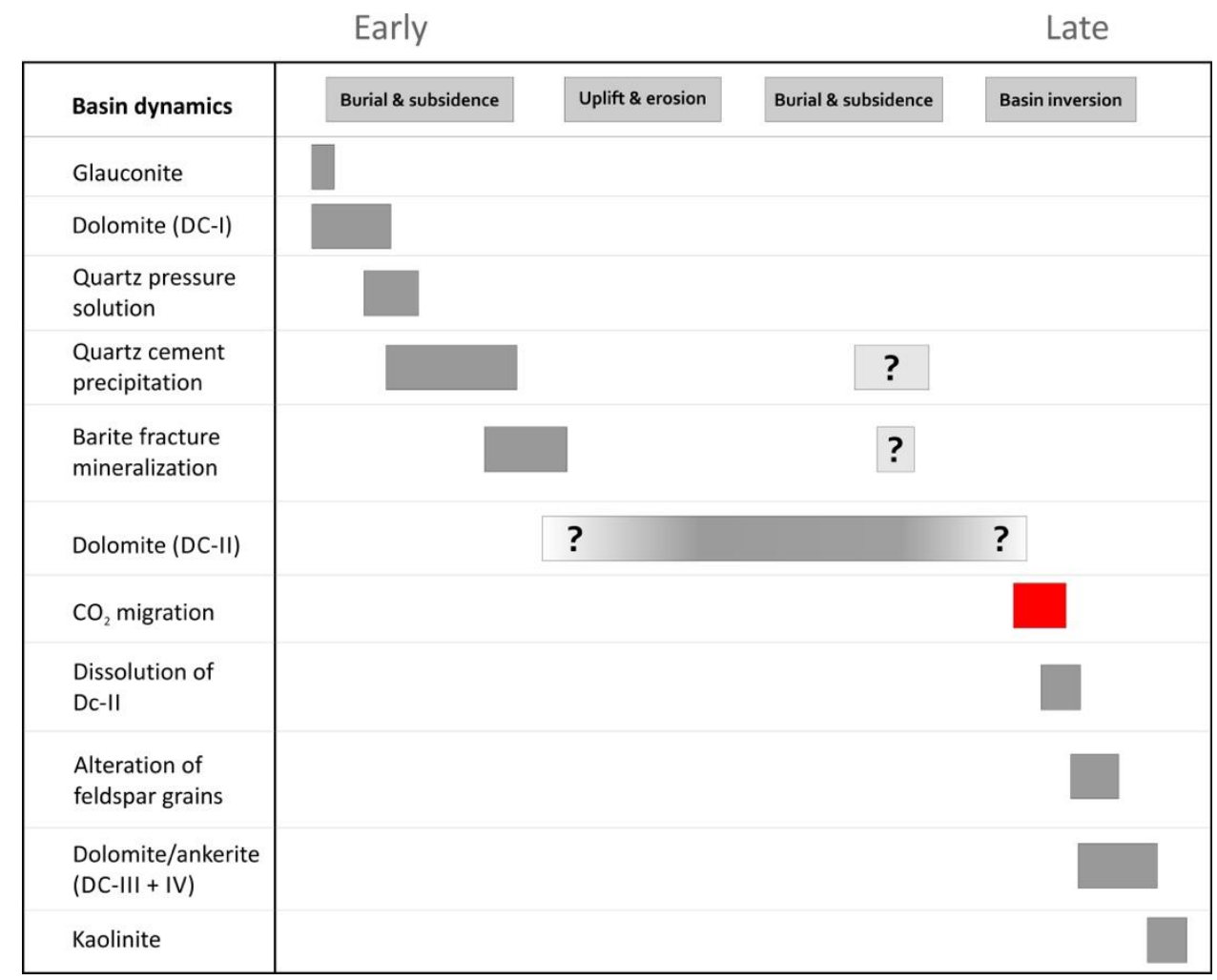

Fig. 3.22. The diagenetic sequence of the Leman Sandstone is characterized by the early diagenetic precipitation of a rhombohedral dolomite cement (DC-I); older glauconite grains are likely a syndepositional product. Mid- to late diagenetic quartz cement was mainly produced during a first episode of burial and subsidence, while barite is only present along extensional fractures that likely formed during extensional thermal uplift. Late diagenetic euhedral dolomitelankerite (DC-II/III/IV) as well as kaolinite cements are the youngest cement phases. The predominant cement phase found in our samples is dolomite (ca. 16\%).

The evolution of brine salinity in the Leman Sandstone Formation over time beginning with early diagenetic dolomite (DC-I) is demonstrated in Fig. 3.23.

Eutectic temperature $\left(\mathrm{T}_{\mathrm{e}}\right)$

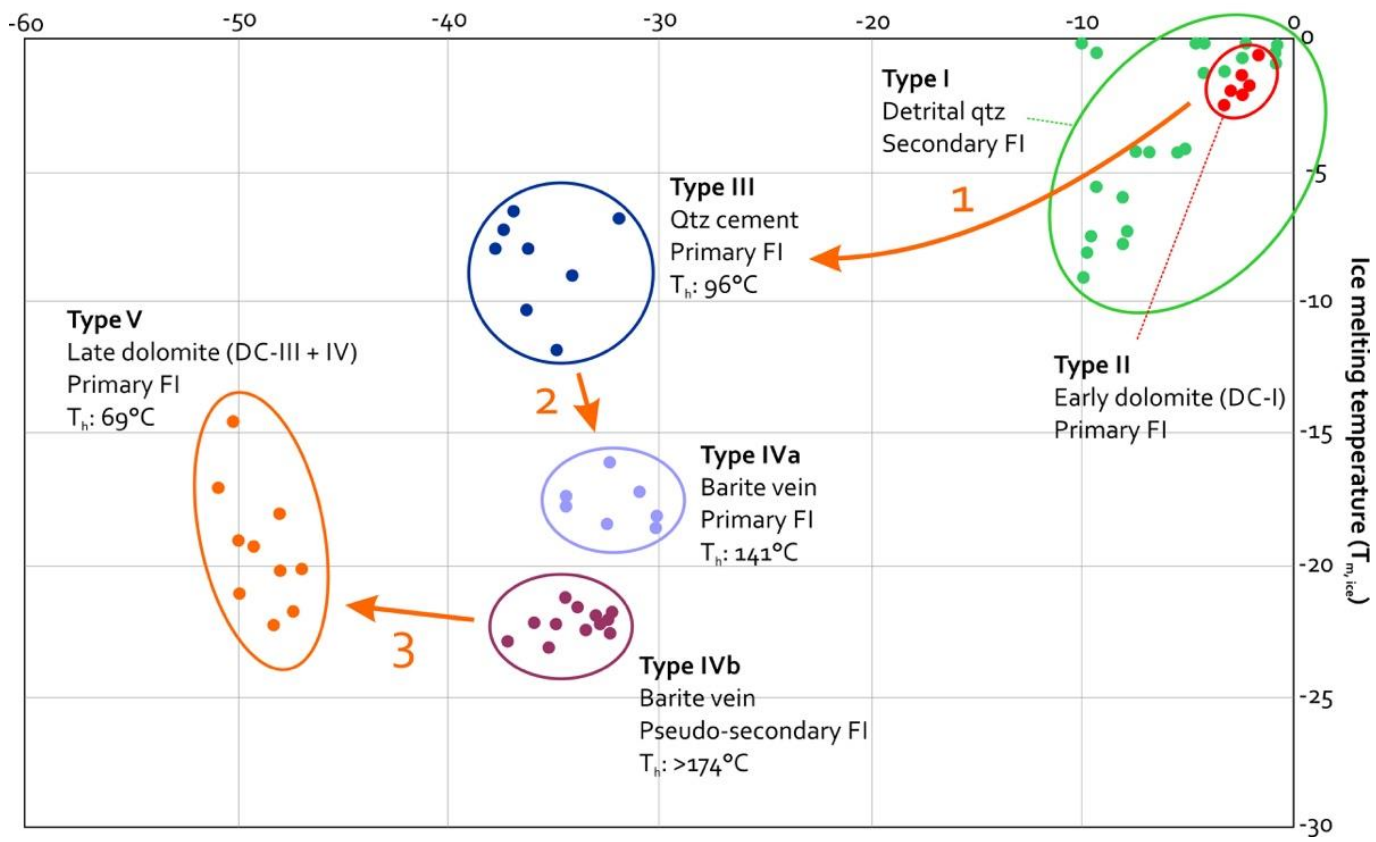


Fig. 3.23. This plot illustrates the composition of various fluid inclusion assemblages found in our samples based on their eutectic temperature (Te) and the temperature of final ice melting $\left(T_{m}\right.$, ice $)$. The increase in salinity from fluid inclusions trapped early diagenetic dolomite (type II), syn-diagenetic quartz cement (Type III) to fracture fluids trapped in barite (type IVa/b) (lower $T_{m}$, ice means higher salinity), as well as the presence of $\mathrm{Ca}$ in the fluid prior to and during basin inversion, leading to significantly lower $T_{e}$ (type $V)$ is obvious. Fluid evolution from early to late diagenesis is outlined by orange arrows and according numbers. Variation in eutectic temperatures (e.g. -51 to -47.8 in type V-fluids) can be explained by the small size of respective fluid inclusions (optical limitation).

\subsubsection{P-T reconstruction and thermobarometric calculations}

Minimum, mean, and maximum homogenization temperatures of primary fluid inclusions found in syntaxial quartz cement (type III), fracture-filling barite (type IVa), and late diagenetic dolomite (type V) were used to calculate respective isochores. Calculated isochores were plotted within a P-T-diagram among various lithostatic gradients typically found in sedimentary basins, and a hydrostatic gradient (Fig. 3.24). The intersection of isochores obtained from fluid inclusions and hydro-/lithostatic gradients determine the pressure and temperature conditions during fluid inclusion trapping (Goldstein, 2001). According to that model, syntaxial quartz cement was formed at temperatures of ca. $125^{\circ} \mathrm{C}$ and pressures of ca. 830 bar, while late diagenetic dolomite (DC-III) was formed at temperatures of ca. $90^{\circ} \mathrm{C}$ and pressures of ca. 580 bar, assuming nearly lithostatic conditions for both cases. Barite instead was probably formed under near hydrostatic conditions as crossing isochore calculations suggest. Petrographic microscopy and microthermometric analysis demonstrate that barite clearly postdates quartz cement, but predates DC-III. Thus, barite formation must have occurred somewhere between positions 1 and 3 as shown in Fig. 3.24; corresponding trapping temperatures vary around $165^{\circ} \mathrm{C}$, formation pressures range between 500 and 750 bar.

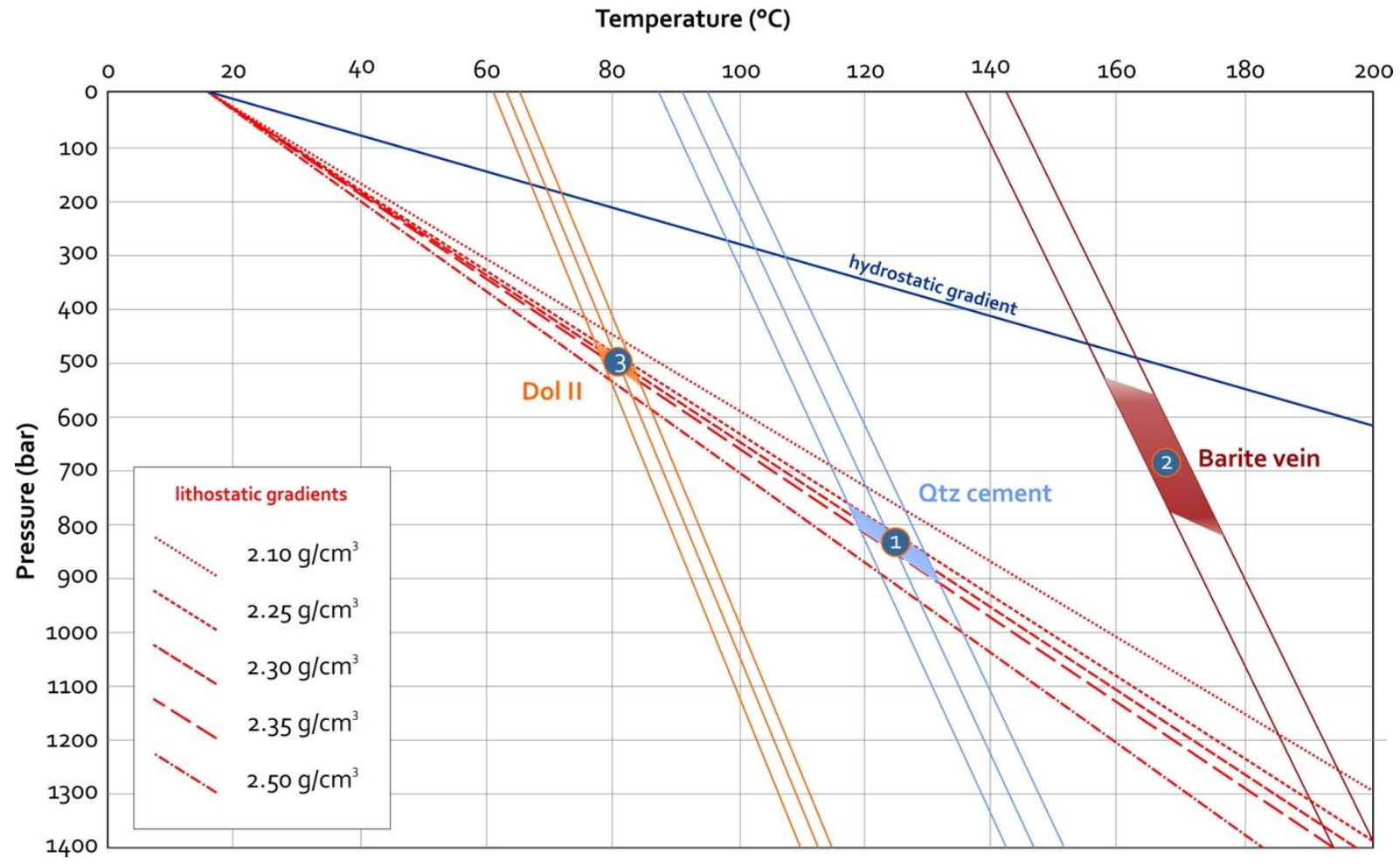

Fig. 3.24. P-T plot showing hydrostatic (blue) and lithostatic (red) gradients for a given geothermal gradient of $30^{\circ} \mathrm{C} / \mathrm{km}$. Isochores of fluid inclusions found in diagenetic minerals and vein mineralizations are 
Chapter 3 - Post-depositional tectonic control on fluid migration in the Southern Permian Basin

indicated with solid lines: orange $=$ DC-III, blue $=$ quartz cement, dark red $=$ barite. Numbers in circles (1 to 3) indicate the chronological sequence of fluid trapping within respective minerals. The intersection of isochores with hydro-/lithostatic gradients determine the P/T conditions during fluid trapping. Fluid inclusions in dolomite and quartz were most likely trapped under pressures close to lithostatic conditions. However, $T_{h}$ of fluid inclusions trapped in barite veins suggest trapping conditions close to hydrostatic, i.e. at pressures between those from quartz cement (1) and DC-III (3).

Once formation pressures and temperatures are known, it is possible to reconstruct the thermal evolution of the area in order to obtain information about thermal anomalies during mineral precipitation. Therefore, formation pressures are converted into depth values. In combination with according formation temperatures formation depths of respective minerals are subsequently plotted in a depth-vs.temperature plot (Fig. 3.25). Now, their positions within this D-T plot can be compared to various geothermal gradients.

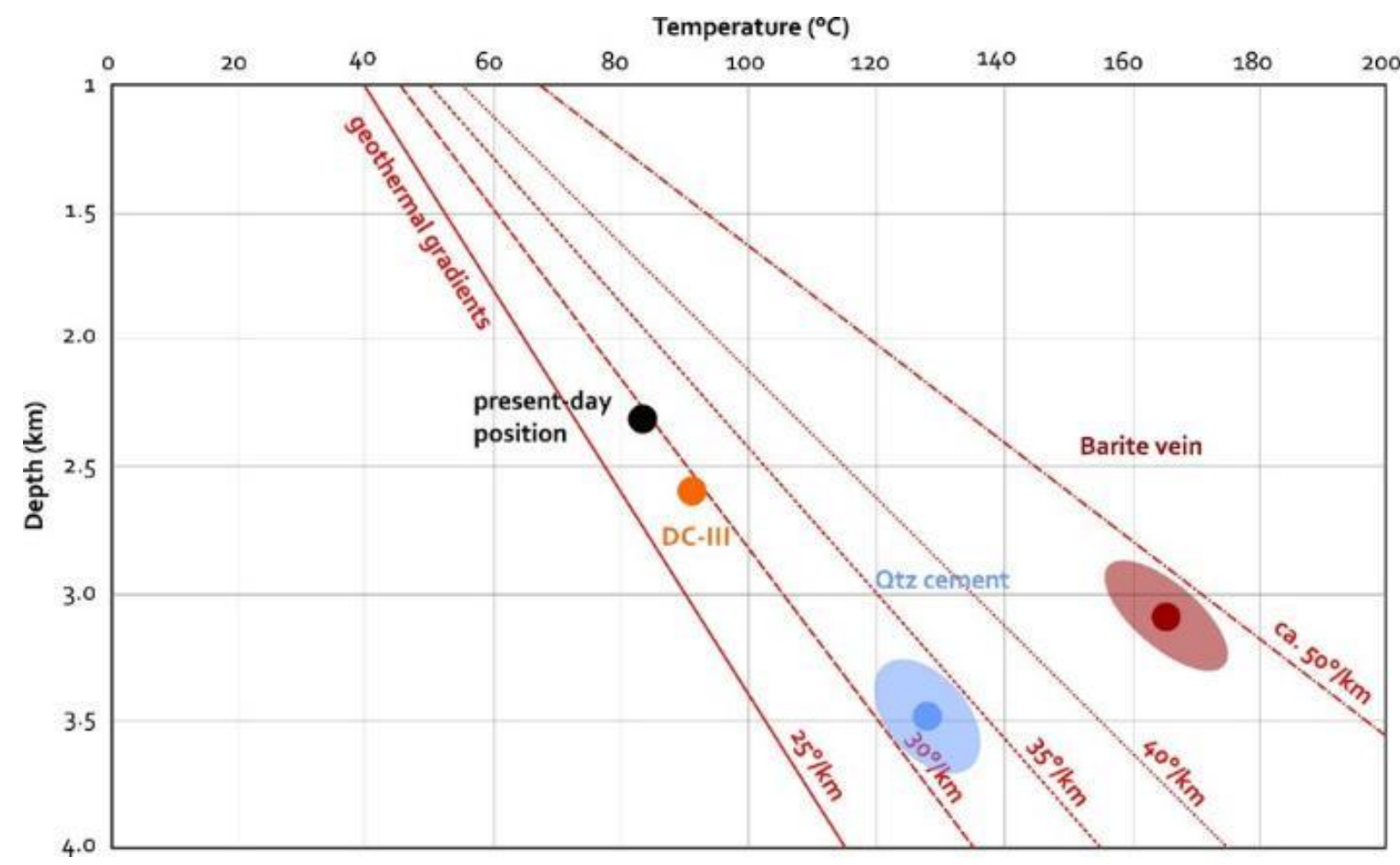

Fig. 3.25. This depth-versus-temperature plot allows to approximate the thermal evolution of the Fizzy Field reservoir based on microthermometric results. Crossing isochores of fluid inclusions with lithostatic gradients (see Fig. 3.24) provided information on trapping pressures $(\rightarrow$ depth) and corresponding temperatures (crustal density: $2.30 * 10^{3} \mathrm{~kg} / \mathrm{m}^{3}$ ). After formation depth and temperature for several heat flow scenarios were calculated, geothermal gradients during fluid precipitation could be estimated. While DC-III growth conditions correspond with the current local geothermal gradient $\left(29^{\circ} \mathrm{C} / \mathrm{km}\right)$, the precipitation of quartz cement most likely occurred during increased heat flow due to rifting and burial $\left(32^{\circ} \mathrm{C} / \mathrm{km}\right)$. The exceptionally high geothermal gradient during barite formation can be explained by hydrothermal convection during fracture propagation $\left(45-50^{\circ} \mathrm{C} / \mathrm{km}\right)$. The assumption of lithsotatic conditions during barite precipitation would result in extremely high burial depths that significantly exceed results of previous investigations from the study area (e.g. Hillis, 1995). Please note that the application of higher geothermal gradients th the P-T plot result in comparatively lower formation temperatures (Fig. 3.24).

According to our calculations, quartz cement formed at a depth between 3.4 and $3.6 \mathrm{~km}$, the corresponding geothermal gradient at that time was ca. $32^{\circ} \mathrm{C} / \mathrm{km}$. The exact formation depth of barite is 
unclear since calculations resulting from crossing the respective isochores and various lithostatic gradients show a strong uncertainty (Fig. 3.24). Nevertheless, we assume a formation depth between 3.0 and $3.2 \mathrm{~km}$, with a corresponding geothermal gradient of ca. $47^{\circ} \mathrm{C} / \mathrm{km}$. Late diagenetic carbonate cement (DC-III) likely formed at a depth of ca. $2.6 \mathrm{~km}$ and a corresponding geothermal gradient close to the present-day gradient of ca. $29^{\circ} \mathrm{C} / \mathrm{km}$.

As derived from our depth and temperature calculations, the geothermal gradient during quartz precipitation was relatively high compared to the present day geothermal gradient of ca. $29^{\circ} \mathrm{C}$. The increased geothermal gradient during burial was probably caused by thinning of the crust during rifting. Anomalous temperatures during barite formation are likely caused by extensional thermal uplift during the late Cimmerian Inversion and simultaneous migration of hydrothermal fluids along extensional fractures (Underhill and Partington, 1993). The geothermal gradient calculated for DC-III is in good agreement with the current reservoir gradient, though the formation of DC-III occurred at a significantly deeper position. This supports the idea of late diagenetic dolomite formation prior to basin inversion during the late Cretaceous - early Paleogene. Our depth calculations show that the reservoir has experienced an uplift of ca. $300 \mathrm{~m}$ since the late Cretaceous, and a total uplift between 1000 and $1200 \mathrm{~m}$ since the late Triassic - early Cretaceous.

\subsubsection{Timing and influence of $\mathrm{CO}_{2}$ migration}

A major goal of the present study is to identify the relative timing of $\mathrm{CO}_{2}$ migration and the subsequent consequences on mineral dissolution and precipitation. Since no carbon dioxide was detected within fluid inclusions using microthermometry and Laser-Raman-spectroscopy, indirect methods such as dissolution of feldspar and carbonate minerals, as well as subsequent precipitation of carbonate phases within the pore space have been used. Though significant dissolution and alteration features have been observed, a direct link between these two processes and an increase in brine acidity due to $\mathrm{CO}_{2}$-input is missing. Stable isotope analysis (C/O), carried out by Heinemann et al. (2013) proved the existence of at least two different dolomite generations within the Leman Sandstone samples from the Fizzy Field discovery. According to their study, the younger dolomite generation (called "sequestration dolomite") shows the same isotopic composition as the present-day carbon dioxide within the reservoir and thus, the carbonate precipitated from a fluid saturated with $\mathrm{CO}_{2}$ of the same origin. Our findings do mostly agree with results from Heinemann et al. (2013), as we can prove the existence of several dolomite generations as well as a dissolution event that affected late diagenetic dolomite (DC-II and DC-III). As Ziegler (2006) described, ankerite (DC-IV) is a very late carbonate phase within Rotliegend sandstones in the Southern Permian Basin that typically forms during deep burial. Since inclusion-free ankerite post-dates DC-II and DC-III, precipitation of the latter must have occurred at relatively deep burial conditions, i.e. prior to uplift during basin inversion. This points to a $\mathrm{CO}_{2}$ migration before or simultaneous to basin inversion, but cannot be definitely proved unless $\mathrm{CO}_{2}$-bearing fluids are found (e.g. within inversion-related fracture mineralizations). Ziegler (2006) also reported that dissolution features among carbonate grains are found in many Rotliegend sandstones from the Southern Permian Basin. As a consequence, the migration of $\mathrm{CO}_{2}$ must have affected larger areas within the Southern Permian Basin, if tectonically induced $\mathrm{CO}_{2}$ migration and the subsequent increase in brine acidity are the main mechanisms responsible for the dissolution of carbonates and the alteration of alkali feldspar grains. However, major carbon dioxide accumulations in the SNSB are restricted to structural traps. A compilation of our results together with a relative chronology of major events is shown in Fig. 3.26. 

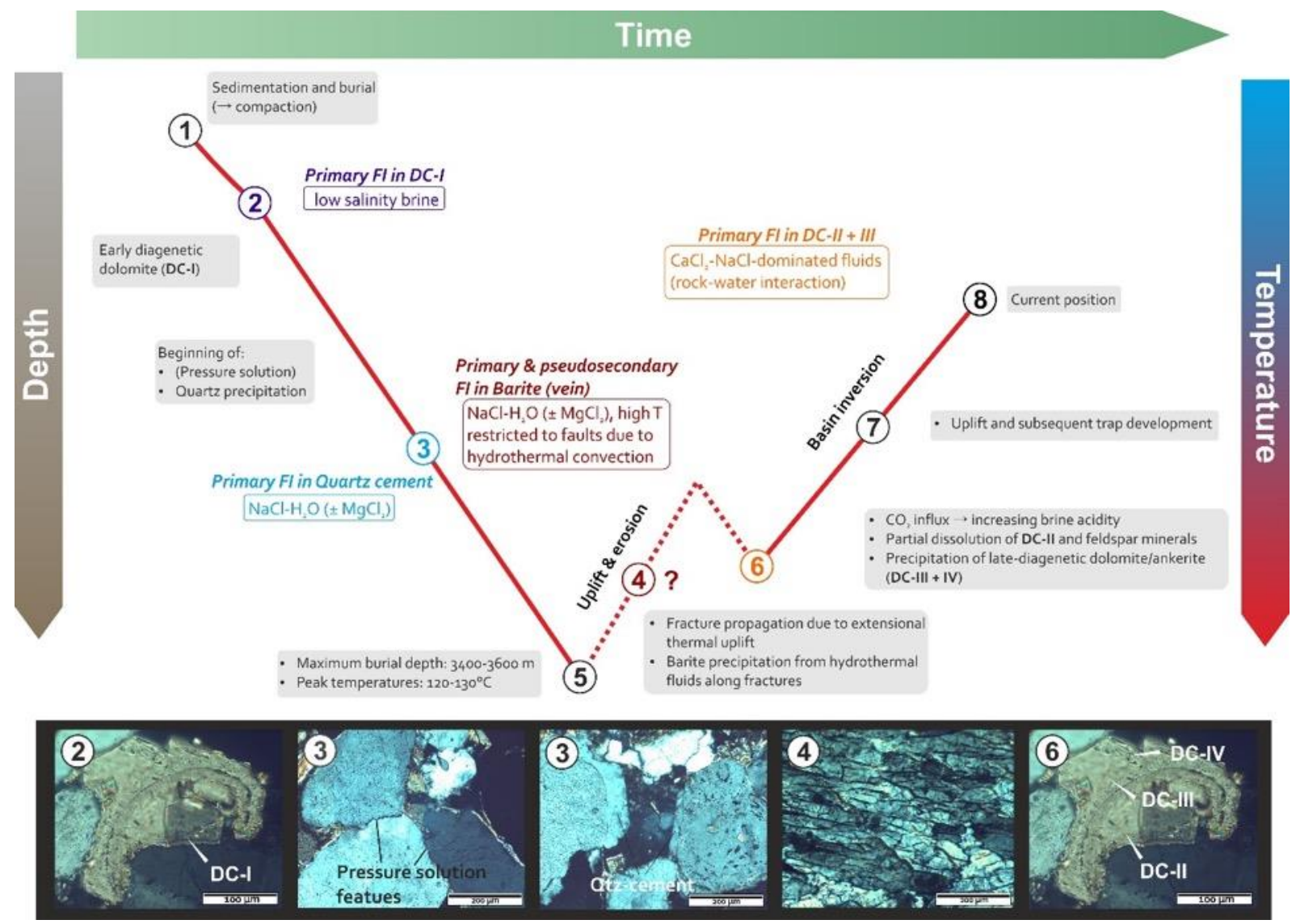

Fig. 3.26. Time chart demonstrating the diagenetic and structural evolution of aeolian Leman sandstone from the Fizzy Field gas accumulation. A first, early diagenetic dolomite cement (DC-I) precipitated from a fluid with meteoric composition. During burial, pressure and temperature increased, leading to pressure solution along quartz grain contacts and subsequent quartz precipitation. Fluid inclusions in quartz cement indicate a fluid composition of medium salinity during trapping (12.3 wt\% (eq.) $\mathrm{NaCl}$ ). An extension phase due to thermal doming initiated fracture propagation and the circulation of hydrothermal fluids within basin sediments, as primary and pseudo-secondary fluid inclusions in barite veins reveal (high salinity, $20.8 \mathrm{wt} \%$ (eq.) $\mathrm{NaCl}$ ). These fluids as well as corresponding high $T_{h}$ are restricted to faults. Maximum burial of the Leman sandstone units as derived from maximum $T_{h}$ found in quartz cement (depth: ca. 3500 mbs, $T_{\text {max }}$ : ca. $120-130^{\circ} \mathrm{C}$ ) was followed by uplift and subsequent burial (Early Triassic). After this second burial episode basin inversion occurred during late Cretaceous leading to trap development in the Fizzy Field Horst. At the same time $\mathrm{CO}_{2}$ entered the reservoir along reactivated faults. When the basin fluid was saturated with $\mathrm{CO}_{2}$, precipitation of DC-III started; fluid inclusions in DC-III prove the presence of high saline, Ca-Na-dominated fluids (intense rock-water interaction) during growth $(23.1 \mathrm{wt} . \%$ (eq.) $\mathrm{NaCl}$ ).

According to Underhill et al. (2009), $\mathrm{CO}_{2}$ and $\mathrm{N}_{2}$ in the Southern Permian Basin may derive from Paleogene igneous intrusions. However, these gas occurrences are usually restricted to reservoir rocks of Triassic age and therefore do not relate to the evolution of the Fizzy Field discovery. Dawsonite as a possible $\mathrm{CO}_{2}$ sink was described by Wilkinson et al. (2009) from the same location, but the carbonate mineral has not been identified by the methods applied in this study. 
Chapter 3 - Post-depositional tectonic control on fluid migration in the Southern Permian Basin

\subsection{Conclusions}

Fluid inclusion studies and microfabric analyses helped to reconstruct the diagenetic and structural development of the Fizzy Field site and adjacent areas, and partly complement the findings of previous studies.

$\mathrm{CO}_{2}$ was not present in the pore space of the reservoir rock during the first burial episode, as the fluid inclusion content in early to mid-diagenetic minerals (DC-I, qtz cement) showed. Moreover, $\mathrm{CO}_{2}$ was not present in hydrothermal fluids accompanying fracture propagation during syn-sedimentary extension due to mantle-driven thermal doming (late Jurassic - early Cretaceous).

Late diagenetic dolomite (DC-II/III) most likely precipitated shortly before or during basin inversion from a then $\mathrm{CO}_{2}$-saturated fluid (compare Heinemann et al., 2013) supposedly at a depth between 2600 and $2800 \mathrm{~m}$ (total uplift due to basin inversion during the late Cretaceous - early Paleogene: ca. $300 \mathrm{~m}$ ) and temperatures of ca. $90^{\circ} \mathrm{C}$. $\mathrm{CO}_{2}$-influx was likely controlled by reactivation of previously existing normal faults. Reservoir integrity was guaranteed even after reverse faulting due to a fault-seal mechanism as previously shown from adjacent Rotliegend reservoirs in the SNSB (compare Leveille et al., 1997).

However, the exact origin of $\mathrm{CO}_{2}$ and its timing of migration and trapping could not be determined unequivocally. It is still not completely understood what role inversion tectonics played for gas migration and trapping, but according to the results presented in this study, the presence of $\mathrm{CO}_{2}$ in the sampled sandstone reservoir prior to basin inversion cannot be excluded. Gas accumulation within the Leman Sandstone Formation may already have occurred during deep burial as dissolution features on carbonate grains suggest. $\mathrm{CO}_{2}$ could also have been stored within the Fizzy Field Horst due to the formation of a structural trap during inversion.

The combination of cathodoluminescence microscopy and fluid inclusion studies in order to discriminate different dolomite and quartz cement generations turned out to be useful, even though difficult to apply. Fluid inclusions in both, dolomite and quartz cement are rare and/or very small $(<5 \mu \mathrm{m})$, and therefore hard to correlate with microscopic evidence.

In order to provide a more detailed description of the diagenetic and tectonic history of the Fizzy Field Horst additional sample material would be necessary. Especially possible inversion-related fractures and fracture-hosted mineralization appear to be most useful for the understanding of fluid flow, fluid mixing and relative timing of fluid migration, and cement precipitation. 


\title{
4. Fluid inclusion and microfabric studies on Zechstein carbonates (Ca2) and related fracture mineralization - Fluid evolution and gas migration in the Lower Saxony Basin *
}

\begin{abstract}
New petrographic and fluid inclusion data from core samples of Upper Permian dolomitic limestone (Hauptdolomit, Zechstein group, Stassfurt carbonate sequence) from a gas field located at the northern border of the Lower Saxony Basin (LSB) essentially improve the understanding of the basin development. The gas production at the locality is characterized by very high $\mathrm{CO}_{2}$ concentrations of 75 $100 \%$ (with $\mathrm{CH}_{4}$ and $\mathrm{N}_{2}$ ). Samples consist of fine grained, mostly laminated and sometimes brecciated dolomitic limestone (mudstone/wackestone) from the transition zone between the shallow water zone (platform) and the upper slope. The study focuses on migration fluids, entrapped as fluid inclusions in diagenetic anhydrite, calcite, and fluorite, and in syn-diagenetic microfractures, as well as on the geochemistry of fluorite fracture mineralization, obtained by LA-ICP-MS analysis. Fluid inclusion studies show that the diagenetic fluid was rich in $\mathrm{H}_{2} \mathrm{O}-\mathrm{NaCl}-\mathrm{CaCl}_{2}$. Recrystallized anhydrite contains aqueous inclusions with homogenization temperatures $\left(\mathrm{T}_{h}\right)$ of ca. $123^{\circ} \mathrm{C}$, but somewhat higher $\mathrm{T}_{\mathrm{h}}$ of ca. $142^{\circ} \mathrm{C}$ was found for calcite cement followed by early Fluorite A with $\mathrm{T}_{\mathrm{h}}$ of $147^{\circ} \mathrm{C}$. A later Fluorite B preserves gas inclusions and brines with maximum $\mathrm{T}_{\mathrm{h}}$ of $156^{\circ} \mathrm{C}$. Fluorite $\mathrm{B}$ crystallized in fractures during the mobilization of $\mathrm{CO}_{2}$-bearing brines. Crossing isochores for co-genetic aqueous-carbonic and carbonic inclusions indicate fluid trapping conditions of $180-200^{\circ} \mathrm{C}$ and $900-1000$ bars. $\delta^{13} \mathrm{C}$-isotopic ratios of gas trapped in fluid inclusions suggest an organic origin for $\mathrm{CH}_{4}$, while the $\mathrm{CO}_{2}$ is likely of inorganic origin.

Basin modelling (1D) shows that the fault block structure of the respective reservoir has experienced an uplift of $>1000 \mathrm{~m}$ since late Cretaceous times. The fluid inclusion study allows us to, 1) model the evolution of the LSB and fluid evolution by distinguishing different fluid systems, 2) determine the appearance of $\mathrm{CO}_{2}$ in the geological record and, 3) more accurately estimate burial and uplift events in individual parts of the LSB.
\end{abstract}

\subsection{Introduction}

The evolution of the Lower Saxony Basin (LSB) as southern part of the Central European Basin has been subject to petroleum geological investigations for many decades with a main focus on the generation of oil and gas resources and their migration within the basin (e.g., Boigk, 1981; Boigk and Stahl, 1970; Plein, 1985). During petroleum exploration, major $\mathrm{CO}_{2}$ occurrences were tapped, with $\mathrm{CO}_{2-}$ concentrations exceeding 75\% (Brand et al., 1982) and accompanied by other gases like methane, nitrogen, and hydrogen sulphide (e.g., Doornenbal and Stevenson, 2010; Krooss et al., 2008; Lüders et al., 2012; Lüders et al., 2005). Although high $\mathrm{CO}_{2}$ concentrations are characteristic for reservoir rocks within the Zechstein units of the LSB, the source of $\mathrm{CO}_{2}$ is still under debate. Apart from thermal

* Part of this Chapter is published in: Duschl, F., van den Kerkhof, A., Sosa, G., Leiss, B., Wiegand, B., Vollbrecht, A., Sauter, M. (2016) Fluid inclusion and microfabric studies on Zechstein carbonates $(\mathrm{Ca} 2)$ and related fracture mineralizations - New insights on gas migration in the Lower Saxony Basin (Germany). - Marine and Petroleum Geology 77C, pp. 300-322. 
decomposition of organic material, degassing of magmatic bodies may have caused $\mathrm{CO}_{2}$-generation (Lokhorst et al., 1998); therefore, plutonic intrusions during the Cretaceous into the basement were discussed by various authors (Bilgili et al., 2009; Bruns et al., 2013; Hahn and Kind, 1971; Kus et al., 2005; Petmecky et al., 1999; Stadler and Teichmüller, 1971; Ziegler, 1990). While some authors favour the existence of plutonic intrusions in order to explain high vitrinite reflectance values between 3.0 and 4.5\% VRr in some parts of the LSB ( Bartenstein et al., 1971; Teichmüller and Teichmüller, 1985), other possible reasons for supporting those levels of thermal maturity include deep burial followed by basin inversion (Adrisola-Muñoz et al., 2007; Adrisola-Muñoz, 2007; Petmecky et al., 1999), and the circulation of hydrothermal fluids along faults during rifting (Reutel and Lüders, 1998; Stadler and Teichmüller, 1971). Basin modelling based on new seismic and thermometric data (e.g. fluid inclusion analysis, apatite/zircon fission track analysis) has revealed, that anomalous thermal maturity values in different parts of the LSB (e.g. anomalies of Bramsche, Vlotho, Uchte, Apeldorn) can be explained by deep burial during the late Jurassic-early Cretaceous and subsequent rapid uplift during the late Cretaceous (e.g. Adrisola-Muñoz, 2007; Brink, 2005; Bruns et al., 2013; Fischer et al., 2006; Petmecky et al., 1999; Senglaub et al., 2005). Fluid inclusion studies of cement phases and mineralized fractures can help to better understand burial and uplift events and their effect on the mobilization of fluids and gases in the LSB. Several studies in the North German Basin suggest a considerable variability of fluid inclusions with respect to chemical composition and gas content as a result of water-rock interaction (formation of Na-/Ca-rich brines due to the presence of evaporates and volcanic rocks), decomposition of organic matter $\left(\mathrm{CH}_{4} / \mathrm{CO}_{2}\right.$-formation), thermochemical sulphate reduction (TSR), and hydrothermal activity (Fischer et al., 2006; Huttel, 1989; Lüders et al., 2012; Lüders et al., 2005; Reutel and Lüders, 1998; Schmidt Mumm and Wolfgramm, 2004; Schmidt Mumm and Wolfgramm, 2002; Siemann and Ellendorff, 2001; Steuer, 2008; Zwart and Touret, 1994). Few fluid inclusion studies are focussed on the source and migration of $\mathrm{CO}_{2}$ in the LSB (Fischer et al., 2006; Lokhorst et al., 1998; Lüders et al., 2012; Lüders et al., 2005). Fluids within the Zechstein limestone are dominated by $\mathrm{CaCl}_{2}-\mathrm{NaCl}$-rich solutions and commonly show salinities between 16 and $23 \mathrm{wt} \%$ (eq) $\mathrm{NaCl}$ and 7-15 wt\% (eq) $\mathrm{CaCl}_{2}$, respectively (e.g. Zwart, 1995; Zwart and Touret, 1994); other salts like $\mathrm{LiCl}$ and $\mathrm{KCl}$ are present as well, but they mostly occur in low concentrations and usually together with $\mathrm{CaCl}_{2}$. Significant changes in brine salinity are often explained with fluid migration from one fluid system to the other (e.g. Huttel, 1989), triggered by extensional fracturing. Aqueous fluid inclusions can contain traces of dissolved gases like $\mathrm{CO}_{2}, \mathrm{CH}_{4}, \mathrm{~N}_{2}$, and $\mathrm{H}_{2} \mathrm{~S}$, while pure gaseous inclusions are rare. $\mathrm{CO}_{2}$ - and $\mathrm{CH}_{4}$-rich gaseous inclusions are reported from fracture mineralization that relate to rifting (extensional fractures) or reverse faulting (shear fractures) (Fischer et al., 2006; Lüders et al., 2012; Lüders et al., 2005; Reutel and Lüders, 1998; Schmidt Mumm and Wolfgramm, 2004; Schmidt Mumm and Wolfgramm, 2002) and thus may provide information about timing and P-T conditions during gas migration. In order to relate changes in fluid and mineral composition to specific geological events special emphasis is given to fluorite geochemistry. Numerous studies on fluorite have shown (Bau and Dulski, 1995; Bau and Möller, 1992, 1991; Jacob, 1974; Lüders, 1991; Möller et al., 1980; Möller et al., 1976; Schulz, 1980; Schwinn and Markl, 2005) how distributions of REE and Y in fluorite may help identifying the environment of crystallization, i.e. distinguish between primary crystallized and recrystallized fluorite (Möller et al., 1976). Thus differences in fluorite chemistry may reveal the importance of hydrothermal and magmatic fluids during basin evolution. Information on fluid migration in sedimentary rocks can be obtained from fluid inclusions in healed micro-fractures, which provide the pressure and temperature of fluid trapping as well as the fluid composition (Goldstein, 2001; Goldstein and Reynolds, 1994). Steep fractures are supposed to form in extensional regimes during rifting and simultaneous subsidence, when vertical stress 
prevails (extensional fracturing or extensional-shear fracturing, see Sibson, 1998); brittle fracturing is favoured also by fluid overpressure. In order to define the burial depth and tectonic activity fracturehosted fluid inclusions have been studied and compared with geothermal and geostatic gradients from the LSB (e.g. Nollet et al., 2009). Anhydrite and fluorite vein mineralization, which follow fracture propagation due to extensional-shear during burial, allow us to calculate pressure and temperature conditions in the reservoir close to maximum burial (P-T calculated from co-existing fluids). This information is used to calibrate the 1D model together with the relative ages of mineral precipitation as obtained from standard optical microscopy and fluid inclusion studies. Fluid migration and mineral precipitation within the LSB are subjected to changing tectonic regimes (e.g., Strohmenger et al., 1996). For example, transpressional forces during reactivation of older normal faults located at the northern margin of the LSB supported the forming of positive flower structures and fault block structures along a ESE-WNW striking thrust belt (Kockel, 1994; Ziegler, 1990). By investigating core samples from an individual fault block, which is limited by a ENE-WSW striking reverse fault, we aim to reconstruct the evolution of the fluid phases at the northern margin of the LSB, and mark the time of $\mathrm{CO}_{2}$ migration and trapping. Our fluid inclusion, micro-structural and petrographic study complements existing evolution models of the LSB based on vitrinite reflectance (Adrisola-Muñoz, 2007; Buntebarth, 1985; Petmecky et al., 1999; Senglaub et al., 2005; Uffmann, 2013) and fission track analyses (Adrisola-Muñoz, 2007; Petmecky et al., 1999; Senglaub et al., 2005).

\subsection{Geological setting}

The study area is located at the north-eastern border of the Lower Saxony Basin, which is part of the North German Basin (NGB). The NGB forms the southern extension of the Central European Basin; it is an intra-cratonic basin that extends from the North Sea in the northwest to Poland in the southeast. The basin is mainly composed of thick sequences of Paleozoic and Mesozoic sediments that filled a complex WNW-ESE oriented graben system (Baldschuhn et al., 2001; Betz et al., 1987; Boigk, 1968; Kley and Voigt, 2008; Kockel, 1994; Kockel et al., 1994) (Fig. 4.1). 


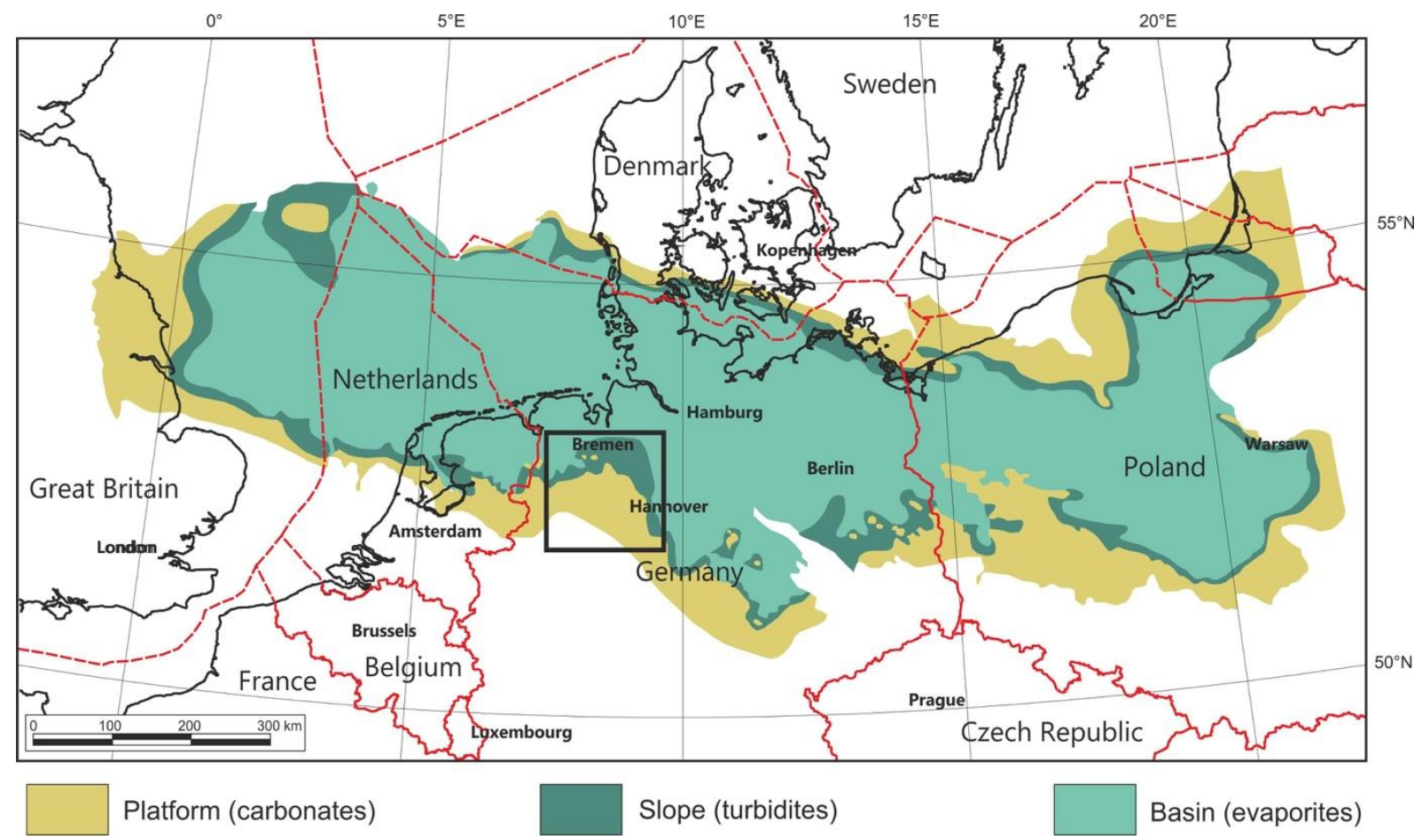

Fig. 4.1. Distribution map of Stassfurt carbonates, turbidites and evaporites outlining the dimensions of the Southern Permian Basin (modified after Lokhorst et al., 1998); the study area is marked by a rectangle.

During the late Carboniferous - early Permian extensional tectonics caused crustal rifting which resulted in the thinning of the crust and the rise of magmas from the mantle (Brink et al., 1992; Ziegler, 1990). In the eastern part of the NGB volcanic sequences have formed continuous layers of several hundreds of meters covering Carboniferous sediments, while to the west of the basin, e.g. in the LSB, Permian volcanic rocks form patch-like spots due to erosion or missing deposition (Lokhorst et al., 1998; Mempel, 1962). Sediments were unconformably deposited on folded Variscan basement rocks (Füchtbauer, 1962; Richter-Bernburg, 1955). During early Triassic a system of NNE-SSW trending horst and graben structures formed due to the evolution of the North Sea rift system (Betz et al., 1987; Doornenbal and Stevenson, 2010; Lokhorst et al., 1998). From mid to late Jurassic thermal doming affected the NGB leading to a period of uplift and thermal subsidence (Ziegler, 1990). During the late Jurassic - early Cretaceous an extensional stress regime resulted in the formation of the ENE e WSW trending LSB (Betz et al., 1987; Brink et al., 1992) when the Permo-Carboniferous fracture system was reactivated (Betz et al., 1987). The LSB is bounded to the north by the Pompeckj Block, and to the south by the Münsterland platform (Brink et al., 1992; Glennie, 1990). The main subsidence occurred during the late Jurassic and early Cretaceous and continued until mid-Cretaceous (Betz et al., 1987; Boigk, 1981; Pharaoh et al., 2010). Subsidence was subsequently followed by three major tectonic inversion phases, likely related to compressional tectonic activity in connection with the beginning of Alpine orogeny during the late Cretaceous (Sub-Herzynian inversion, Turonian-Santonian) (Baldschuhn et al., 1991; Kockel et al., 1994) and early Paleogene (Laramide inversion) (Baldschuhn et al., 1991; Pharaoh et al., 2010; Ziegler, 1990); the last inversion movements occurred in the late Eocene - early Oligocene (Betz et al., 1987; Ziegler, 1995) . Basin inversion forced by compressional tectonics resulted in reverse faulting along the southern and northern slopes of the LSB, where overthrusts propagated onto the Münsterland Block in the south and the Pompeckj Block in the north (Fig. 4.2). 


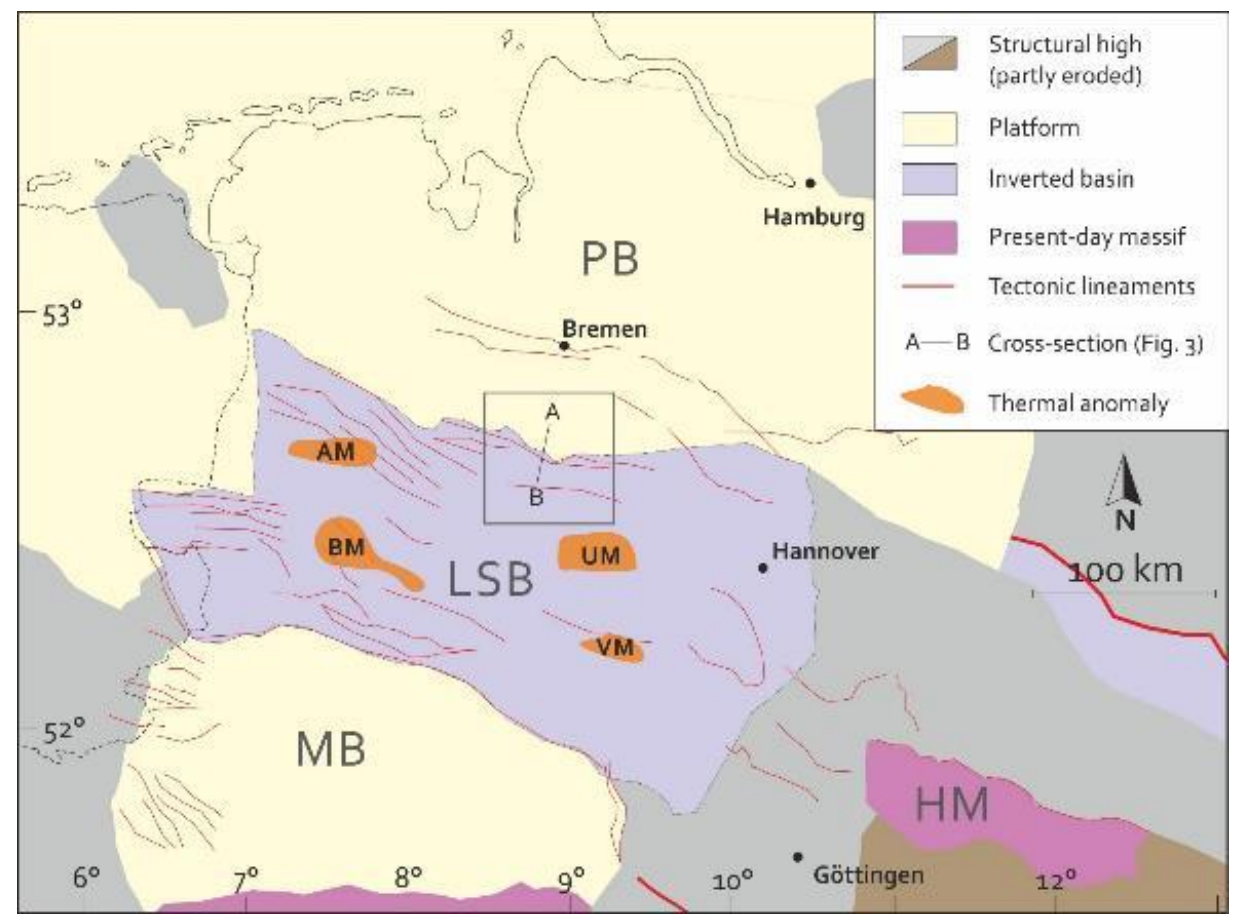

Fig. 4.2. Tectonic sketch of the North German Basin in the late Cretaceous; the study area is marked by a rectangle (modified after Doornenbal and Stevenson, 2010). Outlines of thermal anomalies were taken from Kus et al. (2005). Structural features: PB=Pompeckj Block, LSB=Lower Saxony Basin, MB=Münsterland Block, HM=Harz Mountains. Thermal anomalies: AM=Apeldorn massif, $B M=$ Bramsche massif, $U M=$ Uchte massif, VM=Vlotho massif.

Normal faults, which had formed during the late Jurassic - early Cretaceous rifting phase were reactivated and reversed (Fig. 4.3) (Betz et al., 1987; Lohr et al., 2007; Scheck-Wenderoth and Lamarche, 2005); compressional inversion tectonics were likely accompanied by sinistral convergent wrench faulting (Betz et al., 1987). The late Cretaceous inversion not only resulted in the structural modification of the LSB (Baldschuhn et al., 2001; Baldschuhn et al., 1991; Kockel, 1994), but also largely affected the role of the fluid (Kockel, 1994; Kus et al., 2005; Lüders et al., 2005; Petmecky et al., 1999). When compressive tectonic forces reactivated previously existing normal faults as reverse faults gas migration was initiated (Schmidt Mumm and Wolfgramm, 2004). Thermal maturity data suggest that the effects have been different for different parts of the LSB during basin inversion and tectonic uplift, causing heterogeneous heat flow rates (e.g., Adrisola-Muñoz, 2007; Bruns et al., 2013; Kockel et al., 1994; Kus et al., 2005). Though the deposition of post Zechstein sediments in the area was affected by salt tectonics (Ziegler, 1990), salt structures within the LSB are mostly restricted to compressive overthrusts (Brink et al., 2012). The late Cretaceous inversion was accompanied by exhumation and erosion of early Cretaceous to mid-Jurassic sediments. Marine conditions re-established during Eocene and Oligocene resulted in the deposition of deltaic and shallow marine sediments in the LSB (Betz et al., 1987). The evolution of the Rhine Graben Rift System in the early Miocene caused the thermal doming of the Rhenish Massif and consequently, the LSB was uplifted (Betz et al., 1987; Ziegler, 1992); in some parts of the LSB this uplift continues today (Ziegler, 1992). 


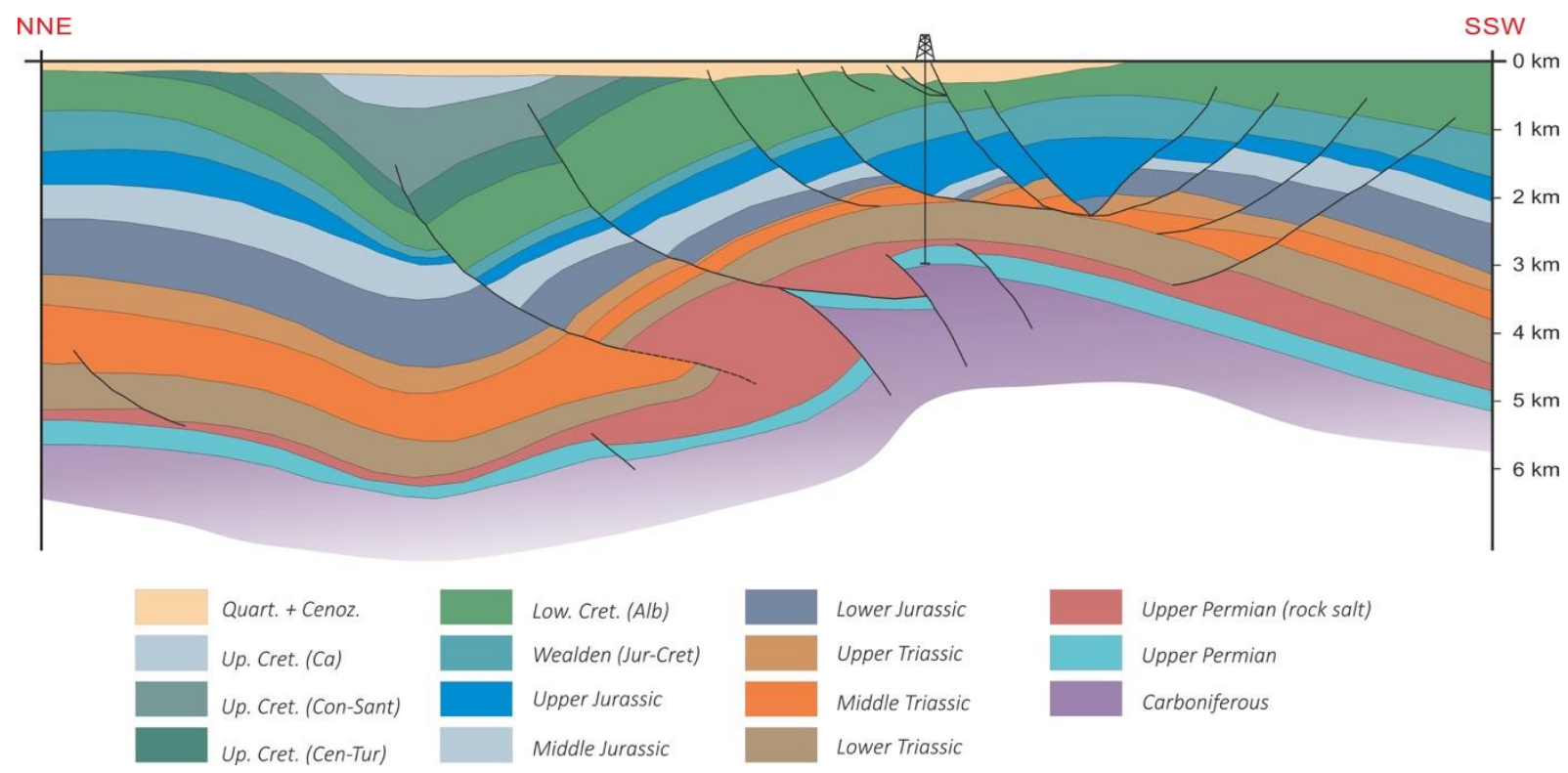

Fig. 4.3. Cross-section showing the present day situation at the northern rim of the LSB (profile line A-B in Fig. 4.2) (modified after Baldschuhn et al., 1991). Samples come from the Zechstein units of an individual fault block that was likely formed during basin inversion in the late Cretaceous (respective fault block indicated by drilling profile). Differences in thickness especially in the Triassic sequence are due to the formation of sub-basins and swells that started in Lower Triassic times.

\subsection{Sample material}

25 drill core samples were collected from the lowermost parts of the Z2-cycle (Ca2, Stassfurtcarbonate); special emphasis during sampling was on fractures and ore mineralization within nodular mineral assemblages related to density-driven inversion structures (Fig. 4.4). Analytical methods including conventional and cathodoluminescence microscopy, microthermometry, fluid inclusion analysis, and Raman spectrometry have been applied. For the examination of petrophysical and petrochemical properties of the Stassfurt carbonate samples 30 standard thin sections $(30 \mu \mathrm{m})$ and 6 doubly polished fluid inclusion wafers were prepared. Fluid inclusion wafers and thin sections of the same samples allowed comparison of features from the same rock orientation.

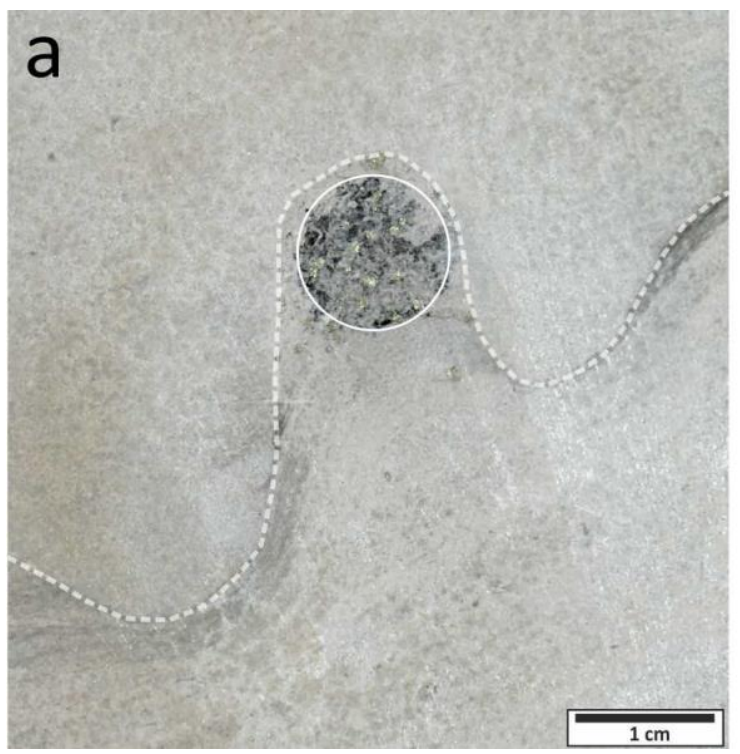

b

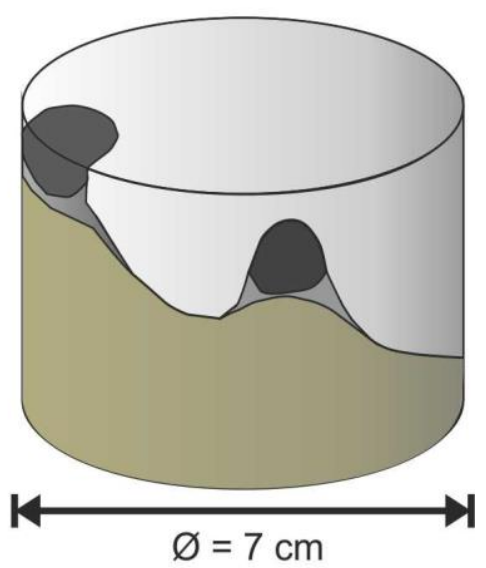


Fig. 4.4. (a) Density-driven inversion structure (flame structure) in Ca2 carbonate. The white dashed line divides the lower, fine grained matrix from the upper, coarse grained matrix. A white circle marks the mineralized, formerly highly porous nodule mostly consisting of algae and shell remnants and pore-filling hydrothermal ore minerals (anhydrite, fluorite, sphalerite, quartz). (b) Idealized sketch of a core sample illustrating dimensions and spatial relation of the flame structure shown in (a). Brown shade $=$ fine grained matrix; white shade $=$ coarse grained matrix; light grey shade $=$ clay-rich matrix; dark-grey shade $=$ mineralized nodule.

\subsection{Results}

\subsubsection{Carbonate petrography}

The sample material was restricted to the Stassfurt carbonate series (Hauptdolomit) of the Zechstein Z2 cycle (Fig. 4.5) as this unit possesses typical characteristics of a reservoir rock as well as fracture-fill mineralization. Core samples were collected from two wells at depth of 3000-3250 m below surface. The samples are mainly composed of dolomitic (microsparitic) limestone with dolomite and sometimes calcite cement. Also present are cement phases consisting of anhydrite, fluorite and gypsum.

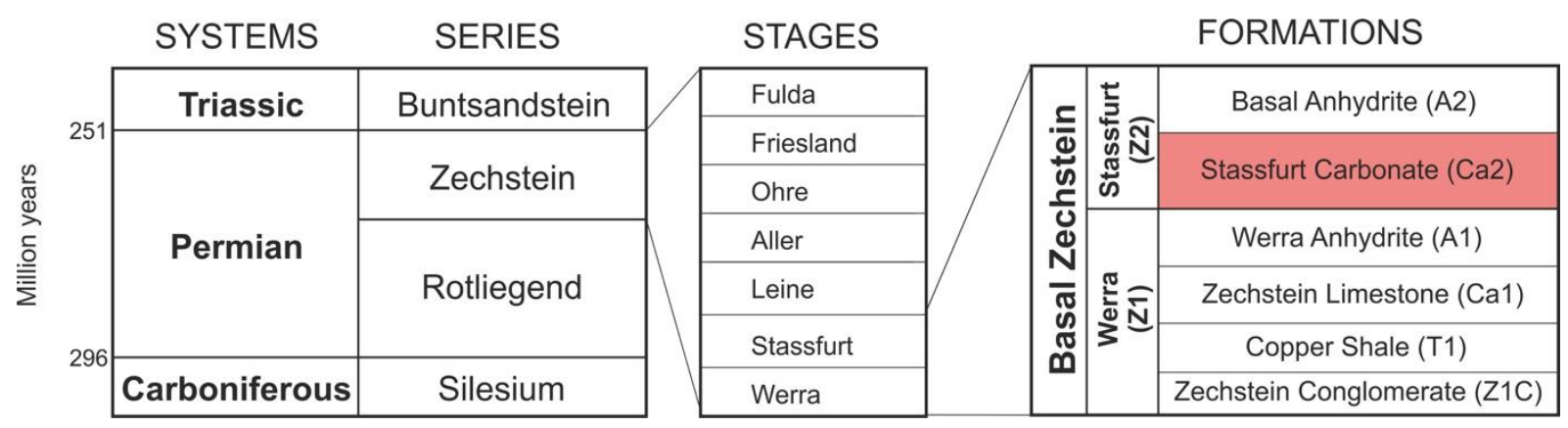

Fig. 4.5. Chronostratigraphic chart of the Zechstein formtion with the Stassfurt carbonate sequence marked in red colour (modified after Steinhoff and Strohmenger, 1996).

Dolomitic limestones are mostly laminated, but brecciated mud- and wackestones are present as well; the lamination is often gently inclined. Sedimentary inversion structures (flame structures) developed between layers with different grain size, or when intercalating impermeable material (e.g. shales) prevented vertical fluid flow forced by pore overpressure (density-inversion). Anhydrite is abundant throughout the cored strata, likely resulting from the conversion of gypsum to anhydrite during diagenesis. White, cloud-shaped nodules consisting of microcrystalline, xenomorphic crystals are common and represent former gypsum nodules, which precipitated in oversaturated shallow marine water. The nodules are slightly elongated and oriented parallel to the bedding. Small fractures and tension gashes formed by hydraulic fracturing (Balzer, 1997; Füchtbauer, 1962; Huttel, 1989; Reijers, 2012) are radially surrounding the nodules, extending into the matrix; they are filled with recrystallized anhydrite. In our study, we observed three different types of anhydrite: (1) a mostly fine-grained, inclusion-free nodular type; (2) thin (>2 mm) stratabound layers and radially arranged aggregates of anhydrite within the rock matrix; and (3) a younger, blocky or slaty-shaped type, that fills off-set veins originating from the anhydrite nodules and extensional-shear fractures (Fig. 4.6); this type contains aqueous fluid inclusions. 


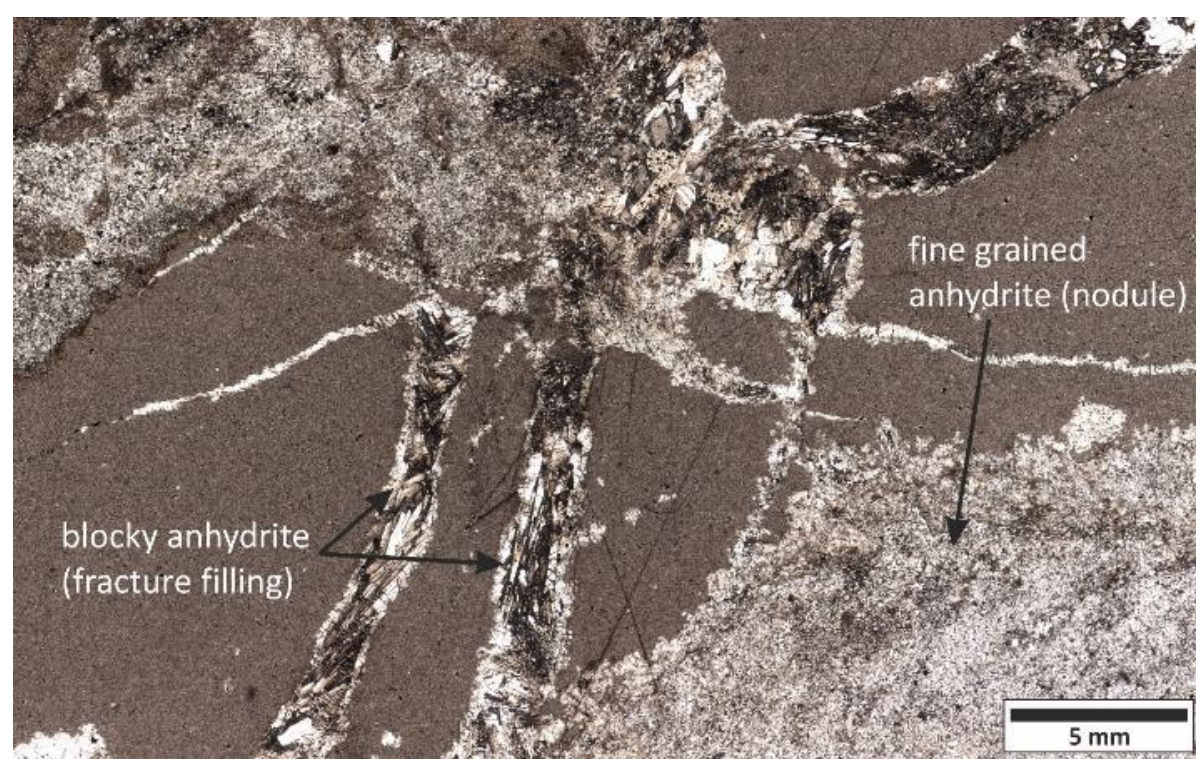

Fig. 4.6. Early diagenetic anhydrite nodule (lower right corner) and coarse grained anhydrite veins in Stassfurt carbonate rock (plane polarized light). The veins filled with blocky coarse grained anhydrite formed during late diagenesis when anhydrite was mobilized and precipitated along fractures. Fine grained anhydrite nodules do not contain fluid inclusions, blocky anhydrite crystals in fractures contain primary aqueous fluid inclusions.

Calcite is mostly present as pore-filling cement. We observed only few calcite veins related to tension gashes oriented perpendicular to stylolites. Calcite cement often occurs together with anhydrite cement which was partly replaced by poikilotopic anhydrite crystals within tension gashes. Fluorite shows two different (micro-) fabrics: Fluorite A forms brownish-zoned aggregates which are commonly related to flame structures (Fig. 4.7-a) and pockets. Small patches rarely also occur within steep extension fractures and are preserved as isolated remnants within a younger fluorite generation (Fluorite B). Fluorite A within nodules and pockets occur together with blocky anhydrite and sulphide minerals (pyrite, chalcopyrite, sphalerite). Bitumen inclusions may decorate crystal growth planes in Fluorite A primarily parallel to the (100) lattice plane; nodules and pockets reach diameters from 1 to $5 \mathrm{~cm}$. Fluorite $\mathrm{B}$, a colourless and non-zoned phase, mostly appears as blocky crystallized fracture fillings, but also as pore-filling cement. Fluorite B fills extensional-shear fractures almost perpendicular (>80_) to the lamination (Fig. 4.7-b). The fractures were initially filled with early blocky anhydrite that was partly replaced by Fluorite B, as indicated by the presence of scarce anhydrite remnants within fracture-filling Fluorite B. Both late Fluorite B and Fluorite A may have replaced anhydrite in fractures, nodules and pockets. 

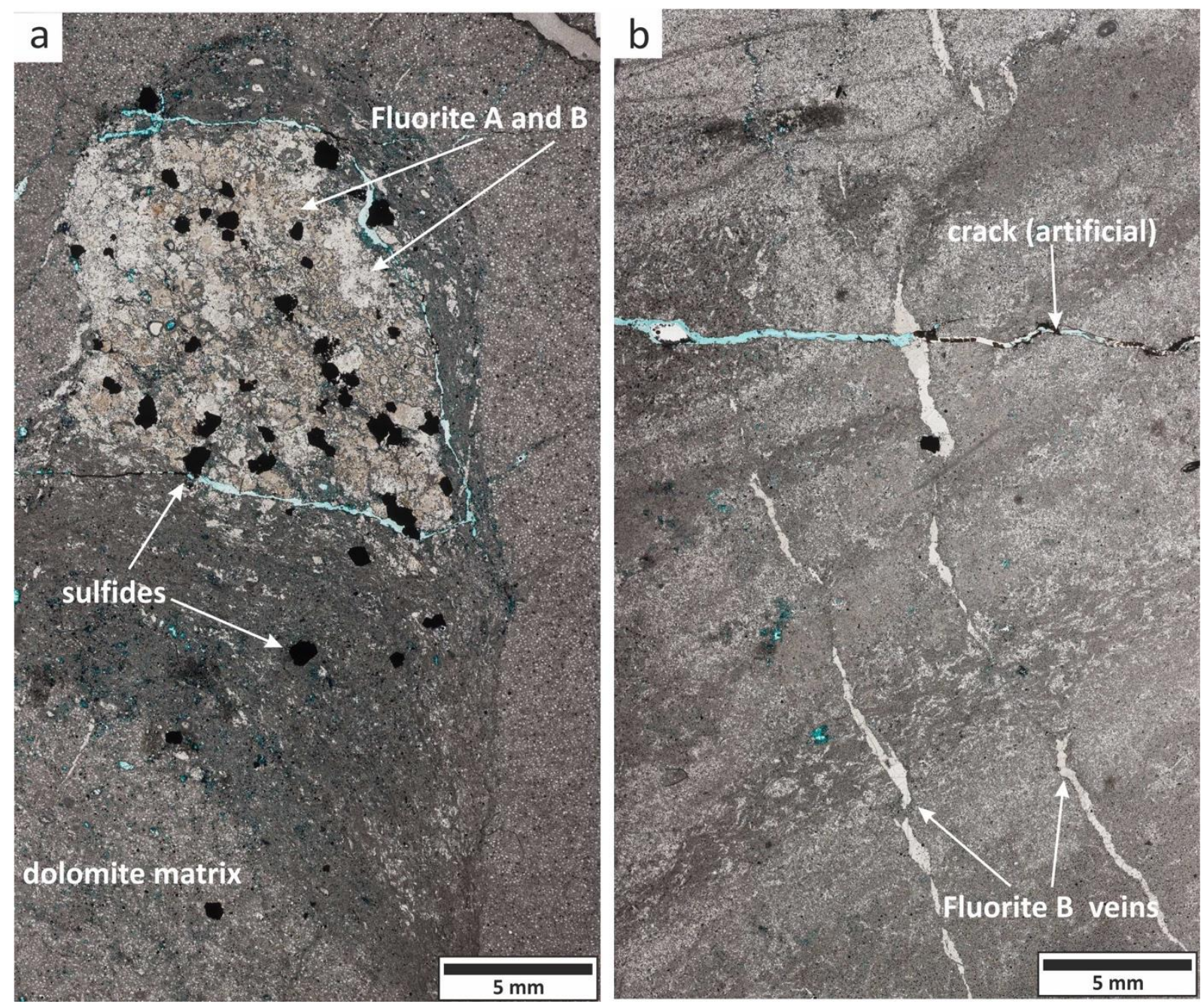

Fig. 4.7. (a) Detail of a flame structure in dolomitic limestone with brownish Fluorite A, colourless Fluorite $B$, and euhedral Fe-sulphides (plane polarized light) (compare Fig. 4.4). Detailed microscopic studies of the top unit reveal a large number of algae structures and ostracod shells in this part. This may explain the possibility of fluid entrapment and the conservation for late diagenetic mineral precipitation. (b) Stratified dolomitic limestone with parallel veins of Fluorite B perpendicular to lamination (plane polarized light). Fractures were formed due to extensional-shear during rifting.

Authigenic quartz crystals are rare; they are commonly found within the dolomitic limestone matrix but also in fractures, pockets and nodules filled with blocky anhydrite and/or fluorite. Euhedral quartz crystals are max. $150 \mu \mathrm{m}$ long and $70 \mu \mathrm{m}$ wide; they usually contain a growth nucleus of detrital quartz in the crystal core. Quartz has been partly replaced by Fluorite B. Ore minerals such as pyrite, chalcopyrite, and sphalerite are rare; they occur in fractures, nodules, and within the dolomitic limestone matrix; pyrite is sometimes enriched along stylolites. While pyrite and chalcopyrite show euhedral shapes, sphalerite is always anhedral. The sulphides sometimes form poikilotopic crystals and sometimes enclose anhydrite and fluorite. Stylolites appear as sub-horizontal dark and serrated structures made up by an insoluble residue. Their relative time of formation in the geological record can be determined by comparing the mineral and cement formation prior and after pressure solution; the stylolites are oriented parallel to the bedding, therefore indicating formation during vertical stress. Stylolites are more common in calcite-dominated layers of the $\mathrm{Ca} 2$ limestone, especially along boundaries between calcitic and dolomitic layers. They affected they affected blocky anhydrite, as well as calcite veinlets. 


\subsubsection{Cathodoluminescence microscopy}

Cathodoluminescence (CL) microscopy has been applied in order to visualize diagenetic and fracturerelated microfabric features. Calcite cement shows bright yellow to dull orange CL colours caused by $\mathrm{Mn}^{+2}$ as activator substituting $\mathrm{Ca}^{+2}$ (Machel, 2000; Marshall, 1988), while the dolomite matrix exhibits intense red to violet emission (Fig. $4.8-\mathrm{a} / \mathrm{b}$ ). Pore-filing calcite usually shows irregular or patchy CL colours; growth zoning has been observed only within very small veinlets related with pressure solution. Euhedral dolomite crystals sometimes show concentric reddish and non-luminescent growth zoning, reflecting changes in fluid chemistry during crystal growth, notably regarding the $\mathrm{Mn} / \mathrm{Fe}$-ratio. Anhydrite and rarely occurring gypsum are virtually non-luminescent.
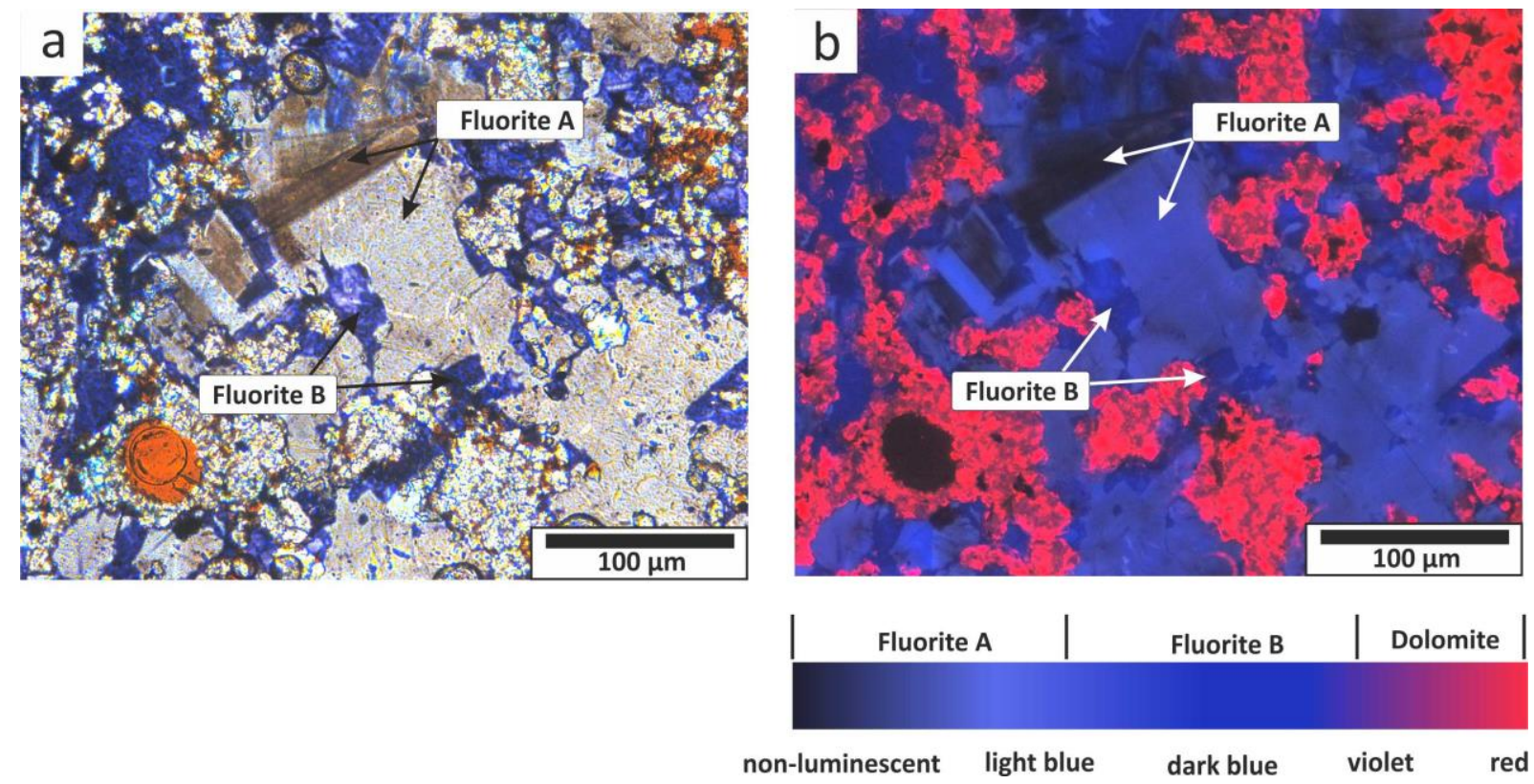

Fig. 4.8. Microstructural details from a fluorite nodule: (a) brownish zoned Fluorite A and bluish Fluorite $B$ (plane polarized light). (b) Same image in CL mode. Especially missing zoning features in Fluorite B and dissolution inlays in Fluorite A demonstrate differences in age and composition and support a direct relation between these two fluorite generations due to remobilization.

Fluorite A shows pronounced concentric growth zoning revealed by bluish CL of various intensity, alternating with non-luminescent zones, as a result of compositional changes during crystallization (Fig. 4.8-b). Light blue CL colours in fluorite (Fluorite A) are due to the incorporation of activators, mainly $\mathrm{Ca}^{+2}$-substituting REEs (Blanc et al., 2000; Boggs and Krinsley, 2006; Marshall, 1988), but also crystal imperfections may cause blue luminescence (Marshall, 1988). Non-luminescent parts are brownish in transmitted light due to fine-grained solid inclusions. Fluorite B, a blocky fluorite generation mainly filling small fissures in the dolomitic bedrock is characterized by dark blue to violet CL, probably caused by REE substituting $\mathrm{Ca}^{+2}$ in the crystal lattice. Fluorite $\mathrm{B}$ shows zoning, neither in CL nor in transmitted light. Fluorite A shows dissolution features due to remobilization and subsequent precipitation of Fluorite B, as shown in CL images (Fig. 4.8-b). Remobilization is evidenced by small inlets in brownish fluorite crystals, which formed within flame structures. Inlets in early fluorite show the same bright blue $\mathrm{CL}$ as Fluorite B in veins, and are equally non-zoned. Both fluorite generations are differently affected by the electron beam: Fluorite B turns from colourless to blue or violet, whereas Fluorite A remains brownish or colourless (Fig. 4.8-a). Most likely the CL emission of Fluorite B is dimmed by artificial 
coloration due to electron irradiation. Sphalerite crystals exhibit bright yellow CL similar to calcite, though emission shows an irregular distribution within the crystals and is sometimes quenched, most probably depending on the Fe-content (compositional zoning, Marshall, 1988). A composite image of a complete fluorite nodule is presented in Appendix-4.1.

\subsubsection{Fluid inclusion petrography}

Fluid inclusions are classified into three categories according to their trapping mechanism (Roedder, 1984). Primary fluid inclusions are trapped along the crystal surface during precipitation and thus contain small amounts of the paleo-fluid present during crystal growth. They are usually arranged along growth planes and formed due to impurities along the crystal surface. Pseudosecondary fluid inclusions decorate healed micro-cracks within a single crystal but never extend to adjacent crystals and thus demonstrate fracturing during crystal growth. Secondary fluid inclusions occur within healed microcracks, that may affect one or several crystals; they form after crystal growth and postdate primary and pseudosecondary fluid inclusions within a single crystal. Aqueous fluid inclusions in recrystallized anhydrite are of primary character. These inclusions show squared to rectangular negative crystal shapes with edges parallel to the cleavage planes; many of them are flat. Their size varies from 6 to $18 \mu \mathrm{m}$ in diameter and they often occur in clusters of 10 or more inclusions. Usually, the inclusions are located in the centre of relatively large anhydrite crystals. They are biphase at room temperature with a water volume fraction $\left(\mathrm{V}_{\text {frac }}\right.$ ) of ca. 0.85 (Fig. 4.9-a). Calcite cement mostly contains irregular primary fluid inclusions and few spherical inclusions. The inclusions are between 10 to $20 \mu \mathrm{m}$ in diameter and sometimes form small clusters of 4 to 7 inclusions within a single calcite crystal, but most are isolated inclusions; they are never arranged along healed microcracks. Larger inclusions are commonly isolated and randomly distributed. The inclusions are mostly biphase $(\mathrm{L}+\mathrm{V})$ and sometimes multiphase in the case that daughter halite crystals are present $(\mathrm{L}+\mathrm{V}+\mathrm{S}) ; \mathrm{V}_{\text {frac }}$ is ca. 0.85 to 0.9 (Fig. 4.9-b).

Primary fluid inclusions in Fluorite A are characterized by elongated, sometimes spherical, and occasionally tubular or acicular morphology with convex edges (when arranged parallel to growth planes). Their diameter ranges from 5 to $14 \mu \mathrm{m}$, while $\mathrm{V}_{\text {frac }}$ varies from 0.75 to 0.85 . The inclusions are either biphase or multiphase with daughter minerals (halite and sylvite) (Fig. 4.9-c). Pseudosecondary fluid inclusions in Fluorite A are spherical or sometimes tubular with convex edges. These inclusions are generally arranged along healed microcracks, range in sizes between 8 and $21 \mu \mathrm{m}$ in diameter, and are monophase gaseous (L) at room temperature (Fig. 4.9-d).

Fluorite B contains monophase, biphase, and multiphase (pseudo-)secondary fluid inclusions. Larger inclusions are typically octahedral with smooth edges. Few inclusions are irregular with angular/sharp edges. Irregular shapes are usually controlled by the incorporation of accidentally trapped dolomite crystals and organic matter, bitumen or char. Daughter minerals are commonly halite and/or sylvite. The size of the inclusions varies between 5 and $25 \mu \mathrm{m}$; $\mathrm{V}_{\text {frac }}$ of bi- and multiphase inclusions are between 0.75 and 0.9 . Largest inclusions show diameters up to $35 \mu \mathrm{m}$. Monophase, secondary gas inclusions appear very dark in transmitted light and are trapped along healed microcracks, which cross-cut both Fluorite A and B (Fig. 4.9-e), while monophase, pseudosecondary inclusions are restricted to Fluorite B only (Fig. 4.9-f). Pseudosecondary fluid inclusions in Fluorite B occur as heterogeneously trapped fluids with monophase and biphase inclusions trapped at the same time (Fig. 4.10). Biphase primary inclusions in Fluorite B sometimes contain elongated particles of organic matter, mostly attached to the bubble. 
Primary fluid inclusions in Fluorite B are relatively rare, but when observed they are randomly distributed and mostly isolated.

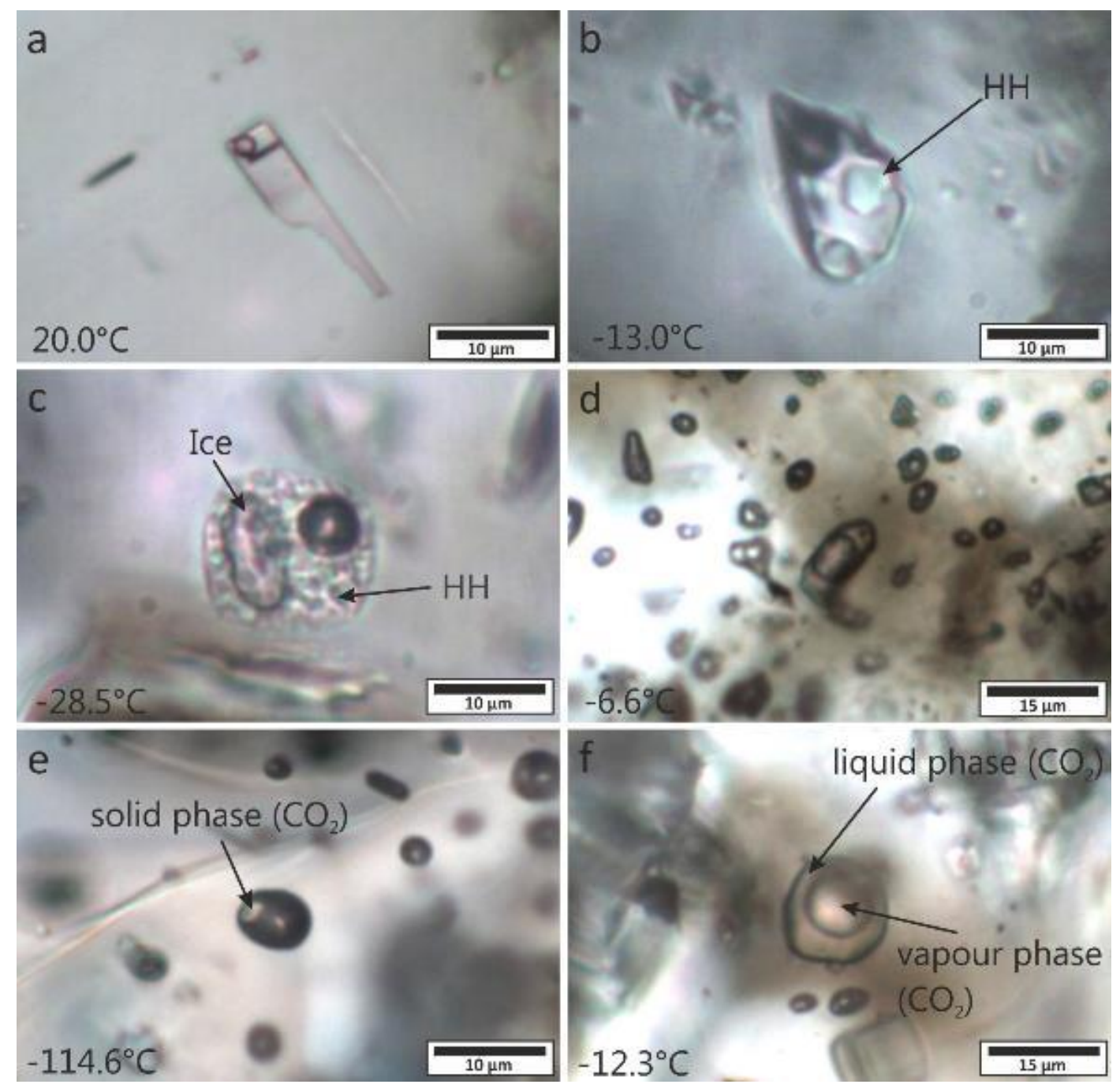

Fig. 4.9. Microphotographs illustrating typical fluid inclusion types found in the samples; a) primary biphase fluid inclusion in recrystallized anhydrite at room temperature; b) primary fluid inclusion in calcite cement with a hexagonal hydrohalite crystal $\left(\mathrm{HH}=\right.$ hydrohalite; $\left.\mathrm{NaCl} \bullet 2 \mathrm{H}_{2} \mathrm{O}\right)$ at $\left.-13^{\circ} \mathrm{C} ; \mathrm{c}\right)$ primary fluid inclusion in Fluorite A with smoothly curved ice crystal among smaller hydrohalite crystals $\left.\left(-28.5^{\circ} \mathrm{C}\right) ; \mathrm{d}\right)$ pseudosecondary, $\mathrm{CO}_{2}$-rich biphase inclusions in Fluorite $A\left(-6.6^{\circ} \mathrm{C}\right)$; e) very dark, methane-rich secondary inclusion in Fluorite B showing single crystal of solid $\left.\mathrm{CO}_{2}\left(-114.6^{\circ} \mathrm{C}\right) ; \mathrm{f}\right)$ pseudosecondary carbonic fluid inclusions in Fluorite $\mathrm{B}$ with liquid $\mathrm{CO}_{2}$-phase $\left(-12.3^{\circ} \mathrm{C}\right)$. 


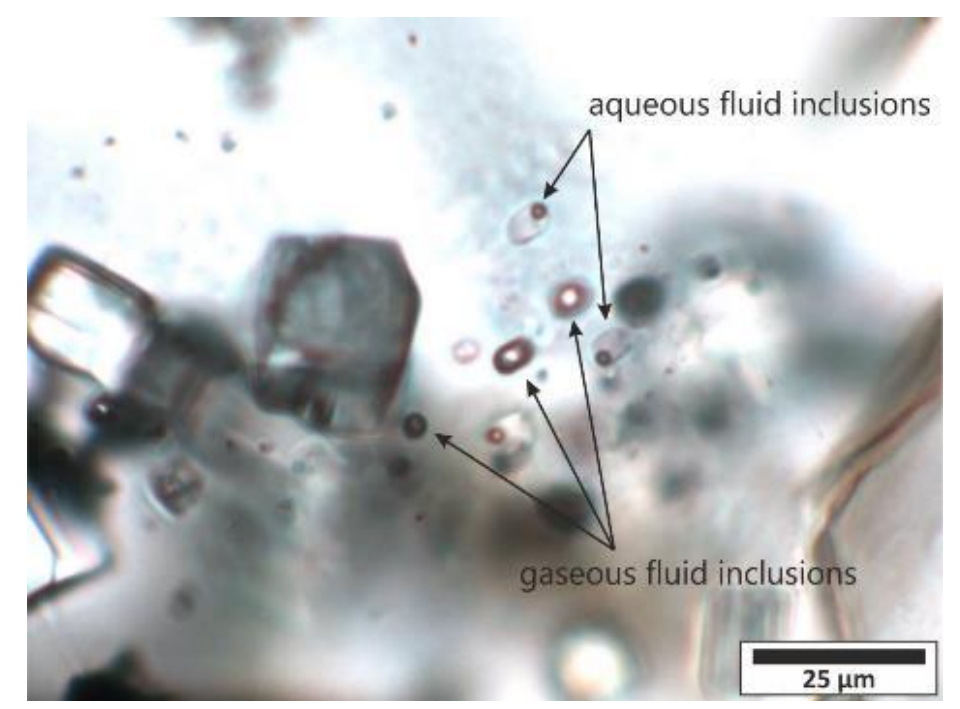

Fig. 4.10. Heterogeneously trapped aqueous and gaseous fluid inclusions in Fluorite B (type VI) form a fluid inclusion plane and thereby trace a healed micro-crack within a single crystal.

Indications of necking-down have not been found. Inclusions with diameters larger than $25 \mu \mathrm{m}$, especially in Fluorite B, are rare and are sometimes leaked. The composition of fluids can be grouped in (1) aqueous fluids (anhydrite, calcite, and Fluorite A), (2) aqueous-carbonic fluids (Fluorite B), and (3) carbonic fluids (Fluorite A/B). Based upon their petrographic characteristics primary, secondary, and pseudosecondary inclusions can be grouped into 6 types of fluid inclusion assemblages (FIA) (Goldstein and Reynolds, 1994): type I = primary biphase $(\mathrm{LV} \rightarrow \mathrm{L})$ fluid inclusions, only occurring in anhydrite; type $\mathrm{II}=$ primary biphase and sometimes multiphase $(\mathrm{LV}(\mathrm{S}) \rightarrow \mathrm{L}(\mathrm{S}))$ fluid inclusions in calcite; type III = primary biphase, and sometimes multiphase aqueous inclusions in Fluorite A $(\mathrm{LV}(\mathrm{S}) \rightarrow \mathrm{L}(\mathrm{S}))$; type $\mathrm{IV}=$ secondary monophase carbonic inclusions in Fluorite $\mathrm{A} / \mathrm{B}(\mathrm{L} \rightarrow \mathrm{V})$; type $\mathrm{V}=$ pseudosecondary monophase carbonic inclusions in Fluorite A. Type VI contains heterogeneously trapped fluids within pseudosecondary fluid inclusions in Fluorite B, namely a carbonic and an aqueouscarbonic phase (with daughter crystals). Both the monophase carbonic inclusions and aqueous-carbonic inclusions homogenize into the liquid phase $(\mathrm{LV} \rightarrow \mathrm{L} / \mathrm{LV}(\mathrm{S}) \rightarrow \mathrm{L}(\mathrm{S}))$.

\subsubsection{Microthermometric results}

Primary and (pseudo-)secondary fluid inclusions (aqueous, aqueous-carbonic, and carbonic inclusions) in anhydrite, calcite, and fluorite were selected for microthermometric studies (for compilation see Tab. 4.1). Fluid inclusions were cooled to $-120^{\circ} \mathrm{C}$ until complete freezing. Aqueous, aqueous-carbonic, and (pseudo-) secondary $\mathrm{CO}_{2}$-rich inclusions homogenized to the liquid phase during the heating cycle, while only secondary methane-rich inclusions (type IV) homogenized to the gas phase. Eutectic melting $\left(\mathrm{T}_{\mathrm{e}}\right.$ ) values in primary aqueous (-carbonic) fluid inclusions (type I/II/III/VI) from anhydrite, calcite, and Fluorite $\mathrm{A}$ and $\mathrm{B}$ has been observed around $-52^{\circ} \mathrm{C}$, indicating a multicomponent $\mathrm{H}_{2} \mathrm{O}-\mathrm{NaCl}-\mathrm{CaCl}_{2}-\mathrm{fluid}$ system. $\mathrm{T}_{\mathrm{e}}$ is characterized by the melting of antarcticite $\left(\mathrm{CaCl}_{2} \cdot 6 \mathrm{H}_{2} \mathrm{O}\right)$, a solid phase typically found in Ca-rich aqueous inclusions at low temperature (Fig. 4.11). All aqueous inclusions show first ice melting $\left(\mathrm{T}_{\mathrm{m} \text {, ice }}\right)$ between -27.2 and $-20.9^{\circ} \mathrm{C}$. Melting temperatures for hydrohalite $\left(\mathrm{T}_{\mathrm{m}}\right.$, hh , hydrohalite $=$ $\mathrm{NaCl} \cdot 2 \mathrm{H}_{2} \mathrm{O}$ ) in brine inclusions in calcite (II) and in Fluorite A and B (type III and VI) cluster around $-22.2 /+22.1^{\circ} \mathrm{C}$, and partly represent metastable conditions (above $0.1^{\circ} \mathrm{C}$ ) due to the failure of halite 
nucleation. The dissolution temperatures $\left(\mathrm{T}_{\mathrm{s}, \mathrm{NaCl}}\right)$ of halite daughter crystals within these inclusions range between 84.4 and $118^{\circ} \mathrm{C}$. The salinity calculated from $\mathrm{T}_{\mathrm{m}}$, ice varies from 1.3 to $3.1 \mathrm{wt} . \%$ (eq) $\mathrm{NaCl}$ in anhydrite, from 15.7 to $24.7 \mathrm{wt} . \%$ (eq) $\mathrm{NaCl}$ in calcite, from 14.1 to $28.2 \mathrm{wt} . \%$ (eq) $\mathrm{NaCl}$ in Fluorite A, and from 14.9 to 20.1 wt.\% (eq) $\mathrm{NaCl}$ in Fluorite B (Fig. 4.11).

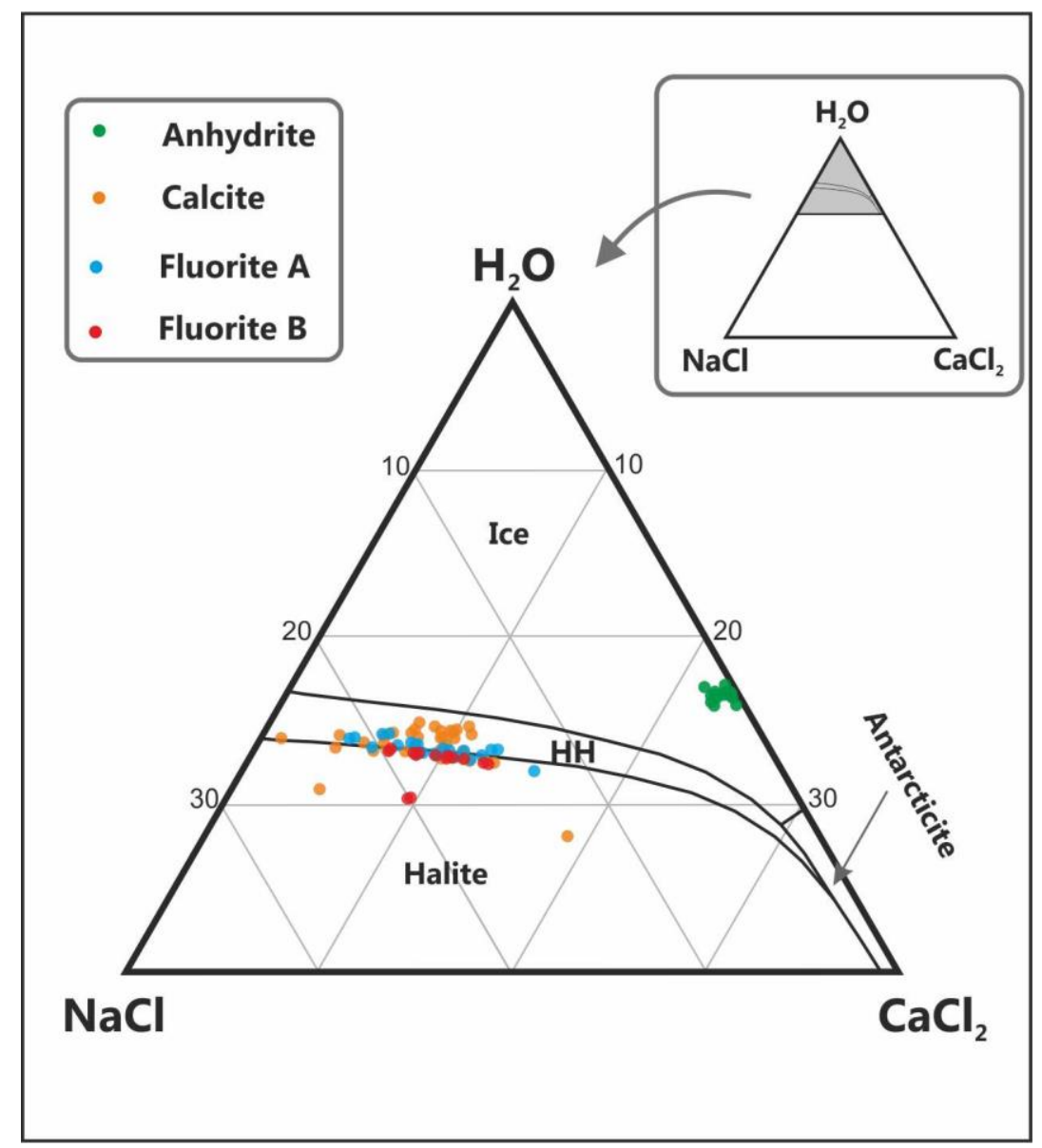

Fig. 4.11. Salinity plot for the system $\mathrm{H} 2 \mathrm{O}-\mathrm{NaCl}-\mathrm{CaCl2}$. The variation in fluid composition from $\mathrm{Ca}$-rich inclusions trapped in syn-diagenetic anhydrite to Na-dominated aqueous fluids in younger inclusions may be due to calcite precipitation severe rock-fluid interaction. Halite $=\mathrm{NaCl}$; Antarcticite $=\mathrm{CaCl} \bullet 6 \mathrm{H} 2 \mathrm{O}$; $\mathrm{HH}=\mathrm{Hydrohalite}(\mathrm{NaCl} \cdot 2 \mathrm{H} 2 \mathrm{O})$. Salinity calculations in the system $\mathrm{H} 2 \mathrm{O}-\mathrm{NaCl}-\mathrm{CaCl} 2$ were done after Steele-MacInnis et al. (2011).

Phase transitions for aqueous (-carbonic) inclusions are described as

a) equilibrium melting (no halite): $\mathrm{I}+\mathrm{HH}+\mathrm{A} \rightarrow \mathrm{I}+\mathrm{HH}+\mathrm{L} \rightarrow \mathrm{HH}+\mathrm{L} \rightarrow(\mathrm{H}+\mathrm{HH}+\mathrm{L}) \rightarrow(\mathrm{H}+\mathrm{L}) \rightarrow \mathrm{L}$; and

b) non-equilibrium melting (halite present): $\mathrm{I}+\mathrm{HH}+\mathrm{A}(+\mathrm{H}) \rightarrow \mathrm{I}+\mathrm{HH}+\mathrm{L}(+\mathrm{H}) \rightarrow \mathrm{HH}+\mathrm{L}(+\mathrm{H}) \rightarrow \mathrm{H}+\mathrm{L}$ $\rightarrow \mathrm{L}$

( $\mathrm{I}=$ ice, $\mathrm{HH}=$ hydrohalite, $\mathrm{A}=$ antarcticite, $\mathrm{H}=$ halite, $\mathrm{L}=$ liquid).

A detailed phase transition sequence for aqueous-carbonic inclusions in Fluorite B is shown in Fig. 4.12. These inclusions show also melting of clathrate characterized by a sudden increase of the bubble volume between $-16.6^{\circ} \mathrm{C}$ and $14.5^{\circ} \mathrm{C}$. Clathrate particles are very small and rarely visible; they are usually surrounding the bubble shortly before melting. 


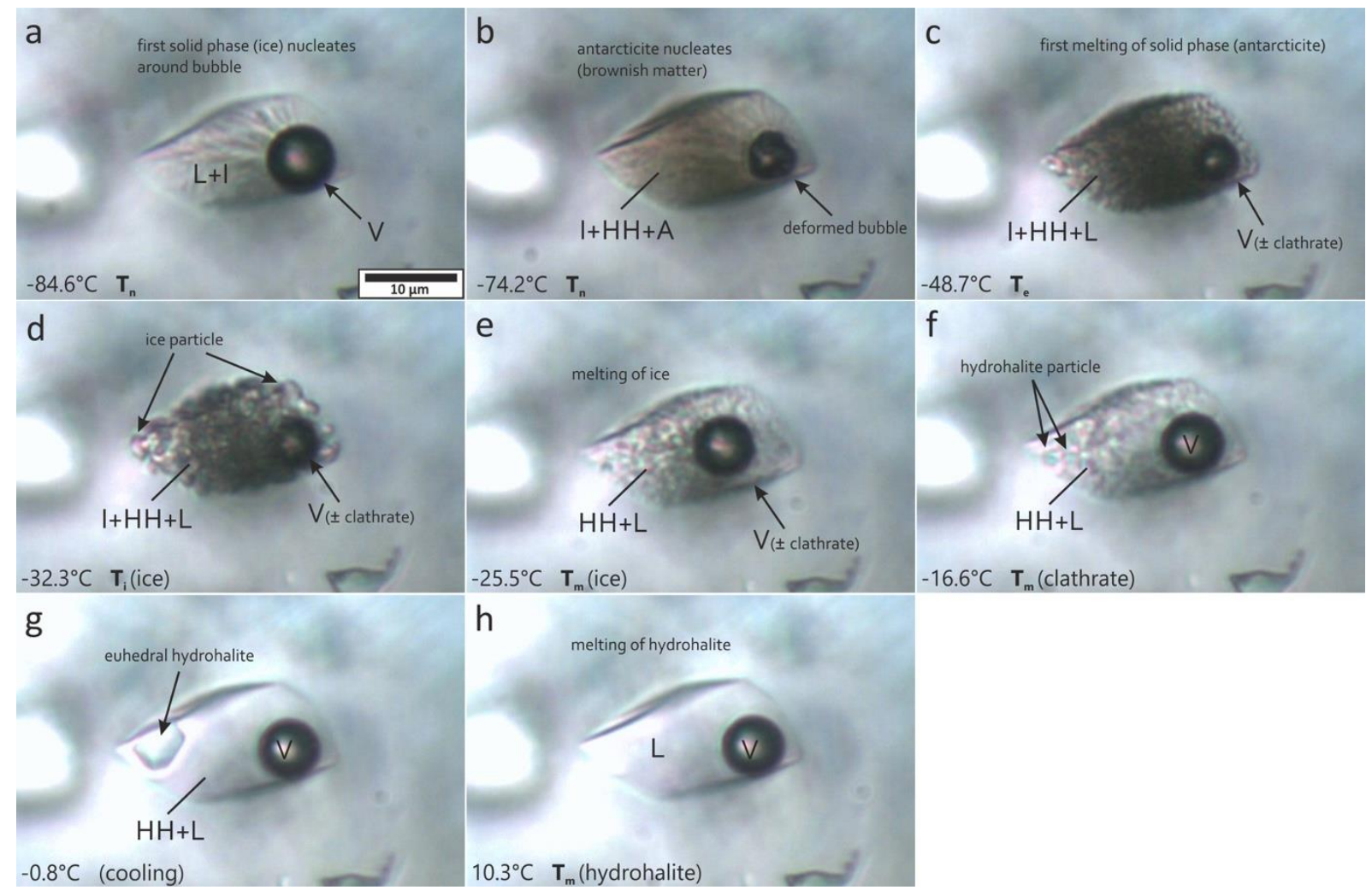

Fig. 4.12. Sequence of microphotographs of an aqueous fluid inclusion in colourless Fluorite B (type VI) at different temperatures. a) $T_{n}=$ temperature of nucleation, defining the moment of appearance of a first solid phase (ice) during cooling; b) a brownish solid phase that nucleated during heating is clearly visible; c) $T_{e}$ = eutectic temperature, minimum temperature of liquid stability in the system $\mathrm{H}_{2} \mathrm{O}-\mathrm{NaCl}-\mathrm{CaCl}_{2} ;$ a first melt appears; d) $T_{i}=$ temperature of initial ice melting; $\left.e\right) T_{m}$, ice $=$ melting temperature of ice; f) $T_{m}$, clathrate $=$ melting temperature of clathrate; $g$ ) a single euhedral hydrohalite crystal is visible during cooling; $h) T_{m}$, hydrohalite $=$ melting temperature of hydrohalite $. L=$ liquid phase, $S=$ solid phase, $V=$ vapour/gas phase.

Homogenization temperatures $\left(\mathrm{T}_{\mathrm{h}}\right.$ aqu $)$ for aqueous fluid inclusions in anhydrite (type $\left.\mathrm{I}\right)$ range from 106 to $145^{\circ} \mathrm{C}$, for type II-inclusions in calcite from 113 to $168^{\circ} \mathrm{C}$, in Fluorite A from 116 to $258^{\circ} \mathrm{C}$, and in aqueous-carbonic inclusions in Fluorite B (type VI) $\mathrm{T}_{\mathrm{h} \text {, aqu }}$ ranges from 145 to $195^{\circ} \mathrm{C}$. Type VI-inclusions in Fluorite B show two sets of homogenization temperatures (Fig. 4.13), where the higher temperatures are probably the result of stretching. Exceptionally high homogenization temperatures were measured in fluid inclusions with diameter larger than $25 \mu \mathrm{m}$, some of them decrepitated before reaching homogenization. Densities of brine inclusions in Fluorite B range from 1.08 to $1.1 \mathrm{~g} / \mathrm{cm}^{3}$. 


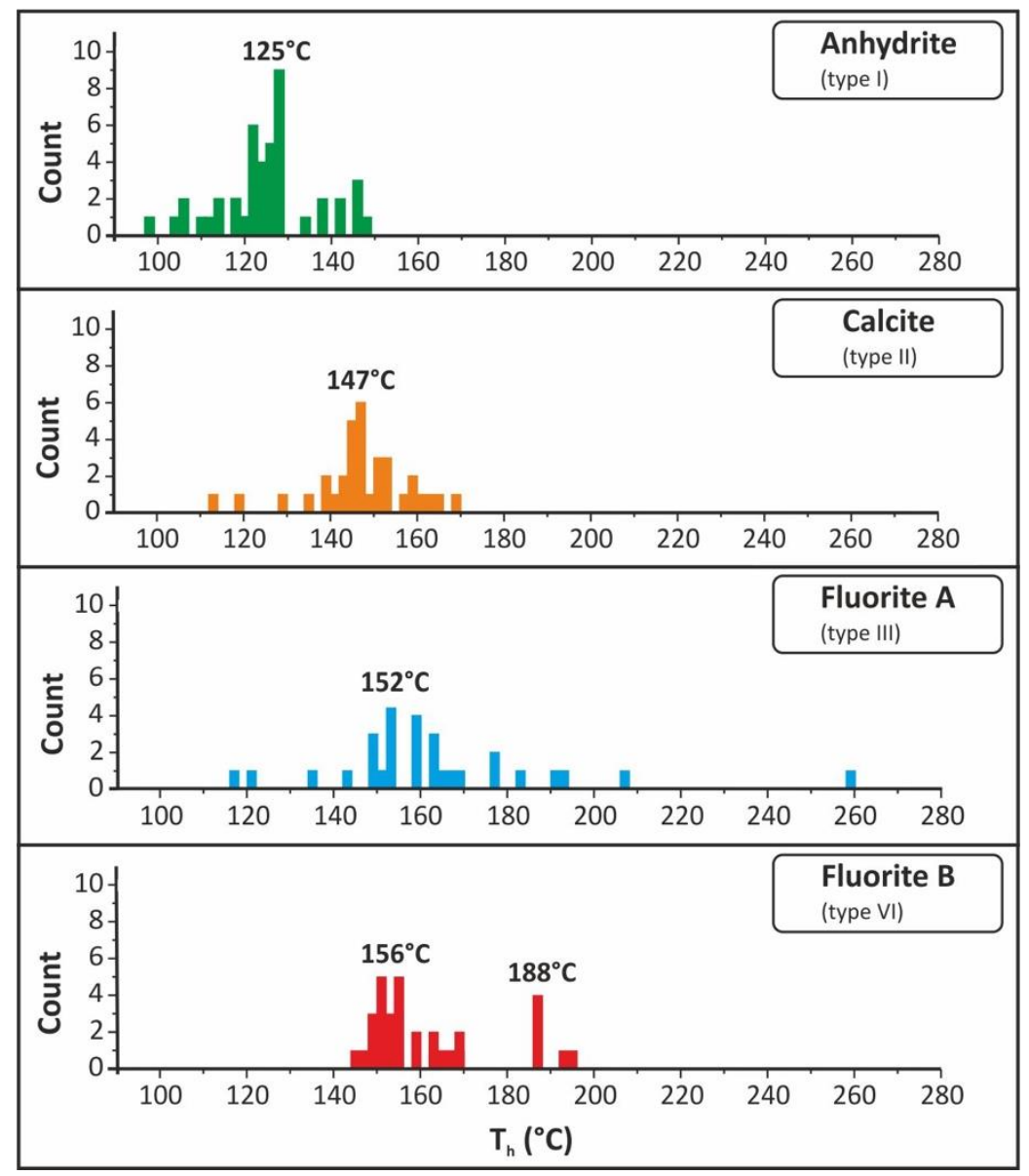

Fig. 4.13. Bar plots showing homogenization temperatures of primary and pseudosecondary aqueous fluid inclusions in four mineral phases. Highest temperatures found in pseudosecondary type VI-inclusions (Fluorite $B$ ) represent minimum temperature conditions during $\mathrm{CO}_{2}$-mobilization.

Aqueous-carbonic inclusions in Fluorite B show no double meniscus during cooling, but as evidenced by the observation of gas clathrates during cooling runs and Laser-Raman analysis, the vapour phase contains low-density carbon dioxide, methane, and nitrogen. The melting temperatures $\left(\mathrm{T}_{\mathrm{m}}\right)$ of gas clathrates $\left(\mathrm{T}_{\mathrm{m}}\right.$, clath) in Fluorite B (type VI) range from -16.8 to $-4.5^{\circ} \mathrm{C}$ and correspond with salinities of 19.4 - 19.6 wt. \% (eq) $\mathrm{NaCl}$ as calculated from ice melting temperatures. A late generation of secondary inclusions in Fluorite A/B (type IV) shows the melting of $\mathrm{CO}_{2}\left(\mathrm{~T}_{\mathrm{m}}\right.$, carb $)$ between -66.1 and $-64.2{ }^{\circ} \mathrm{C}$, while $\mathrm{T}_{\mathrm{m}}$, carb in early pseudosecondary fluid inclusions (type $\mathrm{V}$ ) in Fluorite A ranges from -63.1 to -59.6

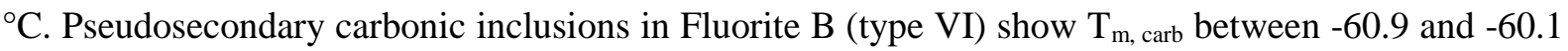
${ }^{\circ} \mathrm{C}$ (Fig. 4.9-f). Homogenization temperatures $\left(\mathrm{T}_{\mathrm{h}}\right.$, carb $)$ of late secondary carbonic inclusions in Fluorite A/B (Fig. 4.9-e) vary between -38.3 and $-16^{\circ} \mathrm{C}$. In early pseudosecondary carbonic inclusions in Fluorite $\mathrm{A}$ and in pseudosecondary carbonic inclusions in Fluorite $\mathrm{B} \mathrm{T}_{\mathrm{h}}$, carb ranges between $6.3-12.9^{\circ} \mathrm{C}$ and 5.6 - $9.7^{\circ} \mathrm{C}$, respectively. The similarity of phase transition temperatures of the two fluid inclusion assemblages (type V and VI) suggests a common source. Unlike type VI-inclusions, type V-inclusions do not show heterogeneous trapping. $\mathrm{CO}_{2}$ densities in those inclusions vary from 0.57 to $0.63 \mathrm{~g} / \mathrm{cm}^{3}$.

Since $\mathrm{T}_{\mathrm{m} \text {, carb }}$ of type IV-, $\mathrm{V}$-, and VI-inclusions is lower than that of pure $\mathrm{CO}_{2}\left(-56.6^{\circ} \mathrm{C}\right)$, considerable amounts of $\mathrm{CH}_{4}$ must be present in the gas mixture, responsible for the observed melting point depression. According to Thiery et al. (1994), the amount of $\mathrm{CH}_{4}$ can be calculated from the $\mathrm{CO}_{2} / \mathrm{CH}_{4}$

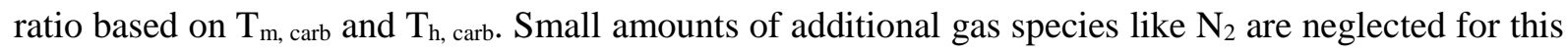


method. Similar proportions of $\mathrm{CH}_{4}$ between $10 \%$ and $20 \%$ in type V-and VI-fluid inclusions contrast with significantly higher concentrations of $\mathrm{CH}_{4}(45-65 \%)$ in the type IV-inclusions (Fig. 4.14). Fluid inclusion data are compiled in Tab. 4.2.

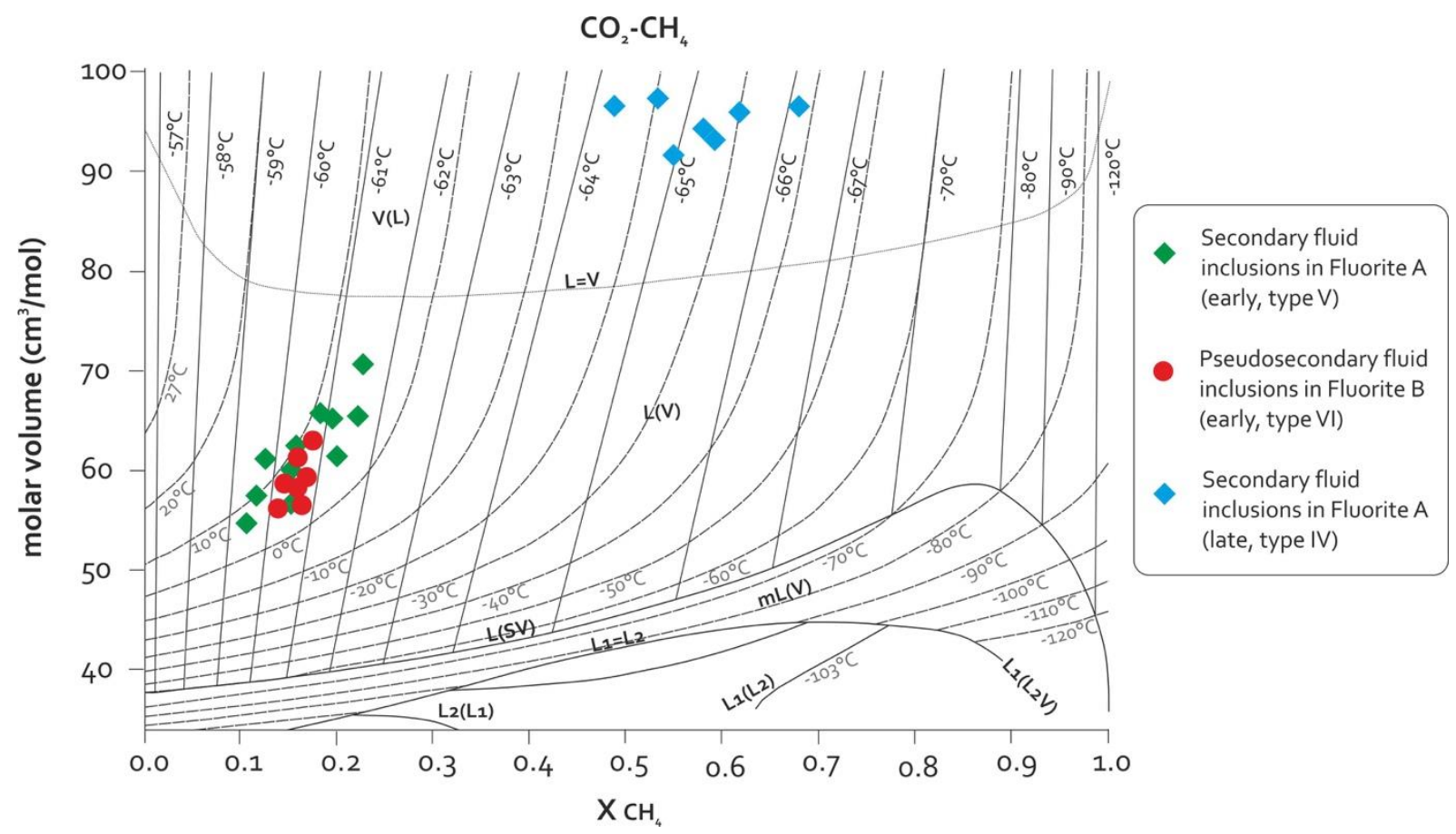

Fig. 4.14. vX diagram for the system $\mathrm{CO}_{2}-\mathrm{CH}_{4}$ for intermediate molar volumes showing the gas composition of gaseous fluid inclusions in Fluorite A and B (type IV, V, and VI) (modified after Thiery et al., 1994). Black lines define the melting temperature of the solid phase, dashed lines represent isothermal conditions of homogenization; $V(L)=$ stability field of the vapour phase; $L=V$-tie-line $=$ liquid and vapour phase are in equilibrium; $L(V)=$ stability field of the liquid phase; $L(S V)=$ tie-line joining the field of liquid phase in co-existence with a vapour and a solid phase; for a detailed explanation refer to Thiery et al. (1994).

Trapping P-T conditions of two immiscible fluids (brine/supercritical $\mathrm{CO}_{2}$ ) were estimated by intersecting of isochores calculated from respective fluid inclusions (Fig. 4.10). Isochores of aqueous inclusions and $\mathrm{CO}_{2}$ inclusions show different slopes and thus intersect at some point in the P-T diagram (Goldstein, 2001; Roedder and Bodnar, 1980; Shepherd et al., 1985) (Fig. 4.15). 
Chapter 4 - Fluid inclusion and microfabric studies on Zechstein carbonates (Ca2)

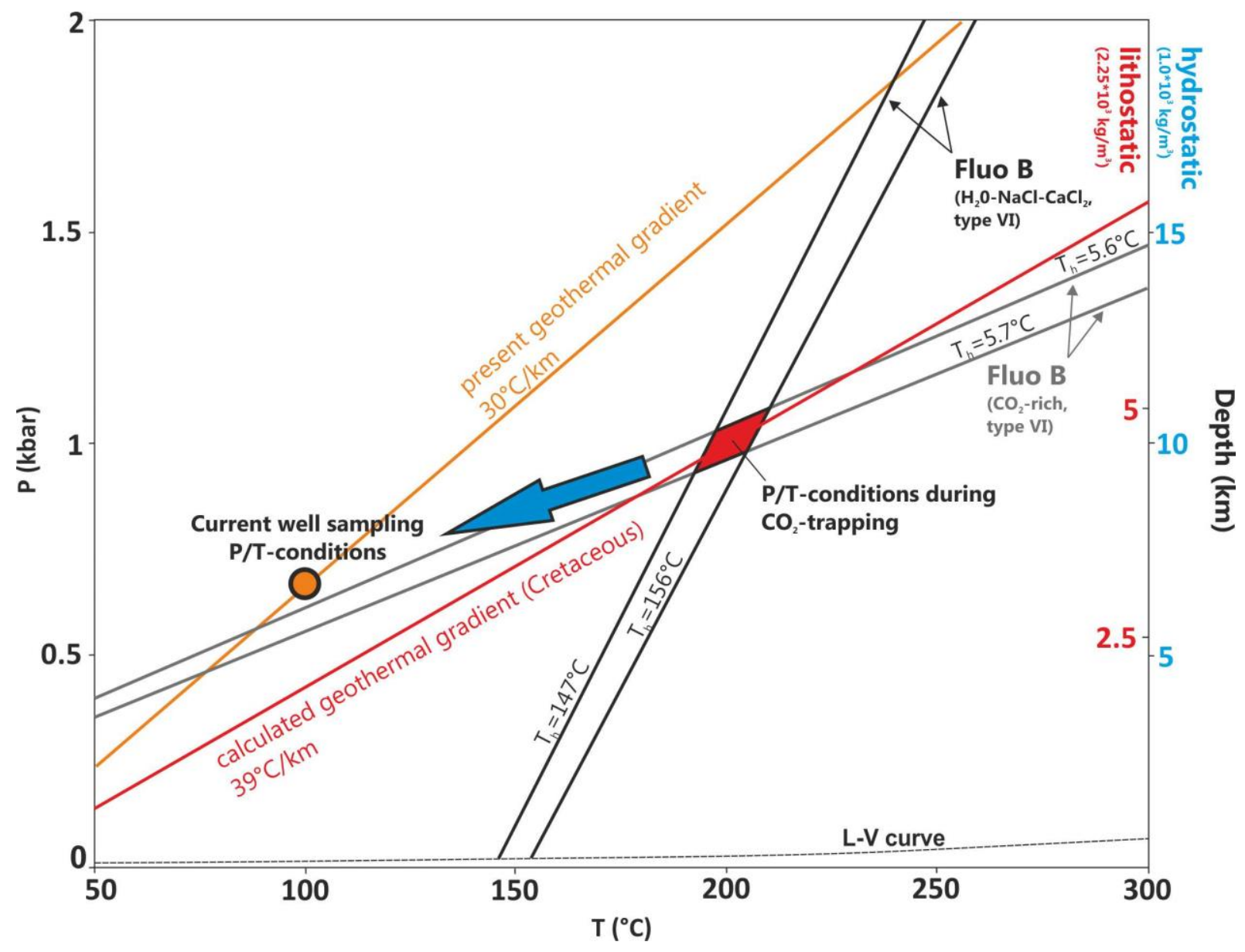

Fig. 4.15. Thermobarometric estimates for co-genetic aqueous-carbonic and carbonic $\left(\mathrm{CO}_{2}\right)$ inclusions in Fluorite B (type VI). Solid black lines represent isochores of carbonic $\left(\mathrm{CO}_{2}\right.$-rich) and aqueous-carbonic $\left(\mathrm{H}_{2} \mathrm{O}-\mathrm{NaCl}-\mathrm{CaCl} \mathrm{C}_{2}\right)$ inclusions; coloured lines represent the present-day (orange) and Cretaceous (red) geothermal gradients. The intersections of isochores from co-genetic pseudosecondary $\mathrm{CO}_{2}$-rich inclusions and aqueous-carbonic inclusions define the area of Fluorite B growth conditions (red area). 1 kbar corresponds to a depth of $4.35 \mathrm{~km}$ (crustal density: $2.30 * 10^{3} \mathrm{~kg} / \mathrm{m}^{3}$ ).

Minimum and mean values of recorded homogenization temperatures were used for isochore calculation, since higher $\mathrm{T}_{\mathrm{h}}$ could be assigned to stretched fluid inclusions (aqueous inclusions, type VI) and assumed not to represent trapping conditions. Isochores for aqueous inclusions were calculated for homogenization temperatures of $147^{\circ} \mathrm{C}$ and $156^{\circ} \mathrm{C}$; isochores for $\mathrm{CO}_{2}$-rich inclusions were calculated for homogenization temperatures of $5.6^{\circ} \mathrm{C}$ and $5.7^{\circ} \mathrm{C}$. Microstructures observed in cathodoluminescence and standard petrographic microscopy revealed the pseudosecondary character of these co-existing inclusions and suggest that they are co-genetic. Crossing isochore calculations of heterogeneously trapped aqueous-carbonic and carbonic (type VI) fluid inclusions in Fluorite B indicate trapping pressures between 900 and $1000 \mathrm{bar}$, and trapping temperatures between 180 and $200^{\circ} \mathrm{C}$. 
Chapter 4 - Fluid inclusion and microfabric studies on Zechstein carbonates (Ca2)

Tab. 4.1. Compilation of fluid inclusion features, microthermometric results and carbon isotopic data.

\begin{tabular}{|c|c|c|c|c|c|c|c|c|c|c|c|c|c|c|}
\hline \multirow[b]{2}{*}{ Mineral } & \multirow[b]{2}{*}{ Phase (FIA) } & \multirow{2}{*}{$\begin{array}{l}\text { Phase } \\
\text { transition }\end{array}$} & \multirow{2}{*}{$\frac{\mathrm{T}_{\mathrm{m}, \text { carb }}}{\left({ }^{\circ} \mathrm{C}\right)}$} & \multirow{2}{*}{$\begin{array}{l}T_{\mathrm{m}, \text { clath }} \\
\left({ }^{\circ} \mathrm{C}\right)\end{array}$} & \multirow{2}{*}{$\frac{T_{h, \text { carb }}}{\left(^{\circ} \mathrm{C}\right)}$} & \multirow{2}{*}{$\frac{\mathrm{T}_{\mathrm{e}}}{\left(^{\circ} \mathrm{C}\right)}$} & \multirow{2}{*}{$\begin{array}{l}T_{\text {m, ice }} \\
\left({ }^{\circ} \mathrm{C}\right)\end{array}$} & \multirow{2}{*}{$\frac{T_{m, \text { hh }}}{\left({ }^{\mathrm{C}} \mathrm{C}\right)}$} & \multirow{2}{*}{$\frac{T_{\text {h, aqu }}}{\left({ }^{\circ} \mathrm{C}\right)}$} & \multirow{2}{*}{$\begin{array}{l}\mathrm{T}_{\mathrm{s}, \mathrm{NaCl}} \\
\left({ }^{\circ} \mathrm{C}\right)\end{array}$} & \multirow{2}{*}{$\begin{array}{l}\text { Salinity } \\
\text { (wt.\% } \mathrm{NaCl} \\
\text { eq.) } \\
\end{array}$} & \multicolumn{2}{|l|}{$\delta^{13} \mathrm{C}\left(\mathrm{CH}_{4}\right)$} & \multirow[t]{2}{*}{$\mathrm{N}$} \\
\hline & & & & & & & & & & & & & & \\
\hline Anhydrite & Aqueous (I) & $L V \rightarrow L$ & & & & $-51 /-48.9$ & $-26 /-23.8$ & & $106 / 145$ & & $1.3 / 3.1$ & & & 44 \\
\hline Calcite & Aqueous (II) & $L V \rightarrow L$ & & & & $-50.9 /-46.4$ & $-27.2 /-22.5$ & $-22.2 / 15.1$ & $113 / 167.8$ & $105.7 / 112.7$ & $15.7 / 24.7$ & & & 35 \\
\hline Fluorite A & Aqueous (III) & $L V \rightarrow L$ & & & & $-50.9 /-47.8$ & $-23.8 /-20.9$ & $9.8 / 22.1$ & $116 / 258$ & $84.4 / 118$ & $14.1 / 28.2$ & & & 32 \\
\hline Fluorite A & Carbonic (V) & $V \rightarrow L$ & $-63.1 /-59.6$ & & $6.3 / 12.9$ & & & & & & & $-27,5$ & $-1,2$ & 11 \\
\hline Fluorite B & Aqu.-carbonic (VI) & $L V \rightarrow L$ & & $-16.8 /-14.5$ & & $-50.9 /-45.2$ & $-26.6 /-23.6$ & $6.2 / 13.9$ & $145 / 195$ & $103.7 / 116.4$ & $14.9 / 20.1$ & & & 32 \\
\hline Fluorite B & Carbonic (VI) & $V \rightarrow L$ & $-60.9 /-60.1$ & & $5.6 / 9.7$ & & & & & & & $-26,1$ & n.d. & 12 \\
\hline
\end{tabular}

\subsubsection{LA-ICP-MS analysis}

In-situ REE analysis has been carried out to distinguish between different fluorite generations in terms of fluid source (pegmatitic/hydrothermal/sedimentary fluid) and crystallization conditions, i.e. precipitation from a primary fluid vs. recrystallization) (e.g. Lüders, 1991; Möller et al., 1998; Schwinn and Markl, 2005). The incorporation of REE in fluorite is controlled either by sorption or complexation (Bau and Möller, 1992, 1991; Möller et al., 1998).We determined REE + Y contents and variations in Fluorite A and B in order to distinguish between different environments of crystallization. LA-ICP-MS analysis proved that $\Sigma$ REE contents in early Fluorite A are relatively low and range from 4.4 to $5.05 \mathrm{ppm}$, while Fluorite B shows even lower values ranging from 0.3 to $0.35 \mathrm{ppm}$. Fluorite B is clearly depleted in REE, especially the content of light rare earth elements (LREE), namely La, Ce, Pr, and Nd is significantly lower than for Fluorite A. Heavy rare earth elements (HREE) and Y contents are depleted as well and show similar trends (Fig. 4.16; total REE concentrations are listed in Tab. 4.2). 


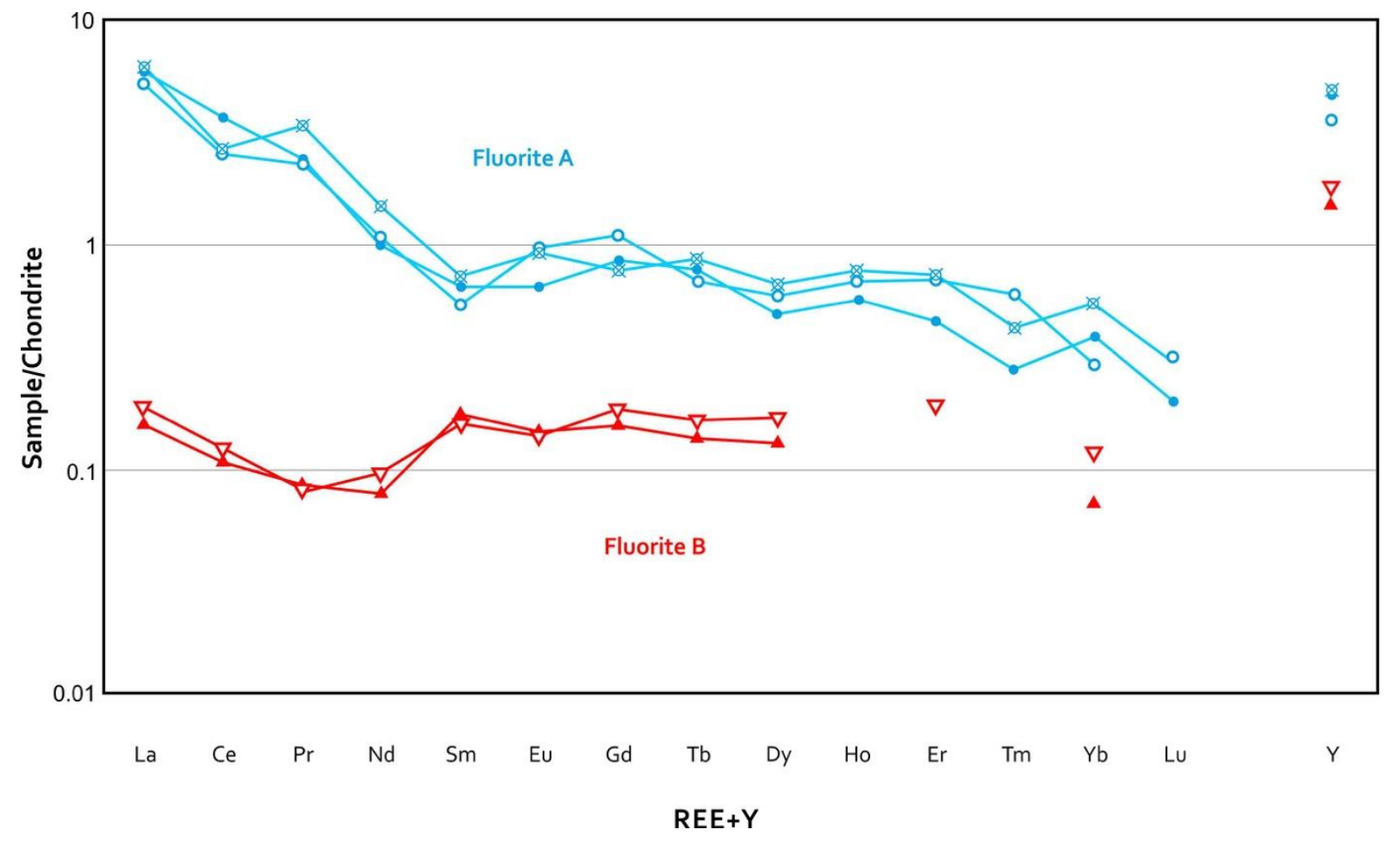

Fig. 4.16. REE and $Y(R E Y)$ distribution patterns of Fluorite A (blue symbols) and B (red symbols). All samples are normalized to chondrite [ppm] (McDonough and Sun, 1995). Fluorite A is characterized by a steep decline in concentration from La to Sm (LREE) followed by a flattened, but still downward trending pattern towards Lu that is typical for fluorites that precipitated from a primary basinal fluid. The depletion in LREEs found in Fluorite B indicates the complexation of those REE with relatively big ionic radii during remobilization (i.e. HREE). Positive anomalies found for Y suggest a hydrothermal mobilization for both fluorite types.

Elements in fluorite showing fractionation due to precipitation or remobilization are typically Eu and $\mathrm{Y}$ (Möller et al., 1998). While Eu does not show any anomaly in both fluorite-types - it is neither enriched nor depleted compared to the trend of other REEs -, Yttrium, however, is characterized by a noticeable positive anomaly in both, Fluorite $\mathrm{A}$ and $\mathrm{B}$; this points to a complexation with $\mathrm{F}^{-}$in the parental fluid. Fractionation of REE in fluorite can be demonstrated by comparing the $\mathrm{Tb} / \mathrm{Ca}$ ratio and $\mathrm{Tb} / \mathrm{La}$ ratios as proposed by Möller et al. (1976). Since Ca is more abundant in sedimentary environments than in hydrothermal or granitic/pegmatitic environments and $\mathrm{Tb}$ concentrations at the same time are more or less invariant, the $\mathrm{Tb} / \mathrm{Ca}$ ratio may help determining the fluorite formation conditions. On the other hand the $\mathrm{Tb} / \mathrm{La}$ ratio is an indicator for fluorite differentiation during progressive precipitation (Möller et al., 1976). $\mathrm{Tb} / \mathrm{Ca}$ versus $\mathrm{Tb} / \mathrm{La}$ ratios indicate a sedimentary origin for both, Fluorite $\mathrm{A}$ and $\mathrm{B}$, while a remobilization trend from the early precipitate to the late fracture-filling fluorite can be recognized (Fig. 4.17). Sample sections used for LA-ICP-MS analysis are shown in Appendix-4.2. 
Chapter 4 - Fluid inclusion and microfabric studies on Zechstein carbonates (Ca2)

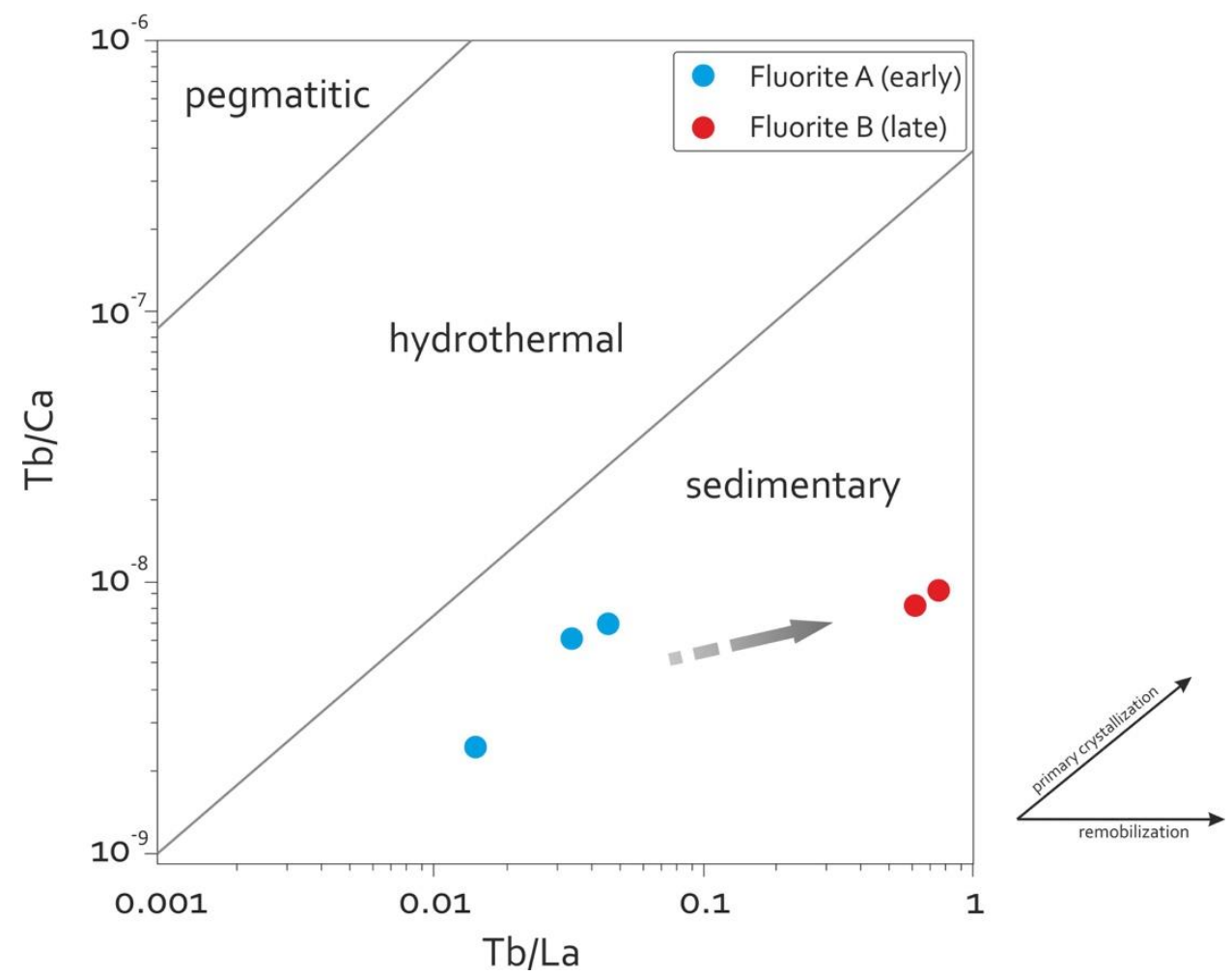

Fig. 4.17. Plots of $T b / C a$ versus $T b / L a$ ratios for early Fluorite A (blue dots) and late fracture-filling Fluorite B (red dots) (after Möller et al., 1976). The geochemical trend clearly supports the idea of Fluorite B being the product of remobilized Fluorite A.

Tab. 4.2. REE $+Y$ and Ca concentrations in Fluorite $A$ and Fluorite $B$ (all values in ppm). Detection limits (ppm) are: $\mathrm{Ca}, \mathrm{Eu}, \mathrm{Tm}, \mathrm{Yb}, \mathrm{Lu}(<0.01)$; $\mathrm{La}, \mathrm{Ce}, \mathrm{Pr}, \mathrm{Sm}, \mathrm{Gd}, \mathrm{Tb}, \mathrm{Ho}, \mathrm{Er}, \mathrm{Y}(0.01)$; Nd, Dy, (0.02); bdl = below detection limit.

\begin{tabular}{llllll}
\hline Sample no. & Fluorite A-1 & Fluorite A-2 & Fluorite A-3 & Fluorite B-1 & Fluorite B-2 \\
\hline Ca & 4020000 & 3860000 & 3260000 & 890000 & 818000 \\
& & & & & \\
$\mathrm{La}$ & 1,4 & 1,41 & 1,28 & 0,04 & 0,04 \\
$\mathrm{Ce}$ & 1,66 & 2,3 & 1,63 & 0,07 & 0,07 \\
$\mathrm{Pr}$ & 0,32 & 0,23 & 0,23 & 0,01 & 0,01 \\
$\mathrm{Nd}$ & 0,69 & 0,48 & 0,5 & 0,04 & 0,04 \\
$\mathrm{Sm}$ & 0,11 & 0,1 & 0,08 & 0,02 & 0,03 \\
$\mathrm{Eu}$ & 0,05 & 0,04 & 0,06 & 0,01 & 0,01 \\
$\mathrm{Gd}$ & 0,16 & 0,17 & 0,22 & 0,04 & 0,03 \\
$\mathrm{~Tb}$ & 0,03 & 0,03 & 0,03 & 0,01 & 0,01 \\
$\mathrm{Dy}$ & 0,16 & 0,12 & 0,15 & 0,04 & 0,03 \\
$\mathrm{Ho}$ & 0,04 & 0,03 & 0,04 & bdl & bdl \\
$\mathrm{Er}$ & 0,12 & 0,07 & 0,11 & 0,03 & bdl \\
$\mathrm{Tm}$ & 0,01 & 0,01 & 0,02 & bdl & bdl \\
Yb & 0,09 & 0,06 & 0,05 & 0,02 & 0,01 \\
$\mathrm{Lu}$ & 0,01 & $\mathrm{bdl}$ & 0,01 & bdl & bdl \\
& & & & & \\
Y & 7,7 & 7,53 & 5,86 & 2,87 & 2,36 \\
& & & & & \\
IREE & 4,84 & 5,05 & 4,4 & 0,35 & 0,3 \\
\hline \hline
\end{tabular}




\subsubsection{Gas compositions of fluid inclusions in fluorite}

By means of Laser-Raman spectrometry, we identified two types of gas inclusions: (a) secondary $\mathrm{CH}_{4}$ $\mathrm{CO}_{2}\left(-\mathrm{N}_{2}\right)$ bearing inclusions in Fluorite A/B (type IV) are characterized by high concentrations of methane (60 to $70 \%$ ), low amounts of $\mathrm{CO}_{2}(<25 \%)$ and $\mathrm{N}_{2}(<10 \%)$, and occasionally small amounts of $\mathrm{H}_{2} \mathrm{~S}(<2 \%)$ and higher hydrocarbons, and (b) pseudosecondary $\mathrm{CO}_{2}-\mathrm{CH}_{4}-\mathrm{N}_{2}$-rich inclusions with 75 $90 \% \mathrm{CO}_{2}$ in Fluorite $\mathrm{A}$ and $\mathrm{B}$ (type V/VI), sometimes also with small amounts of $\mathrm{H}_{2} \mathrm{~S}(\sim 1 \%)$. Two major groups of gas mixtures in the ternary system $\mathrm{CO}_{2}-\mathrm{CH}_{4}-\mathrm{N}_{2}$ can be recognized, as shown in Fig. 4.18. The methane-dominated assemblage correlates with group (a), whereas the $\mathrm{CO}_{2}$-rich inclusions correlate with group (b). The appearance of a late methane-dominated gas phase indicates reducing conditions in the reservoir during or after a major uplift phase, while early $\mathrm{CO}_{2}$-dominated fluids indicate oxidizing conditions during fracture propagation.

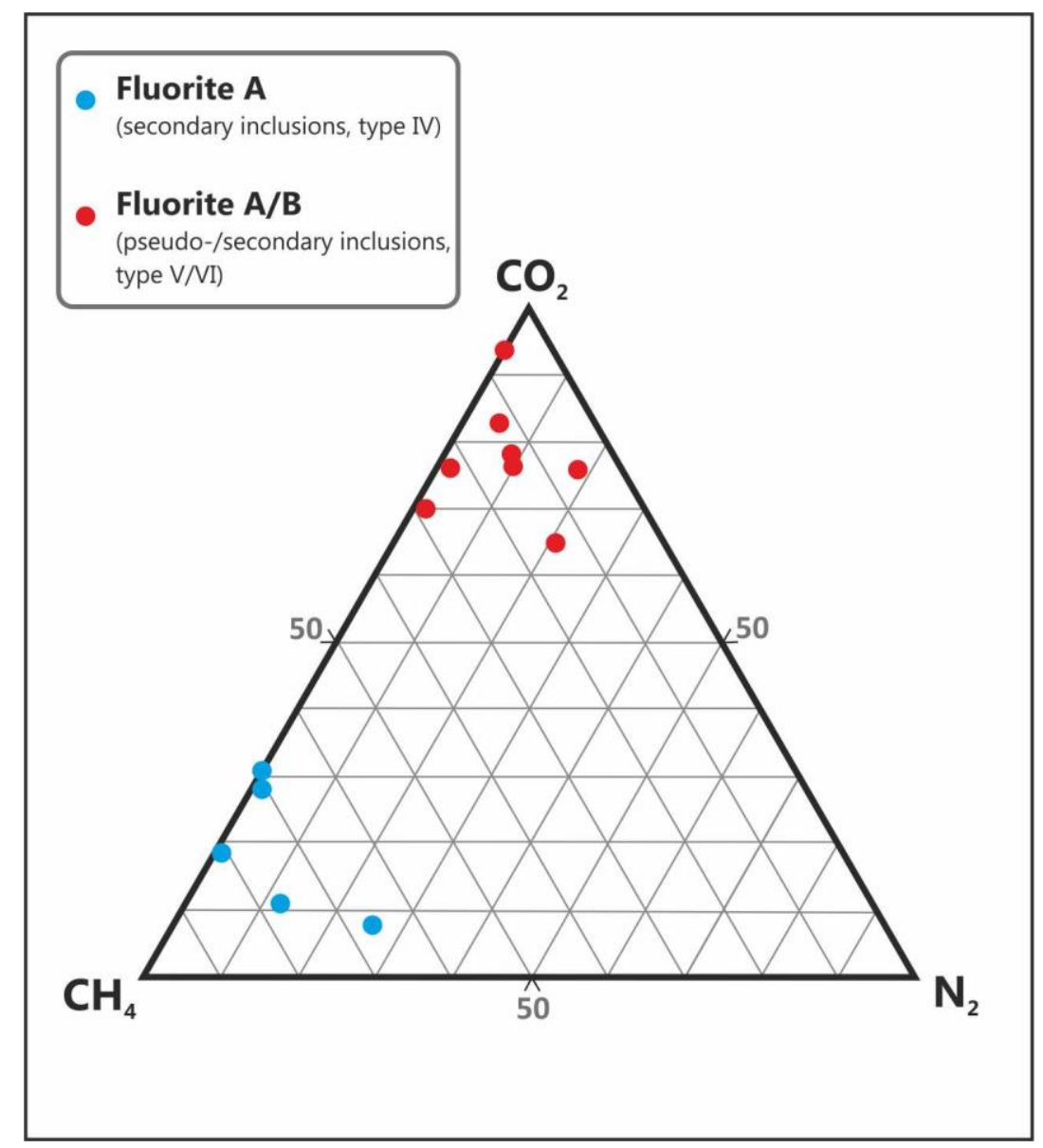

Fig. 4.18. Ternary $\mathrm{CO}_{2}-\mathrm{CH}_{4}-\mathrm{N}_{2}$ diagram representing the two dominating fields of gas mixtures found in fluid inclusions in fluorite. $\mathrm{CH}_{4}$ appears in secondary inclusions within Fluorite A/B (type IV, blue dots), $\mathrm{CO}_{2}$-rich inclusions of pseudosecondary character are found in Fluorite A (type $V$ ) and Fluorite $B$ (type VI, red dots). High density $\mathrm{CO}_{2}$-dominated inclusions were trapped close to maximum burial depth while the younger, low-density $\mathrm{CH}_{4}$-rich inclusions can be attributed to the main stages of basin uplift (Late Cretaceous/Early Paleogene). Therefore, hydrostatic conditions can be expected to explain the relatively low densities. 


\subsubsection{Fracture mechanics}

As described before, the LSB has experienced several episodes of deformation and crustal modification, mostly during the Mesozoic. During Early Triassic times basin formation was initiated, subsequently causing subsidence and simultaneous deposition of sediments. This process in fact continued until Turonian times, when a reversed stress field resulted in horizontal compression and uplift of the sedimentary infill. These tectonic episodes are responsible for the brittle deformation of the $\mathrm{Ca} 2$ reservoir rock, which in consequence triggered fluid migration and ore mineralization. While extension of solid rocks usually produces normal faults accompanied by extensional fractures (Mode I fractures), compression mainly results in reverse faults and vertical stylolites or slickolites. While neither fault planes nor vertical stylolites were found in our samples, Fluorite B is hosted within extensional fractures. As explained by Hancock (1985) and Sibson (1998) three substantial types of extensional fractures can be distinguished according to their formation mechanism (Fig. 4.19): extensional fractures, extensionalshear fractures, and shear fractures.

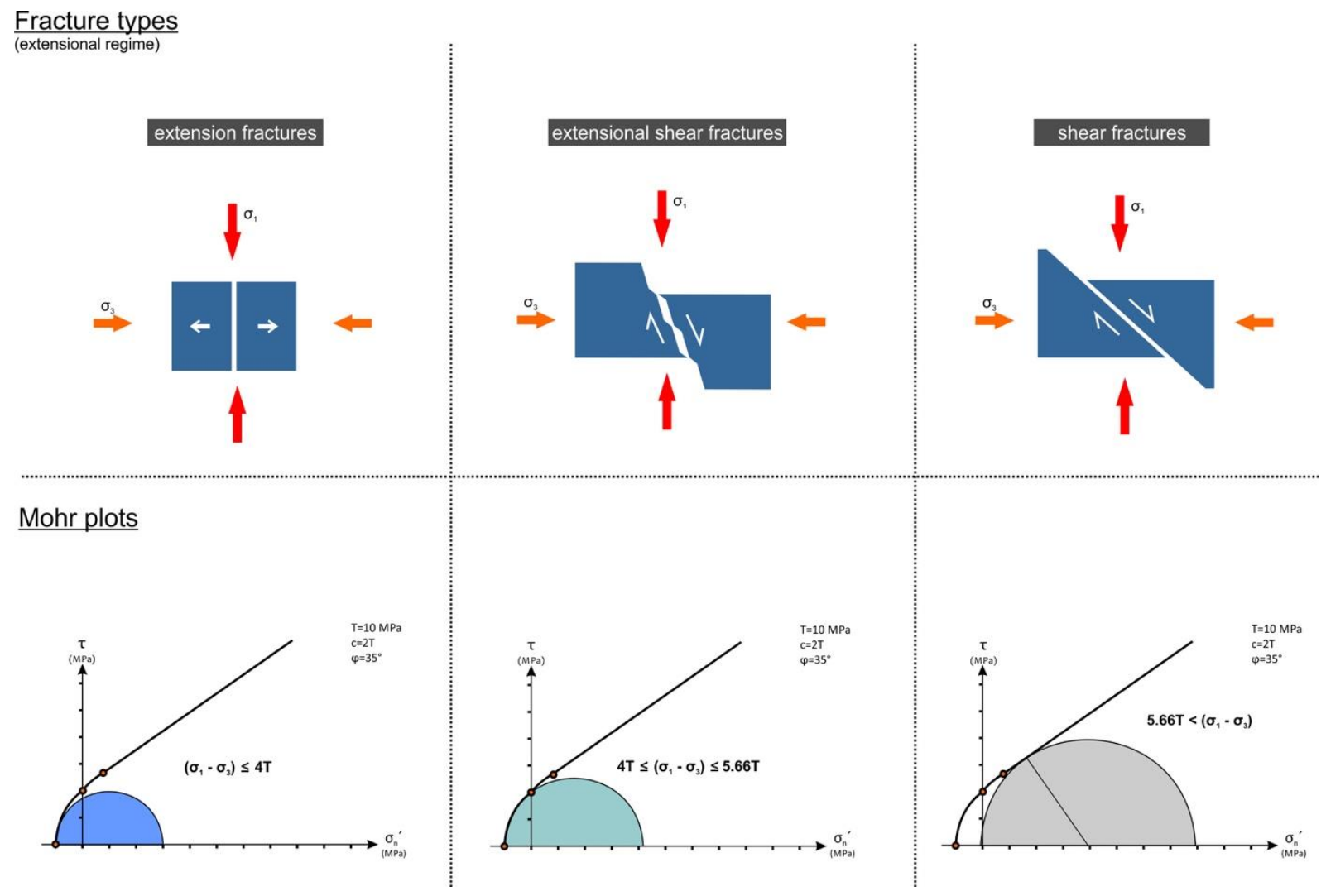

Fig. 4.19. Fracture types and according Mohr plots illustrating the geomechanical background to fracture formation in extensional regimes. For detailed explanation see Sibson (1998).

Vertical extension fractures (pure extension; Mode I) usually form at relatively shallow depth, when both, the rocks tensile strength and differential stress are relatively low. Extension fractures occur where the differential stress $\left(\sigma_{1}-\sigma_{3}\right)$ is equal to or smaller than $4 \mathrm{~T}$ (formula 1 ), with $\mathrm{T}=$ tensile strength (Sibson, 1998):

$$
\left(\sigma_{1}-\sigma_{3}\right) \leq 4 \mathrm{~T}
$$

In this case the Mohr circle touches the failure envelope on the horizontal axis, therefore, $\sigma_{1}$ is normal to $\sigma_{3}$, with $\sigma_{3}$ being oriented normal to the resulting fracture plane. 
Hybrid or extensional-shear fractures however represent an intermediate fracture regime. They are characterized by a set of gradually displaced, vertical extension fractures that are connected by thin, steep dipping $\left(80^{\circ}-89^{\circ}\right)$ shear planes, thus forming an en echelon fracture system (Fig. 4.20). Extensional-shear fractures form according to the following formula:

$$
4 \mathrm{~T} \leq\left(\sigma_{1}-\sigma_{3}\right) \leq 5.66 \mathrm{~T}
$$

Here, the Mohr circle still touches the failure envelope on the horizontal axis, which can result in vertical fractures as well. However, inclined fractures are also possible at the same time, which explains the coexistence of two fracture types: pure extension and shear fractures.

Formation of the last type of fractures, i.e. shear fractures, is expressed in formula 3:

$$
5.66 \mathrm{~T} \leq\left(\sigma_{1}-\sigma_{3}\right)
$$

Shear fractures are in fact normal fault planes with relatively shallow dipping angles $\left(45^{\circ}-80^{\circ}\right)$.
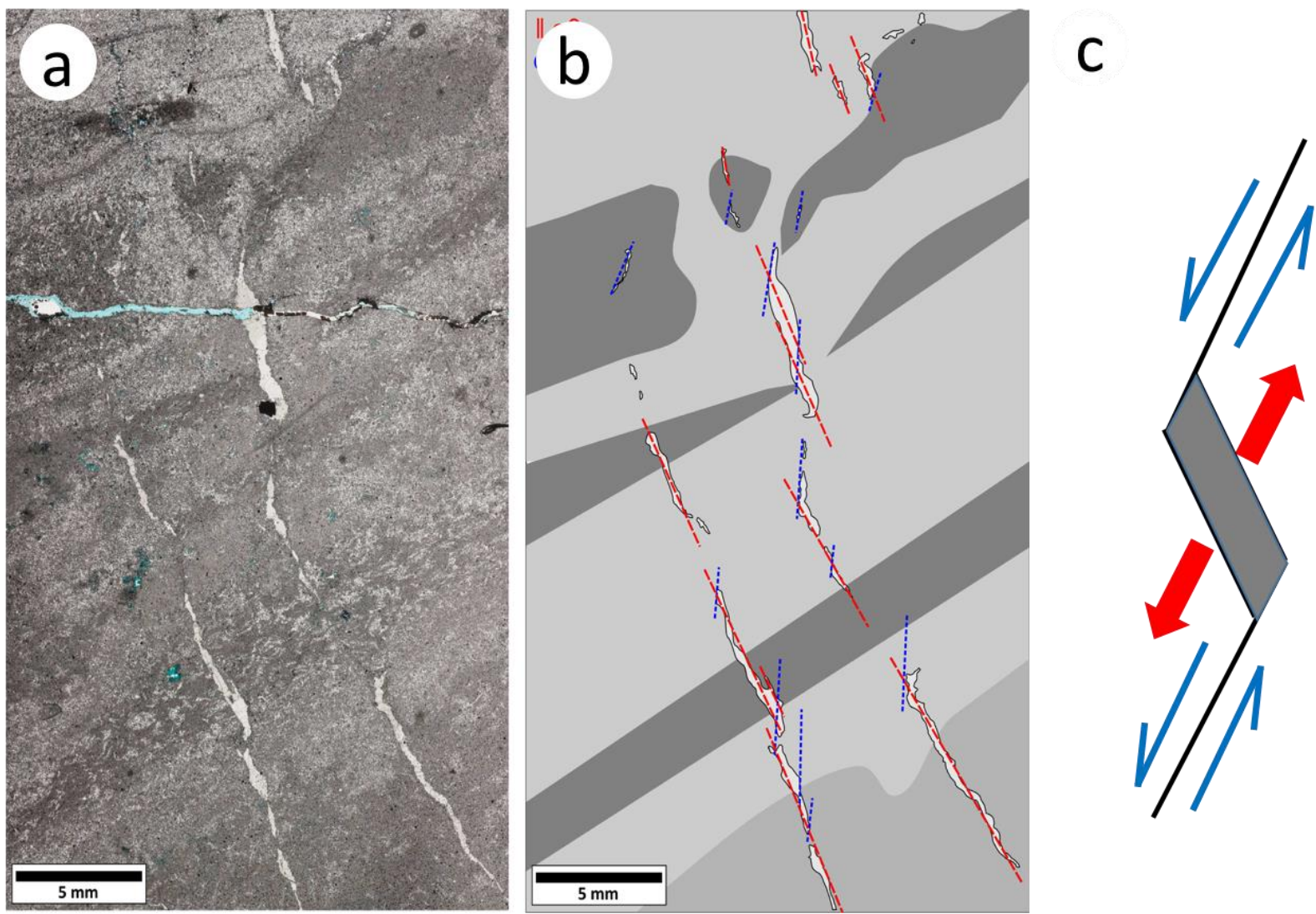

Fig. 4.20. (a) Thin section scan of laminated Ca2 dolomite with fluorite-filled fractures that vertically transect the bedding plane. (b) Figure illustrating the opening mechanism of fractures containing Fluorite $B$. Red lines represent fractures where pure extension occurred, while blue lines indicate fractureconnecting shear planes. (c) Sketch showing the deformation mechanism introduced in (b) with red arrows indicating the direction of extension and blue arrows tracing shear planes with according relative shear sense.

Extensional shear fractures can form in both, compressional and extensional tectonic regimes, however, their formation conditions are restricted to a relatively narrow field in the extensional failure diagram shown in Fig. 4.21. 


\section{Compressional regime}

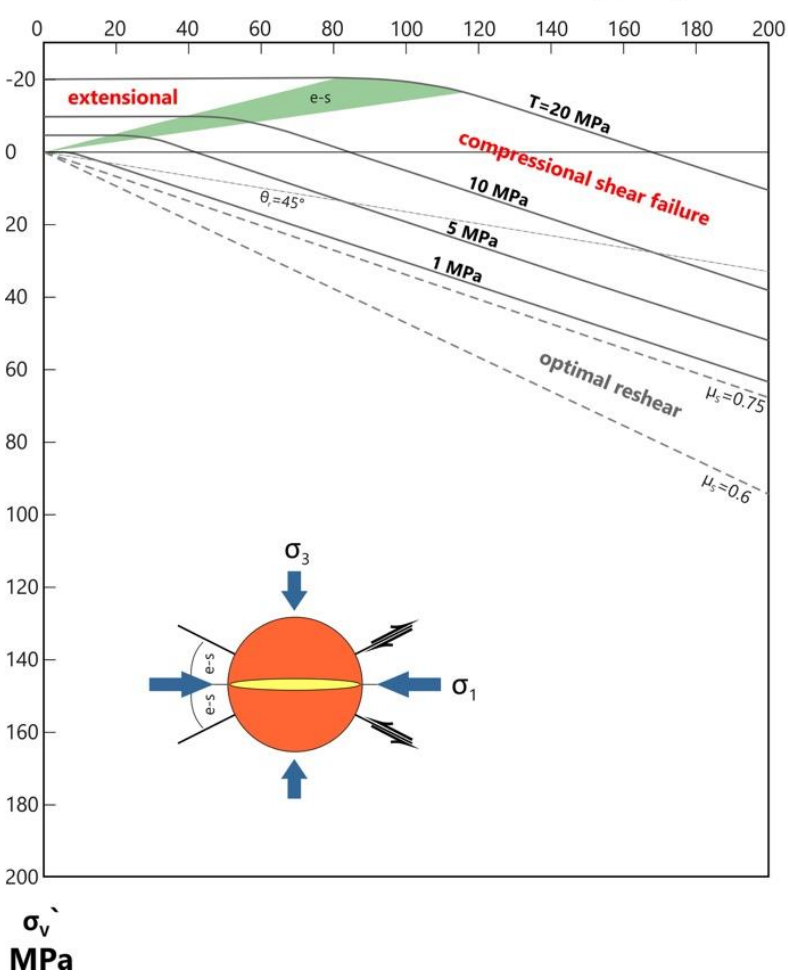

Extensional regime

$\left(\sigma_{1}-\sigma_{3}\right) \mathrm{MPa}$

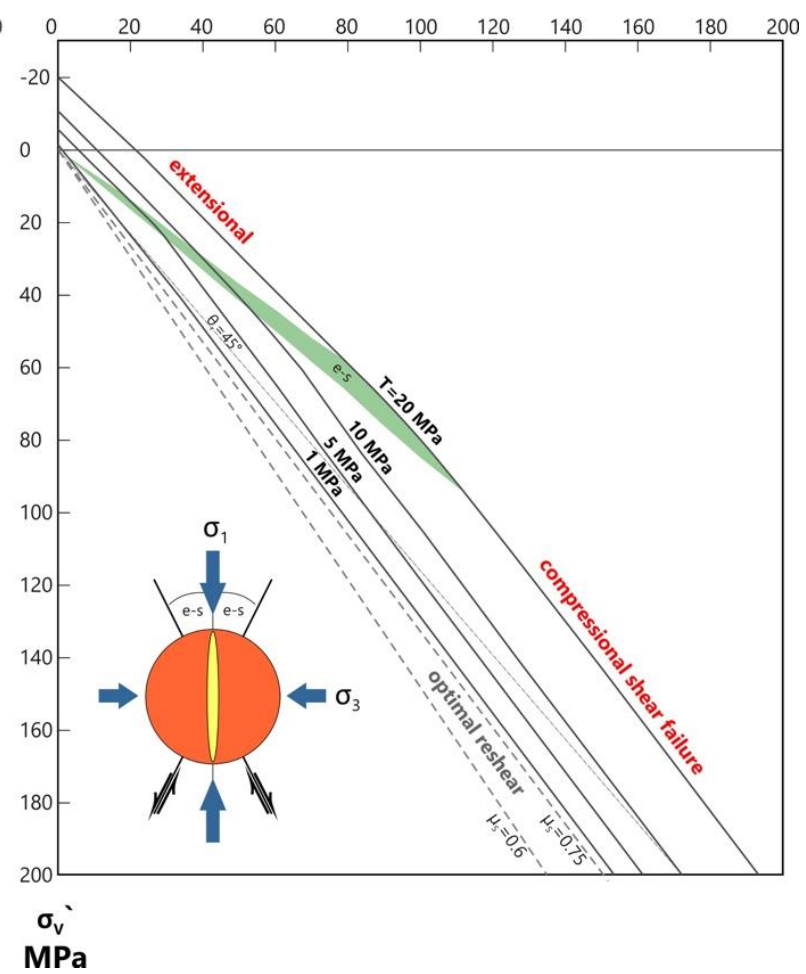

Fig. 4.21. Brittle failure mode diagrams for compressional (left) and extensional (right) tectonic regimes with $\left(\sigma_{1}-\sigma_{3}\right)\left(=\right.$ differential stress at failure) plotted versus $\sigma_{v}{ }^{\prime}(=$ effective vertical stress). The green shaded area marks the area of potential extensional-shear failure (modified after Sibson, 1998).

\subsubsection{Numerical simulation}

Burial and thermal model was calibrated by published and original thermobarometric calculations. Sedimentation and erosion rates of cretaceous sediments in the LSB were fitted using compiled data of Petmecky et al. (1999), Adrisola-Muñoz (2007), and Kus et al. (2005). Data used for calibrating heat flow variations include data of Kus et al. (2005), Norden et al. (2008), and Adrisola-Muñoz (2007) for the Lower Saxony Basin area. These data were complimented with our thermobarometric results. We considered elevated heat flow rates during late Carboniferous-early Permian, late Triassic-early Jurassic, and Oligocene. Vitrinite reflectance values for maturity calibration were obtained from Petmecky et al. (1999). According to Petmecky et al. (1999) vitrinite reflectance values for top Carboniferous units range from $\mathbf{2 . 5 6}$ to $\mathbf{3 . 0 3 \%}$ in the study area. Pressure and temperature values from our crossing isochore calculations of co-genetic fluid inclusions trapped in the latest fracture fillings range from 900 to 1000 bar and suggest temperatures between 180 and $200^{\circ} \mathrm{C}$. The numerical model was constrained in terms of shallow (top Ca2 limestone: $4200 \mathrm{~m}$ b.s.l.) and deep burial depth (top Ca2 limestone: $4600 \mathrm{~m}$ b.s.l.) during fracture formation and $\mathrm{CO}_{2}$ migration, and heat flow (for general input values see

Tab. 4.3). Besides, maximum burial depth of $\mathrm{Ca} 2$ limestone was varied as well assuming different sedimentation rates during late Jurassic - early Cretaceous.

In order to achieve best results with respect to given $\mathrm{P} / \mathrm{T}$ conditions and published vitrinite reflectance values only a heat flow of about $68 \mathrm{~mW} / \mathrm{m}^{2}$ during burial since the late Jurassic - early Cretaceous must be assumed, supporting the idea of extensional fracture formation and $\mathrm{CO}_{2}$ migration at a depth of about 
$4600 \mathrm{~m}$. Another possible burial scenario with a supposed fracture formation during shallow burial conditions (top $\mathrm{Ca} 2$ limestone: $4200 \mathrm{~m}$ ) is limited by minimum pressure values obtained from thermobarometry. The latter conditions require a heat flow of $80 \mathrm{~mW} / \mathrm{m}^{2}$ to fit with the respective vitrinite reflectance values obtained from 1D modelling. The burial history of the WestphalianValanginian succession (Fig. 4.21-a) shows typical burial depths for the Zechstein unit (Z2) in the northern part of the LSB together with respective simulated vitrinite reflectance values (Fig. 4.21-b) for three different burial scenarios. Scenario A suggests fracture propagation at shallow burial conditions and a high heat flow during the early Cretaceous, while scenario B suggests fracture propagation at deeper burial conditions and a lower heat flow. A third burial scenario (C) with lower sedimentation rates (maximum burial depth $\mathrm{Ca} 2$ limestone: $4600 \mathrm{~m}$ ) assuming fracture propagation due to thrusting during the late Cretaceous - early Paleocene inversion is presented as well. Numerical simulations show highest lithostatic pressures during the late Cretaceous with peak pressures above $130 \mathrm{MPa}$. Calculated pressures within fractures in Zechstein Ca2 top units are slightly lower and are around $115 \mathrm{MPa}$ (Fig. 4.22-a).
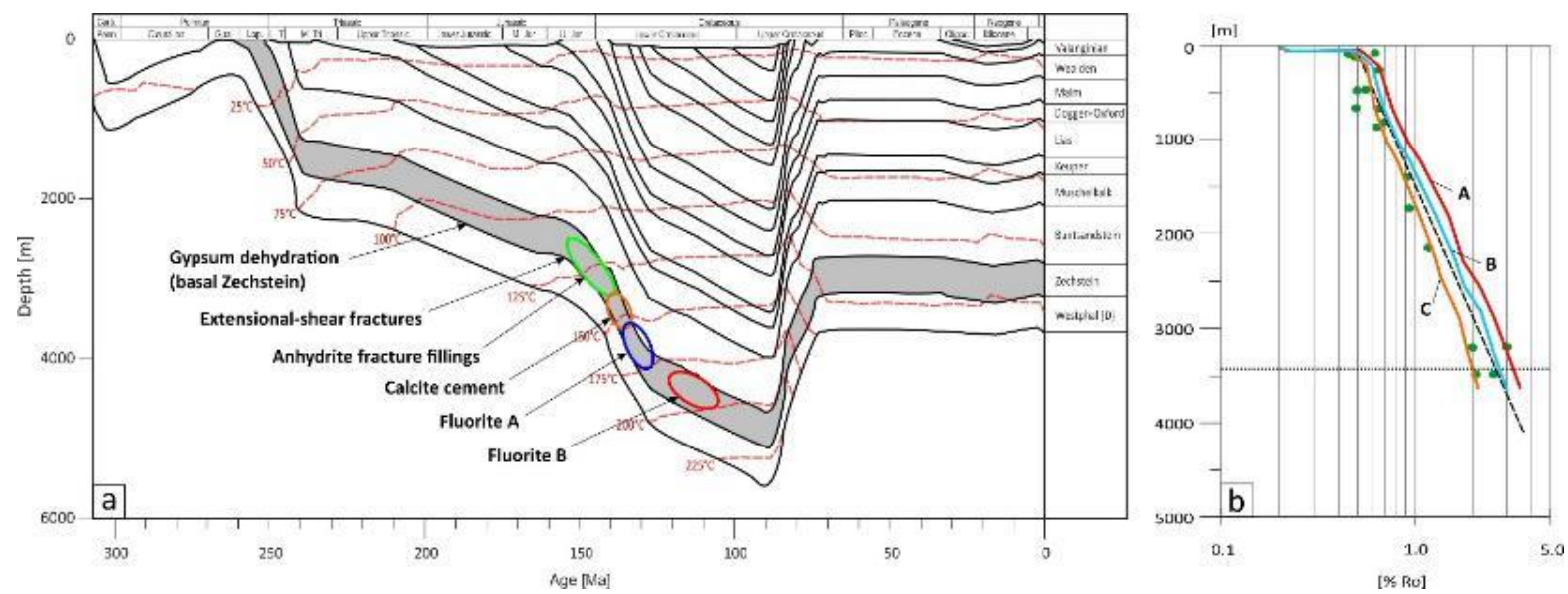

Fig. 4.22. (a) Burial history and temperature distribution of the Westphalian-Valanginian succession constrained by published data (Adrisola-Muñoz, 2007; Petmecky et al., 1999) as well as by original thermobarometric analysis. Solid black lines represent stratigraphic boundaries; red dashed lines mark isotherms (steps: $25^{\circ} \mathrm{C}$ ); the grey range represents Zechstein units. Deeper units (Westphalian $B$ until basement) are excluded in this image for better illustration. Relative time and depth of formation of the four respective mineral phases investigated in this study are marked by coloured circles. In case of Fluorite $B$, the reconstructed $P-T$ conditions coincide with a supposed reactivation of extensional-shear fractures during the final stage of subsidence (Aptian-Albian) and simultaneous $\mathrm{CO}_{2}$ migration. (b) Vitrinite reflectance values/trends versus depth plot. Green dots = measured values from the study area (Petmecky et al., 1999); dashed black line = line of best fit for measured values; solid red line = simulated vitrinite reflectance trend for shallow burial/high heat flow scenario (scenario A); solid blue line = simulated vitrinite reflectance trend for deep burial/low heat flow scenario (scenario B, corresponding burial history is shown in Fig. 4.22-a); solid orange line = simulated vitrinite reflectance trend for a burial scenario with lower sedimentation rates and $\mathrm{CO}_{2}$ migration close to or during basin inversion (scenario $C$ ); dotted black line = top Carboniferous (sampling well). Though both scenarios supporting $\mathrm{CO}_{2}$ migration during rifting do match well with the measured vitrinite reflectance trend, the low heat flow scenario (scenario B) fits the best. Therefore, we favor the idea of fracture propagation and subsequent $\mathrm{CO}_{2}$ migration at depth between 4400 and $4600 \mathrm{~m}$. A burial scenario with lower sedimentation rates and a maximum burial depth of 4600 $m$ short before basin inversion would result in significantly lower vitrinite reflectance values in top Carboniferous units and a steeper trend (scenario $C$ ). 
Numerical simulations show highest lithostatic pressures during the late Cretaceous with peak pressures above $130 \mathrm{MPa}$. Calculated pressures within fractures in Zechstein Ca2 top units are slightly lower and are around $115 \mathrm{MPa}$ (Fig. 4.23-a). The temperature during Fluorite B mineralization in the late Cretaceous estimated from crossing isochores corresponds with a paleo-geothermal gradient of ca. $39^{\circ} \mathrm{C}$. Combining $\mathrm{P} / \mathrm{T}$ estimates and numerical simulations we find good agreement for the geothermal gradient $\left(42^{\circ} \mathrm{C}\right)$ and for the reservoir temperatures (ca. $180^{\circ} \mathrm{C}$, Fig. $4.23-\mathrm{b}$ ) in the sampled Zechstein unit.
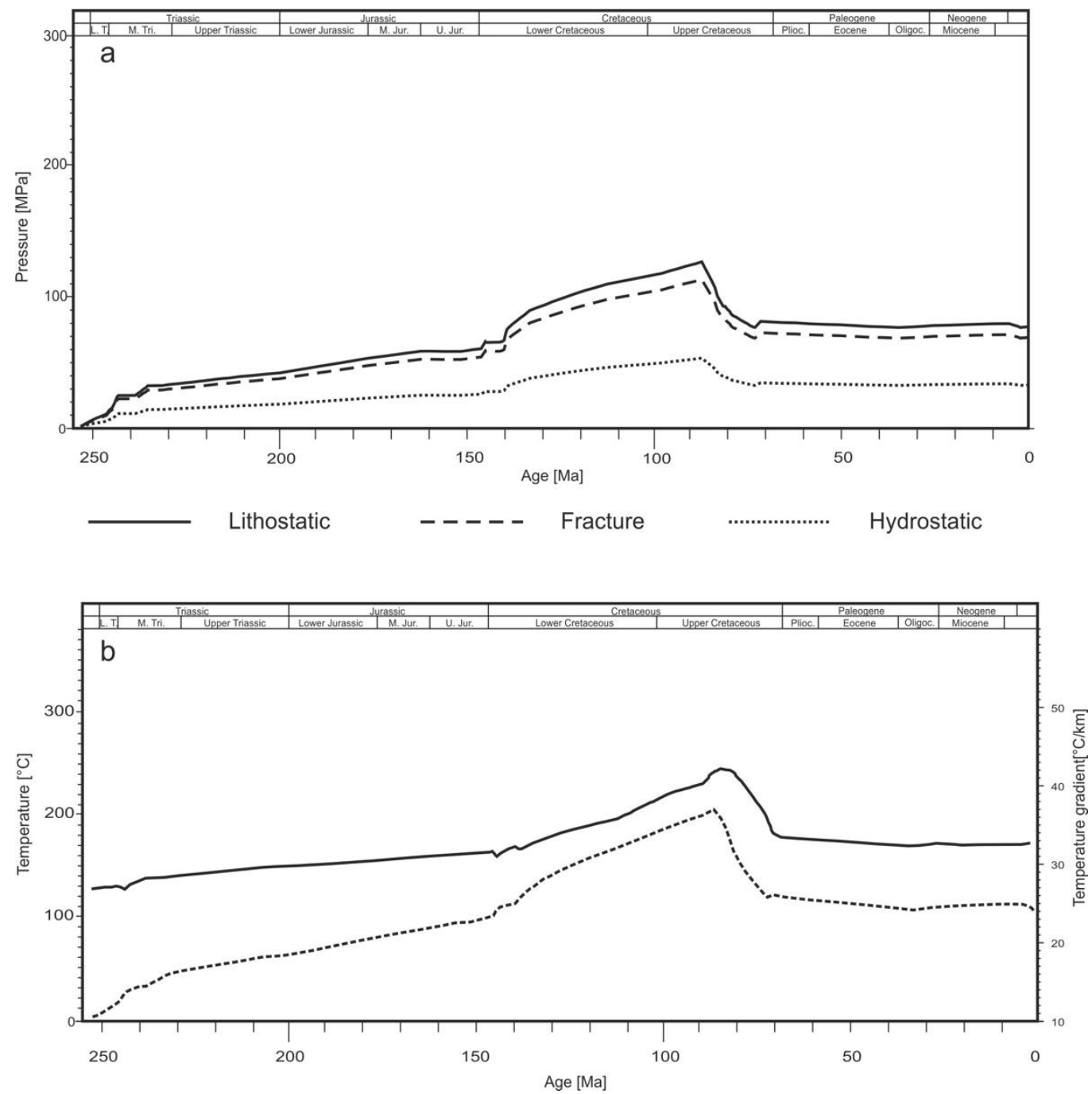

Fig. 4.23. (a) Calculated pressure distribution in Zechstein (Ca2) limestone regarding lithostatic and hydrostatic pressure as well as pressure in open fractures. (b) Temperature (dashed line) and temperature gradient (solid line) distribution in Zechstein (Ca2) limestone over time. Both, pressures (900-1000 bar) and temperatures $\left(180-200^{\circ} \mathrm{C}\right)$ obtained from co-genetic fluid inclusions in Fluorite B coincide with reservoir conditions during early Cretaceous (Aptium-Albium) and suggest a massive $\mathrm{CO}_{2}$-flux during burial.

Tab. 4.3: Basic input values used for $1 D$ basin modelling. 
Chapter 4 - Fluid inclusion and microfabric studies on Zechstein carbonates (Ca2)

\begin{tabular}{|c|c|c|c|c|c|}
\hline Layer & Age (Ma) & $\begin{array}{l}\text { Thickness } \\
\text { (m) }\end{array}$ & $\begin{array}{l}\text { Erosion } \\
\text { (m) }\end{array}$ & Lithology & $\begin{array}{l}\text { Heat flow } \\
\left(\mathrm{mW} / \mathrm{m}^{2}\right)\end{array}$ \\
\hline Quaternary & 1,8 & 40 & & SAND\&SILT & 60 \\
\hline Miocene & 23,8 & 0 & 85 & SHALEsilt & 61 \\
\hline Oligocene & 33,9 & 0 & 70 & SHALEsilt & 67 \\
\hline Campanian & 83,6 & 0 & 230 & SHALEcalc & 63 \\
\hline Upper Cretaceous & 100,5 & 0 & 325 & SHALEcalc & 66 \\
\hline Albian & 112,9 & 0 & 375 & SHALEcalc & 66 \\
\hline Apt & 126,3 & 0 & 275 & SHALEcalc & 68 \\
\hline Barremian & 130,7 & 0 & 300 & SHALEcalc & 68 \\
\hline Hauterivian & 133,9 & 0 & 275 & SHALEcalc & 65 \\
\hline Valanginian & 139,3 & 158 & 400 & SHALEcalc & 62 \\
\hline Wealden & 144 & 290 & & SANDcalc. & 62 \\
\hline Malm & 152,1 & 250 & & Marl & 61 \\
\hline Kimmeridge & 157,3 & 72 & & Marl & 63 \\
\hline Dogger+Oxford. & 174,1 & 205 & & SHALEcalc & 64 \\
\hline Liassic & 201,3 & 525 & & SHALE & 75 \\
\hline Rhät & 208,5 & 70 & & SHALEcalc & 80 \\
\hline Low-Mid Keuper & 235 & 140 & & SHALEcalc & 61 \\
\hline Upper Muschelkalk & 238,5 & 35 & & LIMEshaly & 60 \\
\hline Mid Muschelkalk & 240 & 90 & & LIMEshaly & 60 \\
\hline Lower Muschelkalk & 243 & 305 & & Marl & 60 \\
\hline Upper Bunter & 244,5 & 220 & & EVAPORITE & 60 \\
\hline Mid Bunter & 246 & 240 & & SAND\&SHAL & 60 \\
\hline Lower Bunter & 251 & 266 & & SHALEsilt & 61 \\
\hline Zechstein Salt & 253 & 152 & & EVAPshaly & 64 \\
\hline Zechstein Ca2 & 255 & 140 & & DOLOMITE & 65 \\
\hline Zechstein We & 257,3 & 170 & & EVAPORITE & 70 \\
\hline Stephan & 305 & 0 & 590 & SAND\&SILT & 75 \\
\hline Westphalian D & 308 & 470 & 180 & SANDsilty & 80 \\
\hline Westphalian C & 311 & 385 & & SANDsilty & 63 \\
\hline Westphalian B & 312 & 405 & & SANDsilty & 62 \\
\hline Westphalian A & 316,5 & 375 & & SANDsilty & 62 \\
\hline Namurian & 326,5 & 890 & & SHALE\&SAN & 62 \\
\hline Basement & $>326.5$ & 3000 & & BASEMENT & 62 \\
\hline
\end{tabular}

\subsection{Discussion}

\subsubsection{Diagenetic sequence and fluid evolution}

The diagenetic sequence documents the appearance of mineral phases in the study area after dolomitization, dolomite recrystallization and anhydritization during mesodiagenesis (see Huttel, 1989). As stylolitization is usually restricted to calcitic limestone, calcitization of the dolomitic limestone has taken place prior to major subsidence during the late Jurassic, since extensional-shear fractures are not affected by pressure solution. Horizontal stylolites resulting from vertical $\sigma_{1}$ are accompanied by tension gashes, which contain blocky anhydrite and fibrous, inclusion-free calcite; older radially arranged anhydrite-aggregates were partly dissolved. During progressive subsidence in the mid - late Jurassic, gypsum dehydration in basal Zechstein units is expected to be continued which caused an increased pore pressure (Heard and Rubey, 1966). This led to the formation of extensional-shear fractures and subsequent fluid migration within the Zechstein units during the late Jurassic - early Cretaceous, followed by precipitation of blocky anhydrite within fractures from a Ca-saturated fluid at depths between 2800 and $3200 \mathrm{~m}$. Slightly higher homogenization temperatures of respective primary fluid inclusions prove calcite precipitation in pores simultaneously or right after anhydrite precipitation in 
fractures, probably from the same Ca-rich brine, at a depth of about $3500 \mathrm{~m}$. During progressive burial extensional-shear fractures were reactivated and migration of fluorine-rich hydrothermal fluids was initiated. Fluorite A replaced anhydrite within fractures and nodules. According to our model, formation temperatures of $>150{ }^{\circ} \mathrm{C}$ correlate with a minimum burial depth of $3700 \mathrm{~m}$. Fluid migration was accompanied by the mobilization of organic matter (solid bitumen), as evidenced by solid inclusions in Fluorite A. First fluorite precipitation was followed by the crystallization of authigenic quartz at temperatures above $160{ }^{\circ} \mathrm{C}$ and burial depth of ca. $4000 \mathrm{~m}$. The precipitation of Fluorite B together with the heterogeneous trapping of aqueous-carbonic and carbonic fluids show evidence of reactivation of existing extensional-shear fractures at depths of $4200-4600 \mathrm{~m}$. The appearance of ore minerals such as pyrite, chalcopyrite, and sphalerite in the geological record can be dated after the precipitation of Fluorite B, since anhydrite and both Fluorite A and B have been replaced by these sulfides within the nodular structures and along fractures. The sulfide minerals are a further indication of circulating hydrothermal fluids. Precipitation of blocky anhydrite and Fluorite A within nodular flame structures can be explained by the high concentration of dolomitized algae remnants, ooids and ostracode shells, that may have provided pore space for saturated solutions over longer times (Clark, 1980; Füchtbauer, 1962). Calcareous algae and ostracode shells together with convolute bedding (Fig. 4.7-a) confirm an environment close to the transition zone between platform and upper slope during $\mathrm{Ca} 2$ carbonate sedimentation (Kaiser, 2001; Steinhoff and Strohmenger, 1996; Strohmenger et al., 1998; Ziegler, 1990) and clearly assign it to the Hauptdolomit sequence (Füchtbauer, 1962; Quester, 1962). According to Strohmenger et al. (1998) fluorite precipitation within the Stassfurt carbonate sequence has occurred during diagenesis at burial depths significantly deeper than $500 \mathrm{~m}$. Brine salinity increased during subsidence, which resulted in oversaturation before maximum burial depth was reached. Gaseous fluids revealed a more complex history with the generation of different gases $\left(\mathrm{CH}_{4}, \mathrm{CO}_{2}, \mathrm{~N}_{2}\right.$, and $\left.\mathrm{H}_{2} \mathrm{~S}\right)$. All these fluid systems were preserved in the basin till the early Cretaceous when gas mobilized as result of fracturing. The paragenetic sequence (Fig. 4.24) summarizes all respective minerals and diagenetic features, as well as their appearance during the stratigraphic record.

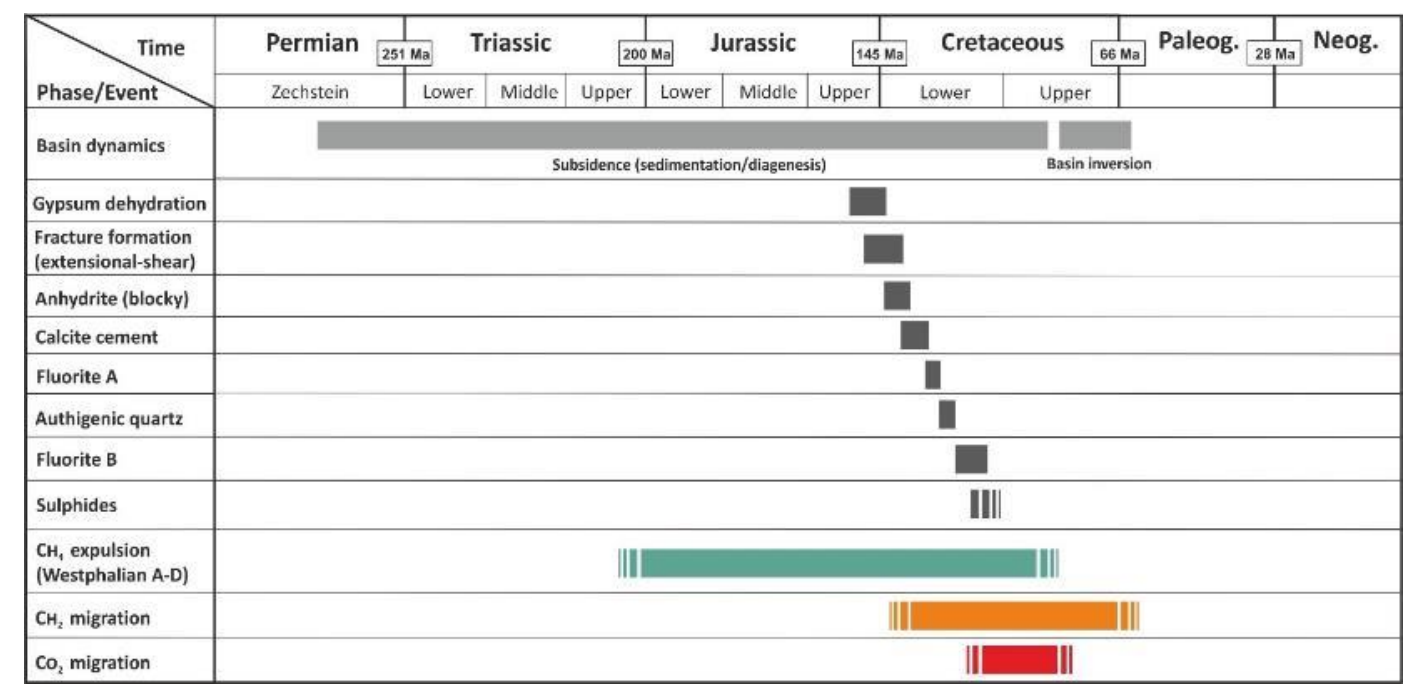

Fig. 4.24. Paragenetic sequence of diagenetic phases organized in relative chronological order from early diagenesis to late-diagenetic fracture mineralization in the considered fault block area. This event chart shows the relative appearance of mineral-/gas phases and diagenetic features within Zechstein Ca2 limestone throughout the geologic record, with respect to results from our numerical simulation. Basin modelling has shown that $\mathrm{CH}_{4}$ must have been present in the Ca2 reservoir rock since late Jurassic times, 
when another burial phase was initiated. However, major amounts of $\mathrm{CH}_{4}$ cannot be determined within fluid inclusions until early Cretaceous times, when $\mathrm{CO}_{2}$-migration was initiated.

Chemical compositions of the aqueous inclusions are in good agreement with published data from the LBS and adjacent areas of the NGB (Lüders et al., 2005; Schmidt Mumm and Wolfgramm, 2002; Zwart, 1995; Zwart and Touret, 1994). Salinity shows few noticeable differences (Fig. 4.11); calcite (II), Fluorite A (V) and also Fluorite B (VI) mostly plot in the hydrohalite field, with few oversaturated inclusions in the halite field. Anhydrite (I) however is enriched in $\mathrm{CaCl}_{2}\left(\mathrm{H}_{2} \mathrm{O}\right.$-field; Fig. 4.11). This can be explained by the fact that mostly Ca-saturated brines must have been present during recrystallization of anhydrite, whereas $\mathrm{Na}$ was relatively underrepresented in the fluid system; high Ca-contents in the fluid were probably caused by the dehydration of gypsum in the underburden during burial (Huttel, 1989). Extension fractures then allowed the interconnection between hydraulic systems. However, high salinities in the LSB are caused by severe alteration of sedimentary rocks (rock-fluid interaction), especially when rock salt is present (Zechstein salt).

All fluid inclusions show higher homogenization temperatures than expected for the present day geotherm. Therefore, burial depths must have been significantly higher, or another thermal source must have existed over time. Pressure solution and temperatures above $170^{\circ} \mathrm{C}$ obviously caused dissolution of calcite and Fluorite A followed by the precipitation of new mineral phases in fractures. This study shows that only traces of $\mathrm{CO}_{2}$ were present during precipitation of Fluorite $\mathrm{A}$, but was dominant during Fluorite $\mathrm{B}$ precipitation in veinlets. Fluorite must have been dissolved and re-precipitated after $\mathrm{CO}_{2}$ accumulation in the reservoir.

As described by Möller et al. (1980) the high concentration of fluorine in the Hauptdolomit sequence can be explained by the mixing of high saline and thus $\mathrm{F}^{-}$-enriched brine (lagoon) and fluorine-rich freshwater ( $\mathrm{F}^{-}$-input from weathering of granitic rocks) in a reef limestone (see also Chapter 5). The dolomitization of calcite in the reef limestone resulted in the release of $\mathrm{Ca}^{2+}$ and the decrease of $\mathrm{Mg}^{2+}$ in the fluid. Thus, fluorine together with now available calcium could form fluorite within the dolomite. However, the prominent zoning features found in Fluorite A, the presence of organic material (bitumen) within the crystals, and the lack of dolomite replacement features due to fluorite precipitation favour the idea of a different formation mechanism at a later stage of diagenesis, when dolomitization was already finished. Microfabric details from a fluorite nodule (Fig. 4.6-a) revealed that this flame structure was in part previously filled with anhydrite, which was subsequently replaced by Fluorite A. Therefore, we assume that Fluorite A had a sedimentary predecessor and was mobilized during burial (see also Chapter 5). This would explain the relatively high homogenization temperatures of primary fluid inclusions found in Fluorite A.

Dissolution and precipitation of fluorite during burial strongly depends on pressure and temperature, but also on the salinity of the fluid, as shown by various authors for low P/T conditions (e.g. MacDonald and North, 1974; Richardson and Holland, 1979a, 1979b; Strübel, 1968; Strübel and Schaefer, 1974) as well as for high P/T conditions (Tropper and Manning, 2007), respectively. As pointed out by Richardson and Holland (1979b) especially high saline brines enriched in $\mathrm{NaCl}\left(-\mathrm{CaCl}_{2}\right)$ tend to dissolve very high amounts of $\mathrm{CaF}_{2}$ compared to pure water. Assuming nearly $\mathrm{CaF}_{2}$ saturation in a high saline fluid short before or during basin inversion, decreasing temperature would result in rapid fluorite precipitation. Sudden pressure decrease (Tropper and Manning, 2007) due to fracture formation during faulting is a more plausible cause to force fluorite precipitation within fractures in the Stassfurt carbonate of the LSB. However, fluorite dissolution only affected by increasing temperatures during burial is 
probably not a sufficient explanation for the remobilization of Fluorite A (type III), since maximum homogenization temperatures found in Fluorite B (type VI) show only slightly higher values than those found in Fluorite A. It is more likely that fluorite dissolution occurred due to rapidly increased pressure during maximum burial. This would explain the beginning of dissolution in Fluorite A at such elevated temperatures and the precipitation along fractures shortly after brittle deformation when pressure in the reservoir dropped significantly.

The REE pattern of Fluorite A shows a steep trend from La downwards to Sm continued by a flattening but still degressive trend towards Lu (Fig. 4.16). As shown by Möller et al. (1998) such a pattern is characteristic for fluorites formed in sedimentary environments and precipitated from a primary fluid. Compared to HREE, LREE are enriched and show decreasing concentration with increasing ionic radii of $\mathrm{REE}^{3+}$. According to Möller (1991) an enrichment of LREE in fluorites signifies a $\mathrm{Ca}^{2+} / \mathrm{F}$ ratio > 1 which again demonstrates a source fluid derived from a sedimentary environment. However, Fluorite B is depleted in REE, especially in LREE such as La, Ce, Pr, and Nd. This behaviour could be interpreted as depletion in LREE under complexation-conditions during remobilization of Fluorite A (Möller et al., 1998), since HREE tend to form more stable and long-lived complexes compared to LREE and thus remain in solution instead of being incorporated (Wood, 1990a, 1990b). The overall depletion in REE (and Y) in Fluorite B can be explained by the preferential incorporation of REE in carbonate minerals during remobilization as shown by Jacob (1974). Assuming remobilization of Fluorite A during burial and subsequent precipitation of Fluorite B from the same fluid at the time of $\mathrm{CO}_{2}$ migration no magmatic influence on fluid chemistry is detectable. As plotted in Fig. 4.17 this points at Fluorite A being an early precipitate from the primary basin solution enriched in trace and rare earth elements while Fluorite B represents recrystallized sedimentary fluorite (see also Möller et al., 1998). Positive $\mathrm{Eu}$ anomalies usually occur when $\mathrm{Eu}$ is thermochemically reduced under hightemperature conditions $\left(>250^{\circ} \mathrm{C}\right.$ ) (Bilal and Müller, 1992). Since no Eu anomaly was detected either in the primary precipitate (Fluorite A) or in the recrystallized fluorite (Fluorite B) temperatures during precipitation and remobilization did not exceed $250^{\circ} \mathrm{C}$, which correlates with measured homogenisation temperatures deduced from primary fluid inclusions; besides, a granitic/pegmatitic source for Fluorite A can be excluded. The parent fluid must have originated from (carbonate) host rock/water interaction or hydrothermal fluids with temperatures below $250^{\circ} \mathrm{C}$, or be a mixture of both (mixing of brine and hydrothermal fluid originating from convective fluid flow along faults during rifting; see Bjørlykke et al., 1988). As demonstrated by microscopic and microthermometric studies Fluorite A precipitated at a relatively late stage of diagenesis when normal faults already may have controlled fluid flow in deeper units of the LSB. But as Tb/Ca versus Tb/La ratios have shown, the predominant fluid must have been basin brine, no magmatic influences can be identified with this method.

Positive Y anomalies are typical for complex-dominated conditions; they are characteristic for fluids with short migration distances between (re)mobilization and precipitation (Möller et al., 1998). This result is in good agreement with observations from CL microscopy that show dissolution of Fluorite A and replacement of Fluorite A by Fluorite B within the same fluorite nodule (Fig. 4.8-a/b).

However, as the precipitation of Fluorite A occurred at a late stage of burial, a sedimentary formation mechanism as proposed by Schulz (1980) is not realistic. Though $\mathrm{Tb} / \mathrm{Ca}$ versus $\mathrm{Tb} / \mathrm{La}$ ratios indicate a sedimentary origin for the parental fluid (Fig. 4.17), microscopic and microthermometric evidence clearly proves that anhydrite was replaced by Fluorite A at temperatures above $125^{\circ} \mathrm{C}$. Since only a fluorite formation under sedimentary conditions could explain such low $\mathrm{Tb} / \mathrm{Ca}$ ratios found in Fluorite A, we assume that Fluorite A precipitated from a remobilized fluid of sedimentary origin. 


\subsubsection{Thermal history and $P-T$ reconstruction}

Thermobarometric calculations show that the temperature in the fractures was about $180-200^{\circ} \mathrm{C}$, at pressures between 900 and 1000 bars. Assuming equilibrium at the time of fluid trapping, the geothermal gradient must have been ca. $39^{\circ} \mathrm{C} / \mathrm{km}$ (see P/T diagram, Fig. 4.15). This corresponds with a paleogeothermal gradient during $\mathrm{CO}_{2}$ mobilization that was significantly higher than the present geotherm of $30^{\circ} \mathrm{C} / \mathrm{km}$ (Doornenbal and Stevenson, 2010; Schmidt Mumm and Wolfgramm, 2002; Wolfgramm, 2001). The influence of plutonic intrusions like the Bramsche massif (e.g. Bilgili et al., 2009; Stadler and Teichmüller, 1971; Ziegler, 1990) or others, notably the anomaly of Uchte in the eastern part of the LSB, on thermal history in the LSB cannot be excluded, since the proposed timing of these thermal anomalies does in some extent coincide with the forming of Fluorite B, assuming a mobilization of fluorite and simultaneous migration of carbonic fluids shortly before inversion started. Betz et al. (1987) and Ziegler (1990) for example stated that intrusions of magmatic bodies below the LSB may have occurred during the Aptian, while other authors showed that inversion started in the late Cretaceous (Turonian-Santonian; e.g. Kus et al., 2005). Actually, $\mathrm{CO}_{2}$ migration in our model coincides with proposed ages of plutonic intrusions in the LSB, though no further evidence for a plutonic body below the study area could be found. Thermobarometric estimates from fluid inclusion study correspond with high lithostatic pressures during deep burial. Co-existing fluids trapped at lower pressures, for example at shallow depth or during inversion, would show significantly lower densities. Resulting heat flow values for the study area during the late Cretaceous (ca. $68 \mathrm{~mW} / \mathrm{m}^{2}$ ) are in good agreement with published data from Adrisola-Muñoz (2007), Adrisola-Muñoz et al. (2007), and Petmecky et al. (1999); they point to an increased fluid-driven thermal conductivity during rifting, probably favoured due to crustal thinning. Compared to the present day basal heat flow in the LSB of ca. 60 to $80 \mathrm{~mW} / \mathrm{m}^{2}$ (Bruns et al., 2013; Norden et al., 2008), this increased heat flow appears negligible and may be caused by migration of hydrothermal fluids restricted to the vicinity of faults (hydrothermal convection; Bjørlykke et al., 1988). As demonstrated by Kus et al. (2005) for the western part of the LSB, heat flow rates of ca. $110 \mathrm{~mW} / \mathrm{m}^{2}$ during the Coniacian would explain thermal maturity at relatively shallow depth of $3000 \mathrm{~m}$. The mismatch of our thermobarometric results and the vitrinite reflectance calibration compared to published heat flow values in adjacent areas (Kus et al., 2005; Zwart, 1995) can be explained by significant differences in basin evolution within the LSB, especially in the western part. Uplift values of more than $1000 \mathrm{~m}$ along the northern margin of the LSB are likely due to reverse faulting and the formation of individual fault blocks controlled by wrench faulting (positive flower structures). Levels of high thermal maturity caused by the Uchte anomaly (distance to sampling location $>25 \mathrm{~km}$ ) does not correlate with our observations, instead calculated pressures confirm a deep burial scenario with ambient pressures significantly higher than hydrostatic pressures, and the migration of hydrothermal fluids along fractures (Reutel and Lüders, 1998).

\subsubsection{Fracture gradient estimation}

Since the calculated mean homogenization temperatures of the investigated minerals do not merely coincide with ambient temperatures at the current sampling positions $\left(\mathrm{ca} .110^{\circ} \mathrm{C}\right.$ ), but rather exceed them, temperatures were higher during mineral precipitation. Homogenization temperatures suggest that precipitation occurred at greater depth, the estimated positions during fluid trapping with respect to the current geothermal gradient of ca. $30^{\circ} \mathrm{C} / \mathrm{km}$ are shown in Fig. 4.25-a. Co-genetic fluid inclusions in Fluorite B define the geotherm during the early Cretaceous and also the depth of fluid entrapment along 
the paleo-geotherm (Fig. 4.15). The minimum depth of trapping of Fluorite B corresponding with a minimum trapping temperature of $190^{\circ} \mathrm{C}$ is ca. $4200 \mathrm{~m}$ (Fig. 4.25-a). This information helps to calculate the fracture gradient within the reservoir rock, i.e. the overpressure necessary for reservoir rock fracturing. Assuming a pressure of ca. 900-1000 bars and a minimum depth of fluid trapping of ca. $4200 \mathrm{~m}$, a lower limit of fluid pressure within fractures can be defined (Fig. 4.25-b).
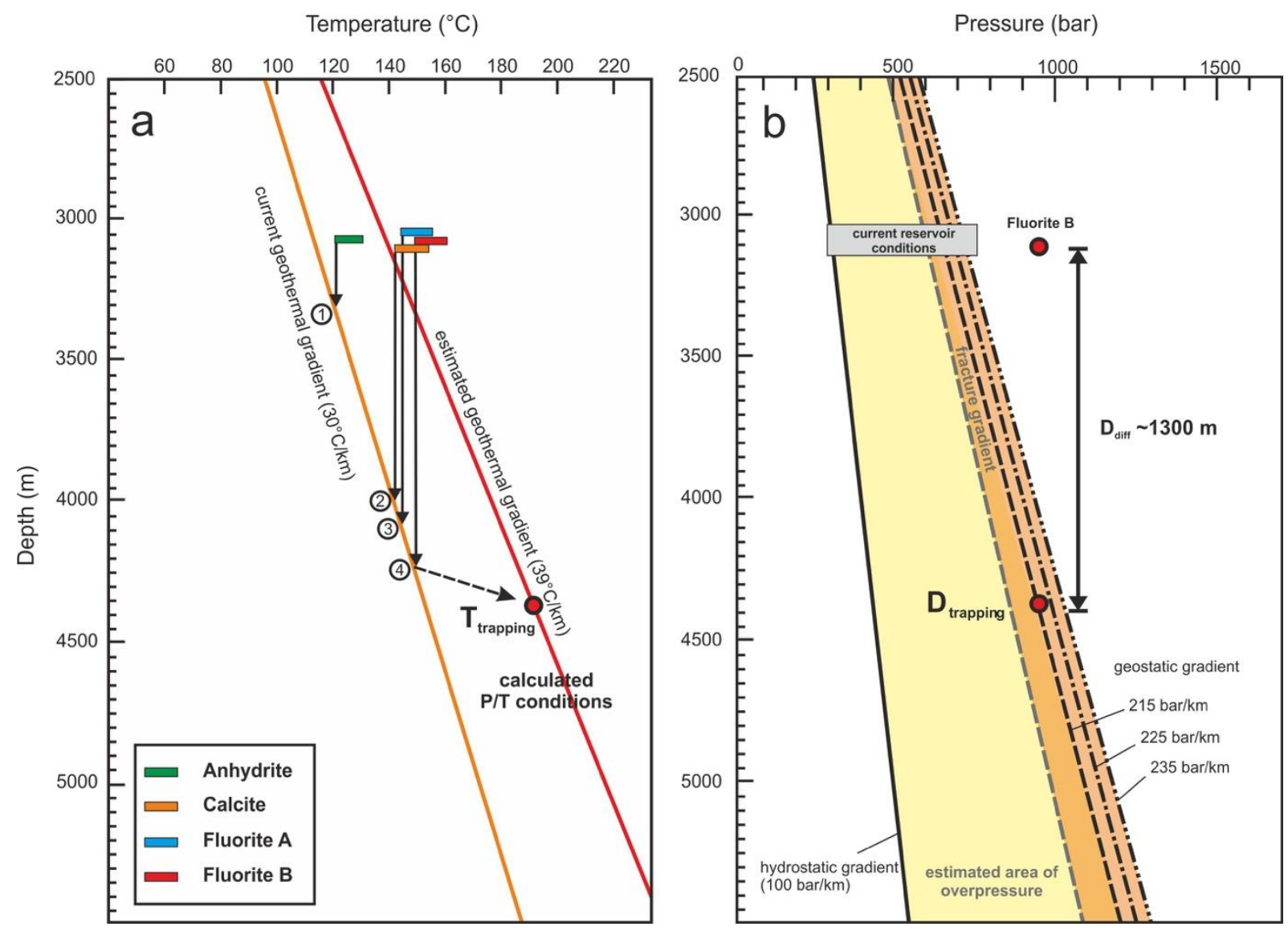

Fig. 4.25. (a) Depth-temperature plot showing the present day position of the four investigated mineral phases in reference to their fluid inclusions homogenization temperatures. Numbers in circles give the order of appearance along the current geothermal gradient (orange solid line). The red dot shows the calculated minimum P/T conditions of Fluorite B after pressure correction and their corresponding depth range (ca.4200 $\mathrm{m}$ below surface). (b) Depth-pressure plot with current reservoir conditions and the calculated position of pseudosecondary type VI-inclusions in Fluorite B during entrapment (red dot). The estimated fracture gradient is between hydrostatic and lithostatic conditions.

Fluid inclusion pressures from fracture fillings reveal fracture gradients between hydrostatic and lithostatic conditions ( $\mathrm{P}_{\text {fracture }}$ is ca. 70 to $80 \%$ of $\mathrm{P}_{\text {lithostatic }}-\mathrm{P}_{\text {hydrostatic }}$ ). This demonstrates the overpressurized character of the reservoir, that was probably favoured by gypsum dehydration in deeper units. Under these conditions the fracturing of the Zechstein reservoir rock and the mobilization of $\mathrm{CO}_{2}$ and brine was initiated. Since fracture propagation was most likely triggered by tectonic movements related to rifting, fluid pressures within fractures can be lower than expected (i.e. below typical fracture gradient). It can be concluded that Zechstein units were buried even below depths of ca. $4600 \mathrm{~m}$, with peak temperatures reaching $200^{\circ} \mathrm{C}$, which is in good agreement with other investigations (Fischer et al., 2006). Therefore, Fluorite B has likely formed in extensional-shear fractures prior to basin inversion. 


\subsubsection{Origin of $\mathrm{CH}_{4}$ and $\mathrm{CO}_{2}$}

Whether the thermal maturity in some parts of the LSB was driven by magmatic intrusions or deep burial, followed by fast uplift is still a matter of discussion. High concentrations of methane are known throughout the LSB (Krooss et al., 2008), the origin of methane, which appears in high concentration within secondary fluid inclusions in fluorite, is likely produced by early decomposition of organic matter. Our model showed, that methane must have been present in the Stassfurt carbonate since late Jurassic - early Cretaceous. The origin of $\mathrm{CO}_{2}$ in the LBS was discussed in the literature; as pointed out by Lokhorst et al. (1998) and Fischer et al. (2006), the composition of gas mixtures varies throughout the LBS, a single source of $\mathrm{CO}_{2}$ could not be determined exactly, but the amount of $\mathrm{H}_{2} \mathrm{~S}$ in the gas phase allows to confine possible sources. Hydrogen sulphide is usually produced by thermochemical sulphate reduction (TSR) after the following reaction (Worden and Smalley, 1996):

$$
\mathrm{CaSO}_{4}+\mathrm{CH}_{4} \rightarrow \mathrm{CaCO}_{3}+\mathrm{H}_{2} \mathrm{~S}+\mathrm{H}_{2} \mathrm{O} \text {, }
$$

thereby reducing the amount of both anhydrite and methane. Another important reaction during thermochemical sulphate reduction,

$$
2 \mathrm{CaSO}_{4}+\mathrm{C}_{2} \mathrm{H}_{6} \rightarrow 2 \mathrm{CaCO}_{3}+\mathrm{H}_{2} \mathrm{~S}+\mathrm{S}+2 \mathrm{H}_{2} \mathrm{O},
$$

also explains the presence of $\mathrm{H}_{2} \mathrm{~S}$ and native sulphur, thus finally leading to a $\mathrm{CO}_{2}$-producing process:

$$
4 \mathrm{~S}+\mathrm{CH}_{4}+2 \mathrm{H}_{2} \mathrm{O} \rightarrow \mathrm{CO}_{2}+4 \mathrm{H}_{2} \mathrm{~S} .
$$

Yang (2001) presented another mechanism for hydrogen sulphide formation, when anhydrite dissolution provides the sulphur:

$$
2 \mathrm{SO}_{4}{ }^{2-}+2 \mathrm{CH}_{4}+4 \mathrm{H}^{+} \rightarrow 2 \mathrm{H}_{2} \mathrm{~S}+2 \mathrm{CO}_{2}+4 \mathrm{H}_{2} \mathrm{O}
$$

Only traces of hydrogen sulphide have been detected in some carbonic inclusions (type V/VI) in Fluorite $\mathrm{A}$ and $\mathrm{B}$ which contain basically $\mathrm{CO}_{2}, \mathrm{CH}_{4}$ and minor $\mathrm{C}_{2} \mathrm{H}_{6}$. Native sulphur has been neither detected in our samples nor has been described at locations nearby. Therefore, TSR is unlikely important for major carbon dioxide production in the study area, but cannot completely be excluded. The presence of scarce pyrite in Fluorite A nodules indicates the precipitation of sulphide at reducing conditions, even though pyrite replaced Fluorite A and B as well.

Secondary methane-rich inclusions (40 to $70 \% \mathrm{CH}_{4}$ ) in Fluorite A/B with low densities (type IV) indicate reducing conditions after or during late stages of uplift and contrast with pseudosecondary $\mathrm{CO}_{2}-$ dominated inclusions ( 75 to $90 \% \mathrm{CO}_{2}$ ) in Fluorite $\mathrm{B}$ which indicate oxidizing conditions during fracture propagation. According to Krooss et al. (2008), sulphate minerals often appear after basin inversion as syn-diagenetic fracture fillings together with $\mathrm{CH}_{4}$-bearing secondary inclusions, as anhydrite is often dissolved and re-precipitated during uplift. The $\left.\delta^{13} \mathrm{C}_{(\mathrm{CH}}\right)$ ratios of gas trapped in fluid inclusions show very similar values between -27.5 in (secondary) type $\mathrm{V}$-inclusions and -26.1 in (pseudosecondary) type VI-inclusions. Measured values correlate with those from gaseous inclusions found in fracture-fill mineralization in Upper Carboniferous sediments in the LSB (Lüders et al., 2012) and confirm the idea of an organic source (coal). However, only slightly negative $\delta^{13} \mathrm{C}\left(\mathrm{CO}_{2}\right)$ values of -1.2 detected in secondary fluid inclusions in Fluorite A (type V) are relatively heavy and do correlate with $\delta^{13} \mathrm{C}\left(\mathrm{CO}_{2}\right)$ values typically obtained from marine carbonates (Hoefs, 2009). These values are too heavy for typical magmatic sources (ca. -5\%) and may point at an inorganic source for $\mathrm{CO}_{2}$ (compare Dai et al., 1996) thus a magmatic source cannot be completely excluded. This supports the assumption that type- $\mathrm{V}$ fluid inclusions contain a gas mixture from different sources as suggested by Fischer et al. (2006) and Krooss et al. (2008), but also a metamorphic origin with $\mathrm{CO}_{2}$ derived from carbonate conversion is possible.

Though microthermometric studies revealed that $\mathrm{P} / \mathrm{T}$ conditions of co-genetic fluid inclusions found in fluorite fracture mineralization can be attributed to a very late stage of basin evolution, it is still not clear 
if rifting (extensional fractures) or basin inversion is the responsible mechanism for triggering the gas migration. Other studies have shown before (e.g. Schmidt Mumm and Wolfgramm, 2002) that the appearance of fracture-hosted fluorite mineralization throughout the LSB is usually linked to inversion tectonics (Late Cretaceous) and not to rifting. Furthermore, the exclusively high $\mathrm{CO}_{2}$ concentration is restricted to the respective fault block that was likely formed during basin inversion and not before. It is most likely that $\mathrm{CO}_{2}$ was formed and stored in Carboniferous units until deep-reaching tectonic faults allowed gas migration into the Zechstein reservoir.

On the other hand, methane-rich gaseous inclusions of type (a) (Fig. 4.18) are probably related to late gas migration following uplift in the late Cretaceous - early Paleogene, as their low density (close to hydrostatic conditions) suggest, whereas $\mathrm{CO}_{2}$-dominated type (b)-inclusions occur only in syndiagenetic minerals related to extensional fractures that formed under high pressure close to lithostatic conditions. Type-(b) fluids are characteristic for the burial sequence in the late Jurassic - early Cretaceous (Lüders et al., 2008). These observations suggest that large amounts of $\mathrm{CO}_{2}$ have been generated or accumulated in deeper units (Carboniferous/upper mantle)) during burial and migrated into the Zechstein reservoir along fractures during rifting-related fluid mobilization. This fact contrasts the idea of $\mathrm{CO}_{2}$-migration during basin inversion and rather points to a massive $\mathrm{CO}_{2}$-flux during the latest stage of subsidence, that was probably terminated due to inversion tectonics. Carbon-rich fluids moving along extensional faults, that have reached upper mantle rocks, may contain fractions of both $\mathrm{CO}_{2}$ originating from mantle rocks or from metamorphic degassing. $\mathrm{CH}_{4}$, however, was present during burial and uplift, therefore originating from a different, most likely shallower source than $\mathrm{CO}_{2}$.

\subsection{Conclusions}

In combination with the chemical differentiation of two fluorite generations (determined with ICP-MS analyses and visualized with cathodoluminescence microscopy), the fluid inclusion studies essentially contributed to the understanding of the timing of fluid and gas migration in the LSB with a special focus on $\mathrm{CH}_{4}$ and $\mathrm{CO}_{2}$, respectively. While brine composition did not show any specific changes during the evolution of the LSB, gas-bearing fluid inclusions with different gas $\mathrm{CH}_{4}-\mathrm{CO}_{2}$ ratios could be identified and assigned at distinct syndiagenetic and tectonic events. Especially the presence of heterogeneously trapped fluid inclusions in fracture-fill mineralization gives rise to the assumption of gas mobilization due to a) rifting $\left(\mathrm{CO}_{2}\right)$ and $\left.b\right)$ tectonic thrusting $\left(\mathrm{CH}_{4}\right)$.

In addition, our study allowed the refinement of existing numerical models. Particularly the mobilization of $\mathrm{CO}_{2}$ could be temporarily correlated with a stage of fracture propagation and fluorite precipitation. Thereby, we could prove the role of basin inversion for the formation of an individual fault block as a structural trap for $\mathrm{CO}_{2}$. As carbon isotopic ratios revealed the methane in the reservoir was very likely produced in coal-bearing sediments of Upper Carboniferous age and mobilized together with $\mathrm{CO}_{2}$ during late stage of burial in early Cretaceous, while the gas flux during basin inversion is characterized by methane. P-T reconstruction using crossing isochores method allowed to estimate an uplift of >1000 $\mathrm{m}$ of an individual fault block at the northern border of the LSB during late Cretaceous. 


\title{
5. Syndiagenetic stratabound fluorite in Zechstein carbonates (Ca2) from the Lower Werra Anticline - A shallow burial analogue for hydrothermal fluorite mineralization in the North German Basin?
}

\begin{abstract}
Core samples of Stassfurt carbonate rocks (Zechstein, Ca2) from various locations in the Lower Saxony Basin (LSB) often contain fluorite which occurs as pore filling cement, replacement fluorite, or as faultrelated fracture mineralization. Recent studies on fluorite geochemistry and fluid migration in the LSB suggest a sedimentary rather than a hydrothermal fluorite source for most of these deep-seated $(>2 \mathrm{~km})$ fracture-hosted accumulations. Outcrop samples of lens-shaped and stratiform fluorite occurrences within oolithic limestone (Ca2) near Eschwege (Hesse, Germany) give insight into syndiagenetic fluorite formation in Zechstein carbonates of the Lower Werra Anticline (LWA). Moreover, investigated sediment-hosted fluorites show evidence of fluid-controlled recrystallization that likely occurred at elevated temperatures and comparably low pressures in the vicinity of a volcanogenic hydrothermal system. They may therefore serve as a shallow-burial analogue for remobilized fluorite within carbonate rocks of the LSB that formed due to deep burial during basin extension in the Mesozoic.

Samples were studied by means of petrographic microscopy, hot-cathode cathodoluminescence microscopy (CL), microthermometry, and laser-ablation inductively coupled plasma mass spectrometry (LA-ICP-MS). Four different fluorite types were identified: a first generation (I) is represented by a very fine-grained dark brownish to violet fluorite that replaced algae remnants and ooids, and filled interparticle pore space during early diagenesis. As pressure and temperature increased during burial the replacement fluorite recrystallized forming aggregates of white fluorite that consists of parallel barshaped crystals (type II). Type (III) consists of white fluorite grains with rectangular and mostly polygonal grain boundaries, and type (IV), a colourless to blueish-violet pore-filling fluorite, is likely the result of local remobilisation. In-situ LA-ICP-MS analyses of respective fluorite types revealed relatively low REE concentrations in general with $\mathrm{Tb} / \mathrm{Ca}-\mathrm{Tb} / \mathrm{La}$ signatures that are commonly associated with sediment-hosted fluorite. REE distributions in fluorite reveal two distinct patterns of which one is characterized by a depletion in LREE, which may reflect a process of recrystallization and remobilization. Therefore, REE distribution in fluorite was probably controlled by crystallographic fractionation. Geochemical and microthermometric analysis proves that a first fluorite generation (typeI) formed due to precipitation from a sedimentary parental fluid during shallow to moderate burial ( $\leq$ $2 \mathrm{~km}$ ), as no external fluid input could be detected. While primary monophase aqueous fluid inclusions within type-I fluorite $\left(\mathrm{H}_{2} \mathrm{O}-\mathrm{NaCl}-\mathrm{H}_{2} \mathrm{~S}\right)$ prove low trapping temperatures, primary high-salinity fluid inclusions $\left(\mathrm{H}_{2} \mathrm{O}-\mathrm{NaCl}-\mathrm{H}_{2} \mathrm{~S}\right)$ trapped within recrystallized type-III fluorite are characterized by homogenization temperatures between $67^{\circ} \mathrm{C}->200^{\circ} \mathrm{C}$; associated halite daughter crystals show even higher melting temperatures $\left(>220^{\circ}\right)$, which usually correspond to burial depth of more than $6.5 \mathrm{~km}$. Primary gaseous fluid inclusions trapped within type-II fluorite that formed simultaneous to fluorite recrystallization, as well as secondary gaseous fluid inclusions, which postdate type-III fluorite, however, point at recrystallization at a relatively shallow position since both fluid inclusion assemblages $\left(\mathrm{CO}_{2}-\mathrm{CH}_{4}-\mathrm{H}_{2} \mathrm{~S}\right)$ homogenize to the vapour phase.

As a detailed comparison of microfabric features found in samples from the LSB and the LWA could prove, fluorite hosted within Stassfurt carbonate in the LSB locally also contain isolated patches of the brownish and bar-shaped syndiagenetic type-I fluorite. Since fluorite recrystallization is apparently
\end{abstract}


triggered by sufficiently high temperatures $\left(\geq 60^{\circ} \mathrm{C}\right)$, this observation suggests that temperatures in some areas of the LSB were likely not high enough for a complete recrystallization. Thus, fluorite recrystallization and remobilization were rather restricted to zones of intense hydrothermal fluid circulation and barely the result of deep burial.

\subsection{Introduction}

Sediment-hosted fluorite mineralization is known from several locations in Central Europe, for example limestone-hosted fluorite in Triassic units of the Alps (Schneider et al., 1975; Schneider, 1954) or stratabound fluorite form Zechstein carbonates in North Germany (e.g. Duschl et al., 2016; Füchtbauer, 1962; Möller et al., 1980; Quester, 1962; Schulz, 1980; Urbigkeit and Liebig, 1987), however, their genetic evolution often remains unclear. Though calcareous reservoir rocks provide both, pore space on one side and Ca-rich fluids on the other side, the according fluorine source as well as a genetic model are still often under debate. While many European fluorite(-barite) ore deposits are of magmatichydrothermal origin, microfabrics of Zechstein-related fluorite occurrences in the Southern Permian Basin of Germany, which are mostly known from drill-core samples, show evidence for a syndiagenetic fluorite formation (Schulz, 1980). A unique well-exposed stratiform fluorite occurrence near Eschwege (Hesse, Germany), first discovered during geological prospection in 1974 and subsequently investigated and described by List (1975), allows to examine syndiagenetic fluorite formation in several road cuts. First observations were complemented by a detailed mapping of the extent of the mineralized zone as well as geochemical investigations (Ziehr et al., 1980; Ziehr et al., 1978) (Ziehretal.,Æ. Furthermore, three core drillings carried out in the study area could prove the stratiform nature of the fluorite occurrence and revealed that its distribution is not restricted to $\mathrm{Ca} 2$ (Hauptdolomit/Stassfurt carbonate) units, but also involves $\mathrm{Ca} 3$ (Plattendolomit). In addition, mostly colourless pore-filling fluorite, as well as bluish-violet fracture-filling fluorite could be confirmed from a quarry near Vockerode, in the immediate vicinity of the Hoher Meissner volcano, therefore extending the previously known fluorite distribution to the west (Duschl et al., 2017; Wischhöfer, 2015). Interpretation of microfabrics suggests a continuous impregnation of the highly porous (ca. 26\%; Füchtbauer, 1962) Stassfurt carbonate and simultaneous replacement of aragonitic ooids and dolomitic oncoids forced by the intrusion of a fluorine-saturated fluid, likely during early diagenesis (List, 1975). Thereby, more porous and ooid-rich layers resulted in higher concentrations of dark fluorite, which contrast with bright dolomitic areas that are likely less permeable. This gives the rock the optical impression of a (pseudo-) layered fabric, but in fact the original rhythmic bedding is simply highlighted thereby. According to Ziehr et al. (1980), the characteristic dark brownish to black colour is caused by incorporation of organic matter (bitumen). Beside microfabric features, the near-total absence of other (hydrothermal) minerals typically accompanying fluorite mineralization such as barite or celestite, as well as the lack of evidence for hydrothermal fluorite directly associated with the dark "oncolithic fluorite" (List, 1975) clearly point at a synsedimentary formation mechanism.

A first genetic model for the formation of stratabound syndiagenetic fluorite within Stassfurt carbonates (Ca2) in the North German Basin was established by Möller et al. (1980) (Fig. 5.1). According to this model, $\mathrm{F}^{-}$-enrichment took place within the lagoon of a shallow marine environment, where either evaporation of seawater or influx of fluorine-rich waters from the nearby mainland resulting from erosion of granitic rocks, or both caused $\mathrm{F}^{-}$-concentration in a high saline brine. As the lagoon was separated from the open sea by a barrier reef consisting of porous limestone, fresh sea water influx into the lagoon also occurred via this porous reef limestone. Thereby, high density brines saturated with 
$\left[\mathrm{MgF}^{+}\right]$coordination complexes mixed with low-density seawater within the open pore space of the reef. Subsequent fluid mixing forced dissolution of the complexes and lead to dolomite $\left(\mathrm{CaMg}\left[\mathrm{CO}_{3}\right]_{2}\right)$ formation. Now free fluorine precipitated as fluorite $\left(\mathrm{CaF}_{2}\right)$ under consumption of excess calcium.

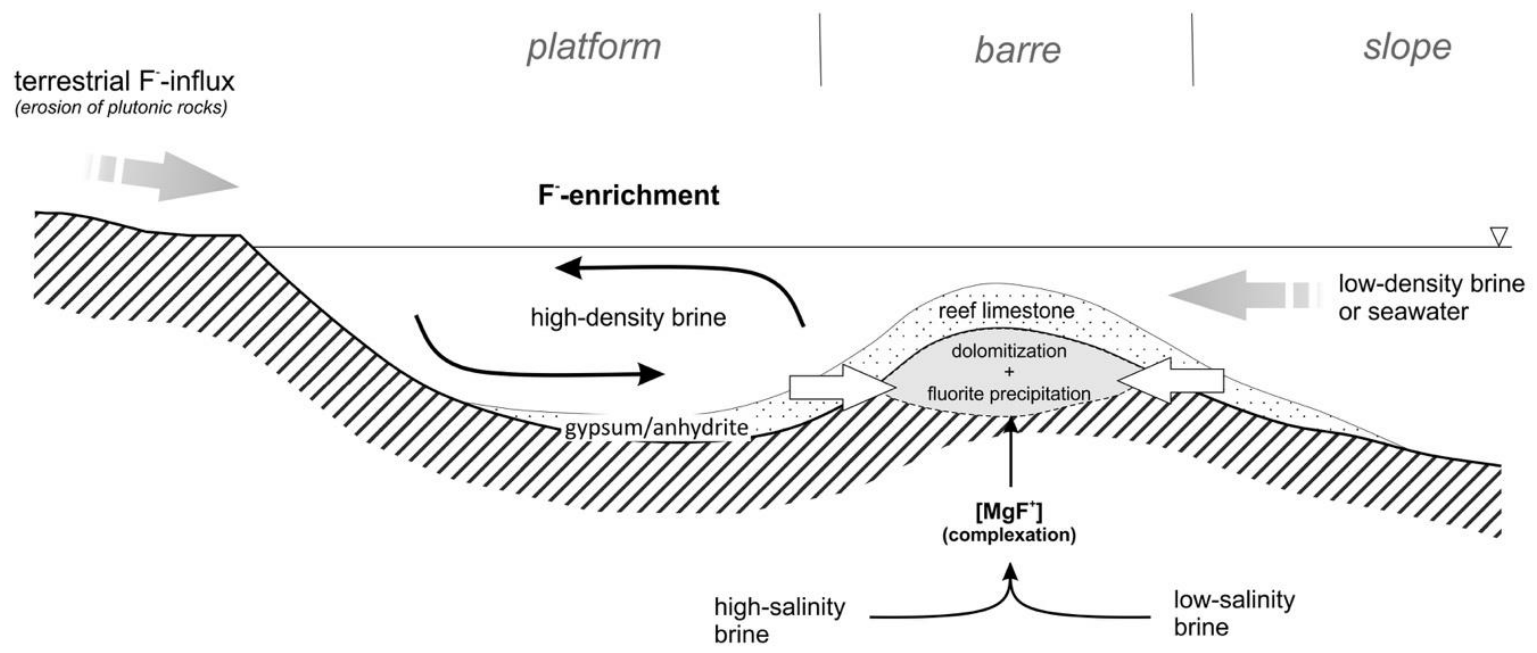

Fig. 5.1. Schematic illustration of a synsedimentary fluorite formation model in algae- and ooid bearing litoral sediments during early diagenesis as introduced by Möller et al. (1980). Fluorite (CaF $\left.F_{2}\right)$ precipitation occurs within reef limestones when previously formed $\left[\mathrm{MgF}^{+}\right]$-coordination complexes are consumed during dolomite $\left(\mathrm{CaMg}\left[\mathrm{CO}_{3}\right]_{2}\right)$ formation. The fluorine source is still under debate, it may derive from seawater itself (evaporation) or it may be a result of the erosion of granitic rocks, but also the alteration of Rotliegend volcanics in the basement units may play a role.

Other possible fluorine sources, such as $\mathrm{F}^{-}$-rich volcanic tuffs as described by Schneider et al. (1975) for the east-Alpine mid-Triassic sequences are missing in the study area. Moreover, a comparative geochemical analysis of $\mathrm{Ca} 2$-hosted fluorites from the LSB clearly proved that $\mathrm{Tb} / \mathrm{Ca}$ vs. $\mathrm{Tb} / \mathrm{La}$ ratios of all investigated samples relate to parental fluids of sedimentary origin (Schneider et al., 1975; Schulz, 1980). Richardson and Holland (1979a) made a first attempt to describe the major factors governing fluorite precipitation in hydrothermal systems, where a decrease in temperature (and pressure) seems to be a key mechanism, especially in Mississippi-Valley-type deposits. A sudden decrease in both pressure and temperature within a sedimentary reservoir is often restricted to faulting and fracture-propagation, when hydraulic contact between different reservoirs is established. Such a scenario can be confirmed for fluorites from the LSB, where remobilized fluorite fills fractures that result from brittle deformation during basin evolution (Duschl et al., 2016). Though not being mentioned in previous studies, similar fracture-hosted fluorites are known from Stassfurt carbonate rocks in the LWA; however, they clearly postdate brownish stratiform fluorite.

As Schneider et al. (1975) have established a detailed classification for diagenetic fluorite from the EastAlpine area, various authors have grouped the fluorite from Eschwege into several types according to their microscopic appearance (List, 1975; Ziehr et al., 1980; Ziehr et al., 1978). However, a new classification seems appropriate as some aspects of this specific fluorite mineralization such as the presence of (a) white or colourless fluorite with polygonal grain boundaries, (b) recrystallization and remobilization features, and (c) aqueous and gaseous fluid inclusion have not been identified before. 
Therefore, we provide a detailed inventory of fluorite microfabrics and related fluid inclusions with the aim to reveal temperature conditions during formation and subsequent recrystallization/-mobilization, as well as the chemical composition of corresponding fluids and their role during recrystallization. As first investigations could confirm similarities between syndiagenetic fluorites from the (deeply-buried) LSB and the LWA in terms of microfabrics (recrystallization fabrics), our study is supposed to develop a simple tool for temperature estimation in the LSB by means of fluorite recrystallization fabrics.

\subsection{Geological setting and study area}

The geological evolution of the Southern Permian Basin in general and the North German Basin (NGB) in particular have already been introduced in detail in Chapter 5. Therefore, in this chapter we focus on the sedimentary record and the tectonic evolution of the LWA and adjacent areas. The LWA is located in the so-called Hessian Depression, a prominent structural element between the Rhenish Massif in the west and the Bohemian Massif in the east, which formed a major depocenter during the late Permian and the Triassic (Pharaoh et al., 2010). Thereby, erosional products from the surrounding massifs were accumulated within the depression, resulting in sedimentary strata of significant thickness. Until the end of mid-Jurassic, the Hessian Depression connected the northern sub-basin of the NGB with its southwestern equivalent, forming a marine channel. During late Jurassic and likely early Cretaceous the Hessian Depression was uplifted and exposed to erosion (Meyer and Schmidt-Kaler, 1996), until structural reactivation and crustal rearrangement due to local graben formation accompanied a new phase of subsidence, which probably prevailed until Cenozoic times (Pharaoh et al., 2010, and references therein). During the late Permian (Zechstein) the study area was located along the southern shoreline of the Zechstein sea; its depositional environment was dominated by shallow-water facies (Füchtbauer, 1962) (Fig. 5.2). Just like the southern and central LSB, Zechstein sediments of the LWA mostly consist of fine-grained dolomitic limestones that relate to a shallow-marine environment between the mainland in the south, and barrier reefs and off-coast islands in the north. Locally, oolithic and oncolithic facies confirm a temporary influence of a lagoonal sedimentary environment (Flügel, 2004).

The stratigraphy of the study area is documented in detail in Jacobshagen et al. (1993a), while a detailed lithostratigraphic sequence of sedimentary rocks accessible in road cuts in the LWA is given by Ziehr et al. (1980) (Fig. 5.3). According to their studies, oldest Permian units (C1, Zechstein Conglomerate) are of marine origin and characterized by a transgression cycle; they thereby unconformably superimpose folded metamorphic rocks of supposedly upper Devonian age. Sediments of Rotliegend age are scarce and only preserved within small NNE-SSW striking graben systems, e.g. in the northern LWA (Möbus, 2004). 


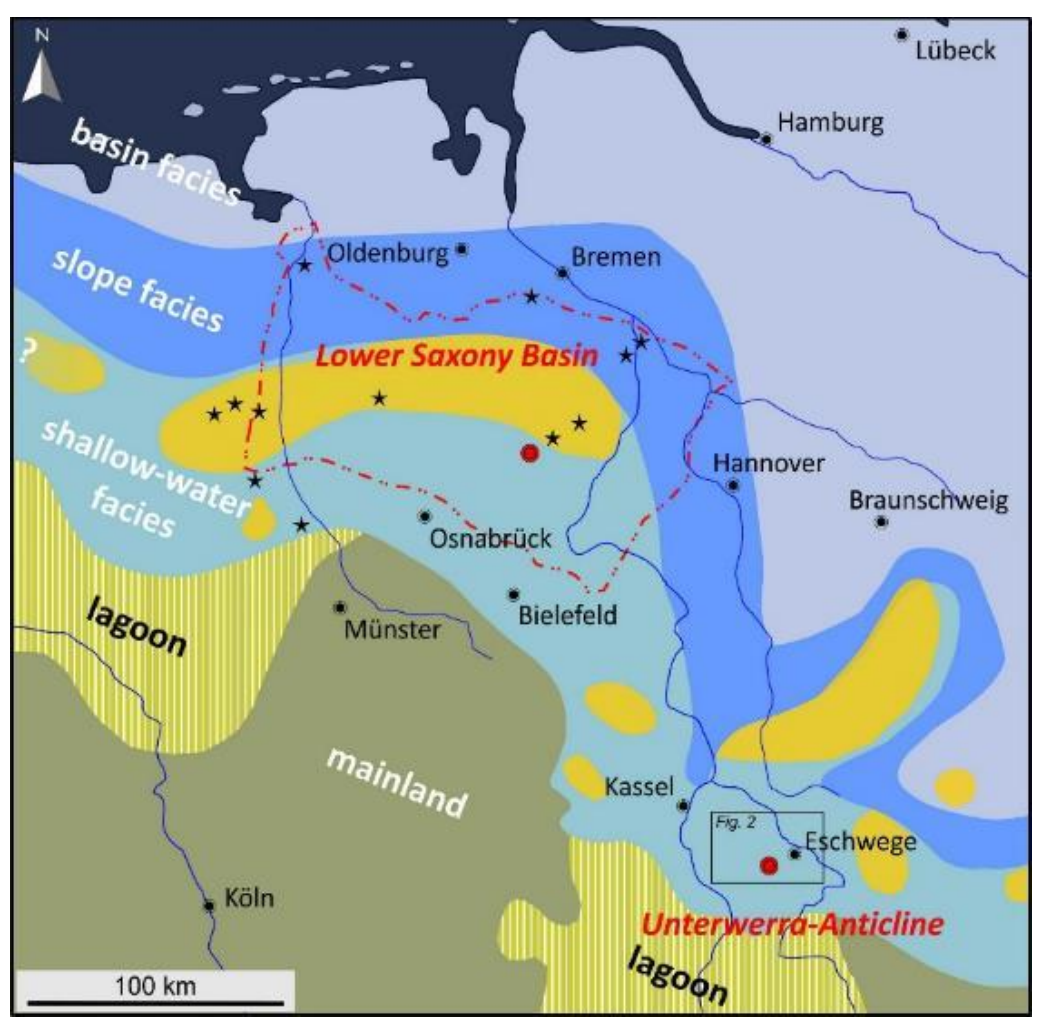

Fig. 5.2. Facies distribution map of Stassfurt carbonate rocks in north Germany. The extent of the Lower Saxony Basin is marked by a red dashed and dotted line, sampling locations of samples considered for this study are indicated by red dots. Oolithic and algae-dominated limestone are shown in orange colours, black stars mark wells with fluorite-rich Stassfurt carbonates (modified from Füchtbauer, 1962; Schulz, 1980).

Thus, most deposited Rotliegend strata were eroded prior to transgression of the Zechstein sea, when the whole area was continuously rising during Rotliegend times, forming the so-called EichsfeldAltmark-Swell (Paul, 1993). The C1 conglomerate then is overlain by a characteristic series of Zechstein units consisting of Copper Shale (T1), Zechstein Limestone (Ca1), and Werra Anhydrite (A1), altogether having a total thickness of ca. $35 \mathrm{~m}$. It is then superimposed by the Stassfurt Carbonate (Ca2), consisting of clay-gypsum-breccias resulting from subrosion along the contact to the Werra Anhydrite, followed by dolostones and dolostone-breccias at the top; fluorite-bearing layers and lenses are mostly restricted to the upper parts of the unit (total thickness: ca. $35 \mathrm{~m}$ ). The clays of the Lower Letten (T3), the locally fluorite-bearing dolostones of the Platy Dolomite (Ca3), and the locally gypsum and anhydrite-bearing clays of the Upper Letten (T4) complete the Zechstein sequence in this area (total thickness: ca. $55 \mathrm{~m}$ ). The Zechstein units are superimposed by medium- to fine-grained sandstones of the Lower Buntsandstein. Lower Triassic units are rare in the LWA, but are common in the surrounding areas, having likely covered the whole area prior to uplift and simultaneous folding of the anticline. Other Lower Triassic (Buntsandstein) and Middle Triassic units (Muschelkalk) are present as well in the Hessian Depression with a total thickness of up to $700 \mathrm{~m}$ in the study area. 
Chapter 5 - Syndiagenetic stratabound fluorite in Zechstein carbonates (Ca2) from the LWA

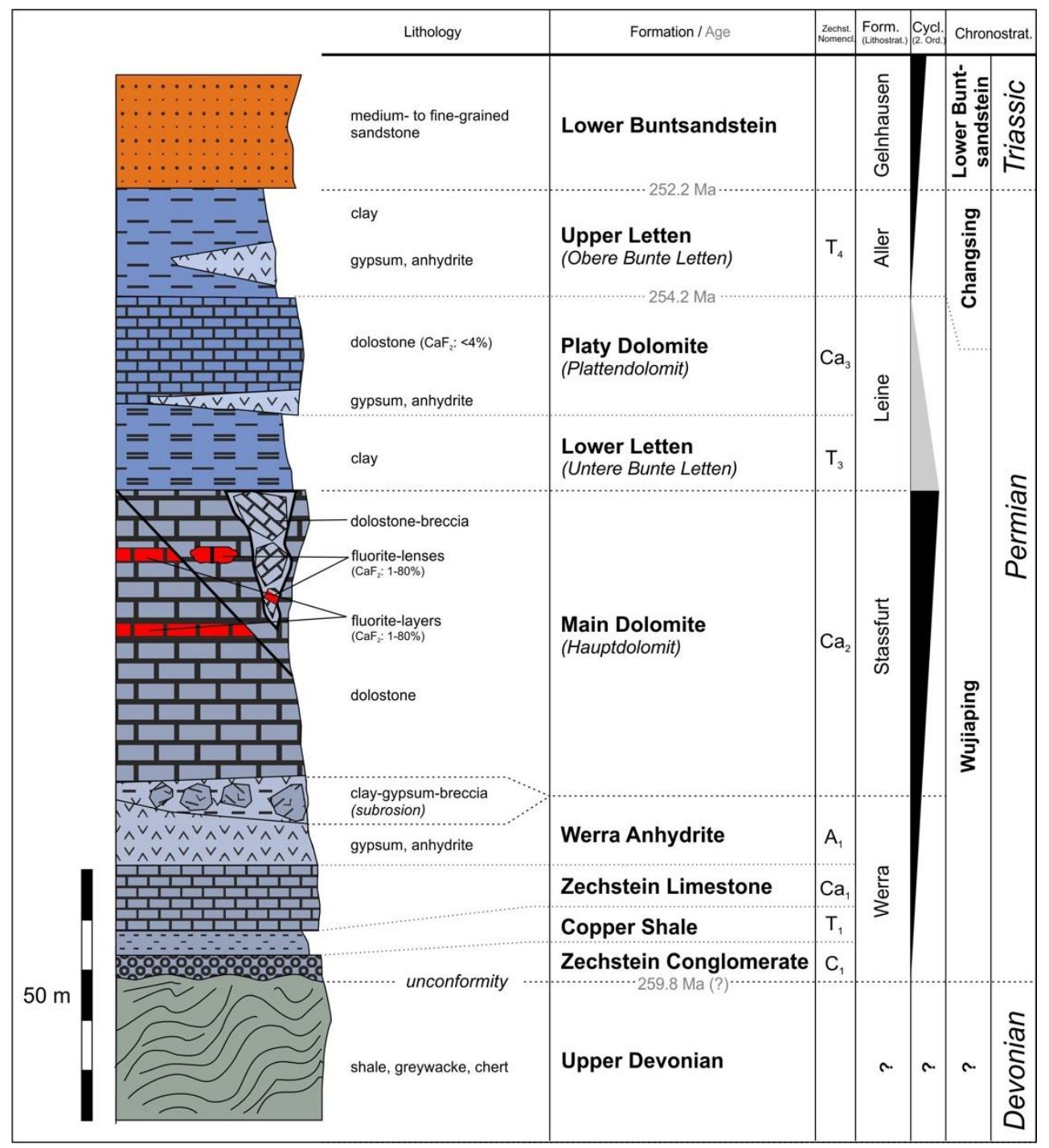

Fig. 5.3. Lithostratigraphic chart of mainly Zechstein units found in outcrops in the LWA (modified from Ziehr et al., 1980).

Keuper sediments however are only known from nearby graben systems (e.g. Lichtenau-Graben), but are described as reaching a thickness of up to $350 \mathrm{~m}$. Jurassic and Cretaceous units are completely missing in the study area, but were likely present to some extent, as locally reworked sediments prove (Jacobshagen et al., 1993a); the total extent and thickness of respective sediments remain unknown. Sedimentation during the Tertiary was comparatively low, total thickness of clastic sediments did probably not exceed a few hundred meters, as sedimentary rocks at the Hoher Meissner suggest. More important was the volcanic activity in the area during the Cenozoic (e.g. Wedepohl, 1985), when prominent volcanoes such as the Hoher Meissner or the Blau Kuppe formed (Fig. 5.4). Especially the Blaue Kuppe, a small volcano seemingly stuck within Triassic Buntsandstein, is best known for the formation of a contact aureole during intrusion of basaltic magmas into the wall-rock (Koritnig, 1978). Another small, barely known volcano called Rosenbühl, located between the Hoher Meissner in the west and the Blaue Kuppe in the east marks the closest point of volcanic activity to the fluorite-bearing Zechstein units (distance: ca. $1800 \mathrm{~m}$ ). Besides, neither volcanoes are known within the pre-Mesozoic units of the LWA nor north of the imaginary line between the three volcanoes mentioned above. 
The tectonic evolution of the Lower Werra Anticline, a doubly kinked NW-SE striking, NE-vergent anticline, was the object of several detailed studies, but is still under debate among structural geologists. As Möbus (2004) presented in his study, four possible scenarios for folding and uplift of the anticline exist, of which only one seems plausible in this context. A first attempt to explain the tectonic structure was given by Schubart (1955) who simply implies that the anticline results from not further defined 'polyphase post-Zechstein tectonics'. Holzapfel (1998) instead supposed uplift during late Jurassic-early Cretaceous along 'hercynian', i.e. WNW-ESE or NW-SE striking faults. The morphology of the LWA, as well as the overall strike of the northern boundary fault together with the fact, that the area was a structural high exposed as an island during late Jurassic-early Cretaceous do actually support this model, however, a tectonic mechanism for according intra-plate deformation at that time is missing. Gundlach and Stoppel (Gundlach and Stoppel, 1966; Stoppel and Gundlach, 1978) in addition proposed uplift and brittle deformation during tectonic compression in the Cenozoic, but again a coherent structural mechanism is not evident. Finally, Möbus (2004) himself introduced a fourth scenario, which appears more appropriate: folding due to inversion tectonics during late Cretaceous-early Paleogene. This formation mechanism is in good agreement with regional intra-continental tectonics that caused many uplift structures related to reverse faulting along similar WNW-ESE striking faults, such as the Harz Mountains, the Flechtingen-Calvörde Block, or the Osning Thrust in the LSB, to name a few (Pharaoh et al., 2010).

It is not clear if the northern boundary fault of the LWA is in fact a normal fault of Jurassic age or older, which was reversed during compression, as proposed by Möbus (2004). However, no according fault exists on the southern flank of the anticline, which rules out the existence of an inverted graben system similar to the LSB. Vertical uplift of ca. $500 \mathrm{~m}$ along the northern boundary fault was inferred from lithostratigraphic comparison of units exposed along the fault zone (Devonian greywacke against Buntsandstein) (Möbus, 2004). A set of smaller, conjugate WNW-ESE and NNE-SSW striking faults likely relates to an extensional deformation phase during the Cenozoic, as most volcanoes in the Eschwege area seem to be linked to this predominant fault system.
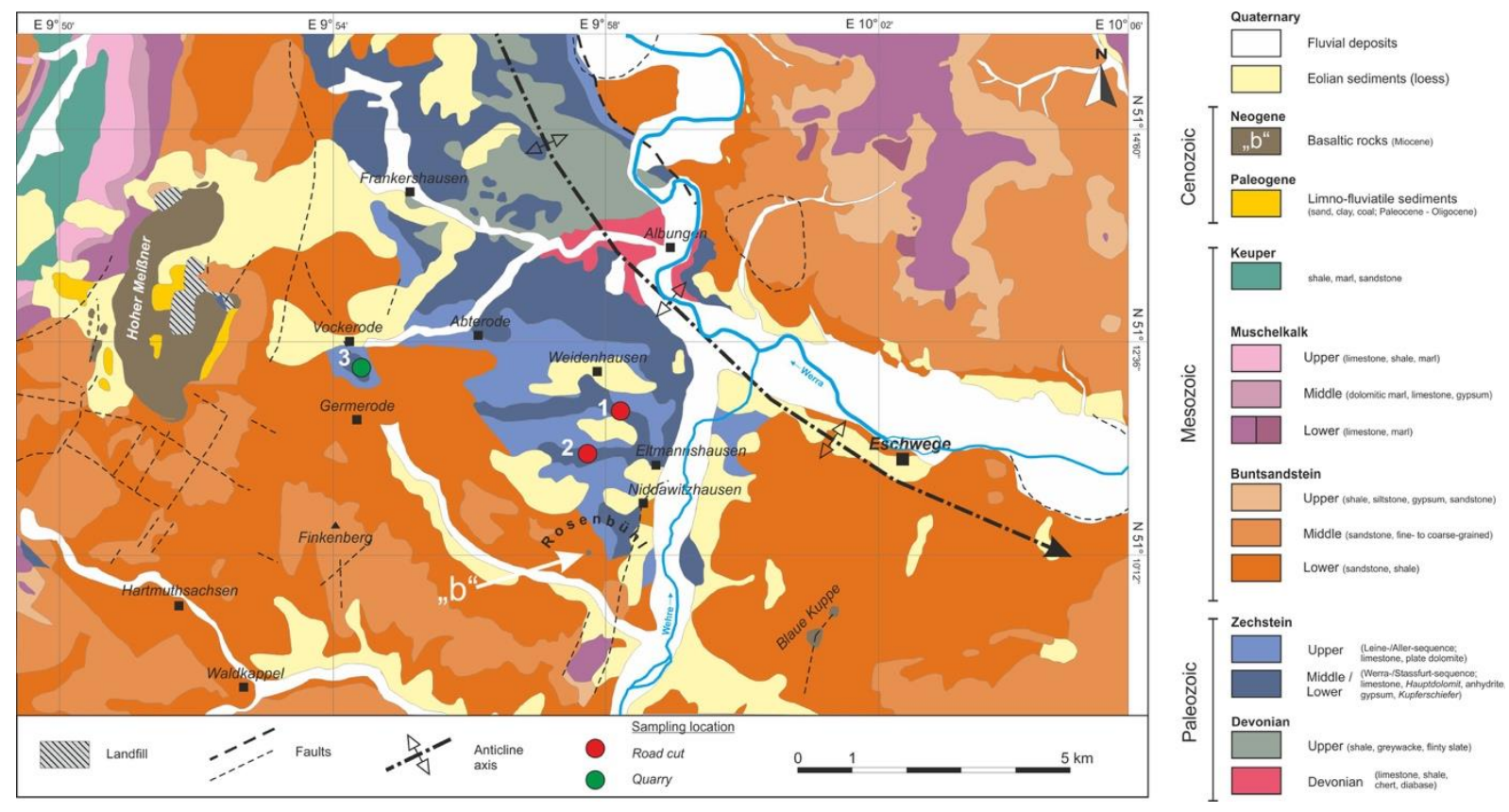

Fig. 5.4. Geologic map of the Eschwege area. Samples come from two road cuts at the southern end of the LWA, indicated by numbers 1 and 2, the Rosenbühl volcano is marked by a white arrow. Another fluorite 
Chapter 5 - Syndiagenetic stratabound fluorite in Zechstein carbonates (Ca2) from the LWA

occurrence characterized by mostly colourless or bluish-violet pore- and fracture-filling fluorites is known from a quarry near Vockerode (3) (modified from Jacobshagen et al. (1993a) and Ritzkowski (1978)).

\subsection{Results}

\subsubsection{Petrography}

Investigated rock samples come from two outcrops (road cuts) in Ca2-carbonates (Fig. 5.4; 1 \& 2) of the southern LWA and consist of layered dolomitic, ooid-bearing carbonate, which is impregnated with or partly replaced by dark brown to black or dark violet fluorite. While the outcrop in sampling location 1 shows a single fluorite-bearing layer (thickness: 6-8 cm) with clearly defined vertical dimensions and unknown lateral extent (Fig. 5.5-a), fluorite in location 2 occurs as lens-shaped bodies within a single ooid-bearing layer very similar to the one found in location 1 (Fig. 5.5-b). However, the latter fluoritebearing layer is characterized by a limited lateral extent varying between 30 and $50 \mathrm{~cm}$, and all respective lenses are related to cavernous and seemingly brecciated, locally fractured areas within the otherwise massive Stassfurt carbonate. Fluorite in location 2 is locally truncated on top by beddingparallel stylolites, which often show slickenfibers consisting of violet fluorite. Its lateral extent is characterized not by mechanical displacement or changes in sedimentary facies; it rather tends to gradually merge into fluorite-free (i.e. yellowish-white) dolomitic carbonate.

Sampling was not restricted to areas impregnated with dark fluorite, but also involved adjacent, seemingly fluorite-free areas (see Fig. 5.5-b). Microscopic analysis thereby revealed, that fluorite from location 1 mostly consists of extremely fine-grained, dark brown to violet fluorite, while samples from location 2 contain fluorite of various colour and grain size. Besides, the presence of fluorite in samples from location 2 could also be confirmed in the lateral extension of the dark lens (Fig. 5.5-b; spot (b)), as well as in the apparently fluorite-free dolomitic carbonate below the lens (Fig. 5.5-b; spot (c)). However, no fluorite was found beyond the stylolite that locally marks the upper layer-boundary. Fig. 5.5-c illustrates the distribution of different fluorite varieties in a sample from the lateral transition zone of a fluorite lens in location 2. Open pore space, which is likely the result of anhydrite dissolution, shows an irregular distribution; locally, single pores are filled with colourless or violet fluorite. 


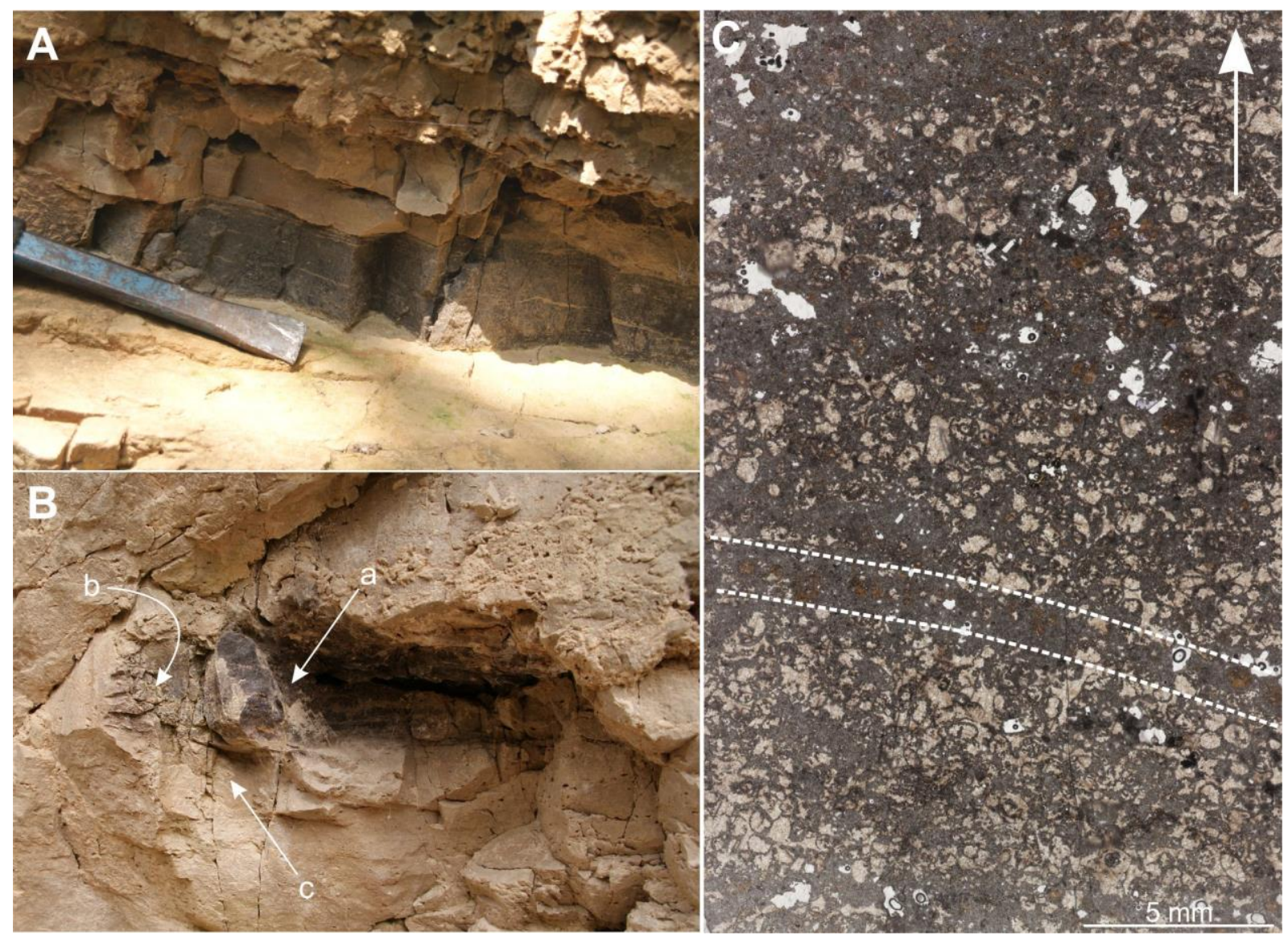

Fig. 5.5. (A) Field image showing a single layer of ooid-bearing Ca2 carbonate, which mostly consists of dark brown or black fluorite and bright dolomite (sampling location 1). (B) Dark fluorite from sampling location 2 is restricted to small lens-shaped bodies that still exhibit features of a layered fabric and bedding planes (a). However, the lateral extent of the fluorite-bearing layer is limited and continuously merges into common dolomitic limestone. (C) Thin section scan of a Ca2-sample from the lower parts of a fluorite lens from sampling location 2 (spot $(c)$ in image $(B)$ ). The grey material consists of fine-grained dolomite crystals; bright areas show colourless to dull yellowish fluorite. Brown areas also consist of fluorite, but are scarce in this sample; it is often restricted to layers (between dashed white lines) or clusters, that are separated from bright fluorite by pressure solution seams or dolomite. In this sample, the occurrence of brown and violet fluorite increases towards the top (arrow points upwards).

\subsubsection{Microfabrics}

Microscopic analysis of fluorite varieties allowed us to distinguish and characterize four different fluorite types by means of colour, grain-shape and -size, and relative age of formation. Type-I is a brown or brownish-violet, (extremely) fine-grained fluorite, which filled inter- and intra-particle pore space, and also replaced aragonitic ooids (Fig. 5.6-a). It is furthermore characterized by a relatively high fluidand solid-inclusion density. Type-II fluorite consists of white bar-shaped or lath-shaped crystals that are typically about $100 \mu \mathrm{m}$ long and between 2 and $20 \mu \mathrm{m}$ wide (Fig. 5.6-b). Crystals are locally isolated within type-I fluorite or form parallel aggregates, or aggregates perfectly perpendicular to each other, but they are always surrounded by or adjacent to type-I fluorite. Wherever type-II crystals agglomerate they are often accompanied by a rim of violet fluorite that usually concentrates between white crystals of type-II and brown type-I fluorite (Fig. 5.6-c). Fluorite of type-III forms a fabric of white or colourless crystals of eventually equigranular-polygonal shape, which apparently result from complete agglomeration and subsequent coalescence of type-II aggregates (Fig. 5.6-c/d), the size of resulting 
fluorite grains ranges between 10 and $200 \mu \mathrm{m}$. Grain boundaries, which often show $120^{\circ}$ angles, are traced by residual brown matter that was probably exsolved from type-I fluorite during progressive recrystallization (accretive crystallization). Type-IV fluorite is a late pore- and fracture-filling fluorite that is typically colourless or contains irregular violet spots and locally exhibits violet concentric growth zoning. It is likely a remobilized fluorite as it fills pores that were previously filled by soluble minerals such as anhydrite, as angular pores, which resemble angular crystal shapes, suggest. Dolomite crystals can be grouped into two generations, of which one is likely the result of dolomitization during early diagenesis. Early fluorite is grey in transmitted light and consists of anhedral or locally subhedral crystals with cloudy, inclusion-rich cores; their size ranges between 5 and $15 \mu \mathrm{m}$. A second dolomite generation consists of pore-lining euhedral, colourless crystals that are restricted to pores that were subsequently filled with type-IV fluorite. Just like the fluorite, they likely relate to late-diagenetic fluid activity and subsequent remobilization, which is in good agreement with observations made by Smykatz-Kloss (1966). In fact, late-diagenetic dolomite forms syntaxial overgrowth on early-diagenetic dolomite crystals. Microscopic evidence cannot clearly determine the age relation between early dolomite and type-I fluorite, however, dissolution features along fluorite-dolomite crystals as well as isolated and partly dissolved dolomite crystals within fluorite point at dolomitization prior to fluorite precipitation. Beside minor amounts of pyrite that locally occurs close to secondary pores that formed due to dissolution, no other minerals were detected in our samples. Age correlations suggest pyrite formation prior to type-IV fluorite precipitation.
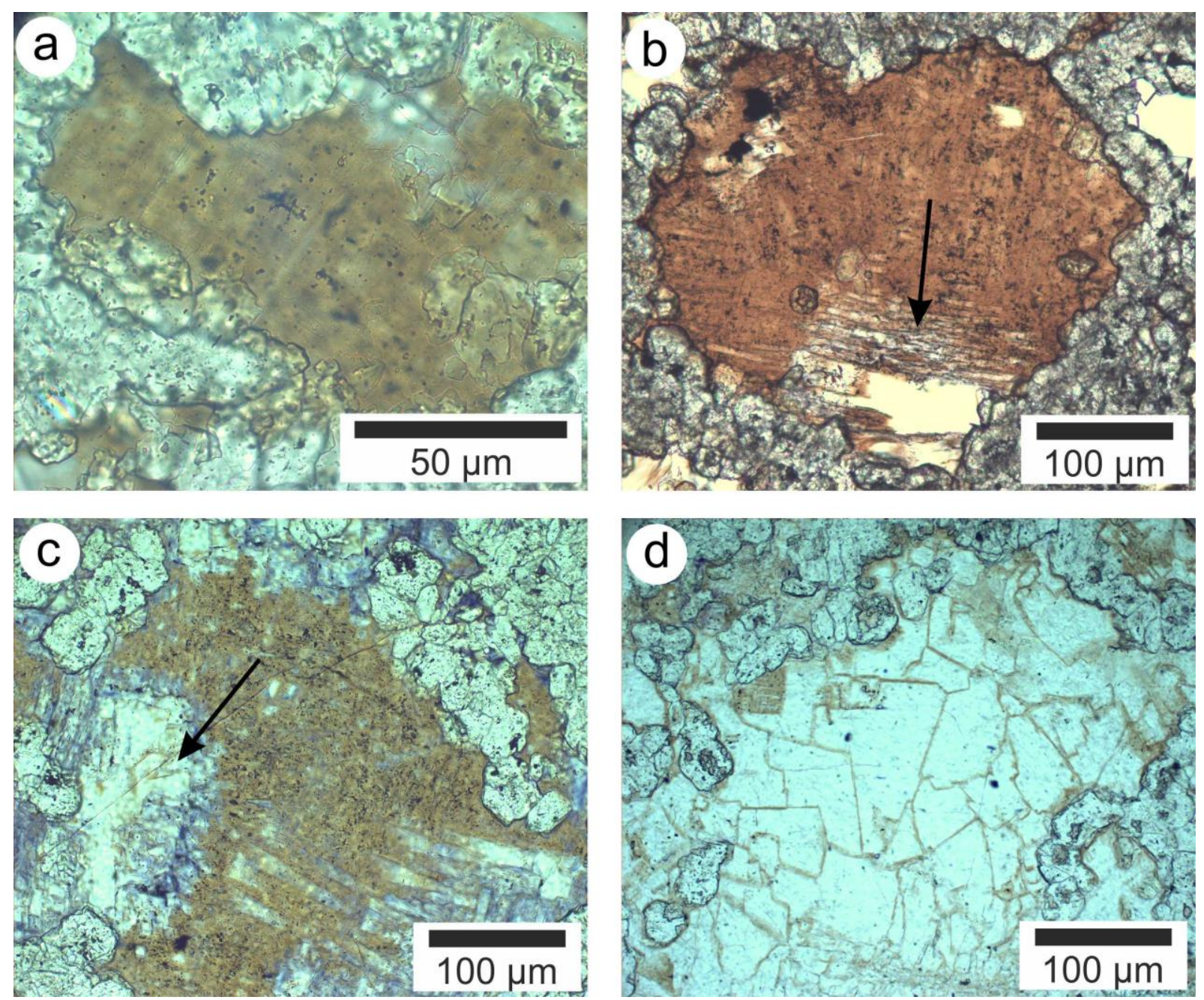
Fig. 5.6. Though fluorite occurs in various forms at the locality, the focus of this study lies on synsedimentary to early-diagenetic fluorite that replaced algae remnants and aragonitic ooids, and filled interparticle pore space in the Zechstein carbonate. It can be subdivided into three groups: (a) brown or violet, impurity-rich replacement fluorite (type I), (b) aggregates of parallel, bar-shaped or fibrous crystals with brown to violet grain boundaries (type II), and (c) white fluorite grains with rectangular to mostly polygonal grain boundaries (type III). Type (III) is the product of merged type-(II) crystal aggregates. Figure (d) shows a fabric of polygonal inequigranular fluorite grains, note the presence of $120^{\circ}$ angle grain boundaries. All images were taken from the same sample.

Where fluorite recrystallization has progressed so far that only type-III fluorite is present, the grainsize of recrystallized fluorite is locally decreasing towards straight lines that resemble fractures or grain boundaries (Fig. 5.7-a/b). These linear features, which consist of (mostly cubic) fluorite grains as well contain solid and - to a lesser extent - fluid inclusions of mostly irregular shape that are arranged between grain boundaries; the size of respective inclusions barely exceeds $2 \mu \mathrm{m}$. As grainsize decreases towards these linear features, inclusion density increases, thus pointing at a mechanism that hinders progressive grain-growth due to the presence of impurities. These linear features, which never crosscut barriers of dolomitic matrix or dolomitized shell fragments, always join or intersect under $45^{\circ}$ or $90^{\circ}$ angles and thus suggest a crystallographic rather than a mechanical formation mechanism.
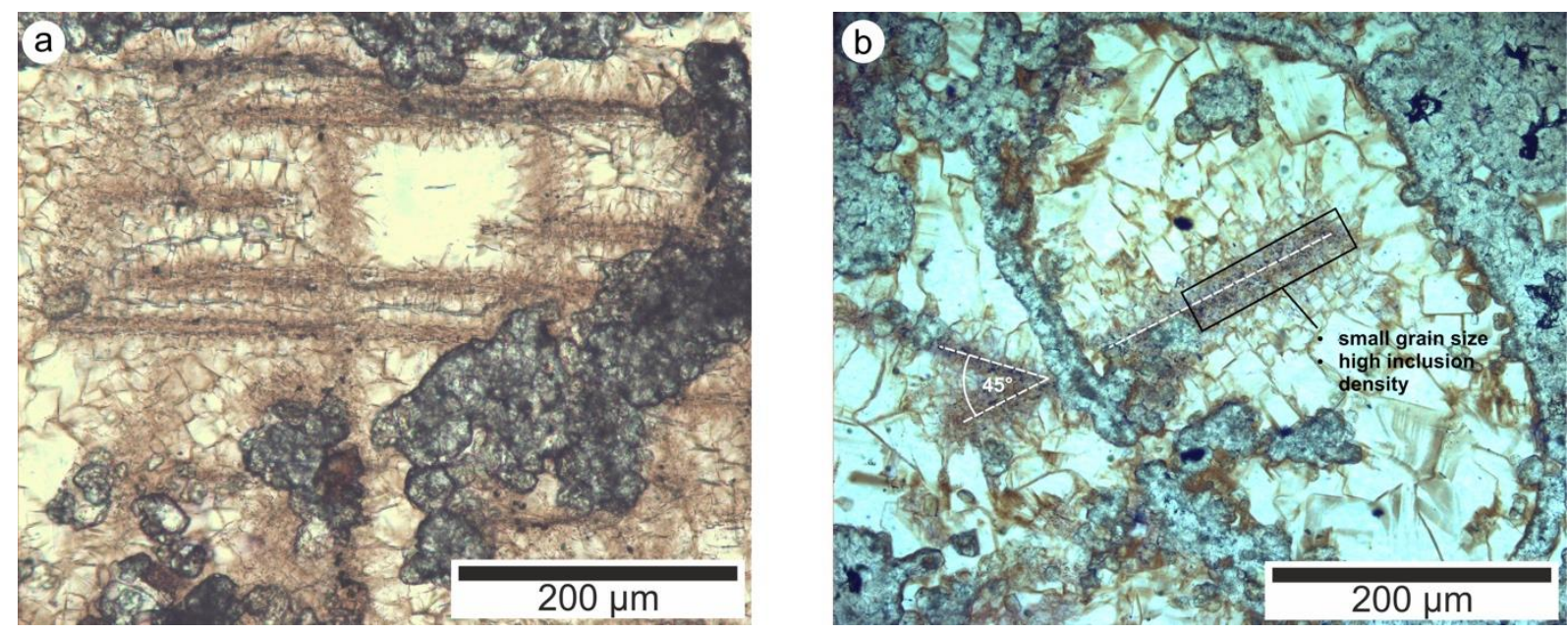

Fig. 5.7. (a) Type-III fluorite aggregates showing a strong differentiation between inequigranular polygonal fluorite grains (white) and minute equigranular grains with mostly cubic shape (brownish). Small crystals are arranged along straight lines that formed parallel to the major stress directions. Angles between lines are usually $90^{\circ}\left(\right.$ or $\left.45^{\circ}\right)$ suggesting a crystallographically controlled recrystallization mechanism. (b) Aggregates of recrystallized fluorite grains (type-III) within a dolomitized shell. White dashed lines mark areas of fine grained, impurity-rich fluorite grains, where further recrystallization has stopped due to increasing impurity density. Dolomite crystals are not affected by these linear features; thus fractures can be clearly ruled out as a responsible mechanism. Note how grain size gradually decreases towards the lines.

\subsubsection{Cathodoluminescence microscopy}

Cathodoluminescence microscopy of different fluorite and dolomite types was carried out in order to reveal differences in composition and to identify growth mechanisms such as zoning features, as well as to clarify age relations. Thereby, a correlation between type-I fluorite and fine-grained fluorite within linear recrystallization-zones (see Fig. 5.7-b) could be identified, as both are characterized by dull CL 
and locally non-luminescent behaviour (Fig. 5.8), which in general suggests extrinsic quenching due to incorporation of impurity atoms $(\mathrm{Fe}, \mathrm{Mg})$ or organic matter. Whereas on the other side, type-II/III and IV fluorites all show intense blue CL, which in fluorites is commonly produced by REE-activation (Marshall, 1988). Growth zoning is only apparent in pore-filling type-IV fluorite, where REE and trace element-activated CL traces concentric growth zoning visible in transmitted light. Both dolomite types identified in transmitted light show the same magenta CL typically known from Mg-rich carbonates, which suggests a late dolomite-precipitation from a remobilized fluid phase.

As evident from Fig. 5.8-a, intense electron irradiation (accelerating voltage: 14kV) produces lattice defects in some fluorites, leading to discolouration of otherwise colourless specimen. This effect, referred to as 'decoration` is probably caused by voids or point-defects within the fluorite crystal lattice (Wilkins and Bird, 1980a, 1980b), when $\mathrm{F}^{-}$is emitted due to collision of high-energy primary electrons, thus resulting on colloidal calcium that likely produces the blue or violet hue (Dill and Weber, 2010).
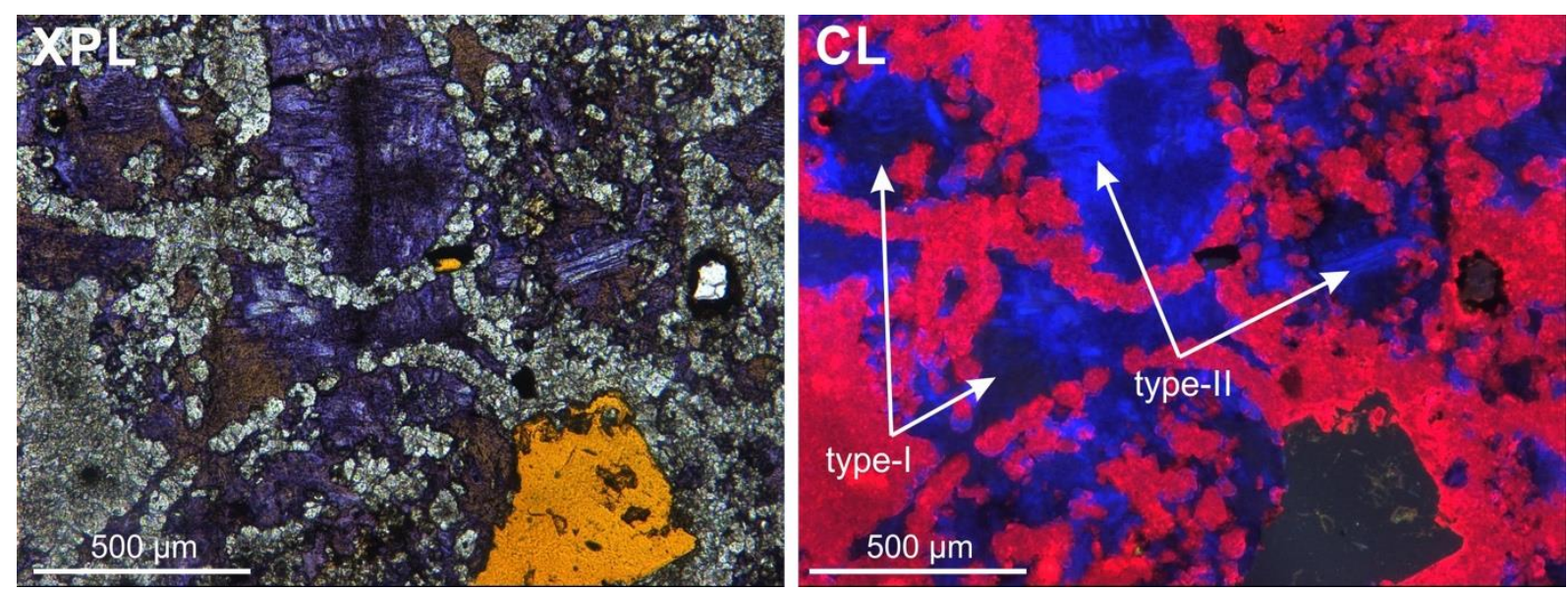

Fig. 5.8. Detail image of fluorite-bearing dolomitic limestone from location 2 showing both, type-I and adjacent type-II fluorite in transmitted light $(L P L)$ and cathodoluminescence $(C L)$. While brown type-I fluorite exhibits only dull blue luminescence and locally even appears non-luminescent, type-II fluorite is characterized by bright blue CL. Note, how fine-grained linear recrystallization-zones in type-II fluorite remain dark as well. In transmitted light, type-II fluorite shows violet colour due to electron irradiation. The orange area with angular shape on the lower right side of the image is epoxy resin that fills residual pore space of a dissolved mineral (anhydrite or halite). Dolomite typically shows magenta CL.

Though the effect responsible for fluorite decolouration is not finally clarified, the decoration of fluorite due to electron irradiation reveals otherwise invisible features that even remain hidden to $\mathrm{CL}$ microscopy. Fig. 5.9 presents several crystallographic features found in both, primary (type-I) and recrystallized (type-II/III) fluorites that can only be detected with electron-induced decoration. Fig. 5.9-a demonstrates how barely visible isolated bar-shaped type-II fluorite crystals are highlighted in blue after electron irradiation. Thereby, the orthogonal orientation of respective crystals, which follows the cubic fluorite crystal structure, becomes most evident. Fig. 5.9-b shows a prominent type-III fluorite grain, which actually consists of several smaller grains or subgrains, as decoration of grain-boundaries and zoning features reveals. Since fluorite is isotropic and thus remains dark in crossed polarized light, this is probably the easiest way to identify subgrains in this mineral. Fig. 5.9-c proves significant zoning in recrystallized type-III fluorite as well as a significant fluid inclusion trail, which is aligned within a subgrain-boundary. Fig. 5.9-d shows decoration of three different fluorite types (I/II/III) adjacent to each 
other, thereby proving that especially type-II fluorite seems to be affected by electron irradiation the most. As decoration mostly seems to affect areas with relatively high lattice-defect density, fluorite decoration probably helps to identify zones of highly disordered crystal lattices. Another explanation for areas prone to artificial decoration may be trace element incorporation, which cannot be resolved with applied methods. However, our observations support the idea of recrystallization and grain coarsening along with grain surface reduction and simultaneous exsolution of impurity atoms, organic matter and trapped fluids.
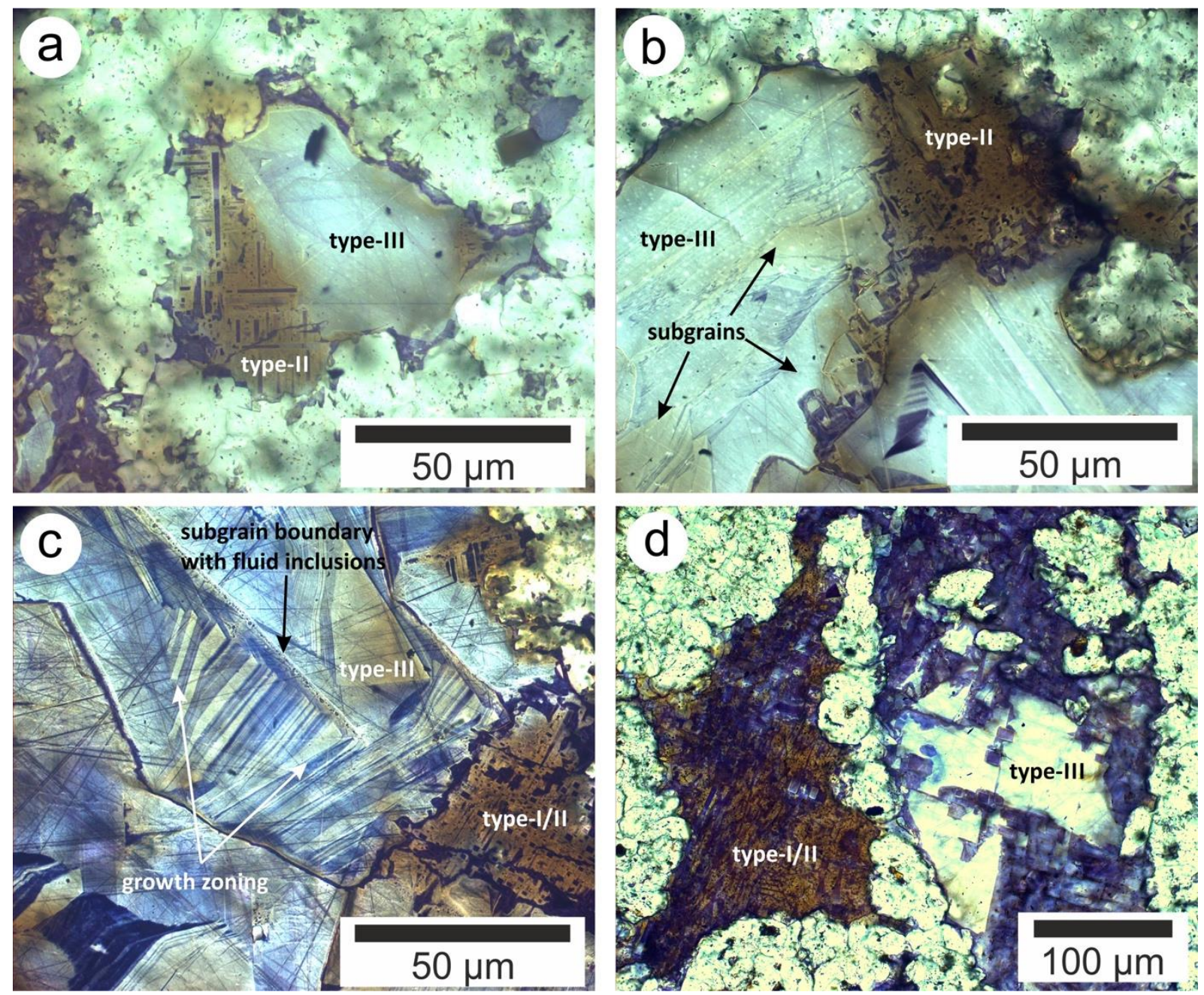

Fig. 5.9. Artificial decoration of microstructures in fluorite occurred due to electron irradiation during cathodoluminescence imaging. Thereby otherwise invisible crystallographic features could be identified. (a) Brownish remnants of type-I fluorite remain brown after electron irradiation while grains of type-II fluorite now appear violet. This image exhibits, how first bar-shaped and cubic crystals formed during beginning of recrystallization. Newly formed crystals are oriented perpendicular to each other following $\{100\}$. (b) Artificial decoration reveals subgrains and subgrain boundaries in type-III fluorite grains. (c) Subgrain boundaries in type-III fluorite locally contain primary aqueous fluid inclusions. As a result of recrystallization growth zoning is characterized by subparallel and partly kinked lines. (d) Locally all three fluorite types are located directly adjacent. Note how especially bar-shaped type-II fluorite is affected by artificial decoration. 
Chapter 5 - Syndiagenetic stratabound fluorite in Zechstein carbonates (Ca2) from the LWA

\subsubsection{Geochemistry}

Geochemical analysis of fluorite mineralization and dolomitic host rock was done using LA-ICP massspectrometry. Results presented in this chapter come from a master's thesis by Philipp Wischhöfer (Wischhöfer, 2015), which was carried out within the scope of this project. Part of the data was previously published as conference contributions (Duschl et al. 2017a, 2017b); however, all figures and data presented in this chapter are directly taken from or based upon the publications referred above.

The shale-normalized REY plot given in Fig. 5.10 shows respective concentrations for primary (i.e. type-I), secondary (type-II/III), and remobilized (type-IV) fluorite, as well as for dolomitic host rock. While REY patterns for syndiagenetic and recrystallized (primary/secondary) fluorite are mostly characterized by comparatively low LREE concentrations, remobilized fluorite is relatively enriched in LREE compared to both, primary/secondary fluorite and host rock, whereas HREE concentrations show inverse trends. Eu concentrations, which are indicative for parental fluid temperatures, don't show any significant anomalies and clearly prove that fluid temperatures did not exceed $250^{\circ} \mathrm{C}$ (Bau, 1991). Positive Y-anomalies present in both fluorite groups on the other hand contrast with a weak Y-anomaly observed in dolomite, which can either be explained by the complexation behaviour of $\mathrm{F}^{-}$-bearing fluids or by a different fluid sources for fluorite and dolomite (Bau and Dulski, 1995).

It is striking that REY concentrations for both groups of fluorite mineralization, which are genetically linked to each other due to static recrystallization and remobilization, show inverse trends in terms of LREE versus HREE. This could either be linked to different fluid sources, i.e. fluid mixing during remobilization; another explanation could be crystallographic fractionation during recrystallization. Thereby, temperature and fluid properties (Eh-pH; Dill and Weber, 2010) apparently control crystal shape (crystal habit), which may have a strong influence on trace element incorporation, as each crystal plane has different adsorption properties (Bosze and Rakovan, 2002; Rakovan, 2009). This mechanism likely appears more plausible when linked to microscopic evidence from fluorite decoration. While early type-II fluorite crystals are commonly arranged within cubic aggregates that often form at comparatively low temperatures, continuous coalescence of respective aggregates leads to expulsion of probably both, organic matter and impurity elements, which is expressed by violet colour along type-II/III boundaries also visible prior to electron irradiation (Fig. 5.6-c). This points towards an exsolution mechanism not only controlled by particle size and charge (organic matter) but also by preferential incorporation of trace elements due to crystallographic properties (REE). Thereby, LREE tend to be enriched in remobilized fluorite (low T), while HREE are show higher concentrations in recrystallized fluorite (high T), and vice versa. 
Chapter 5 - Syndiagenetic stratabound fluorite in Zechstein carbonates (Ca2) from the LWA

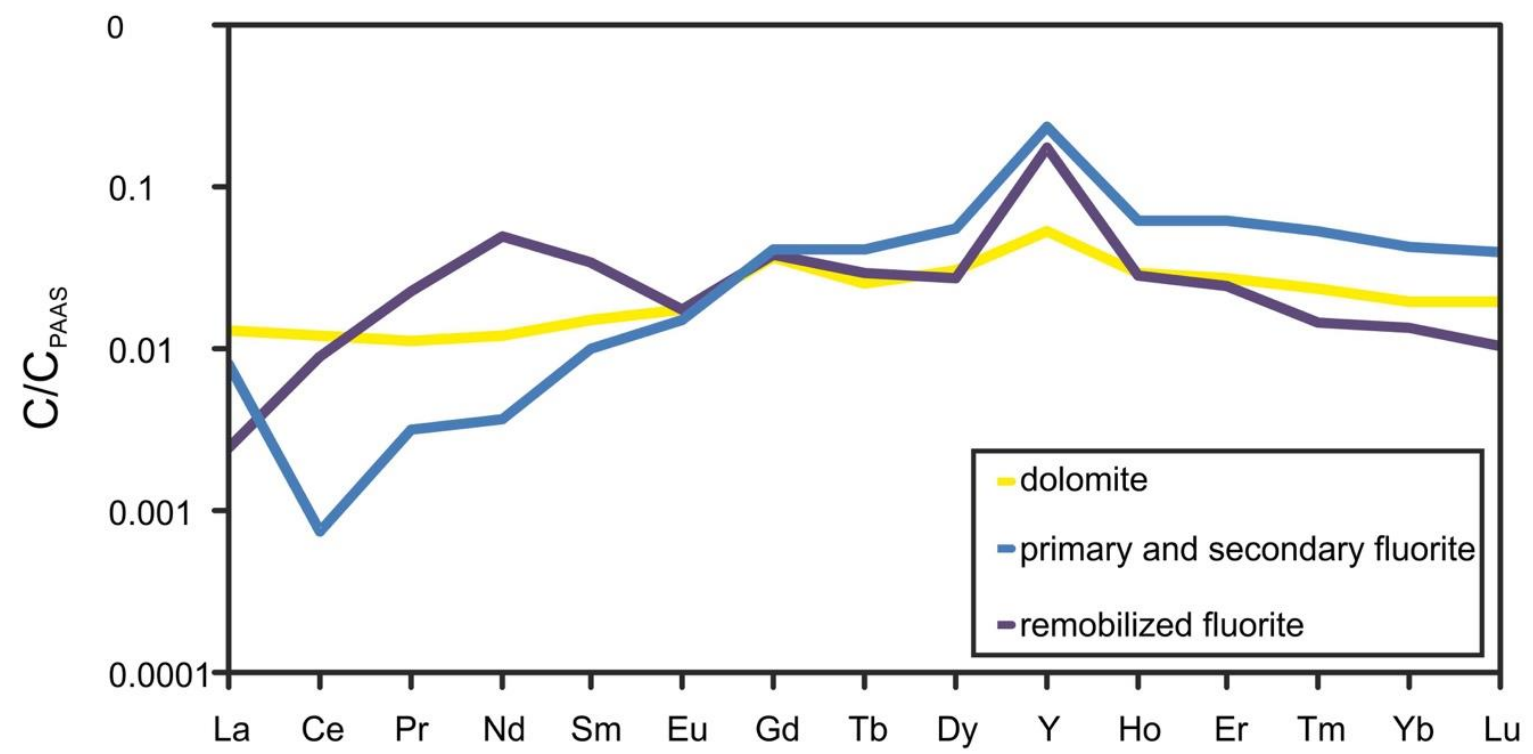

Fig. 5.10. REY concentration in primary and secondary fluorite, remobilized fluorite and the corresponding dolomitic host rock normalized on PAAS (Post Archean average Australian Shale). The absence of Eu anomalies argues against temperatures of the parental fluid above $250{ }^{\circ} \mathrm{C}$. The positive $Y$ anomaly of fluorite relative to dolomite can be explained by the strong complexation of $Y$ in fluorine- bearing solutions, while the possibility of two different fluids contradicts supposed formation mechanisms.

A comparative plot of $\mathrm{Tb} / \mathrm{Ca}-\mathrm{Tb} / \mathrm{La}$ distribution in both fluorite groups is presented in Fig. 5.11-a (after Möller et al., 1976). It clearly proves a sedimentary fluid source for both, syndiagenetic and remobilized fluorite. Furthermore, the pattern indicates REE fractionation during mineralization rather than remobilization. However, as shown in the Y/Ho-La/Ho plot in Fig. 5.11-b, REE fractionation can also occur due to recrystallization. While type-I/II/III fluorites in different samples from location 2 show very similar trends, that clearly prove crystallographic fractionation, remobilized fluorite from sampling location 3 indicates remobilization and local fluid migration.
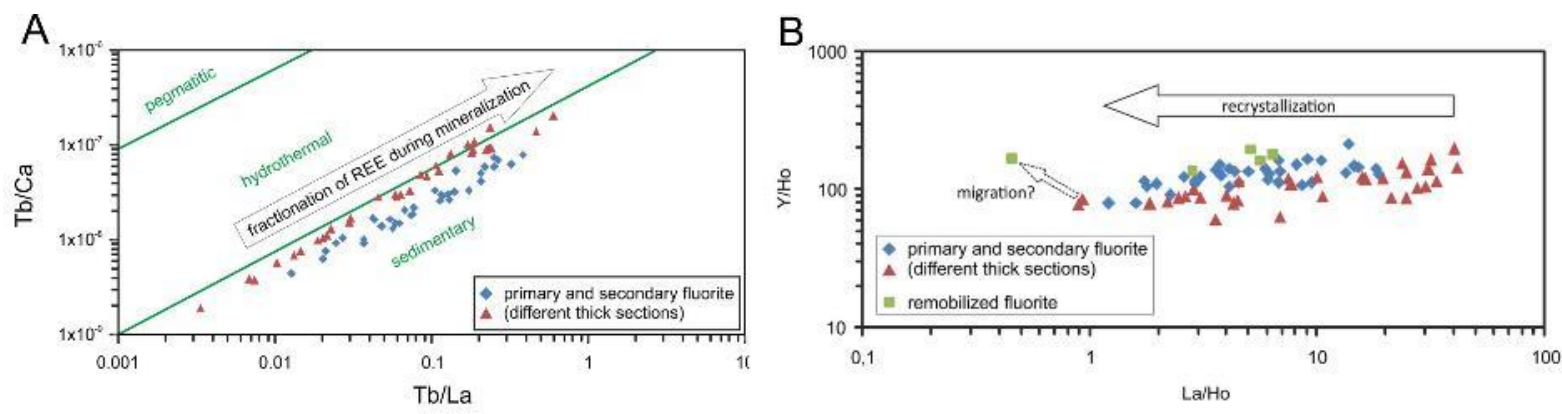

Fig. 5.11. (a) Tb/Ca-Tb/La abundance plot of thick sections containing primary (syndiagenetic/recrystallized) and secondary (remobilized) fluorite. Low Tb/Ca ratios indicate a sedimentary origin of the Eschwege fluorite. Proportional increase of $\mathrm{Tb} / \mathrm{Ca}$ and $\mathrm{Tb} / \mathrm{La}$ ratios represents the fractionation of REEs during mineralization from light REE-enriched early fluorite to heavy REE-enriched late fluorite. The slight difference between fluorite of different thick sections of the same outcrop is probably caused by sectoral zoning of REEs in the crystal lattice (see above), which points at different recrystallization stages. (b) Y/Ho-La/Ho plot according to Bau and Dulski (1995) obtained with ICP-MS (green squares) and LA-ICP-MS analysis. Similar Y/Ho ratios of primary, secondary and remobilized fluorite indicate co-genetic formation. Decreasing La/Ho ratios may represent recrystallization in the form of incompatible light REE being removed from the crystal lattice. Green squares belong to clear violet fluorite crystals which are presumed to have formed by remobilization of type-I/II/III fluorite. 
Chapter 5 - Syndiagenetic stratabound fluorite in Zechstein carbonates (Ca2) from the LWA

\subsubsection{Fluid inclusion petrography and microthermometry}

Fluid inclusions found within type-I/II/III fluorite can be grouped into four fluid inclusion assemblages (FIA) according to their petrographic character (host mineral, shape, size, etc.), fluid composition, fluid phases and daughter minerals (L/V/S), and homogenization temperature (see Goldstein and Reynolds, 1994; van den Kerkhof and Hein, 2001). A compilation of respective data is given in Tab. 5.1.

FIA-I consists of primary monophase aqueous fluid inclusions restricted to type-I fluorite (Fig. 5.12a). Irregularly distributed fluid inclusions are elongated and rounded; their size varies between 3 and $10 \mu \mathrm{m}$. Respective fluids $\left(\mathrm{H}_{2} \mathrm{O}-\mathrm{NaCl}\right)$ show ice melting temperatures $\left(\mathrm{T}_{\mathrm{m} \text { (ice) }}\right)$ between $-7.6^{\circ} \mathrm{C}$ and $-6.1^{\circ} \mathrm{C}$, and corresponding salinities range between 9.3 and 11.2 wt.\% (eq.) $\mathrm{NaCl}$, with a resulting mean fluid density of $1.0798 \mathrm{~g} / \mathrm{cm}^{3}$, which in fact points at a hypersaline marine environment.

Fluid inclusions related to FIA-II are primary gaseous monophase inclusions with elongatedvermicular shape (Fig. 5.12-b); they are commonly arranged between bar- or lath-shaped crystals of type-II fluorite and likely formed during recrystallization, thus proving composition of involved fluids during crystal aggregate formation ((Goldstein, 2003). Gaseous inclusions $\left(\mathrm{CH}_{4}-\mathrm{CO}_{2}\left(-\mathrm{H}_{2} \mathrm{~S}\right)\right)$ with dimensions ranging between 5 and $30 \mu \mathrm{m}$ appear very dark; they homogenize to the vapour phase upon heating $(\mathrm{LV} \rightarrow \mathrm{V})$ at a temperature of $-68.2^{\circ} \mathrm{C}\left(\mathrm{T}_{\mathrm{h}}\right)$, while $\mathrm{CO}_{2}$ melting $\left(\mathrm{T}_{\mathrm{m}, \mathrm{CO} 2}\right)$ occurs at $-78^{\circ} \mathrm{C}$, which leads to a comparatively low density of $82 \mathrm{~cm}^{3} / \mathrm{mol}$.

Data obtained from FIA-II corresponds with fluid properties of FIA-III, which is characterized by secondary monophase gaseous inclusions that occur within type-I/II/III fluorite in form of dark transgranular fluid inclusion trails, thus tracing healed fractures (Fig. 5.12-d). The irregular to elongated fluid inclusions $\left(\mathrm{CH}_{4}-\mathrm{CO}_{2}\left(-\mathrm{H}_{2} \mathrm{~S}\right)\right)$ that homogenize to the vapour phase $(\mathrm{LV} \rightarrow \mathrm{V})$ show $\mathrm{T}_{\mathrm{h}}$ of $-66.2^{\circ} \mathrm{C}$, while $\mathrm{T}_{\mathrm{m}, \mathrm{CO} 2}$ occurs at $-76.6^{\circ} \mathrm{C}$, resulting in a comparatively low density of $83 \mathrm{~cm}^{3} / \mathrm{mol}$. Unlike FIA-II, FIA-III locally shows daughter crystals of unknown composition $(\mathrm{LV}(\mathrm{S}) \rightarrow \mathrm{V}(\mathrm{S}))$.

Aqueous biphase fluid inclusions that belong to FIA-IV are of primary origin; they are restricted to type-III fluorite and often contain daughter crystals with roughly cubic shape, likely halite $\left(\mathrm{H}_{2} \mathrm{O}-\mathrm{NaCl}(-\right.$ $\mathrm{H}_{2} \mathrm{~S}$ )) (Fig. 5.12-c). Inclusion are of slightly elongated or squared shape with typically curved edges, their size varies between 15 and $35 \mu \mathrm{m}$; they often occur isolated within larger grains, but barely cluster. Locally, respective inclusions are also trapped along (sub-)grain boundaries. Eutectic melting $\left(\mathrm{T}_{\mathrm{e}}\right)$ can be observed at temperatures around $-38^{\circ} \mathrm{C}$ upon heating, which is likely related to the presence of minor

traces of $\mathrm{K}$ and $\mathrm{Mg}$. Furthermore, $\mathrm{T}_{\mathrm{m} \text { (ice) }}$ ranges between $-28.2^{\circ} \mathrm{C}$ and $-27^{\circ} \mathrm{C}$; while hydrohalite melting $\left(\mathrm{T}_{\mathrm{m}, \mathrm{HH}}\right)$ was observed at $-19^{\circ} \mathrm{C}$. Fluid inclusions homogenize into the liquid phase (LVS $\rightarrow \mathrm{LS}$ ) starting at temperatures of $\mathrm{T}_{\mathrm{h}}=61.7^{\circ} \mathrm{C}$, however, most inclusions show much higher $\mathrm{T}_{\mathrm{h}}$ of $>200$. Unfortunately, definite values are hard to obtain, as analysed fluid inclusions tend to decrepitate prior to homogenization. This may be caused by the presence of $\mathrm{H}_{2} \mathrm{~S}$, as anomalous behaviour of the vapour phase (bubble) during heating-cooling cycles suggests, when the bubble significantly increases or decreases its volume within comparatively small temperature increments. Therefore, halite melting $\left(\mathrm{T}_{\mathrm{m}}\right.$ (halite) could never be observed, though locally halite daughter crystals were still present even at temperatures around $220^{\circ} \mathrm{C}(\mathrm{LVS} \rightarrow \mathrm{LS} \rightarrow \mathrm{S}$ ). Due to the fact that all primary fluid inclusions (FIA-IV) either already decrepitated upon $\mathrm{H}_{2} \mathrm{O}$ homogenization to the liquid phase or afterwards, no reliable data on maximum halite melting temperatures were obtained. Thus, no isochore calculation could be done for this fluid inclusion assemblage. Nevertheless, observations made during microthermometric analysis support the idea of grain coarsening in fluorite from sampling location 2 at elevated temperatures $\left(61^{\circ} \mathrm{C}\right.$ $\left.220^{\circ} \mathrm{C}\right)$ in the presence of an $\mathrm{NaCl}$-supersaturated fluid and $\mathrm{CH}_{4}-\mathrm{CO}_{2}\left(-\mathrm{H}_{2} \mathrm{~S}\right)$. 
Chapter 5 - Syndiagenetic stratabound fluorite in Zechstein carbonates $(\mathrm{Ca} 2)$ from the LWA
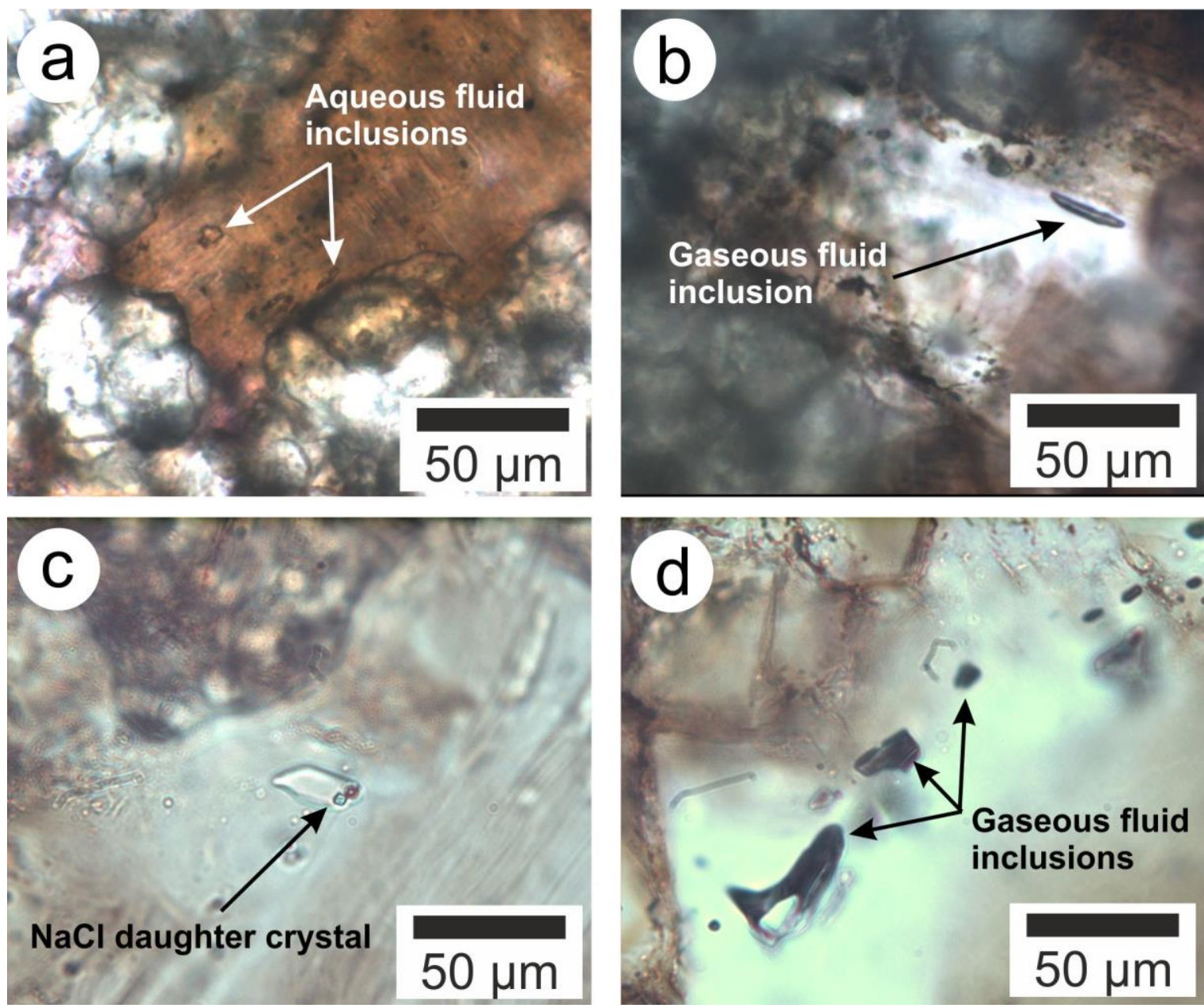

Fig. 5.12. (a) Primary aqueous fluid inclusions in type-I fluorite (FIA-I, system: $\mathrm{H}_{2} \mathrm{O}-\mathrm{NaCl}$ ). (b) Primary gaseous fluid inclusion with vermicular shape in type-II fluorite (FIA-II, system: $\mathrm{CH}_{4}-\mathrm{CO}_{2}\left(-\mathrm{H}_{2} \mathrm{~S}\right)$ ). (c) Primary aqueous fluid inclusion in type-III fluorite with dark bubble and halite daughter crystal (FIA-IV, system: $\mathrm{H}_{2} \mathrm{O}-\mathrm{NaCl}-\mathrm{H}_{2} \mathrm{~S}$ ). (d) Secondary gaseous fluid inclusions decorating healed microfracture in typeIII fluorite (FIA-III, system: $\mathrm{CH}_{4}-\mathrm{CO}_{2}\left(-\mathrm{H}_{2} \mathrm{~S}\right)$ ).

Tab. 5.1. Compilation of fluid inclusion characteristics and microthermometric results. (FIA $=$ fluid inclusion assemblage, $L=$ liquid, $V=$ vapor,$S=$ solid, Te = eutectic temp., $T m=$ melting temp., $T h=$ homogenization temp.).

\begin{tabular}{|c|c|c|c|c|c|c|c|c|c|c|c|c|c|}
\hline \multirow{2}{*}{ Mineral } & \multirow{2}{*}{ FIA } & \multirow{2}{*}{$\begin{array}{c}\text { Petrographic } \\
\text { character }\end{array}$} & \multirow{2}{*}{ Phase transition } & \multirow{2}{*}{$\begin{array}{l}\mathrm{T}_{\mathrm{e}} \\
{ }^{\circ} \mathrm{C}\end{array}$} & \multirow{2}{*}{\begin{tabular}{c|}
$\mathrm{T}_{\mathrm{m} \text { (ice) }}$ \\
${ }^{\circ} \mathrm{C}$
\end{tabular}} & \multirow{2}{*}{\begin{tabular}{|c|}
$T_{m}(\mathrm{CO} 2)$ \\
${ }^{\circ} \mathrm{C}$ \\
\end{tabular}} & \multirow{2}{*}{$\frac{\mathrm{T}_{\mathrm{h}}}{{ }^{\circ} \mathrm{C}}$} & \multirow{2}{*}{\begin{tabular}{|c}
$\mathrm{T}_{\mathrm{m}, \mathrm{HH}}$ \\
${ }^{\circ} \mathrm{C}$
\end{tabular}} & \multirow{2}{*}{\begin{tabular}{|c|}
$T_{m}$ (halite \\
${ }^{\circ} \mathrm{C}$
\end{tabular}} & \multirow{2}{*}{\begin{tabular}{|c|} 
Salinity \\
wt.\% (eq.) NaCl
\end{tabular}} & \multicolumn{2}{|c|}{ Density } & \multirow[t]{2}{*}{ Fluid system } \\
\hline & & & & & & & & & & & $\mathrm{cm}^{3} / \mathrm{mol}$ & $\mathrm{g} / \mathrm{cm}^{3}$ & \\
\hline Fluorite & 1 & Primary & $\begin{array}{l}\text { monophase, } \\
\text { aqueous }\end{array}$ & --- & $-6.1 /-7.6$ & --- & --- & --- & --- & $9.3 / 11.2$ & --- & 1.0798 & $\mathrm{H}_{2} \mathrm{O}-\mathrm{NaCl}$ \\
\hline Fluorite & $\|$ & Primary & $L V->V$ & --- & --- & -78 & -68.2 & --- & --- & --- & 82 & --- & $\mathrm{CH}_{4}-\mathrm{CO}_{2}\left(-\mathrm{H}_{2} \mathrm{~S}\right)$ \\
\hline Fluorite & III & Secondary & $\mathrm{LV}(\mathrm{S})->\mathrm{V}(\mathrm{S})$ & -- & --- & -76.6 & -66.2 & --- & --- & --- & 83 & --- & $\mathrm{CH}_{4}-\mathrm{CO}_{2}\left(-\mathrm{H}_{2} \mathrm{~S}\right)$ \\
\hline Fluorite & IV & Primary & LVS $->$ LS $->$ L & -38 & $-28.2 /-27.0$ & --- & $61.7 />200$ & -19 & $>220$ & --- & --- & --- & $\mathrm{H}_{2} \mathrm{O}-\mathrm{NaCl}-\mathrm{H}_{2} \mathrm{~S}$ \\
\hline
\end{tabular}


Chapter 5 - Syndiagenetic stratabound fluorite in Zechstein carbonates (Ca2) from the LWA

\subsection{Discussion}

\subsubsection{Fluorite formation}

Fluorite formation in dolomitic, ooid-bearing limestones (Ca2, Stassfurt carbonate) of the LWA apparently occurred due to a syndiagenetic process, which was likely restricted to one or several layers within the $\mathrm{Ca} 2$ sequence. The syndiagenetic formation mechanism proposed by Möller et al. (1980) (Fig. 5.1) seems appropriate insofar, as microfabric analysis supports fluorite mineralization within highly porous marine shallow-water facies enriched in aragonitic ooids, as well as oncoids and shell fragments. However, a fluorite precipitation simultaneous to dolomitization could not be confirmed, we rather suggest that dolomitization occurred prior to fluorite impregnation, as indicated by partial replacement of dolomite with fluorite. Aqueous fluid inclusions (FIA-I) trapped within early-diagenetic (primary) type-I fluorite point to fluorite precipitation from a marine $\mathrm{NaCl}$-supersaturated fluid, which is in good agreement with the idea of fluorine-bearing high-density brines mixing with low-density sea water. Thereby, fluorite formation significantly reduced inter- and intra-particle pore space, which consequently resulted in a low-permeable layer. It is still not clear why fluoritization was restricted to single, clearly defined layers within or in the vicinity of a shallow-burial reef complex. A reactive mechanism triggered by the presence of aragonitic ooids, which could be derived from the model suggested by Möller et al. (1980) can be ruled out, as primary fluorite mineralization also impregnated inter-particle pores. Microscopic evidence could prove that locally bedding-parallel stylolites apparently formed barriers for vertical migration of remobilized fluorite. Since stylolitization is often restricted to calcitic carbonates and pressure solution thus likely occurred prior to dolomitization, highly-porous ooid-bearing Ca2-layers may have favoured lateral fluid flow, thereby acting as permeable horizontal conduits that allowed hydraulic contact between the lagoon and the open sea. Apart from this first established fluid mixing model, Dill (2012) supposed a rather simple fluorite formation related to sabkha environments, where halide concentration occurs due to sea water evaporation as a consequence of sea level drop. Some of our observations confirm this model, as it could explain both, the presence of anhydrite and probably halite crystals within the Stassfurt carbonate, and the simultaneous absence of a clear indicator for reef complexes in the study area (compare Fig. 5.2). In this context the restriction of fluorite to several distinct layers seems more plausible, as even minute sea level variations can have an immense impact on the sedimentary environment of a shallow platform and related temporary evaporation can explain the limited vertical fluorite extension quite easily.

Subsequent burial of the Hessian Depression then lead to an increase in pressure and temperature, which locally resulted in a first static recrystallization of the dark, organic-rich primary fluorite (type-I $\rightarrow$ type-II), which can be found in sampling locations 2 and 3 within the extent of the LWA (Fig. 5.4). Primary gaseous fluid inclusions (FIA-II), which were trapped at relatively low pressures, formed between aggregates of type-II fluorite, thus proving migration of $\mathrm{CO}_{2}$-rich fluids at that time (Fig. 5.12b). As recrystallization continued, first fluorite aggregates started to coalesce, forming larger grains characterized by equigranular-polygonal fabrics (type-III).

High-saline fluids trapped within primary fluid inclusions in type-III fluorite (FIA-IV) confirm exceptionally high formation temperatures of locally more than $200^{\circ} \mathrm{C}$, that apparently favoured grain coarsening. The wide spectrum of homogenization temperatures $\left(61^{\circ} \mathrm{C}-200^{\circ} \mathrm{C}\right)$ found within this fluid inclusion assemblage is likely the result of recrystallization in the vicinity of a hydrothermal system, where fluid temperatures were controlled by magmatic activity. Thereby, the heterogeneous distribution 
of $T_{h}$ proves inconsistent ambient temperatures during recrystallization. A simplified model explaining the main stages of fluorite formation and static recrystallization is shown in Fig. 5.13.

\section{Stage 1}

Dolomitization, fluorite precipitation and fluid trapping

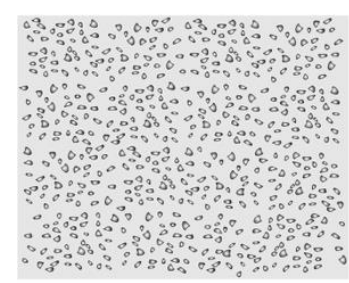

Stage 2

Grain coarsening:

development of cubic to rectangular fluorite grains

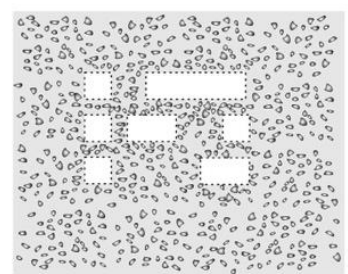

Stage 3

Grain coalescence (aggregates), trapping of primary fluid inclusions along grain boundaries

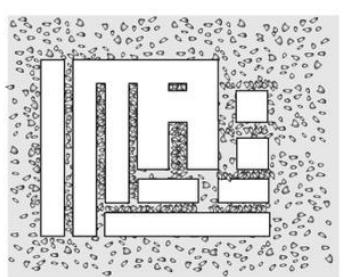

Stage 4

Development of cubic to polygonal fabric, locally with $120^{\circ}$-angles. Primary aqueous fluid inclusions: $\mathrm{T}_{\mathrm{h}}>200^{\circ} \mathrm{C}$

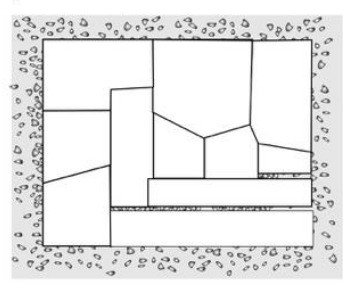

Fig. 5.13. Illustration demonstrating the main stages of fluorite precipitation, grain coarsening and grain coalescence from early diagenesis until present.

\subsubsection{Thermal evolution - Deep burial versus local thermal anomaly}

Halite melting temperatures of $>220^{\circ} \mathrm{C}$ found within FIA-IV inclusions correspond with high-saline fluids that are characterized by salt concentrations of ca. $32.9 \mathrm{wt} \%$ (equ.) $\mathrm{NaCl}$ or more (Bodnar, 2003). Since similar high-saline fluids are not known from the study area and are even barely known from the NGB (Schmidt Mumm and Wolfgramm, 2004), their origin remains unclear. As fluid salinity in sedimentary basins is either controlled by fluid-rock interaction or the presence of rock salt (Roedder, 1984), Zechstein units often contain high saline brines. However, as halite solubility in water increases with temperature, a heat source is necessary, which may explain temperatures above $200^{\circ} \mathrm{C}$. In this context only two options appear plausible, of which one is deep burial and the other one is a local magmatic-hydrothermal system (Fig. 5.14).

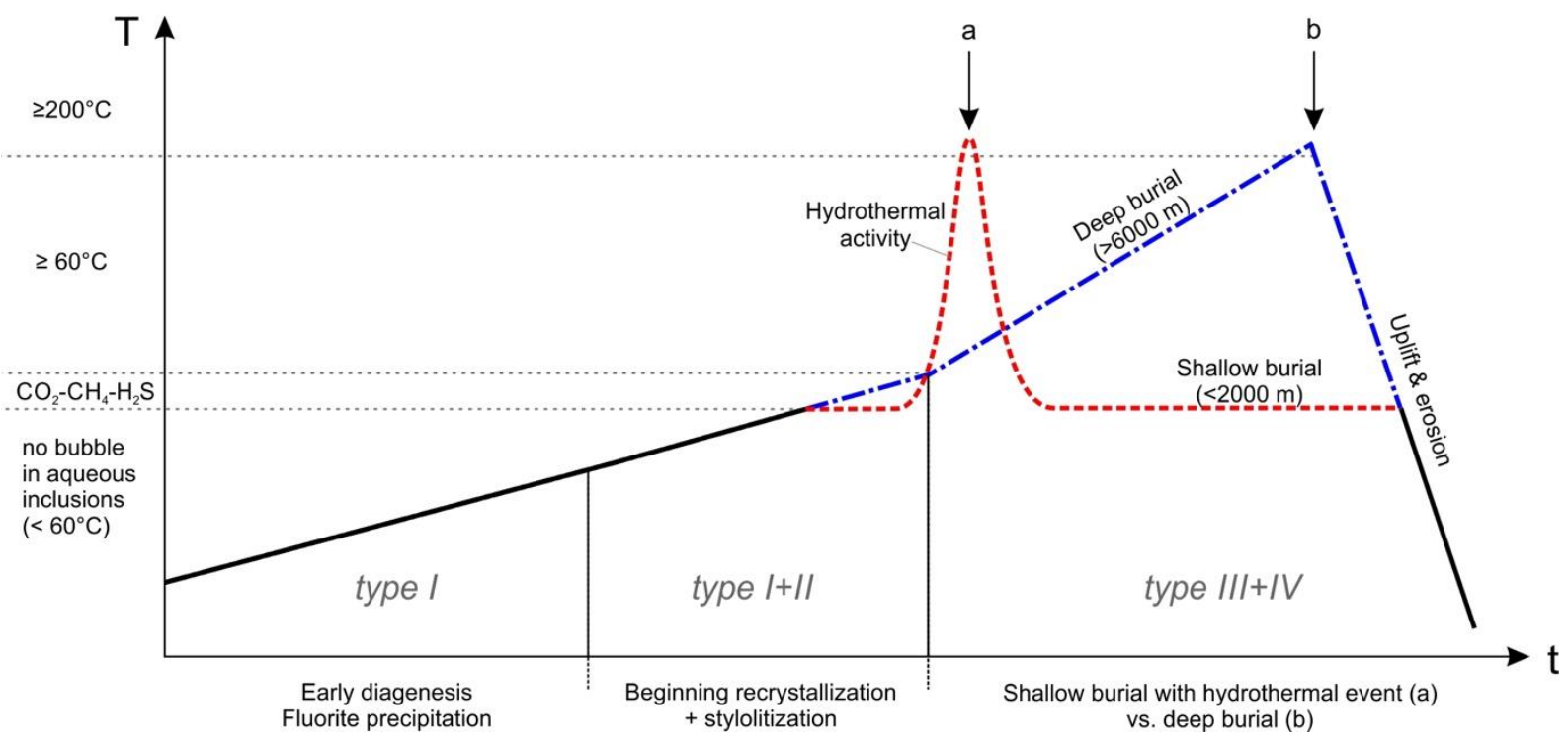


Chapter 5 - Syndiagenetic stratabound fluorite in Zechstein carbonates (Ca2) from the LWA

Fig. 5.14. Temperature-time chart illustrating the evolution of fluorite formation and recrystallization. Two different scenarios may have favoured fluorite recrystallization: (a) hydrothermal activity or $(b)$ deep burial.

Assuming a geothermal gradient of $30^{\circ} \mathrm{C} / \mathrm{km}$, burial of the Zechstein sequence below $6 \mathrm{~km}$ would be necessary in order to provide temperatures around $200^{\circ} \mathrm{C}$. Though according burial depth are known from the NGB and the LSB in particular (Adrisola-Muñoz, 2007; Littke et al., 2008), a similar scenario cannot be implied for the LWA, as the structural evolution of the area in terms of extension prior to basin inversion is different in comparison to the LSB. Besides, the stratigraphic record gives rise to the assumption that during late Jurassic and early Cretaceous, the area of the LWA was exposed to erosion (Jacobshagen et al., 1993a). A burial curve simulating the geologic evolution of the southern LWA based on published data and complemented by sedimentation rates, which were inferred from adjacent subbasins is presented in Fig. 5.15. Although this model cannot provide a final solution to the question, what the maximum burial depth in this area was, as important information required for a proper model calibration such as vitrinite reflectance data is missing, a first approach can still be made. Using a constant heat flow of $56 \mathrm{~mW} / \mathrm{m}^{2}$, which approximately corresponds to the present-day crustal heat flow in the NGB (Doornenbal and Stevenson, 2010), a maximum temperature of $69^{\circ} \mathrm{C}$ within the $\mathrm{Ca} 2$ unit can be derived. Given continuous burial during Jurassic and Cretaceous, a burial depth of at least $7 \mathrm{~km}$ must be assumed in order to reach temperatures of about $190^{\circ} \mathrm{C}$. Since homogenization temperatures are usually lower than true formation temperatures, and halite melting in fluid inclusions (FIA-IV) had not occurred even at $220^{\circ} \mathrm{C}$, this scenario doesn't seem realistic. Besides, if the Hessian Depression was exposed to erosion during late Jurassic-early Cretaceous necessary maximum burial depth are even more unlikely. We therefore propose a magmatic-hydrothermal fluid system related to volcanic activity in the Cenozoic in order to explain according temperatures. This model is supported by the following facts: (a) No evidence for according burial depth in the study area so far; (b) volcanic activity in the vicinity of the sampling location 2 (Rosenbühl), as well as a corresponding fault system in the study area, that might provide hydrothermal fluid circulation; (c) increase in fluorite-'maturity', i.e. recrystallization, grain coarsening, and remobilization (type-I $\rightarrow$ type-IV) towards the Hoher Meissner volcano. This heterogeneous distribution contradicts the idea of a deep burial scenario for the whole area; (d) presence of various, with respect to the study area otherwise untypical gases $\left(\mathrm{CO}_{2}-\mathrm{CH}_{4}-\mathrm{H}_{2} \mathrm{~S}\right)$ trapped within fluid inclusions. Besides, the distribution of subrosion features in the LWA and adjacent areas locally coincides with areas of fluorite mineralization of type-III/IV (compare Jacobshagen et al., 1993b and references therein), which leads to the assumption that assumed volcanogenic hydrothermal activity had a major influence on dissolution of gypsum, anhydrite and halite within the Zechstein sequence. 


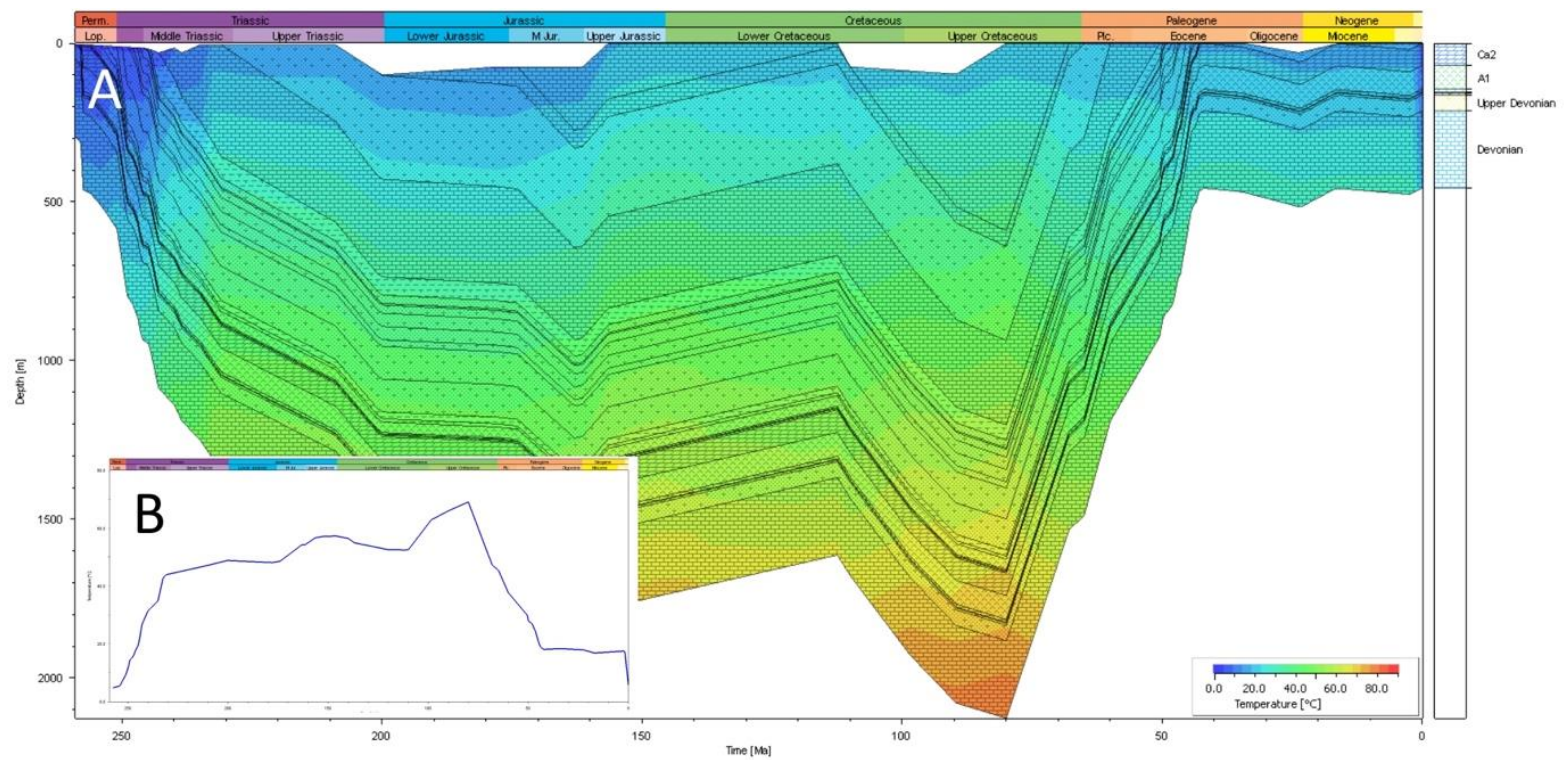

Fig. 5.15. (a) Burial plot for the southern LWA with a supposed constant heat flow of $56 \mathrm{~mW} / \mathrm{m}^{2}$ and (b) a corresponding temperature curve for Ca2 carbonate rocks. A modelled temperature maximum of ca. $69{ }^{\circ} \mathrm{C}$ during maximum burial does not match homogenization temperatures of $>200^{\circ} \mathrm{C}$ measured in primary fluid inclusions trapped within recrystallized fluorite (type-IV). Thus, either much deeper burial (i.e. $>6 \mathrm{~km}$ ) or a magmatic-hydrothermal event must be assumed in order to explain such high formation temperatures. While a deep burial scenario including an overburden of more than $6 \mathrm{~km}$ seems unlikely, the presence of a short-termed volcanogenic hydrothermal system during the Cenozoic could explain necessary heat flow values (>>200 mW/m $\mathrm{m}^{2}$, time-dependent). Sediment load for Zechstein, Triassic, and Cenozoic times is based on data from Jacobshagen et al. (1993a), Jurassic and Cretaceous sediment thickness is derived from comparison with sedimentation rates in the LSB and adjacent areas, as no reliable published data is available.

\subsubsection{Syndiagenetic fluorite in the LSB and the LWA}

A comparative study of fluorite mineralization in Ca2 carbonate samples from the NGB carried out by Schulz (1980), proved the presence of various mineralization types throughout the basin, which show features of hydrothermal as well as synsedimentary or syndiagenetic mineralization. However, geochemical analysis of respective fluorites indicates a common sedimentary fluid source for almost all of them (Duschl et al., 2016; Möller et al., 1980; Möller et al., 1976; Schulz, 1980). Therefore, the recrystallization behaviour of stratiform fluorite depending on ambient temperature and fluid activity presented in this chapter may help to better understand fluorite remobilization in the LSB. Moreover, since fluid inclusions trapped within coarse-grained type-IV fluorite suggest that significant graincoarsening and a complete polygonal recrystallization of early-diagenetic fluorite only occurs when according temperatures $\left(\mathrm{ca} . \geq 200^{\circ} \mathrm{C}\right.$ ) are established, knowledge concerning the local temperature evolution within the NGB may be complemented by the study of fluorite microfabrics.

Fig. 5.16 provides a comparative presentation of microscopic evidence for different fluorite types from the LWA (Fig. 5.16-a/b) and the LSB (Fig. 5.16-c/d). It is especially noticeable that the presence of brown type-I fluorite together with partly recrystallized, bar-shaped type-II fluorite can be verified for samples from both localities, which points towards similarities in terms of primary fluorite mineralization and recrystallization conditions. While a colourless, locally zoned remobilized fluorite (type-IV) can also be proven for both study areas, coarse-grained polygonal type-IV fluorite is only known from the LWA. 

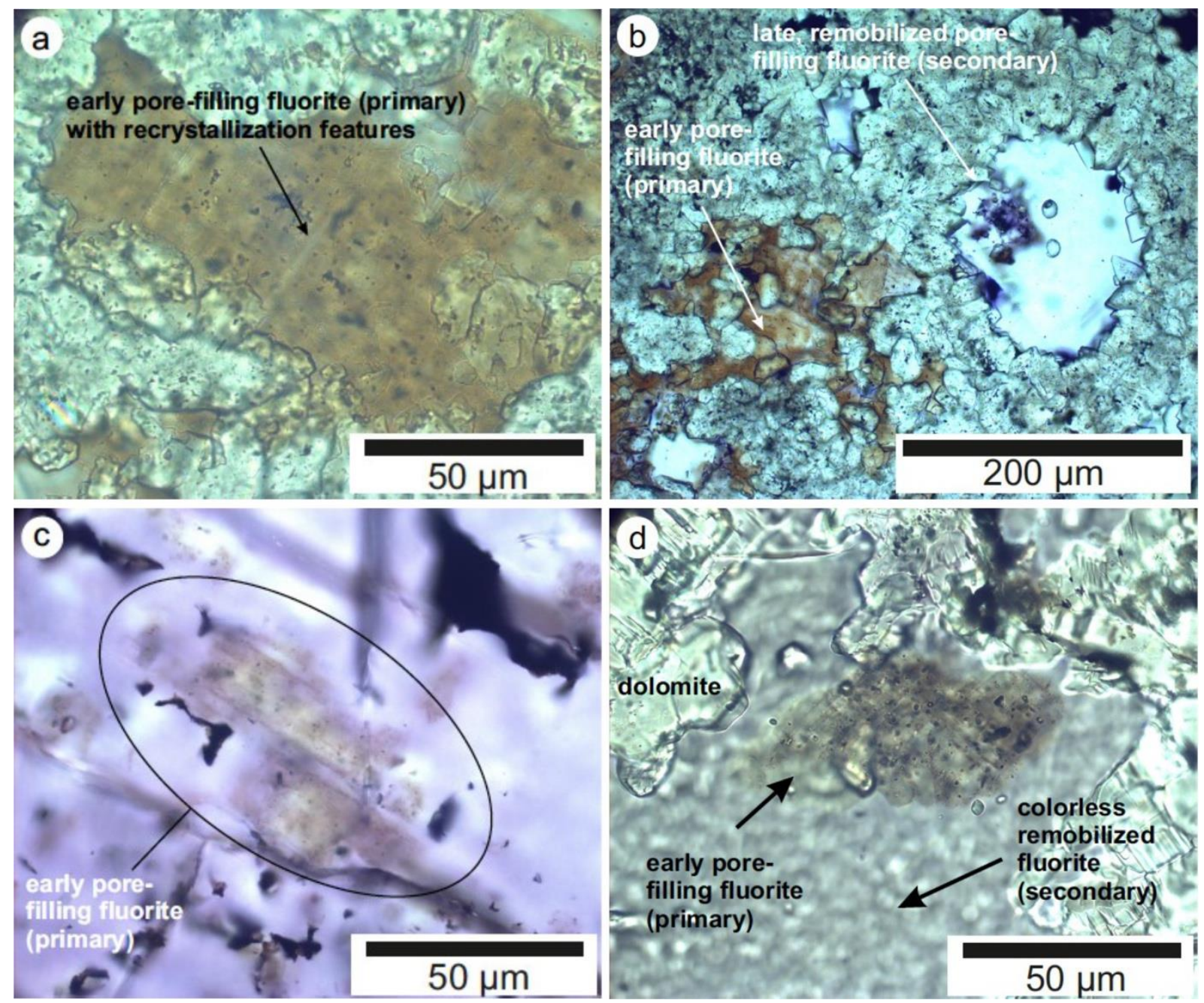

Fig. 5.16. Microfabric comparison between partly recrystallized stratabound fluorite from Eschwege (a/b) and from two wells in the Lower Saxony Basin (c/d). Early (i.e. primary, type-I) fluorite is characterized by brownish colour and a comparatively high fluid and solid inclusion density, as well as recrystallization features such as white, bar-shaped crystals (type-II) (see arrow, image (a)). Colourless to violet secondary (remobilized; type-IV) fluorite fills pores and fractures (b), or encloses remnants of older fluorite aggregates (Figs. c/d); locally it also coats stylolites.

This observation finally leads to the assumption that - at least locally - temperatures in the LSB were either not high enough or prevailed not long enough to allow complete recrystallization and graincoarsening. However, hydrothermal activity possibly controlled by extensional tectonics during the Mesozoic apparently resulted in partial dissolution of primary fluorite and the subsequent precipitation as colourless type-IV fluorite within reactivated or newly formed fractures and residual pores. The assumption of short-termed hydrothermal pulses directly initiating fluorite remobilization rather than recrystallization is confirmed by isolated remnants of type-II fluorite aggregates, which are completely surrounded by type-IV fluorite (Fig. 5.16-c/d). Thus, partial dissolution due to temporarily higher reservoir temperatures and simultaneous fluid migration (see Chapter 5) had occurred before further surface reduction due to polygonal grain-coarsening could be established. 
Chapter 5 - Syndiagenetic stratabound fluorite in Zechstein carbonates (Ca2) from the LWA

\subsection{Conclusions}

The typology of carbonate-hosted fluorites from the LSB and the LWA based on microfabric features and geochemical and fluid inclusion analysis revealed a direct correlation between primary fluorite mineralization from a parental fluid of sedimentary origin, subsequent recrystallization and graincoarsening accompanied by impurity-exsolution, and partial remobilization, mainly controlled by temperature variations due to hydrothermal fluid circulation. The results from field observations in the southern LWA and microscopic and geochemical analysis of collected samples indicate a heterogeneous distribution of fluorite types, which suggests the presence of a local heat source in connection with hydrothermal systems of limited range that were most likely stimulated by Cenozoic volcanism. These small-scaled hydrothermal cells resulted in the formation of a variety of clearly distinguishable fluorite types at relatively low pressures, and thus serve as high temperature analogues for deeply buried rock volumes $(>6-7 \mathrm{~km}$ ) in the NGB. In conclusion, burial of Zechstein carbonates in both study areas at depth below $6 \mathrm{~km}$ cannot be ruled out completely, however, our observations rather point towards a mixed scenario with deep burial (ca. $4.5-5 \mathrm{~km}$ ) and a simultaneous, relatively short-lived hydrothermal fluid-circulation for the LSB; maximum burial in the LWA likely never exceeded depth below $2.5-3 \mathrm{~km}$, while high temperatures of $\geq 220^{\circ} \mathrm{C}$ were favoured by a volcanogenic-hydrothermal system. 


\title{
6. Progressive fracture-network development in a carbonate reservoir - A combined paleo-stress field and microstructural analysis on sedimentary rocks from the Lower Jurassic of the western Basque-Cantabrian Basin (N-Spain)
}

\begin{abstract}
This study focuses on the microstructural development of sedimentary carbonate and carbonatesiliciclastic rocks controlled by diagenetic and tectonic processes. Investigated sample material comes from the so-called Cantabrian Transitional Area, which represents a structural link between the Asturian Massif and the inverted Basque-Cantabrian Basin (Plataforma Burgalesa; N-Spain). The samples have been investigated with regard to their suitability as cap rock and reservoir rock for natural and anthropogenic $\mathrm{CO}_{2}$-storage, with special emphasis on structural diagenesis and fracture porosity. The main focus lies thereby on the study of microstructural deformation patterns such as progressive fracturing of carbonate rocks that explain fracture-related fluid flow in sedimentary basins due to alternating extensional and compressional tectonic regimes. Moreover, the role of mineral dissolutionprecipitation within fracture systems and its influence on fluid pathways was examined.

Oriented samples of four different carbonate carbonate-siliciclastic rocks of early Jurassic age, i.e., 1) a cellular dolomite (Fm. Puerto de la Palombera; Hettangian), 2) a siliciclastic sandstone (Fm. Areniscas del Rio Polla; Lower Sinemurian), 3) an oolithic limestone (Fm. Villanueva de Puerta; Lower Sinemurian), and 4) an organic-rich calcilutite (Fm. Camino; Pliensbachian) were collected at outcrops in the westernmost part of the Basque-Cantabrian Basin (Aguilar de Campóo - Bercedo area).

Petrographic and microfabric analysis was performed by means of optical polarization microscopy and point counting microscopy; digital image analysis was carried out to quantify the residual rock porosities and rock composition. In order to define the spatial orientation of mineralized fractures a set of three thin sections with orthogonal orientation was prepared of each sample, which allows to derive fracture orientations, and thus, minimum principal stress directions. Microthermometry was applied to determine the composition of fluid inclusions found within different cement phases, as well as to estimate formation pressures and temperatures. Hot-cathode cathodoluminescence microscopy (CL) was mainly used for the visualization of cement generations with a special focus on cement stratigraphy, dissolution and replacement features, and mineralized (micro-) fractures, which provided information about the development of paleo-porosity and -permeability. Textural crosscutting relations visualized in CL revealed the relative age of fracture mineralization. Finally, our data was correlated with and compared to burial-history curves by means of pressure and temperature during cement precipitation and fracture formation.

Detailed petrographic investigations clarified that fluid flow in the studied carbonate rock was mainly restricted to fracture porosity, as different cemented fracture populations reveal. Although fluid flow is enhanced especially in extensional tectonic regimes, tectonic compression leads to increased fracture permeability as well due to both, formation of new inter-formational fractures and reactivation of existing fractures.
\end{abstract}


Chapter 6 - Progressive fracture-network development in a carbonate reservoir

\subsection{Introduction}

The prediction of fracture permeability in siliciclastic and carbonate reservoirs has become increasingly important in recent years thanks to the development of CCS technologies (Agada et al., 2016; Elkhoury et al., 2013; Gheibi et al., 2017), advances in the field of combined CCS and geothermal energy research (Kaya and Zarrouk, 2017; Li et al., 2016; Mohan et al., 2015; Salimi et al., 2012), and the application of induced seismicity and hydraulic fracturing techniques in unconventional oil and gas production (Davies et al., 2013). Information on dimensions and scaling of opening-mode fractures (Mode I fractures or wall-normal displacement, see Atkinson, 1989) helps to estimate the permeability of fractured reservoir rocks, however, other major features that may reduce or favour subsurface fluid conductivity such as cementation, mineral dissolution-precipitation, effects of local stress fields on rock mechanics and fracture formation (fracture modes), as well as fluid chemistry and - not to forget - the time-dependence of named processes are often underestimated and also hard to determine simultaneously. In combination these effects define the maximum fracture opening and also its occlusion due to compression, shear-enhanced cataclasis or cementation, and therefore describe the rocks fracture permeability over time (e.g., Laubach et al., 2004; Fossen et al., 2007; Hesthammer and Fossen, 2000). This information is crucial for understanding fluid migration and trapping in sedimentary basins with respect to both, natural and artificial storage. Within the scope of the PANACEA-project selected natural analogues as well as test injection sites were studied with respect to fluid migration and trapping, caprock integrity, failure predictability, and related properties.

The Hontomín $\mathrm{CO}_{2}$ pilot injection site, located in northern Spain in the province of Burgos, was chosen for the installation of a test injection well in order to characterize reservoir properties, and to set up and test a newly developed well monitoring system for $\mathrm{CO}_{2}$ injection and storage (Alcalde et al., 2013; Andrés et al., 2016; Dios et al., 2017; Ogaya et al., 2014). In order to describe brittle failure behaviour due to pressure build-up during $\mathrm{CO}_{2}$ injection and to evaluate possible dissolution reactions of the target rock due to acidic brine injection, (oriented) outcrop samples of respective units from the western part of the Basque-Cantabrian Basin (BCB) were taken and analysed with respect to their $\mathrm{CO}_{2}$ storage properties. Therefore, this study mainly focuses on the diagenetic and tectonic development of the western BCB in order to point out substantial geological criteria leading to reservoir formation, fracture development and subsequent fluid activity, and finally fracture occlusion under both, extensional and compressional tectonic conditions.

Previous studies dealing with reservoir properties of the Hontomín $\mathrm{CO}_{2}$ pilot injection site, i.e. Andrés et al. (2016) above all, provided detailed insights into the basement structure of the Hontomín dome and its petrophysical properties with special emphasis on salt flow (Keuper evaporites) in order to explain structural doming and trap formation. However, most studies focus on the current structural situation at the test site, whereas petrological and microstructural data with regard to pore space evolution and fracture formation is still lacking. Therefore, this study pays special attention to sedimentary units of the Lower Jurassic sequence from a back-stepping carbonate ramp that was located along the western slope of a major depocenter in the $\mathrm{BCB}$, close to the onset of the Paleozoic basement (Quesada et al., 2005). We aim to deliver a proper petrographic and microfabric characterization of the reservoir rock units originally supposed for $\mathrm{CO}_{2}$ injection.

After a major rifting phase that occurred during the Triassic the structural situation of the $\mathrm{BCB}$ during early Jurassic times was characterized by crustal relaxation and only moderate subsidence with pronounced trans- and regressive sedimentary cycles resulting in shallow carbonate ramps and carbonate-siliciclastic ramps (García-Mondéjar, 1996; Quesada et al., 2005). These rocks, which mostly coincide with those intended for $\mathrm{CO}_{2}$ injection at Hontomín pilot site, mainly consist of organic-rich 
marls, calcilutites, oolithic grainstones, cellular dolomites, and siliciclastic sandstones. Deposited sediments typically had relatively high porosities as recorded in outcrop samples coming from the BCB and thus seem to represent ideal storage targets. However, porosity of course was drastically reduced during basin subsidence and simultaneous diagenesis. Fracture networks that formed during the Mesozoic rifting phases and the subsequent Alpine orogeny favoured fluid flow during burial and uplift, but were cemented afterwards and hence permeability was reduced again. In order to characterize paleoporosity/permeability and fluid pathways in the target layers, the focus of our study lies a) on the mechanical and chemical behaviour of fractured porous carbonate rocks from the study area in general (Al-Aasm et al., 1995; Antonellini and Mollema, 2000), and b) on macro- and microfracture characterization and its relevance for fracture porosity/-permeability estimation (e.g. Anders et al., 2014; Becker et al., 2010; Fall et al., 2014).

The influence of fractures on pore space and permeability in carbonate rocks directly correlates with the fracture connectivity, and therefore with fracture dimensions (i.e. length and width) and the spatial fracture orientation (McCaffrey et al., 1999 and references therein). While the latter is clearly controlled by tectonic deformation, fracture propagation itself also depends on fluid pressures (i.e. overpressure), which can be estimated using fluid inclusion data of pore and fracture cements (Goldstein, 2001). Besides, basin modelling software can assist to approximate fluid pressures in reservoirs, given that solid information on basin lithology and burial history is provided (Doré et al., 1993).

In the past ten years, research on structural diagenesis has proven the importance of (micro-)fracture and microfabric analysis in petroleum geosciences and related fields of earth sciences, with special regard to the timing of fluid migration and permeability evolution in sedimentary basins (Laubach et al., 2010). Fracture networks propagate in brittle rocks either due to unroofing (mostly restricted to igneous and metamorphic rocks) or in response to tectonic stress (folding, faulting), but also salt diapirism may play a - minor - role (Anders et al., 2014). The evolution of fracture networks can be quite complex and may cover large periods of time, thus reflecting the impact of different tectonic events on brittle deformation patterns (Delle Piane et al., 2017; Peacock et al., 2016). For that reason, the detailed characterization of macro- and microfracture networks and their crosscutting relationships on different scales (core sample - outcrop - regional) and in different dimensions (vertical/lateral connectivity) is crucial for unravelling the fracture-restricted fluid flow history in a sedimentary basin (Becker et al., 2010; Peacock et al., 2018).

Working on core and outcrop samples only is usually accompanied by several problems, the most prominent being the scaling of fracture densities and dimensions when regional data on fracture properties is scarce or completely missing. Following the assumption that microfracture properties (hand specimen) directly correlate with those of macrofractures and related fault systems (field observation) and therefore represent brittle deformation patterns caused by the same tectonic event, an extrapolation of e.g. fracture orientations from lab to field should be possible. However, the extrapolation of microfracture orientation for example is only justified under special circumstances, as several authors have documented (e.g. Ortega and Marrett, 2000, among others). Using (oriented) outcrop samples for petrographic and microfabric analysis without having direct information on fracture length and density on the field scale is problematic, but can be compensated, at least in parts, by literature research. More problematic is the lack of information on the relation between fracture patterns found in hand specimen and related regional fault systems. Several deformation mechanisms can be responsible for extensional fracturing in rocks, such as folding (fractures normal to bedding due to stretching along the hinges), shearing (fractures \pm normal to shear plane), and pure extension (fractures \pm parallel to shear plane), to name only the most common (e.g., Bons et al., 2012; Fossen, 2016), and one can hardly distinguish 
between them without information about the surrounding rock volume (Blenkinsop, 2008; Blenkinsop and Drury, 1988). On the other hand, Franzke et al. (2007), among others, could show that, for example, microstructures of hydrothermal veins and fracture mineralization in the Harz Mountains (Germany) correspond very well with regional paleo-stress regimes and related fault systems, and therefore a direct link between microfractures and faults is most likely. We thus conclude that data on fracture orientation derived from lab-based analytical methods (i.e., universal stage microscopy) is only useful, when comparison with field data is applicable and a direct relation between microfracture sets and superordinate tectonic structures seems plausible. Since stratigraphy and tectonic framework of the BCB have been introduced and discussed in detail by numerous authors (e.g. Ábalos, 2016; Gibbons and Moreno, 2006; Quesada et al., 2005; Quinta et al., 2012; Tavani et al., 2013; Tavani, 2012a; Tavani et al., 2011; Tavani and Granado, 2015; Tavani and Muñoz, 2012, among others) solid information on the structural evolution is available. Fracture patterns concerning the post-Early Jurassic structural evolution of the Plataforma Burgalesa are best described and documented in Tavani (2012a), and therefore, fracture orientation found in our samples is mostly compared to features presented in cited article. Microfabrics of carbonate rocks from the study area with special emphasis on fluid-rock interaction and cement fabrics have been introduced, for example, by Swennen et al. (2012) and Rosales and PerezGarcia (2010), the latter also providing detailed information on basin subsidence and burial history. However, according information on porosity evolution due to diagenesis and tectonic fracturing, as well as burial curves explaining the temperature development in Lower Jurassic units of the BCB are incomplete or missing; they are therefore major subjects of our investigation.

This study is completely based on the investigation of oriented outcrop samples from the BCB. Standard methods for rock characterization include petrographic microscopy, hot-cathode cathodoluminescence microscopy, combined fluid inclusion petrography and microthermometry, and universal-stage microscopy. Quantitative fabric characterization and strain analysis of selected samples was done using EllipseFit software (Vollmer, 2017), burial curves and thermal history were modelled using Schlumberger's PetroMod software. This approach was chosen to effectively combine the results from straight-forward petrographic and laboratory analysis on one side, and basin modelling techniques on the other side. The goal was to exemplify a simple, but comprehensive tectonic reconstruction of the western BCB from early Jurassic to present, with special emphasis on fluid migration along tectonically induced pathways under both, extensional and compressional stress conditions. 
Chapter 6 - Progressive fracture-network development in a carbonate reservoir

\subsection{Geological outline}

\subsubsection{Overview and structural framework}

The study area is located in the western part of the Basque-Cantabrian Basin, an inverted sedimentary basin of Mesozoic origin in northern Spain, which forms a link between the major structural units of the Asturian Massif to the west (Cantabrian-Asturian Mountains) and the Pyrenaean domain to the east (Western/Central Pyrenees), both characterized by large complexes of Paleozoic basement rocks (Fig. 6.1-a, see Aurell et al., 2006). In terms of plate tectonics, the Pyrenean mountain belt represents the collision zone between the Iberian and Eurasian plates. Fig. 6.1-b features a paleogeographic map of the Iberian realm that shows the relative position of the $\mathrm{BCB}$ prior to the Alpine orogeny. According to that, the basin was located within a WNW-ESE striking rift system that stretched between the Iberian Massif in the SW and the Armorican Massif in the NE from early Jurassic to late Cretaceous times. At that time this predominant extensional fault system induced the formation of a seaway between the tropical Tethys ocean in the south and the temperate Boreal ocean in the north, both being part of the mid-Pangea epeiric sea (Quesada et al., 2005).
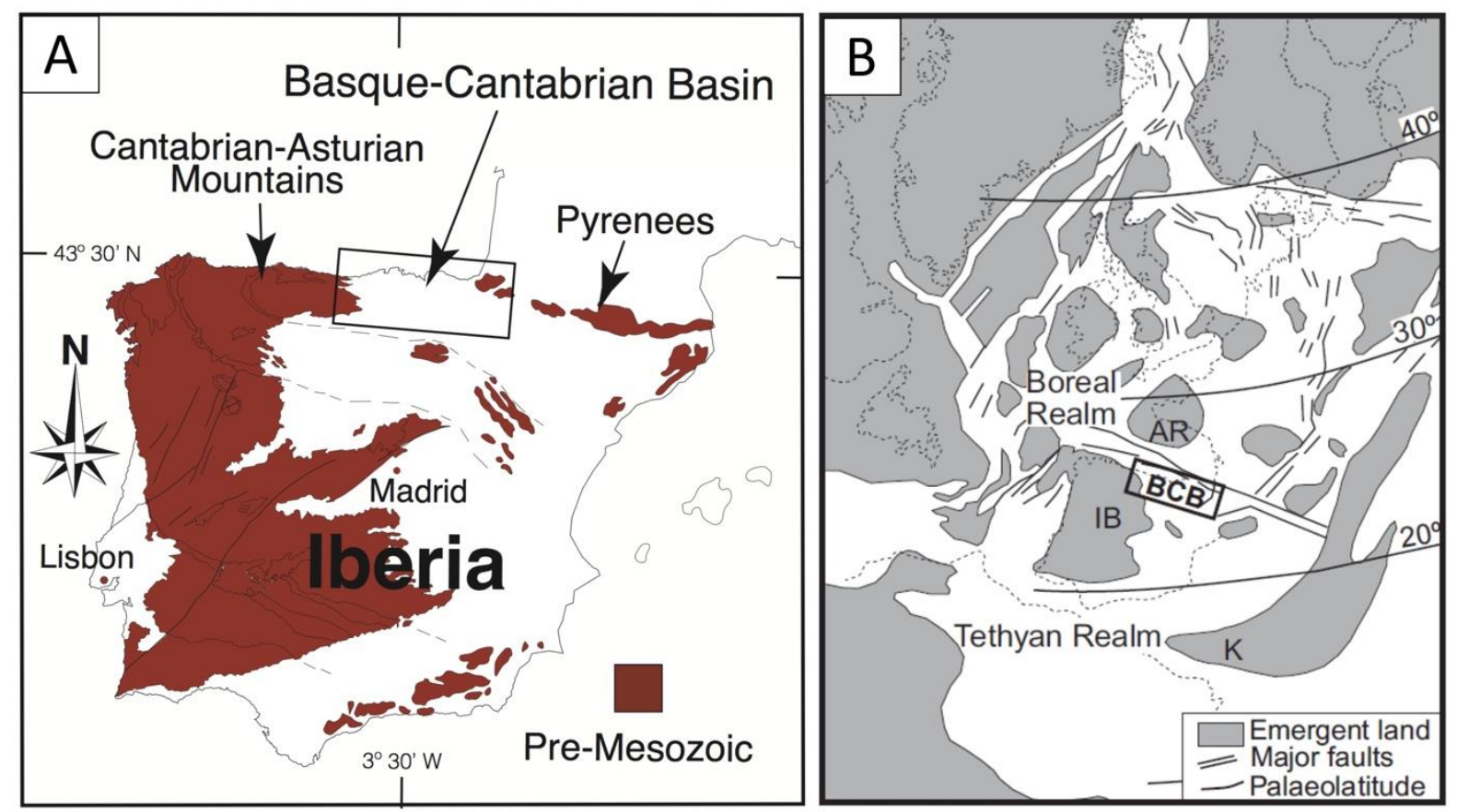

Fig. 6.1. (a) Distribution map of pre-Mesozoic units in the Iberian domain. The BCB (black rectangle) is located between the Cantabrian-Asturian Mountains in the west and the Pyrenees in the east. A detailed distribution map of Mesozoic units of the BCB is given in Fig. 6.3 (from Ábalos, 2016). (b) Paleogeographic map of Europe illustrating the position of the $B C B$ relative to the surrounding terranes prior to the Alpine orogeny (modified from Quesada et al., 2005). IB: Iberian Massif; AR: Armorican Massif; K: Kabylia.

Today, the BCB as a part of the Basque-Cantabrian Pyrenees is delimited to the north by the Bay of Biscay, while to the south the basin is separated from the adjacent Cenozoic Ebro and Duero Foreland Basins, respectively, by a set of WNW-ESE striking faults (e.g. Sierra de Cantabria Thrust Fault); the Ebro and Duero Basins, however, are sub-basins and together form the so-called North Spanish Trough (Capote et al., 2006). As illustrated in Fig. 6.2, the Basque-Cantabrian Pyrenees represent the western part of the Pyrenean mountain belt; they can be further subdivided into the Cantabrian Pyrenees in the 
west, which consist of Paleozoic units mostly, and the Basque Pyrenees in the east that comprise the BCB sensu stricto. The northern continuation of the BCB towards the Bay of Biscay (continental shelf) is occupied by the so-called Bay of Biscay accretionary prism, an accretionary wedge consisting of oceanic crust and marine sediments that formed as a result from compressional deformation during Alpine inversion.

The whole Pyrenean domain is traversed by numerous fault systems of mostly Mesozoic to Cenozoic age, which show two predominant striking directions: a) WNW-ESE striking faults ( \pm parallel to the major deformation fronts) mainly representing thrust faults and, to a certain amount, strike-slip faults; b) a conjugate set of NE-SW and NW-SE striking strike-slip faults (Capote et al., 2006; GarcíaMondéjar, 1996). Investigated samples come from the so-called Cantabrian Transitional Area, an orogenic sub-domain that represents the tectonic transition zone between the Cantabrian mountain belt and the Basque Pyrenees (Tavani, 2012a).

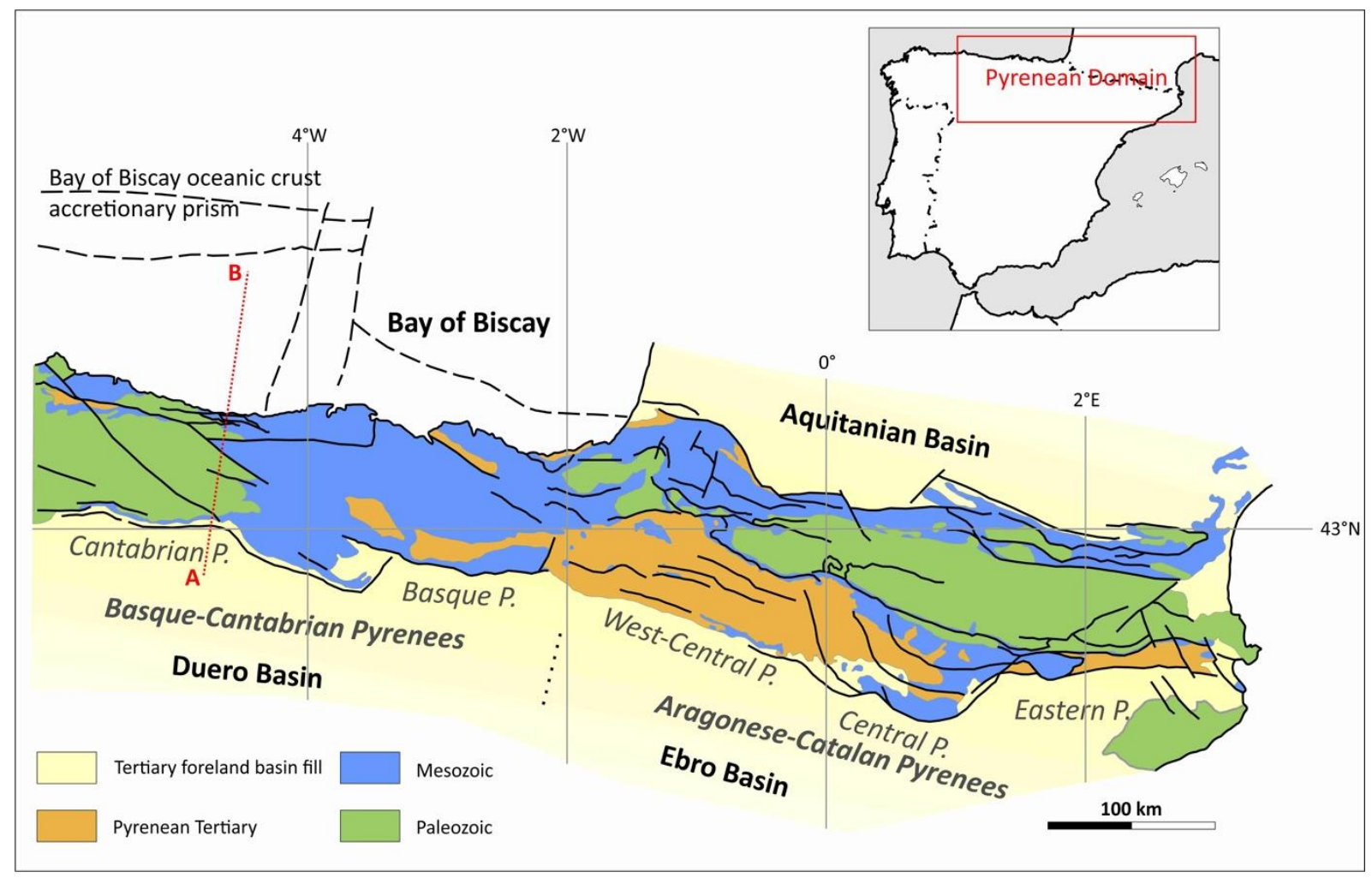

Fig. 6.2. Simplified structural and geological map of the Pyrenean domain along the France-Spain border showing important fault zones (black lines) and names of major tectonic (sub-) units commonly used in literature (modified from Capote et al., 2006). Red line A-B delineates the cross section shown in Fig. 6.4.

Prior to the Alpine orogeny, which finally lead to the folding of the Pyrenean mountain belt during Paleogene, the BCB and adjacent areas experienced several stages of rifting during late Permian and Mesozoic times. According to García-Mondéjar (1996) four major post-Variscan rift phases, which more or less correlate with rifting phases known from the North Atlantic rift system, can be distinguished in the Iberian domain: 1) (late Permian-) early Triassic, 2) late Triassic, 3) middle to late Jurassic, and 4) early Cretaceous (Aptian-Albian). However, Capote et al. (2006) summarizes a simpler history of crustal extension in the Pyrenees with only two major rifting phases occurring during a) Triassic and b) from late Jurassic until early Cretaceous times. 
Widespread extensional deformation of the Iberian domain was already initiated in late Permian when numerous (half-)grabens formed, which were simultaneously filled with thick red bed sequences that show a cyclic depositional character (thickness up to $1500 \mathrm{~m}$ in the Cantabrian-Pyrenean basins); this first rifting stage resulted in the formation of WNW-ESE and E-W striking fault systems (GarcíaMondéjar, 1996). Sedimentation was controlled by inhomogeneous rifting pulses in an asymmetric spreading regime, which locally lead to an unbalanced sediment support and rapidly migrating depocenters (López-Gómez et al., 2006). Unlike in Central Europe Permian rifting in the Iberian domain was not accompanied by major volcanic activity (with few exceptions in the western and central Pyrenees) since steep normal faults did usually not exceed depth of ca. $15 \mathrm{~km}$ and thus did not reach into the asthenosphere (Arche and López-Gómez, 1996).

After a time of uplift and erosion, the Iberian domain was again restructured when a new extensional regime came into effect during late Permian and early Triassic times resulting in symmetric E-W striking basin systems in the Pyrenean domain (López-Gómez et al., 2006). Basin subsidence was quite homogeneous with only minor episodic pulses of tilting and erosion, as recorded by sedimentary basin infill (Buntsandstein facies). Since basin orientation in the Pyrenees show significant differences in terms of orientation compared to other basins of the Iberian domain, Arche and López-Gómez (1996) suggest two different coexisting stress fields in the Iberian plate at that time. The subsequent (post-)rift stage, which prevailed from mid-Triassic to late Jurassic times was controlled by thermal subsidence that allowed progradation of the Tethys sea onto the Iberian domain (López-Gómez et al., 2006), forming an epeiric sea that surrounded the emergent Iberian massif (Aurell et al., 2006). Sedimentation during the Triassic was characterized by at least five cycles of transgression and regression, that successively prograded westward over time. Evaporitic Keuper sequences of the Iberian domain are of special interest since they contain significant amounts of rock salt, which later was partly mobilized along faults and locally forms diapirs.

The Jurassic tectonism of the BCB area can be subdivided into two different extension phases. The first, less pronounced one during early Jurassic is considered as the continuation of the Triassic rifting phase (Aurell et al., 2006). The second rifting stage during late Jurassic - early Cretaceous times had an immense impact on the crustal architecture of the northern Iberian domain; it marks the beginning reconfiguration of the BCB as the southern part of the Bay of Biscay - Pyrenean rift system During this stage the extensional fault system previously established during Lower Triassic times was partly reactivated and extended within an NNE-SSW orientated extensional stress field (Tavani and Muñoz, 2012). Crustal extension was accompanied by a significant drop in sea-level, which explains the deposition of siliciclastic sediments within reactivated graben systems. The latter rifting period again is characterized by three different rifting stages, the first of which started in late Tithonian - Barremian times, initiating strong differential subsidence and graben formation (Martín-Chivelet et al., 2006). The second rifting stage occurred during Aptian - early Albian times; it marks the onset of the opening of the Bay of Biscay and the simultaneous production of oceanic crust. There is still discussion going on about the nature of the opening mechanism of the Bay of Biscay. One model favours an anticlockwise scissor-type rotation of the Iberian domain, while another possible solution may be simple transtensional strike-slip tectonics (García-Mondéjar, 1996; Jammes et al., 2009; Tavani, 2012a). However, this event was locally accompanied by submarine volcanic activity and intrusion of igneous bodies, and thus caused high heat flow in the BCB and surrounding areas (Rosales and Perez-Garcia, 2010). At that time structural differentiation in the $\mathrm{BCB}$ was mainly controlled by left-lateral transtension, locally forming pull apart basins, e.g. in the north-eastern parts of the BCB (Al-Aasm et al., 1995; GarcíaMondéjar, 1996; Martín-Chivelet et al., 2006). A third and final rift stage can be defined for early - 
Middle Albian times; it was subsequently followed by the transition to the late Albian - early Cenomanian post-rift stage. This last rifting episode resulted in maximum differential subsidence in the BCB and the formation of flysch troughs (Martín-Chivelet et al., 2006).

Locally, Mesozoic normal faults were later reactivated and inverted due to a contractive stage during the Cenozoic (Pyrenean compression) (Quintà and Tavani, 2012; Tavani, 2012a). This inversion phase led to the formation of a complex fault system in the BCB when WNW-ESE and E-W striking, rightlateral and left-lateral reverse faults were reactivated (Fig. 6.3). According to Tavani et al. (2013) the Asturian Massif and the westernmost part of the $\mathrm{BCB}$ experienced a tectonic reconfiguration caused by a transpressional reactivation of basement faults, while the central and eastern parts of the BCB are characterized by thin-skinned dip-slip inversion (Gallastegui et al., 2016; Tavani, 2012a, 2012b).

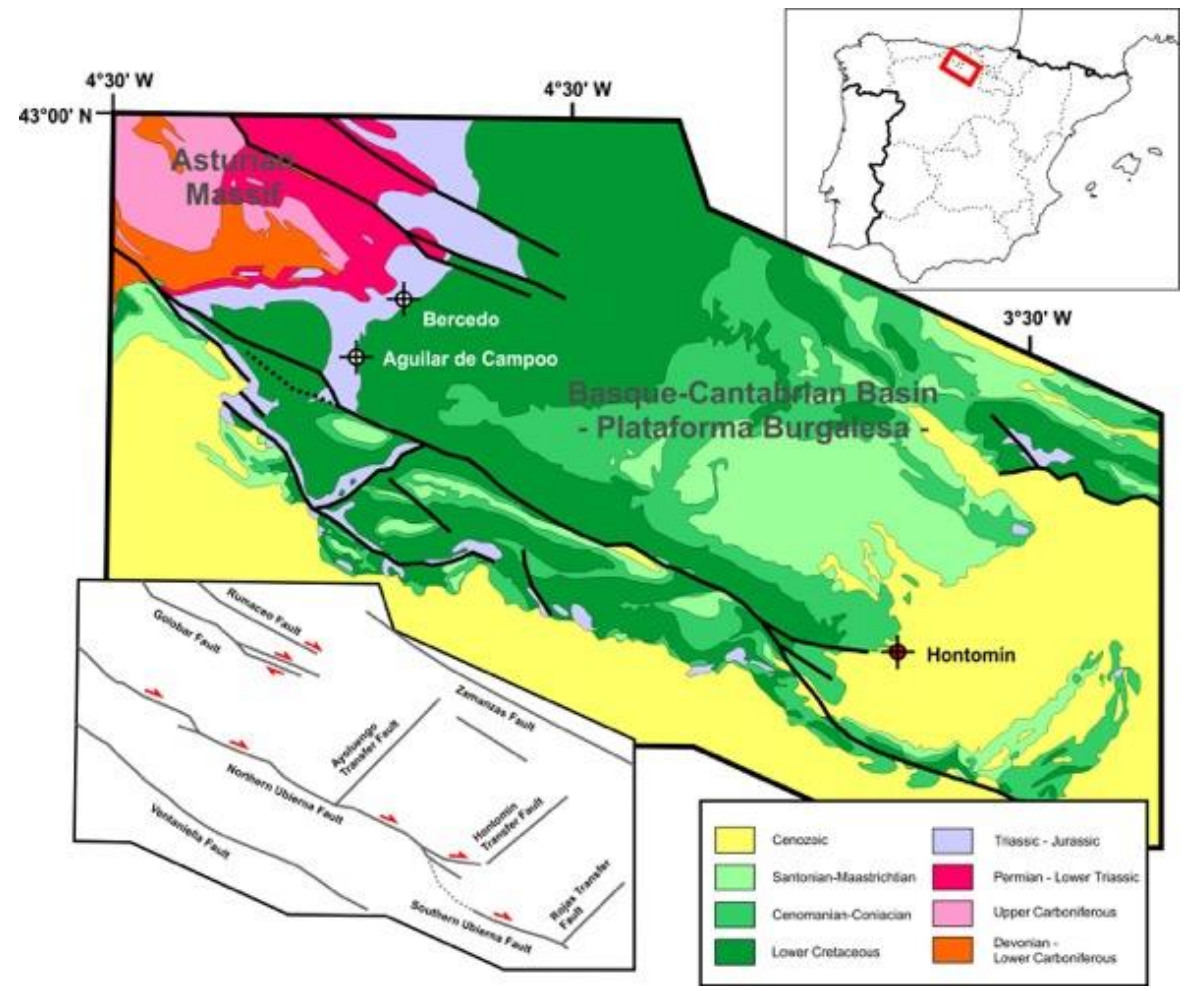

Fig. 6.3. Simplified geologic (top) and tectonic map (bottom) of the southwestern part of Basque-Cantabrian Basin (Plataforma Burgalesa) with major structural lineaments (black lines) and sampling locations, indicated with crosshairs in white circles. The Hontomín pilot site is marked by a crosshair in a red circle (modified from Tavani et al., 2013).

As pointed out by Espina et al. (1996), and Tavani and Muñoz (2012) crustal deformation in the western part of the BCB during tectonic convergence in Cenozoic times mainly occurred along the WNW - ESE striking Ubierna Fault (Ubierna Fold Belt); its southernmost branch in fact also delimits the southern margin of the basin and separates it from the Duero Basin. Other WNW - ESE striking faults such as the Golobar Fault in the north or the mostly covered Ventaniela Fault system in the south of the study area were also affected by Cenozoic inversion tectonics (see Espina et al., 1996). Alpine tectonism in the Iberian domain not only resulted in subduction of Iberian lithosphere and simultaneous accretion of oceanic crust in the Bay of Biscay (see above), but also lead to the formation of accretionary wedges along the southern (pro-wedge) and northern margins (retro-wedge) of the Basque-Cantabrian and Western/Central Pyrenean domains, respectively (Fig. 6.4). Thereby, the retro-wedge flanking the northern margins of the Basque-Cantabrian Pyrenees is more pronounced in terms of lateral extent and 
overall shortening (see Aasen et al., 1994; Capote et al., 2006; Tavani, 2012a, 2012b); it is commonly characterized by shallowly southward dipping thrust faults, while displacement of the pro-wedge is typically associated with steeper faults (strike-slip and oblique slip?). Moreover, Tavani (2012a) suggests the presence of a lithospheric anticline below the pro-wedge, which directly overlays the associated subduction plane. The author relates this structure to a thrust stack of several south-dipping reverse faults in the obducted lower crust, which forms a covered lithospheric wedge between the subducted slab and the obducted upper crust (Fig. 6.4). The anticline was preceded by a syncline that presumably formed during Paleocene-Early Eocene and was subsequently inverted during basin inversion in the Miocene.

\section{Pro-wedge}

$S$

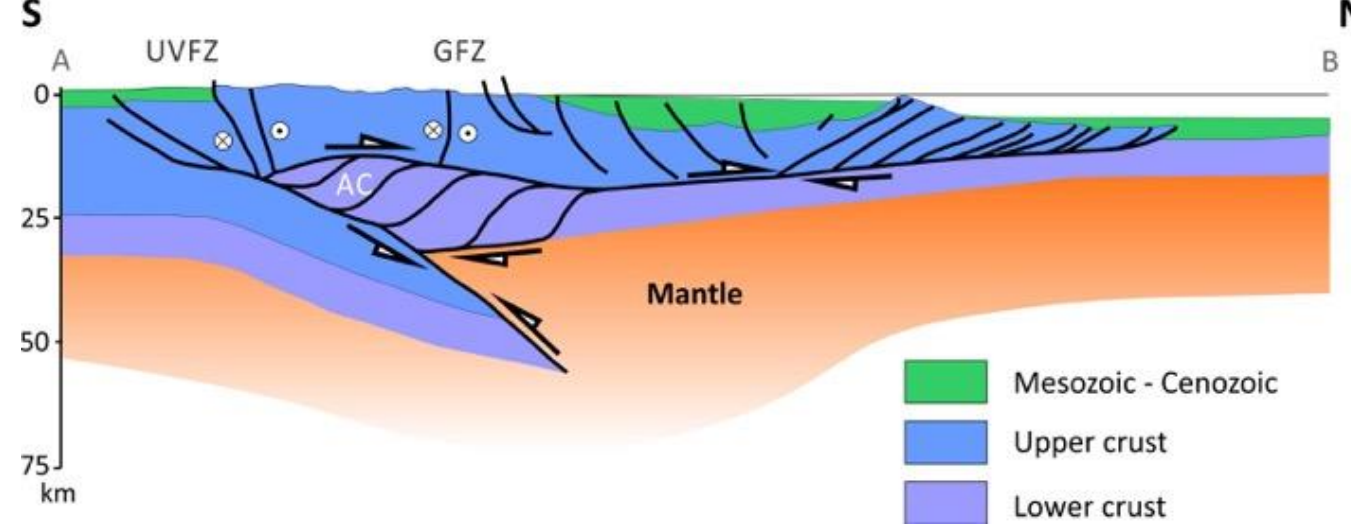

Fig. 6.4. Simplified cross section through the Cantabrian Pyrenees illustrating the crustal architecture and fault arrangement in the study area (modified from Tavani, 2012a). UVFZ: Ubierna-Ventaniella Fault Zone; GFZ: Golobar Fault Zone; AC: lithospheric anticline.

The evolution of fault systems in the so-called Cantabrian Transitional Area (CTA), which marks the structural transition between the Asturian Massif and the BCB, dates back to Paleozoic times as most E-W and WNW-ESE striking faults in the study area are inherited from tectonic structures of preMesozoic age (Ábalos, 2016; Espina et al., 1996; Lepvrier and Martínez-García, 1990; Tavani and Muñoz, 2012). As presented by Tavani (2012a) and Quintà and Tavani (2012), WNW-ESE and W-E striking faults in the CTA have been reactivated in the early Triassic, while tectonic activity of NW-SE and NE-SW striking faults can be verified since early Cretaceous.

A comprehensive reconstruction of plate kinematics and fault (re-)activation in the BCB introduced by Tavani (2012a) covers the time frame from Mesozoic rifting until the Miocene. According to this study, tectonic activity along the Ubierna-Ventaniella Fault Zone can be verified for at least Triassic times, when normal faulting occurred. However, corresponding normal faults were then reactivated during late Jurassic - early Cretaceous rifting. Simultaneously, a set of NE-SW striking and NW dipping transversal faults formed as a result of E-W extension in the BCB. During the Pyrenean orogeny the Ubierna-Ventaniella Fault System was again reactivated as a right-lateral strike-slip system, while on the other side the Sierra de Cantabria Fault System, which delineates the southern margin of the central BCB area, is characterized by right-lateral strike slip and reverse fault kinematics (Quintà and Tavani, 2012; Tavani et al., 2011; Vicente et al., 2011). Thus, deformation of Mesozoic units in the BCB during tectonic convergence first resulted in the formation of E-W striking fold belts and thrusting mainly along the Sierra de Cantabria Fault System where Triassic evaporites favoured decollement (Tavani and Muñoz, 2012); this stage was accompanied be reverse reactivation of formerly normal faults. Later on, 
an E-W to WSW-ENE directional compressional stage reactivated both, the Ubierna-Ventaniella Fault System as well as the Sierra de Cantabria Fault System as right-lateral and left-lateral strike slip faults, respectively; simultaneously reverse faulting occurred along NNE-SSW ramps in the hanging wall of the south eastern Ubierna fault (Tavani, 2012a). Concerning our study area, brittle deformation of Lower Jurassic units was mainly controlled by two WNW-ESE striking faults, the Ubierna fault and the Golobar fault, which encompass the study area in the south and in the north, respectively. Both faults strike in WNW-ESE direction, but unlike the Ubierna fault, which was reactivated during Cenozoic compression as a right-lateral transpressional fault, the shear sense of the Golobar fault changed from right-lateral to left-lateral strike-slip during E-W compression. In fact, since the Golobar fault represents the north-western kinematic extension of the Sierra de Cantabria Fault System, its change in shear sense can be attributed to the activation of the Sierra de Cantabria fault as a transpressive left-lateral fault during the latest stage of the Pyrenean orogeny. Brittle deformation features of Mesozoic units in the study area between the Asturian Massif and the Plataforma Burgalesa, such as faults, joints, and veins, are well studied; they are compiled and linked in detail with respective tectonic deformation stages, for example, by Tavani (2012a). Our findings regarding microstructures and fracture sets will be compared to results in cited article in Chapter 6.5.2.

\subsubsection{Stratigraphy and sedimentary record}

The depositional history in the study area starts with the deposition of conglomerates and sandstones during the first rifting phase in Permo - Triassic times (Buntsandstein facies) that are unconformably superimposed on Paleozoic basement units of the Asturian Massif (Fig. 6.5). Post-rift sediments of Triassic age typically consist of dolostones and carbonates (Muschelkalk facies), as well as evaporites and clays (Keuper facies) (Quesada et al., 2005), that document the progressive drowning and backstepping of a carbonate ramp during the late Triassic - early Jurassic sea level rise. Triassic evaporites play an important role in fault kinematics of the Basque Pyrenees, as they often act as decollement horizons during faulting. Tavani (2012a) could demonstrate how Keuper facies distribution in the BCB coincides with major fault systems, where especially the formation of thrust faults seems to be influenced by the presence of Keuper rock salt in the footwall. 


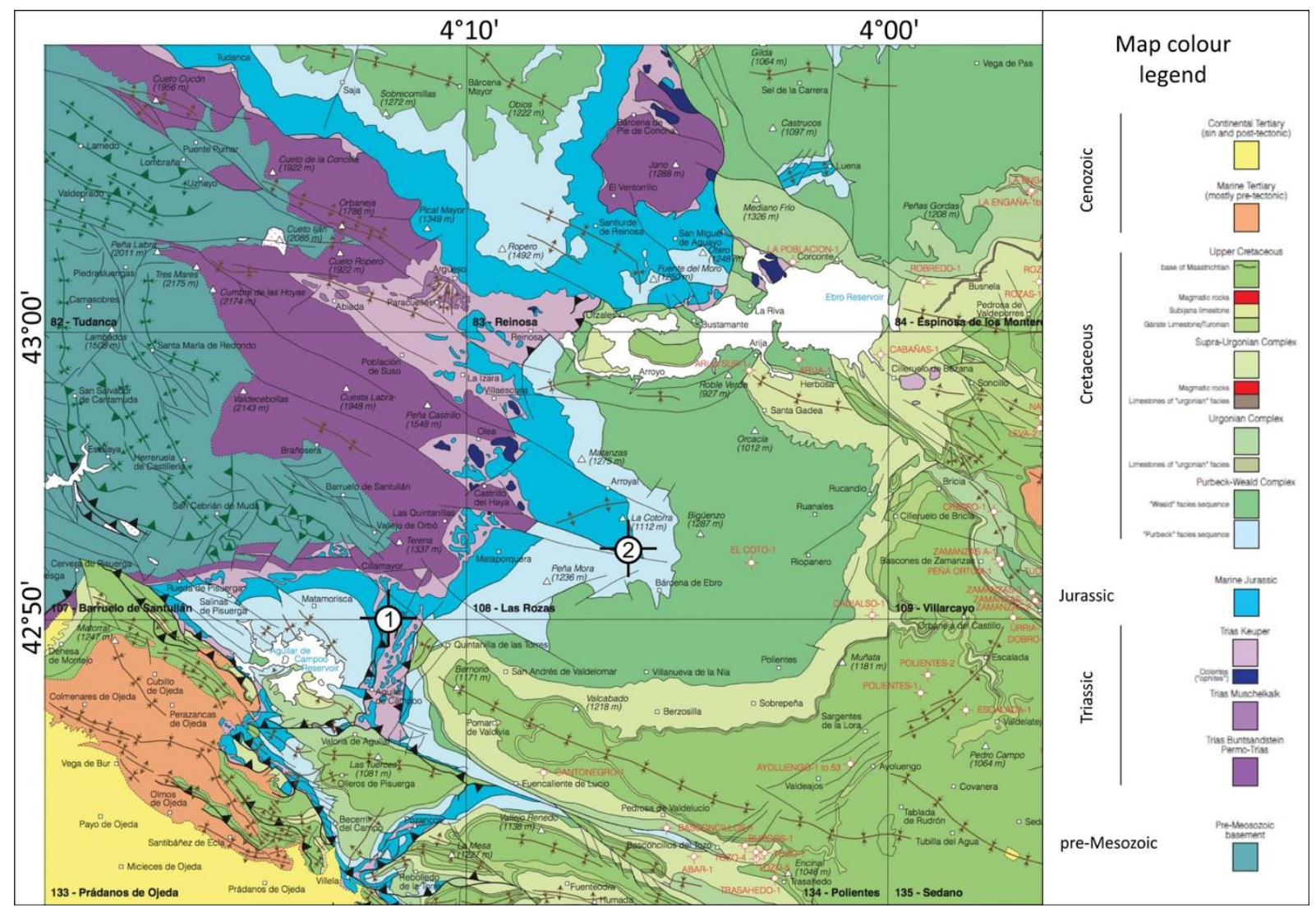

Fig. 6.5. Detailed geologic map of the CTA. Samples come from the overlapping area of Mesozoic units onto (pre-)Mesozoic units of the Asturian Massif in the west, sampling locations are indicated by numbers in crosshairs (modified from Ábalos, 2016).

The succession of Lower Jurassic units starts with the continued sedimentation of the Puerto de la Palombera Formation, which consists of dolomicrites, dolomitic limestones, and anhydrites. Theses sediments represent the depositional environment of sabkhas and supratidal flats that prevailed from Rhaetian to Hettangian times. During the early Sinemurian, peritidal conditions favoured the precipitation of mostly laminated limestones and dolomitic limestones of the Villanueva de Puerta Fm. on a shallow carbonate ramp, which were continuously replaced by limestones of shallow subtidal origin (Sopeña Fm.). Both units can locally show lateral replacement with oolithic grainstones, since lateral changes of facies in cited sedimentary rocks are quite common and manifold, as described by Aurell et al. (2006), among others. Subsequently, shallow marine sediments of the Villanueva de Puerta and Sopeña Fm. were conformably replaced by shallow marine to fluvial siliciclastic and carbonatesiliciclastic sediments of the Rio Polla Fm. (late early Sinemurian). The stratigraphic succession of this Lower Jurassic shallow marine carbonate ramp ends with an erosional unconformity, which is dated as mid-Sinemurian (Quesada et al., 2005). During the rest of the Liassic, the shallow carbonate ramp is continuously transformed into a hemipelagic ramp, which consists of alternating layers of mudstones and wackestones, as well as limestones, organic-rich/lean marles, black shales and bioclastic packstones and grainstones (late Sinemurian: Puerto del Pozazal Fm.; Pliensbachian: Camino Fm.; Toarcian: Castillo Pedroso Fm.). Fig. 6.6 illustrates the vertical and lateral distribution of Liassic units in the BCB exemplified by a schematic cross section through the Polientes-Tudanca Trough (see Fig. 6.7 for explanation). All in all, according to Gibbons and Moreno (2006) and references therein, as well as Quesada et al. (2005), compiled thickness of Lower Jurassic sediments in the CTA is ca. $500 \mathrm{~m}$. 
Chapter 6 - Progressive fracture-network development in a carbonate reservoir

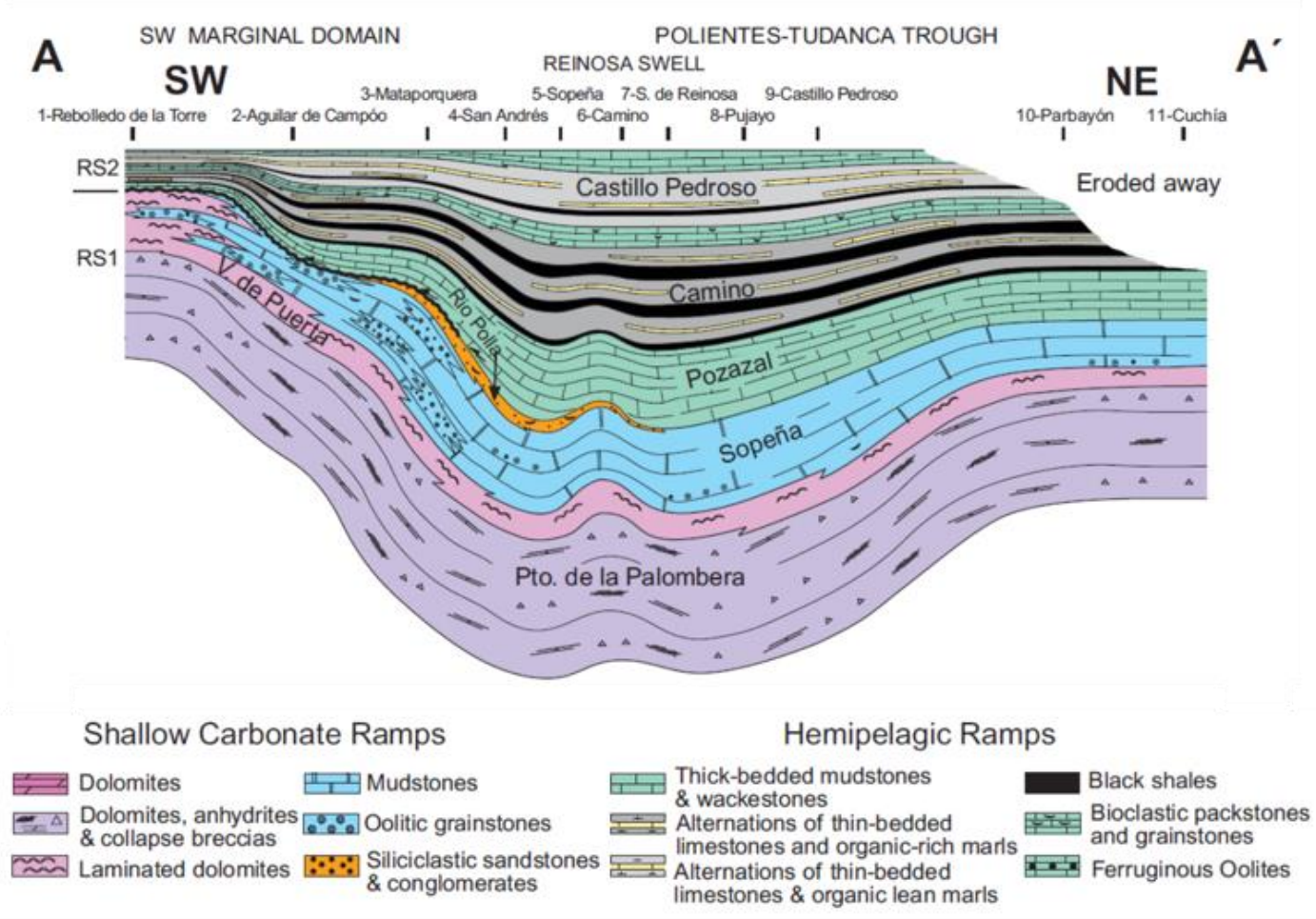

Fig. 6.6. Cross section through Upper Triassic and Liassic units from the western BCB, the study area is located near the town of Aguilar de Campóo (\#2, marginal domain) (modified from Quesada et al., 2005).

During the early Jurassic the E-W striking BCB was structurally dominated by two major depressions located along its western and eastern margins, respectively, which acted as the main depocenters (Fig. 6.7). The study area is located along the western flank of the so-called Polientes-Tudanca Trough, a NNW-SSE striking depression where a maximum sedimentary thickness of about $600 \mathrm{~m}$ was accumulated. The structural origin of the through cannot be determined with certainty, but it is likely the result of Triassic rifting. 


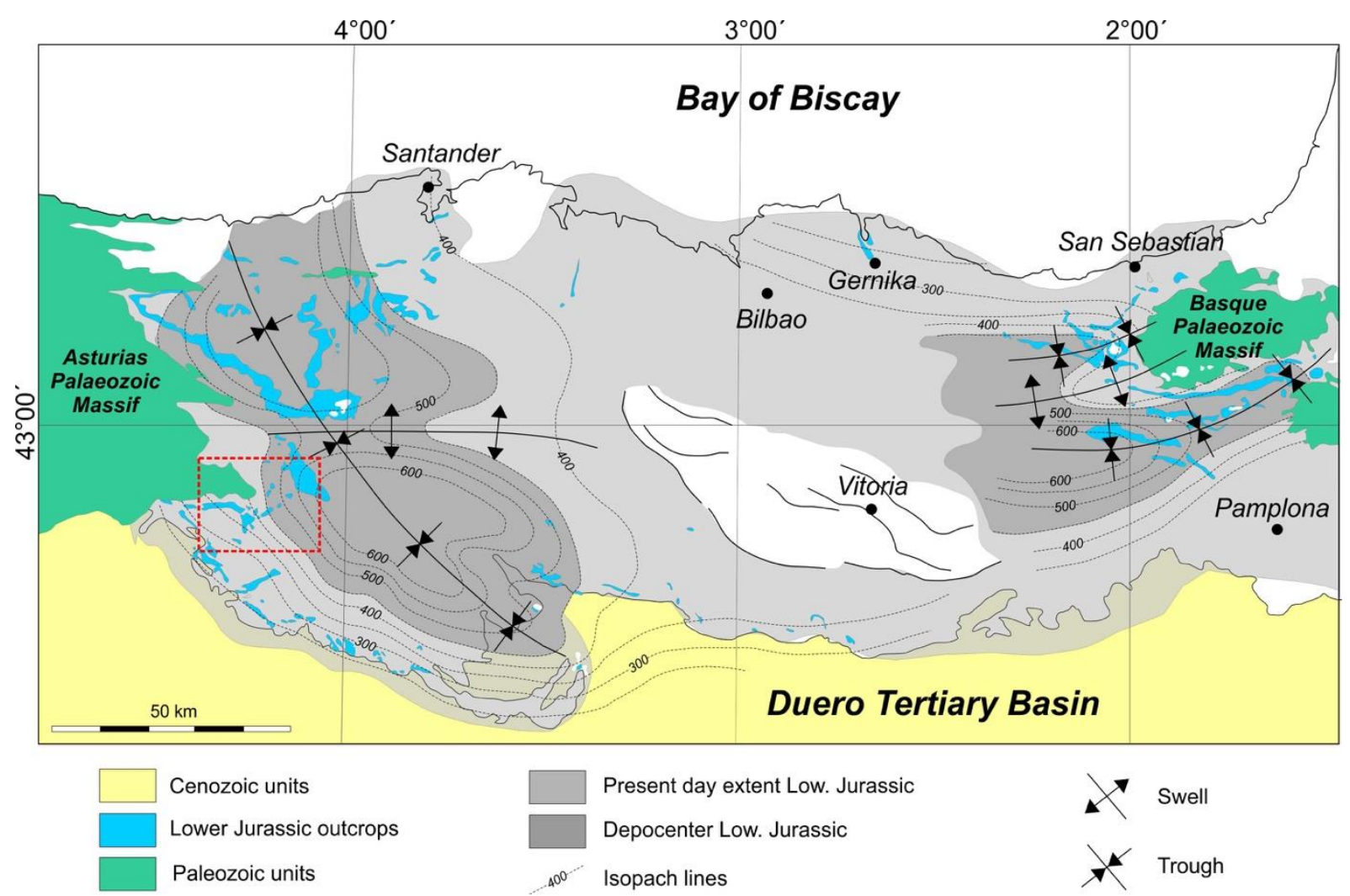

Fig. 6.7. Distribution map of Lower Jurassic units in the Basque-Cantabrian Basin (light grey); present day outcrops of respective units are shown in blue. Main depocenters (dark grey) are located along the western and eastern margins of the basin close to the present day paleozoic outcrops (modified from Quesada et al., 2005). The study area, indicated with a dashed red rectangle, is located along the western slope of a NW-SE striking trough (Polientes-Tudanca Trough).

In Middle Jurassic times, the sedimentary record is characterized by a hiatus located at the early to Middle Jurassic, discontinuously followed by marine mudstones, wackestones, and dark grey marls. Especially during the Aalenian, the deposition of sediments in the BCB was controlled by tectonically induced subsidence, as thickness of according sediments is typically higher compared to adjacent basins (Aurell et al., 2006). From Bajocian to Callovian times, several cycles of mainly mudstones, organicrich marls, bioclastic wackestones were deposited in a highly variable depositional environment controlled by differential subsidence. The whole sequence again is marked by an intra-Jurassic erosional surface (Aurell et al., 2006). During Upper Jurassic (Kimmeridgian - Tithonian) and Lower Cretaceous times (Valanginian), the previously prevailing depositional environment continuously changed due to the opening of the Bay of Biscay. Kimmeridgian sediments mostly consist of oolithic packstones and grainstones, laterally gradually interfingering with sandstones of deltaic origin (Aurell et al., 2006). These marine sediments were subsequently replaced by mostly continental (fluvial and palustrine) to transitional deposits of the Purbeck mega sequence (Tithonian - Valanginian; Campóo + Cabuérniga Groups), which show high variabilty in thickness (ca. $500 \mathrm{~m}$ in the study area). Deposits of the Weald facies (Valanginian - Barremian), which are separated from the Purbeck mega sequence by the Los Llares Unconformity (Pujalte, 1981), consist of siliciclastic channel-fill sandstones and various, locally organic-rich (lacustrine) mudstones (Pas Group). The late Jurassic - early Cretaceous sedimentary succession in the western BCB is marked by a hiatus concerning deposits of Callovian to Tithonian age, locally also Berriasian strata is missing (Aurell et al., 2006). Estimated total thickness of Middle to 
Upper Jurassic and early Cretaceous units (Purbeck + Weald facies) in the CTA is approximately $1375 \mathrm{~m}$.

After a short hiatus, this terrestrial depositional sequence was later on followed by a marine transgression resulting in the deposition of shallow-marine Urgonian-type carbonate sediments and the development of large carbonate platforms and separating sub-basins across the BCB (Aptian - early Albian) (Martín-Chivelet et al., 2006). In late Albian - early Cenomanian times turbiditic sequences of the so-called 'black flysch' facies formed within depressions, locally continuosly merging into calcareous flysch and limestone deposits (Late Cenomanian - early Turonain). Garcia-Mondejar et al. (2005) could prove a pulsating tectonic subsidence behavior for the BCB during Aptian - Albian times (time interval: $25.4 \mathrm{my}$ ) with an estimated total subsidence of ca. $1.8 \mathrm{~km}$ in the central western BCB. Tectonic burial curves presented in cited paper state a burial depth of 3.1 to $3.7 \mathrm{~km}$ within the PolientesTudanca Trough prior to the Aptian - Albian rifting phase. As shown by Rosales and Perez-Garcia (2010) total thickness of the Aptian - Albian sedimentary succession is about $1300-1700 \mathrm{~m}$ in the central and northern $\mathrm{BCB}$, however, in the westernmost parts total thickness is expected to have been significantly less (i.e. $800-1000 \mathrm{~m}$ ) (Martín-Chivelet et al., 2006).

Late Cretaceous sediments in the western BCB comprise five stratigraphic mega sequences (Mena Fm., Angulo Fm., Losa Fm., Sedano Fm., Urbasa Fm.) from early Cenomanian to Maastrichtian times which are characterised by the deposition of a large variety of (hemi-)pelagic to mostly marine sediments, depending on local topography. Apart from marls, limestones, claystones, calcareous flysch deposits, and - locally - sandstones, tuffites and basaltic volcanics are also quite common. This proves volcanic activity due to spreading in the Bay of Biscay and even during the post-rift interval (Albian Santonian) (Martín-Chivelet et al., 2006). Total thickness of Cenomanian - Maastrichtian sequences in the study area is hard to determine and can only be approximated by comparison with the stratigraphic record in adjacent areas (ca. $800-1200 \mathrm{~m}$ ).

As is the case with Cretaceous units, sedimentary rocks of Cenozoic age are not preserved in the study area, they were completely eroded during exhumation related to Alpine orogeny. However, several deposits in the Basque Pyrenees prove the former presence of syn- and post-tectonic clastic sediments within intramontane troughs and synclines (Ábalos, 2016), according to which a maximum thickness between 200 and $600 \mathrm{~m}$ can be estimated. The complete regional stratigraphy of the BCB from Lower Jurassic to Neogene is presented in Fig. 6.8. 
Chapter 6 - Progressive fracture-network development in a carbonate reservoir

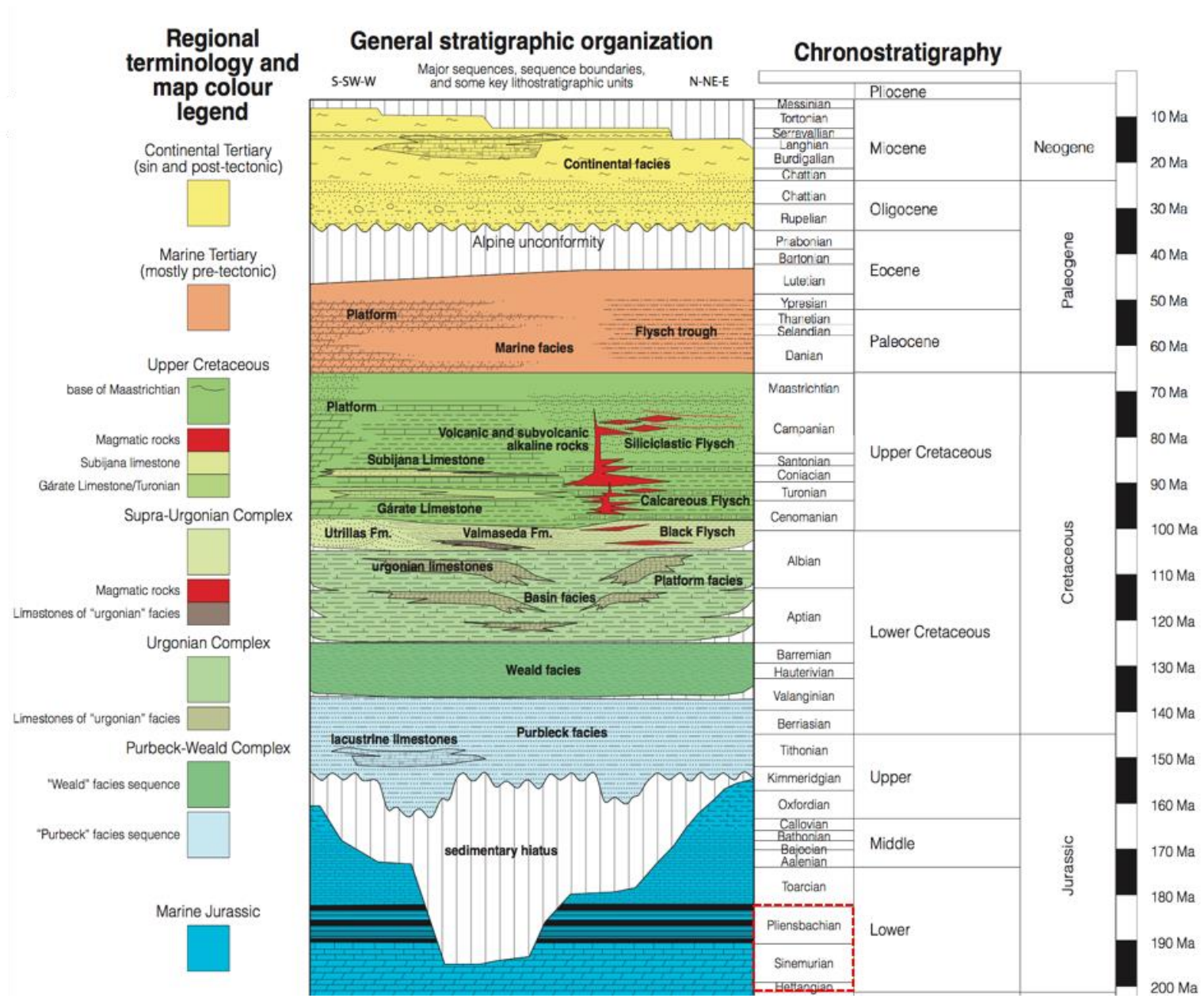

Fig. 6.8. Stratigraphic chart of Lower Jurassic to Pliocene units from the BCB. The chronostratigraphic section of investigated samples is marked with a red rectangle (modified from Ábalos, 2016). 
Chapter 6 - Progressive fracture-network development in a carbonate reservoir

\subsection{Sample material and methodology}

\subsubsection{Sample material}

Studied sample material comes from outcrops in Lower Jurassic units located between the towns of Aguilar de Campóo and Reinosa in the western Basque Pyrenees (see Fig. 6.5). Samples of the investigated units that are supposed for $\mathrm{CO}_{2}$ injection at the Hontomín pilot site belong to the depositional environment of a shallow carbonate ramp (Puerto della Palombera Fm., Villanueva de Puerta Fm., Rio Polla Fm.) of Hettangian - Sinemurian age, whereas one sample of Pliensbachian age, which possesses caprock properties, is related to the depositional environment of a hemipelagic ramp (Camino Fm.) (see Fig. 6.9). Field images and pictures of hand-specimen of sampled units are presented in Appendix 6-1.

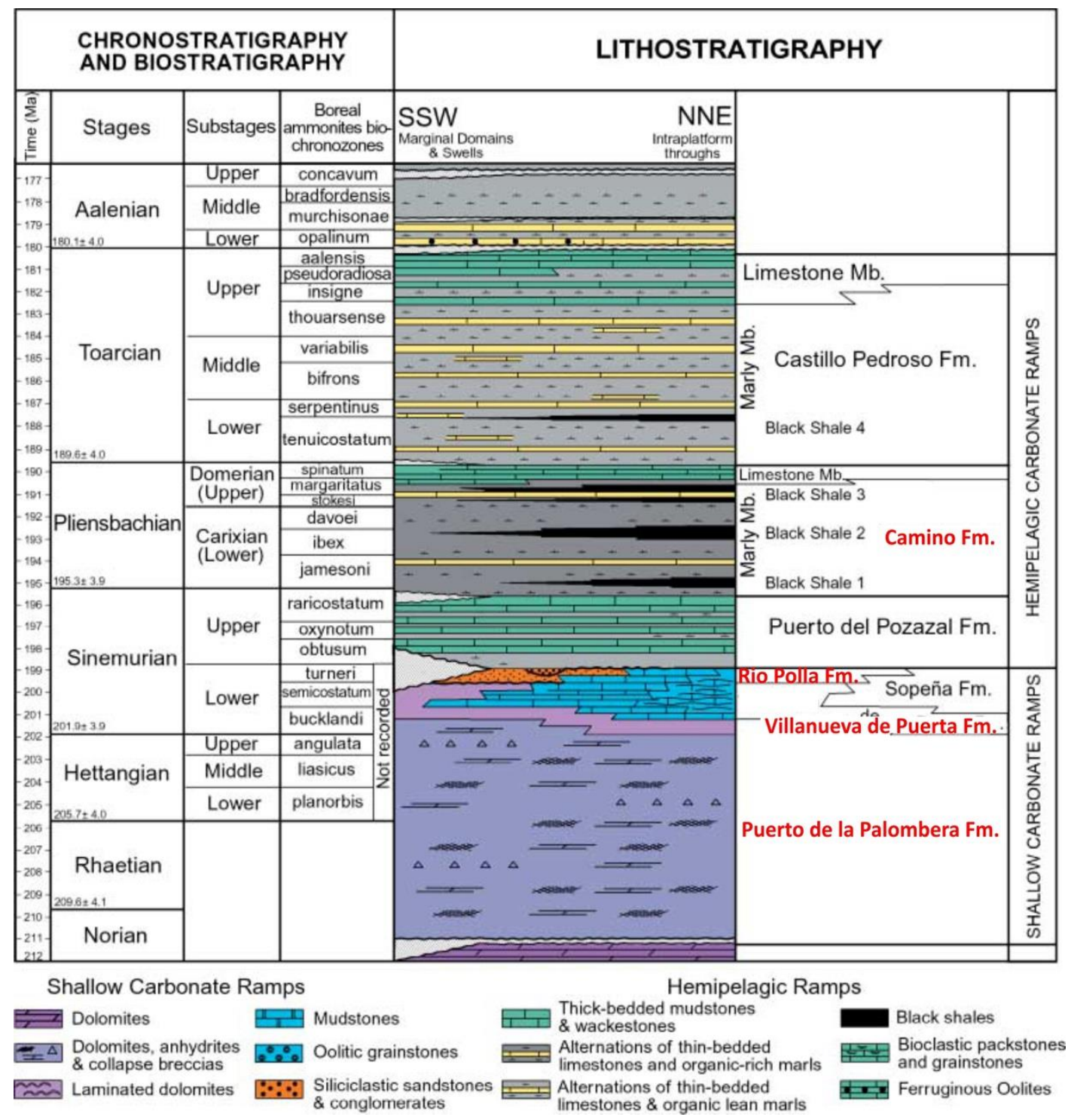

Fig. 6.9. Chrono-, bio-, and lithostratigraphic chart of Upper Triassic to Middle Jurassic units from the western section of the Basque Pyrenees. Names of sampled units are given in red letters (modified from Quesada et al., 2005). Units of the Norian - Lower Sinemurian shallow carbonate ramps tend to have good reservoir properties with porosities ranging between $10-20 \%$, while marly to shaly units of the Pliensbachian Camino Fm. typically possess good sealing properties (caprock). 
Chapter 6 - Progressive fracture-network development in a carbonate reservoir

All samples were drilled from outcropping rock units, one sample (B2.1) out of a total of four samples is oriented by means of true north and vertical orientation (top/bottom), whereas for all other samples strike, dip and vertical orientation were documented according to the scheme demonstrated in Fig. 6.10. Drilled cylindrical samples have a diameter of ca. $5 \mathrm{~cm}$ (2 inches) and a height of ca. $4 \mathrm{~cm}$. A set of three drill cores was provided for each sampled unit, out of which at least one set of three thin sections and three corresponding mirrored thick sections with an orthogonal orientation (ABC) were produced for each unit (for further explanation see Chapter 2). Samples were kindly provided by Timea Kovacs and Jordi Cama (IDAEA, CSIC), in cooperation with GEA Asesoría Geológica (Llanera, Asturias/Spain).

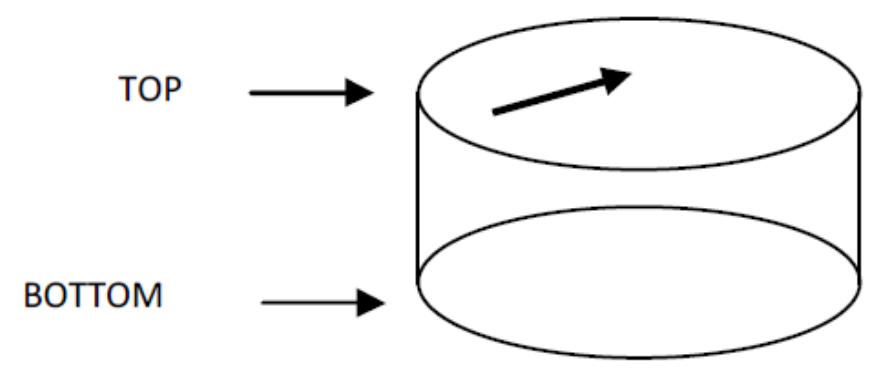

Arrow on top-side indicates either north (N) OR strike line.

Fig. 6.10. Schematic sketch illustrating nomenclature of drill core orientation features. 
Chapter 6 - Progressive fracture-network development in a carbonate reservoir

\subsubsection{Methodology}

This study is based on microstructural and fluid-chemical analyses on petrographic thin and thick sections, and the correlation of respective findings with 1D numerical basin models. Samples used for thin/thick section preparation were selected with respect to the presence of healed and/or sealed fractures, as fluids trapped within fracture cements provide information on fluid chemistry, pressure and temperature conditions during fluid migration, and the (relative) timing of fracturing during basin evolution. After petrographic microscopy was applied in order to determine mineral composition and to characterize rock microfabrics, point counting of selected thin sections (500 counts per sample) was carried out to quantify the mineral composition and to additionally approximate the residual porosity of the investigated samples (Dickinson, 1970; Gazzi, 1966). Results for samples B10N and B13.4 were inherited and modified from Nolte (2013) and Hillebrand (2013), respectively. Thin section-based porosity measurements were finally supplemented by digital image analysis (DIA). Both, thin and thick sections were then used for universal stage microscopy, which allows to collect data on paleo-stress directions and strain, and therefore helps to reconstruct the rock's deformation history. Strain of sample B10N (oolithic grainstone) due to compaction-related pressure solution during tectonic subsidence prior to fracturing was estimated using the Fry method. Subsequently, polished thin sections were carbon coated and hot-cathode cathodoluminescence microscopy was done to distinguish different cement and fracture generations, and to visualize age relations between pore and fracture cements. After petrographic analysis was finished, chemistry of paleo-fluids trapped within (fracture-) cement-hosted fluid inclusions was identified using microthermometry. By applying paleo-pressures and temperatures, which were derived from crossing-isochore calculations of aqueous fluid inclusions, existing burial curves for the Basque Pyrenees (Rosales \& Peréz-García, 2010) were customized according to our data in terms of fracture formation, maximum burial and heat flow, with particular focus on Mesozoic rifting phases in the BCB. 
Chapter 6 - Progressive fracture-network development in a carbonate reservoir

\subsection{Results}

\subsubsection{Carbonate petrography and microstructures}

\section{B2.4: Calcilutite (Fm. Camino; Pliensbachian)}

Coming from the Camino formation (location \#2 in Fig. 6.5), sample B2.4 is a dark micritic limestone that appears dull grey to brownish-grey in hand specimen and brownish in transmitted light (see Fig. $6.11-\mathrm{a} / \mathrm{b}$ ). The brownish colour varies locally and shows lighter areas in the matrix, which are probably the result of chemical reduction during diagenesis. The matrix represents $>80 \%$ of the rock mass and mostly consists of microcrystalline calcite grains ( $\varnothing<0.063 \mu \mathrm{m}$; calcilutite/pelite); besides, the limestone contains microfossils with typically circular shape (foraminifera), bivalve shells and dark opaque mm-sized particles that probably consist of $\mathrm{Mn}$-/Fe-hydroxides or organic matter. The limestone shows distinct bedding on the field scale where $\mathrm{dm}$-wide limestone strata alternate with $\mathrm{cm}$-wide shale layers (field image: Appendix 6-1); however, no lamination is apparent neither in hand specimen, nor in thin section.

The dense limestone (porosity: $<5 \%$ ) is characterized by $\mu \mathrm{m}$-wide fractures which are filled with colourless calcite. Microfractures show various orientations and often occur in parallel sets (Fig. 6.11), at least three fracture sets with distinct orientation and cement characteristics can be divided: one of them is completely (I) and the other one only partially (II) cemented with a residual fracture porosity of $<15 \%$. Sharp wallrock contacts prove brittle deformation and wall-normal fracture opening without subsequent dissolution. Equigranular blocky to subhedral calcite fracture cements show no deformation lamellae; no signs of recrystallization are apparent and no fluid inclusions are visible. Classification after Folk (1959): biomicrite; classification after Dunham (1962): mudstone (alternative: calcimudstone).
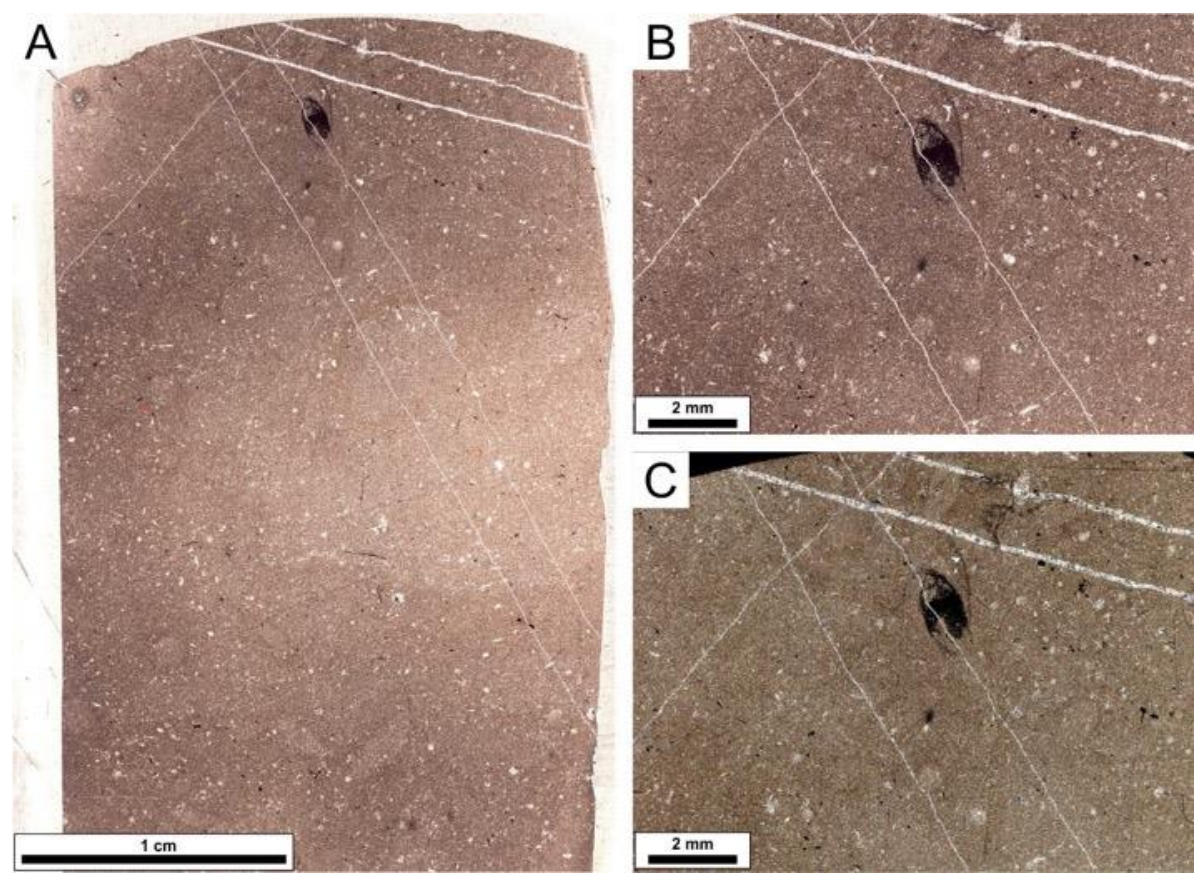

Fig. 6.11. Microscan of sample B2.4 (A-slide) in plane polarized light $(A+B)$ and crossed polarized light $(C)$. At least two different fracture sets are visible. Note the dark organic particle in the upper center (A) crosscut by a minute calcite-filled fracture. Older conjugate fracture sets are completely cemented with calcite, while younger parallel fracture set are only partially cemented with calcite. 


\section{B13.4: Siliciclastic sandstone (Fm. Areniscas del Rio Polla; Lower Sinemurian)}

The grain-supported sandstone, which appears grey to yellowish-grey in the field (see Appendix 6-1) mainly consists of poly- and mono-crystalline quartz grains and carbonate particles such as ooids, peloids, and lithoclasts, along with minor amounts of detrital potassium feldspar and carbonate bioclasts (Fig. 6.13; see Fig. 6.12 for a detailed compilation); accessory detrital constituents are tourmaline and zircon. Grain size of the moderately sorted quartz grains varies between $0.1 \mathrm{~mm}$ and $2 \mathrm{~mm}$ (arenite); the common occurrence of detrital quartz, feldspar grains, and ooids is indicative for a proximal deposition within a shallow marine environment (Flügel, 2004).

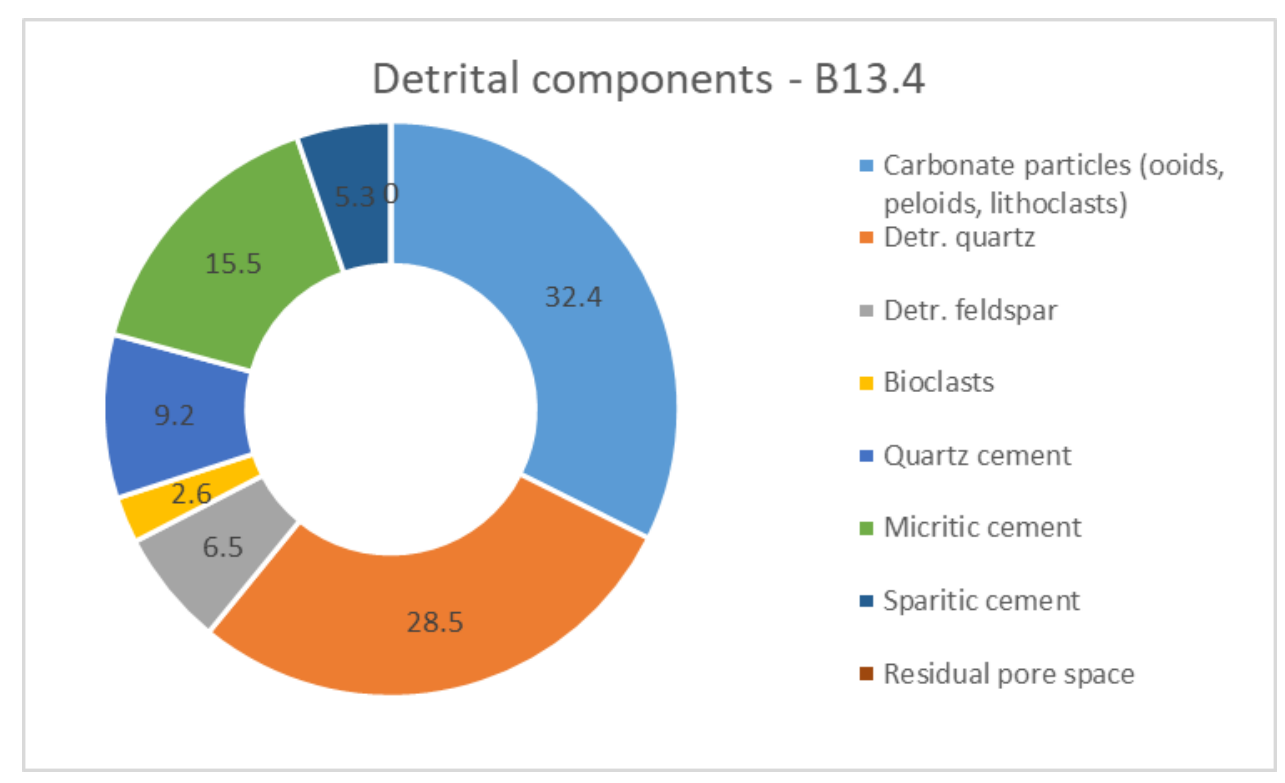

Fig. 6.12. Major (detrital) components and cement fractions of sample B13.4 in \% (modified from Hillebrand, 2013).

The micritized ooids are mostly spherical and occasionally show radial fibres; they often contain growth nuclei of quartz and feldspar grains. The sub-angular to sub-rounded quartz and feldspar grains locally show subhedral to euhedral shape with rhombohedral faces that prove diagenetic syntaxial overgrowth; quartz cements locally incorporate micritic calcite cement. Locally, detrital quartz grains and subhedral quartz cements are affected by dissolution and subsequent calcite replacement during micritization. Syntaxial quartz cement precipitation is usually restricted to monocrystalline quartz grains, polycrystalline quartz grains are only affected when relatively large subgrains are present. Intergranular pores are mostly filled with clear calcite cement; besides, syntaxial quartz and feldspar cements, as well as micritic calcite cement reduced primary porosity, which currently is $<1 \%$. Polycrystalline quartz grains reveal deformation features such as foliation, undulose extinction and bulging, which suggests a metamorphic origin; monocrystalline quartz grains are likely of igneous origin. Brownish sutured and serrated lines along ooid and quartz grain contacts locally prove pressure solution due to compaction, however, no mineralized (macro-) fractures are detectable in the sample. Where brittle deformation along quartz grain contacts took place, intragranular microfractures were subsequently filled with calcite. Locally pressure solution features are visible, which are likely indicative for vertical compaction (vertical sigma 1) and therefore allow a relative orientation of the sample; they are mostly restricted to ooids, micritic cement, and quartz grain contacts. Micritization not only of ooids, but also of calcitic and aragonitic particles (shells), as well as pore cements is a common phenomenon in this sample. 

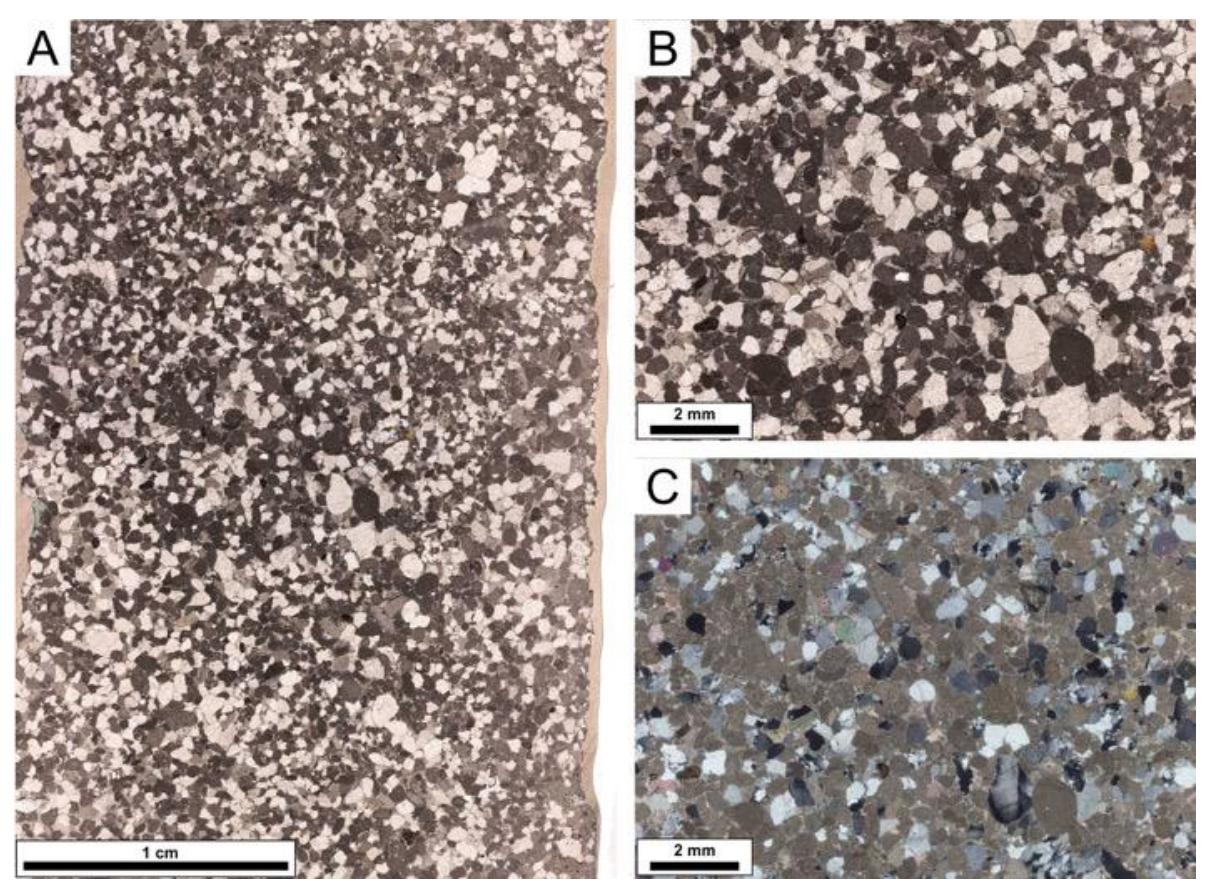

Fig. 6.13. Microscan of sample B13.4 (B-slide) in plane polarized light $(A+B)$ and crossed polarized light

(C). Colorless grains in plane polarized light indicate detrital quartz and feldpsar, and, to a minor extent, pore-filling calcite cement. Darker grains are ooids, peloids, and lithoclasts. No apparent bedding is visible.

\section{B10N: Oolithic grainstone (Fm. Villanueva de Puerta; Lower Sinemurian)}

The oolithic limestone (sampling location \#1 in Fig. 6.5) mainly consists of ooids, bioclasts, peloids, detrital quartz and minor amounts of potassium feldspar grains; components of the grain-supported limestone are cemented with clear intergranular pore-filling calcite (sparite). In addition, apparent calcite-filled microveins are characteristic for this sample. Primary porosity decreased stepwise by episodes of pressure solution and cementation from initially ca. $40 \%$ to a residual porosity of less than $5 \%$, of which most residual pore space is hosted within fractures (partially cemented fractures) (Fig. 6.15; see Fig. 6.14 for details). In its present state, the limestone is largely sealed and shows a low residual permeability, which in fact does not favour the penetrative migration of fluids through the volume. In the course of diagenesis, a temporarily much higher permeability has to be assumed during several episodes of vein-formation (classification after Folk (1959): oosparite). 


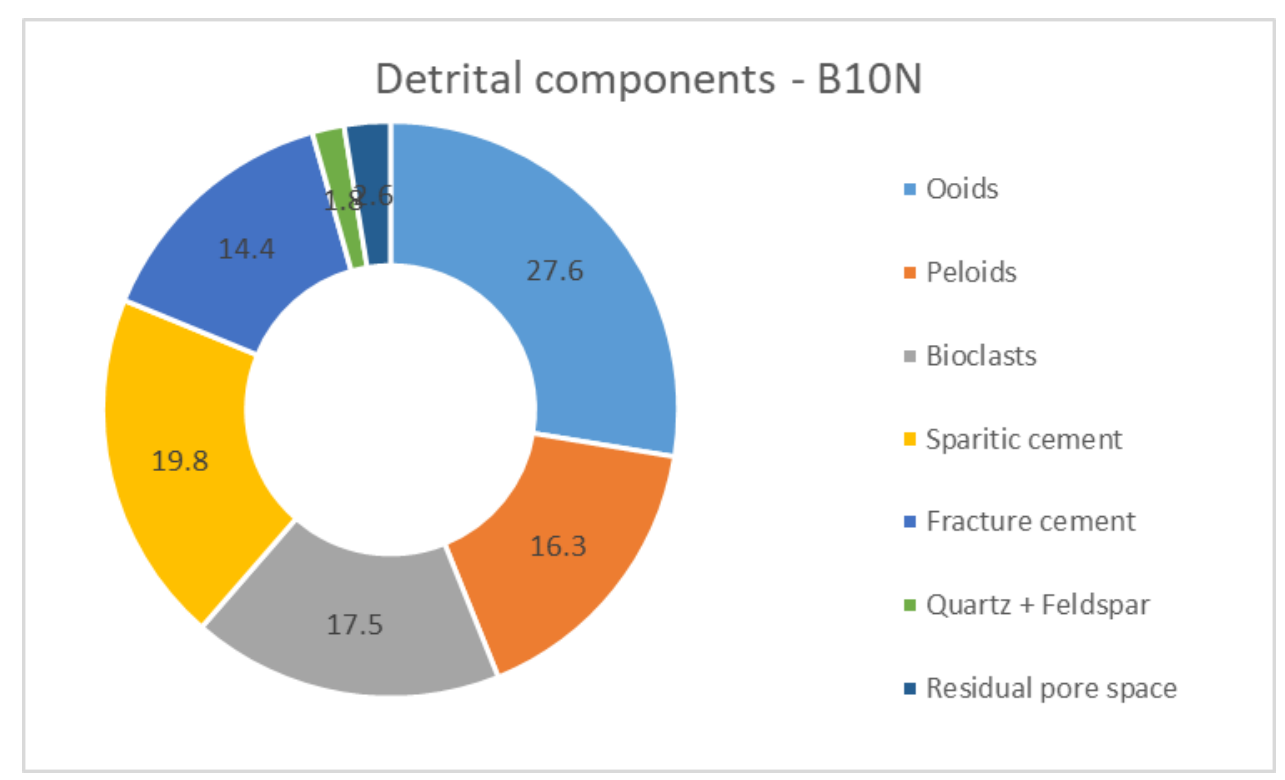

Fig. 6.14. Major (detrital) components and cement fractions of sample B10N in \% (modified from Nolte, 2013).

Healed fractures crosscut the rock in various directions, locally fracture width increases where dissolution occurred due to fluid-rock interaction during diagenesis. Carbonate particles locally exhibit pressure solution features along grain contacts, moreover, stylolites are visible along wallrock-vein contacts. Orientation of stylolite teeth indicate at least two different paleo-stress directions (sigma 1) that can be related to a) compaction during burial (vertical sigma 1), and b) compression during tectonic convergence (horizontal sigma 1). Ooids and bioclasts are locally covered with micritic coatings (circumgranular micritic envelopes), the fine-grained cryptocrystalline components are the result of diagenetic micritization. Ooids often contain growth nuclei consisting of bioclast fragments or detrital quartz and feldspar grains; related quartz grains typically show euhedral crystal shape due to syntaxial overgrowth. Ooids appear micritic, however, locally the mostly spheroidal to ellipsoidal ooids exhibit recrystallized remnants of radial fibres, which suggests severe diagenetic micritization (see Flügel, 2004). The bedding plane is traced by shells and shell fragments, geopetal indicators such as filled cavities indicate the vertical orientation. 

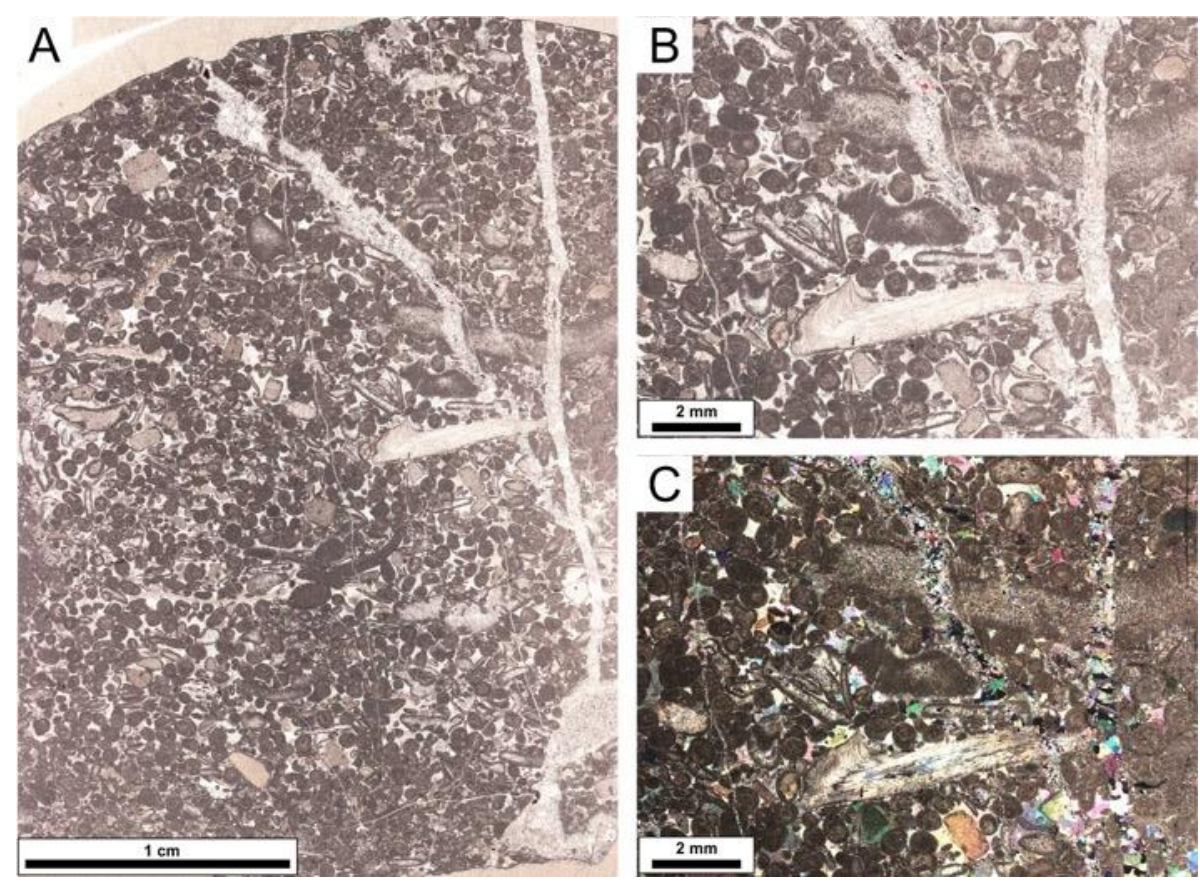

Fig. 6.15. Microscan of sample B10N (A-slide) in plane polarized light $(A+B)$ and crossed polarized light (C). Despite the grain-supported matrix consisting of ooids, peloids, and bioclasts of various size, calcitefilled fractures of different dimensions, orientation, and shape are clearly visible. The \pm horizontal shell fragment right from the center $(A)$ indicates the bedding plane.

Several fracture sets of various width and morphology are apparent; they are mostly filled with blocky to euhedral fracture cements. Beside calcite cement characteristics such as crystal size and shape, crosscutting relations between these fractures clearly prove multiple fracture events. Moreover, fracture cement-wallrock contacts locally show significant differences in surface characteristics (rough vs. smooth) which suggest at least one dissolution-precipitation episode. Microfractures give evidence of dislocation during fracturing which can mostly be related to simple dilation (mode I fractures) due to extension, and, to a minor extent, transtension. We can clearly distinguish between (at least) three different fracture cement generations: 1) FA-I: clear, blocky calcite cement, rough fracture surface with clear fracture cement-wallrock contacts, locally fluid inclusion-rich, 2) FA-II: clear, blocky calcite cement, smooth fracture surface, 3) FB: cloudy to brownish, inclusion-rich calcitic to dolomitic cement filling small fractures with rough surfaces as well as residual pore space in large FA-II fractures. While FA-I und FA-II fractures show similar orientation, FB is crosscutting both generations. Locally, porefilling calcite cements and, above all, fracture cements show (partly kinked) twin lamellae which evidence mechanically induced strain likely due to compaction and/or tectonic compression subsequent to cement precipitation. Some fracture cements exhibit heterogeneous twin densities within a single grain, which therefore points to various calcite growth events that experienced different strain (Fig. 6.16a). Fractures clearly postdate compaction-related stylolitization, whereas most of them predate stylolitization due to horizontal shortening as a result of tectonic compression. Locally, a clear relative dislocation due to pressure solution of both, bioclasts and pore cement (deformed twin lamellae) can be observed. Fluid inclusions of various size and shape are present within some fracture cements, especially in the older fracture sets. Younger fracture sets also contain fluid inclusions of which most are decrepitated or empty. 
The numerous microfabric features found within this oolithic grainstone allow to develop a relative chronology of syn-tectonic events, which is summarized below and additionally illustrated in Fig. 6.16b to f:

a) Deposition, subsidence and compaction

b) Early-diagenetic recrystallization of fossil fragments and matrix, partial aragonite dissolution

c) Micritization of ooids and fossil fragments (Fig. 6.16-b)

d) Pore-lining cement precipitation in an intertidal environment (meniscus or dogtooth cement) (Fig. 6.16-b)

e) Syntaxial cement overgrowth on detrital quartz and feldspar grains (Fig. 6.16-c)

f) Pressure solution (first stylolitization event) along grain contacts as a result of vertical maximum stress; indentation of pore-lining cements (Fig. 6.16-d) and syntaxial quartz cements into ooids

g) Pore-filling calcite cement precipitation (Fig. 6.16-b/c/d)

h) Formation of a first set of vertical fractures (FA-I) with varying width and cement features

i) Second set of vertical fractures (FA-II) with similar orientation compared to FA-I, but with smooth wall-rock contacts that prove severe dissolution prior to cement precipitation. Partial reactivation of FA-I fractures

j) Second stylolitization event with horizontal maximum stress, mostly affecting FA-fracture cement-wall-rock contacts (Fig. 6.16-f). Deformation of calcite grains within FA-II causing twinning (Fig. 6.16-a).

k) Second dissolution event during fracture cement precipitation and simultaneous formation of fracture set FB evidenced by corroded crystal surfaces, emplacement of Fe-(hydr)oxides or bituminous matter (Fig. 6.16-e). Filling of residual fracture pore space in set FA-II by FB-type cements (dolomitic cement).
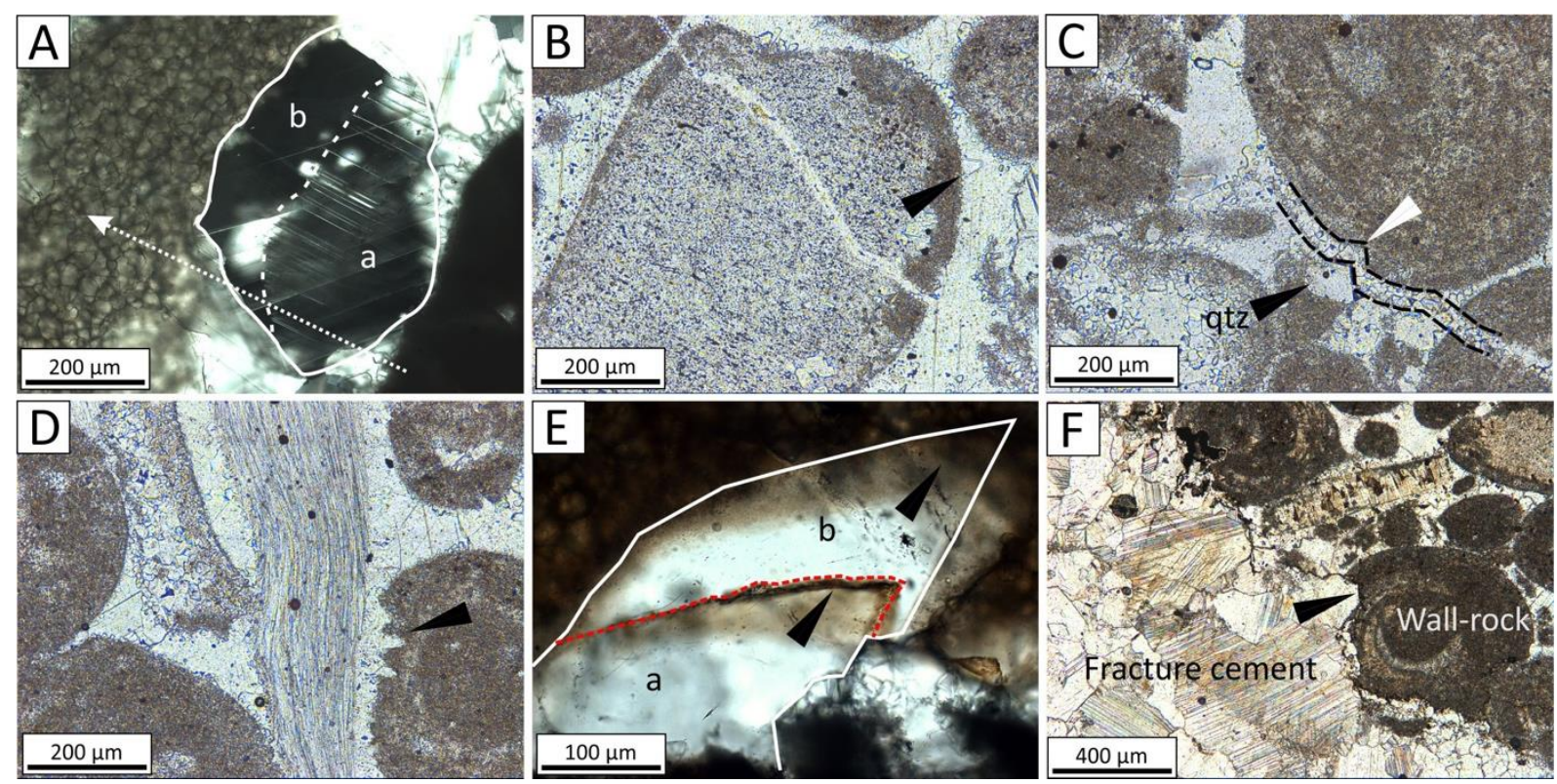

Fig. 6.16. Microphotographs illustrating significant microstructural features observed in sample B10N. Unless otherwise specified, images were taken in plain polarized light. A) Single fracture-wall lining calcite grain (white line) showing two areas with different deformation twin densities (a: high/old and b: low/young) /thick section, XPL). Growth direction is indicated with an arrow. The fine-grained, brownish material on the left side is late dolomite cement. B) Micritized fossil fragment with dog tooth cement (black arrow). Note the fracture crosscutting both fragment and pore cements. C) Epitaxial dog tooth cement 
indenting an ooid during compaction. D) The shape of a euhedral quartz grain with syntaxial cement overgrowth (black arrow) is preserved as a negative imprint (white arrow) on the opposite wall of an extension fracture (black dashed lines) therefore proving fracturing after quartz cement precipitation. E) Euhedral wall-lining calcite grain (white outline) exhibiting two growth zones (a/b; separated by red dashed line)), both showing a corroded surface covered with brownish matter, supposedly Fe-(hydr)oxides or bituminous matter (thick section, XPL). F) Stylolite (black arrow) separating a fracture cement and wall rock. Vertical fracture orientation and horizontal stylolite tooth orientation suggest pressure solution due to horizontal maximum stress.

\section{B2.1: Cellular dolomite (Fm. Puerto de la Palombera; Hettangian)}

Sample B2.1 is a whitish to yellowish-white, mainly dolomitic to slightly calcitic porous limestone (sampling location \#2 in Fig. 6.5) that is characterized, above all, by its cellular or "vuggy" appearance in hand-specimen (Appendix 6-1; german equivalent: 'Rauwacke'; spanish: carniola). It contains numerous isolated and irregularly formed cavities with diameters ranging between $5 \mathrm{~mm}$ and $2 \mathrm{~cm}$ that locally contain yellowish to reddish-brown alteration products, which probably represent sulfur-based compounds or Fe-(hydr)oxides. The relatively high porosity, which, according to DIA measurements, varies between $16.3-27.8 \%$ in investigated samples, is probably of secondary origin, as microfabrics suggest (Fig. 6.17). Vuggy pores are locally lined with subhedral calcite or dolomite crystals.

Thin section analysis reveals the brecciated nature of the carbonate rock, which shows strong inequigranular recrystallization fabrics of various size in both, matrix and breccia particles that are likely the result of fabric destructive dolomitization. Breccia particles show diameters of up to $5 \mathrm{~cm}$ and were originally matrix-supported, although no original sediment fabrics indicating the rocks facies prior to recrystallization are visible anymore. Single carbonate grains show recrystallization features with clear grain cores (not always visible), surrounded by a coarse, micritic calcite-generation, which is finally overgrown by a clear dolomitic rim cement that often forms euhedral dolomite rhombs. Though the cellular dolomite locally appears severely brecciated, almost no brittle deformation features such as healed fractures are apparent in hand-specimen; this observation is supported by field images that prove the total absence of macroscopic fractures and joints (see Appendix 6-1).

Residual porosity may either be the result of mineral dissolution (gypsum, anhydrite?) in the course of brecciation or of volume reduction due to dolomitization (calcite: $2.72 \mathrm{~g} / \mathrm{cm}^{3}$; dolomite: $2.86 \mathrm{~g} / \mathrm{cm}^{3}$ ), or a combination of both effects. It is questionable whether brecciation occurred as a result of fluidinflux during rifting and simultaneous fracturing relatively short after deposition (burial), which led to the conversion of anhydrite to gypsum (anhydrite-hydration) and subsequent swelling or due to the influx of freshwater (and the subsequent anydrite-gypsum transformation) during uplift and erosion in Paleocene times. As microfabric analysis suggests, recrystallization likely occurred prior or simultaneous to brecciation.

The near-total absence of deformation twins in (recrystallized) dolomite and calcite crystals, which contrasts findings from samples B10N and B13.4, suggests no mechanically induced strain after brecciation and recrystallization, and therefore points at a relatively late brecciation event. However, Quesada et al. (2005) refer to this kind of rock as 'collapse breccia'. 

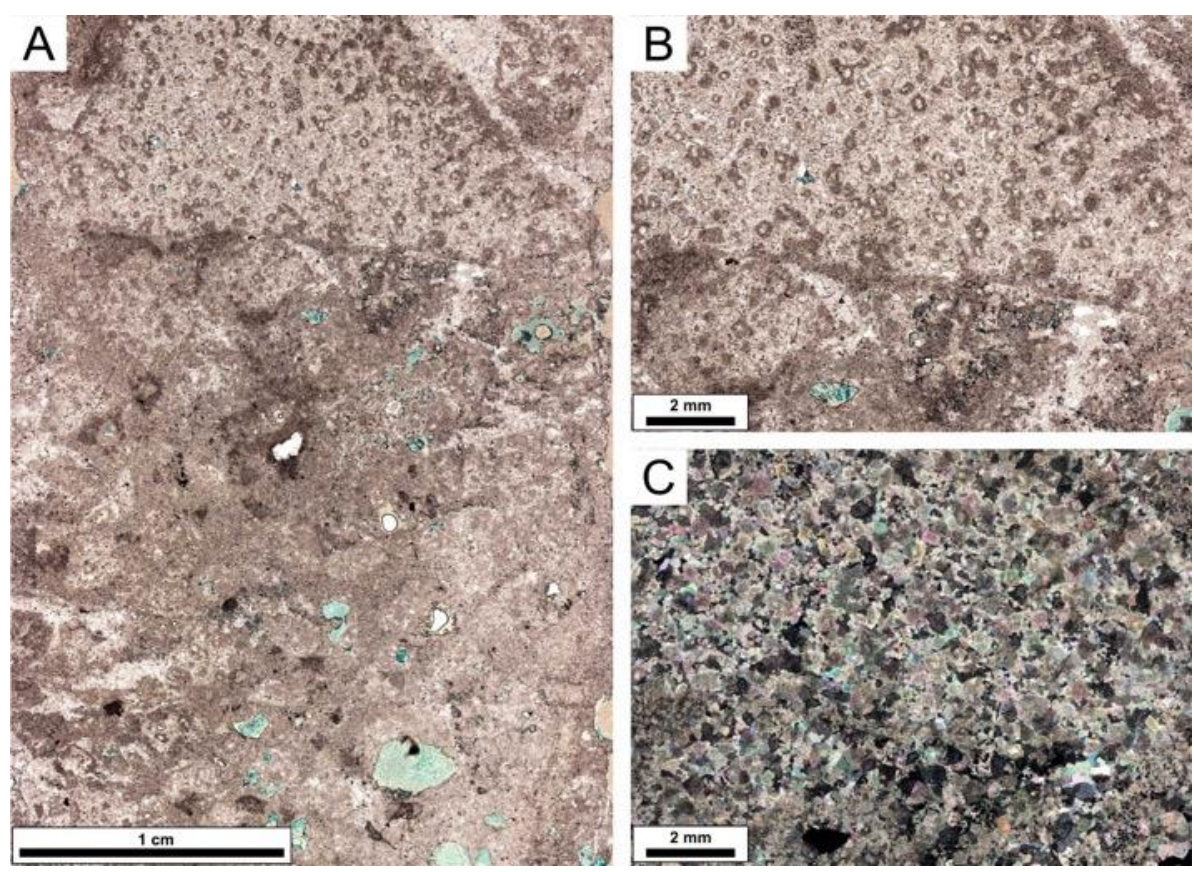

Fig. 6.17. Microscan of sample B2.1 (A-slide) in plane polarized light $(A+B)$ and crossed polarized light $(C)$ illustrating microfabric details of the recrystallized breccia. A single breccia fragment is visible in images $A$ (top) and B. Note the blue dyed adhesive compound that fills open pores and was therefore used for digital image-based pore space calculation (DIA).

\subsubsection{Cathodoluminescence microscopy of microstructures}

In this chapter, the cement stratigraphy of all sampled units is briefly introduced and interformational genetic links between the four different stratigraphic units with respect to fracture and pore cement characteristics are presented. Results are correlated and interpreted according to CL-based cement stratigraphy following the method introduced by Bruckschen et al. (1992) with special emphasis on calcite and dolomite cements in similar diagenetic environments. Cement correlation between different units was done with regard to specific genetic criteria that are characteristic for each cement-type, such as distinct growth and sectoral zoning patterns. Cement types are labelled with abbreviations in order to correlate and compare them later on (see compilation Tab. 6.1).

\section{B2.4: Calcilutite (Fm. Camino; Pliensbachian)}

Cathodoluminescence imaging of the fine-grained limestone revealed moderate matrix recrystallization (R-CEM) that occurred during early diagenesis; this is evidenced by local grain-coarsening and variations in related CL colours throughout the calcitic matrix (Fig. 6.18-a/b). Early diagenetic porelining cement or dog tooth-cement (P-DT) can also be attributed to this shallow marine environment; it is locally found within fragments of fossils such as algae and molluscs that always remain completely dark in CL. Euhedral to subhedral P-DT-type calcite crystals show radial growth normal to cavity walls and are typically non-luminescent (Fig. 6.18-c/d). Pore-lining cement crystals are overgrown by a dull orange to yellowish orange pore-filling calcite cement (P-1, Fig. 6.18-d) that proves reducing conditions during early burial.

Minute fractures crosscutting the rock matrix contain blocky calcite with orange CL characteristics (type FA-I; Fig. 6.18-a/b). Slight differences in CL intensity give evidence for repeated fracturing under 
Chapter 6 - Progressive fracture-network development in a carbonate reservoir

increasingly reducing conditions during burial. While a first generation of fractures (Fig. 6.18-a/b, arrow \#1), characterized by a wavy shape, is filled with dull orange calcite cement, a younger fracture generation, which is clearly transecting the first one, exhibits calcite cement with bright orange CL (arrow \#2). Similarities in CL colour and intensity between early diagenetic pore-filling calcite (P-CEM) and mid to late diagenetic fracture-filling calcites (FA-I) suggest a continuous transition in cement precipitation from the same fluid.
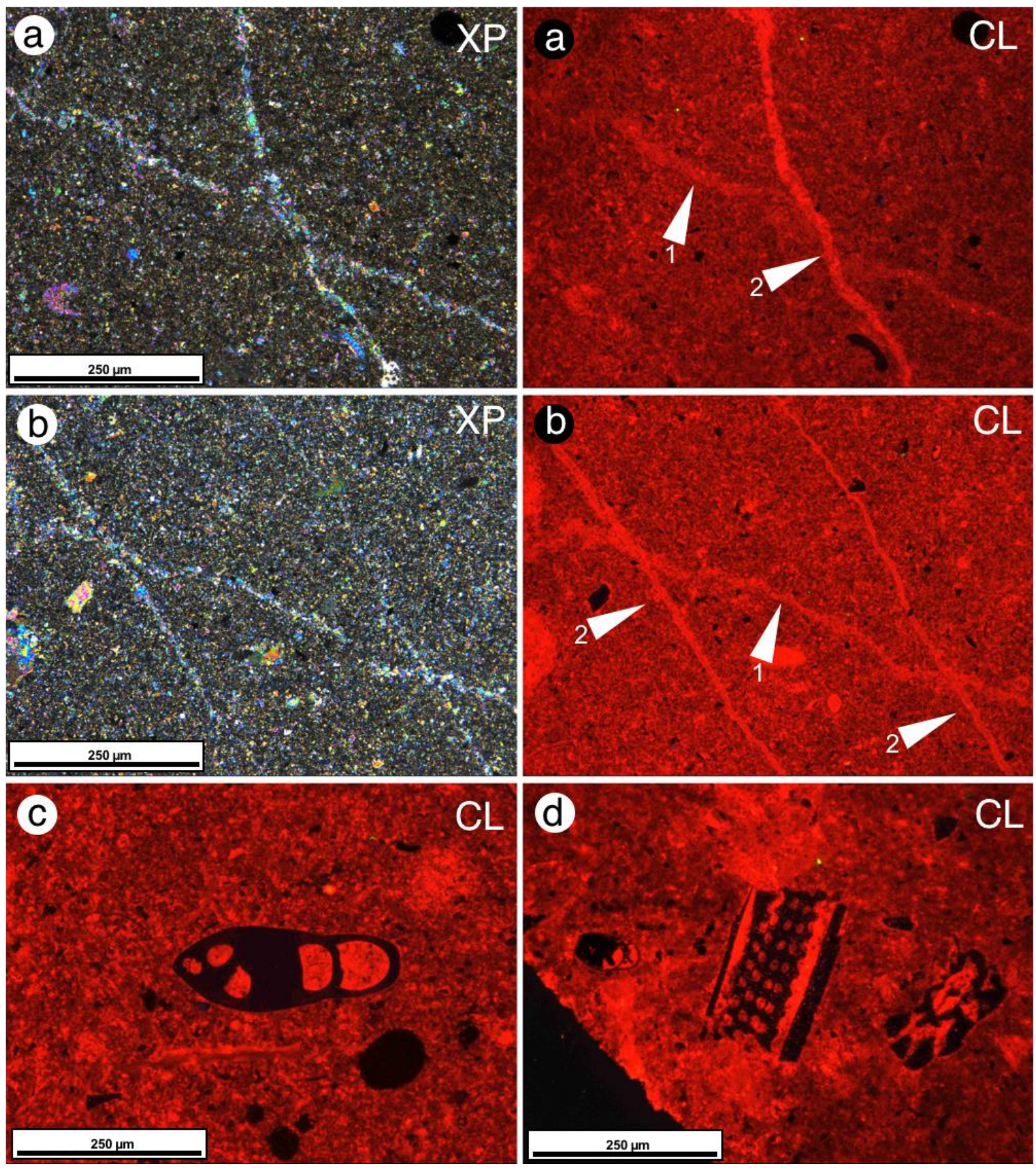

Fig. 6.18. (a): Fine-grained limestone matrix showing irregularly distributed calcite recrystallization (micritization) expressed as a patchy distribution of various reddish to orange calcite CL shades. The matrix is intersected by two healed calcite-filled fractures of different age (CL, white arrows). (b): Another section with same orientation as image (a) proving preferred orientation of fracture sets with same CL characteristics. (c): Foraminifera shell (non-luminescent high-Mg calcite/HMC) filled with early diagenetic pore-filling calcite cement (P-CEM, low-Mg calcite/LMC); (d): algae remnants cemented with early diagenetic pore-filling calcite cement (P-CEM). 


\section{B13.4: Siliciclastic sandstone (Fm. Areniscas del Rio Polla; Lower Sinemurian)}

The grain-supported sandstone comprises a number of different cement-types, of which the calcitic, orange to reddish-orange cement type P-CEM and the syntaxial, non-luminescent to dull brownish quartz and feldspar cements (S-CEM) (Fig. 6.19-a/b) are the most prominent, both filling intergranular pore space, the latter locally replacing carbonate. After an early diagenetic phase of recrystallization and micritization of detrital carbonate particles such as ooids (R-CEM), characterized by cements with a dull orange to reddish CL, cementation is continued by a non-luminescent to yellowish meniscus or dogtooth cement (P-DT) that is only locally present as it was prone to dissolution and displacement during diagenesis. This early pore-filling cement was then overgrown or replaced with type P-CEM and SCEM cements. Within P-CEM, several concentric growth zones (at least 9) can be distinguished that vary in CL colour and intensity and form a characteristic sequence; transition between concentric zones is usually diffuse. Besides, sectoral zoning with sharp outlines is also detectable in this cement type; it often shows dull orange and light bluish CL. A continuous transition from early to intermediate and late diagenesis is documented by two clearly distinguishable quartz- (S-CEM) and two calcite-cement generations (P-CEM) that are forming a complex succession of repeated quartz-calcite replacement within the open pore space during early burial due to dissolution-precipitation (Fig. 6.19-b). After detrital quartz (and P-DT?) was partly replaced with early calcitic pore-filling cement (P-CEM-1), a first generation of syntaxial, non-luminescent quartz cement was growing (S-CEM-1), partly replacing or incorporating the calcite cement. This process was repeated once more until a third calcite cement (P-CEM-3) partly replaced the second and last quartz cement (S-CEM-3). Dull brownish CL of S-CEM-3 suggests slightly increasing temperatures over time, as quartz CL intensity in sedimentary environments is usually increasing with higher formation temperatures (Zinkernagel, 1978).

Although macroscopic fractures are missing in this sandstone, locally intergranular microfractures along quartz grain contacts can be observed (Fig. 6.19-c) that prove brittle deformation due to compaction. CL of fracture-filling calcite cements suggests that fracture formation occurred simultaneous to P-CEM precipitation, as both pore and fracture cements contain calcite with the same CL characteristics. 

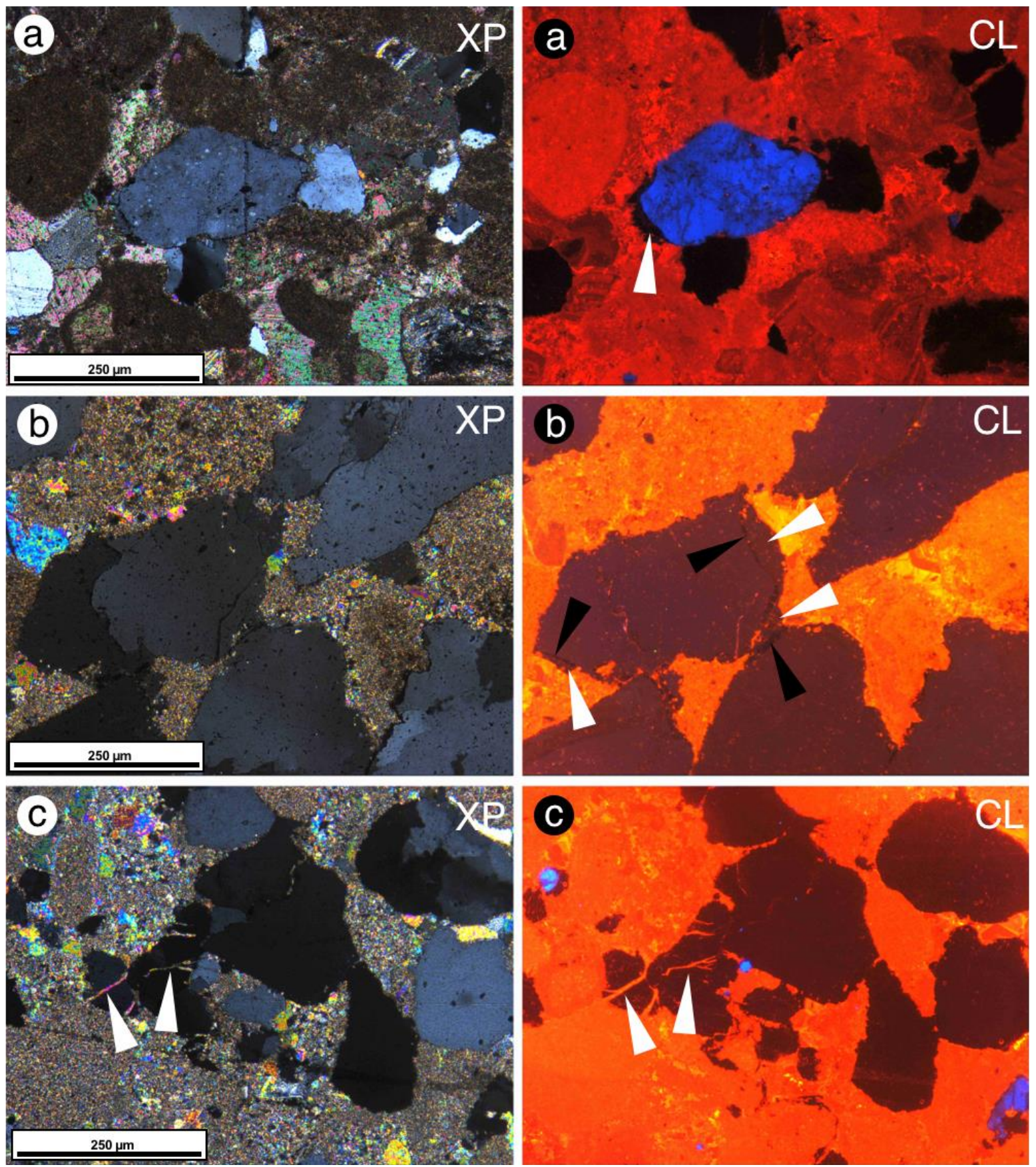

Fig. 6.19. (a) Microphotograph of a detrital potassium feldspar grain (center) in crossed polarized light (XP) and in CL mode. The white arrow indicates subhedral, syntaxial feldspar overgrowth, which is nonluminescent, while the detrital grain exhibits intense blue CL typical for potassium feldspar. (b) Images illustrating syntaxial quartz cement precipitation around detrital quartz grains and subsequent replacement with calcite cement. Black arrows indicate non-luminescent type S-CEM-1 cement; white arrows mark brownish type S-CEM-2 cement. (c) Microfractures within detrital quartz grains induced by mechanical compaction (white arrows). Fractures are typically originating from grain contacts; CL of fracture-filling calcite suggests precipitation under reducing conditions (shallow to intermediate burial diagenesis).

B10N: Oolithic grainstone (Fm. Villanueva de Puerta; Lower Sinemurian)

Sample B10N exhibits a broad variety of cements that allow a detailed reconstruction of the diagenetic and tectonic framework in the study area and clearly complement findings from microfabric analysis. The diagenetic record starts with the recrystallization and micritization of the fine-grained calcitic matrix 
as well as detrital components such as fossil fragments and ooids (R-CEM) that is expressed by fine grained calcite crystals with dull orange to dark reddish CL. Type R-CEM cement precipitation is followed by the formation of radiaxial blocky to bladed meniscus and dogtooth cement (P-DT) that coats spore walls and partially fills interparticle pore space (Fig. 6.20-a/c). In CL, type P-DT cement, which can be related to formation in intertidal-marine to brackish-marine pore waters (Flügel, 2004), typically shows a first generation of non-luminescent to dull brownish and orange calcite grains, while later growth generations locally exhibit bright yellowish-orange CL. After or during late compaction and pressure solution along ooid-ooid contacts interparticle pore space was continuously filled with coarse blocky calcite cement (P-CEM) that can be subdivided into at least 11 different concentric growth generations, as CL proves (Fig. 6.20-a/b). The clear cement often contains deformation lamellae that demonstrate local strain (Fig. 6.20-a/b). CL colour of respective growth zones ranges from dull orange and brownish to red and intense orange; often concentric growth zones show a wavy shape. Locally single growth zones can be further subdivided as illustrated in Fig. 6.20-a; occasionally sectoral zoning with a typical bluish CL hue is visible as well. The concentric growth zoning pattern is well-defined and can be observed throughout all B10N thin sections. Moreover, it shows similarities with zoning patterns found in sample B13.4 pores and thus suggests pore connectivity between respective stratigraphic units and precipitation from the same fluid under increasingly reducing conditions during burial.

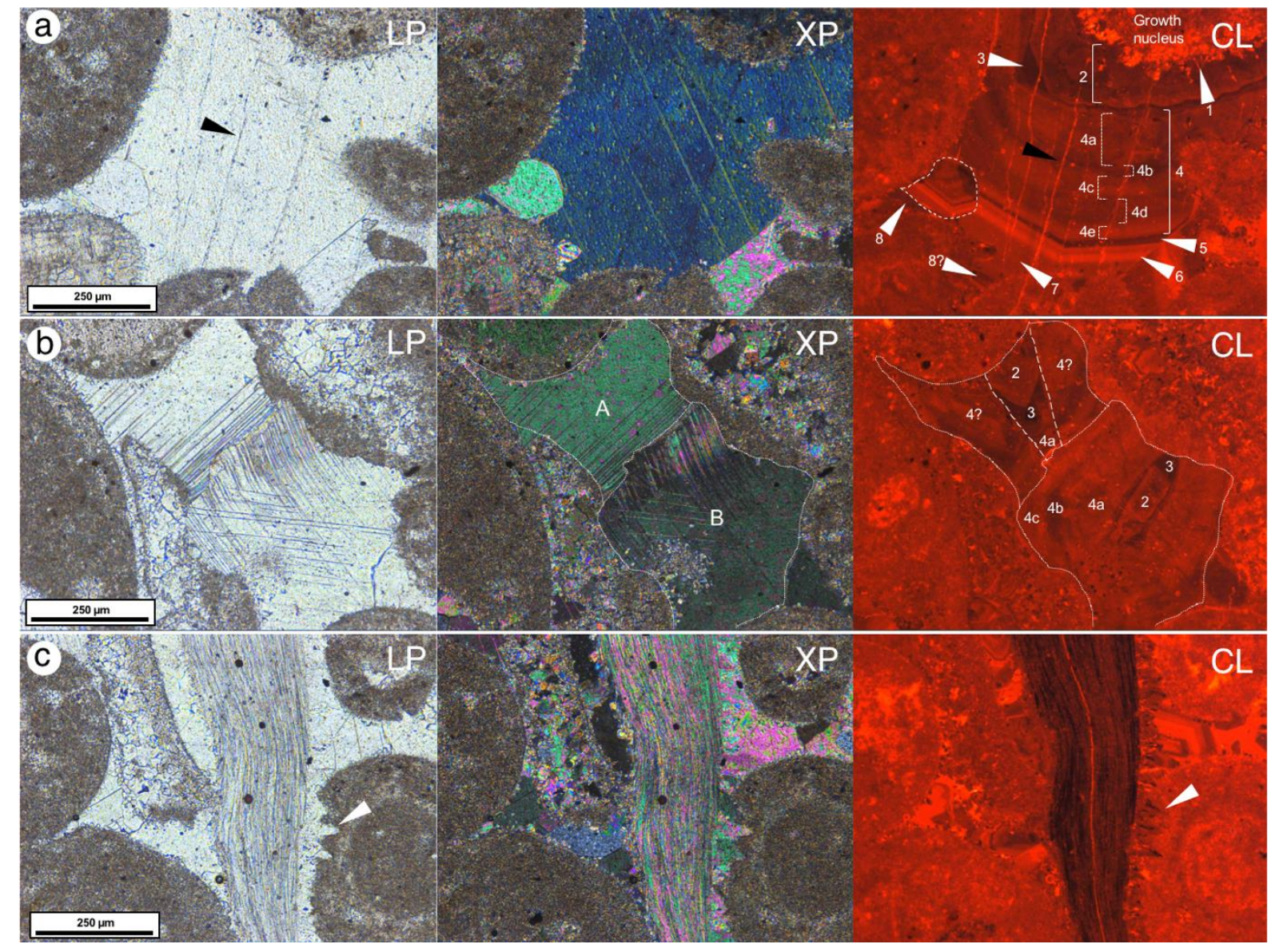

Fig. 6.20. (a) Pore-filling inequigranular calcite cement (P-CEM) mainly consisting of a single predominant crystal. This calcite crystal exhibits a set of parallel microfractures (black arrow) visible in LP and characterized by bright orange CL that prove brittle deformation. White arrows indicate growth zones of pore-filling calcite revealed in CL (P-CEM-1 to -8). At least 8 distinct growth zones can be distinguished, some of them (e.g. 4; dashed brackets) can be subdivided into finer growth zones ( $P$-CEM-4a to-4e). Note how some but not all growth zones are repeated in a smaller adjacent calcite grain (zones 4a-7?; dashed 
white outline). Ooid surfaces are covered with dogtooth cements $(P-D T)$. (b) Pore-filling calcite cement $(P-C E M)$ exhibiting partially kinked deformation twins along grain boundary (grains $A$ and $B)$ in both, linear and crossed polarized light. Note how deformation twin density increases towards grain boundary. Different cement growth generations are indicated by numbers (compare Fig. 6.17-a). (c) Circumgranular bladed pore cement $(P-D T)$ surrounding shell fragment (elongated vertical fragment, dark in $C L)$. Note partial penetration of pore lining calcite crystals into ooid (white arrow) due to mechanical compaction (see also Fig. 6.16-d). Early-diagenetic pore lining cement is continued by drusy mosaic cement (P-CEM).

Intermediate to late pore-filling calcite cementation was likely accompanied by a first brittle deformation event as various sets of steep, (sub)parallel calcite-filled fractures with mostly dull orange to orange and reddish-orange CL (FA-type fractures, see above) indicate. FA-type fractures can be further subdivided into types FA-I (early), FA-II (intermediate) and FA-III (late), distinguished by their fracture cementwall rock-contact character, CL properties, and crosscutting-relationships.

FA-I-type fracture cements consist of clear, blocky to coarse-feathery calcite grains of relatively large size $(50-300 \mu \mathrm{m})$ that commonly show deformation twin lamellae (Fig. 6.21-a). Fracture width varies between few hundred $\mu \mathrm{m}$ up to one $\mathrm{mm}$. Fracture cement-wall rock contacts are mostly sharp, while moderate dissolution features are rare. Fractures locally separate the grain-supported matrix intergranularly pointing at a first onset of fracture formation prior to complete pore cementation. This observation is furthermore supported by a strong similarity between P-CEM cements and FA-I-type cements in terms of CL colours (Fig. 6.21-a), which suggest a simultaneous calcite cement precipitation, i.e. opening of early FA-I fractures during latest P-CEM cementation. Larger grains are often fractured and healed with younger cements (FA-II), which explains the occurrence of (pseudo-) secondary fluid inclusions. Fracture reactivation and subsequent precipitation of FA-II calcite cement suggest a continuous transition from FA-I to FA-II type cements and might explain local dissolution along FA-I type-wall-rock contacts. CL is dark to dull orange in grain cores and intensifies towards the rims getting more orange. Grain boundaries often are bright orange again pointing at the transition to FA-II cement.

Type FA-II cement is characterized by a significant dissolution event prior to cement precipitation. Dissolution mostly affected fine grained matrix and ooids forming irregular dissolution-cavities (Fig. 6.21-b), but also younger P-CEM cements and shell fragments were partly replaced. Distribution of dissolution features appears irregular; it often follows pre-existing fractures or grain boundaries, newly formed fractures prove both inter- and transgranular extension. Calcite grains are clear in transmitted light and usually show blocky growth with an increase in size from early to late precipitation, however, grain size rarely exceeds $50 \mu \mathrm{m}$. The calcite cement is characterized by bright orange to yellowishorange CL colours. In CL the bright cement locally reveals an irregular, narrow-banded concentric growth zoning, which makes it sometimes hard to distinguish it from type FA-III cement (see below) where direct comparison is not possible; it is likely that respective cement types belong to the same diagenetic event. However, microfabrics and CL patterns as well as CL intensities allow to distinguish between them when directly compared.

Type FA-III cement typically exhibits orange CL colours starting with relatively high intensity (bright orange) and continuously becoming dull orange towards younger growth generations (Fig. 6.21c). It often continues FA-II cement, but not necessarily; locally a direct growth on fresh fracture surfaces can be observed as well. Younger growth zones with orange to dull orange CL show a uniform oscillatory growth zoning (zebra-type zoning); locally individual growth zones can be slightly broader, especially in larger grains. In larger grains (intra-)sectoral zoning can occur (Fig. 6.21-c, lower centre). FA-III fracture cements commonly contain a high deformation twin density; youngest and largest grains with subhedral shape and thus free crystal surfaces often show corrosion features; partly dissolved 
surfaces are locally covered with a thin brownish layer of supposedly Fe-(hydr)oxides (see Fig. 6.16-e) that is not evident in CL. However, this coating marks the transition to another type of fracture cement (FB-I) that is supposedly related to a new diagenetic and tectonic phase.

Type FB fracture cements differ from older fractures in terms of spatial orientation, fracture-fill-wall rock contact, and - above all - CL characteristics. FB fracture cements are mostly dominated by no luminescence or locally weak blue and violet luminescence in CL mode, while brownish or orange colours are rare in general; yellow CL is completely missing. Type FB fractures can be further subdivided into three separate groups according to significant differences in appearance and age (FBI/II/III).

Precipitation of type FB-I fracture cement is preceded by a dissolution event as corrosion features along subhedral FA-II calcite cement within (reactivated) fractures (Fig. 6.16-e) and wall-rock surfaces demonstrate. After moderate dissolution of older calcite FB-I cement continues (mostly syntaxial) calcite precipitation locally starting with a bright orange initial growth band of varying thickness (Fig. $6.21-\mathrm{d} / \mathrm{e}$ ), which is then followed by a mostly non-luminescent cement that locally exhibits brownish or blue CL. The initial orange growth band is usually exceptionally broad and intense where pre-existing calcite grains provide surfaces for syntaxial overgrowth, thus, grain size of the nucleating calcite grains strongly depends on substrate properties. When cut through in an acute angle, i.e. (sub-)parallel to the growth zones these orange calcite crystals reveal a pattern of very fine alternating growth bands that may locally form a ‘zebra-type`zoning pattern (Fig. 6.21-e).

Type FB-II fracture cements either occur as blocky subhedral or anhedral wall-lining cements (FBIIa), or as fine-grained equigranular cements filling residual fracture porosity (FB-IIb) (Fig. 6.21-c). Beside these microfabric details, both cement types show similar CL characteristics; however, FB-IIb cement always postdates FB-IIa cements. FB-IIa cement continues type FB-I cements, but is preceded by a dissolution event; it is characterized in CL by intense orange growth bands with blurry edges that are alternating with several thin non-luminescent growth zones (Fig. 6.21-d). FB-IIa is then replaced by a final non-luminescent to bluish growth zone. After that, residual pore space is completely filled with type-FB-IIb cement (Fig. 6.21-c).

Fine-grained blocky type-FB-III cement either fills reactivated early FA-type fractures or cuts through older fracture cements in relatively high angle (Fig. 6.21-e). A striking difference between previous FB-type fractures is the fact that FB-III fracture-wall rock contacts are sharp and do not show any signs of chemical dissolution prior to cement precipitation. Simultaneously, FB-III cement occurs along stylolites, which trace zones of pressure solution that resulted from horizontal maximum stress (Fig. 6.21-f). FB-III fractures often show en-echelon-type patterns that indicate shear stress or they split up into several smaller cracks (Fig. 6.21-e). 

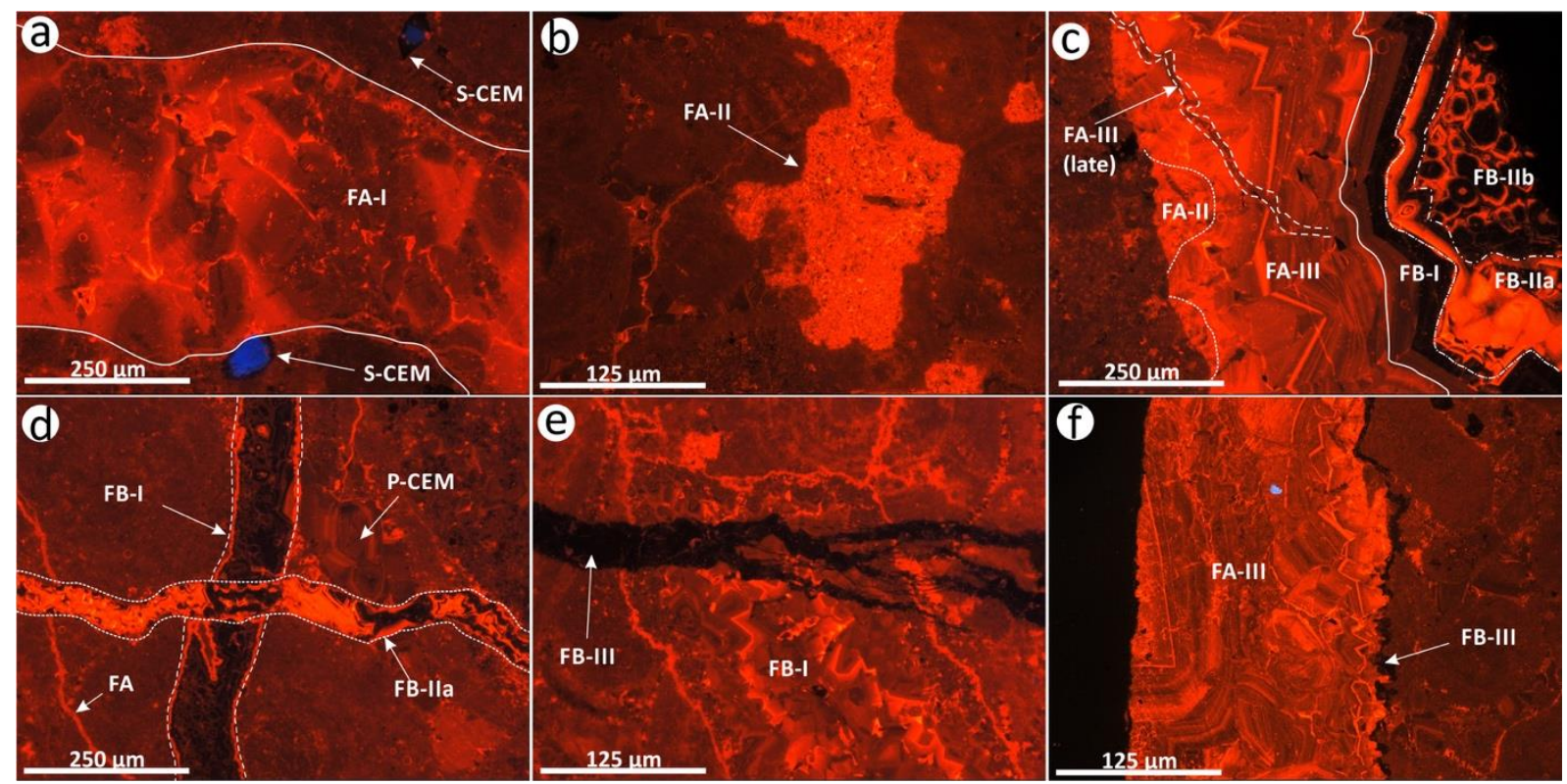

Fig. 6.21. (a) Type FA-I fracture cement with coarse blocky calcite grains that exhibit a "patchy" dull orange to orange $C L$ pattern. This calcite cement resembles $P$-CEM-type cements in many ways, e.g. similar grain size and same CL characteristics (colour, zoning features, intensity). The locally patchy and seemingly disturbed CL pattern may be the result of repeated fracture reactivation. Blue grains are potassium feldspar that show syntaxial non-luminescent S-CEM overgrowth. (b) Irregularly shaped dissolution/displacementcavity filled with fine grained, bright orange FA-II-type cement. (c) Macro fracture filled with a variety of calcite cements ranging from type FA-II cement to type FB-II cements. Note how late FA-III cement fills a small fracture transecting older FA-III growth zones. (d) Type FB-IIa cement crosscutting FB-I cement almost perpendicular. Both FB-cements are characterized by wall-normal extension. In this image, FB-I shows a thin bright orange wall-lining cement phase, which is not always apparent. (e) Late, nonluminescent FB-III cement crosscutting FB-I cement. This relatively narrow FB-I fracture was cut almost parallel to the fracture wall which explains the apparent width and the predominant bright orange cement phase, while the typical non-luminescent to brownish cement is not visible in this detail image. Note how wall rock contacts are irregularly sutured due to severe dissolution prior to cementation. (f) Nonluminescent FB-III cement tracing the sutured line of a stylolite that formed along a wall rock-fracture contact due to horizontal shortening.

B2.1: Cellular dolomite (Fm. Puerto de la Palombera; Hettangian)

In CL the cellular dolomite exhibits a complex pattern of pore filling cementation and recrystallization that is barely apparent in transmitted light. Several cement types can be distinguished according to CL characteristics, which often show striking similarities to those found in sample B10N. However, since no fractures are present in sample B2.1, neither in hand specimen nor on transmitted light or CL mode, age relationships between different cement types are hard to determine. Fig. 6.22 shows a representative composite CL image of the sample. Rectangles marked by white dotted lines outline three different cement types, which are subsequently introduced in detail. 


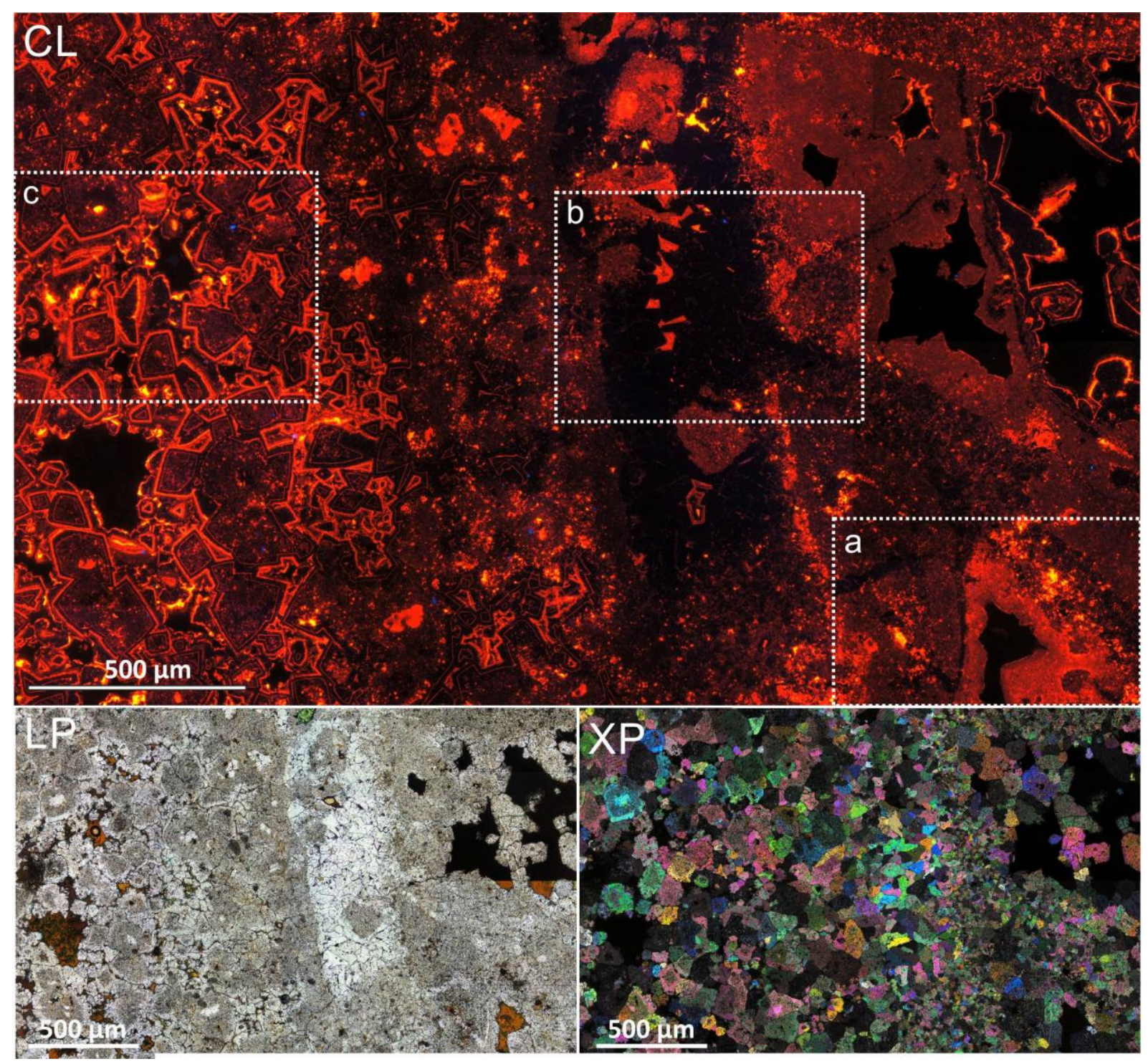

Fig. 6.22. Composite CL image of recrystallized limestone (sample B2.1, 'carneolas ') showing a comprehensive overview on growth zoning characteristics found in this rock type, with LP and XP images for comparison. Note the in general inequigranular fabric revealed in XP that is not apparent in CL mode. Areas framed by a white dotted line are presented in detail in Fig. 6.23.

Type B2.1-A cement is a cloudy pore filling calcite cement characterized by orange CL; early cement typically shows brighter CL with decreasing intensity towards later growth generations (Fig. 6.23-a), pointing at increasingly reducing growth conditions. Especially larger grains $(>200 \mu \mathrm{m})$ often exhibit regular concentric growth zoning; free crystal surfaces are locally corroded. The pore cement is always linked to a fine grained, dull to dark red carbonate matrix, which is locally recrystallized (R-CEM) or replaced with B2.1-A cement. This carbonate type itself is restricted to angular and sub-rounded fragments, which often contain non-luminescent linear fragments that resemble shell fragments.

The dolomitic type B2.1-B cement, which appears clear in transmitted light, fills pores between larger breccia fragments (Fig. 6.23-b). It is mostly non-luminescent in CL, but locally exhibits a blueishviolet hue at longer exposure times. Its blocky, inequigranular-interlobate grains barely show direct contact with B2.1-A cement, however, sporadically a filling of residual pores in B2.1-A cement can be observed. In general, breccia fragments described above are hardly affected by B.21-B cementation. 
B2.1-B cement typically concludes with a number of intense orange to bright yellow oscillatory growth zones that fill residual pores.

The dolomitic type B2.1-C cement is similar to B2.1-B cement in terms of CL colour and zoning features, but its presence is mostly restricted to a recrystallized groundmass that initially consisted of fine grained carbonate particles. This groundmass may have been similar to the matrix related to breccia fragments described above, but no comparable fragments are apparent (Fig. 6.23-c). The cement rather consists of single dolomite grains that show irregular shapes and grain boundaries in crossed polarized light, whereas CL reveals a subhedral to euhedral rhombic shape. The groundmass, cloudy in transmitted light, is mostly non-luminescent with intense orange dots and exhibits blueish to violet CL at longer exposure times, while the clear rims are characterized by alternating concentric growth zones of nonluminescent and bright orange to yellow CL. Residual pore space in these parts may be the result of dolomitization during burial.

In summary, according to their CL characteristics the three cements presented here can be compared to those found in sample B10N as follows:
B2.1-A $\leftrightarrow$ FA-III
B2.1-B $\leftrightarrow$ FB-I
B2.1-C $\leftrightarrow$ FB-IIa 

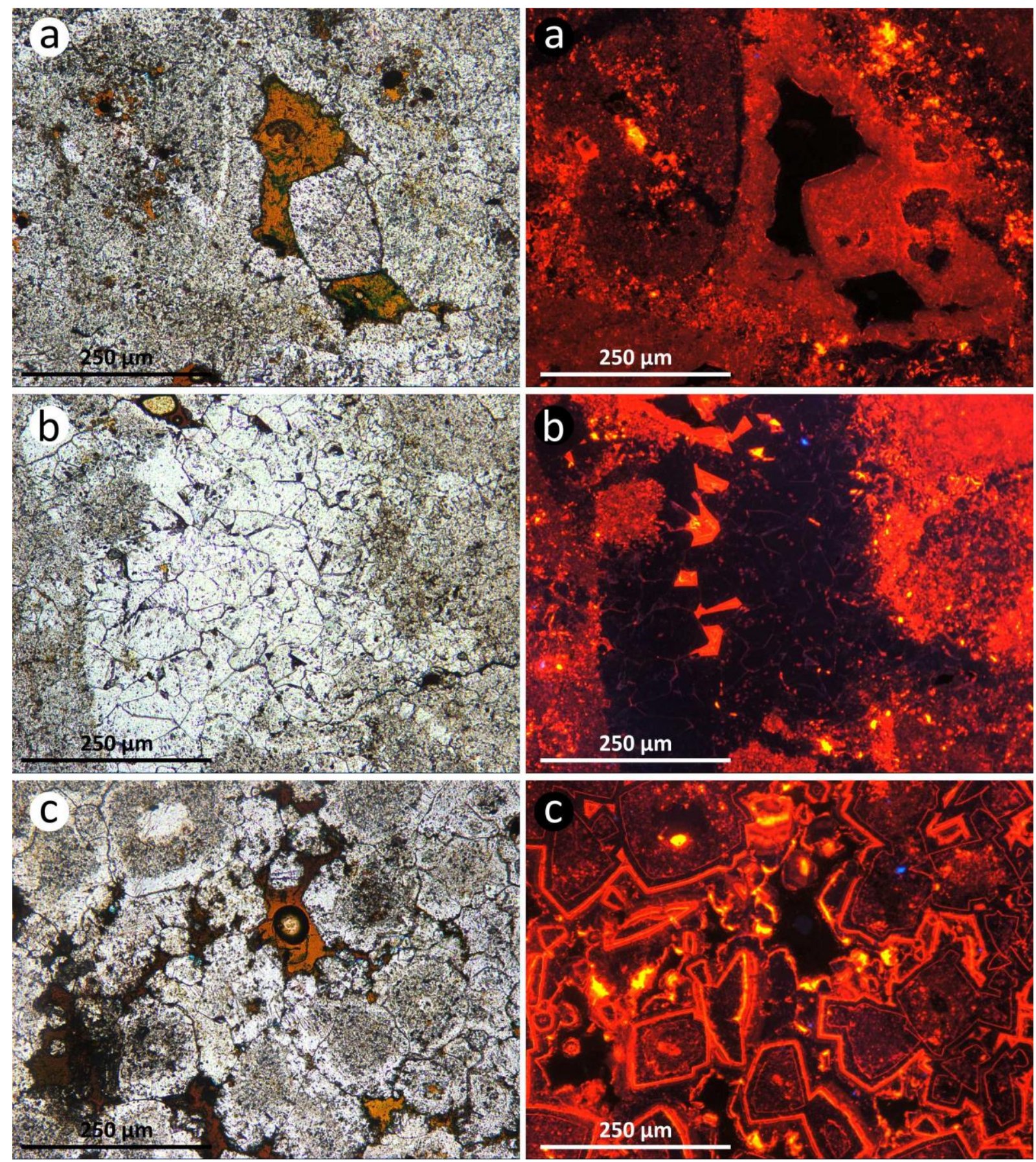

Fig. 6.23. (a) Bright orange to dull orange B2.1-A cement filling pores within breccia fragments. (b) The mostly non-luminescent B2.1-B cement is typically found within interparticle pore-space. Note the slightly blueish hue in the upper regions of the detail image (intense blue dot $=$ detrital potassium feldspar grain). (c) B2.1-C cement is above all characterized by its rhombic shape which is only apparent in CL. The cement is likely the result of dolomitization of a calcitic mudstone. 
Chapter 6 - Progressive fracture-network development in a carbonate reservoir

Tab. 6.1. Cement stratigraphy as derived from combined petrographic microscopy and CL characteristics. For abbreviations see text.

\begin{tabular}{|c|c|c|c|c|c|}
\hline Name & Description & CL characteristics and microscopic features & Diagenetis & Interpretation & Occurrence \\
\hline R-CEM & $\begin{array}{l}\text { micritization and recrystallization of carbonate } \\
\text { particles and matrix }\end{array}$ & dull orange to reddish-orange colour, clear fine-grained cement & early diagenesis & intertidal-marine, oxidizing to slightly reduzing & $\begin{array}{l}\text { B10N, B13.4, B2.4, } \\
\text { B2.1 }\end{array}$ \\
\hline P-DT & $\begin{array}{l}\text { pore-lining calcite cement (meniscus or } \\
\text { dogtooth cement) }\end{array}$ & $\begin{array}{l}\text { non-luminescent to orange and bright yellowish-orange colour, clear blocky to radiaxial- } \\
\text { bladed cement }\end{array}$ & early diagenesis & $\begin{array}{l}\text { intertidal-marine to brackish-marine pore } \\
\text { waters, oxidizing to slightly reduzing, fluctuating } \\
\text { fluid chemsitry }\end{array}$ & B10N, B13.4, B2.4 \\
\hline $\begin{array}{l}\text { S-CEM } \\
(1-3)\end{array}$ & $\begin{array}{l}\text { syntaxial quartz and feldspar cement, locally } \\
\text { up to three different growth zones } \\
\text { distinguishable }\end{array}$ & non-luminescent to dull brownish, clear overgrowth cement & $\begin{array}{l}\text { early to } \\
\text { intermediate } \\
\text { diagenesis }\end{array}$ & burial, basinal fluids, low temperature $\left(<90^{\circ} \mathrm{C}\right)$ & B10N, B13.4 \\
\hline $\begin{array}{l}\text { P-CEM } \\
(1-11)\end{array}$ & $\begin{array}{l}\text { pore-filling calcite cement, locally up to } 11 \\
\text { different growth zones distinguishable }\end{array}$ & $\begin{array}{l}\text { dull orange and brownish to orange and reddish-orange, irregularly alternating growth } \\
\text { zones with unsharp transitions, locally patchy, often with sectoral zoning, also bluish CL, } \\
\text { locally deformation twins, clear blocky cement }\end{array}$ & $\begin{array}{l}\text { intermediate to } \\
\text { late diagenesis }\end{array}$ & $\begin{array}{l}\text { burial, basinal fluids, reducing conditions, HMC } \\
\rightarrow \mathrm{LMC} \text {, fluctuating fluid chemsitry }\end{array}$ & B10N, B13.4, B2.4 \\
\hline FA-I & $\begin{array}{l}\text { fracture-filling calcite cement of varying } \\
\text { intensity }\end{array}$ & $\begin{array}{l}\text { dull orange to orange } \mathrm{CL} \text {, locally reddish hue, deformation twins very common, clear blocky } \\
\text { to coarse-feathery cement, moderate dissolution features, typically large grain size }\end{array}$ & $\begin{array}{l}\text { intermediate to } \\
\text { late diagenesis }\end{array}$ & burial, basinal fluids, reducing conditions & B10N, B2.4 (?) \\
\hline FA-II & $\begin{array}{l}\text { calcite cement filling fractures, pores and } \\
\text { dissolution-cavities, locally displacing older } \\
\text { cement }\end{array}$ & $\begin{array}{l}\text { intense orange to yellowish CL with often cloudy or irregular distribution, locally very fine } \\
\text { oscillatory zoning visible, clear blocky cement, calcite grains relatively small }\end{array}$ & late diagenesis & burial, basinal fluids, reducing conditions & B10N, B2.4 (?) \\
\hline FA-III & $\begin{array}{l}\text { fracture-filling calcite cement (B10N) and pore- } \\
\text { filling cement (B2.1), following dissolution } \\
\text { event }\end{array}$ & $\begin{array}{l}\text { dull orange CL, oscillatory growth zoning (zebra-type) and sectoral zoning common, high } \\
\text { deformation twin density, clear blocky cement, calcite grains relatively large }\end{array}$ & late diagenesis & burial, basinal fluids, reducing conditions & B10N, B2.1 \\
\hline FB-I & $\begin{array}{l}\text { calcitic fracture-filling cement, partly corroded } \\
\text { (dissolution) }\end{array}$ & $\begin{array}{l}\text { brownish to non-luminescent or blue CL, locally continuous growth on FA-II with bright } \\
\text { orange initial growth zone, brownish grains with zebra-type zoning, following dissolution } \\
\text { event, Fe-(hydr)oxides, few deformation twins, mostly clear, locally cloudy blocky cement }\end{array}$ & late diagenesis & onset of basin inversion & B10N, B2.1 \\
\hline FB-lla & calcitic fracture- and pore-filling cement & $\begin{array}{l}\text { intense yellowish-orange growth bands, divided by thin non-luminescent bands, continued } \\
\text { by non-luminescent to blue CL, following dissolution event, Fe-(hydro)xides, no } \\
\text { deformation twins, mostly clear to cloudy blocky cement }\end{array}$ & late diagenesis & inversion and uplift, oxidizing conditions ? & B10N, B2.1 \\
\hline FB-IIb & $\begin{array}{l}\text { Residual fracture porosity-filling equigranlar } \\
\text { calcite cement }\end{array}$ & $\begin{array}{l}\text { non-luminescent to blue with thin alternating growth bands of bright orange } \mathrm{CL} \text {, no } \\
\text { deformation twins, cloudy equigranular cement }\end{array}$ & late diagenesis & inversion and uplift, oxidizing conditions? & B10N \\
\hline FB-III & $\begin{array}{l}\text { Fracture-filling calcite cement, similar to FB-I } \\
\text { and FB-Ill, commonly associated with } \\
\text { stylolites }\end{array}$ & $\begin{array}{l}\text { brownish to non-luminescent or blue, locally dull brownish growth zones, no deformation } \\
\text { twins, clear to brownish cloudy and blocky cement in XP }\end{array}$ & late diagenesis & inversion and uplift, oxidizing conditions? & B10N \\
\hline
\end{tabular}


Chapter 6 - Progressive fracture-network development in a carbonate reservoir

\subsubsection{Fry analysis of compactional volume reduction: compaction and pressure solution}

As a consequence of preconditions necessary for the application of Fry analysis, which are explained in detail in Chapter 2.2.9, only sample B10N is worth considering due to its high number of spheroidal, homogeneously distributed particles. In consideration of various calculation methods applied, twodimensional strain of sample B10N due to subsidence and vertical compaction, and prior to fracturenetwork initiation, as evidenced from microfabric analysis, ranges between $\mathbf{R}_{\text {smin }}=\mathbf{1 . 1 8}$ and $\mathbf{R}_{\text {smax }}=\mathbf{1 . 5 9}$ with a median of $\mathbf{R}_{\mathrm{s}}=\mathbf{1 . 3 5}$. However, comparison between purely ooid-bearing sections and sections containing up to $10 \%$ of shell fragments with elongated shapes and comparatively large dimensions showed that particle size and shape significantly influence the results, as shell-rich sections tend to produce higher R-values in comparison to purely ooid-bearing sections. Thus, realistic strain values seem to range at the lower end of the measured spectrum, i.e. between $\mathbf{R}_{s}=\mathbf{1 . 1 8}$ and $\mathbf{R}_{s}=1.35$. Fig. 6.24 illustrates several methods applied in order to achieve realistic results; a comparison of results from two different strain calculation methods is shown in Tab. 6.2.
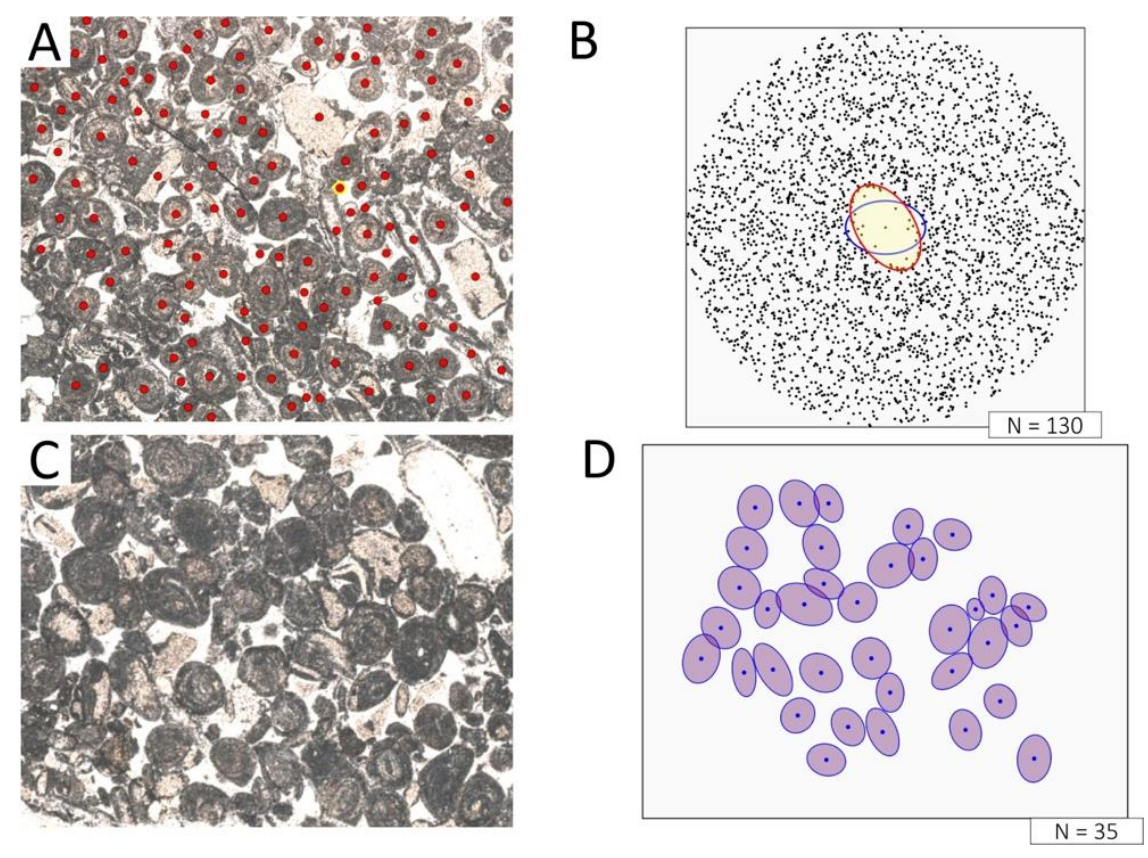

Fig. 6.24. Microphotograph of a representative section from thin section B10N-C with particle centres marked with red dots $(A)$ and corresponding Fry plot $(B)$ with strain ellipse outlined in red. The bedding plane is indicated with an orange dashed line in (A). Note that the bedding plane is parallel to the longitudinal axis of the strain ellipse in $(B)$. Therefore, compression occurred normal to the bedding plane due to sediment loading. A way of directly illustrating volume loss due to strain is demonstrated in images $(C)$ and $(D)$. While $(C)$ shows another example of thin section B10N-C, image $(D)$ is a simplified view of measured particles showing both, particle centres and outlines. Since outlines correspond to initial particle shapes, ellipse overlaps represent areas of volume loss (darker shade). 
Tab. 6.2. Strain calculation results for two exemplary frames from sample B10N-C. (A) Void fit method, (B) Rf/ $\phi$ graph method:

\begin{tabular}{ll}
\hline \multicolumn{1}{c}{ (A) Void Fit Results } & \multicolumn{1}{c}{$(\mathrm{B}) \mathrm{Rf} / \phi$ Graph Results } \\
B10N-C_3 & B10N-C_3 \\
\hline $\mathrm{N} \quad: 92$ & $\mathrm{~N}=35$ \\
Pairs : 4186 & Projection: Logarithmic \\
Time : 00:00:00 & Centroid: \\
Digitized & $\mathrm{N}=35$ \\
Normalized : False & $\mathrm{R}=1.375$ \\
Delaunay : False & $\mathrm{Phi}=12.52^{\circ}$ \\
Best-Fit Ellipse & \\
$\mathrm{n}=10$ & \\
$\mathrm{~A}=31.692$ & \\
$\mathrm{~B}=19.986$ & \\
$\mathrm{R}=1.586$ & \\
$\Phi=47.10^{\circ}$ & \\
\hline
\end{tabular}

\subsubsection{Paleo-stress field analysis}

Mineralized fractures preserved in sample B10N not only give valuable information on the timing of fracture formation, but also allow to determine the paleo-stress fields responsible for specific fracture sets. Thereby, minimum principal stress directions $\left(\sigma_{3}\right)$ are assumed \pm normal to the fracture planes (e.g., Twiss and Moores, 2007). Since different cement generations are hard to distinguish in transmitted light, a CL composite image of every thin section, consisting of ca. 320 single images, was produced in order to identify all respective fracture networks and to reveal age relations between them (see Appendix 6.2/3/4). Please note that in this context the relative fracture age was determined according to the oldest fracture cement present, younger cements (continuous overgrowth or due to fracture reactivation) were not considered. Then, lineation of the bedding plane and of every single fracture in all of the three samples was measured relative to a given coordinate system (see Chapter 3). The values were plotted in a stereonet (Stereonet 10 by Rick Allmendinger) and common planes were calculated from related lineation sets (common plane method). Moreover, U-stage microscopy was applied a) to verify orientation of microfractures in comparison with according values obtained with the common plane method, and b) to determine orientation of fluid inclusion planes. Fractures were plotted according to their position in the respective thin sections (Fig. 6.25-a) with sections having the following orientation: section $A=000 / 00$, section $B=180 / 90$, and section $C=090 / 90$. Since this spatial fracture arrangement does not reflect true orientation of planar elements as resulting from brittle deformation and pressure solution, all planes were therefore rotated with respect to the bedding plane, which is assumed to have been horizontal during deposition and prior to fracturing and deformation (Fig. 6.25-b). The now resulting spatial orientation of fracture sets likely represents the true spatial arrangement of planar elements and thus allows to make statements on principal (paleo-)stress directions. A likely more accurate restoration is given in Fig. 6.25-c. 

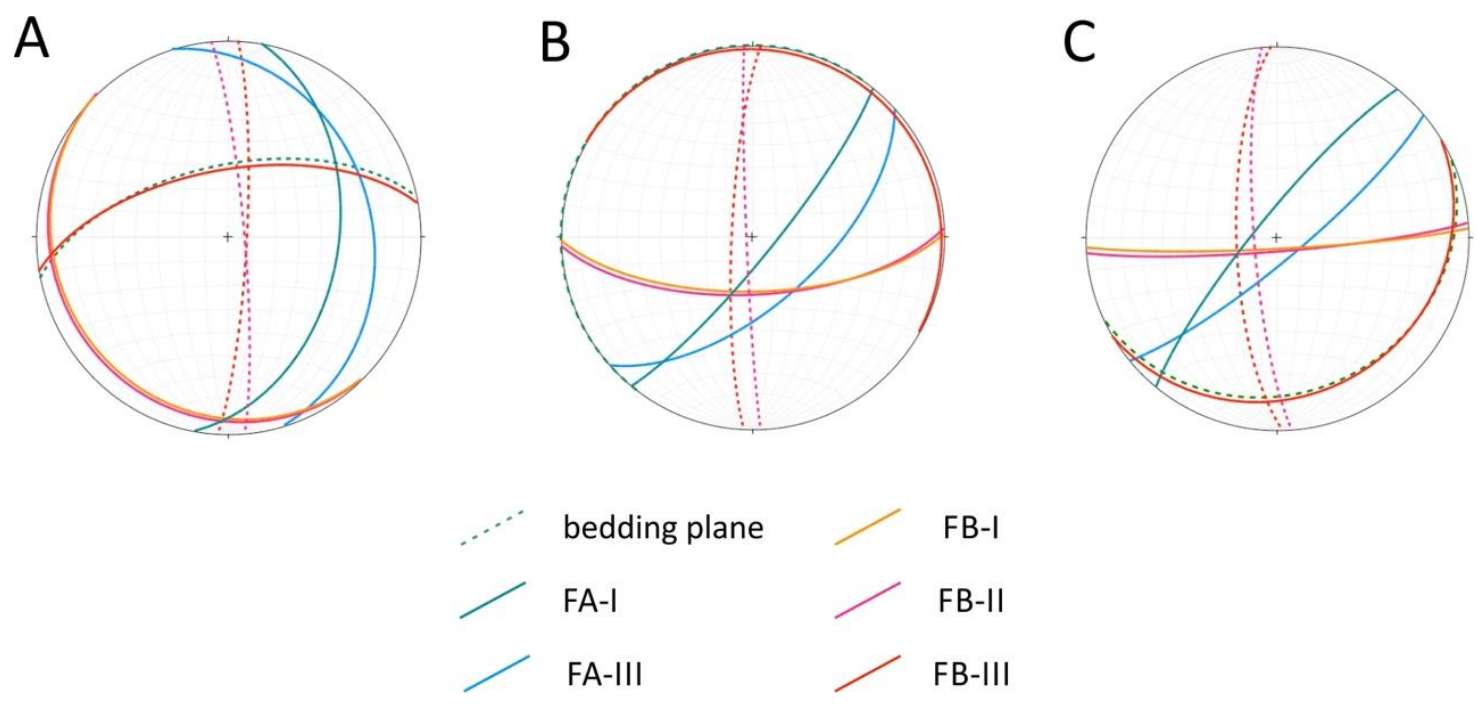

Fig. 6.25. Stereoplots of planar elements in sample B10N before (A) and after (B) bedding unfolding and rotation into the original position (i.e., with respect to a horizontal bedding plane). Note that shown planar elements do not represent all measured bedding and fracture planes, but only represent mean resulting planes. Dashed lines for FB-II and FB-III fractures mark short reaching fractures that are normal to the corresponding fractures. Since all FB-fractures show en-echelon patterns, which suggests a horizontal shearing component (strike-slip), these smaller offset fractures may represent planar extension fractures normal to a shear plane. Fracture set FB-III is parallel to the bedding and proves vertical $\sigma_{3}$ during formation. (C) Assuming Andersonian stress conditions (i.e., all three stress directions are normal to each other; Anderson, 1951), another correction seems plausible in order to explain steep FA-fractures almost parallel to vertical $\sigma_{l}$ during burial.

\subsubsection{Fluid inclusion petrography and microthermometry}

Fluid inclusions are surprisingly rare in all investigated samples; samples B2.1 and B2.4 do not contain any considerable fluid inclusions at all. Sample B2.4 does not contain apparent pore cements and fracture cements are too small to detect inclusions suitable for microthermometry; fluid trapping or preservation of fluid inclusions in sample B2.1 was probably prevented due to severe recrystallization. Primary and secondary, biphase aqueous fluid inclusions in sample B13.4 are rare and restricted to intergranular pore cements. They are mostly angular and locally show acute offsets; their size ranges between 5 and $12 \mu \mathrm{m}$, larger inclusions are very rare. Homogenization temperatures $\left(T_{h}\right)$ range between $68^{\circ} \mathrm{C}$ and $95^{\circ} \mathrm{C}$, ice melting temperatures $\left(\mathrm{T}_{\mathrm{m} \text {,ice }}\right)$ vary between $-5.7^{\circ} \mathrm{C}$ and $-8.5^{\circ} \mathrm{C}$; homogenization upon heating occurs into the liquid phase $(\mathrm{LV} \rightarrow \mathrm{L})$. Nucleation temperatures $\left(\mathrm{T}_{\mathrm{n}}\right)$ observed upon freezing cluster between $-28^{\circ} \mathrm{C}$ and $-24^{\circ} \mathrm{C}$. CL analysis suggests that measured fluid inclusions in P-CEM cements found within sample B13.4 are related to a relatively late stage of cement precipitation, which can be associated with FA-I and FA-II fracture cement formation.

Sample B10N contains primary, biphase aqueous fluid inclusions in pore cements (P-CEM), as well as pseudosecondary, biphase aqueous fluid inclusions in fracture cements of cement-types FA-II and FA-III. However, fluid inclusions found in FA-III cements are mostly decrepitated and are therefore barely useful for analysis. Their shape is typically angular and size ranges between 5-10 $\mu \mathrm{m}$ ((Fig. 6.26a), locally inclusions with diameters up to $20 \mu \mathrm{m}$ are apparent, but often decrepitated. Fluid inclusions trapped in FA-II-type cements can be grouped into two different fluid inclusions assemblages (FIA, see Goldstein and Reynolds, 1994) according to their homogenization temperatures. FIA-1 is characterized by $\mathrm{T}_{\mathrm{h}}$ ranging between $68.9^{\circ} \mathrm{C}$ and $98.2^{\circ} \mathrm{C}$, while according ice melting temperatures $\left(\mathrm{T}_{\mathrm{m} \text {,ice }}\right)$ range between $-9.9^{\circ} \mathrm{C}$ and $-14.7^{\circ} \mathrm{C}$. Fluid density varies between $1.1114-1.041 \mathrm{~g} / \mathrm{cm}^{3}$ and salinity in mass\% 
( $\mathrm{NaCl}$ equiv.) ranges between 13.83 and 18.38. Fluid inclusions related to FIA-2 show $\mathrm{T}_{\mathrm{h}}$ between $105.3^{\circ} \mathrm{C}$ and $120.2^{\circ} \mathrm{C} ; \mathrm{T}_{\mathrm{m}, \text { ice }}$ vary between $-15.3^{\circ} \mathrm{C}$ and $-15.5^{\circ} \mathrm{C}$. According fluid density varies between $1.069-1.084 \mathrm{~g} / \mathrm{cm}^{3}$ and salinity ranges between $18.83-19.04$ mass\% ( $\mathrm{NaCl}$ equiv.). Moreover, all fluid inclusions are characterized by a phase transition into the liquid phase $(\mathrm{LV} \rightarrow \mathrm{L})$ upon heating. However, despite the differences in $\mathrm{T}_{\mathrm{h}}$, which can probably be explained by fracture reactivation during different stages of basin evolution, fluid properties in both FIAs are quite similar. $\mathrm{T}_{\mathrm{n}}$ of all measured fluid inclusions range between $-63.8^{\circ} \mathrm{C}$ and $-64^{\circ} \mathrm{C}$, which again supports the idea of a single fluid system that was reactivated at different temperature and pressure conditions. Besides, FIA-A corresponds quite well with fluid inclusions detected within P-CEM cements in sample B13.4.

Solid inclusions are apparent in pore cements (B13.4) and especially along growth surfaces of fracture cements in sample B10N (Fig. 6.26-b). Their origin may be organic, however, they always occur together with $\mathrm{Fe}$-(hydr-)oxides (brown to yellowish matter), which points at oxidizing conditions during trapping.
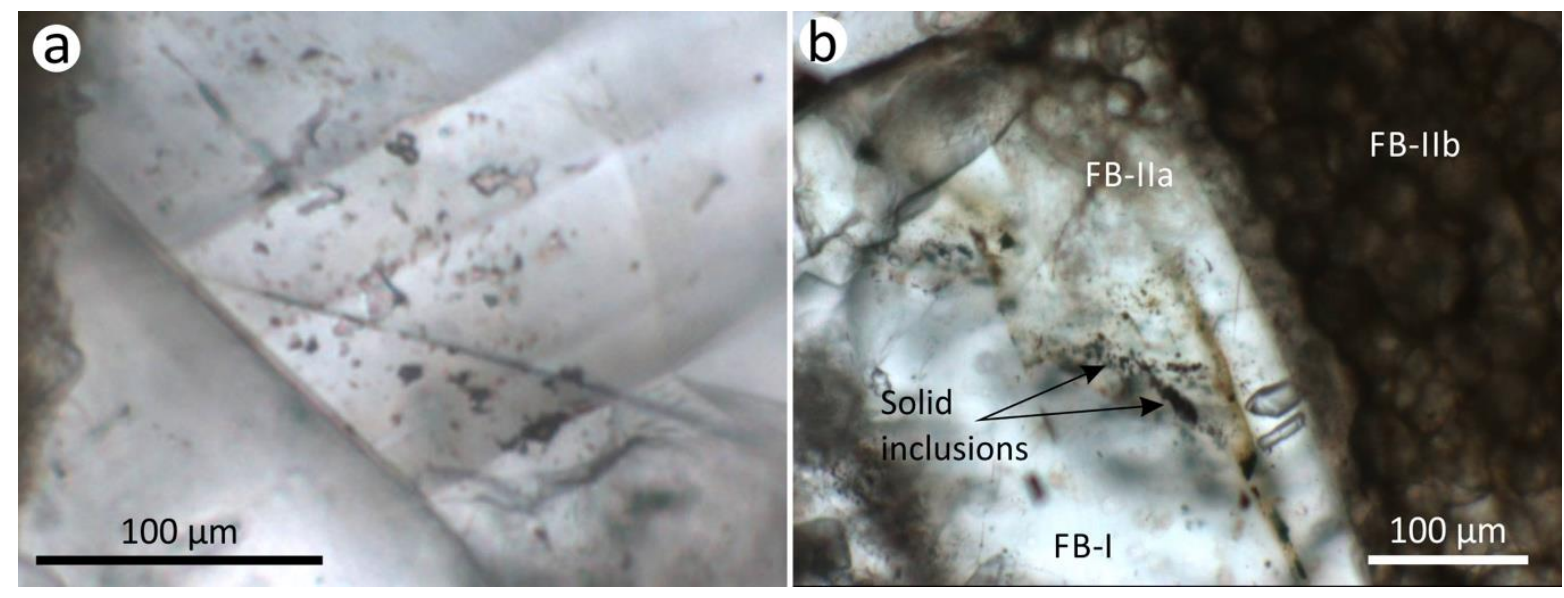

Fig. 6.26. (a) Pseudosecondary fluid inclusions in FA-I calcite cement (sample B10N). Inclusions are relatively small $(\varnothing 5-10 \mu \mathrm{m})$ and show angular shape; they are commonly arranged in clusters along healed microcracks. (b) Solid inclusions of likely organic origin within FB-cements (sample B10N). Note, how solid particles trace growth surfaces between older euhedral crystals and new overgrowth cements $(F B-I \leftrightarrow F B-I I)$.

\subsection{Discussion}

\subsubsection{Diagenetic evolution and structural elements}

Based upon microscopic and microthermometric evidence found in our samples we are able to outline the diagenetic and structural evolution of the western Basque-Cantabrian Basin from deposition in the early Jurassic until basin inversion in the Paleogene. Thereby, we focus on cement stratigraphy and fracture analysis in order to identify different stages of cementation and fracturing and, hence, variations in porosity and permeability, as well as fluid chemistry and trapping temperatures. Fig. 6.27 shows a compilation of all diagenetic events in chronological order. For a detailed explanation of abbreviations and according cement types, see compilation in Tab. 6.1.

Early diagenesis: After deposition in the early Jurassic the sedimentary sequence subsequently underwent a moderate stage of subsidence and compaction. Thereby, carbonate particles, ooids, and shell fragments were partly micritized and micritic mud was recrystallized (R-CEM). Beside 
compaction-controlled pore space reduction, wall-lining meniscus or dogtooth cements reduced porosity as well, marking the first stage of pore cementation (P-DT).

Early to intermediate diagenesis: During advanced subsidence grain contacts of ooids and other carbonate particles were partly dissolved when compaction-related pressure solution was initiated, thus reducing pore space and leading to the formation of horizontal stylolites. This process of bulk volume reduction is best documented by the Fry analysis, which clearly points out how pressure solution along grain contacts forced by a vertical $\sigma_{1}$ contributed to pore volume loss and grain size decrease. Simultaneously, detrital quartz and feldspar grains served as growth nuclei for syntaxial cements, when silica-enriched fluids enhanced authigenic silicate-precipitation along grain surfaces (S-CEM), thereby partly replacing surrounding carbonate particles, forming euhedral crystals. As non-luminescent or weak brownish CL characteristics of respective carbonate cements suggest, temperatures during S-CEM precipitation likely did not exceed $60^{\circ} \mathrm{C}$.

Intermediate to late diagenesis: Pore space was continuously further reduced close to a minimum when precipitation of blocky calcitic pore cement (P-CEM) started. Simultaneous to the final stage of P-CEM cementation lateral extension allowed the propagation of a first steep fracture generation, characterized by inter- and transgranular fracturing and calcite mineralization with cements similar to P-CEM (FA-I). As revealed by homogenization temperatures of (pseudo-)secondary fluid inclusions trapped within P-CEM and FA-I cements, late pore cementation of P-CEM cements and simultaneous fracture cementation occurred at minimum temperatures of about $70^{\circ} \mathrm{C}$, which corresponds to a burial depth of ca. $2 \mathrm{~km}$. Salinity of trapped fluids is commonly moderate and reflects the typical composition of basinal brines. The lateral extension was likely initiated by the onset of rifting in the BasqueCantabrian Basin during Late Jurassic, marking a new phase of burial evolution.

Late diagenesis: During advanced burial another brittle deformation stage caused the formation of a new set of steep fractures, which is above all characterized by the severe dissolution of fossil fragments and fracture surfaces resulting in small cavities and comparatively wide fractures, that were subsequently completely (cavities) or in part (fractures) mineralized (FA-II cement). Fracture set FA-II was continuously followed by fracture set FA-III, which formed relatively small fractures, and furthermore reactivated larger fractures that had opened during the previous fracturing phase. FA-III cement filled small fractures, but also continued FA-II precipitation within wider fractures, forming large subhedral calcite crystals. All FA-fracture sets share the same spatial orientation; besides, related calcite cements show similar CL characteristics, i.e. dull orange, orange and reddish CL typically found in diagenetic regimes, where pore fluids are increasingly reduced (Boggs and Krinsley, 2006). Only the bright orange to yellow CL found in FA-II cements may be an exception, especially since its formation was preceded by severe dissolution. Swennen et al. (2012) described hydrothermal karstification in the Basque-Cantabrian Basin in the vicinity of a major fault system (Pozalagua Fault), which may explain this dissolution event due to influx of Ca-undersaturated fluids, however, no other evidence was found in our samples that supports the idea of a comparable hydrothermal system in the study area at that time. A remarkable feature found especially in P-CEM and FA-cements, FA-III above all, is the surprisingly high deformation twin density, which proves mechanical stress at some point during basin evolution, most likely during fault reactivation (dip-slip) or due to a compressive stress field (basin inversion).

Basin evolution continued with the formation of a series of fracture sets with different orientation compared to FA-fractures, which therefore relate to a changed paleo-stress field (FB-fractures). The oldest fracture set, characterized by steep en-echelon fracture planes, is mineralized with calcite cements (FB-I) that either fill newly formed fractures or continue calcite precipitation on FA-III cements. FB-I cementation again is preceded by a minor dissolution event as corroded surfaces of wall-rocks and 
FA-III crystals prove. Corroded surfaces are locally covered with brownish coatings, likely Fe-(hydr-) oxides, which may be associated with oxidizing conditions during fracture formation and fresh fluid influx. The simultaneous occurrence of dark solid inclusion that resemble bituminous matter (char) probably points at the migration of carbonic fluids. CL analysis of FB-I cements could prove that this fluid was not restricted to fractures in sample B10N, as recrystallization features in sample B13.4 reveal the same CL pattern. This observation suggests interformational fluid flow during fracture propagation that likely resulted in (repeated) brecciation and subsequent recrystallization of sample B13.4. This process of recrystallization obviously continued as fracture propagation continued, thus forming another set of steep fractures. These fractures are mineralized with Mg-rich calcite (FB-II, which, after another short phase of dissolution and corrosion (see FB-I) precipitated within newly formed fractures or directly continues precipitation of FB-I cement within reactivated fractures. The last stage of fracture formation resulted in shallow-dipping, bedding parallel fractures that are accompanied by the formation of vertical stylolites, caused by horizontal shortening due to tectonic convergence. Related FB-III cement, which is non-luminescent in CL, not only occurs within fractures, but is also present as an interparticle porefilling cement within sample B13.4, thus, brecciation of sample B13.4 was likely completed before FB-III cement formed.

The detailed reconstruction of the diagenetic and structural history of the study area not only demonstrates the repeated structurally-controlled fracture propagation had a heavy influence on permeability and thus, fluid flow. Moreover, dissolution and partly reactivation of pre-existing fracture systems strongly contributed to the (temporarily) increase in fracture porosity and permeability. Besides, our observations are in good agreement with findings by Rosales and Perez-Garcia (2010), who documented the porosity development and diagenetic history of a comparable carbonate platform of Albian age located in the coastal range of the BCB. 
Chapter 6 - Progressive fracture-network development in a carbonate reservoir

\begin{tabular}{l|c|c|c} 
Time & Early & & Late \\
\hline Event & Deposition + Subsidence & Burial + Rifting & Horizontal compression \\
\hline Tectonic regime & Vertical compression & Extension & \\
\hline R-CEM & & & \\
P-DT & & & \\
\hline S-CEM & & & \\
\hline Stylolitization & & & \\
\hline P-CEM & & & \\
\hline FA-I & & & \\
\hline Dissolution & & & \\
\hline FA-II & & & \\
\hline FA-III & & & \\
\hline FB-I & & & \\
\hline Brecciation & & & \\
\hline Recrystallization & & & \\
\hline FB-II & & & \\
\hline FB-III & & & \\
\hline
\end{tabular}

Fig. 6.27. Sequence chart of the simplified chronology of diagenetic events, tectonic regimes, and according cement types.

\subsubsection{Paleo-stress field and fracture-network development}

Fig. 6.28 shows all simplified principal stress regimes that correspond to different stages of basin evolution as derived from our 3D fracture network analysis. While a stage of vertical compaction (1) likely reflects a stress regime typical for early to intermediate diagenesis, stage (2) is dominated by horizontal extension and vertical displacement along steep dipping fractures (FA-fractures), which can be associated to rifting. Stages (3) and (4) relate to compressional regimes with horizontal $\sigma_{1}$ and therefore likely reflect inversion tectonics. However, stage (4) is characterized by vertical $\sigma_{3}$ and, moreover, simultaneous stylolitization (vertical stylolites) that proves horizontal shortening, while stage (3) coincides with horizontal displacement likely resulting from strike-slip tectonics. 

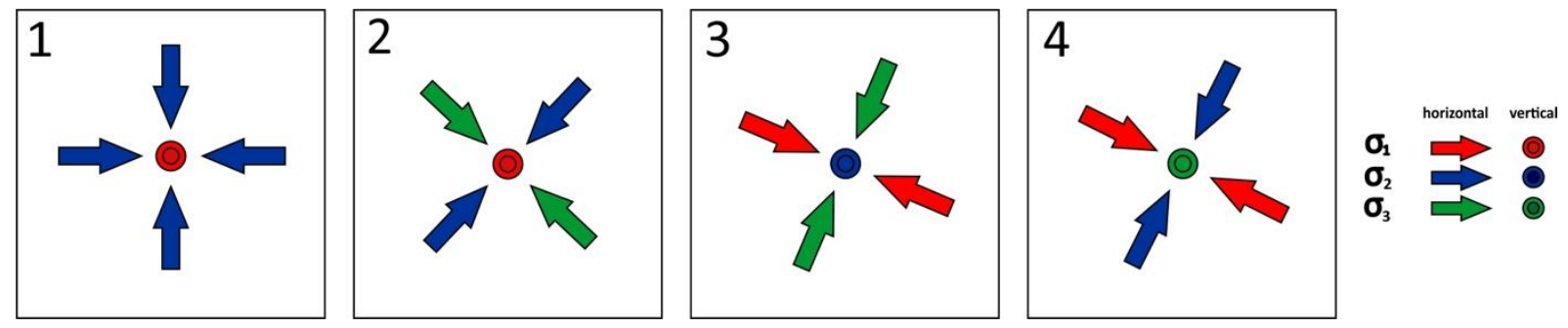

Fig. 6.28. Simplified illustration of resulting paleo-stress fields as derived from stereoplot construction (based on Fig. 6.25-c). Image (1) shows a state of local compression with $\sigma_{1}=$ vertical and $\sigma_{2}=\sigma_{3}$. This stress field represents the time of compaction during subsidence, as evidenced by horizontal pressure solution seams. Image (2) demonstrates the stress state during fracture formation due to rifting. Images (3) and (4) show a somewhat reversed and rotated stress field with a horizontal $\sigma_{1}$. Note, how $\sigma_{3}$ rotates from horizontal (3, strike-slip) to vertical (4) over time. This process is proven by the change from vertical fracture formation (FB-I+II) to bedding-parallel fractures (FB-III). However, it is not clear if $\sigma_{1}$ in (3) and (4) coincide; it may have a different orientation, which cannot be determined by microscopic analysis.

Fracture networks established in our samples can now be attributed to the above proposed paleo-stress field chronology and interpreted accordingly; a simplified visualization of respective results is given in Fig. 6.29. Thus, fracture sets mineralized with type FA-cements apparently first opened at depth of ca. $2 \mathrm{~km}$ in response to an extensional tectonic regime, when pore cementation was almost completed. While FA-I fractures formed \pm perpendicular to the bedding plane, FA-II and FA-III fractures show inclined conjugate fracture networks. FA-III fractures are moreover characterized by a slight wallparallel displacement component apart from wall-normal extension detected in all FA-fracture sets.

A

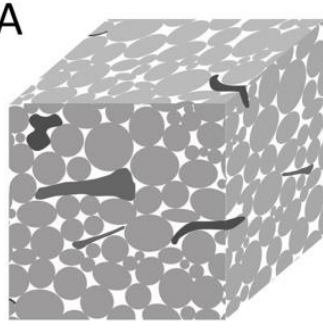

Deposition, micritization, compaction, and subsequent pressure solution

\section{$\mathrm{E}$}

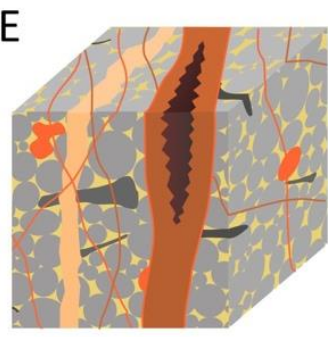

Extension: formation of fracture cement FA-III
B

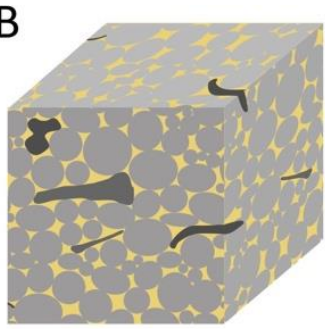

Pore cementation (P-CEM)

$\mathrm{F}$

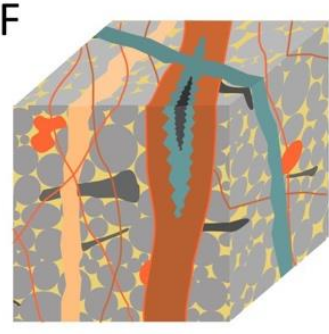

Compression: dissolution prior to cement FB-I precipitation, partial reactivation of FA-fractures

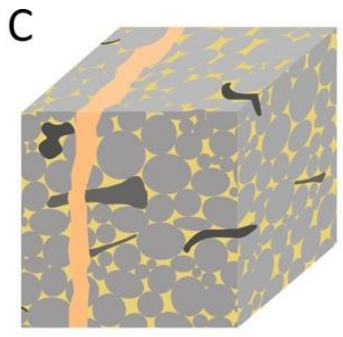

Extension: formation of fracture cement FA-I

G

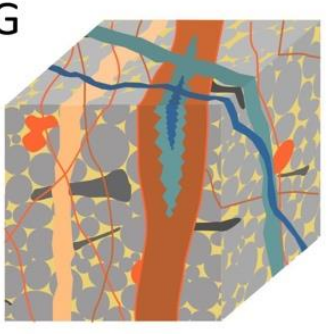

Compression: formation of cement FB-II, partial reactivation of FA-fractures

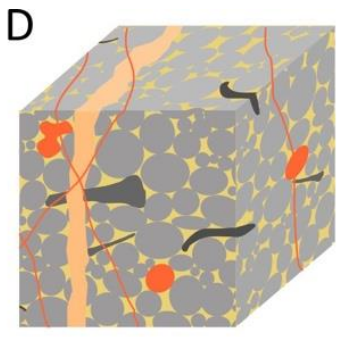

Extension: dissolution of fossil fragments and fracture surfaces (karstification?), formation of FA-II cement

H

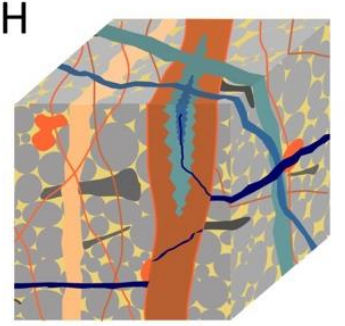

Compression: formation of cement FB-III (bedding-parallel, vertical $\sigma_{3}$ ) 
Fig. 6.29. Block diagrams illustrating the cementation and deformation history of an oolithic limestone from the western BCB (sample B10N). The bedding plane is supposed as perfectly horizontal.

In contrast, type FB-I and FB-II cements, which fill fractures that also opened \pm normal to the bedding plane, are characterized by en-echelon patterns and minor horizontal displacement. This gives rise to the assumption that a strike-slip mechanism may have controlled their formation rather than extension. FB-III fractures prove a final stage of fracture formation, when bedding-parallel fractures formed likely due to thrusting and prominent horizontal shortening. However, the near-total absence of deformation twins observed in FB-type cements contrasts observations from FA-type cements and suggests that the sedimentary sequence has experienced less mechanical stress during strike-slip faulting and thrusting. This observation also leads to the assumption that recrystallization of sample B13.4 occurred at a relatively late stage of basin evolution, when differential stresses were comparatively low.

The deformation history of our outcrop samples can now be brought into context with the regional tectonic history of the BCB. Tavani et al. (2011) for example could prove that from late Jurassic until late Cretaceous times rifting in the western BCB resulted in extensional faulting, while during the Cenozoic intense right-lateral fault activity in the study area lead to a transpressive deformational regime locally accompanied by dip-slip inversion tectonics, which could explain all deformational features observed in our samples. Taking into account the significantly different CL characteristics found in fracture and pore cements, a more or less closed fluid system with increasingly reducing conditions can be assumed for the time of rifting, while transpressive tectonics apparently favoured influx of fresh fluid and the establishment of an oxidizing regime. It is not clear, if FB-cements formed close to the onset of inversion at great depth or at shallow depth after significant uplift had already taken place. However, a fluid inclusion study carried out by Schneider et al. (2008) could prove that fluids associated with oxidizing conditions are widespread in the $\mathrm{BCB}$ and apparently relate to meteoric or marine waters. This large-scale fluid migration event was likely triggered by Alpine tectonics.

\subsubsection{Basin modelling}

1D basin modelling was applied in order to complement published burial curves and vitrinite reflectance values with our own findings and thereby develop a burial curve for our study area, which is supposed for reconstruction of the structural and thermal history of the western BCB. Beside extensive literature research with emphasis on the sedimentary record of the study area, homogenization temperatures obtained from fluid inclusions that were trapped within pore and fracture cements were used for pressure and temperature (P-T) correction (crossing isochore method) in order to determine trapping depth. Since accuracy of P-T correction in fact highly depends on the geothermal gradient applied for calculation (Fig. 6.30; see Chapter 2), two different published burial curves (Rosales and Perez-Garcia, (2010) were used for a first approximation, of which one curve is characterized by a constant heat flow, while the second one takes heat flow variations due to rifting into account. 

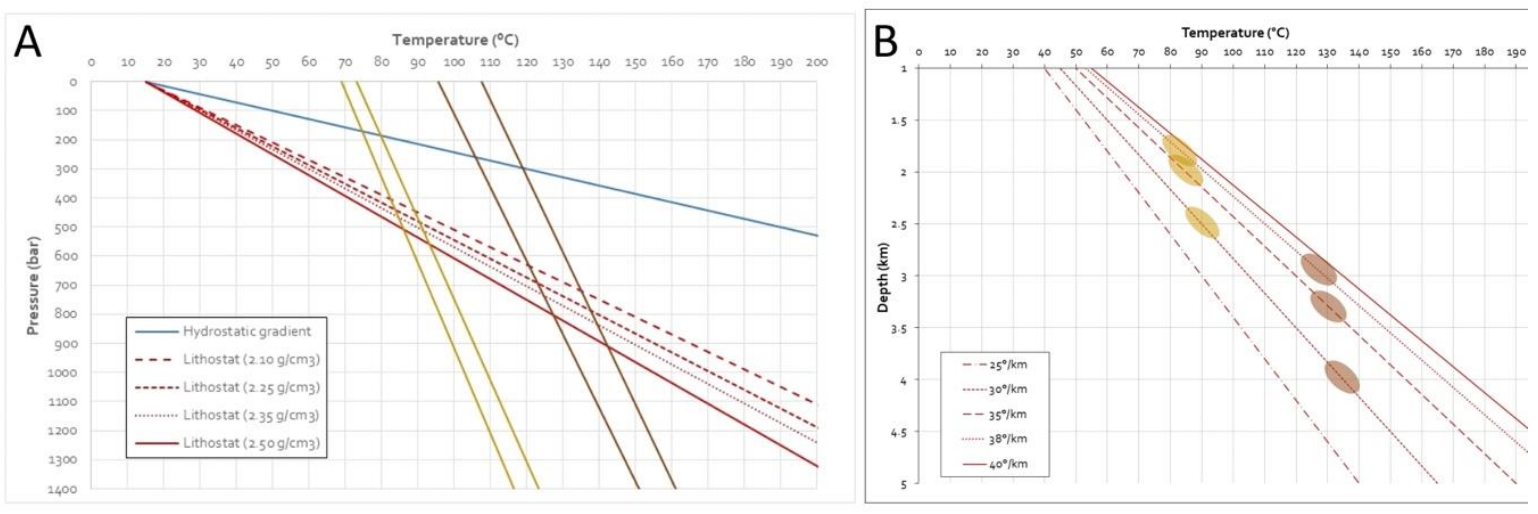

Fig. 6.30. Image (a) shows isochores for FIA-A (light brown) and FIA-B (dark brown) as well as a hydrostatic gradient and several lithostatic gradients within a P-T plot. Please note, that lithostatic and hydrostatic gradients correspond to a specific geothermal gradient $\left(30^{\circ} \mathrm{C}\right)$ and change their inclination when a different geothermal gradient is applied. The D-T plot shown in image (b) illustrates the different resulting formation depth for FIA-A (light brown ellipses) and FIA-B (dark brown ellipses) with respect to different geothermal gradients. Only minimum and mean $T_{h}$ values were used for isochore construction.

As proposed by McKenzie (1978), in basin modelling special attention should be paid on the boundary conditions (crustal model) that describe the development of sedimentary basins during extension and inversion. This means high heat flow is commonly to be expected during extension as a consequence of different properties such as increased hydrothermal convection, crustal thinning and thus, magmatic activity. This simple assumption is barely applied in basin models and many studies use constant heat flow values for their models as heat flow variations are hard to prove. Rosales and Perez-Garcia (2010) however compared a constant heat flow scenario with a second scenario based on vitrinite reflectance values (according models customized for our study area are presented in Fig. 6.31 and Fig. 6.32). The authors could thereby show that vitrinite maturity in the BCB can best be explained by several pulses of increased heat flow during late Jurassic - early Cretaceous times. These results coincide with observations made by Martín-Chivelet et al. (2006) who describe two extensional pulses in the BCB at that time, with a maximum heat flow event during Abtian-Albian. 
Chapter 6 - Progressive fracture-network development in a carbonate reservoir

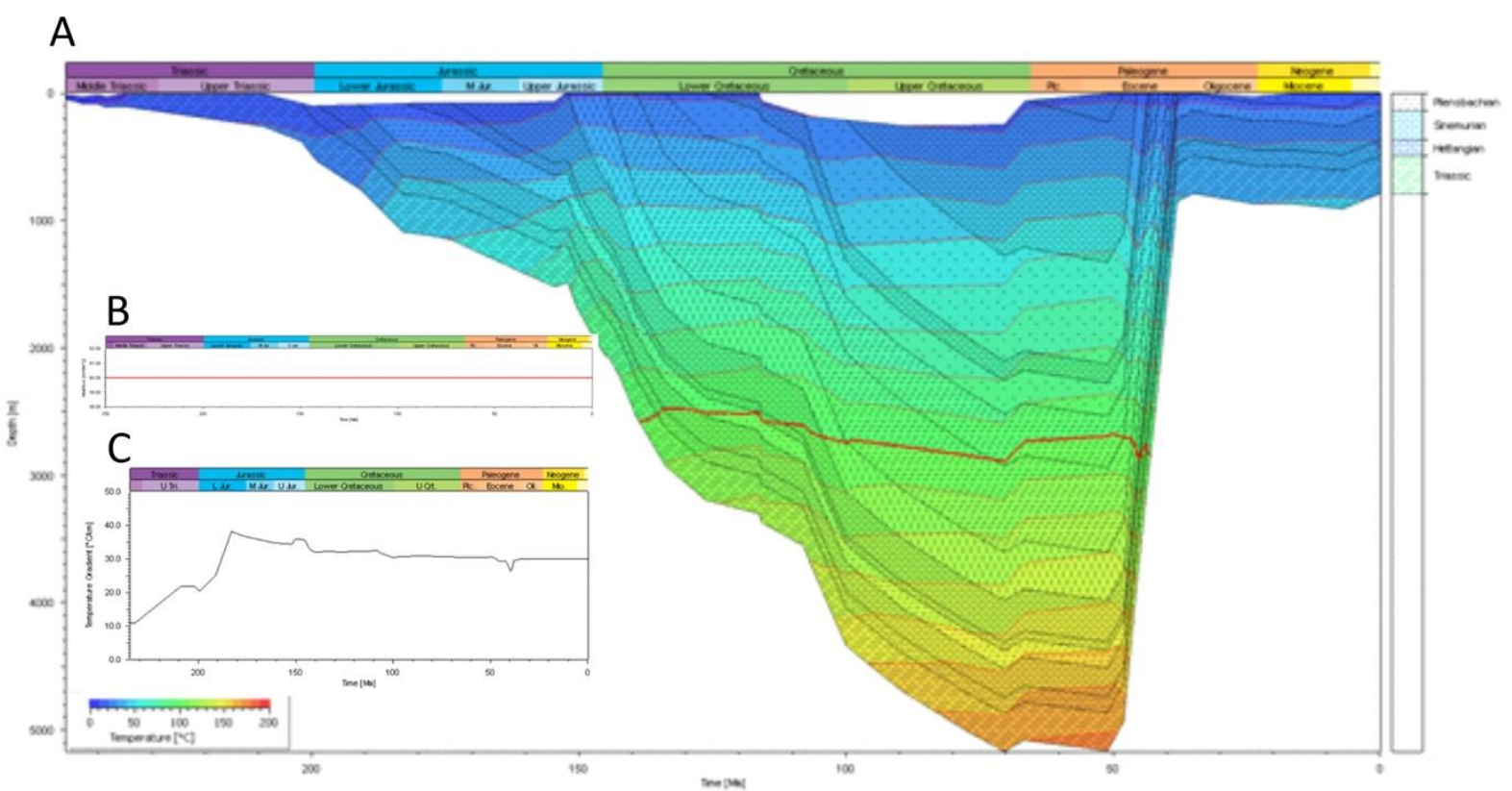

Fig. 6.31. (a) Burial curve for the western BCB. The sedimentary record was adjusted to the local conditions in our study area. (b) A constant heat flow of $60 \mathrm{~mW} / \mathrm{m}^{2}$ was applied for this burial curve. (c) Average geothermal gradient $\left({ }^{\circ} \mathrm{C} / \mathrm{km}\right)$ at Mid of Sinemurian derived from $1 D$ numerical modelling using a constant heat flow of $60 \mathrm{~mW} / \mathrm{m}^{2}$. Variation seems to be controlled by velocity of vertical displacement (burial and uplift), and lithology.
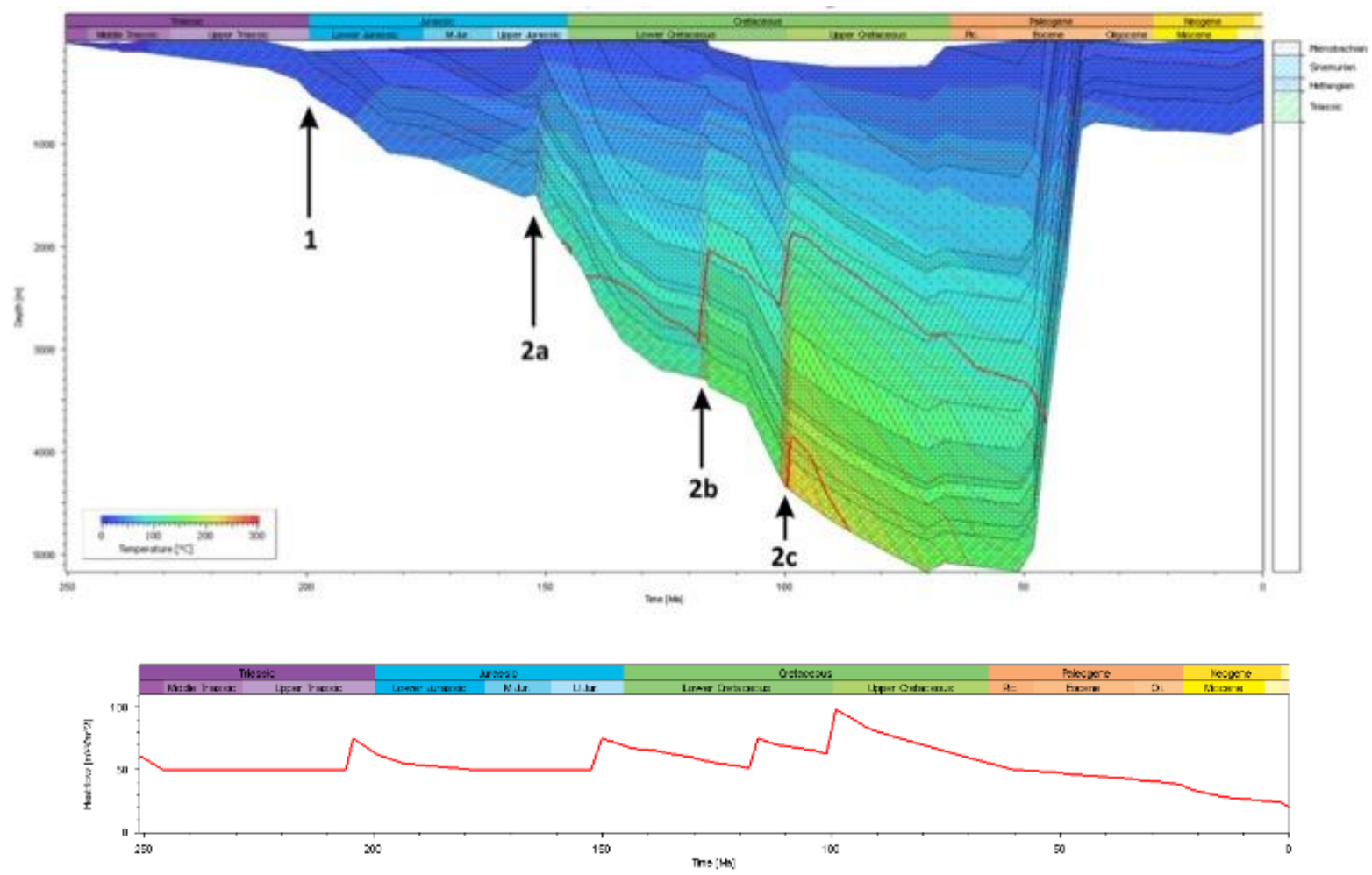

Fig. 6.32. Top: Temperature development of the western BCB showing two major rifting phases that were accompanied by increased heat flow, as suggested by Rosales and Perez-Garcia (2010): (1) late Triassic - early Jurassic rifting, (2) late Jurassic - early Cretaceous rifting characterized by three prominent heat flow events (onset marked by labelled arrows: 2a-c) (black lines: layers, red lines: isotherms). Bottom: Heat flow curve for the western BCB according to Rosales and Perez-Garcia (2010). 
Chapter 6 - Progressive fracture-network development in a carbonate reservoir

Application of crossing isochore method on our fluid inclusion data lead to corrected formation temperatures of ca. $85^{\circ}-95^{\circ} \mathrm{C}$ for FIA-1 and $125^{\circ}-130^{\circ} \mathrm{C}$ for FIA-2. According pressure correction provided formation depth between 1800 and 2500 meter below surface for FIA-1, and between 2800 and $3300 \mathrm{mbs}$ for FIA-2, respectively. Geothermal gradients considered for this estimation range between $30^{\circ} \mathrm{C} / \mathrm{km}$ and $40^{\circ} \mathrm{C} / \mathrm{km}$, as lower values do not seem realistic and higher values would exceed data obtained from our burial models (Fig. 6.33 and Fig. 6.34).
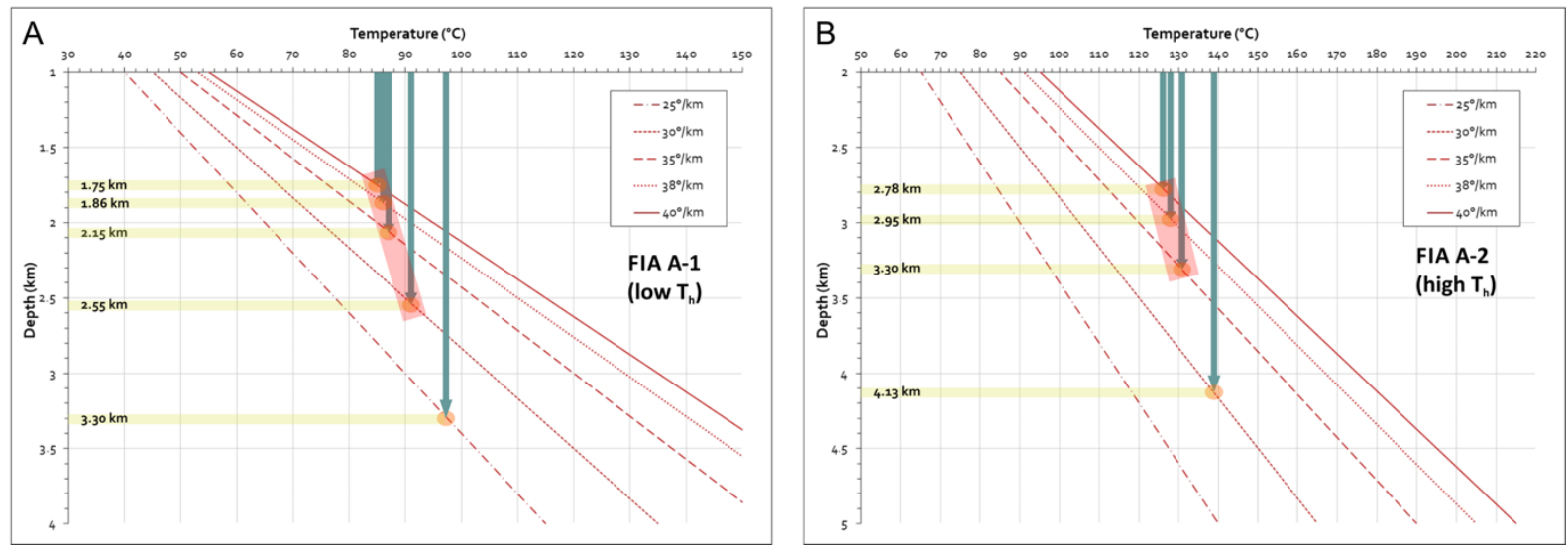

Fig. 6.33. (a) D-T plot for FIA-1 showing area of realistic D-T conditions (red bar), image (b) shows the same area for the FIA-2 data set.
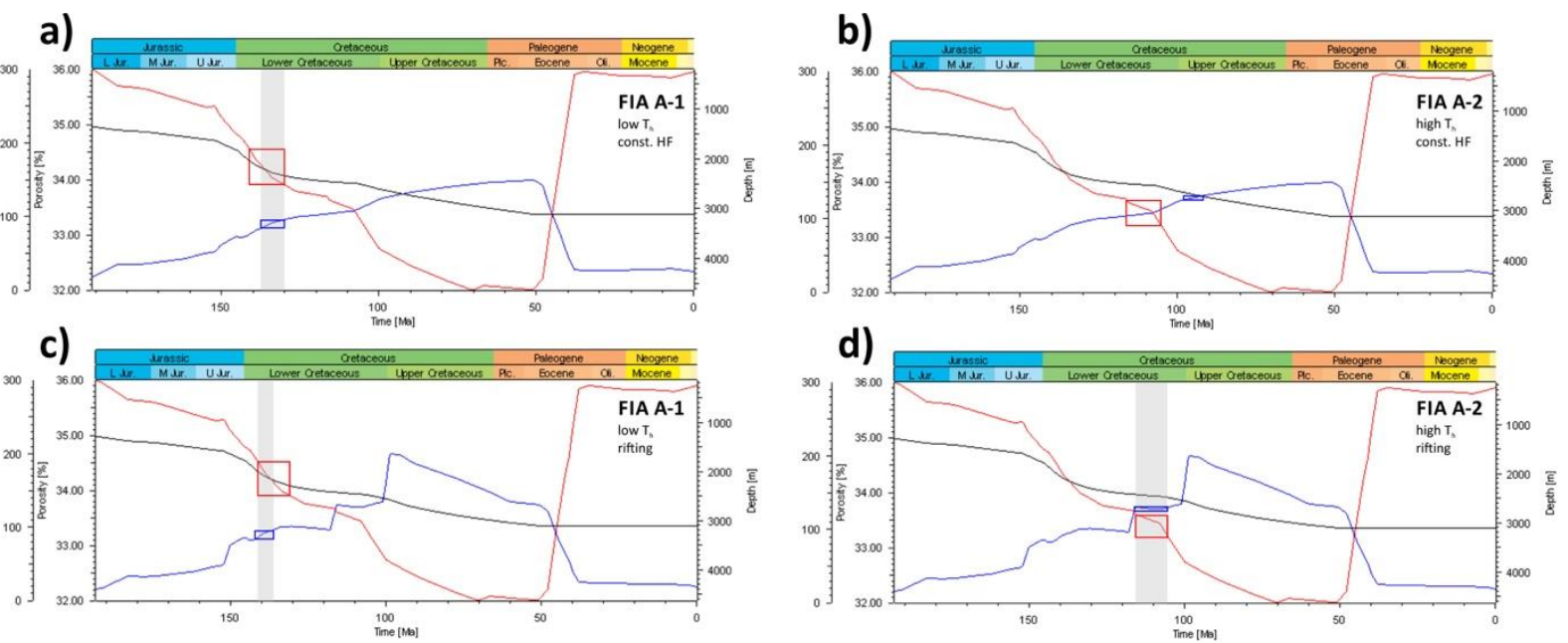

Fig. 6.34. Depth (red lines) versus temperature (blue lines) versus porosity (black lines) plots of Lower Sinemurian oolithic grainstone (B10N equivalent) with constant heat flow $(a, b)$ and applied peak rifting temperatures $(c, d)$. A red rectangle marks the corresponding depth time frame, whereas the blue rectangle defines the corresponding temperature time frame. When an estimated formation depth from crossing isochore calculations is considered (ca. $1800-2500 \mathrm{mbs}$ ), subsequent fracture formation between 142 to 136 my ago at temperatures between 85 and $98^{\circ} \mathrm{C}$ seems plausible for FIA-1 (grey shade: plausible time frame of formation). FIA-2 likely formed between 115 - 105 my ago, when temperatures between $125^{\circ} \mathrm{C}$ and $140^{\circ} \mathrm{C}$ at a depth of ca. $2800-3300 \mathrm{mbs}$ are assumed. As evident from (b) a constant heat flow scenario does not fit the estimated temperatures at corresponding depth and time for FIA-2. Thus, only an adjusted model, which takes enhanced heat flow pulses during rifting into account, may explain homogenization temperatures found in fracture-hosted inclusions in sample B10N.

Basin modelling in combination with fluid inclusion analysis turned out to be very helpful for the understanding of basin development in terms of timing of fluid migration and P-T evolution. Thereby, 
the time of precipitation of P-CEM cements and fracture sets FA-I and FA-II could be estimated, which is in good agreement with previous estimations derived from the structural reconstruction and published data. Moreover, our data seem to complement findings from Rosales and Perez-Garcia (2010) after which various heat flow pulses triggered by rifting in late Jurassic - early Cretaceous have caused high vitrinite maturity in the $\mathrm{BCB}$.

\subsection{Conclusions}

Microfabric analyses testify that pore space in the investigated sedimentary rocks from the BCB was drastically reduced during early diagenesis, while subsequent subsidence in an extensional tectonic regime induced crack propagation. Fracture formation is associated with a temporarily enhanced permeability that favoured the migration of basinal fluids likely during rifting in late Jurassic-Early Cretaceous and mid-Cretaceous times. Differences in the chemistry of fracture-filling cements revealed by CL prove a stepwise generation and partly reactivation of two distinct fractures sets (FA and FB), that resulted from reverse paleo-stress fields. Dissolution features found within early fractures (FA) point at carbonate dissolution and subsequent precipitation of blocky calcite cement in a marine to meteoric fluid regime. Subsequent burial diagenesis is characterized by a change from early oxidizing conditions to increasingly reducing conditions, as CL of pore cements demonstrates. Moreover, varying intensity and zoning characteristics of CL in carbonate cements show a continuous trend from early diagenetic non-ferroan calcite in pore cements (P-CEM) to low-ferroan calcite cement precipitation during shallow to medium burial (FA) at temperatures between $85^{\circ} \mathrm{C}$ and $130^{\circ} \mathrm{C}$, as revealed by fluid inclusion microthermometry. A second generation of non-ferroan calcite cement (FB) was found in latest fracture fillings accompanying related tectonic stylolites, which suggests formation during basin inversion in mid-Paleogene times. Our study demonstrates that fracture formation started after mechanical compaction was completed and continued in stepwise manner until deep burial conditions were reached and inversion tectonics were initiated. While pore cements show CL features characteristic for shallow marine formation conditions, fracture set FA contains calcite typically forming in reducing basinal environments ('closed fluid system'). Fracture cements in set FB supposedly formed under oxidizing conditions, either close to the surface ('open fluid system') or resulting from influx of oxygenrich fluids. The detailed reconstruction of reservoir conditions in terms of maximum pressure and temperature evolution during basin development was supported by a burial curve simulation using PetroMod 1D.

Our study could demonstrate, how fluid flow in sedimentary basins is restricted to fracture systems resulting from brittle deformation that equally form in both, extensional and compressional tectonic regimes. While extension usually supports wall-normal displacement and therefore creates maximum fracture volume, compression mostly favours fluid migration due to fracture reactivation. 


\section{Final discussion and conclusions}

\subsection{Discussion}

\subsubsection{Porosity and permeability}

Observations on pore space reduction and brittle deformation in clastic reservoir rocks (e.g. Lemans Sandstone/Fizzy Field or oolithic grainstone/BCB) suggest a correlation between the amount of cementation and the rate of compaction on one side and the capacity of brittle response to mechanical stress in the reservoir rock on the other side. As microscopic investigations and Fry analysis have shown, fracturing usually postdates compaction-related pressure solution and interparticle pore cementation or coincides with latest stages of both processes (see Fig. 7.1), which in consequence means that fracture porosity and permeability commonly first occur after open pore space has been reduced to a nearmaximum due to pressure solution and cementation. Thus, with regard to the burial history of the two reservoirs mentioned above, a minimum burial of ca. $2000 \mathrm{~m}$ was necessary in order to provide according reservoir conditions. After compaction and cementation were more or less completed, strain in the reservoir rock could no longer be buffered by compaction-related matrix reconfiguration, consequently resulting in brittle deformation. Besides, at that time of reservoir evolution cap rock was sealed as well, leading to increased pore overpressure, which favours fracturing. As test injections into shallow, poorly-cemented reservoirs in Maguelone (France) carried out by project partners have demonstrated, barely compacted reservoirs with a relatively short diagenetic history may serve as analogues for monitoring purposes, but are of little benefit for comparison with large-scale $\mathrm{CO}_{2}$ injection sites. Therefore, a reservoir's suitability for $\mathrm{CO}_{2}$ injection strongly depends on its cementation and compaction history, thus its diagenetic evolution, which must be well understood in order to be eligible for consideration.

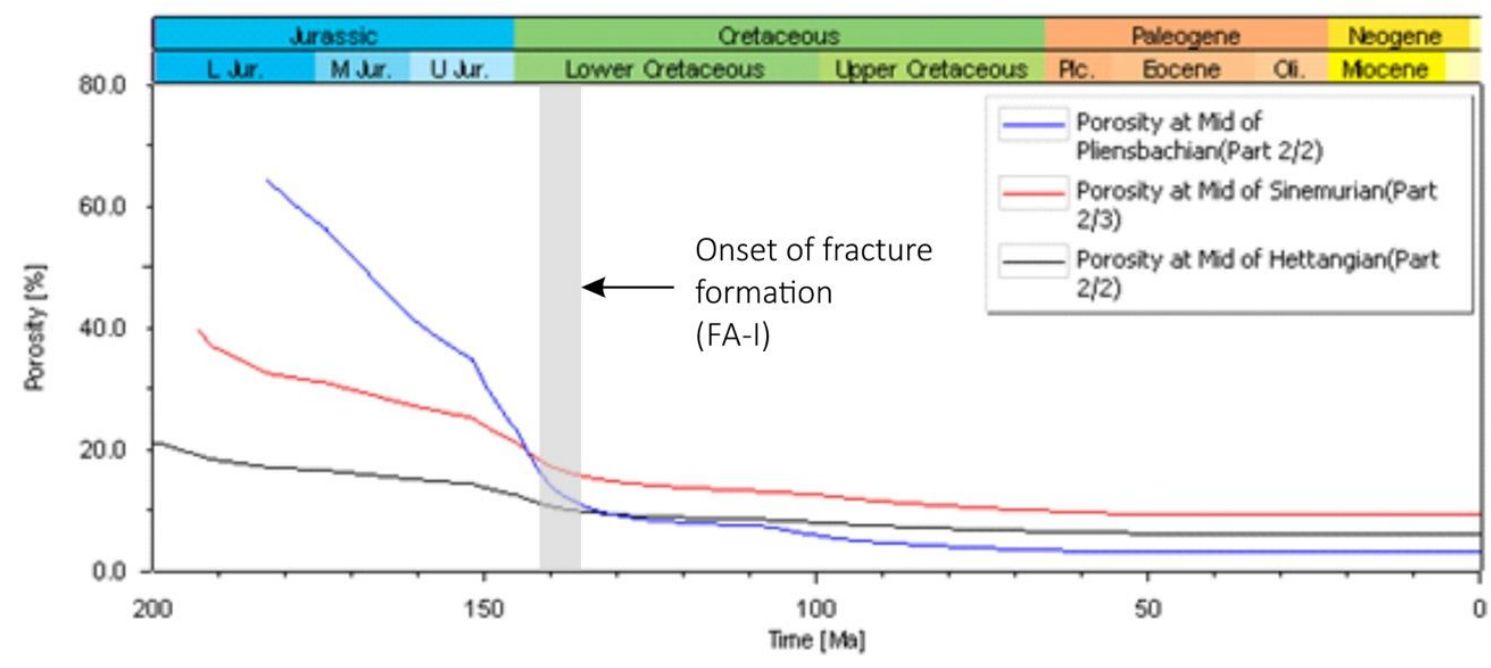

Fig. 7.1. Compaction-controlled porosity reduction of lithological units equivalent to samples B10N (red), B2.1 (black), and B2.4 (blue) according to our 1D basin model of the Basque-Cantabrian Basin. Note, how onset of fracture formation (grey shaded area) coincides with near-maximum of pore space reduction.

\subsubsection{Geomechanics}

Microstructural analysis of studied samples revealed a variety of features that give insight into brittle behaviour of reservoir rocks during both, extension and basin inversion. The detailed investigation of 
microfractures found in our samples showed that Mode I fractures seem to be predominant in both calcareous and siliciclastic reservoir rocks, and only Stassfurt carbonate rocks from the LSB contain (partly reactivated) extensional-shear fractures. A comprehensive comparison between observations made on sample material and numerical models allowed us to narrow down the timing of fracture formation. Furthermore, pressure conditions derived from fluid inclusion microthermometry and according pressures from burial curves showed that most pressures formed under the influence of overpressured pore fluids. Thus, cap rock failure and reservoir fracturing often occur during burial and extension, when the local stress field is characterized by horizontal minimum principal stress $\left(\sigma_{3}\right)$ and vertical $\sigma_{1}$. Besides, a second scenario of reservoir rock failure is evident from en-echelon fractures in sample B10N from the BCB, which possibly formed during strike-slip faulting (transtension); hereby, $\sigma_{1}$ and $\sigma_{3}$ are both horizontal. However, horizontal $\sigma_{3}$ seems to increase the probability of fracture-related fluid flow in both scenarios; thus, the influence of $\sigma_{3}$ is crucial for fluid mobility and fault reactivation (see Sibson, 1995).

Since cap rock or reservoir rock fracturing due to pressure build-up during injection and simultaneous fault (re-)activation are likely the main factors for leaking of $\mathrm{CO}_{2}$ injection sites, the determination of local stress fields at anticipated injection sites is a major goal of risk assessment. We propose the selection of reservoir rocks where the local stress field is characterized by vertical $\sigma_{1}$, while $\sigma_{2}=\sigma_{3}$ in order to minimize fracture propagation.

\subsubsection{Fluid chemistry}

Fluid chemistry of basinal fluids trapped within pore and fracture hosted cements provided valuable information on basin evolution from sedimentation and burial to rifting and inversion. Fluid analysis gave us the opportunity to study changes in the reservoirs fluid regime due to diagenetic processes or tectonic events. Thereby, several observations may be of importance for the understanding of $\mathrm{CO}_{2}$ migration in sedimentary basins. Significant changes in aqueous fluid composition, i.e. salinity, above all, are barely provable; most fluid inclusions show fluid content typical for the formation conditions of the host mineral (e.g. early diagenesis $=$ low salinity $\rightarrow$ marine-meteoric, burial $=$ high salinity $\rightarrow$ intense fluid-rock interaction, etc.); noticeable differences in $\mathrm{Ca}$ and $\mathrm{Na}$ concentrations found in sample from the LSB can be related to mineral conversion (anhydrite $\rightarrow$ gypsum) during burial. It turned out, that from sedimentation to deep burial no significant changes in fluid composition are evident, even though fracturing had taken place, which commonly favours inter- and intra-formational fluid flow. This points at relatively limited fracture systems only covering short distances. Whereas tectonic compression in conjunction with basin inversion (transpression/-tension) apparently had a major impact on reservoir integrity, as gaseous fluid inclusions trapped under near-hydrostatic conditions (LSB) and clear evidence for influx of fresh water under oxidizing conditions (BCB) prove. Our investigation could not clearly assign according reservoir position during fracturing in terms of depth, however, a density comparison between fluids trapped close to maximum burial and those trapped during inversion suggest trapping in the latter case occurred under comparatively shallow conditions $(<2000 \mathrm{~m})$. As fracture analysis of samples from the $\mathrm{BCB}(\mathrm{B} 10 \mathrm{~N})$ suggest that local extension with horizontal $\sigma_{3}$ was mainly responsible for the propagation of quasi-vertical fractures and the simultaneous downward migration of oxidizing water, strike-slip faulting was likely the governing factor for widespread vertical fluid activity, while burial-related fracturing is apparently less dominant in terms of fracture permeability. Consequently, migration of carbonic fluids in the LSB for example could have been the result of wrench-faulting (late Jurassic - early Cretaceous) rather than pure extension due to rifting. 
Therefore, our study demonstrated that a proper investigation of the local stress field and the fault mechanisms of related fault systems in combination with reservoir depth $>2000 \mathrm{~m}$ seem to be of major importance for the selection of future $\mathrm{CO}_{2}$ injection sites.

\subsubsection{Fluid-rock interaction}

Microfabrics revealed severe dissolution in carbonate rocks due to the influx of undersaturated water or acidic brines along fluid conduits that formed due to brittle deformation (LSB, BCB), which may affect both cap rock and reservoir rock. While dissolution in reservoir rock may temporarily enhance fracture permeability, at the same time it definitely reduces cap rock integrity and therefore is an unwanted sideeffect of fracture propagation.

In the $\mathrm{BCB}$, fresh-water influx in the course of basin inversion resulted in transformation of anhydrite into gypsum and subsequent swelling, accompanied by volume increase of ca. $60 \%$ and brecciation of carbonate rocks. Furthermore, this change in fluid chemistry enabled recrystallization of brecciated carbonate rocks; gypsum dissolution eventually caused exceptionally high pore space (B2.1), which accordingly cannot be confirmed from the Hontomín well, since respective rock units were not in contact with fresh water.

Similar conditions, i.e. migration of hot, undersaturated fluids along fractures, lead to the widespread dissolution of gypsum, anhydrite and possibly halite in the LWA, which consequently resulted in brecciation and subrosion.

In order to minimize the risk of similar scenarios caused by cap rock failure or inter-formational fracture formation in reservoirs, the influence of evaporitic strata should be avoided during $\mathrm{CO}_{2}$ injection.

\subsubsection{Thermal evolution and $1 D$ modelling}

A detailed reconstruction of the thermal evolution of studied reservoirs thanks to fluid inclusion analysis and corresponding burial curves helped to complement respective models and furthermore emphasised the need for detailed vitrinite reflectance studies in some study areas (LWA, BCB).

Above all, 1D modelling turned out to be the only reliable method for a more or less precise timing of fracture formation, as fluid inclusion trapped within fracture cements provide information on pressure and temperature during trapping. However, the accuracy of this method highly depends on the quality of both, microthermometric results and burial model. Though timing, i.e. the onset of respective processes is very helpful in order to evaluate the different steps of fracture formation and fluid mobility, the duration of such processes still remains unknown and time-dependent mechanisms that may have a major impact on reservoir properties are therefore hard to estimate.

In the LSB for example, $\mathrm{CO}_{2}$ migration could be assigned to either extensional or transtensional tectonics, while the role of inversion tectonics seems to have a minor effect on fluid mobility, as obtained from P-T correlations.

\subsection{Conclusions}

The presented thesis could demonstrate that the application of petrographic studies including fluid inclusion studies, as well as geochemical and structural analyses to natural analogues provide information on $\mathrm{CO}_{2}$-mobility in relation to tectonic processes at a geological timescale. Thus, not only 
valuable information about pressure and temperature conditions during fluid migration, as well as brine composition of respective fluids could be revealed; we could furthermore also determine the time of cap rock sealing and the accumulation of $\mathrm{CO}_{2}$ for example in the Zechstein carbonates (LSB). Results of our structural analysis demonstrate the development of $\mu \mathrm{m}$ to mm-wide fractures throughout brittle rocks (limestone, sandstone) in the consequence of varying (paleo-)stress regimes (extensional/compressional). Knowledge about fracture development, the distribution of migration paths, pressure and temperature conditions in gas reservoirs and rock properties emphasize the importance of geological studies in order to support computational simulation models, as well as to provide useful selection criteria for future large-scale $\mathrm{CO}_{2}$ storage sites.

Our comprehensive methodological approach turned out to be well applicable with regard to the characterization of natural analogues. However, we must finally point out that the comparability of natural analogues and injection sites is limited, since analogues are similar by definition, but not identical! As illustrated in Fig. 7.2 significant differences especially with regard to time-dependent processes between natural analogues and injection sites demand for a precise evaluation of timesensitive properties.

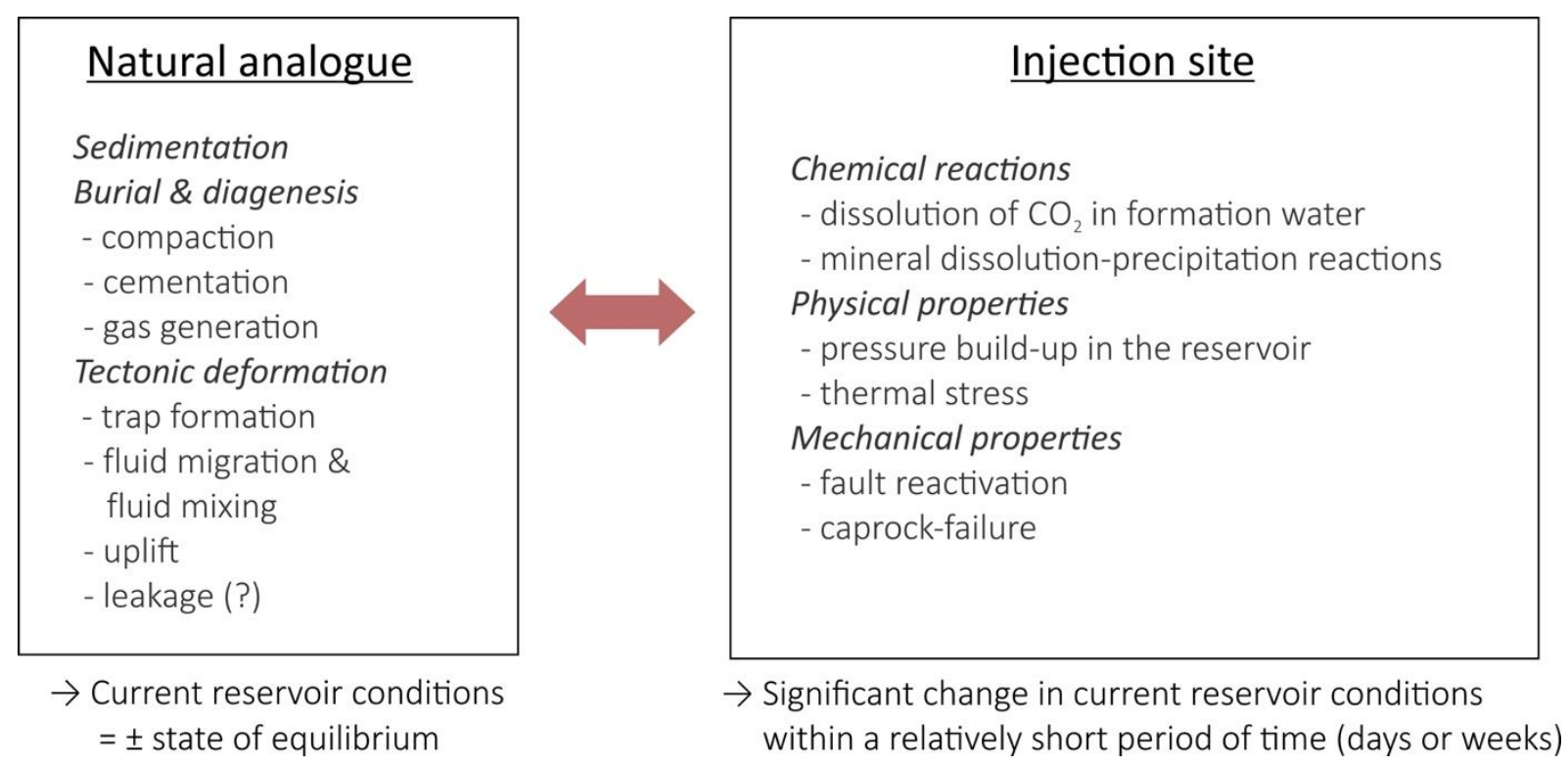

Fig. 7.2. Comparison of major, often time-dependent processes that define reservoir conditions in natural analogues and anticipated $\mathrm{CO}_{2}$ injection sites. 


\section{References}

Aasen, J.O., E. Berg, A.T. Buller, O. Hjelmeland, R.M. Holt, J. Kleppe, O. Torsaeter (Eds.), 1994. North Sea Oil and Gas reservoirs III. Kluwer, Dordrecht.

Ábalos, B., 2016. Geologic map of the Basque-Cantabrian Basin and a new tectonic interpretation of the Basque Arc. Int J Earth Sci (Geol Rundsch) 105, 2327-2354. 10.1007/s00531-016-1291-6.

Adrisola-Muñoz, Y., 2007. The thermal history of the western Lower Saxony Basin, Germany. PhDThesis, Aachen, 153 pp.

Adrisola-Muñoz, Y., Littke, R., Brix, M.R., 2007. Fluid systems and basin evolution of the western Lower Saxony Basin, Germany. Geofluids 7, 335-355. 10.1111/j.1468-8123.2007.00186.x.

Agada, S., Geiger, S., Doster, F., 2016. Wettability, hysteresis and fracture-matrix interaction during $\mathrm{CO} 2 \mathrm{EOR}$ and storage in fractured carbonate reservoirs. International Journal of Greenhouse Gas Control 46, 57-75. 10.1016/j.ijggc.2015.12.035.

Al-Aasm, I.S., Coniglio, M., Desrochers, A., 1995. Formation of complex fibrous calcite veins in Upper Triassic strata of Wrangellia Terrain, British Columbia, Canada. Sedimentary Geology 100, 83-95. 10.1016/0037-0738(95)00104-2.

Alcalde, J., Martí, D., Calahorrano, A., Marzan, I., Ayarza, P., Carbonell, R., Juhlin, C., Pérez-Estaún, A., 2013. Active seismic characterization experiments of the Hontomín research facility for geological storage of CO2, Spain. International Journal of Greenhouse Gas Control 19, 785-795. 10.1016/j.ijggc.2013.01.039.

Anders, M.H., Laubach, S.E., Scholz, C.H., 2014. Microfractures: A review. Journal of Structural Geology 69, 377-394. 10.1016/j.jsg.2014.05.011.

Anderson, E.M., 1951. The dynamics of faulting and dike formation with application to Britain. Oliver and Boyd, Edinburgh.

Andrés, J., Alcalde, J., Ayarza, P., Saura, E., Marzán, I., Martí, D., Martínez Catalán, J.R., Carbonell, R., Pérez-Estaún, A., García-Lobón, J.L., Rubio, F.M., 2016. Basement structure of the Hontomín $\mathrm{CO}_{2}$ storage site (Spain) determined by integration of microgravity and 3-D seismic data. Solid Earth 7, 827-841. 10.5194/se-7-827-2016.

Antonellini, M., Mollema, P.N., 2000. A natural analog for a fractured and faulted reservoir in dolomite: Triassic Sella Group, Northern Italy. AAPG Bulletin 84, 314-344.

Arche, A., López-Gómez, J., 1996. Origin of the Permian-Triassic Iberian Basin, central-eastern Spain. Tectonophysics 266, 443-464. 10.1016/S0040-1951(96)00202-8.

Arthur, T.J., Pilling, D., Bush, D., Macchi, L., 1986. The Leman Sandstone Formation in U.K. Block 49/28 Sedimentation, Diagenesis and Burial History. Geological Society, London, Special Publications 23, 251-266. 10.1144/gsl.sp.1986.023.01.16.

Atkinson, B.K., 1989. Fracture Mechanics of Rock. Elsevier Science, Burlington, 547 pp.

Aurell, M., Melendez, G., Oloriz, F., Badenas, B., Caracuel, J.E., Garcia-Ramos, J.C., Goy, A., Linares, A., Quesada, S., Robles, S., Rodriguez-Tovar, F.J., Rosales, I., Sandoval, J., Suarez de Centi, C., Tavera, J.M., Valenzuela, M., 2006. Jurassic, in: Gibbons, W., Moreno, T. (Eds.), The Geology of Spain. Geological Society, London, pp. 213-253.

Badley, M.E., Price, J.D., Backshall, L.C., 1989. Inversion, reactivated faults and related structures: seismic examples from the southern North Sea, in: Cooper, M.A., Williams, G.D. (Eds.), Inversion Tectonics, pp. 201-219. 
Baines, S.J., Worden, R.H., 2004. The long-term fate of CO2 in the subsurface: Natural analogues for $\mathrm{CO} 2$ storage. Geological Society, London, Special Publications 233, 59-85. 10.1144/gsl.sp.2004.233.01.06.

Bakker, R.J., 1997. Clathrates: Computer programs to calculate fluid inclusion V-X properties using clathrate melting temperatures. Computers \& Geosciences 23, 1-18. 10.1016/s00983004(96)00073-8.

Bakker, R.J., 2003. Package FLUIDS 1. Computer programs for analysis of fluid inclusion data and for modelling bulk fluid properties. Chemical Geology 194, 3-23. 10.1016/s0009-2541(02)00268-1.

Baldschuhn, R., Best, G., Kockel, F., 1991. Inversion tectonics in the north-west German basin, in: Spencer, A.M. (Ed.), Generation, accumulation, and production of Europe's hydrocarbons. Special publication of the European Association of Petroleum No. 1. Oxford University Press, Oxford, pp. 149-159.

Baldschuhn, R., Binot, F., Fleig, S., Kockel, F., 2001. Geotektonischer Atlas von Nordwestdeutschland und dem deutschen Nordsee-Sektor, Stuttgart. Geologisches Jahrbuch A, 93 pp.

Balzer, D., 1997. Mikrofazies-Analyse von Ca-Sulfatgesteinen des Zechstein: Ein Beitrag zur petrographischen und petrologischen Bearbeitung salinarer Wirtsgesteine für die Endlagerung radioaktiver Abfälle in der Bundesrepublik Deutschland. Schweizerbart, Hannover, 99 pp.

Bartenstein, R., Teichmüller, R., Teichmüller, M., 1971. Die Umwandlung der organischen Substanz im Dach des Bramscher Massivs. Fortschr. Geol. Rheinl. Westfal. 18, 501-538.

Bau, M., 1991. Rare-earth element mobility during hydrothermal and metamorphic fluid-rock interaction and the significance of the oxidation state of europium. Chemical Geology 93, 219-230. 10.1016/0009-2541(91)90115-8.

Bau, M., Dulski, P., 1995. Comparative study of yttrium and rare-earth element behaviours in fluorinerich hydrothermal fluids. Contr. Mineral. and Petrol. 119, 213-223. 10.1007/bf00307282.

Bau, M., Möller, P., 1991. REE systematics as source of information on minerogenesis, in: Source, transport and deposition of metals. Proceedings of the 25 years SGA anniversary meeting, Nancy, 30 August - 3 September 1991. Balkema, Rotterdam, pp. 17-20.

Bau, M., Möller, P., 1992. Rare earth element fractionation in metamorphic hydrothermal calcite, magnesite and siderite. Mineralogy and Petrology 45, 231-246.

Bauer, R.A., Carney, M., Finley, R.J., 2016. Overview of microseismic response to CO2 injection into the Mt. Simon saline reservoir at the Illinois Basin-Decatur Project. International Journal of Greenhouse Gas Control. 10.1016/j.jjggc.2015.12.015.

Becker, S.P., Eichhubl, P., Laubach, S.E., Reed, R.M., Lander, R.H., Bodnar, R.J., 2010. A 48 m.y. history of fracture opening, temperature, and fluid pressure: Cretaceous Travis Peak Formation, East Texas basin. Geol Soc America Bull 122, 1081-1093. 10.1130/B30067.1.

Betz, D., Führer, F., Greiner, G., Plein, E., 1987. Evolution of the Lower Saxony Basin. Tectonophysics 137, 127-170. 10.1016/0040-1951(87)90319-2.

Bilal, B.A., Müller, E., 1992. Thermodynamic Study of Ce4+/Ce3+ Redox Reaction in Aqueous Solutions at Elevated Temperatures: 1. Reduction Potential and Hydrolysis Equilibria of $\mathrm{Ce} 4+$ in HCIO4 Solutions. Zeitschrift für Naturforschung A 47. 10.1515/zna-1992-0908.

Bilgili, F., Götze, H.-J., Pašteka, R., Schmidt, S., Hackney, R., 2009. Intrusion versus inversion-a 3D density model of the southern rim of the Northwest German Basin. Int J Earth Sci (Geol Rundsch) 98, 571-583. 10.1007/s00531-007-0267-y. 
Birkholzer, J.T., Oldenburg, C.M., Zhou, Q., 2015. CO 2 migration and pressure evolution in deep saline aquifers. International Journal of Greenhouse Gas Control 40, 203-220. 10.1016/j.ijggc.2015.03.022.

Bjørlykke, K., 2010. Heat transport in sedimentary basins, in: Bjørlykke, K. (Ed.), Petroleum Geoscience. From Sedimentary Environments to Rock Physics. Springer-Verlag Berlin Heidelberg, Berlin, Heidelberg, pp. 253-257.

Bjørlykke, K., Mo, A., Palm, E., 1988. Modelling of thermal convection in sedimentary basins and its relevance to diagenetic reactions. Marine and Petroleum Geology 5, 338-351. 10.1016/02648172(88)90027-x.

Blanc, P., Baumer, A., Cesbron, F., Ohnenstetter, D., Panczer, G., Rémond, G., 2000. Systematic Cathodoluminescence Spectral Analysis of Synthetic Doped Minerals: Anhydrite, Apatite, Calcite, Fluorite, Scheelite and Zircon, in: Pagel, M., Barbin, V., Blanc, P., Ohnenstetter, D. (Eds.), Cathodoluminescence in Geosciences. Springer, Berlin, Heidelberg, pp. 127-160.

Blenkinsop, T.G., 2008. Relationships between faults, extension fractures and veins, and stress. Journal of Structural Geology 30, 622-632. 10.1016/j.jsg.2008.01.008.

Blenkinsop, T.G., Drury, M.R., 1988. Stress estimates and fault history from quartz microstructures. Journal of Structural Geology 10, 673-684.

Bodnar, R., 2003. Introduction to aqueous-electrolyte fluid inclusions, in: Samson, I., Anderson, A., Marshall, D. (Eds.), Fluid inclusions. Analysis and interpretation. Mineralogical Assoc. of Canada, Ottawa, pp. 81-100.

Boggs, S., Krinsley, D., 2006. Application of Cathodoluminescence Imaging to the Study of Sedimentary Rocks. Cambridge University Press, Cambridge, 176 pp.

Boigk, H., 1968. Gedanken zur Entwicklung des Niedersächsischen Tektogens. Geologisches Jahrbuch, 861-900.

Boigk, H., 1981. Erdöl und Erdölgas in der Bundesrepublik Deutschland. Enke, Stuttgart, 330 pp.

Boigk, H., Stahl, W., 1970. Zum Problem der Entstehung nordwestdeutscher Erdgaslagerstätten. Erdöl und Kohle 23, 325-333.

Bons, P.D., Elburg, M.A., Gomez-Rivas, E., 2012. A review of the formation of tectonic veins and their microstructures. Journal of Structural Geology 43, 33-62. 10.1016/j.jsg.2012.07.005.

Boot-Handford, M.E., Abanades, J.C., Anthony, E.J., Blunt, M.J., Brandani, S., Mac Dowell, N., Fernández, J.R., Ferrari, M.-C., Gross, R., Hallett, J.P., Haszeldine, R.S., Heptonstall, P., Lyngfelt, A., Makuch, Z., Mangano, E., Porter, R.T.J., Pourkashanian, M., Rochelle, G.T., Shah, N., Yao, J.G., Fennell, P.S., 2014. Carbon capture and storage update. Energy Environ. Sci. 7, 130-189. 10.1039/C3EE42350F.

Bosze, S., Rakovan, J., 2002. Surface-structure-controlled sectoral zoning of the rare earth elements in fluorite from Long Lake, New York, and Bingham, New Mexico, USA. Geochimica et Cosmochimica Acta 66, 997-1009.

Brand, E., Fricke, K., Hedemann, H., 1982. Die Vorkommen natürlicher Kohlensäure (CO2) in der Bundesrepublik Deutschland, in: Behrmann, R., Albertsen, M. (Eds.), Über die Verfügbarkeit von Kohlendioxid zur Ausbeute-Steigerung in Erdöllagerstätten der Bundesrepublik Deutschland. Forschungsbericht 202-1, Hamburg, pp. 1-90.

Brink, H.J., Dürschner, H., Trappe, H., 1992. Some aspects of the late and post-Variscan development of the Northwestern German Basin. Tectonophysics 207, 65-95. 10.1016/0040-1951(92)90472-i.

Brink, H.-J., 2005. The evolution of the North German Basin and the metamorphism of the lower crust. Int J Earth Sci (Geol Rundsch) 94, 1103-1116. 10.1007/s00531-005-0037-7. 
Brink, H.-J., Gajewski, D., Baykulov, M., Yoon, M.-K., 2012. Examples of the North German Basin revisited by applying seismic common reflection surface processing., in: Peters, K.E., Curry, D.J., Kacewicz, M. (Eds.), Basin Modelling: New Horizons in Research and Applications, 71-86.

Bromhal, G.S., Neal Sams, W., Jikich, S., Ertekin, T., Smith, D.H., 2005. Simulation of CO2 sequestration in coal beds: The effects of sorption isotherms. Chemical Geology 217, 201-211. 10.1016/j.chemgeo.2004.12.021.

Bruckschen, P., Neuser, R.D., Richter, D.K., 1992. Cement stratigraphy in Triassic and Jurassic limestones of the Weserbergland (northwestern Germany). Sedimentary Geology 81, 195-214.

Bruns, B., Di Primio, R., Berner, U., Littke, R., 2013. Petroleum system evolution in the inverted Lower Saxony Basin, northwest Germany: A 3D basin modeling study. Geofluids 13, 246-271. 10.1111/gfl.12016.

Buntebarth, G., 1985. Das Temperaturgefälle im Dach des Bramscher Massivs aufgrund von Inkohlungsuntersuchungen im Karbon von Ibbenbüren. Fortschritte in der Geologie von Rheinland und Westfalen 33, 255-264.

Burke, E.A.J., 2001. Raman microspectrometry of fluid inclusions. Lithos 55, 139-158. 10.1016/s00244937(00)00043-8.

Burkhard, M., 1993. Calcite twins, their geometry, appearance and significance as stress-strain markers and indicators of tectonic regime: A review. Journal of Structural Geology 15, 351-368. 10.1016/0191-8141(93)90132-T.

Capote, R., Munoz, J.A., Simón, J.L., Liesa C.L., Arlegui, L.E., 2006. Alpine tectonics I: The Alpine system north of the Betic Cordillera, in: Gibbons, W., Moreno, T. (Eds.), The Geology of Spain. Geological Society, London, pp. 367-400.

Cawley, S., M.Y. Saunders, B. Le Gallo, S. Carpentier, G.A. Holloway, T. Kirby, L. Bennison, R.Wickens, T. Wikramaratna, S.L.B. Bidstrup, M.A.E. Arkley Browne, J.M. Ketzer, 2005. Th eNGCAS project - assessing the potential for EOR and $\mathrm{CO} 2$ storage at the Forties oil field, off shore UK, in: Benson, S.M. (Ed.), Results from the CO2 Capture Project, v.2: Geologic Storage of Carbon Dioxide with Monitoring and Verification, vol. 2. Elsevier Science, London, UK, pp. 1163-1188.

Clark, D., 1980. The diagenesis of the Zechstein carbonate sediments, in: Füchtbauer, H., Peryt, T. (Ed.), The Zechstein Basin with emphasis on carbonate sequences. Schweizerbart, Stuttgart, pp. 167-203.

Cooper, M.A., Williams, G.D. (Eds.), 1989. Inversion Tectonics.

Corfield, S.M., Gawthorpe, R.L., Gage, M., Fraser, A.J., Besly, B.M., 1996. Inversion tectonics of the Variscan foreland of the British Isles. Journal of the Geological Society 153, 17-32. 10.1144/gsjgs.153.1.0017.

Cuéllar-Franca, R.M., Azapagic, A., 2015. Carbon capture, storage and utilisation technologies: A critical analysis and comparison of their life cycle environmental impacts. Journal of $\mathrm{CO} 2$ Utilization 9, 82-102. 10.1016/j.jcou.2014.12.001.

Dai, J., Song, Y., Dai, C., Wang, D., 1996. Geochemistry and Accumulation of Carbon Dioxide Gases in China. AAPG Bulletin 80, 1615-1626. 10.1306/64eda0d2-1724-11d7-8645000102c1865d.

Davies, R., Foulger, G., Bindley, A., Styles, P., 2013. Induced seismicity and hydraulic fracturing for the recovery of hydrocarbons. Marine and Petroleum Geology 45, 171-185. 10.1016/j.marpetgeo.2013.03.016.

Delle Piane, C., Clennell, M.B., Keller, J.V.A., Giwelli, A., Luzin, V., 2017. Carbonate hosted fault rocks: A review of structural and microstructural characteristic with implications for seismicity in the upper crust. Journal of Structural Geology 103, 17-36. 10.1016/j.jsg.2017.09.003. 
Dickinson, W.R., 1970. Interpreting detrital modes of graywacke and arkose. Journal of Sedimentary Petrology 40, 695-707.

Dill, H.G., 2012. Diagenetic and epigenetic mineralization in Central Europe related to surfaces and depositional systems of sequence stratigraphic relevance. International Association of Sedimentologists Special Publications 45, 151-182.

Dill, H.G., Weber, B., 2010. Variation of color, structure and morphology of fluorite and the origin of the hydrothermal F-Ba deposits at Nabburg-Wölsendorf, SE Germany. N. Jb. Miner. Abh. 187, $113-$ 132. 10.1127/0077-7757/2010/0169.

Dios, J.C. de, Delgado, M.A., Martínez, C., Ramos, A., Álvarez, I., Marín, J.A., Salvador, I., 2017. Hydraulic characterization of fractured carbonates for CO 2 geological storage: Experiences and lessons learned in Hontomín Technology Development Plant. International Journal of Greenhouse Gas Control 58, 185-200. 10.1016/j.ijggc.2017.01.008.

Doornenbal, H., Stevenson, A. (Eds.), 2010. Petroleum geological atlas of the Southern Permian Basin Area. EAGE Publ, Houten, 342 pp.

Doré, A.G., Augustson, J.H., Hermanrud, D.S., Stewart, D.S., Sylta, O. (Eds.), 1993. Basin modelling: advances and applications, 3rd ed. Norwegian Petroleum Society (NPS); Elsevier, Amsterdam, $675 \mathrm{pp}$.

Dunham, R.J., 1962. Classification of carbonate rocks according to depositional texture, in: Ham, W.E. (Ed.), Classification of Carbonate Rocks, pp. 108-121.

Duschl, F., van den Kerkhof, A., Sosa, G., Leiss, B., Wiegand, B., Vollbrecht, A., Sauter, M., 2016. Fluid inclusion and microfabric studies on Zechstein carbonates $(\mathrm{Ca} 2)$ and related fracture mineralizations: New insights on gas migration in the Lower Saxony Basin (Germany). Marine and Petroleum Geology 77C, 300-322. 10.1016/j.marpetgeo.2016.06.020.

Duschl, F., Wischhöfer, P., Vollbrecht, A., 2017. Geochemistry and microfabrics of syndiagenetic strata-bound fluorite from Eschwege, Germany. EGU General Assembly, 2017, Vienna.

Ehrenberg, S.N., 1989. Assessing the Relative Importance of Compaction Processes and Cementation to Reduction of Porosity in Sandstones: Discussion; Compaction and Porosity Evolution of Pliocene Sandstones, Ventura Basin, California: Discussion. American Association of Petroleum Geologists $73,1274-1275$.

Ehrenberg, S.N., 1995. Measuring sandstone compaction from modal analyses of thin sections: how to do it and what the results mean. Journal of Sedimentary Research A65, 369-379.

Elkhoury, J.E., Ameli, P., Detwiler, R.L., 2013. Dissolution and deformation in fractured carbonates caused by flow of $\mathrm{CO} 2$-rich brine under reservoir conditions. International Journal of Greenhouse Gas Control 16, S203-S215. 10.1016/j.ijggc.2013.02.023.

Emmons, R.C., 1943. The Universal Stage, with Five Axes of Rotation. Geological Society of America Memoir 8, 1-205.

Espina, R., Alonso, J.L., Pulgar, J.A., 1996. Growth and propagation of buckle folds determined from syntectonic sediments (the Ubierna Fold Belt, Cantabrian Mountains, N Spain). Journal of Structural Geology 18, 421-430. 10.1016/0191-8141(95)00103-4.

Fall, A., Eichhubl, P., Bodnar, R.J., Laubach, S.E., Davis, J.S., 2014. Natural hydraulic fracturing of tight-gas sandstone reservoirs, Piceance Basin, Colorado. Geological Society of America Bulletin 127, 61-75. 10.1130/B31021.1.

Fedorov, E.S., 1892. Eine neue Methode der optischen Untersuchung von Krystallplatten in parallelem Lichte. Tschermak's Mineralogische und Petrographische Mittheilungen, 505-509. 
Fedorov, E.S., 1894. Universal- (Theodolith-) Methode in der Mineralogie und Petrographie. Zeitschrift für Kristallographie und Mineralogie 22, 229-268.

Fischer, M., Botz, R., Schmidt, M., Rockenbauch, K., Garbe-Schönberg, D., Glodny, J., Gerling, P., Littke, R., 2006. Origins of CO2 in permian carbonate reservoir rocks (Zechstein, Ca2) of the NWGerman Basin (Lower Saxony). Chemical Geology 227, 184-213. 10.1016/j.chemgeo.2005.09.014.

Flügel, E., 2004. Microfacies of Carbonate Rocks: Analysis, Interpretation and Application. Springer, Berlin, Heidelberg, s.l., 976 pp.

Folk, R.L., 1959. Practical petrographic classification of limestones. Bulletin 43, 1-38.

Fossen, H., 2016. Structural geology, XV, 510 Seiten.

Fossen, H., Schultz, R.A., Shipton, Z.K., Mair, K., 2007. Deformation bands in sandstone: A review. Journal of the Geological Society 164, 755-769.

Franzke, H.J., Müller, R., Voigt, T., Eynatten, H. von, 2007. Paleo-Stress Paths in the Harz Mountains and surrounding areas (Germany) between the Triassic and the Upper Cretaceous. Zeitschrift für geologische Wissenschaften 35, 141-156.

Fry, N., 1979. Random point distributions and strain measurement. Tectonophysics 60, 89-105.

Füchtbauer, H., 1962. Fazies, Porosität und Gasinhalt der Karbonatgesteine des norddeutschen Zechsteins. Zeitschrift der deutschen geologischen Gesellschaft 114, 484-531.

Gallastegui, J., Pulgar, J.A., Gallart, J., 2016. Alpine tectonic wedging and crustal delamination in the Cantabrian Mountains (NW Spain). Solid Earth 7, 1043-1057. 10.5194/se-7-1043-2016.

Garcia-Mondejar, J., Lopez-Horgue, M.A., Aranburu, A., Fernandez-Mendiola, P.A., 2005. Pulsating subsidence during a rift episode: Stratigraphic and tectonic consequences (Aptian-Albian, northern Spain). Terra Nova 17, 517-525. 10.1111/j.1365-3121.2005.00644.x.

García-Mondéjar, J., 1996. Plate reconstruction of the Bay of Biscay. Geol 24, 635. 10.1130/00917613(1996)024<0635:PROTBO>2.3.CO;2.

Gazzi, P., 1966. Le Arenarie del Flysch Sopracretaceo dell'Appennino Modenese: Correlazioni con il Flysch di Monghidoro. Mineralogica e Petrografica Acta 12, 69-97.

Geluk, M.C., 2005. Stratigraphy and tectonics of Permo- Triassic basins in the Netherlands and surrounding areas. $\mathrm{PhD}$ thesis, Utrecht.

Gheibi, S., Holt, R.M., Vilarrasa, V., 2017. Effect of faults on stress path evolution during reservoir pressurization. International Journal of Greenhouse Gas Control 63, 412-430. 10.1016/j.ijggc.2017.06.008.

Gibbons, W., Moreno, T. (Eds.), 2006. The Geology of Spain. Geological Society, London, 649 pp.

Gibbs, J.F., J.H. Healy, C.B. Raleigh, J. Coakley, 1973. Seismicity in the Rangely, Colorado area: 1962 1970. Bulletin of the Seismological Society of America 63, 1557-1570.

Glennie, K.W., 1990. Rotliegend sediment distribution: A result of late Carboniferous movements. Geological Society, London, Special Publications 55, 127-138. 10.1144/gsl.sp.1990.055.01.06.

Glennie, K.W., 1998. Lower Permian-Rotliegend, in: Glennie, K.W. (Ed.), Petroleum Geology of the North Sea: Basic concepts and recent advances. Blackwell Science, Oxford, pp. 137-173.

Glennie, K.W., Underhill, J.R., 1998. The development and evolution of structural styles in the North Sea, in: Glennie, K.W. (Ed.), Petroleum Geology of the North Sea: Basic concepts and recent advances. Blackwell Science, Oxford, pp. 42-84.

Goldstein, R.H., 2001. Fluid inclusions in sedimentary and diagenetic systems. Lithos 55, 159-193. 10.1016/s0024-4937(00)00044-x. 
Goldstein, R.H., 2003. Petrographic analysis of fluid inclusion, in: Samson, I., Anderson, A., Marshall, D. (Eds.), Fluid inclusions. Analysis and interpretation. Mineralogical Assoc. of Canada, Ottawa, pp. 1-53.

Goldstein, R.H., Reynolds, T.J., 1994. Systematics of Fluid Inclusions in Diagenetic Minerals: Society for Sedimentary Geology Short Course,. SEPM (Society for Sedimentary Geology), Tulsa, Okla, $199 \mathrm{pp}$.

Grobe, M., Pashin, J.C., Dodge, R.L., 2009. Carbon dioxide sequestration in geological media: State of the science. AAPG, Tulsa, 715 pp.

Gundlach, H., Stoppel, D., 1966. Zur Geologie und Geochemie der Schwerspatlagerstätten im Unterwerra-Grauwackengebirge. Notizblatt des hessischen Landesamtes für Bodenforschung 94, 310-337.

Hahn, A., Kind, E., 1971. Eine Interpretation der magnetischen Anomalie von Bramsche. Fortschritte in der Geologie von Rheinland und Westfalen 18, 387-349.

Hancock, P.L., 1985. Brittle microtectonics: principles and practice. Journal of Structural Geology 7, 437-457.

Harper, M.L., 1971. Approximate Geothermal Gradients in the North Sea Basin. Nature 230, 235-236. 10.1038/230235a0.

Hayward, A.B., Graham, R.H., 1989. Some geometrical characteristics of inversion, in: Cooper, M.A., Williams, G.D. (Eds.), Inversion Tectonics, pp. 17-40.

Healy, J.H., Ruby, W.W., Griggs, D.T., Raleigh, C.B., 1968. The Denver earthquakes. Science 161, $1301-1310$.

Heard, H.C., Rubey, W.W., 1966. Tectonic Implications of Gypsum Dehydration. Geological Society of America Bulletin 77, 741. 10.1130/0016-7606(1966)77[741:TIOGD]2.0.CO;2.

Heinemann, N., Wilkinson, M., Haszeldine, R.S., Fallick, A.E., Pickup, G.E., 2013. CO2 sequestration in a UK North Sea analogue for geological carbon storage. Geology 41, 411-414. 10.1130/G33835.1.

Hentschel, K., 2010. Die Funktion von Analogien und Naturwissenschaften // Analogien in Naturwissenschaften, Medizin und Technik: Fachtagung der Deutschen Akademie der Naturforscher Leopoldina und der Abteilung für Geschichte der Naturwissenschaften und Technik der Universität Stuttgart vom 17. bis 20. März 2008 ; mit 14 Tabellen. Wiss. Verl.-Ges, Stuttgart, $452 \mathrm{pp}$.

Hesthammer, J., Fossen, H., 2000. Uncertainties associated with fault sealing analysis. Petroleum Geoscience 6, 37-45.

Hillebrand, C., 2013. Petrographie und Gefüge eines Quarz-Kalksandsteins (Sinemurium) der Lokalität Bercedo (Kantabrien) (PANACEA-Projekt). Bachelor Thesis, Göttingen, 32 pp.

Hillis, R.R., 1995. Quantification of Tertiary exhumation in the United Kingdom Southern North Sea using sonic velocity data. AAPG Bulletin 79, 130-152.

Hoefs, J., 2009. Stable Isotope Geochemistry, 6th ed. Springer Berlin Heidelberg, Berlin, Heidelberg, $286 \mathrm{pp}$.

Holzapfel, M., 1998. Die allochthonen Triasschollen bei Hundelshausen/Nordhessen. Dissertation, Würzburg.

Houseknecht, D.W., 1989. Assessing the Relative Importance of Compaction Processes and Cementation to Reduction of Porosity in Sandstones: Reply. AAPG Bulletin 73. 10.1306/44b4aa23170a-11d7-8645000102c1865d. 
Huttel, P., 1989. Das Staßfurt-Karbonat (Ca2) in Süd-Oldenburg - Fazies und Diagenese eines Sediments am Nordhang der Hunte-Schwelle. Göttinger Arbeiten zur Geologie und Paläontologie 39, 1-94.

IPCC, 2005. IPCC Special Report: Carbon Dioxide Capture and Storage. Summary for Policy Makersand Technical Summary, Cambridge University Press, New York.

Ivanova, A., Lüth, S., 2015. Quantitative Seismic Monitoring of a Saline Aquifer: A Feasibility Study for the CO2 Injection (The Pilot Site Ketzin, Germany). Energy Procedia 76, 543-548. 10.1016/j.egypro.2015.07.907.

Jacob, K., 1974. Zur genetischen Interpretation von Fluoriten anhand ihrer Spurengehalte an Seltenen Erden. Schriften der GDMB Gesellschaft Deutscher Metallhütten- und Bergleute 28, 55-68.

Jacobshagen, V., Brede, R., Hampel, M., Kuhnert, C., 1993a. Zur Geologie der Umgebung von Eschwege in Nordhessen, in: Jacobshagen, V., Möller, K., Jäkel, D. (Eds.), Hoher Meißner und Eschweger Becken. Geowissenschaftliche und vegetationskundliche Charakteristik einer nordhessischen Landschaft, Berlin, pp. 1-49.

Jacobshagen, V., Möller, K., Jäkel, D. (Eds.), 1993b. Hoher Meißner und Eschweger Becken: Geowissenschaftliche und vegetationskundliche Charakteristik einer nordhessischen Landschaft, Berlin.

Jammes, S., Manatschal, G., Lavier, L., Masini, E., 2009. Tectonosedimentary evolution related to extreme crustal thinning ahead of a propagating ocean: Example of the western Pyrenees. Tectonics 28, n/a-n/a. 10.1029/2008TC002406.

Jevons, W.S., 1874. The principle of science, London.

Johnson, H., Warrington, G., Stoker, S.J., 1994. Permian and Triassic of the southern North Sea, v. 6, in: Knox, R.W.O.'B., Cordey, W.G. (Eds.), Lithostratigraphic Nomenclature of the UK North Sea. British Geological Survey, Nottingham.

Kaiser, R., 2001. Fazies und Sequenzstratigraphie: Das Staßfurtkarbonat (Ca2) am nördlichen Beckenrand des südlichen Zechsteinbeckens (NE-Deutschland). PhD-Thesis, Köln.

Kaya, E., Zarrouk, S.J., 2017. Reinjection of greenhouse gases into geothermal reservoirs. International Journal of Greenhouse Gas Control 67, 111-129. 10.1016/j.ijggc.2017.10.015.

Kerr, P.F., 1977. Optical mineralogy, 4th ed. McGraw-Hill, New York, 492 pp.

Kley, J., Voigt, T., 2008. Late Cretaceous intraplate thrusting in central Europe: Effect of Africa-IberiaEurope convergence, not Alpine collision. Geol 36, 839. 10.1130/g24930a.1.

Kockel, F., 1994. Geotektonischer Atlas von NW-Deutschland 1 : 300.000: Hannover: Bundesanstalt für Geowissenschafen und Rohstoffe.

Kockel, F., Wehner, H., Gerling, P., 1994. Petroleum Systems of the Lower Saxony Basin, Germany, in: Magoon, L.B., Dow, W.G. (Ed.), The petroleum system - From source to trap, Tulsa, Okla, pp. 573-586.

Koritnig, S., 1978. Die "Blaue Kuppe " bei Eschwege, in: Koritnig, S. (Ed.), Zur Mineralogie und Geologie der Umgebung von Göttingen, pp. 237-247.

Krooss, B.M., Hanebeck, D., Leythaeuser, D., 1993. Experimental measurement of the molecular migration of light hydrocarbons in source rocks at elevated temperatures, in: Doré, A.G., Augustson, J.H., Hermanrud, D.S., Stewart, D.S., Sylta, O. (Eds.), Basin modelling: advances and applications, 3rd ed. Norwegian Petroleum Society (NPS); Elsevier, Amsterdam, pp. 277-291.

Krooss, B.M., Plessen, B., Machel, H.G., Lüders, V., Littke, R., 2008. Origin and distribution of nonhydrocarbon gases, in: Littke, R., Bayer, U., Gajewski, D., Nelskamp, S. (Eds.), Dynamics of Complex Intracontinental Basins. Springer, Berlin, Heidelberg, pp. 433-458. 
Kruhl, J.H., Erdmann, S., Büttner, S.H., 2007. Brittle-ductile microfabrics in naturally deformed cordierite: Evidence for significant short-term strain-rate variations. Journal of Structural Geology 29, 355-374. 10.1016/j.jsg.2006.09.002.

Kus, J., Cramer, B., Kockel, F., 2005. Effects of a Cretaceous structural inversion and a postulated high heat flow event on petroleum system of the western Lower Saxony Basin and the charge history of the Apeldorn gas field. Netherlands Journal of Geosciences 84, 3-25.

Laubach, S.E., Eichhubl, P., Hilgers, C., Lander, R.H., 2010. Structural diagenesis. Journal of Structural Geology 32, 1866-1872. 10.1016/j.jsg.2010.10.001.

Laubach, S.E., Reed, R.M., Olson, J.E., Lander, R.H., Bonnell, L.M., 2004. Coevolution of crack-seal texture and fracture porosity in sedimentary rocks: Cathodoluminescence observations of regional fractures. Journal of Structural Geology 26, 967-982. 10.1016/j.jsg.2003.08.019.

Le Quéré, C., Andres, R.J., Boden, T., Conway, T., Houghton, R.A., House, J.I., Marland, G., Peters, G.P., van der Werf, G. R., Ahlström, A., Andrew, R.M., Bopp, L., Canadell, J.G., Ciais, P., Doney, S.C., Enright, C., Friedlingstein, P., Huntingford, C., Jain, A.K., Jourdain, C., Kato, E., Keeling, R.F., Klein Goldewijk, K., Levis, S., Levy, P., Lomas, M., Poulter, B., Raupach, M.R., Schwinger, J., Sitch, S., Stocker, B.D., Viovy, N., Zaehle, S., Zeng, N., 2013. The global carbon budget 19592011. Earth Syst. Sci. Data 5, 165-185. 10.5194/essd-5-165-2013.

Le Quéré, C., Moriarty, R., Andrew, R.M., Canadell, J.G., Sitch, S., Korsbakken, J.I., Friedlingstein, P., Peters, G.P., Andres, R.J., Boden, T.A., Houghton, R.A., House, J.I., Keeling, R.F., Tans, P., Arneth, A., Bakker, D.C.E., Barbero, L., Bopp, L., Chang, J., Chevallier, F., Chini, L.P., Ciais, P., Fader, M., Feely, R.A., Gkritzalis, T., Harris, I., Hauck, J., Ilyina, T., Jain, A.K., Kato, E., Kitidis, V., Klein Goldewijk, K., Koven, C., Landschützer, P., Lauvset, S.K., Lefèvre, N., Lenton, A., Lima, I.D., Metzl, N., Millero, F., Munro, D.R., Murata, A., Nabel, J. E. M. S., Nakaoka, S., Nojiri, Y., O'Brien, K., Olsen, A., Ono, T., Pérez, F.F., Pfeil, B., Pierrot, D., Poulter, B., Rehder, G., Rödenbeck, C., Saito, S., Schuster, U., Schwinger, J., Séférian, R., Steinhoff, T., Stocker, B.D., Sutton, A.J., Takahashi, T., Tilbrook, B., van der Laan-Luijkx, I. T., van der Werf, G. R., van Heuven, S., Vandemark, D., Viovy, N., Wiltshire, A., Zaehle, S., Zeng, N., 2015. Global Carbon Budget 2015. Earth Syst. Sci. Data 7, 349-396. 10.5194/essd-7-349-2015.

Leischner, K., Welte, D.H., Littke, R., 1993. Fluid inclusions and organic maturity parameters as calibration tools in basin modelling, in: Doré, A.G., Augustson, J.H., Hermanrud, D.S., Stewart, D.S., Sylta, O. (Eds.), Basin modelling: advances and applications, 3rd ed. Norwegian Petroleum Society (NPS); Elsevier, Amsterdam, pp. 161-172.

Lepvrier, C., Martínez-García, E., 1990. Fault development and stress evolution of the post-Hercynian Asturian Basin (Asturias and Cantabria, northwestern Spain). Tectonophysics 184, 345-356. 10.1016/0040-1951(90)90447-G.

Leung, D.Y.C., Caramanna, G., Maroto-Valer, M.M., 2014. An overview of current status of carbon dioxide capture and storage technologies. Renewable and Sustainable Energy Reviews 39, 426-443. 10.1016/j.rser.2014.07.093.

Leveille, G.P., Knipe, R., More, C., Ellis, D., Dudley, G., Jones, G., Fisher, Q.J., Allinson, G.J., 1997. Compartimentalizationof Rotliegendes gas reservoirs by sealing faults, Jupiter Fields area, southern North Sea, in: Ziegler, K., Turner, P., Daines, S.R. (Eds.), Petroleum Geology of the Southern North Sea: Future Potential, pp. 87-104.

Lewicki, J.L., Birkholzer, J., Tsang, C.-F., 2006. Natural and industrial analogues for leakage of CO2 from storage reservoirs: identification of features, events, and processes and lessons learned. 
Lawrence Berkeley National Laboratory. http://escholarship.org/uc/item/6dr2298r. Accessed 6 May 2016.

Li, L., Khorsandi, S., Johns, R.T., Dilmore, R.M., 2015. CO2 enhanced oil recovery and storage using a gravity-enhanced process. International Journal of Greenhouse Gas Control 42, 502-515. 10.1016/j.ijggc.2015.09.006.

Li, M.X., Ricard, L.P., Underschultz, J., Freifeld, B.M., 2016. Reducing operational costs of CO 2 sequestration through geothermal energy integration. International Journal of Greenhouse Gas Control 44, 238-248. 10.1016/j.ijggc.2015.11.012.

List, K.-A., 1975. Über ein Flußspat-Vorkommen in den Dolomiten des Mittleren Zechsteins (Ca2) westlich von Eschwege. Der Aufschluß 26, 487-491.

Littke, R., Bayer, U., Gajewski, D., Nelskamp, S. (Eds.), 2008. Dynamics of Complex Intracontinental Basins. Springer, Berlin, Heidelberg.

Lohr, T., Krawczyk, C.M., Tanner, D.C., Samiee, R., Endres, H., Oncken, O., Trappe, H., Kukla, P.A., 2007. Strain partitioning due to salt: Insights from interpretation of a 3D seismic data set in the NW German Basin. Basin Research 19, 579-597. 10.1111/j.1365-2117.2007.00338.x.

Lokhorst, A., Adlam, K., Brugge, J.V.M., David, P., Diapari, L., Fermont, W.J.J., Geluk, M., Gerling, P., Heckers, J., Kockel, F., Kotarba, M., Laier, T., Lott, G.K., Milaczewski, E., Milaczewski, L., Nicholson, R.A., Platen, F. von, Pokorski, J., 1998. NW European Gas Atlas - composition and isotope ratios of natural gases. NITG, Haarlem.

López-Gómez, J., Arche, A., Pérez-López, A., 2006. Permian \& Triassic, in: Gibbons, W., Moreno, T. (Eds.), The Geology of Spain. Geological Society, London, pp. 185-212.

Lüders, V., 1991. Formation of hydrothermal fluorite deposits of the Harz Mountains, Germany, in: Source, transport and deposition of metals. Proceedings of the 25 years SGA anniversary meeting, Nancy, 30 August - 3 September 1991. Balkema, Rotterdam, pp. 325-328.

Lüders, V., Plessen, B., Di Primio, R., 2012. Stable carbon isotopic ratios of CH4-CO2-bearing fluid inclusions in fracture-fill mineralization from the Lower Saxony Basin (Germany) - A tool for tracing gas sources and maturity. Marine and Petroleum Geology 30, 174-183. 10.1016/j.marpetgeo.2011.10.006.

Lüders, V., Plessen, B., Sippel, J., 2008. Fluid and gas migration in thesouthwestern part of the LowerSaxony Basin (Germany). Goldschmidt Conference Abstracts 2008. Geochimica et Cosmochimica Acta 72, A572. 10.1016/j.gca.2008.05.015.

Lüders, V., Reutel, C., Hoth, P., Banks, D.A., Mingram, B., Pettke, T., 2005. Fluid and gas migration in the North German Basin: Fluid inclusion and stable isotope constraints. Int J Earth Sci (Geol Rundsch) 94, 990-1009. 10.1007/s00531-005-0013-2.

MacDonald, R., North, N., 1974. The effect of pressure on the solubility of CaCO3, CaF2 and SrSO4 in water. Canadian Journal of Chemistry 52, 3181.

Machel, H.G., 2000. Application of cathodoluminescence to carbonate diagenesis, in: Pagel, M., Barbin, V., Blanc, P., Ohnenstetter, D. (Eds.), Cathodoluminescence in Geosciences. Springer, Berlin, Heidelberg, pp. 271-301.

Marshall, D.J., 1988. Cathodoluminescence of geological materials. Unwin Hyman, Boston, 146 pp.

Martín-Chivelet, J., Berástegui, X., Rosales, I., Vilas, L., Vera, A., Caus, E., Gräfe, K.-U., Mas, R., Puig, C., Segura, M., Robles, S., Floquet, M., Quesada, S., Ruiz-Ortiz, P.A., Fregenal-Martínez, M.A., Salas, R., Arias, C., García, A., Martín-Algarra, A., Meléndez, M.N., Chacón, B., Molina, J.M., Sanz, J.L., Castro, J.M., García-Hernandez, M., Carenas, B., García-Hidalgo, J., Gil, J., Ortega, F., 
2006. Cretaceous, in: Gibbons, W., Moreno, T. (Eds.), The Geology of Spain. Geological Society, London, pp. 255-292.

McCaffrey, K.J.W., Lonergan, L., Wilkinson, J.J., McCaffrey, K., Lonergan, L., Wilkinson, J. (Eds.), 1999. Fracture, Fluid Flow and Mineralization, London, 1328 pp.

McDonough, W.F., Sun, S.-s., 1995. The composition of the earth. Chemical Geology 120, 223-253.

McKenzie, D., 1978. Some remarks on the development of sedimentary basins. Earth and Planetary Science Letters 40, 25-32.

McNeil, B., Shaw, H.F., Rankin, A.H., 1998. The timing of cementation in the Rotliegend sandstones of the Southern North Sea: A petrological and fluid inclusion study of cements. Journal of Petroleum Geology 21, 311-327. 10.1111/j.1747-5457.1998.tb00784.x.

Mempel, G., 1962. Verbreitung und Genese der Buntmetallerzspuren in den paläozoischen und mesozoischen Sedimenten Nordwestdeutschlands. Zeitschrift für Erzbergbau und Metallhüttenwesen 15, 62-72.

Meyer, R.K., Schmidt-Kaler, H., 1996. Gesteinsabfolge des Deckgebirges nördlich der Donau und im Molasseuntergrund: Jura., in: Freudenberger, W., Schwerd, K. (Eds.), Erläterungen zur Geologischen Karte von Bayern 1 : 500 000, München, pp. 90-110.

Michael, K., Arnot, M., Cook, P., Ennis-King, J., Funnell, R., Kaldi, J., Kirste, D., Paterson, L., 2009. $\mathrm{CO} 2$ storage in saline aquifers I-Current state of scientific knowledge. Energy Procedia 1, 31973204. 10.1016/j.egypro.2009.02.103.

Miocic, J.M., Gilfillan, S.M.V., McDermott, C., Haszeldine, R.S., 2013. Mechanisms for CO2 Leakage Prevention - A Global Dataset of Natural Analogues. Energy Procedia 40, 320-328. 10.1016/j.egypro.2013.08.037.

Möbus, H.-M., 2004. Allochthone Triasschollen am Unterwerrasattel als Schlüssel zum Verständnis saxonischer Grabentektonik. Dissertation, Marburg, 197 pp.

Mohan, A.R., Turaga, U., Subbaraman, V., Shembekar, V., Elsworth, D., Pisupati, S.V., 2015. Modeling the CO 2 -based enhanced geothermal system (EGS) paired with integrated gasification combined cycle (IGCC) for symbiotic integration of carbon dioxide sequestration with geothermal heat utilization. International Journal of Greenhouse Gas Control 32, 197-212. 10.1016/j.ijggc.2014.10.016.

Möller, P., 1991. REE fractionation in hydrothermal fluorite and calcite, in: Source, transport and deposition of metals. Proceedings of the 25 years SGA anniversary meeting, Nancy, 30 August - 3 September 1991. Balkema, Rotterdam, pp. 91-94.

Möller, P., Bau, M., Dulski, P., Lüders, V., 1998. REE and yttrium fractionation in fluorite and their bearing on fluorite formation, in: Proceedings of the Ninth Quadrennial IAGOD Symposium. Schweizerbart, Stuttgart, pp. 575-592.

Möller, P., Parekh, P., Schneider, H.-J., 1976. The application of Tb/Ca-Tb/La abundance ratios to problems of fluorspar genesis. Mineralium Deposita 11, 111-116.

Möller, P., Schulz, S., Jacob, K., 1980. Formation of fluorite in sedimentary basins. Chemical Geology 30, 97-117.

Moscariello, A., 2005. Exploration potential of the mature Southern North Sea basin margins: some unconventional plays based on alluvial and fluvial fan sedimentation models, in: Doré, A.G., Vining, B.A. (Eds.), Petroleum Geology: North-West Europe and Global Perspectives-Proceedings of the 6th Petroleum Geology Conference. Geological Society, London, pp. 595-605.

Muir, I.D., 1981. The 4-Axis Universal Stage. Microscope Publications, Ltd., Chicago, 145 pp. 
Nollet, S., Koerner, T., Kramm, U., Hilgers, C., 2009. Precipitation of fracture fillings and cements in the Buntsandstein (NW Germany). Geofluids 9, 373-385. 10.1111/j.1468-8123.2009.00261.x.

Nolte, S., 2013. Petrographie und Gefüge eines oolithischen Kalksteins (Sinemurium) der Lokalität Bercedo (Kantabrien) (PANACEA-Projekt). Bachelor Thesis, Göttingen, 32 pp.

Norden, B., Förster, A., Balling, N., 2008. Heat flow and lithospheric thermal regime in the Northeast German Basin. Tectonophysics 460, 215-229. 10.1016/j.tecto.2008.08.022.

Ogaya, X., Queralt, P., Ledo, J., Marcuello, Á., Jones, A.G., 2014. Geoelectrical baseline model of the subsurface of the Hontomín site (Spain) for $\mathrm{CO} 2$ geological storage in a deep saline aquifer: A 3D magnetotelluric characterisation. International Journal of Greenhouse Gas Control 27, 120-138. 10.1016/j.ijggc.2014.04.030.

Oldenburg, C.M., J.L. Lewicki, R.P. Hepple, 2003. Near-Surface Monitoring Strategies for Geologic Carbon Dioxide Storage Verification. LBNL-54089, Lawrence Berkeley National Laboratory,Berkeley, CA.

Omre, H., K. Solna, N. Dahl, B. Torudbakken, 1994. Impact of fault heterogeneity in fault zones on fluid flow, in: Aasen, J.O., E. Berg, A.T. Buller, O. Hjelmeland, R.M. Holt, J. Kleppe, O. Torsaeter (Eds.), North Sea Oil and Gas reservoirs III. Kluwer, Dordrecht, pp. 185-200.

Ortega, O., Marrett, R., 2000. Prediction of macrofracture properties using microfracture information, Mesaverde Group sandstones, San Juan basin, New Mexico. Journal of Structural Geology 22, 571588. 10.1016/S0191-8141(99)00186-8.

Pagel, M., Barbin, V., Blanc, P., Ohnenstetter, D. (Eds.), 2000. Cathodoluminescence in Geosciences. Springer, Berlin, Heidelberg.

Paul, J., 1993. Anatomie und Entwicklung eines permo-triassischen Hochgebietes: Die EichsfeldAltmark-Schwelle, in: Müller, P.E., Porth, H. (Eds.), Zur Geologie und Kohlenwasserstoff-Führung des Perm im Ostteil der Norddeutschen Senke. Schweizerbart, Hannover, pp. 197-218.

Peacock, D.C.P., Nixon, C.W., Rotevatn, A., Sanderson, D.J., Zuluaga, L.F., 2016. Glossary of fault and other fracture networks. Journal of Structural Geology 92, 12-29. 10.1016/j.jsg.2016.09.008.

Peacock, D.C.P., Sanderson, D.J., Rotevatn, A., 2018. Relationships between fractures. Journal of Structural Geology 106, 41-53. 10.1016/j.jsg.2017.11.010.

Pearce, J., Holloway, S., Wacker, H., Nelis, M., Rochelle, C., Bateman, K., 1996. Natural occurrences as analogues for the geological disposal of carbon dioxide. Energy Conversion \& Management 37, $1123-1128$.

Pearce, N.J.G., Perkins, W.T., Westgate, J.A., Gorton, M.P., Jackson, S.E., Neal, C.R., Chenery, S.P., 1997. A Compilation of New and Published Major and Trace Element Data for NIST SRM 610 and NIST SRM 612 Glass Reference Materials. Geostandards and Geoanalytical Research 21, 115-144. 10.1111/j.1751-908x.1997.tb00538.x.

Petmecky, S., Meier, L., Reiser, H., Littke, R., 1999. High thermal maturity in the Lower Saxony Basin: Intrusion or deep burial? Tectonophysics 304, 317-344. 10.1016/s0040-1951(99)00030-x.

Pharaoh, T.C., Dusar, M., Geluk, M.C., Kockel, F., Krawczyk, C.M., Krzywiec, P., Scheck-Wenderoth, M., Thybo, H., 2010. Tectonic evolution, in: Doornenbal, H., Stevenson, A. (Eds.), Petroleum geological atlas of the Southern Permian Basin Area. EAGE Publ, Houten, pp. 25-57.

Plein, E., 1985. Die Entwicklung und Bedeutung der Erdöl/Erdgasfunde zwischen Weser und Ems. Oldenburger Jahrbuch 85, 267-311.

Poelchau, H., Baker, D.R., Hantschel, T., Horsfield, B., Wygrala, B., 1997. Basin simulation and the design of the conceptual model, in: Welte, D.H., Horsfield, B., Baker, D.R. (Eds.), Petroleum and Basin Evolution. Springer, Berlin, Heidelberg, pp. 71-166. 
Pujalte, V., 1981. Sedimentary succession and palaeoenvironments within a fault-controlled basin: The 'Wealden' of the Santander area, northern Spain. Sedimentary Geology 28, 293-325. 10.1016/00370738(81)90051-8.

Purvis, K., 1992. Lower Permian Rotliegend sandstones, Southern North Sea: A case study of sandstone diagenesis in evaporite-associated sequences. Sedimentary Geology 77, 155-171. 10.1016/00370738(92)90123-9.

Quesada, S., Robles, S., Rosales, I., 2005. Depositional architecture and transgressive-regressive cycles within Liassic backstepping carbonate ramps in the Basque-Cantabrian basin, northern Spain. Journal of the Geological Society 162, 531-548. 10.1144/0016-764903-041.

Quester, H., 1962. Petrographie des erdgashöffigen Hauptdolomits im Zechstein 2 zwischen Weser und Ems. Zeitschrift der deutschen geologischen Gesellschaft 114, 462-483.

Quinta, A., Tavani, S., Roca, E., 2012. Fracture pattern analysis as a tool for constraining the interaction between regional and diapir-related stress fields: Poza de la Sal Diapir (Basque Pyrenees, Spain). Geological Society, London, Special Publications 363, 521-532. 10.1144/SP363.25.

Quintà, A., Tavani, S., 2012. The foreland deformation in the south-western Basque-Cantabrian Belt (Spain). Tectonophysics 576-577, 4-19. 10.1016/j.tecto.2012.02.015.

Rakovan, J., 2009. Sectoral zoning. Rocks \& Minerals 84, 171-176.

Raleigh, C.B., J.D. Healy, J.D. Bredehoeft, 1976. An experiment in earthquake control of Rangely, Colorado. Science 191, 1230-1237.

Rasband, W.S., 1997. ImageJ: Webpage. http://imagej.nih.gov/ij/ (accessed 24.03.17). U.S. National Institutes of Health.

Reijers, T.J.A., 2012. Sedimentology and diagenesis as 'hydrocarbon exploration tools' in the Late Permian Zechstein-2 Carbonate Member (NE Netherlands). Geologos 18. 10.2478/v10118-0120009-x.

Reinhard, M., 1931. Universal Drehtischmethoden: Einführung in die kristalloptischen Grundbegriffe und die Plagioklasbestimmung. B. Wepf \& Cie, Basel, 119 pp.

Reutel, C., Lüders, V., 1998. Fluid-Evolution und Gasmigration im südlichen Randbereich des Nordostdeutschen Beckens - Untersuchungen an Flüssigkeitseinschlüssen in Kluftmineralisationen und Werra-Anhydrit. Geologisches Jahrbuch A, 169-183.

Richardson, C.K., Holland, H.D., 1979a. Fluorite deposition in hydrothermal systems. Geochimica et Cosmochimica Acta 43, 1327-1335. 10.1016/0016-7037(79)90122-4.

Richardson, C.K., Holland, H.D., 1979b. The solubility of fluorite in hydrothermal solutions, an experimental study. Geochimica et Cosmochimica Acta 43, 1313-1325. 10.1016/00167037(79)90121-2.

Richter-Bernburg, G., 1955. Stratigraphische Gliederung des deutschen Zechsteins. Zeitschrift der deutschen geologischen Gesellschaft 105, 843-854.

Ritzkowski, S., 1978. Geologie des Unterwerra-Sattels und seiner Randstrukturen zwischen Eschwege und Witzenhausen (Nordhessen), in: Koritnig, S. (Ed.), Zur Mineralogie und Geologie der Umgebung von Göttingen, pp. 187-204.

Roedder, E., 1984. Fluid inclusions. Reviews in mineralogy 12, 644.

Roedder, E., Bodnar, R., 1980. Geologic pressure determinations from fluid inclusion studies. Annual Reviews in Earth and Planetary Sciences 8, 263-302.

Rosales, I., Perez-Garcia, A., 2010. Porosity development, diagenesis and basin modelling of a Lower Cretaceous (Albian) carbonate platform from northern Spain. Geological Society, London, Special Publications 329, 317-342. 10.1144/SP329.13. 
Salimi, H., Wolf, K.-H., Bruining, J., 2012. The influence of capillary pressure on the phase equilibrium of the $\mathrm{CO} 2-$ water system: Application to carbon sequestration combined with geothermal energy. International Journal of Greenhouse Gas Control 11, S47-S66. 10.1016/j.ijggc.2012.09.015.

Scheck-Wenderoth, M., Lamarche, J., 2005. Crustal memory and basin evolution in the Central European Basin System — new insights from a 3D structural model. Tectonophysics 397, 143-165. 10.1016/j.tecto.2004.10.007.

Schenk, O., Urai, J.L., Piazolo, S., 2006. Structure of grain boundaries in wet, synthetic polycrystalline, statically recrystallizing halite - evidence from cryo-SEM observations. Geofluids 6, 93-104. 10.1111/j.1468-8123.2006.00134.x.

Schmidt Mumm, A., Wolfgramm, M., 2002. Diagenesis and fluid mobilisation during the evolution of the North German Basin - evidence from fluid inclusion and sulphur isotope analysis. Marine and Petroleum Geology 19, 229-246. 10.1016/s0264-8172(02)00015-6.

Schmidt Mumm, A., Wolfgramm, M., 2004. Fluid systems and mineralization in the north German and Polish basin. Geofluids 4, 315-328. 10.1111/j.1468-8123.2004.00090.x.

Schneider, H.-J., 1954. Die sedimentäre Bildung von Flussspat im oberen Wettersteinkalk der nördlichen Kalkalpen. Abhandlungen der Bayerischen Akademie der Wissenschaften 66.

Schneider, H.-J., Möller, P., Parekh, P.P., 1975. Rare Earth Elemets distribution in fluorites and carbonate sediments of the East-Alpine mid-Triassic sequences in the Nördliche Kalkalpen. Mineralium Deposita 10, 330-344.

Schneider, J., Bakker, R.J., Bechstadt, T., Littke, R., 2008. Fluid Evolution During Burial Diagenesis and Subsequent Orogenetic Uplift: The La Vid Group (Cantabrian Zone, Northern Spain). Journal of Sedimentary Research 78, 282-300. 10.2110/jsr.2008.032.

Schubart, W., 1955. Zur Stratigraphie, Tektonik und den Lagerstätten der Witzenhäuser Grauwacke. Abhandlungen des hessischen Landesamtes für Bodenforschung 10.

Schulz, S., 1980. Verteilung und Genese von Fluorit im Hauptdolomit Norddeutschlands. Berliner Geowissenschaftliche Abhandlungen A, 85.

Schwinn, G., Markl, G., 2005. REE systematics in hydrothermal fluorite. Chemical Geology 216, 225248. 10.1016/j.chemgeo.2004.11.012.

Senglaub, Y., Brix, M.R., Adriasola, A.C., Littke, R., 2005. New information on the thermal history of the southwestern Lower Saxony Basin, northern Germany, based on fission track analysis. Int J Earth Sci (Geol Rundsch) 94, 876-896. 10.1007/s00531-005-0008-z.

Shepherd, T., Rankin, A., Alderton, D., 1985. A Practical Guide to Fluid Inclusion Studies. Blackie and Son, Glasgow, 239 pp.

Sibson, R.H., 1995. Selective fault reactivation during basin inversion: potential for fluid redistribution through fault-valve action, in: Buchanan, J.G., Buchanan, P.G. (Eds.), Basin Inversion, London, pp. 3-10.

Sibson, R.H., 1998. Brittle failure mode plots for compressional and extensional tectonic regimes. Journal of Structural Geology 20, 655-660. 10.1016/s0191-8141(98)00116-3.

Siemann, M.G., Ellendorff, B., 2001. The composition of gases in fluid inclusions of late Permian (Zechstein) marine evaporites in Northern Germany. Chemical Geology 173, 31-44. 10.1016/s0009-2541(00)00266-7.

Sminchak, J., N. Gupta, C. Byrer, P. Bergman, 2002. Issues related to seismic activity inducedby the injection of $\mathrm{CO} 2$ in deep saline aquifers. Journal of Energy \& Environmental Research 2, 32-46. 
Smykatz-Kloss, W., 1966. Sedimentpetrographische und geochemische Untersuchungen an Karbonatgesteinen des Zechsteins: Teil II: Spezieller Teil. Contributions to Mineralogy and Petrology 13, 232-268.

Stadler, G., Teichmüller, R., 1971. Zusammenfassender Überblick über die Entwicklung des Bramscher Massivs und des Niedersächsischen Tektogens. Fortschritte in der Geologie von Rheinland und Westfalen 18, 547-564.

Steele-MacInnis, M., Bodnar, R.J., Naden, J., 2011. Numerical model to determine the composition of $\mathrm{H} 2 \mathrm{O}-\mathrm{NaCl}-\mathrm{CaCl} 2$ fluid inclusions based on microthermometric and microanalytical data. Geochimica et Cosmochimica Acta 75, 21-40. 10.1016/j.gca.2010.10.002.

Steinhoff, I., Strohmenger, C., 1996. Zechstein 2 carbonate platform subfacies and grain-type distribution (Upper Permian, Northwest Germany). Facies 35, 105-132. 10.1007/bf02536959.

Steuer, S., 2008. Neukorrelation der Bohrungen und Erstellung eines Strukturmodells für den Buntsandstein und das Staßfurt Karbonat im Gebiet Bahrenborstel-Burgmoor-Uchte Konzession Dümmersee-Uchte, Niedersachsen. Diploma-Thesis, Freiburg, p. 186.

Stoppel, D., Gundlach, H., 1978. Zur Geologie und Bergbaugeschichte der Schwerspat und Kobalterzvorkommen im Unterwerra-Grauwackengebirge und Richelsdorfer Gebirge, in: Koritnig, S. (Ed.), Zur Mineralogie und Geologie der Umgebung von Göttingen, pp. 261-285.

Streit, J.E. \& Siggins, A. F., 2005. Predicting, monitoring and controlling geomechanical effects of CO2 injection, in: Greenhouse gas control technologies 7. Proceedings of the 7th International Conference on Greenhouse Gas Control Technologies, Vancouver. Elsevier, pp. 643-651.

Streit, J.E. \& Watson, M., 2005. Estimating rates of potential CO2 loss from geological storage sites for risk and uncertainty analysis, in: Greenhouse gas control technologies 7. Proceedings of the 7th International Conference on Greenhouse Gas Control Technologies, Vancouver. Elsevier, pp. 13091314.

Strohmenger, C., Antonini, M., Jäger, G., Rockenbauch, K., Strauß, C., 1996. Zechstein 2 carbonate reservoir facies distribution in relation to Zechstein sequence stratigraphy (Upper Permian, Northwest Germany): an integrated approach. Bulletin du Centre de recherches Elf Exploration Production, Elf-Aquitaine 20, 1-35.

Strohmenger, C., Rockenbauch, K., Waldmann, R., 1998. Fazies, Diagenese und Reservoirentwicklung des Zechstein 2-Karbonats (Ober-Perm) in Nordostdeutschland. Geologisches Jahrbuch A, 81-113.

Strübel, G., 1968. Hydrothermale Lösungen. Geol Rundsch 58, 259-273. 10.1007/bf01820607.

Strübel, G., Schaefer, B., 1974. Experimentelle Untersuchungen zur hydrothermalen Löslichkeit von Fluorit im System CaF2-NaCl-H2O. Schriften der GDMB Gesellschaft Deutscher Metallhütten- und Bergleute 28, 19-26.

Sullivan, M.D., Macaulay, C.I., Fallick, A.E., Haszeldine, R.S., 1997. Imported quartz cement in aeolian sandstone grew from water of uniform composition but has complex zonation. Terra Nova 9, 237 241. 10.1111/j.1365-3121.1997.tb00020.x.

Sweeney, J.J., Burnham, A.K., 1990. Evaluation of a Simple Model of Vitrinite Reflectance Based on Chemical Kinetics (1). AAPG Bulletin 74, 1559-1570. 10.1306/0c9b251f-1710-11d7$8645000102 \mathrm{c} 1865 \mathrm{~d}$.

Swennen, R., Dewit, J., Fierens, E., Muchez, P., Shah, M., Nader, F.H., Hunt, D., 2012. Multiple dolomitization events along the Pozalagua Fault (Pozalagua Quarry, Basque-Cantabrian Basin, Northern Spain). Sedimentology 59, 1345-1374. 10.1111/j.1365-3091.2011.01309.x. 
Tanner, D., Krawczyk, C.M., 2016. Detachment depth and isostatic restoration of the Cretaceous uplift of the Harz Mountains, in: Friedel, C.-H., Leiss, B. (Eds.), Harzgeologie 2016. Göttingen University Press, Göttingen, pp. 41-45.

Tavani, S., 2012a. Plate kinematics in the Cantabrian domain of the Pyrenean orogen. Solid Earth 3, 265-292. 10.5194/se-3-265-2012.

Tavani, S., 2012b. The boundary between the eastern and western domains of the Pyrenean Orogen: A Cenozoic triple junction zone in Iberia? Solid Earth Discuss. 4, 507-564. 10.5194/sed-4-507-2012.

Tavani, S., Carola, E., Granado, P., Quintà, A., Muñoz, J.A., 2013. Transpressive inversion of a Mesozoic extensional forced fold system with an intermediate décollement level in the BasqueCantabrian Basin (Spain). Tectonics 32, 146-158. 10.1002/tect.20019.

Tavani, S., Granado, P., 2015. Along-strike evolution of folding, stretching and breaching of supra-salt strata in the Plataforma Burgalesa extensional forced fold system (northern Spain). Basin Res 27, 573-585. 10.1111/bre.12089.

Tavani, S., Muñoz, J.A., 2012. Mesozoic rifting in the Basque-Cantabrian Basin (Spain): Inherited faults, transversal structures and stress perturbation. Terra Nova 24, 70-76. 10.1111/j.13653121.2011.01040.x.

Tavani, S., Quintà, A., Granado, P., 2011. Cenozoic right-lateral wrench tectonics in the Western Pyrenees (Spain): The Ubierna Fault System. Tectonophysics 509, 238-253. 10.1016/j.tecto.2011.06.013.

Teichmüller, M., Teichmüller, R., 1985. Inkohlungsgradienten in der Anthrazitfolge des Ibbenbürener Karbons. Fortschr. Geol. Rheinl. Westfal. 33, 231-253.

Thiery, R., Vidal, J., Dubessy, J., 1994. Phase equilibria modelling applied to fluid inclusions: Liquidvapour equilibria and calculation of the molar volume in the $\mathrm{CO} 2 \cdot \mathrm{CH} 4 \cdot \mathrm{N} 2$ system. Geochimica et Cosmochimica Acta 58, 1073-1082. 10.1016/0016-7037(94)90573-8.

Tropper, P., Manning, C.E., 2007. The solubility of fluorite in $\mathrm{H} 2 \mathrm{O}$ and $\mathrm{H} 2 \mathrm{O}-\mathrm{NaCl}$ at high pressure and temperature. Chemical Geology 242, 299-306. 10.1016/j.chemgeo.2007.03.017.

Tucker, M.E., 1991. Sequence stratigraphy of carbonate-evaporite basins: models and application to the Upper Permian (Zechstein) of northeast England and adjoining North Sea. Journal of the Geological Society $148,1019-1036$.

Twiss, R.J., Moores, E.M., 2007. Structural geology, 2nd ed. Freeman, New York, 736 pp.

Uffmann, A.K., 2013. Paleozoic petroleum systems of northern Germany and adjacent areas: A 3D modeling study. PhD-Thesis, Aachen, 156 pp.

Underhill, J.R., 2003. The tectonic and stratigraphic framework of the United Kingdom's oil and gas fields. Geological Society, London, Memoirs 20, 17-59. 10.1144/GSL.MEM.2003.020.01.04.

Underhill, J.R., 2009. Role of intrusion-induced salt mobility in controlling the formation of the enigmatic 'Silverpit Crater', UK Southern North Sea. Petroleum Geoscience 15, 197-216. 10.1144/1354-079309-843.

Underhill, J.R., Lykakis, N., Shafique, S., 2009. Turning exploration risk into a carbon storage opportunity in the UK Southern North Sea. Petroleum Geoscience 15, 291-304. 10.1144/1354079309-839.

Underhill, J.R., Partington, M.A., 1993. Jurassic thermal doming and deflation in the North Sea: implications of the sequence stratigraphic evidence, 337-345. 10.1144/0040337. 


\section{References}

Underschultz, J., Boreham, C., Dance, T., Stalker, L., Freifeld, B., Kirste, D., Ennis-King, J., 2011. CO2 storage in a depleted gas field: An overview of the CO2CRC Otway Project and initial results. International Journal of Greenhouse Gas Control 5, 922-932. 10.1016/j.ijggc.2011.02.009.

Urbigkeit, K., Liebig, L., 1987. Die Mineralien der Kalkgrube Lieth bei Elmshorn. Lapis, 27-29.

US Environmental Protection Agency, OAR, Climate Change Division, 2008. Vulnerability Evaluation Framework for Geologic Sequestration of Carbon Dioxide Technical Support Document July102008.

van den Kerkhof, A., Hein, U.F., 2001. Fluid inclusion petrography. Lithos 55, 27-47. 10.1016/s00244937(00)00037-2.

van den Kerkhof, A., Thiéry, R., 2001. Carbonic inclusions. Lithos 55, 49-68. 10.1016/s00244937(00)00038-4.

Vicente, G. de, Cloetingh, S., van Wees, J.D., Cunha, P.P., 2011. Tectonic classification of Cenozoic Iberian foreland basins. Tectonophysics 502, 38-61. 10.1016/j.tecto.2011.02.007.

Vollmer, F.W., 2017. EllipseFit: Strain and Fabric Analysis Software.

Wedepohl, K.H., 1985. Origin of the Tertiary basaltic volcanism in the northern Hessian Depression. Contr. Mineral. and Petrol. 89, 122-143. 10.1007/BF00379448.

Whittaker, S., Rostron, B., Hawkes, C., Gardner, C., White, D., Johnson, J., Chalaturnyk, R., Seeburger, D., 2011. A decade of CO2 injection into depleting oil fields: Monitoring and research activities of the IEA GHG Weyburn-Midale CO2 Monitoring and Storage Project. Energy Procedia 4, 60696076. 10.1016/j.egypro.2011.02.612.

Wilkins, R.W.T., Bird, J.R., 1980a. Characterization of healed fracture surfaces in fluorite by etching and proton irradiation. Lithos 13, 11-18.

Wilkins, R.W.T., Bird, J.R., 1980b. The use of proton irradiation to reveal growth and deformation features in fluorite. American Mineralogist 65, 374-380.

Wilkins, S.J., Naruk, S.J., 2007. Quantitative analysis of slip-induced dilation with application to fault seal. Bulletin 91, 97-113. 10.1306/08010605177.

Wilkinson, M., Haszeldine, R.S., Fallick, A.E., Odling, N., Stoker, S.J., Gatliff, R.W., 2009. CO2Mineral Reaction in a Natural Analogue for CO2 Storage--Implications for Modeling. Journal of Sedimentary Research 79, 486-494. 10.2110/jsr.2009.052.

Williams, G.D., Powell, C.M., Cooper, M.A., 1989. Geometry and kinematics of inversion tectonics, in: Cooper, M.A., Williams, G.D. (Eds.), Inversion Tectonics, pp. 3-16.

Wischhöfer, P., 2015. Fluorite mineralization in dolomites of the Zechstein west of Eschwege: microfabrics, petrography and geochemistry. unpublished Master's Thesis, Göttingen, 86 pp.

Wo, S., Liang, J.T., 2005. CO2 storage in coalbeds: CO2/N2 injection and outcrop seepage modeling,carbon dioxide capture for storage in deep geologic formations, in: Benson, S.M. (Ed.), Results from the CO2 Capture Project, v.2: Geologic Storage of Carbon Dioxide with Monitoring and Verification. Elsevier Science, London, UK, pp. 897-924.

Wo, S., Liang, J.T., Myer, L.R., 2005. CO2 Storage in Coalbeds: Risk Assessment of CO2 and Methane Leakage, in: Benson, S.M. (Ed.), Results from the CO2 Capture Project, v.2: Geologic Storage of Carbon Dioxide with Monitoring and Verification. Elsevier Science, London, UK, pp. 1263-1292.

Wolfgramm, M., 2001. Fluidentwicklung und Diagenese im Nordostdeutschen Becken - Petrographie, Mikrothermometrie und Geochemie stabiler Isotope. PhD-Thesis, Halle-Wittenberg, p. 165.

Wood, S.A., 1990a. The aqueous geochemistry of the rare-earth elements and yttrium: Review of available low temperature data for inorganic complexes and the inorganic REE speciation of natural waters. Chemical Geology 82, 159-186. 10.1016/0009-2541(90)90080-q. 


\section{References}

Wood, S.A., 1990b. The aqueous geochemistry of the rare-earth elements and yttrium: Theoretical predictions of speciations in hydrothermal solutions to $350^{\circ} \mathrm{C}$ at saturation water vapour pressure. Chemical Geology 88, 99-125. 10.1016/0009-2541(90)90106-h.

Worden, R.H., Smalley, P.C., 1996. H2S-producing reactions in deep carbonate gas reservoirs: Khuff Formation, Abu Dhabi. Chemical Geology 133, 157-171. 10.1016/s0009-2541(96)00074-5.

Wycherley, H., Fleet, A., Shaw, H., 1999. Some observations on the origins of large volumes of carbon dioxide accumulations in sedimentary basins. Marine and Petroleum Geology 16, 489-494. 10.1016/S0264-8172(99)00047-1.

Wygrala, B., 1989. Integrated study of an oil field in the southern Po-basin,Northern Italy: Berichte Forschungszentrum Jülich, 2313,. PhD-Thesis, Köln, 217 pp.

Yang, C., 2001. Fluid inclusion and stable isotopic studies of thermochemical sulphate reduction from Burnt Timber and Crossfield East gas fields in Alberta, Canada. Bulletin of Canadian Petroleum Geology 49, 149-164. 10.2113/49.1.149.

Yielding, G., Lykakis, N., Underhill, J.R., 2011. The role of stratigraphic juxtaposition for seal integrity in proven CO2 fault-bound traps of the Southern North Sea. Petroleum Geoscience 17, 193-203. 10.1144/1354-0793/10-026.

Ziegler, K., 2006. Clay minerals of the Permian Rotliegend Group in the North Sea and adjacent areas. Clay Miner. 41, 355-393. 10.1180/0009855064110200.

Ziegler, P.A., 1982. Triassic rift and facies patterns in western and central Europe. Geol Rundsch 71, 747-772.

Ziegler, P.A., 1990. Geological atlas of western and central Europe, 2nd ed. Shell Internationale Petroleum Maatschappij BV, The Hague, 56 pp.

Ziegler, P.A., 1992. European Cenozoic rift system. Tectonophysics 208, 91-111.

Ziegler, P.A., 1995. Dynamics of intra-plate compressional deformation: the Alpine foreland and other examples. Tectonophysics 252, 7-59.

Ziehr, H., Matzke, K., Ott, G., Vouttsidis, V., 1980. Ein stratiformes Fluoritvorkommen im Zechsteindolomit bei Eschwege und Sontra in Hessen. Geologische Rundschau 69, 325-348.

Ziehr, H., Matzke, K., Ott, G., Sawary, E., 1978. Flußspat im Zechsteindolomit bei Eschwege, Hessen, in: Koritnig, S. (Ed.), Zur Mineralogie und Geologie der Umgebung von Göttingen, pp. 248-259.

Zinkernagel, U., 1978. Cathodoluminescence of quartz and its application to sandstone petrology. Schweizerbart, Stuttgart, 69 pp.

Zwart, E., 1995. Fluid inclusions in carbonate rocks and calcite cement. PhD-Thesis, Amsterdam, p. 157.

Zwart, E., Touret, J., 1994. Melting behaviour and composition of aqueous fluid inclusions in fluorite and calcite: Applications within the system $\mathrm{H} 2 \mathrm{O}-\mathrm{CaCl} 2-\mathrm{NaCl}$. European Journal of Mineralogy 6, 773-786. 10.1127/ejm/6/6/0773. 
Appendix

\section{Appendix}

4-1 Composite images of fluorite nodule sample P9 (LP-XP-CL)

4-2 ICP-MS data of fluorite mineralization from the LSB

6-1 Table of sampled rock units from the western Basque Pyrenees

6-2 Thick section scans sample B10N (A-B-C)

6-3 CL composite images of thin sections sample B10N (A-B-C)

6-4 Exemplified fracture network chronology section B10N-A 
Appendix 4-1

P9 - Fluorite nodule (LP)

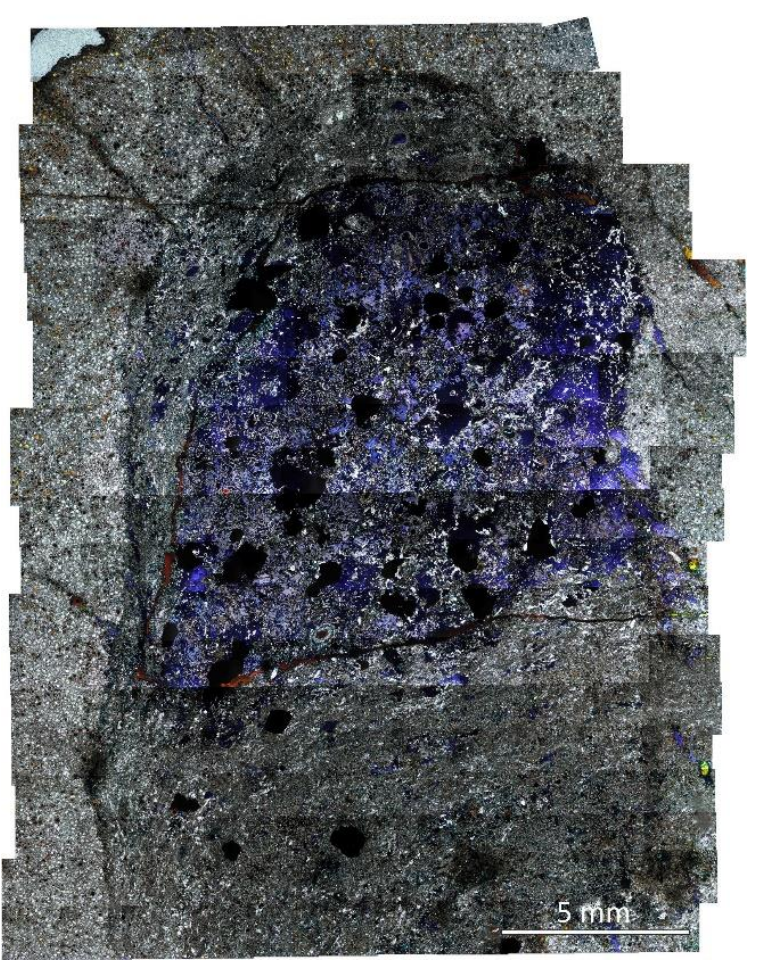

P9- Fluorite nodule (XP)

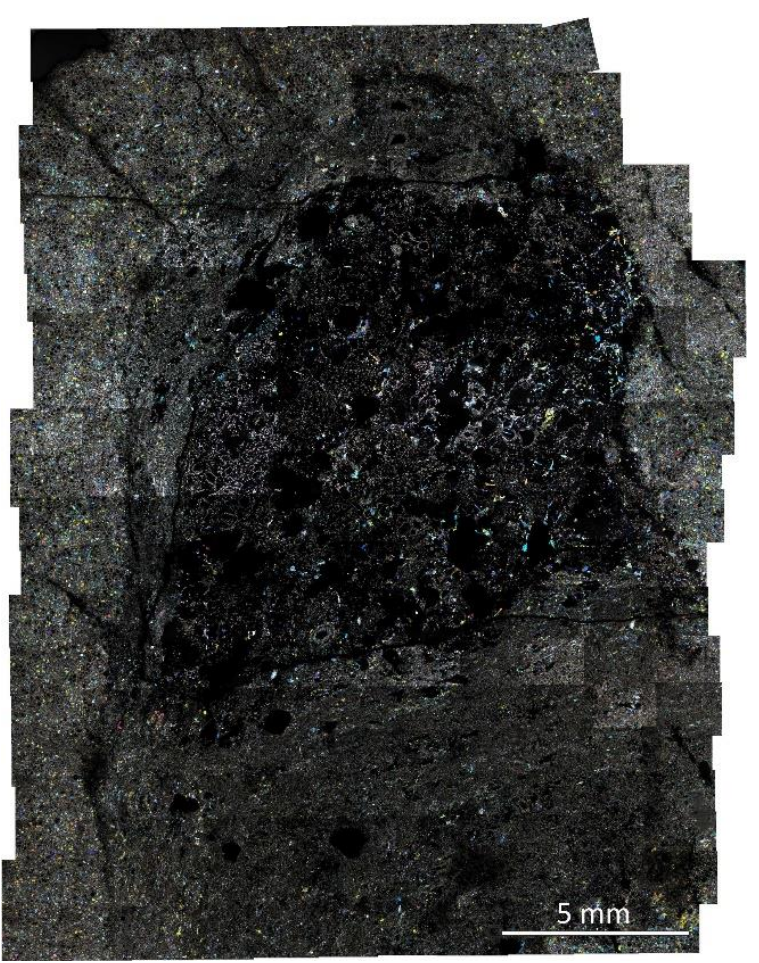


Appendix 4-1

P9- Fluorite nodule (CL)

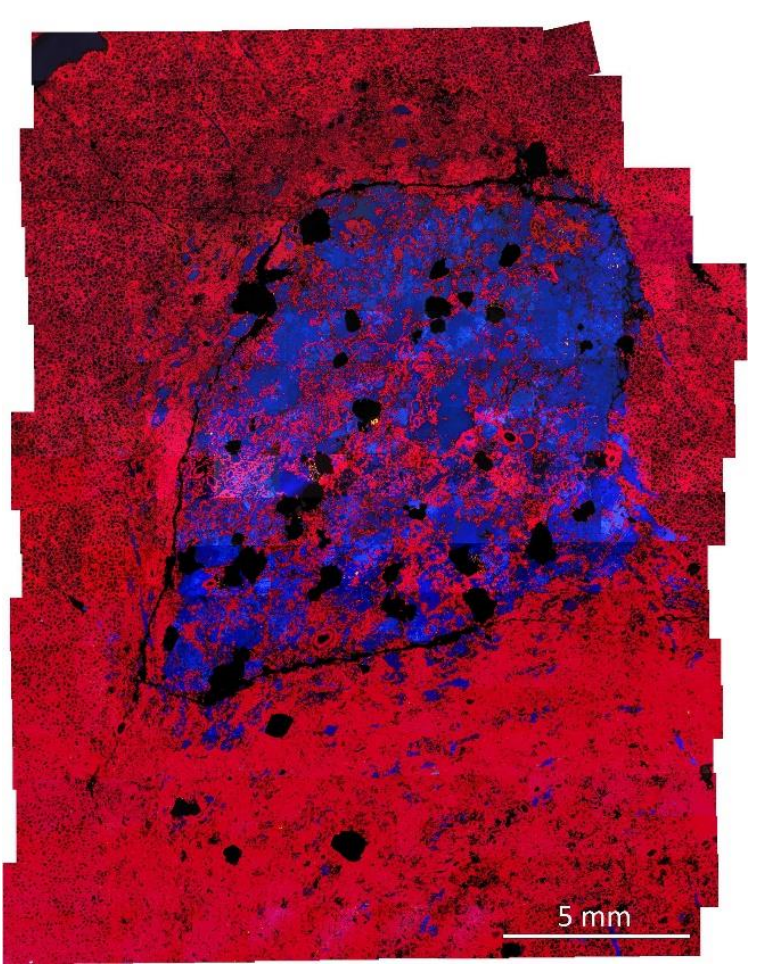


Appendix 4-2

P- 9 Fluorite nodule

Section 1: $12750 \mu \mathrm{m}$ $10.6 \mu \mathrm{m} / \mathrm{s}$ $0,768 \mathrm{~s}$ $\mathrm{T}=80 \mu \mathrm{m}$ $\alpha=33^{\circ}$

Section II: $21250 \mu \mathrm{m}$ $17.7 \mu \mathrm{m} / \mathrm{s}$ $0,768 \mathrm{~s}$ $\mathrm{T}=50 \mu \mathrm{m}$ $\alpha=22^{\circ}$

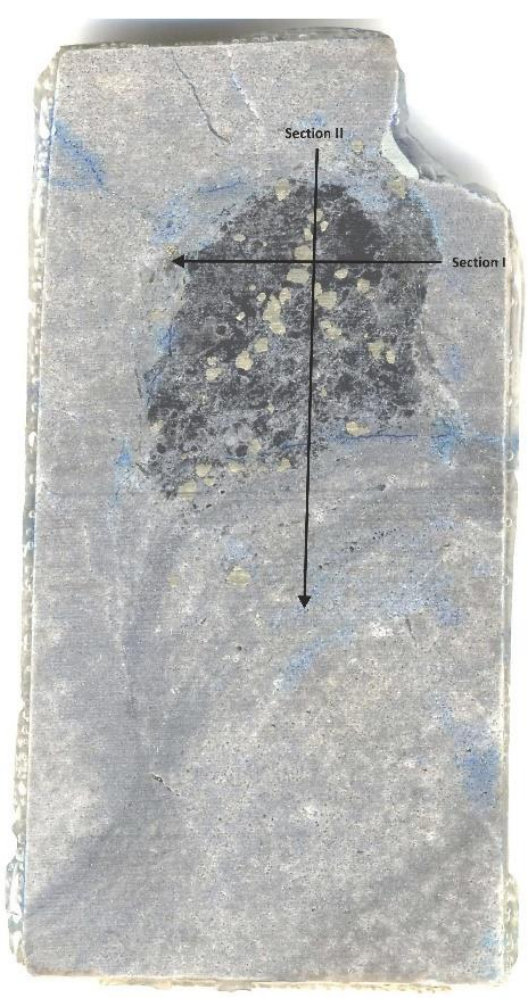

$7 \mathrm{~Hz}$

$\mathrm{D}=120 \mu \mathrm{m}$

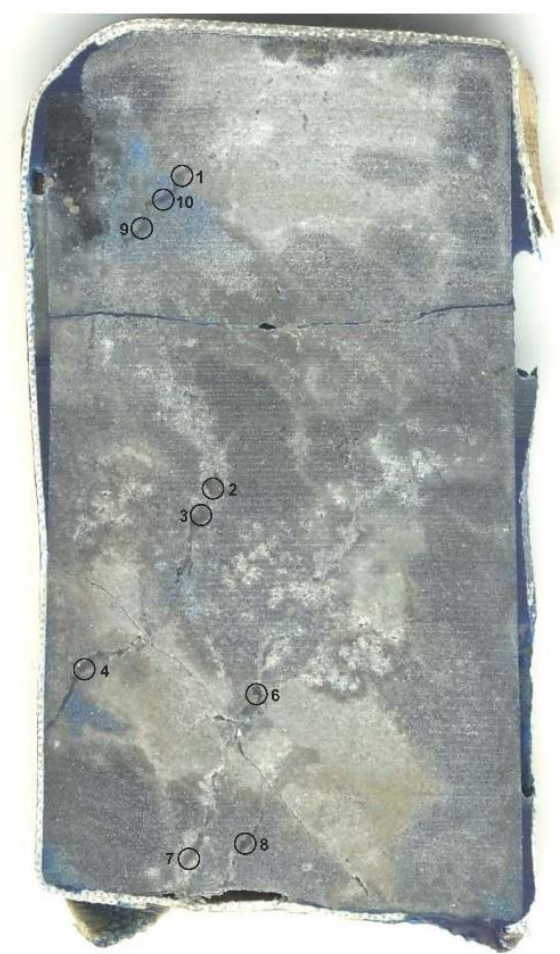

\section{P- 9 Fluorite nodule}
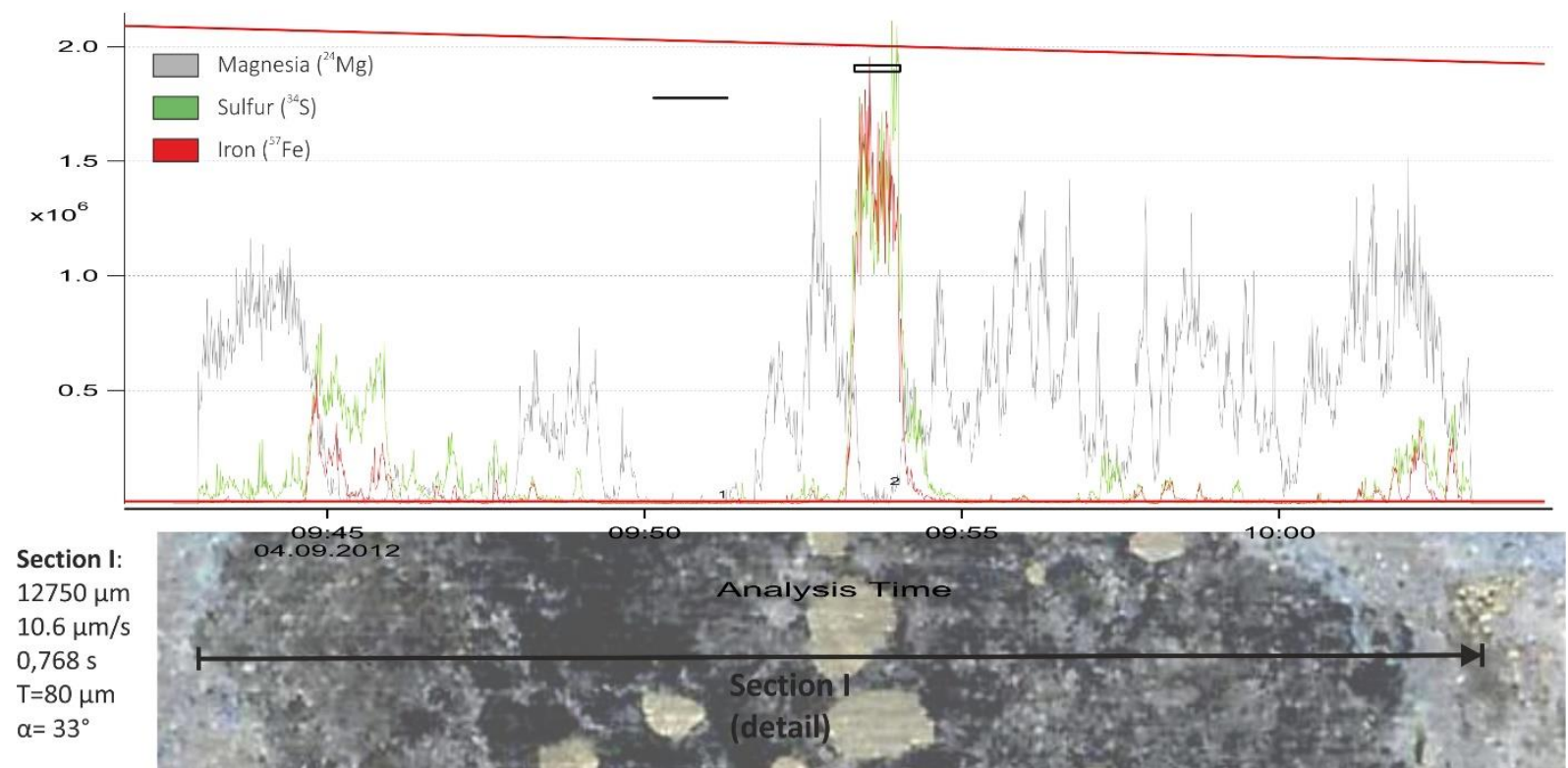


\section{Appendix 6-1}
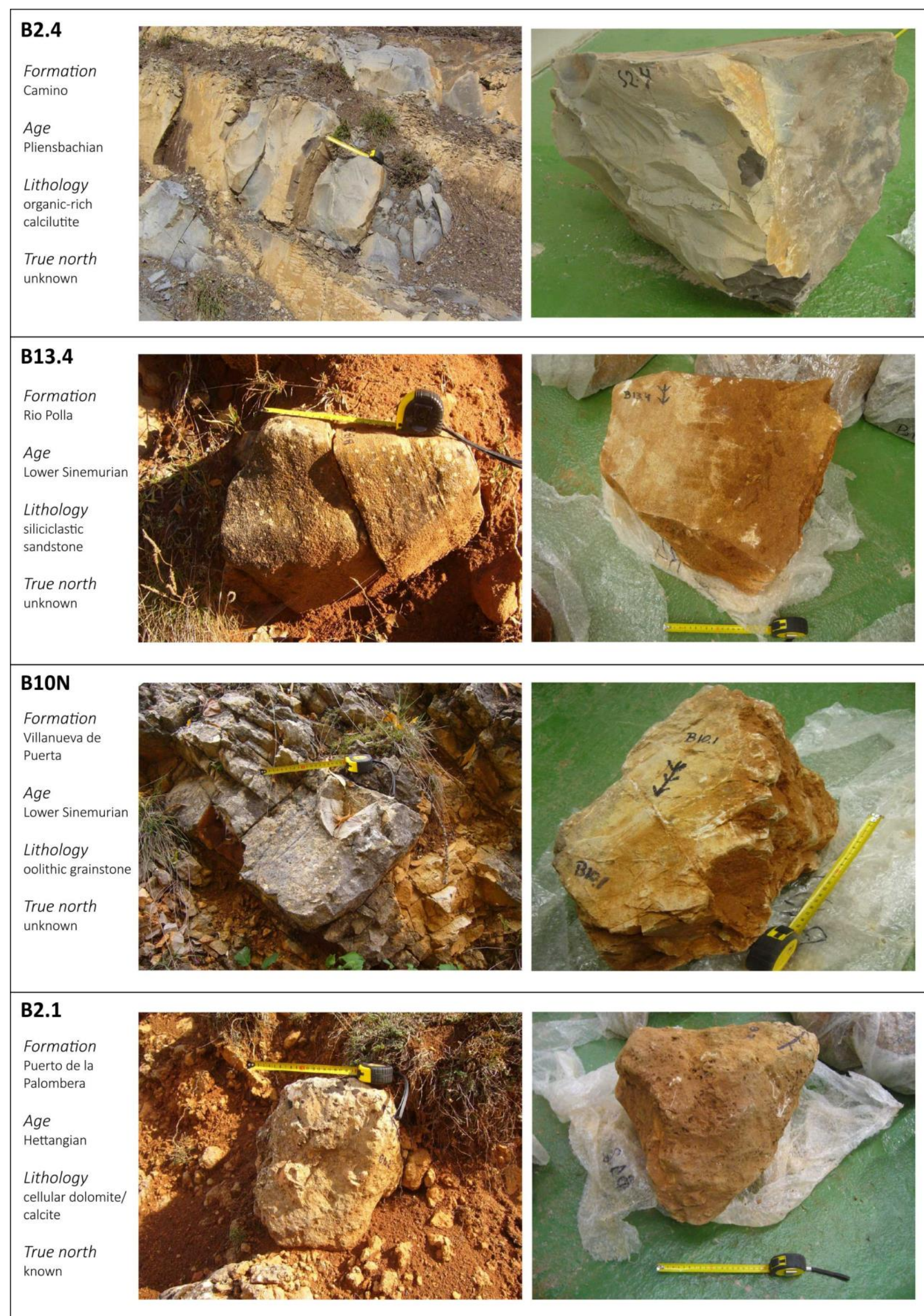

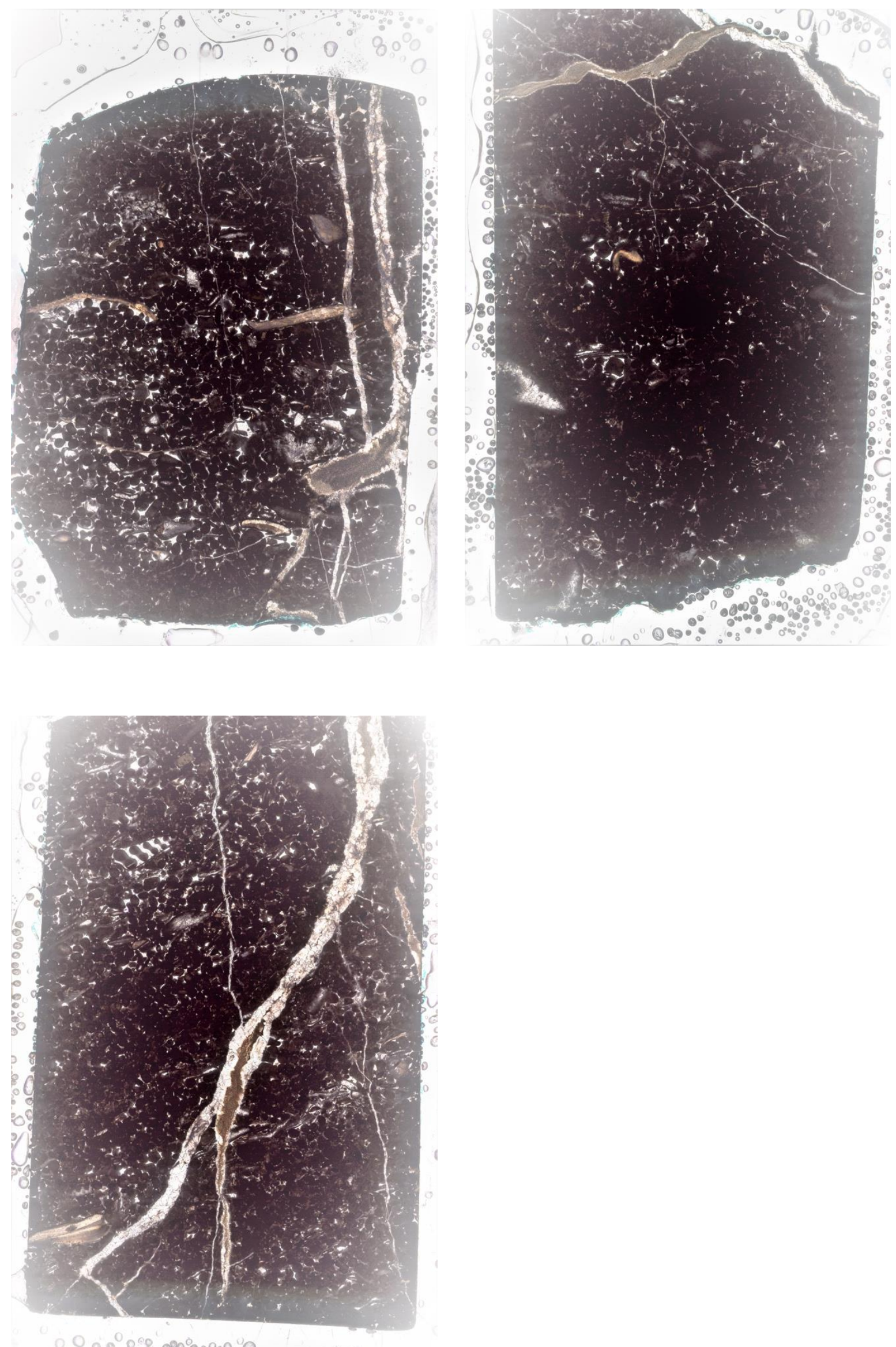
Appendix 6-3

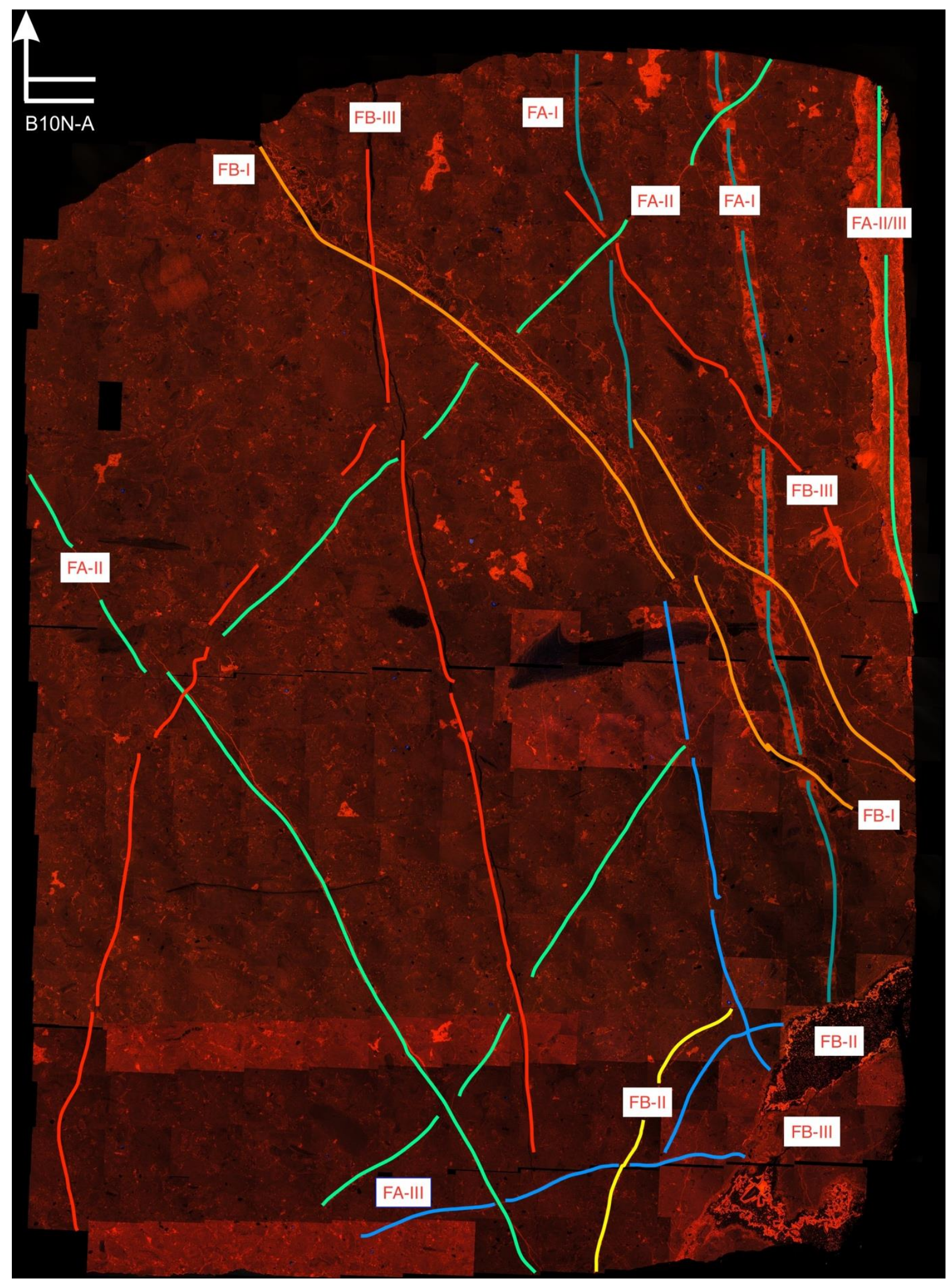




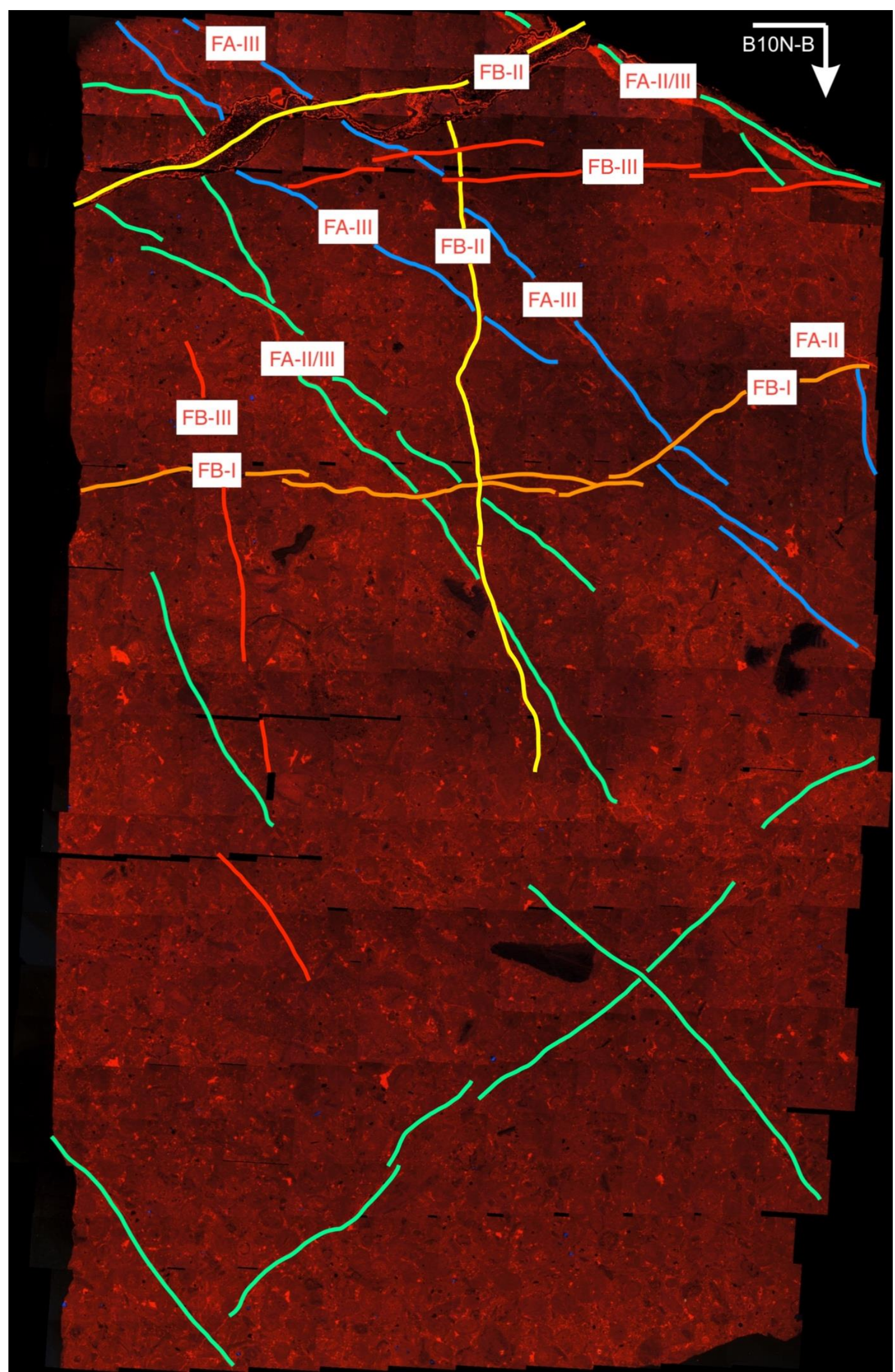


Appendix 6-3

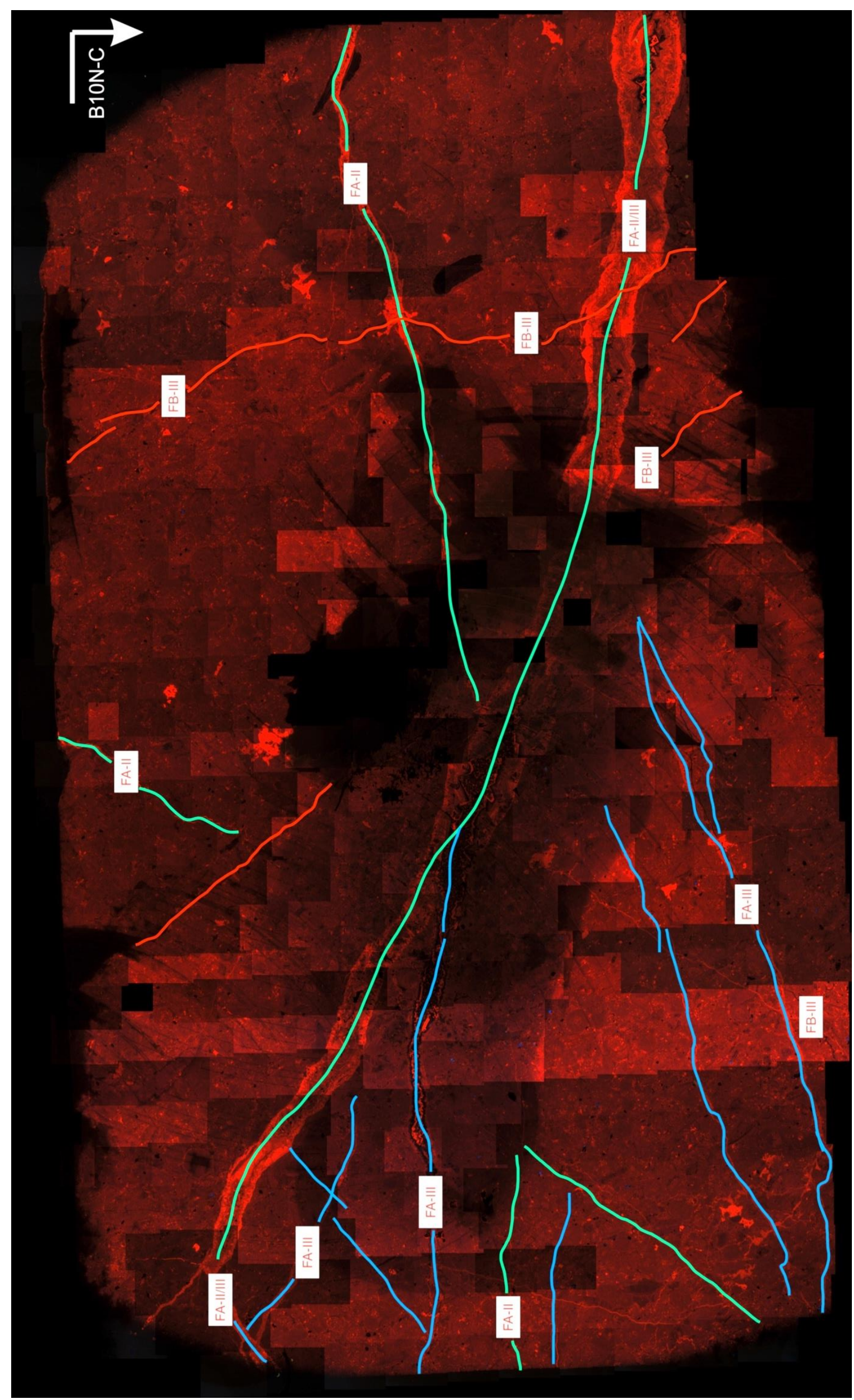




\section{Hontomín - B.10.N_A (TS, LP)}

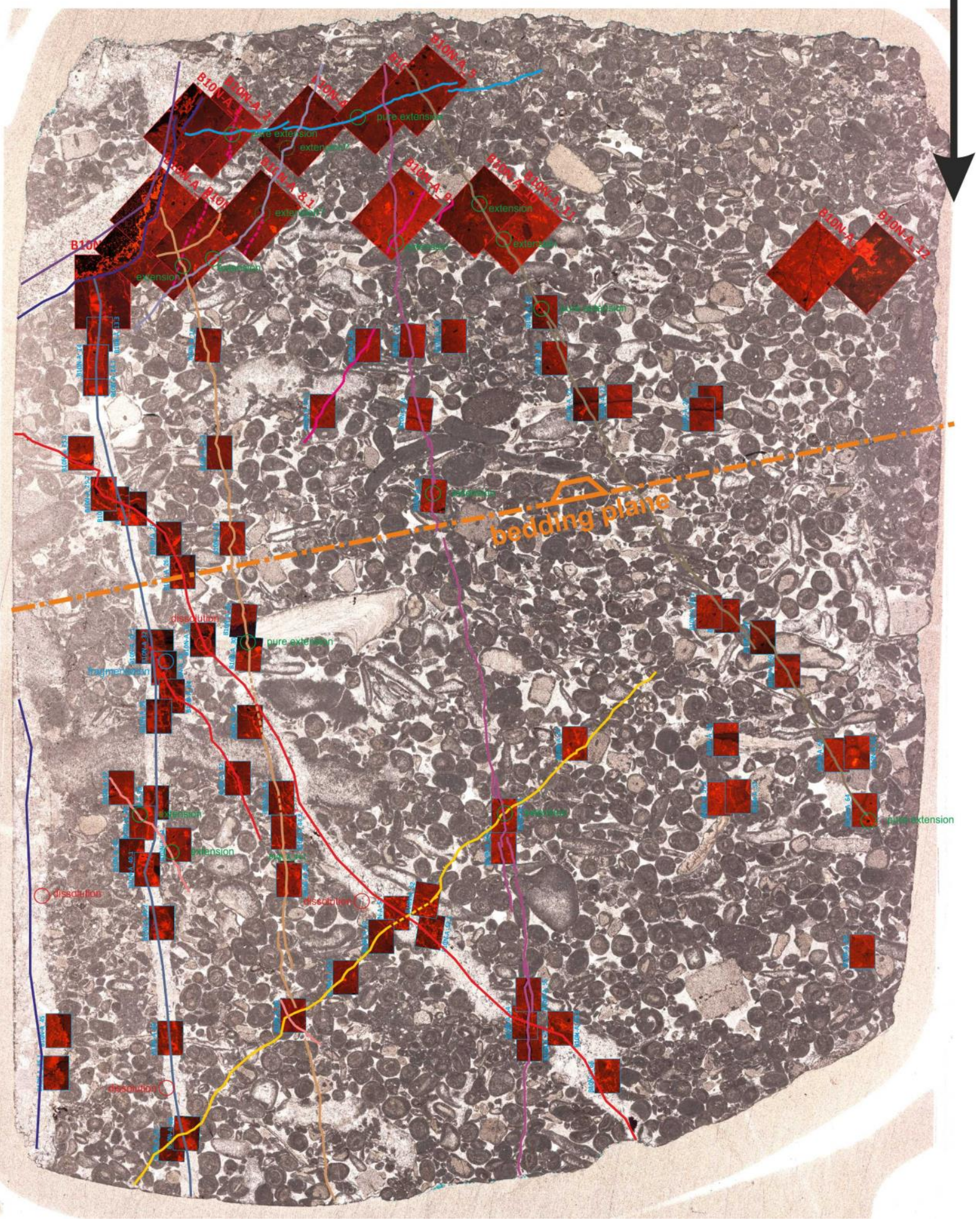




\section{Curriculum Vitae}

\section{Personal information}

Name:

Florian Duschl

Nationality:

German

Date of birth:

25.01.1982

Place of birth:

Passau

\section{Scientific education}

Doctoral studies ( $\mathrm{PhD})$ in Applied Geology

$10 / 2012$ - present

University of Göttingen

Master program (M.Sc.) in Hydro- and Engineering Geology

$10 / 2008-02 / 2011$

Technical University of Munich

Bachelor program (B.Sc.) in Geosciences

$10 / 2005-09 / 2008$

Ludwig-Maximilians-University Munich / Technical University of Munich

Magister Artium (bachelor studies, equiv.)

$10 / 2003-07 / 2005$

University of Passau

Major: $\quad$ Art history

Minor: $\quad$ German literature, Geography 


\section{Eidesstattliche Erklärung/Affidativ}

Hiermit versichere ich an Eides statt, dass ich die vorliegende Dissertation Structural control on fluid migration in inverted sedimentary basins selbstständig angefertigt habe, mich außer der angegebenen keiner weiteren Hilfsmittel bedient und alle Erkenntnisse, die aus dem Schrifttum ganz oder annähernd übernommen sind, als solche kenntlich gemacht und nach ihrer Herkunft unter Bezeichnung der Fundstelle einzeln nachgewiesen habe.

I hereby confirm that the dissertation $\underline{\text { Structural control on fluid migration in inverted sedimentary basins }}$ is the result of my own work and that I have only used sources or materials listed and specified in the dissertation.

Göttingen, den/ Unterschrift / signature

Göttingen, date 